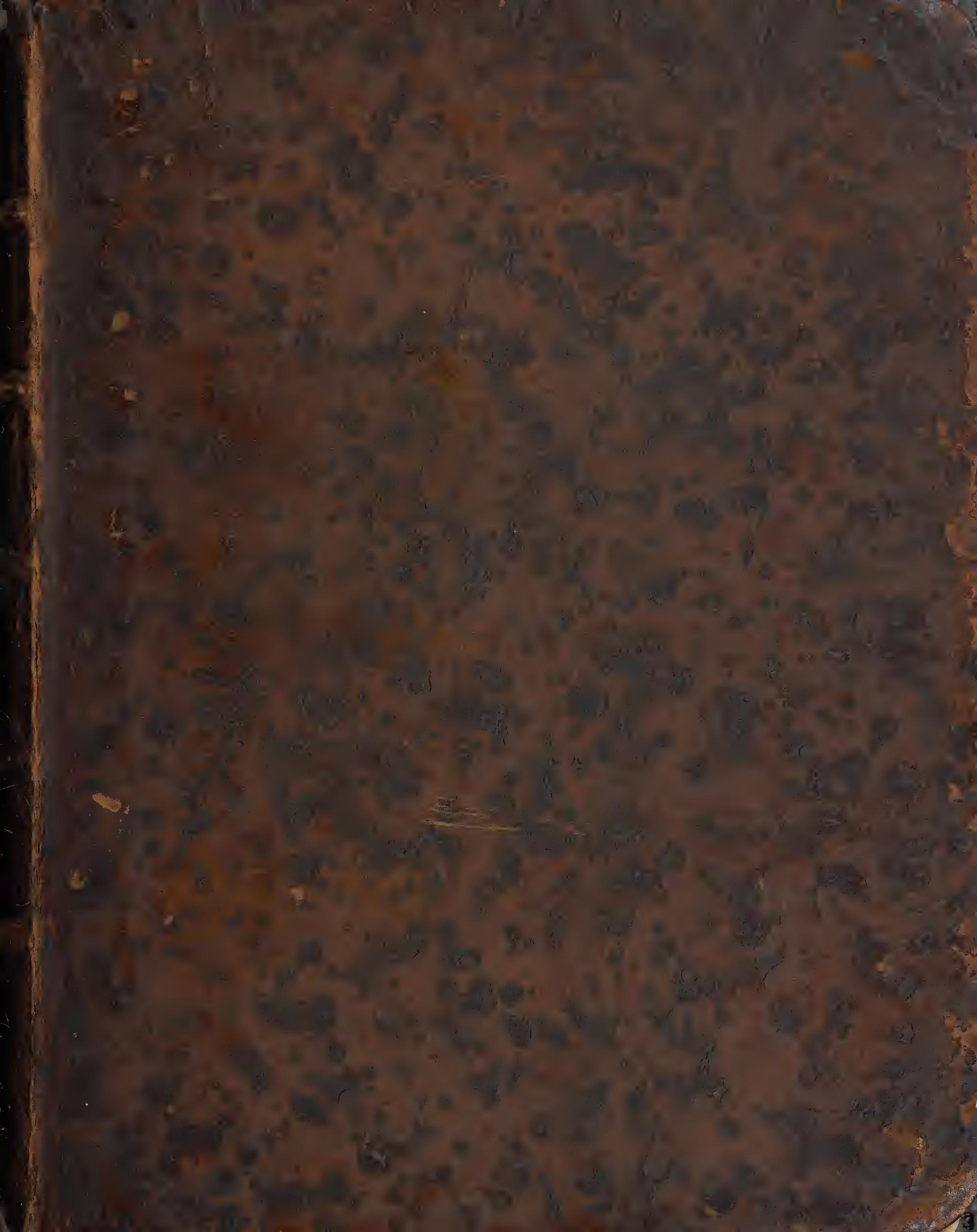






\section{A TH E O R I E E T}

\section{LA PRATIQUE}

D U

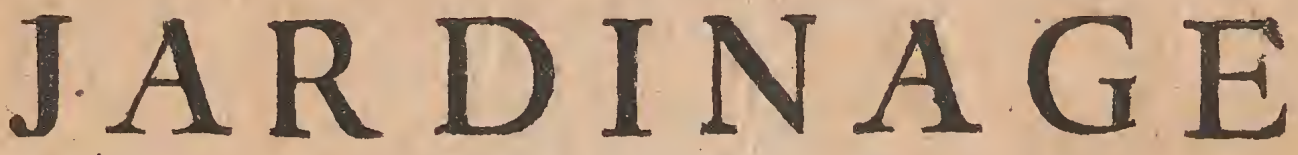

OU L'ON TRAITE A FOND DES BEAUX JARDiLS apellés communément,

LES JARDINS DF REGularile de plaisance
ET DE PROPRETE

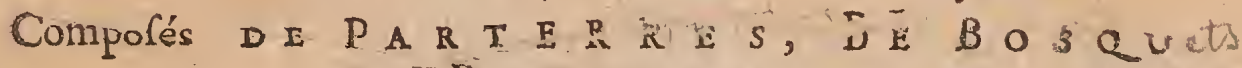
DE BO U I INGR IN $S$, \& .

CONTENANT PLUSIEURS PLANS ET DISPOSITIONS generales de Jardins; nouveaux Deffeins de Parterres, de Bofquets, de Boulingrins, Labirinthes, Salles, Galeries, Portiques \& Cabinets de Treillages, Terraffes, Efcaliers, Fontaines, Cafcades, \& autres ornemens fervant à la Décoration \& Embéliffement des Jardins.

Pair le sieur ALEXANDRE-LE BLOND.

AVEC LA MANIEREDE DRESSER UN TERRAIN, a'inventer des Deffeins felon le lieu, \& de les y tracer \& executer, fuivant les prinsipes de las Geometrie; \&o las Méthode de planter o élever en pen de tems tous les Plants qui conviennent aux béaux fardins, avec un nouvean Traité de Fleurs \& d'orangers: Comme aufs celle de rechercher les Eaux, de les conduire dans les fardins, \& d'y conftruire des Bafjins \& des 'Foniaines, avec des Remarques of Regles generales fur tout ce qui concerme l'Art drs fardinage.

$$
\text { NOV VELLLE E'DITION. }
$$

\section{A P A R I S,}

Chez JEAN MARIETTE, ruë faint Jacques, aux Colonnes d'Hercule.

M. DCCXXII. AVEG PRIVILEGE DU ROI. 



\section{A V I S}

\section{SUR CETTE NOUVELLE EDITION.}

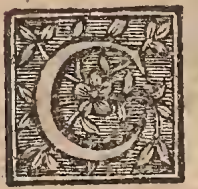

OMME l'onn'a eu en vâë dans cet Ouvrage, que l'utilité publique, on a profité.des avis de plufieurs perfonnes qu'on a recuëillis avec foin. Lés uns ont trouvé qu'il y avoit trop peu de Planches de Parterres, \& que le Chapitre qui en traite n'étoir pas affés étendu; on y a fupléé par une nouvelle Planche, quien contient trois differents, a vec leur def cription \& quelque augmentation de difcours: Les autres ont dit, quil manquoit des Gradins \& des Efcaliers de gazon, \& qu'il n'y en avoic que de pierre ; la planche que l'on en donne en fournit fix exemples. On a fait encore quelques objections fur la régularité des places où l'on a renferméles deffeins de Jardins : on a tâché d'y fatisfaire par une Planche de difpofitions generales dans des emplacemens des plus irreguliers: Celle des Parterres comprend aufi des terrains biaifés, de même que quelques delleins trop reguliers que l'on a changé dans les dix Planches de Bofquets" , pour faire connoitre de quelle maniere on corrige ces Biais: On a même ajoùté une Planche de beaux Boulingrins, unede Paliffades extraordinaires, \& une autre de Portiques champêtres ou de verdure. Ces nouvellés Planches font au nombre de fix; qui ne font pas des moindres du livre: elles renferment des delleins trés-nouveaux en ce genre, \& generalement tout ce qu'il y a de plus a la mode dans les Jardins de propreté. L'on a encore augmenté des agrémens dans plufieurs endroits des anciennes Planches, ce qu'on remarquera facilement pour peu qu'on les confronte avec celles de la I ere Edition.

A l'égard du Corps de l'Ouvrage, il eft augmenté de plus. d'un tiers, par quantité de remarques que des experiences. nouvelles \& des recherches exactes ont fournies depuis, principalement dans la troifiéme Partie; l'on y trouvera de fuite 4 Chapitres qui n'ont point encore paru:Les deux premiers con- 
tiennent la culture des Orangers, des Jafmins \& des autres A rbriffeaux de fleurs, avec la maniere de les greffer, de les élever de graine, de marcotte, ou de les choifir tout grands. On voit dans les deux autres Chapitres tout le détail \& le gouvernement des Fleurs qui fourniffent les grands Parterres \& les Gradins des Amphitéâtres dans chaque faifon, ce que beaucoup de gens ont demandé, vû que les Orangers \& les Fleurs font le principal ornement des beaux Jardins. Pour ce quii eft de la quatriéme Partie qui traite des Eatu; , on avoit eu deffein ( comme on l'avoit promis dans la premiere Edition) de la refondre entierement, \& d'y ajoûter neuf ou dix Chapitres fort utiles fur l'origine des Sources, le nivellement \& Ia jauge des Eaux', fur les Machines hy árauliques, \&c. mais comme cela a paru paffer la portée ordinaire d'un volume; $\&$ qu'il auroit été \& trop gros \& trop cher, on s'eft refervé de donner dans la fuite un fecond volume : l'on y traitera à fond, des Eaux \& des Fontaines avec nombre de Planclies, matiere curieufe \& dont il n'y a eu jufqu' rci aucun bon Traité. $L^{\prime}$ on a crû devoir divifer tout l'Ouvrage en 4 Parties ; cela en détache mieux les matieres, \& met chaque chofe en fa place. On trouvera auffi pour la commodité, une Table exacte de tout ce qui eft contenu dans ce Traité: Pour contribuer au goût que l'on a pour-les beaux Jardins ( perftuadé que lon eft prefentement, que leur culture pectit amufer les Grands fans les avilir, à 'exemple des Romains ) on donne non-feulement la maniere dinventer des deffeins de Jardins, \& de les difpofer \& ordonner fuivant la frtuation du Terrain, mais encore celle de rétablir \& de remettre en état les anciens Plants dans toutes leurs parties : ce qui peut rendre un homme confommé dans cer Art. Voilà les principales objections \& les plus raifonnables que l'on ait pû́ concilier, fans s'arrêter aux idées bizarres de quielques Architectes \& Jardiniers, qui n’approuvent que ce qu'ils font eux-mêmes. On efpere que l'attention que l'on a eu d'y répondre, joint à toutes les autres addicions, pourront être agreables au Public. Pouvoit-on trop faire pour mériter de nouveau le favorable accüeil qu'il déja bien voulu faire à cet Ouvrage. 


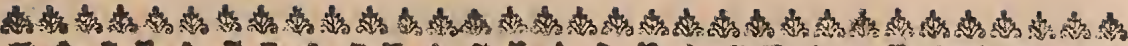

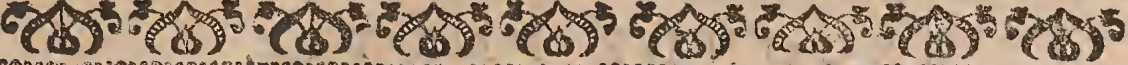

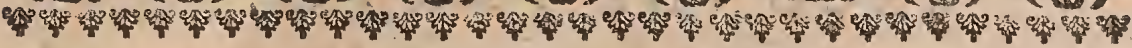

\section{T A B L E \\ DES CHAPITRES CONTENUS \\ DANS CET OUVRAGE.}

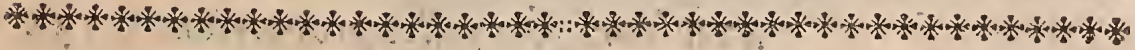
P.R E I ER E P A R TIIE.

Cha pitre I. SErvant d'Avertiffement. page I. C н A P.-II. Dela fituation du Terrain, er duchoix quion en doit faire.

C u P. III Dies Difpofitions of : p. 7

C H A P. I V. Des Parterres o Plates-bandes de differentes efpeces. $\quad \therefore$ p. 39

C н А P. V. Des Allées, Contre-allées er Palifadesp. s I

C н A P. VI. Des Bois er Bofquets en general. p.63

C H A.P. V II. Des Boulingrins ou renfoncemens de gazon, des grandes Rampes, Glacis, $T$ alus, GT Tapis de gazon, avec la maniere de lesplaquer, emer entretenir.p.75

Chap. VIII. Des Portiques, Berceaux, Cabinets de Treillage onde Verdure, Figures, $V$ ajes $\mathcal{C}$ autres Ornemens fervant à la décoration embéliffement des fardins: page 85 
CHA P I TE I. Déliminaire dequelques Pratiques de Geometrie, décrites fur le Papier, avec la maniere de les raporter fidelement furle Terrain.

page 96

C $\mathrm{H}$ A P. I I. De lamaniere de dreffer un Terrain, 2 de foüiller of tranfporter lesT erresp.IIg

CH A P. III. Des differentes Terrafjes of Efcaliers, avecleurs plus juftes proportions:p 132 CHA P. IV. De la maniere de tracer fur le Terrain, toutes fortes de Defleins.

p I 47

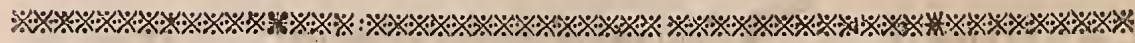

\section{TR O I S IE'M E P A R T I:E.}

Chapitre I. U choix que l'on doit faire des Arbres convenables aux $\mathrm{F}$ ardins de Propreté, er de leurs bonnes $\mathcal{O}$ manvaifes qualités.

P. 160

C H A P. I I: Delamaniere de planter toutes les differentes parties d'un beau fardin. p.195

C.H A P: III. Du foin que l'on doit prendre des jeunes Plantspour les bien 'élever, avec les moïens de les garantir des maladies infectes quiles attaquent.

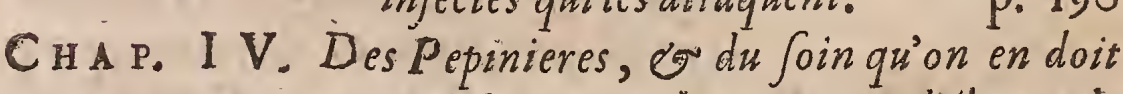
prendre, avec la maniere d'élever de graine tous les Plants qu'on emploïe dansles Fardins de Propreté p. 203

C $А$ н P. V. Des.Orangers, Fafmins, Grenadiers, Myrthes, 'o autres Arbriffeaux de fleurs, 
avec la méthode d'enélever de graine, de marcottes, 'ou de choifir ces Arbres tout grands o la maniere de les planter, greffer, o le tems où ils fleurifjent.p.213

C н A p. VI. De la culture des Orangers, 'ं des autres Arbriffeaux de fleurs, avecle moïen de rétablirles infirmes. $\quad$ P 226

- C н A P. VII. Desfleurs emploiés ordinairement dans les Plates-bandes des Parterres, avec la maniere de les Jemer, de les cultiver multiplier.

p. 250

C.нA в. VIII. De la place convenable à chaquefleur dans les Fardins, eo des differentes décorations des $P$ arterres fuivant les faifons. p. 2 ss

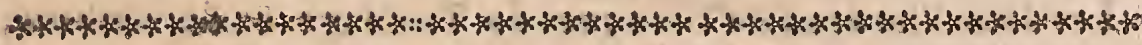

QUATR IEME PAR TIE,

Chapitre I. E la recherche des Eaux, oN des differenies manieres de les conduire dans les fardins. page 26.2

CH A P.I I . Des Fontaines, Baffins, Cafcades d'Eau, o de leur Confruition.

p. 277

FIN DE LA T A L E. 


\section{$A V I S$ A $V X$ R E L IEVRS pour placer les Figures.}

\section{P R E M I E R E P A R T I E.}

TES cing grandes Planches cotées $A$, feront mifes tout Le fuite fuivant leurs chifres, vis-à-vis la page 38 . Les deux premieres feront pliées pour être tirées hors du Livre

Les fept Planches de Parterres cotées $B$, feront placées tout defuite fuivant leurs chifres, vis-à-vis la page go. Les 5 premieres feront pliées pour être tirées hors du Livre.

La Planche de Paliffades cotée ** fera placée entre les pages $62 \& 63$.

Les dix Planches de Bofquets cotées $C$, feront mifes tout de fuite fuivant leurs chifres, entre les pages $74 \& 75$. La feptiéme fera mife en hauteur.

Les deux planches de Boulingrins, cotées $D$, feront placées entre les pages $78 \& 79$.

Les deux Planches de Portiques de Treillage \& de verdure, cotées $E$, feront placées entre les pages $90 \&$ 9.I.

$$
S E C O N D E \text { P A R T I E }
$$

T ES quatre Planches de Pratiques de Géometrie cotées $L_{F}$, feront pliées pour être tirées hors du Livre, \& feront mifes tout de fuite fuivant leurs chifres vis-à-vis la page îs 8.

La Planche de Terraffes cotée $G$, fera pliée pour être tirée hors du Livre, \& fera placée vis-à-vis la page I 38 .

Les trois Planches d'Efcaliers dé pierre \& de gazon, cotées $H$, feront mifes tout de fuite fuivant leur chifres entre les pages $146 \& 147$.

La Planche cotée $I$, fèra pliée pour être tirée hors du Livre, \& regardera la page $x$ so.

La Planche cotée $K$, fera pliée pour être tirée hors du Livre, \& regardera la page 156 .

II n'y a point de Planches dansla troifiéme Partic.

$$
\text { QUA TR I E' ME PAR T I E. }
$$

T A Planche de Cafcades cotée $L$, fera mile entre les pages $290 \& 25 \mathrm{I}$. 


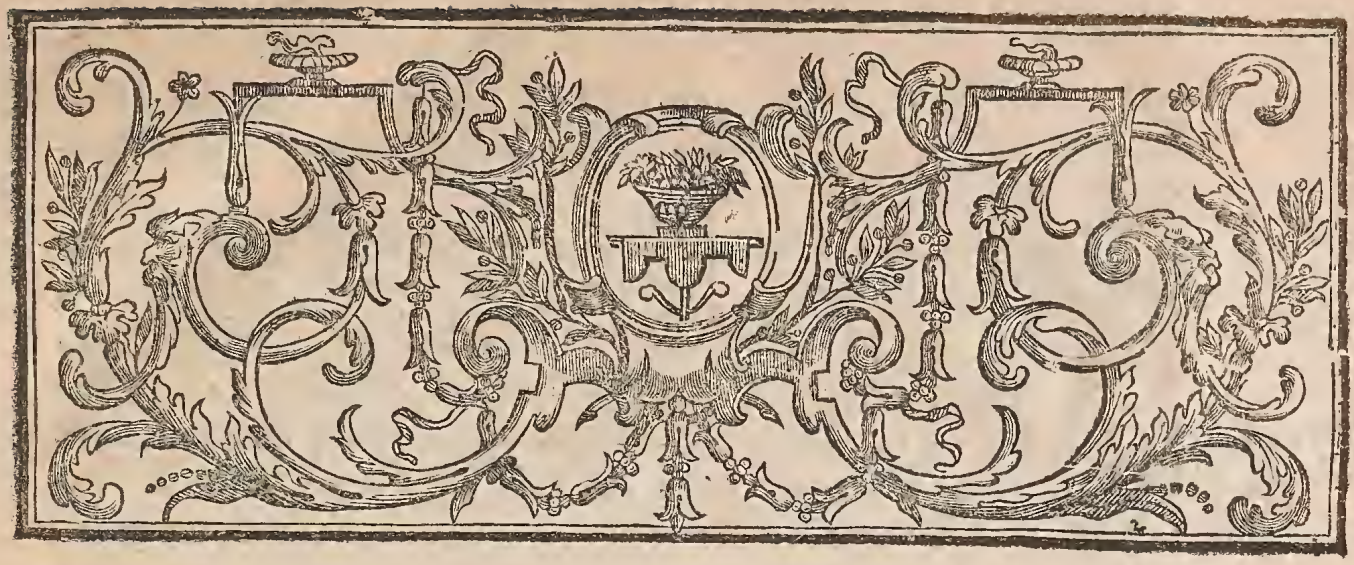

\section{PREMIERE PARTIE}

\section{QUI CONTIENT}

\section{A THEOR I E \\ D U}

J A R I N A G E.

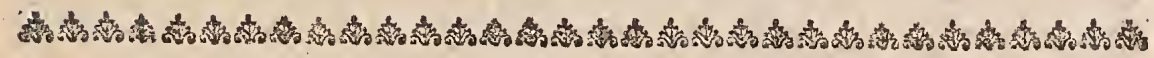
CHAPI TRE PREMIER.

\section{$\Im E R V A N T$ \\ D'AVERTISSEMENT:}

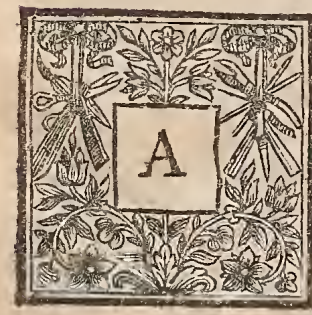

PRE'S avoir examiné la plûpart des Art. teurs, qui ont écrit de l'Agriculture \& dı Jardinage, l'on n'en a trouvé aucun, qui fe foit étendu fur la matiere qu'on a entrepris de traiter. C'eft ce qui d'abord avoit prefque ôté le courage d'y travailler, ne pouvant efperer aucun fecours étranger. On s'écarte aifément dans une route dont perfonne ne rous a fraié le chemin. Ainfi l'on peut dire fansvanité, qu'il y a 
du nouveau dans cet Ouvrage, \& cela doit engager les Lec? teurs à excufer les fautes qu'ils y trouveront; il pourra venir dans la fuite quelque main plus habile, qui perfectionera ce qu'on ne fait qu'ébaucher.

Le deffein de cet Ouvrage eft, d'écrire des Jardins qu'on. peut appeller fardias de plaifance ou ds propreté, c'eft à dire, des beaux Jardins qu'on a foin d'entretenir proprement, $\&$ ou l'on recherche principalement la régularicé, l'arrangement, \& ce qui peut flatter davantage la vuë, comme font les Parterres, les Bofquets, les Boulingrins, ornez de Portiques, de Cabinets de treillage, de Figures, de Fontaines, Cafcades, \&c. On n'a rien negligé pour s'inftruire de fon fujet. La lecture de quantite d'Auteurs Latins, Italiens, Efpagnols \& François, quoique bonne d'elle-même, n'y a. pas fervi de grand'-chofe. Nous n'avons parmi nos FranMolet.

* Boiceau, çois, * que deux ou trois Auteurs qui aïent parlé des beauxJardins; mais ils n'ont fait qu'entamer \& qu'éfleurer, pour ainfi dire, cette matiere; outre que les delfeins qu'ils ont donnés à la fin de leurs Livres, lont d'un goût fort commun, \& ne font plus d'ufage prefentement. Les aurres qui ye:
Le Jardinier

Ia Quinti- ont écrit de l'Agriculture, ont apparemment crù cette ma-

Irançois.

L. Liger.

Le Jardiaier Solitaire.

Le Jardinier Botanifte. J.B.deTournefort. tiere indigne de leur plume; les uns parlent de la Taille des Arbres fruitiers, de la Culture des Jardins potagers, du Jardin Botanifte, \& de la proprieté des Simples, \&c: les autres du ménage des Champs, du devoir d'un bon pere de famille, d'un Laboureur \& Fermier, de la Vigne \& des Vendanges, de la Pêche, de la Chaffe, \& de la maniere de faire la Cuifine, \& toutes fortes de Confitures, en quoi l'on voit Le Jardinier la difference de cet Ouvrage, d'avec les leurs.
Fleurife.

Liebaut.

La paffion que l'Auteur a toûjours euë pour l’Agricul-

De Serres. ture \& pour le Jardinage; le féjour de Verfailles \& de Paris, dont les environs font autant de merveilles en ce genre; le plaifr qu'il s'eft fait de parcourir toutes leurs beautés, \& les foins qu'il a donnés à faire planter plufieurs beaux Jardins, l'ont porté à faire des remarques de tems en tems; la Nacure qu'il a confultée tant de fois, la pratique du Terrain, une longue experience, \& le comnierce qu'il a eu avec les plus habiles gens de la Profeffion, ont pù lui acquerir quelque lumiere là-deffus; les fautes confiderables. 


\section{IA THEORIE DU JARDINAGE'}

\& les dépenfes inutiles qu'il a remarquées en plufieurs Jardins, jointes à l'ignorance de la plû part des Jardiniers, l'ont enfin déterminé à faire part au Public de fes obfervations.

Il y a même lieu de s'étonner, que tant de gens aïant écrit des Jardins Fruitiers \& Potagers, il ne s'en foit trouvé aucun jufqu'à prefent, qui ait parlé à fond des fardins de propreté, qui fans contredit, font les plus beaux \& les plus nobles de tous; quoiqu'en dife un * Auteur moderne, qui tâche de donner la préference aux Fruitiers \& aux Potagers: en effet, y a-t-il rien de plus agréable \& de plus délicieux, qu'un beau Jardin, bien difpofé \& bien entretenu, rien dont l'afpect contente plus les yeux, \& donne plus de fatisfaction aux gens de bon goût.

Ce n'elt pas qu'on blâme les Jardins Fruitiers \& Potagers, ils ont leur mérite; l'on convient même qu'il en faut avoir, \& que pour compofer un Jardin parfait, ils font auffi neceffaires que les Parterres \& les Bofquets; nous avons des exemples de cela dans les plus magnifiques Jardins, où les Fruitiers \& les Potagers font auffi curieux à voir que le refte. Cependant tous ces Potagers, tous ces Fruitiers, quelque beaux qu'ils puiffent être, font toû jours placés dans des lieux écartés, \& feparés des autres Jardins; preuve évidente qu'on les croit plus neceffaires pour l'utilité d'une maifon, que pour en augmenter la beauré \& la magnificence: ce font de ces chofes qu'il faut aller chercher pour les voir, \& qui d'abord ne fe doivent point prefenter à la vî̈ë d'un beau Jardin.

On fçait bien que tout le monde ne fera pas de cet avis, fur tout les perfonnes qui ont écrit des Fruits, \& ceux qui les aiment; ils font confilter toute la perfection de l'Art du Jardinage, \& toute la beauté d'un Jardin, dans un Potager, dans un Fruitier planté en Quinconce, \& en de longs Efpaliers; c'eft oì ils renferment \& bornent tous leurs defirs en fait de Jardinage; ils comptent les Parterres, les Bofquets \& le refte pour rien : Ils crö̈ent même fous prétexte qu'ils fçavent tailler un arbre fruitier, \& drefier une planche de potager, avoir une parfaite connoiffance des Jardins de propreté, dont la difpofition \& la culture font tresdifferentes. S. Cloud, Meudon, Sceaux, Chantilly:

* La Quina \&c. 
On ne croit donc pas que cet Ouvrage paiffe être fort utile à ces fortes de gens; ils font infenfibles à toutes les beautés dont il traite, \& l'interêt chez eux l'emporte pardeffus toutes chofes : ils aiment mieux avoir un Jardin femblable à une pleine campagne couverte de Pommiers, de Cerifiers, \&c:ou bien à un Marais rempli de legumes, que de joüir d'un beau \& d'un magnifique Jardin. Cet efprit de ménage heureufement n'eft pas general, \& ne regarde point les perfonnes dont les penfées font plus nobles \& plus élevées, \& pour lefquelles en partie, l'on a eu deffein d'écrire, afin de faciliter l'execution de leurs belles idées, \& de donner lieu à leur bon gout de fe montrer au Public. On fe flate que ce Traité leur fera de quelque utilité, \& leur fervira de guide, quand ils voudront planter un beau Jardin.. Il eft toḱjours fûr, qu'un Jardin tel quion le propofe dans les Chapitres fuivans, fera plus d'honneur à un Particulier, que tous les plus beaux Fruitiers \& Potagers du monde, qui font connoître que leur. Maître fonge plus au profit, qu'à toute autre chofe.

On fuppofe donc un Particulier riche, \& curieux de Jardinage, qui veut faire la dépenfe neceffaire pour planter un beau Jardin. On le conduit pas à pas depuis le choix qu'il. doit faire d'un bon terrain, jufqu'a l'execution \& derniere perfection de fon Jardin, en l'inftruifant de tout ce qu'il doit 'çavoir, pour n'être point.trompé par les gens de la Canıpagne, \& par les Ouvriers qu'il emplö̈era dans fes travaux.

On lui donne les mö̈ens de connoître les bons Plants, de les bien planter \& élever en peu de tems, la maniere de faire des Bafins, des Fontaines jailliffantes, \& d'en conduire les Eaux dans fon Jardin; celle de conftruire des Terrafles, des Efcaliers, \&c. \& fur tout de fe former un bon goutt l'égard des difpofitions gencrales de Jardins, \& des deffeins de Parterres, de Boulingrins, de Bofquets, Treillages, Cafcades, $z$ autres ornemens convenables; ce quil connoîtra par les 32. Planches qui font inferées dans ce Volume..

On pretend auffi inftruire à fond ce riche Curieux de ce qui regarde les Jardinages, enforte qu'il puiffe lui - même dreffer un terrain, aligner \& tracer fon Jardin avec fes domeftiques, fans être obligé d'avoir recours aux gens du métier. Mais il faut pour cela qu'il aime la Campagne \& l'Agri- 

les perfonnes les plus qualifiées, que plufieurs Rois \&. Princes n'ont pas dédaigné après leurs travaux guerriers, d'y donner quelques foins. Les anciens fur tout s'en faifoient un fort grand honneur.

Suppofé même que des affaires, ou quelque Clrarge publique, ne permifrent pas à notre Curieux de s'appliquer luimême à planter \& à élever fon Jardin, la lecture de cet Ouvrage ne laifferoit pas de lui être fort utile : il feroit fùr, en fuivant les préceptes qu'on y donne, de n'être point trompé, \& de fçavoir à quoi s'en tenir, quand il s'entretiendroit avec des Ouvriers touchant quelque Ouvrage qu'il a deffein de faire. Il retiendruit dans le devoir fon Jardinier, qui fçauroit que fon Maître a de la connoiffance dans cet Art; au lieu que quand ces fortes de gens voïent, qu'au lieu d'entendre le Jardinage, il n'en fçait pas. même les principaux termes, ils ne font point de difficulté de lui en faire accroire, \& fe mettre fur le pied de le reprendre, \& de rire quelquefois de fes demandes. Outre qu'un Jardin en eft toujours mieux, quand il a l'oil d'un Mâtre un peu connoilfeur.

Quoiquel'on fe propofe ici d'inftruire un Particulier, \& que ce foit en partie l'intention que l'on a eue, l'on compte cependant, que cet Ouvrage ne fera pas moins utile aux Jardiniers \& aux gens de la Campagne, qui la plûpart n'ont qu'une mauvaife routine, \& un méchant goût en fait de deffein de Jardinage; ils trouveront ainfi que les gens du métier, la vräie methode d'inventer \& de difpofer facilement tous les deffeins de Jardins, felon les differentes ficuations du Terrain: Ce Traité fervira aufi à inftruire à fond les jeunes Jardiniers, $\&$ à affermir ceux qui ne font pas tout à fait fi novices, dans ce qu'ils fçavent de bon, \& à les fortifier \& éclairer fur bien des chofes. C'eft ce qui a engagé à. écrire pour tout. le monde, \& à emplö̈er un ftile fimple, convenable à la matiere, \& à la portée des Jardiniers, fuivant ce précepte: d'Horace.

\section{Ornari res ip a negat, contenta docer:}

Il ne refte plus qu'à dire un mot touchant la divifion do ce Traité 2 dont les titres fe trouvent ci-deffus dans la Table

Imperatorum olima mas ribus colebantur agri, éc. Pliil. Hift, nai, Li 18. c, 3 .

Infelis agey cujus dominus villicum audit, nors docet. Colue mella lib. 2 ; 


\section{PREMIERE PARTIE, ChAP. I.}

des Chapitres. Il eft divifé en quatre Parties, qui contiennent en tout vingt-deux Chapitres.

Dans la premiere Partie l'on apprendra toute la Theorie du Jardinage, étant neceffaire, comme l'on fçait, d'être inftruit de la Theorieavant la Pratique, qui n'eft que la fuite \& l'execution des confequences, \& des certitudes que l'on en tire. Cette Theorie eft remplie de regles generales, de mefures \& de proportions des Parties d'un Jardin; elle eft appuïée par des Exemples \& des deffeins affés bien imaginés, qui renferment toute la délicateffe $\&$ le bon goût de l'Art du Jardinage. L'on a expliqué ces deffeins par de petites defcriptions particulieres, pour en donner une plus parfaite intelligence. C'eft ce qu'on trouvera dans les huits premiers Chapitres.

La feconde Partie enfeigne la Pratique de tracer,ce qui eft le plus de confequence à fçavoir, \& auffi ce qu'on n'a point encore donné au Public jufqu'à prefent, comme la maniere de dreffer un Terrain, foit de niveau, en pente douce, ou en Terraffes, \& d'y tracer \& executer toutes fortes de deffeins les plus difficiles; le tout démontré par des principes \& des figures de Geometrie, \& prouvé par quantité d'experiences \& d'ufages, qui lont des chofes de fait.

La troifiéme Partie renferme la maniere de planter \& d'élever en peu de tems, les plants \& les fleurs qui conviennent aux Fardins de propreté.

Enfin la quatriéme \& derniere Partie donne la méthode de rechercher les Eaux, de les conduire dans les Jardins, \& d'y conftruire des Baffins, des Fontaines, \& des Cafcades.

On peut dire certainement qu'il ne manquoit plus que ce Traité pour la perfection de l'Agriculture \& du Jardinage; les Fruits, les Potagers, la Culture \& le ménage des Champs ont été traités plufieurs fois, \& affés bien, pour qu'il ne foit pas neceffaire d'en écrire de nouveau. Il n'y avoit que les beaux fardins de propreté, dont on n'avoit point encore parlé affés amplement. On eft fûr en joignant tous ces differens Traités enfemble, de fe rendre un parfait Jardinier, \& de pouvoir former un Jardin complet en toures fes parties. 


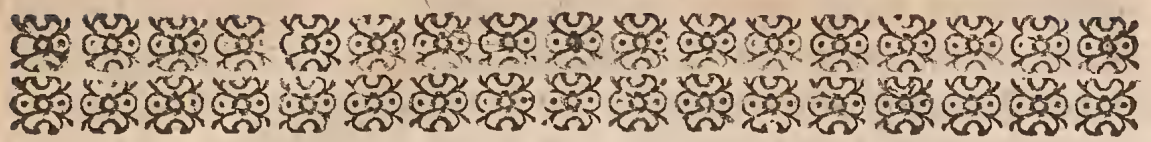

\section{H A P I T R E I I.}

\section{DE LA SITUATION DU TERR AIN, of du choix quion en doit faire.}

T A premiere chofe, \& la plus effentielle qu'on doit ob1 ferver, en choifffant un endroit pour planter un Jardin, eft la fituation \& l'expofition du Terrain. C'elt de-là que dépend la réüflite d'une entreprife : car fi l'on fçait faire un bon choix, les arbres deviendront beaux \& grands en peu de tens, au lieu que fi l'on s'y trompe, tous- les foins. \& toutes les dépenfes qu'on pourroit faire deviendront inutiles.

Il eft prefque impoffible dans un mauvais Terrain d'élever un beau Jardin, quoiqu'il y ait des mo:̈ens pour ameliorer les Terres, ils font de grande dépenfe, \& fouvent il arrive que tout un Jardin périt, quand les racines des arbres ont atteint le fond naturel du lieu, quelque dépenfe que l'on ait fait d'y faire rapporter de bonne Terre.

Certe ficuation elt de fi grande confequence, que tous les. Auteurs qui ont traité jufqu'à prefent l'A griculture, fe font toûjours fort étendus fur fa neceffité, \& fur le bon choix qu'on en devoit faire. L'on ne s'amufera point ici à citer tous. ces Auteurs: on fe contentera feulement de rapporter ce qu'en. dit* Vitruve, en parlant de la fituation des Míaifons de Campagne, il dit, ** qu'il faut avoir égard dans la fituation d'une Maifon de Campagne à la région de l'air, au climat, \& à la commodité du lieu : qu'il faut choifir un endroit accefible, fertile, abondant de foi-même, \& voifin de Rivieres \&z de Ports capables de lui fournir toutes les commodités des lieux circonvoifins : qu'il faut fur tout qu'un lieu foit fain, qu'il ne doit pas être fitué dans un endroit bas \& marécageux, à caufe de la corruption caufée par l'haleine infectée des ani* Famear Architecte du tems: "d'Augufte.

\section{"} "** Liv. $\nabla$ III. ch. I.

"Trois cona ditions requifes pous "tendre un. lieu fain. maux venimeux qui s'y engendrent, d'ou naiffent quantité “ 
* Liv.vir., eh. IX.

Pritandum eft autem quod plerigue fecerunt aqua causa, villas in infimis vallibus mergere, is pascorum dierum voluptatem priferre habitatorum $\int a-$ luti. Palladius de re rufica lib. $I$. tit, XVI.

* Rambouiillet.

Dampierre. Liancourt.

Palus omnimodo vitanda eft; quia Jiccari confuevit aftate, eo propter peftilentiam vel animalia hortis inimica qua senerat. Columella lib. 2 .

* On dit vul. gairement la mi-côte.
PREMIERE PARTIE, CHAP.II.

d'humeurs \& de maladies: qu'il ne doit pas auffiêtre fitué dans un lieu trop élevé, afin d'être moins fujet aux brouillards \& aux grands vents qui ravagent \& renverfent tout; Ex enfin que la Maifon ne doit point être toumée au Midi ou au Couchant, parce que le chaud affoiblit les corps, \& le froid les'affermir trop. Dans un autre endroir * il dit, que pour bien fituer une Maifon de Campagne, il faur confiderer en premier lieu, quelle expoficion ent la plus faine, \& tourner la Maifon de ce côté-là.

En effer, c'eft à quoi l'on doit le plus prendre garde, Quel défagrément feroit-ce de bâtir une Maifon de Campagne, \& de planter un Jardin, dans un lieu qu'on ne pût habiter que quatre mois de l'année, fans alterer fa fanté, comme il y en a un grand nombre? * Tâchons donc d'éviter ce défaut autant qu'il fera poffible, \& voïons quelles conditions font neceffaires à une bonne fituation.

Il y en a cinq principales; la premiere, une expofition faine, la feconde, un bon terroir ; la troifiéme, l'eau ; la quatriéme la vûe d'un beau Païs ; \& la cinquiéme, la commodité du. lieu.

La premicre eft une expofition faine, c'eft à dire, un lieu qui ne foit point fitué ni trop haut ni trop bas; trop haut, parcequ'un Jardin feroit trơp expofé aux vents, quifont tresnuifibles aux arbres; trop bas, parceque l'humidiré des lieux bas \&r marécageux, caufe des humeurs, des fluxions, \& plu. fieurs autres maladies; outre un mauvais air qu'on y refpire provenant des Crapauds, des Couleuvres, des Serpens \& autres animaux venimeux, qui s'engendrent dans les eaux des Etangs \& des Marais.

C'eft ce qui doit nous déterminer à fuir les fituations des montagnes, \& celles des fonds \& des. vallées. Il y en a de deux autres fortes qui font infiniment meilleures, \& c'eft celles-là qu'on peut appeller des fituations heureufes, comme la demi-côte \& la plaine.

La fituation de la * demi-côte eft tres-recherchée : elle eft des plus avantageufes, pourvû qu'elle ne foit point trop roide, que la pente en foit douce \& imperceptible, oit l'on puiffe avoir beaucoup de plein pied \& quantité d'eau : car fi cette pente étuit trop roide, comme pourroit être un Jardin fitué fur 


\section{IA THEOKIE DU JARDINAGE. ,} fur la cruine d'une Montagne, l'on auroit le défagrément de voir fouvent les arbres arrachés \& entraînés par les Torrents \& les Ravines, les terres d'enhaut s'ébouler fur celles d'enbas, les allées toutes gâtées, les murs abatus : en un mot on ne pourroit jamais joüir d'un Jardin propre \& bien entretenu, tandis qu'il feroit fujet à tant d'accidens. Au lieu que fi cette pente fe trouve donce, imperceptible, \& fur tout abondante en fources, elle vous donnera une expofition coute des plus raines \& des plus agréables, le haut de la Montagne vous mettant à l'abri des grands vents \& des grandes ardeurs du Soleil, vous fera joüir d'un air temperé; les eaux qui viendront du haut de cette Montagne formeront dans vos Jardins des Fontaines, des Canaux, \& même des Cafcades. Ces mêmes eaux après avoir fait leur effet, trouveront un écoulement naturel dans les vallées: Perfonne n'ignore qu'un lieu en eft beaucoup plus fain, quand les eaux n'y font que paffer fans y croupir: cela s'entend des eaux de pluye, comme des eaux de fontaine.

La fituation de la. Plaine a de l'agrément, fon terrain plat eft moins laffant pour la promenade, \& de nioindre entretien quie le Côteau : les murs de terraffè, les glacis, \& les Efcaliers n'y font point néceffaires. Les ravines \& les pluyes $n^{9} y$ font aucun dégat, ce qui eft fort confidérable dans un Jardin. On joüit dans la Plaine d'un beau pleinpied naturel, \& d'un air encore plus pur que celui de la Côte: des Campagnes vaftes, entrecoupées de Rivieres, d'Etangs \& de Ruiffeaux, de belles Prairies, des Montagnes couvertes de bâtimens \& de bois, fe prefentent fans celfe à la vûë , $\&$ forment un fond agréable, \& une perfpective naturelle qu'on nefçauroit trop eftimer, outre l'agrément de la pêche \& la commodité des Rivieres pour voiturer toutes les chofes dont on a befoin.

La plûpart des gens font fort partagés fur ce choix, les uns aiment mieux les Côteaux, les autres donnent la préférence aux plaines. On laife au Lecteur cette déeifion, après lui avoir rapporté tous les avantages de ces deux fituations. On ajoutera ici ce que les Anciens faifoient (au rapport de plufieurs Auteurs) pour connoître fi un lieu étoit fain. Ils zoient accuutumé de juger de la qualité de l'air, de l'eau
Folix borte pofitio eft cuti leniver inclia. nato planiries, minimss chrrius aque frentis per Spatia difiresta derivat. Pal= ladius de Re ruftica lib. I: tit. $x \times x \perp 1 \%$

Boycear traité du Jardinage 1. I. page 29.

La Quintinye Tome $r$. part. 2. page 165. 
\& des Fruits d'un Pays, par la conftitution du corps des animaux, qui y étoient nourris; ils en confideroient les entrailles, \& quand ils les trouvoient gâtées \& corrompuës, ils con: jecturoient de là que celles des hommes deviendroient de même, s'ils venoient habiter ces mêmes lieux.

Il eft bon de dire ici, qu'en fait de Jardinage, l'on compte quatre expofitions differentes du Soleil; l'expofition du Levant, du Couchant, du Nord, \& du Midi.

Quatre Ex- L'expofition du Levant, eft celle où le Soleil luit depuis le pofitions differentes du Soleil. matin jufqu'à Midi.

L'expofition du Couchant, eft celle où le Soleil darde fes rayons depuis leMidi jufqu'au foir.

L'expofition du Nord ou Septentrion, eft celle ou le Soleil fe montre le moins, car il n'y paroît qu'environ deux heures le matin, \& autant le foir: auffi eft-ce la plusmauvaife expofition de toutes. Elle eft oppofée entierement à celle du Midi, où le Soleil fe montre le plus ardent dans toute l'étenduë de la journée, on la juge pour cette raifon la meilleure des quatre, \& la plus néceffaire de toutes pour les Jardins.

Revenons à la feconde condition, qui eft un bon terroir, c'eft - à- dire, une terre fertile \& abondante d'elle - même. Ce ne fervit pas affés d'avoir trouvé une expofition faine, tournée au Midi, \& qui auroit tous les avantages dont on a parlé ci-devant, fi cette expofition n'elt accompagnée d'un bon fond de terre, \& d'un terroir fertile de lui-même, car fans cela l'on pourroit craindre, que tout ce qu'on y plantera ne languît pendant un tems, \& enfin ne mourût; c'eft à quoi l'on doit le plus prendre garde, fuivant l'inftruction qui fuit.

Pour connôtre fi. le fond d'une terre eft bon, il faut diftinguer premierement fi c'eft un vieux Jardin ruiné qu'on veuille remettre fur pied, ou fi c'eft une place neuve qu'on ait deffein de choifir: Si ce n'eft qu'un vieux Jardin qu'on defire replanter \& regarnir ; on fera foüiller la terre aux endroits ou l'on executera quelque deffein nouveau, foit Parterre, Bofquet, Boulingrin, \&c. Et s'il fe trouve que la terre n'y foit pas bonne, ou bien qu'elle foit ufée, l'on fera foüiller a deux pieds de profondeur par tout; lon enlevera la 
mauvaife terre, \& l'on y en fera rapporter de la meilleure quife puiffe trouver aux environs, ou bien on fera feulement retourner les terres, \& l'on y jettera du fumier dans le fond; ce qui eft d'une groffe dépenfe, mais on ne peut faire autrement : c'eft ainfi qu'on ameliore les mauvais Terrains. On eft quelquefois obligé de faire cette dépenfe, quand on achepte une Maifon de Campagne toute faite, ou qu'il nous en vient une par fuccefíon. Voila tout ce qu'on peut faire pour réparer les défauts naturels d'un ancien Jardin. Si c'eft une place neuve qu'on ait deffein de choifir en pleine Campagne, où l'on puiffe, pour ainfi dire, tailler en plein drap, il y a beaucoup plus de chofes à confiderer. On doit examiner d'abord ce qui couvre la terre aux environs: fi l'on y voit des Bruïeres, Serpolets, Chardons, \& autres mauvaifes herbes qui croiffent d'elles-mêmes, on peut juger de là que le terrain eft fort mauvais, $\&$ on le doit rebuter entierement, fans craindre de fe tromper dans ce jugement. On peut encore, s'il y a de grands Arbres près de là, remarquer s'ils font tortus, mal faits, rabougris, d'un verd alteré, \& pleins de mouffe; s'ils font tels, on fera bien de quitter cet endroit, \& d'en aller chercher un autre loin de là. Mais fi ces Arbres fe trouvent droits, élevés, vigoureux, d'un beau verd, s'ils ne font point couverts de moufe \& de vermine, \& que la terre foit couverte de bonnes herbes, comme de pâturages \& autres, cela doit engager ceux qui voudront fe fervir de ce Terrain, à en examiner de plus près la qualité.

Pour cela, dans l'efpace à peu près qu'on aura deffein de faire enclorre pour un Jardin, on fera faire cinq ou fix fouilles en differents endroits, comme aux extrêmités \& dans le milieu, pour fonder la terre, \& par là en connô̂tre la qualité. Ces foüilles doivent avoir environ fix pieds de large, fur quatre de profondeur. On fera vuider cette terre, enfuite avec la toife l'on examinera combien il y a de hauteur. de bonne terre, il s'en doit trouver trois pieds de hauteur pour bien faire, ou pour le moins deux pieds.

La terre pour être bonne ne doit point être pierreufe, Qualiez re. ni difficile à labourer, il ne faut pas qu'elle foit ni trop fe- quites à une che ni trop humide, trop fablonneufe \& trop legere, \& fur. 
* La Quintinye.

L. Liger.

Le Jardinier Erançois.

Tels font les fruits qui croiflent aux enviions de Marly.

Algus mestrix omnium virsuliorum do diveros fingulis ufus miaffrat.
12 PREMIERE P.ARTIE, CHA P. II. tout clle ne doit point être trop forte, comme font les ter res franches \& glaifeufes, qui font les plus méchantes de toutes pour les Jardins.

A l'égard de la couleur de la bonne terre, elle doit être d'un gris tirant fur le noir ; les terres blanchâtres ne valent jamais rien. Il faut encore une qualité à la terre, c'eft qu'à l'afpect, elle n'air point l'air trop fec ou trop humide , \& qu'en la maniant, elle foit d'une moiteur temperée.

Les Jardiniers Fruiticrs * ajoutent à cela que pour connoître une bonne terre, l'on doit en confulter le goutt \& l'odeur; le goût, en mettant une poignée de terre dans un verre plein d'eau : paffant enfuite cetre eau dans un linge : Si vous trouvés en la bûvant qu'elle ait un goût âpre \& amer, les fruirs \& $z$ les legumes auront le même défaut. Pour l'odeur, il faut prendre un peu de terre dans la main, \& la flairer, ce qui fera connoître fa bonne ou mauvaife odetrr.

Ces deux dernieres qualités regardent plûtôt les Fruiciers. \&. les Potagers, que les Jardins de propreté, où le goutt \& l'odeur ne font rien. Cependant, comme dans une belle Maifon les Jardins Fruitiers \& Potagers font néceffaires, on ne fera pas mal d'avoir encore égard à ces deux derniẹres qualités. Rien n'eft de plus defagréable que de manger des fruits qui ont un gôtu âpre, amer, infipide, \& qui lentent le choux ou le naver.

La troifiéme condicion qui eftl'eau, eft une des plus confiderables de toutes : outre qu'elle eft fort néceflaire à la vie; elle l'eft encore à tant de chofes, que fi elle manquoic dans une Maifon de Campagne, ce feroit une très grande incommodité, \& qui caúferoit la mortalité de tout ce qu'on y pourroit planter. Le Jardinage demande quatre ehofes, le Soleil, l'eau, la bonne terre, \& le foin du Jardinier: On en pourroit encore ajouter une cinquiéme, qui feroit l'oil du Maître, fans cela point de Jardin, \& ce feroit une folie à qui planteroir un Jardin dénué d'une feule de ces quatre chofes. L'eau fur tout eft d'une néceflité indifpenfable dans tous les. Jardins: c'eft par les arrofemens qu'on remedie aux grandes fechereffes de l'Eté, qui brûleroient tous les plants fans le fe cours de l'eau, qui tempere ces excellivè axdeurs. 
On doit donc bien prendre garde dans le choix qu'on fera d'un Terrain, qu'il s'y trouve aifément de l'eau, l'on en voit la néceffité, joint à la beanté qu'elle y ajoûtera, en formant des Jets d'eaux, des Canaux, \&x des Cafcades, qui font les pius beaux ornemens des Jardins.

Il ne faut pas aufi qu'il y ait une fi grande quantité d'ean dans un Pays, * que les terres en foient noïées: le trop n'en vaut rien pour les Jardins, ourre que cela rendroit ces lieux aquatiques \& mal fains, comme l’on a déja remarqué cidevant.

La quatriéme condition que demande une heureure fituar tion, c'eft la vû.ë \& l'ápect d'un beau Païs, elle n'eft pas fi nécellaire que les précedentes, mais elle eft une des plus agréables. Quel avantage y auroit-il de planter un Jardin dans un endroir enterré où il n'y eut aucune vû̈: Cette fituation feroit très-ennuiante \& très-mal faine: les arbres mêmes n'y viendroient pas fi beaux., ëtant trop offufqués: il n'y a rien de plus divertiflant ni de plus agréable dans un Jardin, qu'une belle vâuë, \& l'afpect d'un bean Pä̈s. Le plaifir de découvrir du bout d'une allée, ou de defius une terrafCe, à quatre ou cinq lieuës à la ronde un grand nombre de villages, de Bois, de Rivieres, de Côteaux, de Prairies, \& mille autres eliverfités qui font les beaux Païfages, furpaffe tout ce qu'on enpourroit dire ici, ce font de ces chofes qu'il faut voir pour juger de leur beauté.

La cinquiéme \& derniere condition, eft la commodité du lieu, qui doir être de quelque confidération pour un particulier, par rapport à l'utilité qu'il en peut retirer. On entend par la commodiré du lieu, qu'une Maifon foit voifine de quelque Riviere, pour y pouvoir apporter facilement tontes les chofes nécelfaires, \& en rapporter les provifions pour la Ville, ee qui eft d'une grande épargne, quand l'on les voiture par eats, qu'outre cela clle tienne à quelque Village, car dans les Maifons ifolées en pleine campagne, on ne joüit pas fi facilement des commodités de la vie, \& des fecours néceffaires en cas d'accident. Il faut encore qu'une Maifon ne foit pas éloignée d'une Forêt, pour avoir du bois aifément, que le chemin pour y aller foit beau en Hyver, comme entité, que ce foir du pavé ou bien des fables, \& B iij.

* Ainfi qu'a Rüel, Gentilly, \&sc.
Vitruve Liv, VII. ch. I. 
14 PREMIERE PARTIE, CHA P. II. en un mot, qu'on y puiffe voiturer en tout tems ce qu'on aura de befoin. L'avantage qu'une Maifon aura d'être fituée proche d'une Riviere, c'eft qu'elle aura au moins de bons puits, \& peu profonds : ( $f$ elle ne peut avoir des eaux de fource ) \& l'on pourra par le moyen d'une pompe élever les eaux, pourles conduire enfuite dans des baffins, c'eft ce qu'on expliquera plus au long dans la derniere Partie de cet Ouvrage.

Ces deux dernieres conditions ne font pas abfolument fi néceffaires que les trois premieres, qui font indifpenfables, \& pour lefquelles on doit avoir beaucoup plus de circonfpection. Cependant fi elles étoient jointes toutes enfemble, elles formeroieut une de ces fituations heureufes, qui font fi fort eftimées de tout le monde.

Voila tout ce qu'on peut dire touchant la fituation d'un lieu. Heureux font ceux qui peuvent trouver en un même terrain tous ces divers avantages! Suppofons donc, en finiffant ce Chapitre que quelqu'un ait fait un choix tel que nous venons de le dire, \& donnons lui les moyens de bien difpofer fon Terrain, pour former uu beatu \& un magnifique Jardin. 
พบพ *

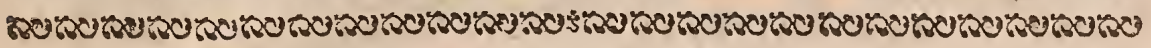

\section{H A P I T R E I I I.}

\section{$D E S \quad D I S P O S I T I O N S$, of diftributions generales des fardins.}

T A difpofition \& la diftribution d'un Plan general pour être parfaites, doivent fuivre la fituation du terrain: Car la plus grande fcience de bien difpofer un Jardin, eft de bien connoître \& examiner les avantages \& les défauts naturels du lieu, afin de profiter des uns, \& de corriger les autres, les fituations étant differentes à chaque Jardin.

La varieté \& la diverfité de la compofition, outre une fage diftribution bien entenduë \& bien raifonnée, contribuëne auffi beaucoup à rendre un Jardin parfait, puifqu'au fentiment de tout le monde les Jardins les plus variés font les plus eftimés \& les plus magnifiques.

C'eft à quoi un Architecte ou un Deffinateur de Jardins doit principalement prendre garde, quand il veut inuenter un beau Plan, en fe fervant avec art \& œconomie, des avantages d'une Place, \& en corrigeant par fon induftrie les défauts, les biais \& les inegalités du Terrain. C'eft avec ces précautions qu'il doit conduire \& regler l'impetuofité de fon genie, en ne s'écartant jamais de la raifon \& de ce qui peut s'executer de mieux, fuivant la fituation naturelle du lieu, à la quelle il doit toujours s'affujettir \& s'accommoder.

Un Architecte eft quelquefois bien à plaindre, d'être obligéde gêner fon genie \& fon bon goût, en les foumettan aux mauvaifes idées d'un particulier, fouvent entêté de fon opinion, cela fait gâter tous les jours de bons morceaux, fans que les Critiques en cherchent la vraye caufe, finon qu'ils l'attribuënt toujours à l'Architecte : c'eft la maxime generale quoiqu'injufte, mais le prix de leur aveugle complaifance. 
Un Plan général peut devenir difficile à inventer, par l'irrégularité d'une Place neuve, dans laquelle des chemins tortus, \& des enclaves de mairons voifines, affujettiffent à des formes bizarres, \& à des biais confidérables : ce peut être aufil par la chute \& l'inégalité du Terrain, qui contraignent à decertaines terraffes, qui partagent quelquefois fort mal tout un Enclos.

On fe trouve encore gêné quand on veut rajuftel un vicux Jardin fans le ruiner entierement: il faut alors en lever le Plan exactement, \& examiner chaque piece l'une après l'autre devant que de la condamner. On s'accommodera fur tout aux Bâtimens, aux Murs, aux Baffins, \& Canaux déja faits, à moins qu'ils ne foient très-mal placés, \& fans vouloir trop couper, pour réformer tous les défauts d'un Jardin, on ne corrigera que les plus effentiels : on confervera tout ce qui fera pofible, principalement les Bois, les Paliffades, \& les Allées de haute futaye, qui font très-longues à s'élever, \& qui doivent être regardées dans un rétabliffẹment, comme une chofe facrée à laquelle on ne doit jamais, ou très-peu toucher : cela demande une main ménagere \& entenduë dans cet Art \& \& non de ces gens qui abattent \& renverfent tout, pour pouvoir execter leurs deffeins bizarres. On ne voit que trop de ces exemples.

Tout cela n'eft pas fi aifé qu'on fe l'imagine; un beau Jardin eft du moins aufi difficile à inventer\& à diftribuer qu'un beau Bâtiment, cela fait que la plûpart des Archirectes, \& de ceux qui fe mêlent de donner des deffeins de Jardinage, ne réüfffínt pas toujours, la plûpart formant dés deffeins en I'air qui ne conviennent pointa la fituation du lieu, \& dont le meilleur eft pillé de côté \& d'autre.

Une des principales raifons pourquoi ces gens-là n'ont pas l'inceligence néceffaire pour compofer un beau deffein, c'eft que cette connoiffance yenant de plus loin qu'on ne penfe, ils lont dépourvûs des qualités requifes à cette perfection. Il faut être un peu Geometre, fçavoir l'A rchitecture, \& la bien defliner, entendre l'ornement, connoître la propricté \& l'effet de tous les plants dont on fe fert dans les beaux Jardins, inventer facilement, $\&$ avec tout cela, avoir une intelligence \& un bon gout naturel, qu'il faut 
LA THEORIEDUJARDINAGE.

s'être formé par la vûë des belles chofes, par la critique des mauvaifes, \& par une pratique confommée dans l'Art du Jardinage.

Il n'y pas jufqu'à de pauvres Jardiniers, qui quittant la bêche \& le rateau, fe mêlent de donner des deffeins de Jardins, où ils n'entendent rien du tout : tant pis pour ceux qui tombent dans les mains de ces fortes de gens là, qui leur font faire beaucoup de dépenfes pour planter un vilain Jardin, car il ne coute pas plus d'executer un beau deffein, qu'un mauvais: ce font toujours les mêmes arbres, les mêmes plants, qui ne font un méchant effetque par leur mauvaife difpofition.

Un homme riche qui veut planter un beau Jardin, doit faire trois chofes effentielles, choifir en premier lieu une perfonne, dont la capacité dans l'Art de Jardinage, foit déja prouvée par quantité de bons morceaux : c'eft le mö̈en d'éviter l'execurion de ces deffeins fondés feulement fur le caprice. En fecond lieu, il ne doir pas fuivre le train de la plüpart des gens du monde, qui font executer des deffeins avec une precipitation infinie, croiant par là fe donner plus de relief, en imitant les travaux du Roi, une execution $f i$ prompte réüffit rarement: on n'a pas le tems de digerer un deffein, \& de le laiffer un peu meurir avant que de l'executer : fouvent même on eft obligé de le changer l'année fuivante, faute d'y avoir fait aflés de réflexion auparavant; c'eft ce qui arrive à ces fortes de gens qui fe font un plaifir de changer \& d'abattre ce qu'à peine l'on a achevé; dépenfe terrible, joint au chagrin de ne pouvoir jamais joüir! Les Bâtimens font quelquefois du nombre de ces folies: il doir donc laiffer un Plan general expofé à la vîe ë des connoiffeurs, \& prendre leur avis là-delfus, fans en négliger aucun : il en connoîtra par là le fore, \& le foible, \& il pourra s'affurer d'une execution permanente: l'on connô̂t des défauts dans un deffein au bout de fix mois, qu'on $1 \mathrm{e}$ voyoit pas les premiers jours qu'on fe laifie éblouiir par des bagatelles. Enfin il faut qu'il fe confulte fur la dépenfe qu'il veut faire, pour y proportioner la grandeur de fon Bâtiment \& l'étenduê de fon Jardin, \& confidérer que plus fon Jardin lera grand, plus il lui coûtera à en drefier le terrain, 
à planter, à executer tous les deffeins, \& à l'entretenir de tout. S'il y a des Fontaines, les Baffins \& les Fieces d'eau deviendront plus grandes, les conduites plus longues, 8 par conféquent coûteront infiniment davantage.

Il vaut donc mieux fe contenter d'une étenduë raifonna:

Melior enim eft culta exiguitas, quidm magnitidoneglect. Pallaladius de Re ruftica L. I. rit. $x \times 287$. ble, bien cultivée, que d'avoir l'ambition de vouloir de ces Parcs d'un fi grand efpace, dont les rrois quarts font ordinairement négligés. La vraye grandeur d'un beau Jardin, ne doit gueres paffer 30 ou 40 arpens: il n'en faut pas davantage. A l'égard du Bâtiment, qui abforbe le plus fouvent la moitié de la dépenfe, il n'eft pas néceffaire qu'il foit fi grand ni fi magnifique, quoique bien des gens le piquent d'avoir des Palais, \& d'être mieux logés à la Campagne qu'à la Ville. L'on peut dire avec raifon, qu'un Bâtiment de Campagne doit être proportionné à l'étenduë du Jardin : il feroit aufli peu convenable de voir un magnifique Bâtiment dans un petit Jardin, qu'une petite Maifon dans un Jardin d'une vafte étenduë ; ce font deux extremités qu'il faut éviter, \& faire enforte que le Bâtiment réponde au Jardin, \& le Jardin au Bâtiment. Cependant il vaudroit encore micux fe contenter d'une petite Maifon, accompagnée d'un grand Jardin ; parce qu'une Maifon de Campagne doit differer de celle d'une Ville, oì la grandeur des Bâtimens cft plus néceffaire que celle des Jardins, par rapport à une habitarion ordinaire, \& à la valeur du terrain: on ne recherche même la Campagne, que pour y avoir des Jardins plus vaftes \& plus magnifiques.

On difingue quatre maximes fondamentales pour bien difpofer un Jardin: la premiere, de faire ceder l'art à la Nature; la feconde, de ne point trop offufquer un Jardin; la troifiéne, de ne le point découvrir ; \& la quatriéme, de le faire toûjours paroître plus grand qu'il n'eit effectivement, cela demande les quatre remarques fuivantes.

Ies Jardins Il faut en plantant un Jardin, confiderer, qu'il doit plus de Meudon très- extraortenir de la Nature que de l'Art, dont il ne doit emprundinaires, ceus ter que ce qui peut fervir à faire valoir la Nature. Il y a de $S$. Clond, des Jardins ou vous ne voyés que des chofes extraordinai-
de Chantilly
\& de Sceaux; res, gênées, hors du naturel, $\&$ qui ne font faites qu'à fortrès-a -aturels. ce d'argent, comme font des Murs de terraffe très-élevés. 
I A THEORIE DU JARDINAGE. I9 de grands Efcaliers de pierre, qui font de vrayes carrieres, des Fontaines trop décorées, \& quanticé de Berceaux , Cabinets, Portiques de Treillage ornés de figures, de vafes, \&xc. qui fentent plus la main de l'homme, que tout autre chofe. Cette affectation n'a pas l'air naturel, \& le doit ceder à la noble fimplicité des Efcaliers, Talus \& Rampes de gazon, de Berceaux naturels \& des Palliffades fimples fans Treillage, foûtenuës \& rehauffées en certains endroits par quelques figures \& autres ornemens de Sculpture. A l'égard des parties d'un Jardin, elles doivent être fi bien placées, qu'on les croye faites \& plantées naturellement oì elles font, par l'Auteur, pour ainfi dire de la Nature : un Bois, par exemple, pour couvrir des hatteurs ou remplir des fonds, fitué fur les â̂les d'une Maifon: un Canal, dans un endroir bas, \& qui paroiffe être l'égout de quelque hauzeur voifine, enforte que l'embeliffement \& l'Art qu'on y a donné dans la fuite, cede entierement à cette Nature. C'eft une foible raifon de dire, qu'on doit plus eftimer ce qui eft fait de mains d'hommes, par rapport aux grandes fommes que ces travaux ont coûté, que ce qui vient des mains de la Nature, à caufe que la dépenfe en a été peu confidérable : l'un eft moins bien placé \& plus extraordinaire, l'atttre moins furprenant $\alpha$ dans fa vraye place.

On ne doit pas rendre les Jardins triftes \& fombres, en les offufquant par trop de brouffailles \& de couvert, il faut laiffer regner de belles Efplanades autour du Bâtiment, \& dans de certains endroits qu'il eft à propos de tenir découverts, à caufe du bel afpect de la campagne : c'eft pour cela qu'on ne met dans les Parterres, les Terrafles, les Boulingrins, Rampes, \&c. que des petits Ifs \& Arbriffeaux, afin que n'occupant point tout l'efpace de l'air, on joüiffe d'une belle échapée.

Préfentement on tombe dans un défaut tout oppofé : c'eft de trop découtvrir un Jardin, fous prétexte de faire de grandes pieces : 11 y a vingt Jardins confidérables autour de Paris, manqués par cet endroit, \& oì il eft inutile de defcendre pour les vifiter : on les voit tout d'un coup d'œil du Veftibule du Bâtiment, fans être obligé de fe laffer ; cela n'en eft pas plus beau: l'agrément eft d'arrêter la vûë 
dans de certains endroits d'un Jardin, pour exciter l'envie d'aller voir des pieces agréables, comme de beaux Bofquets, des Salles verces ornées de Fontaines \& de Figures. Ces grandes pieces plates, \& leurs grands ratifiés dérobent, pour ainfi dire, la place des Bofquets, \& du relief qui fait Poppofition \& la varieté des Jardins, \& peut feul faire valoir tous ces morceaux unis: Cet ombrage fi néceffaire étant ôté, ne permet pas de s'y promener en Eté fans être rôti, qui eft un défaut des plus confidérables.

Ces Jardins fi découverts joüiffent ordinairement d'une belle vû̀ë fort étenduë, les murs étant en terraffe, \& n'y ayant rien qui bouche de toutes parts, mais c'eft juftement ce qui les fait paroître une fois plus petits qu'ils ne font naturellement : car étant comparés avec la Campagne voifine avec laquelle ils fe confondent, ils ne paroiffent pas plus grands, pour ainfi dire, que la main, contre la maxime fondamentale de faire toujours croire un Jardin beaucoup plus grand qu'il n'eft, foit en arrêtant le coup d'œil avec adreffe par des Paliffades, des Allées, des Bois placés à propos, \& contraints à une hauteur convenable à la vûë ; ou en pratiquant des lizieres de bois contre les murs, pour tromper agréablement par l'étenduë confiderable dont cela fait paroître un Enclos.

La proportion generale des Jardins eft, d'être un tiers plus longs que larges, \& même de la moirié, afin queles pieces en deviennent barlongues \& plus gracieufes à l'cil, une fois ou deux plus long que large, fait une place défagréable, n'étant qu'un boyau.

Voici à peu près les autres regles generales qu'on doit fuivre dans les difpofitions \& diftributions des Jardins.

Il faut toujours defcendre d'un Bâtiment dans un Jardin par un Perron de trois marches au moins, cela rend le Bâtiment plus fec \& plus fain, \& l'on découvre de deffus ce Perron toute la vî̈ë generale d'un Jardin, ou une bonne partie qui forme un afpect fort agréable.

Un Parterre eft la premiere chofe qui doit fe préfenter a la vûë, il doit occuper les places les plus proches du Bâtiment, foit en face ou fur les côtés, tant par rapport à la découverte qu'il caufe au Bâtiment, que par rapport à fa 
IA THEORIE DU JARDINAGE. 2I beauté $\&$ à fa richeffe, qui fe trouvent fans ceffe fous les ýeux, \& fe voyent de toutes les fenêtres d'une Maifon. On doit accompagner les côtés d'un Parterre, de morceaux qui le faffent valoir. Comme c'eft une piece plate, il lui faut du relief, tels que font les Bofquets \& les Palifades. Mais cela fe doit faire felon la fituation du lieu. L'on remarquera avant que de les planter, fi l'on joüit d'une belle vû̀e de ce côté-là, alors on doit tenir les côtés d'un parterre tout découverts, en y pratiquant des Boulingrins \& autres pieces plates, afin de profiter de cette belle vûë, \& fe donner de garde de la boucher par des Bofquets, à moins que ce ne foit des Quinconces, des Bofquets découverts avec des Paliffades baffes, qui n'empêchent point l'œil de fe promener entre les tiges des Arbres, \& de découvrir la belle vîuë de tous côtés.

Mais s'il n'y a point de vî̀e , \& qu'ilfe rencontre au contraire une Montagne, un Côteau, une Forêt, ou un Bois, qui par leur proximité en ôtent l'agrément, ou quelque Village trop voifin, dont les Maifons préfentent un vilain afpect, on pourra alors border le Parterre de Paliffades \& de Bofquets, pour cacher ces objets défagréables: de cette maniere l'on ne perd \& l'on ne regrette rien dans la fuite.

Ne feroit-ce pas un grand défagrément d'être obligé après quelques années, d'arracher un Bois ou de le refeper à une certaine hauteur, parce qu'il a d'abord été mal placé, ôtant la vûë qui eft la plus belle chofe des Maifons de Campagne.

Les Bofquets font le Capital des Jardins : ils font valoir toutes les autres parties, \& l'on n'en peut jamais trop planter, pourvü que les places qu'on leur deftine, n'occupent point celle des Potagers \& des Fruitiers, qui font des chofes néceffaires, utiles à une grande Maifon, \& qu’il faut toujours placer près des baffecours, afin que la malpropreté inévitable dans ces lieux, fe trouve toute réünie enfemble, par un mur qui les fépare d'avec les autres Jardins.

On choifit pour accompagner les Parterres, les deffein's de bois les plus mignons, comme Bofquets découverts à Compartimens, Quinconces, Sales vertes avec des Boulingrins, des Treillages \& des Fontaines dans le milieu : Ces

Ciij 
On voit â

Liancour, $\grave{a}$

Ruel; \& au Jardin du Roi, des bois verds, alfés beaux, \& rrèsélevés.

22 PREMIERE PARTIE, CHA P. IIT. petits Bofquets font d'autant plus agréables, étant près d'unt Bâtiment, que vous trouvés tout d'un coup de l'ombre fans en aller chercher fi loin; outre une fraîcheur qu'ils commu. niquent aux appartemens, qui eft ce qu'on recherche le plus dans la grande chaleur.

Il feroit bon de planter quelques petits Bofquets d'arbres verds, afin que dans les plus grands froids de l'Hiver, on eût le plaifir de joüir de leur verdure. Ils feroient un bel effet, étant vîs du Bâtiment, \& l'on peut en planter quelques quarrés dans un beau Jardin, cela varie auprès des autres Bois, qui par la chute de leurs feuilles, paroiffent tous nuds pendant l'hyver.

On décore la tête d'un Parterre, de Baflins nu Pieces d'eau, \& au deffus d'une forme circulaire de Paliffades, ou de Bois, percée en patte d'oïe, qui mene dans de grandes allées, \& l'on remplit l'efpace depuis le Baffin jufqu'à la Paliffade, de petites Pieces de broderie ou de gazon, ornées d'Ifs, de Caiffes \& de Pots de Fleurs.

Dans les Jardins en terraffe, foit de profil ou en face d'un Bâtiment oì l'on a une belle vùë; comme l'on ne peut pas boucher la tête d'un Parterre par une Demi-Lune de Paliffades, il faut alors pour continuer cette belle vüë, pratiquer plufieurs pieces de Parterre tout de fuite, foit de Broderie, de Compartiment à l'Angloife, ou de Fieces coupées, qu'on féparera d'efpace en efpace, par des Allées de traverfe, en obfervant que les Parterres de broderie foient toujours près du Bâtiment, comme étant les plus riches.

On fera la principale Allée en face du bâtiment, \&z une autre grande de traverfe, d'équerre à fon alignement; bien entendu qu'elles feront doubles \& très-larges. Au bout de ces Allées on percera les murs par des grilles, ou des ouvertures, avec des foffés au pied, qui continuëront les enfilades \& le coup d'œil. On tâchera de faire fervir les grilles $\&$ les percés à plufieurs Allées, en les difpofant en pattes d'oïe, en étoiles, \&c.

S'il y avoit quelqu'endroit de terre naturellement bas \& marécageux, \& qu'on ne voulut pas faire la dpéenfe de le remplir, on y pourra pratiquer des Boulingrins, des Pie- 
ces d'eau, \& même des Bofquets, en relevant feulement les Allées, pour les mettre de niveau avec celles qqui en font proches, \& qui y conduifent.

A près avoir difpofé les maîtreffes Allées, \& les principaux Alignemens, \& avoir placé les Parterres \& les Pieces. qui accompagnent fes côtés $\& z$ fa tête, fuivant ce qui convient au terrain, on pratiquera dans le haut \& le refte du Jardin, plufieurs differens deffeins, comme Bois de HauteFutaïe, Quinconces, Cloîtres, Galeries, Salles vertes, Cabinets, Labyrintes, Boulingrins, Amphitéatres, ornés de Fontaines, Canaux, Figures, \&c. Toutes ces Pieces diftinguent fort un Jardin du commun, \& ne contribuënt pas peu à le reńdre magnifique.

On doit obferver en plaçant \& en diftribuant les differentes parties d'un Jardin, de les oppofer toujours l'une contre l'autre : par exemple, un Bois contre un Parterre, ou un Boulingrin, \& ne pas mettre tous les Parterres d'un côté , \& tous les Bois d'un autre, comme aufin un Boulingrin, contre un Baffin, qui feroit vuide contre un vuide, ce qu'il faut toujours éviter en mettant le plein contre le vuide, \& le plat contre le relief pour faire oppofition.

Il faut de la varieté, non feulement dans le deffein general d'un Jardin, mais il en faut encore dans chaque piece féparée: Si deux Bofquets, par exemple, font à côté d'un Parterre, quoique leur forme exterieure \& leur grandeur foient égales, il ne faut pas pour cela répeter le même deffein dans tous les deux, mais en varier le dedans. Il feroit défagréable de trouver le même deffein des deux côtés, \& I'on peut dire qu'un Jardin ainfi répeté ne peut paffer que pour un demi deffein : c'eft une faute ou l'on eft tombé autrefois, \& que l'on évite préfentement, perfuadé que l'on eft, que la plus grande beauté des Jardins, eft la varieté. II faut encore dans une Piece en varier les parties féparées, fi un Baffin eft circulaire, l'Allée du tour doit être octogone: il en elt de même d'un Boulingrin, \& des pieces de gazon qui font au milieu des Bofquets.

On ne doit répeter les mêmes pieces des deux côtés que dans les lieux découverts, où l'oeil en les comparant enfermble, peut juger de leur conformité, comme dans les

Le Jardiri des Tuilleries pareil des deux côtés, : quelque chole près.
Comme les Bofquets de S. Cloud.

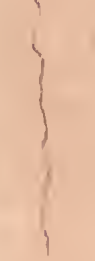


Parterres, les Boulingrins, les Bofquets découverts à comä partimens, \& Quinconces : au lieu que dans les Bofquets formés de Palifiades \& d'Arbres de Haute-Futaie, il faut toujours en varier les deffeins \& les parcies détachées, 'qui néanmoins quoique differentes, doivent toutes avoir un rapport \& une convenance entre elles, de forte qu'elles s'alignent \& s'enfilent l'une l'autre, pour faire des Percées, des Pertes de vî̀ë, \& des Enfilades très a agréables.

Eńfait de deffeins, évités les manieres mefquines, donnés toujours dans le grand \& dans le beau, en ne faifant ' point de petits Cabinets \& Retours, des Baflinets \& des Allées fi étroites, qu'à peine deux perfonnes s'y peuvent promener de frone: il vaut mieux n'avoir que deux ou trois pieces un peu grandes qu'une douzaine de petites, qui font de vrais colifichers.

Avant que d'executer un deffein de Jardin, on doit confiderer ce qu'il deviendra vingt ou trente ans après, quand les Arbres feront groflis \& les Palirlades elevées; un deffein quelquefuis paroît beau \&z d'une belle proportion dans le commencement qu'il eft planté, qui dans la fuite devient trop petit $\&$ ridicule: on eft fouvent par là obligé à le changer, ou à l'arracher entierement pour en planter un autre.

On doit prendre garde dans la difribution générale d'un Jardin, à fi bien placer les Arbres des extrêmités de chaque Allée, qu'ils ne choquent point la vîë, en échancrant les encoignures \& les angles de toutes les Pieces, on évite ce défaut $\&$ l'on forme des carrefours plus agréables à la vâ̈ë, \& plus commodes pour la promenade, que detrouver des pointes $\&$ des angles faillans qui font très-difficiles fur le terrain.

Il y a encore plufieurs autres regles touchant la proportion, la convenance, \& la place des differentes parries \& ormemens des Jardins que l'on trouvera dans les Chapirres fuivans.

Après toutes ces regles generales, il faut diftinguer les differentes fortes de Jardins qui fe peuvent pratiquer, lef. quelles fe réduifent à trois. Le Jardin de niveau parfait, les Jardin en pente douce, \& les Jardins dont lo niveau 
IA THEORIE DU JARDINAGE. $2 \xi$ $\&$ le terrain font entre-coupés par des chutes de terraffes, glacis, talus, rampes, \&c.

Les Jardins de niveau parfait font les plus beaux, tant à caufe de la commodité de la promenade, que par rapport aux longues allées \& enfilades, où il n'y a point du tout à defcendre ni à monter, cela les rend d'un moindre entretien que les autres.

Les Jardins en pente douce ne font pas fi agréables \& fif commodes, quoique leur pente foit imperceptible, elle ne laiffe pas de fatiguer \& de laffer extraordinairement, puifque l'on monte ou que l'on defcend toujours, fans trouver prefque aucun repos. Ces pentes font fort fujettes à être gâtées par les ravines, \& font d'un entretien continuel.

Les Jardins en terraffes ont leur mérite \& leur beauté particuliere, en ce que du haut d'une Terraffe, vous découvrés tout le bas d'un Jardin, \& les pieces des autres Terraffes, qui forment autant de differens Jardins, qui fe fuccedent l'une à l'autre, \& caufent un alpect fortagréable, \& des fcenes differentes : ces Jardins le peuvent difpurer à ceux ceux de niveau, pourvîu qu'ils ne foient pas coupés par des Terraffes trop fréquentes, \& qu'on y trouve de longs pleinpieds, ils font forc avantageux pour les eaux, qui fe répétent de l'une à l'autre: mais ils font d'un grand entretien, \& d'une grande dépenfe.

C'eft felon ces differentes fituations, que l'on doit inventer la difpofition generale d'un Jardin, \& la diftribution de fes parcies : cela eft fi vrai, qu'un beau deffein, qui conviendroit fort bien à un Jardin uni, \& de niveau parfait, ne vaudroit rien à executer dans un terrain coupé de plufieurs Terraffes qui en rompent le niveau \& la continuité.

Les cinq Planches fuivantes fourniffent des exemples de toutes ces differentes fituations, \& donnent l'idée de ce que l'on y peut pratiquer de meilleur goût. Les deffeins en paroîtront peut-être trop magnifiques, \& d'une trop grande dépenfe pour l'execution, aufi bien que tous les autres deffeins de cet Ouvrage, mais on n'en prend que ce que l'on veut, \& l'on trouve bien mieux fon compte dans un deffein compofé \& bien travaillé, que dans un deffein tout 
fimple. L'on en peut donc détacher ce que l'on jugera à propos. A l'égard de la magnificence, comme les Figures, Fontaines, Berceaux \& autres ornemens, on peut les retrancher, ou bien pratiquer à la place des Baffins, \& pieces d'eau, des ronds \& tapis de gazon, qui ne laifferont pas de faire un bel effet.

Quoiqu'on ait déterminé la grandeur de ces Plans generaux de $60,30,20$, ou Io arpens, on pourra néanmoins s'en fervir dans des terrains plus ou moins grands, en diminuantou en agrandiffant les parties quiles compofent.

On dira ici, pour aider les perfonnes qui ne fçavent pas la Toife, \& qui voudront fçavoir combien ces difpofitions occupent de terrain, \& chaque piece en particulier, qu'ils n'ont qu'à mefurer avec le compas 30 toifes fur l'échelle, \& les porter en quarré fur le plan : ce fera l'étenduë d'un arpent, parce que trente toifes de tous fens, c'eft-à-dire, mul. ripliées par elles-mêmes, compofent 900 toifes quarrées, qui eft le contenu d'un arpent. En lignes droites, il faut IOO. perches ou 300 toifes delong.

La premiere planche offre un des plus beaux deffeins; \& des plus magnifiques qui fe puiffent executer. Il eft fait pour un terrain plat, \& d'environ 50 à 60 arpens d'étenduë. L'on fuppofe une grande avenuë, qui conduit à la grille de l'avant-cour, féparée par les murs de deux baffe-cours furles aîles, qui font entourées de bâtimens fort réguliers; ils fervent d'un côté d'Ecuries, de Ménagerie, de Coulombier, d'Etables, de Granges, \& d'autres pieces convenables à une baffe-cour ; \& de l'autre, de logemens pour les Domeftiques, d'une Chapelle, \& d'une longue ferre, en face de l'Orangerie : cette avant-cour vous mene dans la cour du Château, qui n'en eft feparée que par un foffé rempli d'eau. Le bâtiment eft compofé d'un gros pavillon double dans le milieu, avec des corps de logis qui viennent fe joindre aux deux pavillons des bouts, en face defquels font deux petites Terraffes, d'où vous découvrés fur la gauche, un parterre de compartiment, \& au - deffus une piece de gazon, entourée de caiffes \& d'Ifs, avec des goulettes \& bouillons d'eau pratiqués dans le milieu. Au-de-là eft un grand Potager fermé de murs \& $\&$ compofé de deux pieces 
I A THEOR IE DU JARDINAGE.

partagées en quatre avec des Baffins. Il eft terminé par un long berceau, avec trois Cabinets en face des allées \& des Pavillons. Sur la droite, l'on y voit un pareil Parterre de compartiment, avec un Boulingrin au bout, au - deffus ce font des Tapis de gazon, coupés aux enfilades, avec des goulettes \& boüillons d'eau, ainfi que de l'autre côté. Ces pieces font terminées par une double allée de caiffes \& d'ifs, \& derriere par des niches de verdure, pour placer des bancs \& des figures. A côté eft un Parterre d'Orangerie fermé de murs ouverts par des portes de fer aux enfilades des allées; il y a un Baffin au bout, avec des cabinets $\&$ des niches de verdure pour des bancs.

Pour entrer dans le grand Jardin, vous defcendés le Perron du bâtiment, \& vous trouvés une grande allée de traverfe, terminée par des grilles de fer, \& en face une autre grande allée double, qui perce d'un bout à l'autre du Jardin, auffi-bien que les deux qui font autour des murs de l'Enclos. On voit d'abord quatre pieces de parterre; deux de broderie, \& deux de compartiment, avec des Baffins atu milieu. Elles font. accompagnées de deux Bofquets découverts, ornés de Boulingrins. Au deffus de ces fix pieces, on trouve uné autre grande allée de traverfe, formée par des ifs, au milieu de laquelle eft le principal baffin. La tête de ce parterre eft compofée de quatre perites pieces de gazon, avec des traits de buïs \& des ifs, \& au-deffus, d'une demi-lune de Paliffades dont l'allée circulaire vient enfiler celle qui fépare les quatres grandes pieces de parterre devant le Château. Cette demi.lune eft percée en patte d'oye, \& fes enfilades font très-belles; elles vous conduifent à d'autres Baffins, \& dans des Cabinets tous differens. Entre chaque allée, elle eft ornée de niches pour des figures, ce qui forme une belle décoration de tous les côtés. Ces Bofquets font accompagnés de deux quinconces, ornés de cabinets \& d'une falle dans le milieu, avec des figures. Il fe trouve encore une allée de traverfe, formée par les Paliffafades \& les arbres de Bofquets, oì il y a deux Baffins, dont les jets s'enfilent avec les grands de l'allée du milieu. Audeffus font quatre Bofquets percés en croix de faint André, \& tous differens. Les deux à droite de la grande allée, pré? 
fentent une falle ornée de Bancs \& de figures avec un Boulingrin, \& une autre falle avec des gradins fervant d'amphitéatre \& de téatre pour jouer la Comedie. Dans les deux à gauche, l'on y voit une falle ovale avec un Boulingrin different de l'autre, \& une petite falle de Fontaines, qui font pratiquées dans les quatre milieux, fans interrompre l'enfilade. Toutes ces pieces deviennent magnifiques dans l'execution; elles font féparées par des allées, quil s'enfilent avec celles d'en-haut \& d'en-bas du Jardin, foit par des lignes droites ou diagonales, ce qui fait des percés, \& des enfilades très-longues.

Au deffus de ces Bofquets, eft un grand Canal tenant toute la largeur du Jardin; il a dans fon milieu un grouppe de figures, comme un Neptune, avec des Tritons, d'où il fort un gros jet, \& de l'eau de plufieurs côtés. A l'enfilade de ce Canal, il y a des percés aux murs, avec des foffés pleins d'eau, pour conferver la belle vûë. Par de-là ce fon deux grands Bois de haute-futaie percés en étoiles, dont les allées font doubles \& plantés d'arbres ifolés, avec un tapis verd regnant par tout, d'où elles prennent le nom d'allées vertes. Au milieu de ces Bois font deux Inles differentes, avec des figures \& des Ifs. Au bout de la grande allée \& au deffus de ces Bois, on trouve un petit nur de terraffe, d'où l'on découvre tout le païs d'alentour; il y a un foffé plein d'eau, qui regne le long de ce mur, \&z en face de la demi-lune, au bout de la grande allée, l'on y a pratiqué une Cafcade formée par trois mafques, \& par des nappes qui retombent dans une piece d'eau, ornée de deux. jets, dont l'eau vient du Canal, \& fournit tout le foffé qui eft dans la Campagne. Cette terminaifon eft des plus magnifiques, \& fans parler davantage des.belles enfilades d'un bout du Jardin à l'autre, \& de la convenance des parties, joint à ce qu'on découvte dans toutes les allées des figures, des fontaines, des percés, des grilles, \&c. on peur convenir que ce deffein a dequoi fatisfaire par fa difpofition, fa varieté, \& par la diftribution de fes ornemens, \& defes eaux qui viennent d'un refervoir hors du Parc.

La deuxiéme Planche donne l'idée d'un Jardin, qui n'eft gueres moins beau dans fon efpece que l'autre. Il n'elt pas 
¿̀ beaucoup près $\mathrm{fi}$ grand, ne contenantque 25 arpens. Il elt fitué dans un terrain coupé de terraffes en face du Bâtiment, qu'on fuppofe planté au milieu du Parc ou d'une Campagne, où l'on a continué les enfilades d'allées à travers les bois \& les prez. On entre dans une belle avantcour, accompagnée de tapis de gazon, \& de Barrieres de bois, qui vous mene du côté gauche dans un grand Potager, coupé en fix pieces avec un Baffin, \& du côté droit dans une baffe-cour entourée de bâtimens, d'où vous paffés dans une autre cour, où il y a un abreuvoir \& un Coulombier à pied, avec d'autres bâtimens: on entre auffi par la Campagne dans cette cour, qui eft une décharge de la baffe-cour. Au deffus eft un Parterre d'Orangerie, avecun Baffin, terminé par un Berceau de treillage, de forme circulaire, orné de trois Cabinets, derriere lequel on a prariqué un petit Bofquet très-mignon. Au bout de l'avantcour, vous trouvés une grande cour bordée de galeries, de pavillons, \& d'un long corps de logis dans le fond qui rendent ce Bâtiment fort régulier.

Vous defcendés par un Perron dans les Jardins, qui vous préfentent d'abord une grande Terraffe toute découverte à caufe de la vî̈ë, \& remplie de deux pieces de Parterre de broderie, avec des plates bandes ifolées \& accompagnées de Boulingrins, dont le fond eft enrichi de pieces de gazon découpées. A côté font deux miroirs d'eau, fervant de refervoir aux fontaines pratiquées dans le bas du Jardin. On defcend de cette terraffe par les deux bouts, \& en face de l'allée du milieu, par un grand efcalier en fer à cheval, orné de trois boüillons d'eau, qui font à niveau de la premiere Terrafle, \& qui font nappe dans le Baflin d'en-bas. Sur la feconde terraffe, l'on trouve quatre Bofquets, dont deux font découverts à compartiment, \& les deux autres plantés en quinconce, ce qui n'interrompt point la vû̈e. Les deffeins en font fort gracieux, ornés de baflins \& de figures. La grande allée du milieu, \& les autres font continués, \& plantées d'ifs \& d'arbres ifolés. Il y. a un grand Baffin, avec un Champignon \& des bouillons d'eau en face de l'allée du milieu, \& d'une allée de traverfe plantée de marroniers au-deffus des Bofquets. L'allée D iij 
du tour de ce Baflin fait avancer la Terraffe en forme circulaire, où font deux efcaliers, avec des rampes, des pail. liers \& des perrons vis-à-vis des pattes d'oye, qui font percées dans le grand bois de haute-futä̈e quil eft en bas, ce qui forme une demi-lune de charmille, décorée de figures dans des niches. On defcend encore par des efcaliers pratiqués à chaque bout de cette terraffe.

Les deux rampes dn gra ad efcalier dumilieu renferment un Baffin, avec des boüillon; , qui tombent dans un autre où il y a quatre jets qui font nappe dans un bafin plus bas, ce qui compole la tête d'une Cafcade, qui regne jufqu'au grand Canal d'en-bas. Toute cette eau coule par des rigoles, \& tombe en moutonnast dans des baflins oir il y a des boüillons d'éau : à côté de ces rigoles font de petits chandeliers qui fe répetent jufqu'au bas, aufli-bien que les Baffins \& les boüillons de cette Cafcade, qui vient toute fe rendre dans le Ganal, ò dans le milieu il s'éleve un grand jet d'eau. Il y a de petites Gondoles pour s'y promener. Ce Canal fert auffi de clôture, \& fépare le Jardin d'avec le Parc. Le grand bois de haute-futaie, qui accompagne cette Cafcade, eft percé d'allées diagonales, \& d'une grande allée circulaire, où l'on trouve des carrefours, avec des pieces de gazon. Ces diagonales vous conduifent par des allées retournées d'équerre, dans quatre Cabinets tout differens. Dans les deux à droite vous trouvés un grand cercle, entourré d'une Paliffade percée en arcade, avec un Boulingrin octogone dans le milieu, \& une fallelongue coupée de niches pour des figures, avec deux renfoncemens pour des coquilles \& buffets d'eau; dans le milieu l'on voit une piece à l'Angloife, entourée d'une plate-bande de fleurs. Les deux Bofquets à gauche font compofés d'une falle verte, avec un rang d'arbres ifolés, \& d'un cloître à pans, formé par des arbres pliés en berceaux naturels, le milieu eft rempli d'un Boulingrin, avec des ifs. On obfervera que le niveau des allées de ces Bofquets, doit être raccordé avec celui des grandes allées du milieu \& des côtés, qu'on fuppofe être en pente douce, à caufe de la Cafcade.

Ia, difporition generale de la troifiéme Planche repre: 


\section{IA THEORIE DU JARDINAGE.}

Cente un Jardin fitué fur une côte, dont les Terrafles font fur le côté à la difference du deffein précedent, oì elles font en face. Les Bâtimens en font fort fimples, \& il n'y a point d'avant-cour ; ce deffein par là vient de moindre dépenfe en execution que les autres. La cour eft accompagnée de deux Pavillons, avec une grande grille, \& d'une bafle cour entourée de bâtimens, où il y a un Coulombier à pied \& un abreuvoir; derriere cette baffe-cour, il y a quatre pieces de Potager, avec un baffin au milieu. De l'autre côté de la baffe-cour, eft une petite Terraffe d'alignement au Pavillon d'entrée, \& à l'encoignure du Bâtiment, qui vous conduit le long de la cour dans le Jardin. En face du Bâtiment, vous trouvés fur une longue Terrafle, fix pieces de Parterre avec une grande allée dans le milieu, \& deux fur les côtés, avec des allées de traverfe pour féparer ces pieces, dont deux font de broderie, deux de compartiment avecun grand baffin dans le milieu, \& les deux aurres font à l'Angloife, entourées d'une plate-bande, coupée, garnie de fleurs, d'ifs \& d'arbriffeaux. Le bout de cette Terrafle eft terminé par une clair-voye, qu'on appelle autrement un ah ah, avec un foffé fec au pied. De cette Terraffe, vous montés par des efcaliers à chaque bout, \& en face du Baffin, fur une autre plus élevée, où vous trouvés un grand bois percé en étoile, avec une allée circulaire, $8 x$ huit carrefours; dans le milieu il y a une piece d'eau, avec un jet, laquelle fert de refervoir aux autres Baffins d'en bas; à côté èf une galerie verte, entourée d'arbres ifolés, \& de pieces de gazon avec des figures : cette galerie eft accompagnée d'une grande allée double, auec un tapis de gazon au milieu qui conduit vers leBâtiment.

A l'égard des Jardins d'en-bas, vous defcendés de la Terraffe en face duBâtiment, pardeux efcaliers qui vous menent fur une autre Terraffe remplie de deux Boulingrins, avec des Baffins ovales, d'un Bofquet découvert à compartiment, \& d'un quinconce, ornés de figures \& de tapis de gazon. Toutes ces Pieces font coupées d'allées qui répondent à celles des Terraffes d'en-haut. Cette Terraffe eft foû. cenuë par un talus de gazon, oì vous trouvés trois efcaliers tous differens, qui vous defcendent fur une autre Terow 
32 PREMIEREPARTIE, CHA P. III. rafle, dont la moitié eft occupée par une grande piece d'eau ou Canal, avec un gros jet dans le milieu. Le refte du terrain eft planté en bois d'un affés beau compartiment; cette Terrafie eft foûtenuë de même que l'autre par un grand talus de gazon, avec un folfé au pied, dans la Campagne. Ces quatre Terraffes font bordées' d'ifs, de caiffes, d'arbriffeaux, \& font ornées de plufieurs autres chofes que l'on connôtra aifément, fans qu'il foit befoin de les expliquer.

La quatriéme Planche contient deux difpofitions differentes de petits Jardins, pour des Maifons particulieres.

La difpofition de la premiere Figure peut s'executer dans l'efpace de cinq à fix arpens; \& cependant renferme tout ce qu'on peut fouhaiter dans un auff petit Jardin. On entre en face du Bâtiment, dans une cour ornée de tapis de gazon \& d'allées, accompagnée fur la gauche d'une baffe cour, derriere laquelle il y a une Pépiniere. Sur la droite cft un Potager fermé de murs. Le Bâtiment eft ifolé, \& par les deux grilles qui fon à fes côtés, il fépare le Jardin d'avec la Cour. C'eft un fimple corps de logis, dont les façades font differentes : celle du côté de la cour fait avant corps dans le milieu par un Pavillon, avec un Perron au bas; la façade du Jardin forme deux Pavillons à chaque bout avec des Perrons. Sur les côtés, il y a des allées de traverfe, terminées par des grilles de toute la largeur. En face du Bâtiment fe préfente un parterre coupé en diagonales ou croix de faint A.rudré, oì l'on entre par les bouts, ce qui a rapport aux deux Perrons des Pavillons. Sur les â̂les de ce Parterre il y a deux allées, qui viennenten face des grilles de la cour, \& qui font terminées par des figures \& des niches, pratiquées dans la Paliffade da Bois; à côté de ces allées font deux Bofquets, l'un une falle verte avec un Boulingrin, \& l'autre un Cloître formé par des Berceaux naturels, tous deux ornés de figures qui fe regardent. Au-deffus de ces Bolquets, on trouve une grande allée de traverfe, double \& plantée de marroniers, avec des ifs entre-deux : elle vient rendre au grand Baflin qui eft au bout du Parterre, \& qui eft vî de toutes les allées, principalement de la grande allée double, en face du Bâtiment, qui va d'un bout 
LA THEORIE DU JARDINA GE. 33 bout à l'autre. Cette allée eft très-large, \& eft percée dans un Bois de haute futäe, oì l'on trouve dans le milieu un grand cercle, oì aboutifent les allées d'une étoile pratjquée dans ce bois, \& entrecoupée d'autres allées droites., avec quatre carrefours circulaires \& des diagonales qui rendent aux deux baffins des bouts : celui qui termine cette grande allée eft à pans, \& eft vû de l'allée de traverfe dï bout. Toute cette enfilade eft terminée par une grande grille au deffus de cebaflin; \& le long du mur, eft un boïair de bois, tant pour le cacher, que pour faire paroître le Jardin plus grand. A chaque Angle il y a des niches \& des figures qui font vùës des allées du pourtour des murs, \& des allées diagonales du bois,

Dans la leconde Figure, l'on voit un Jardin un peu plus magnifique, \& plus grand de la moitié. Le Bâtiment eft parillement ifolé , mais c'eft un gros Favillon double, ä̈ant quatre perrons, dont l'un eft en face d'une cour qui le précecie, bordée de detux â̂les de Bâtiment, renfermant d'un côté un potager, \& de l'autre une baffe-cour, d'où l'on monte dans un endroit plus élevé, où il y a un réfervoir buté , pour donner plus d'hauteur aux fontaines du Jardin. Ce réfervoir eft fourisi par une pompe à Cheval, que l'on voit dans la baffe cour. Les deux' faces des côtés ont la vîuë, l'une fur un parterre à l'Angloife, \& l'autre fur un Boulingrin, ornés chacun d'un baifin. Ces deux pieces font accompaguées d'allées doubles, terminées par des foffés pour joüir de la belle vûë. Dans la principale façade du Bâtiment, on voit un grand tableau ou parterre de broderie, avec deux allées garnies de caiffes \& d'ifs, qui viennent rendre aux Pavillons des aîles de la Cour. Sur les côtés du parterre, l'on trouve deux Bofquets, l'un découvert à compartiment, l'autre planté en quinconce, tous deux percés en étoile \& ornés de figures. Au deffus de ces bofquets, on a pratiqué à l'ordinaire une grande allée de traverfe, terminée par des grilles, \& découvrant le grand ballin au bout du Parterre.

On fuppofe au deffus de ce baffin \& de cette allée qu'il y a une petite pente douce qui a obligé de foûtenir le terrain par un petit mur, avec deux efcaliers en face des con- 
tre allées du parterre. Ce mur ne regne que de la largeur de la découverte du milieu, \& l'on defcend dans les bois , par des rampes douces, qui fe raccordent au niveau des autres allées, Entre les efcaliers, il y a une petite Cafcade, formée par trois mafques, dont l'eau venant du baffin, fait une nappe dans le Canal, qui tient toute la longueur de la grande allée. Ce Canal eft cintré par le bout d'enhaut, \& eft accompagné de deux allées doubles, plantées d'ifs à l'enfilade de celle du Parterre, \& de deux bois de haute futaye qui le renferment fort agréablement, par la varieté \& la richeffe de leur deffein.

Cette difpofition, quoiqu'inférieure en grandeur \& en magnificence, à celles qui font contenuës dans les trois premieres Planches, n'eft pourtant pas la moindre de toutes, par fon heureufe diftribution, \& par les enfilades d'allées qui fe trouvent dans le milieu des Bofquets, \& qui viennent aboutir aux jets du Boulingrin \& du Parterre à l'Angloife, placés fur les aîles du Bâtiment. Toures ces pieces font bordées de grandes allées doubles, \& de pallifiades contre les murs, qui font coupés aux enfilades des allées par des grilles, \& par des petits murs à niveau des allées avec des foffés, tant au bout du Canal, que vis-à-vis les faces laterales du Bâtiment, ce qui caufe une belle découverte.

Quoiqu'on fe fut flatté que ces quatre Planches de difpofitions générales pourroient farisfaire tout le monde, l'on a cependant été obligé d'en ajouter une cinquiéme, pour répondre aux objections que quelques perfones ont faites, que les deffeins qu'on a donnés dans cet Ouvrage éroient tous fairs pour des places régulieres: \& que ce feroit une 'nouvelle dificulté de les ajuiter ou d'en inventer d'autres, dans des terrains irréguliers coupés de differens biais. Cela demande en effet de l'intelligence \& de l'induftrie, la Planche fuivante pourra contenter là-deffus. Il eft impoflible de voir des Places fi biaifées, \& fi irrégulieres fur le terrain: cela ne fe rencontre jamais en fi grand nombre : furtout avec des biais fi finguliers, \& de toute forte de formes imaginables, ce qu'on a affecté ici pour ne rien laiffer à defirer la-deffus. On trouvera encore dans la fuite des planches de parterres \& de bofquets, oir l'on a pratiqué quelques biais. pour le foulagement d'un chacun. 
LA THEORIE DU JARDINAGE.

Cette planche eft compofée de deux pecits Plans genéraux, convenables à des particuliers. Celui de la premiere Figure, eft d'environ 4 arpens, \& renferme d'auffi grandes. Pieces, \& auffi régulieres quil fe puiffe, dans un terrain auffi bizarre \& auffi extraordinaire. L'iffuë en eft biaitée par un Bâtiment \& par un mur voifins, qui font dẹ fujettions fans remęde, aufquelles il faut s'affujettir comme l'on peut. On a ouvert audevant de la cour, une demi-lune, rachevée par des arbres de l'autre côté, avec un bout d'avenuë en face; cela tient lieu d'avant-cour.

Il fe préfente d'abord une cour proportionnée au Bâtiment qui eft un Pavillon double, avec un toit en Manfarde. Les deux portes de communication pratiquées dans les murs de la cour, menent d'un côté dans une petite baffe-courr, ớr l'on a menagé des bâtimens aux deux bouts, felon que le biais l'a put permettre, \& de l'autre dans un Potager raifonnablement grand, \& affés bien placé, par rapport à la proximité des Bâtimens : il eft coupé de 4. pieces irrégulieres, avec un petit baffin au milieu, \& tout fermé de murs. On y entre encore par une grille, en face de l'allée du grand bois, pour continuer lienfilade. En fortant du Bâtiment vous voyés un parterre à l'A ingloife tout d'une piece, dont les bouts font ornés, l'un d'une coquille de gazon ou. de marguerites, l'autre d'un baffin enclavé dans le Parterre, la platé-bande en eft coupée, \& garnie d'ifs \& de fleurs.

Pour prolonger un peu le coup d'oil, on a menagé deux. petits quinconces de fimettrie fur les â̂les du parterre, l'un bouche par un peu de garni dans le fond, le mur de clôture trop proche du Bâtiment, l'autre n'ôte rien de la régularité de la falle du grand bois: carla brouffaille du fond fe rapporte aux autres côtés, l'allée de traverfe paralelle à celle versle corps de logis, \& à l'enfilade du ballin du Parterre, avec l'allée d'un bout à l'autre, qui vient à la grille du Potager, coupent ce bois en quatre parties, dont le centre eft occupé par un tapis de gazon octogone, avec une figure vuë de toutes les allées, \& des falles pratiquées dans ce bois : elles font affes bien variés, çelle à côté de la grande allée de face, eft la plus grande, on a placé dans le haut une figure qui 
fe voit de la grille du bout, \& de deffus le gradin qui eft vis-à vis l'allée du bois: de l'autre côté de cette grande allée, l'on voit une autre falle differente, dont une fortie vient auffi aboutir à cette grille, ce qui ouvre en cet endroit une patte d'ö̈e auffi réguliere que la place la peut donner. Les bancs placés dans ces deux Salles enfilent, les uns les grilles du. bout $\&$ le baflin du Parterre, les autres les deux figures, enforte que le coup d'œil y eft agréablement terminé par tout.

Il eft bon de faire remarquer ici l'adreffe que l'on a eû en difpofant ce Jardin, \& en corrigeant fes biais : on a placé le bâtiment à un coin, \& l'on a biaifée la grande allée en face, afin de profiter de toute la longueur du terrain pour cette allée qui dans tout autre endroit, fe feroit trouvée plus courte; le bafin enclavé dans le parterre eft encore pour gagner de la place à cette grande allée, qui feroit racourcie, fi l'on a voit pris une allée autour d'un baffin ifolé. Les murs d'en-bas font redreffés par les murs du Potager $\&$ de la baffe-cour d'alignement au corps de logis, \& ceux d'enhaut par une Paliffade, avec du garni derriere. Dans l'endroit le plus large, l'on y a renfoncé un gradin de trois marches de gazon, ornés de caiffes $\&$ de pots de fleurs fur lequel on a affujetti l'allée du grand bois, aboutiffante au balin du Potager, \& cela pour décorer cette belle enfilade. L'on a placé dans liangle de cette paliffade un banc qui corrige un peu le défaut du coude. Comme dans les petits Jardins il ne faut pas percer toutes les allées d'un bout à l'autre: car on en verroit tout d'un coup l'étenduë, l'on a tâché autant qu'on a pû d'arrêter l'oil dans lés falles, afin de faire parô̂tre ce Jardin beaucoup plusgrand qu'il n'eft. Il n'y a que deux allées qui aillent d'un bout à l'autre, \& deux autres de traverfe, toutes terminées par des grilles, avec les allées du pourtour des murs à gauche, car del'autre côté à droite, l'on a pouffé les bois jufqu'au mur pour le mieux cacher, \& faire croire ces languettes de bois beaucoup plus fpacieufes. Le petit berceau dans le coin au deffus du Potager, eft encore placé là pour fauver le peu de longueur de cette allée. Ces brouffailles grofliffent certainement l'idée que l'ón a d'un Jardin, \& ne contribuënt pas peu à tromper les yeux. 
LA THEORIE DU JARDINAGE. 37 La difpofition de la deuxiéme Figure eft encore dans un terrain plus petit \& plus irrégulier que le premier : on conviendra néanmoins, fil l'on veut rendre juftice, que le coup d'œil n'y eft point bleffé dans aucun endroit, \& qu'il s'y trouve du grand dans l'ordonnance de chaque piece. L'entrée en eft réguliere en face du Bâtiment: d'un côté, c'eft une baffe-cotir, d'où l'on paffe dans un Potager diftribué affés ingenieufement, les allées en patte d'oïe venant toutes aboutir à un baffin contre le mur; l'enclos dı Potager redreffe tout ce terrain en échaudé. De l'autre côté de la cour, eft un pecit parterre à l'Angloife avec une coquille garnie de fleurs ou de marguerites, dont l'afpect eft agréable des fenêtres du bâtiment, à l'alignement duquel \& pour fermer la baffe-cour \& le petit parterre, l'on a planté de chaque côté quatre berceaux naturels en portiques qui font des merveilles fur le terrain : il y a un mur qui les ferme du côté de la baffe-cour ; mais du côté du Parterre à l'Angloife, les portiques font ouverts pour y entrer, \& viennent fe rendre dans une falle couverte naturellement, avec un banc à l'enfilade. L'os a pratiqué deux forties du Bâtiment fous chaque galerie de berceaux pour y venir prendre le frais. On trouve encore en face de l'entrée du peit Parterre un grand banc dans une niche de verdure, renfoncée dans ce boyau de bois, qui fauve tous les biais de cet emplacement.

L'efplanade en face du Bâtiment eft très-large, à caufe de la décoration des portiques: elle eft remplie par deux grandes pieces de broderie repetées, avec deux plates-bandes ifolées dans le milieu, le tout coupé de 5 allées : les contre-allées fur les aîles font bordées par un rang de maroniers plantés dans une plate-bande, avec des arbriffeaux de fleurs entre chaque arbre: elles font terminées par des figures dans des niches renfoncées dans le bois. La grille, l'allée \& le baffin du Potager, enfilent une de ces niches. Au deffus de toutes ces pieces eft un baffin long cintré par les deux bouts, avec deux jets qui viennent aux contre-allées du parterre, \& de l'allée double en face, au milieu de laquelle l'on a femé un tapis de gazon pour varier. L'allée de traverfe \& l'allée de face font percées par un foffé en 
ahah, pour joïir d'une plus belle vûë, \& pour conferres mieux le niveau de ces allées, que la place n'a pu permettre d'alonger davantage; c'eft une adreffe qu'il ne faut pas. oublier dans ces fortes d'occafions, non plus que de les continuer par des avenuës dans la Campagne. L'allée de traverfe, outre l'enfilade des deux jets du baffin, eft encore terminée à l'autre bout par un portique de treillage avec un banc. Le biais à gauche de la grande allée eft fauvé par une languette de Bois, où l'on a menagé un cabinet à l'enfilade d'un des jets du baflin, \& qui fait fimetrie avec la diagonale du grand bois : il y a encore une petite routequi fort dans la grande allée; l'on en a retourné d'équerre le bout, avec un banc en face de l'allée qui traverfe le bois pour prolonger autant qu'on peut ces fortes d'allées. Le grand bois eft coupé d'une croix de faint André ou d'une étoille : une des diagonales découvre le jet du Parterre, \& eft terminée par une figure dans l'angle du mur, l'autre l'ent par les deux percés des murs : toutes ces allées viennen rendre dans une grande falle ronde, ou fe voit un boulingrin d'une forme finguliere: Dans les quatre quarés du bois cefont de petits cabinets tous differens, dont deux font remplis de tapis de gazon, \& les autres d'arbres ifolés, avec des bancs placés à propos. Au deffus de ce bois, comme il y a une pointe qui auroit été défagréable, étant toute remplie, on l'a dégagé par une allée circulaire \& par deux petites pieces de gazon bordées d'ormes, taillés en boules, avec des ifs entre deux, cela eft fort nouveau. Il fe forme une patte d'ö̈e au bout \& en face de la figure, qui eft vî̀̈ des allées du pourtour, aúqquels on a afiujetri les perces des murs. Le biais de ce côté, qui eft un mur tournant, eft racheté par une pallifiade brouffaillée derriere:l'endroit le plus épais

Il y a en tout 8 plans generaux, dont on en trouge 7 ici tout de fuite: le 8 e. eft dans leChap. $4^{\mathrm{e}} 2^{\mathrm{e}}$. Part. a donné lieu d'y placer un berceau de treillage, avec un banc en face des falles a de l'allée du bois,

On ne fe plaindra pas que ces jardins foient trop magnifiques, n'y ayant rien de plus fimple, tant pour la difpofition \& la grandeur de chaque piece, que pour la décoration, foit des figures, fontaines, portiques, bâtimens, \&c. cela pourra contenter les perfonnes qui ont trouvé les deffeins ṕrécédens trop riches \& trop compofés pour des particuliers, 




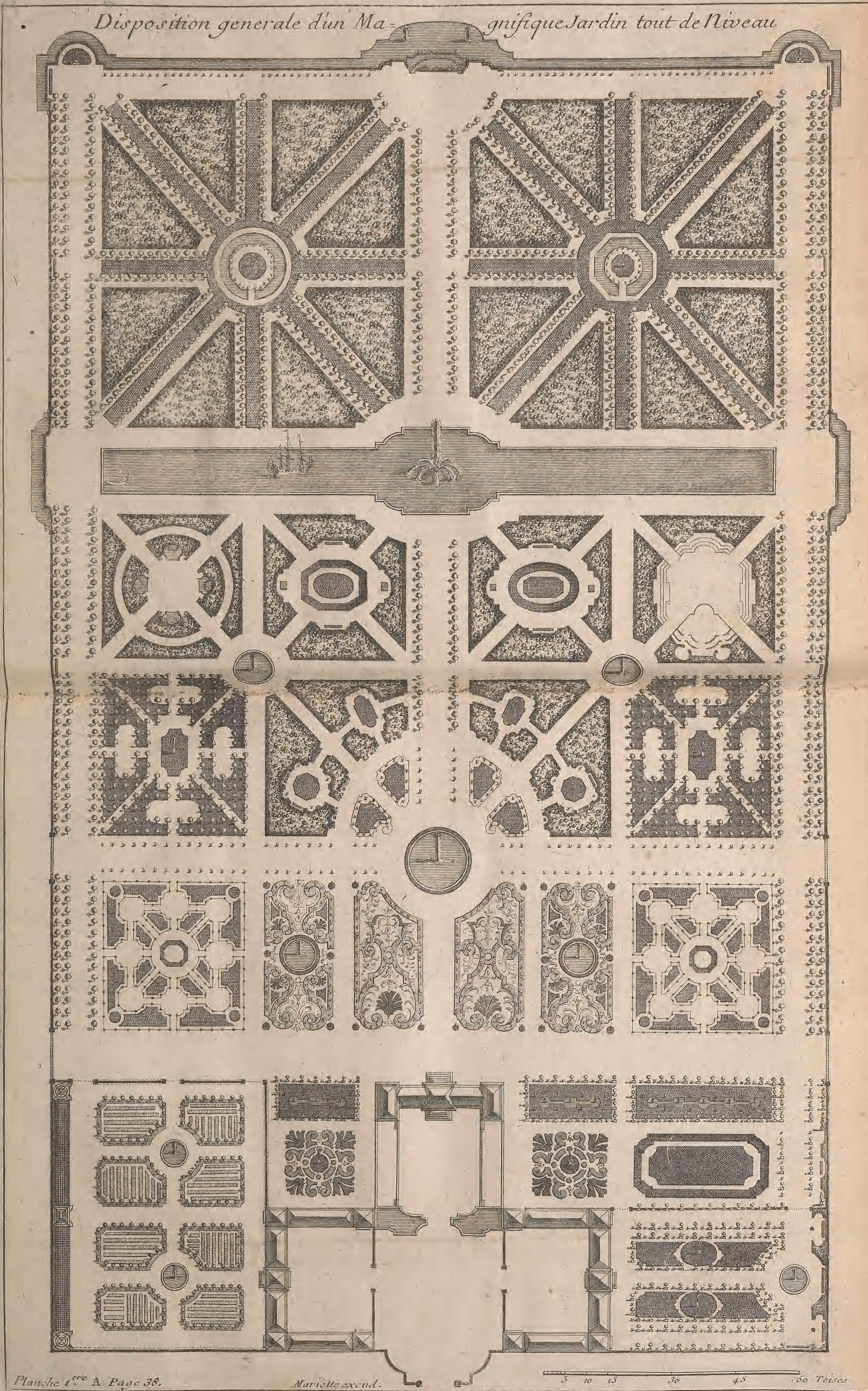




. 1

( 
Dusposition generale dün grand Jardin dont la pente est en façe du Bâtiment

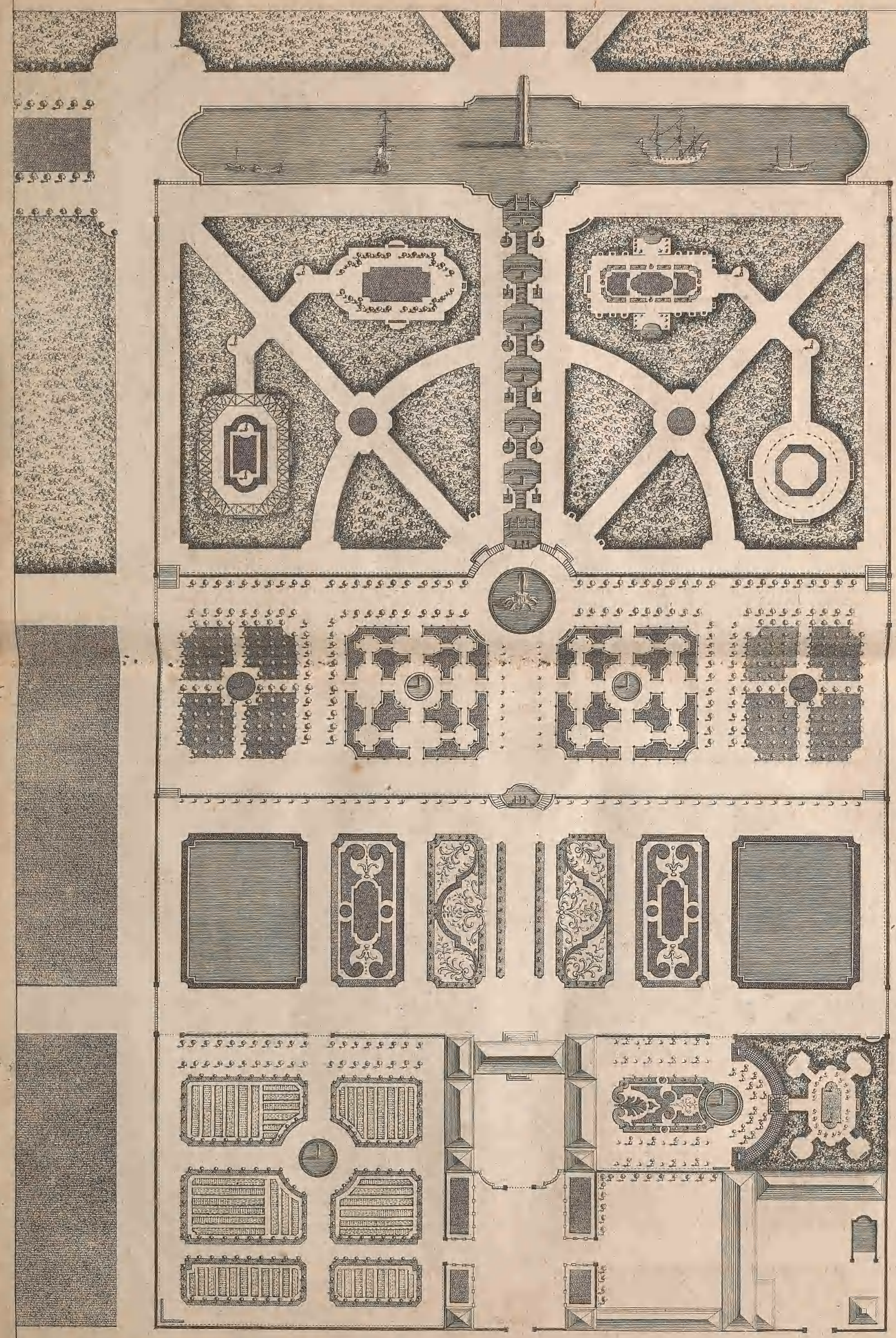

10.

95395

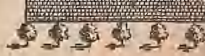
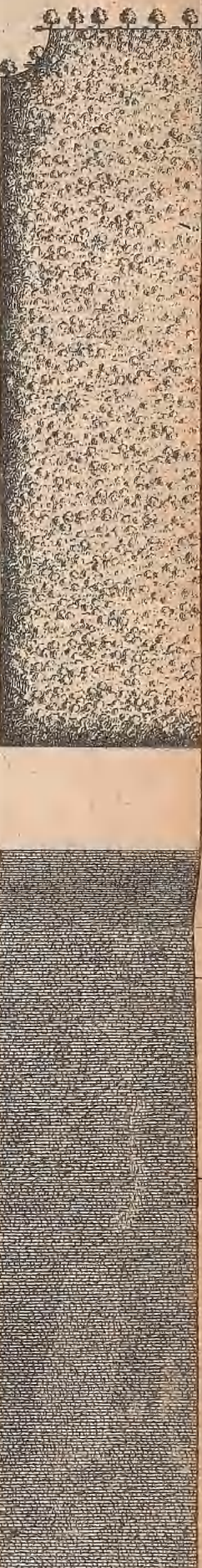




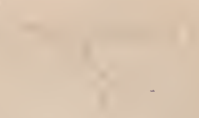




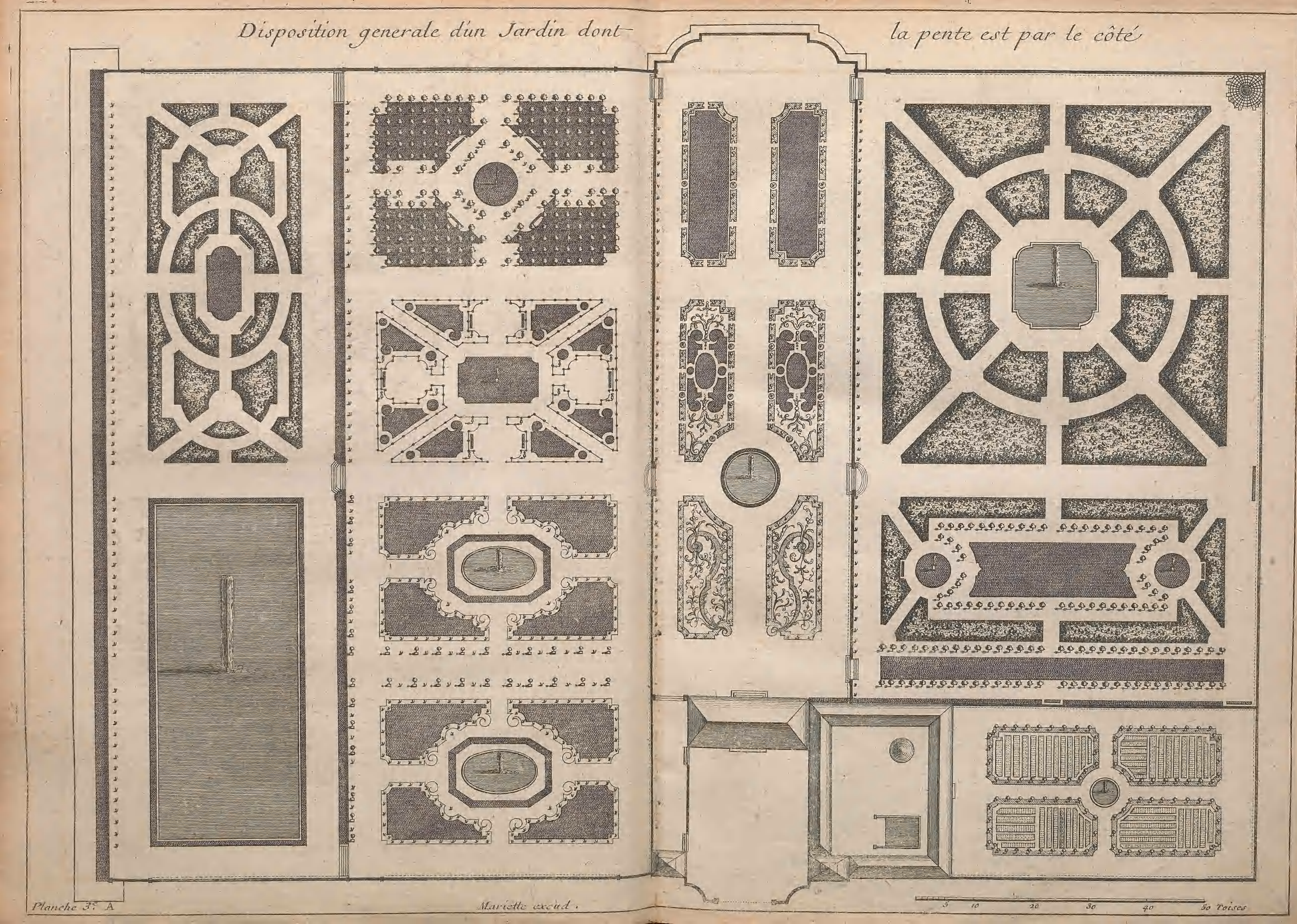



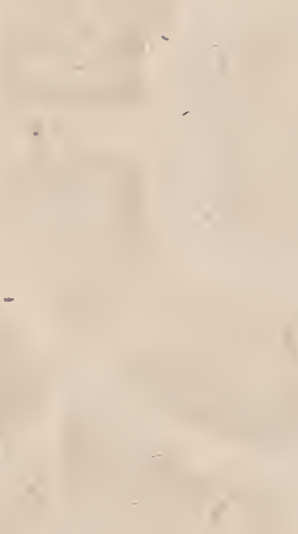

-

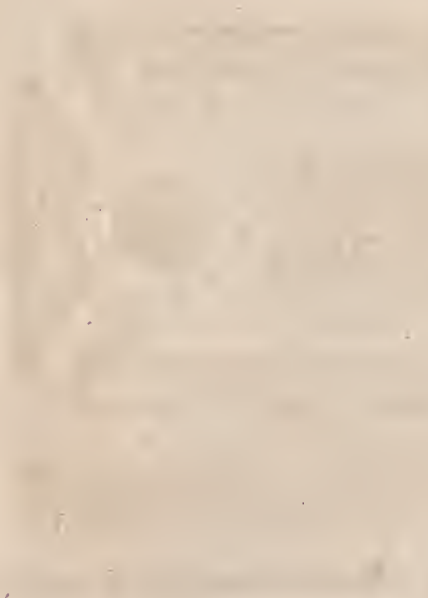

$x^{2}$

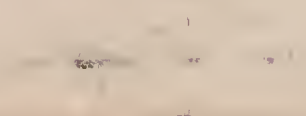




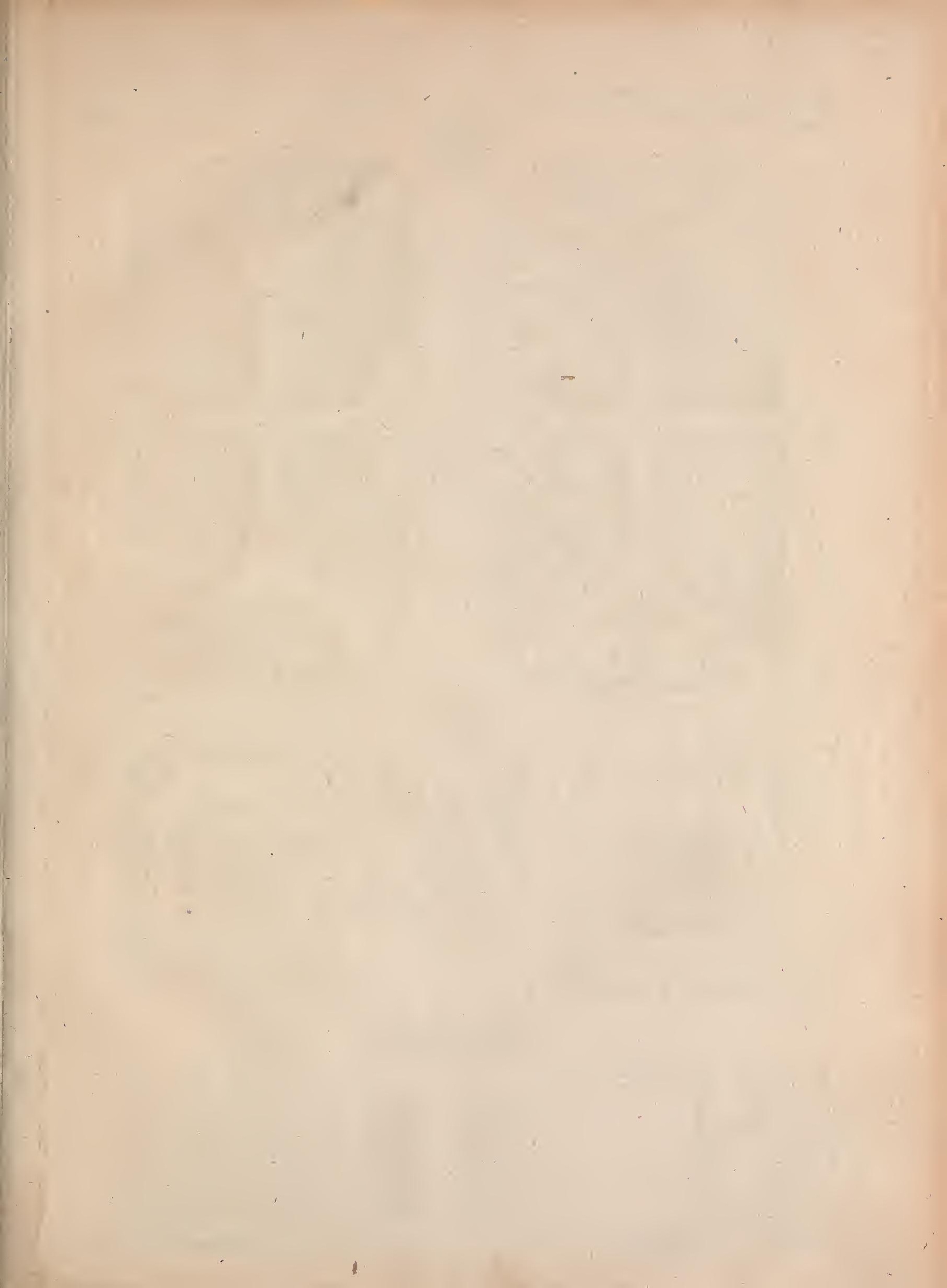





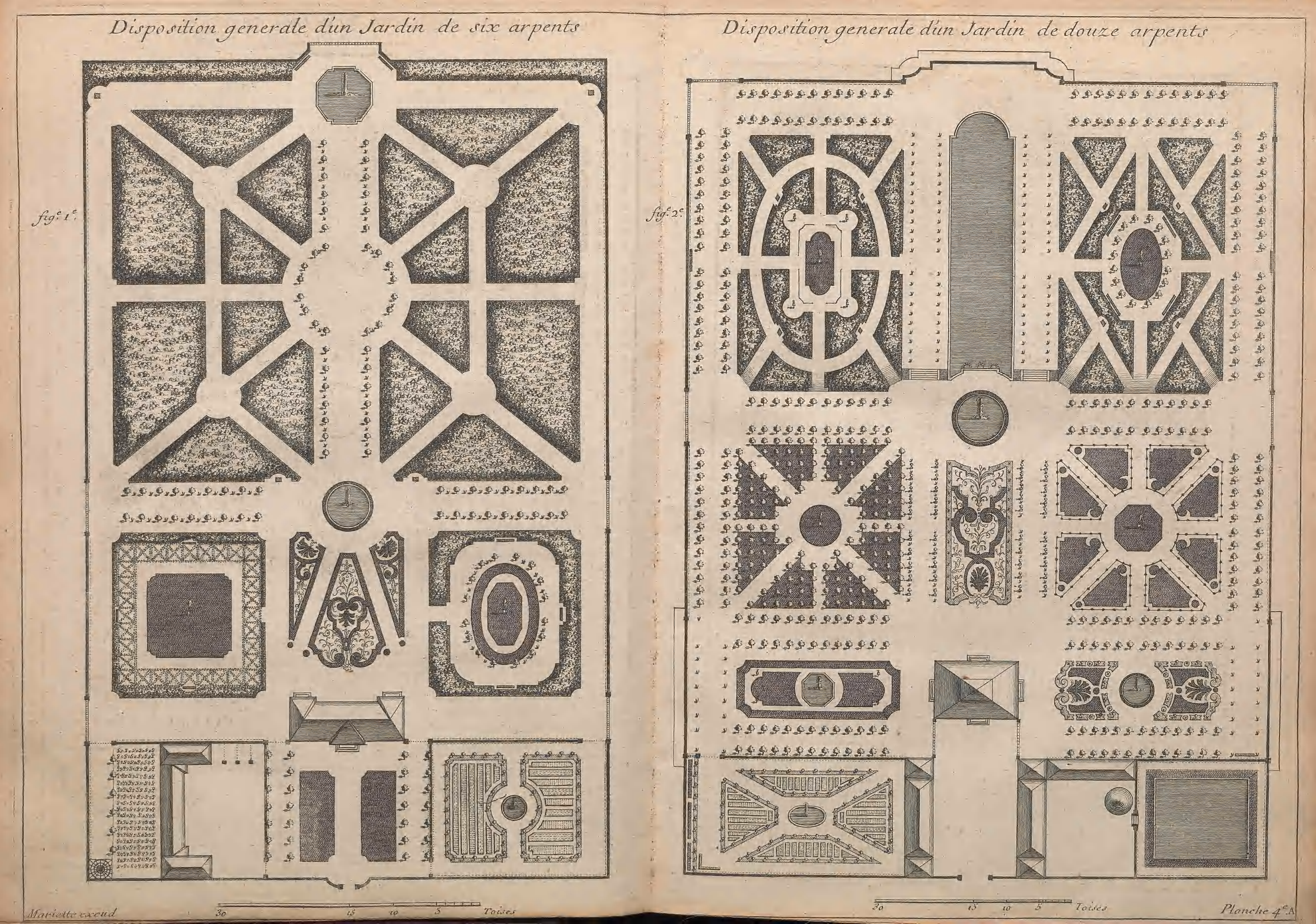








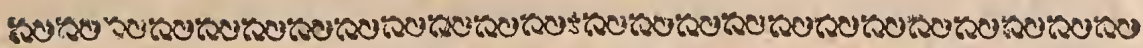

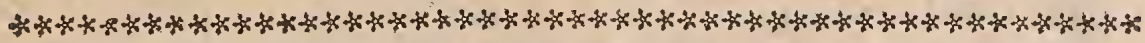

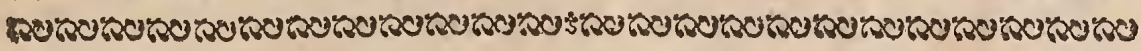

\section{H A P I T R E I V. \\ $D E S \quad P A R T E R R E S \quad E T$} Plates-bandes de differenies ejpeces.

T'Origine du nom de Parterre vient du mot Latin LPartiri \& felon quelques uns, un Parterre fignifie une Aire plate \& unie.

Les compartimens \& broderies des Parterres font tirées des figures de Geometrie, tant de lignes droites, que circulaires, mixtes, \&c Il entre dans leur compofition differens deffeins, comme rinçeaux, fleurons, palmettes, feuilles refenduës, becs de corbin, traits, nilles, volutes, nœuds, naiffance, agraffes, chapelets, greines, culots, cartouches, attaches, feüilles tronquées, dents de loup ou treffles, panaches, compartimens, guillochis ou entrelas, enroulemens, maffifs \& coquilles de gazon, fentiers, plates-bandes, \&c. Quelquefois on y joint des deffeins de fleurs, comme des rolettes, aillets, tulipes, \&c.

On y mettoit autrefois des têtes de Levrettes, de Griffons \& autres animaux avec leurs pattes \& griffes; qui faifoient un fort mauvais effet. \& rendoient ces Parterres trèslourds.

On veut prefentement des deffeins tout differens, \& l'on prétend que la broderie pour être belle, doit être legere, bien entenduë, \& fans confution, ce qui fait tomber fouvent dans un défaut oppofé à celui ou l'on étoit autrefois, c'eft qu'à force de voutoir faire les Parterres legers, on les fait tout dégarnis, \& d'une broderie fi maigre \& fi mince, qu'elle ne figure pas alfés fur la terre, \& qu'on eft obligé de la faire arracher quatre ou cinq ans après, les traits de buis fe touchant \& fe confondant - $l^{\prime}$ un dans l'autre. Il faut dans ces fortes de chofes un jufte temperamment, en évitant également

Diction. de l'A cadémic Francoife.

-Menage Richelet. 
la trop grande legereté, comme la trop grande pefanteut d'ornemens.

Il eft bon de prévenir le Lecteur fur l'idée que certaines gens veulent donner, que.les Parterres font des Pieces trèsdifficiles à inventer, \& que ces morceaux demandent plus d'attention \& de fcience que les difpofitions generales. Quoique l'on convienne, que les Parterres font les plus riches \& les plus délicates parties d'un Jardin, ils ne font cependant que les parties d'un beau tout, $c^{2} e f$-à-dire d'un Plan general. Il en feroit de même de dire, qư une chambre eit plus difficile à inventer $\&$ à décorer, que tout un grand bâtiment, dont elle ne fait que partie. Ainfi l'on doit regarder les parterres comme peu de chole pour l'invention, en comparaifon des difpoficions $\&$ des diftributions générales des Jardin.

Tous les Parterres font à peu-près femblables, la matiere s'en trouve épuifée dans 5 ou 6 deffeins, on retombe toujours dans les mêmes traits, \& la forme en eft prefqu'ordinaire: mais les difpofitions generales font toujours differentes, c'eft la fituation du lieu qui les regle : elles demandent chacune un genie nouveau, qui fçache s'aftujettir à leur nature, en corrigeant avec induftrie leur défaut, \& profitant d'un heureux emplacement: une preuve de cela, c'eft qu'il n'y a pas deux Jardins qui fe reffemblent auffi parfaitement que le font deux parterres, fans avoir affecté de les faire reffembler.

Peutêtre -quela raifon pour laquelle ces perfonnes font un miftere de deffiner $\& x$ d'inventer un parterre, c'eit qu'ils nefont capables que de cela, \& qu'un plan general, qu'un Bofquet décoré les feroient échouer facilement: femblables en cela à un Peintre, qui ne fçauroit deffiner qu'une tête, fans pouvoir achever la figure entiere C'eft peutetre aufil par un plus grand befoin que les particuliers ont d'avoir un parterre, que d'autres pieces qui ne peuvent trouver place dans leur petit jardin, \& qui par là leur paroiffent inutiles, \& infiniment au deffaus des Parterres. Au refte, quand tout un Jardin eft bien inventé, bien difpofé, \& qu'il n'y a que le Parterre qui falfe un mauvạis effet, il eft aifé de le faire arracher, les meẹmes buis refervirone 
LA THEORIE DU JARDINAGE. 4 I referviront à planter le nouveau deffein, \& cette dépenfe eft. peu confiderable. Mais il n'en eft pas de-même d'un Plan general ou d'un grand Bofquet, quand ils font une fois plantés, ils ne fe peuvent changer, fans de très-groffes dépenfes. On voit donc par là de quelle conféquence il eft qu'une difpofition générale foit bonne. Il fe trouve un grand nombre de Parterres paffables, \& même de bons, mais il y a peu de difpofitions generales parfaites \& bien raifonnées par rapport à la nature du lieu; il femble que l'on y ait toujours quelque chofe à defirer.

Il y a de plufieurs-fortes de Parterres, qui fe réduifent aux quatre efpeces fuivantes; fçavoir, les Parterres de Broderie, les Parterres de Compartiment, les Parterres à l'Angloife, \& ceux de Pieces coupées: il y a encore les Parterres d'eau, mais ils ne font plus d'ufage préfentement.

Les Parterres de Broderie font ainfi appellés, à caufe que le buis dont ils font plantés imite fur la terre la Broderie. $\mathrm{Ce}$ font les plusbeaux \& les plus riches de tous, on les accompagne quelquefois de maffifs \& d'enroulemens de gazon. Leur fond doit être fablé, afin de mieux détacher les feuilles \& rinceaux de la broderie, que l'on remplit de machefer ou de terre noir.

Les Parterres de compartiment different de ceux de Bro'derie, en ce que le deffein fe répete parfimetrie, tant en haut qu'en-bas \& fur les côtés. Ces Parterres font mêlés de maffifs \& de pieces de gazon, d'enroulemens \& plates-bandes de fleurs, avec de la broderie en petite quantité, mais bien placée : ce mélange forme un effet très-agréable ì la vûee. L'on en doitlabourer le fond, fabler le dedans des feuilles, \& l'on met du ciment dans le petit fencier qui fépare les compartimens.

Les Parterres à l'A Angloife font les plus fimples \& les moin'dres de tous. Ils ne doivent être compofés que de grands tapis de gazon tout d'une piece, ou peu coupés, \& entourésd'une plate-bande de Heurs, avec un fentier ratiffé de deux ou trois pieds de large, qui fépare le gazon d'avec la plate-bande, \& que l'on table, afin de les détacher. On lui donne ce nom de Parterre à l'Angloife, parce que la mode en vient d'Angleterre. 


\section{PREMIERE PARTIE, ChA P. III.}

Les parterres de pieces coupées ou de découpé ne font plus gueres à la mode, cependant ils ne laiffent pas d'avoir leur mérite. Ils different des autres, en ce que toutes les Pieces qui les compofent y doivent être coupées par fimetrie, \& qu'il n'y entre ni gazon ni broderie, mais fimplement des plates-bandes bordées d'un trait de buis, quifervent à élever des fleurs, \& par le moïen d'un fentier un peu large regnant autour de chaque piece, l'on peut fe promener dans tout le Parterre fans rien gâter. On doit fabler tous ces fentiers.

Les Parterres de Broderie, comme étant les plus beaux; doivent aufi occuper les principales places, \& les plus proches du bâtiment, ceux de compartiment les doivent accompagner, \& les Parterres à l'Angloife fervent à remplir de grands lieux \& dans les Orangeries : on les appelle alors Parterres d'Orangerie. Les découpés font bons pour de petits endroits où l'on veut élever des Fleurs, ce qui s'appelle aufif ParterreFleurifte.

On peut difpofer les Parterres de plufieurs façons, felon le lieu, foit en les coupant en deux longues pieces répetées avec une allée dans le nilieu, ou en ne faifant qu'un feul tableau de broderie, avec des allées fur les côtés: ou bien en les coupant par des alléés diagonales, en quatre pieces, qui forment une croix de faint André; quelquefois auffi en demi-croifée cintrée par un bout: on en verra des exemples dans les Planches fuivantes.

La meilleure maniere d'inventer un Parterre, c'eft de lự donner une figure \& une forme convenable at lieu \& aux Bâtimens, en ne le coupant pas par exemple en deux pieces, quand le terrain par fon peu de largeur, ne permet que d'en faire une feule, car c'eft gâter la place; ou en difpolant for Parterre en croix de faint André, quand la fortie du Bâtiment eft dans les Pavillons, afin que chaque allée diagonale vienne enfiler les portes.

Comme la vraye place des Parterres eft près du bâtiment, leur largeur doit être de toute la façade du corps de logis \& même plus large : à l'égard de leur longueur, elle ne doir jamais paifer une jufte proportion pour le coup d'oil, de maniere qu'on en puiffe découvrir toute la Broderie \& 
LA THEORIE DU JARDINAGE. 43 tous les Compartimens étant proche du Bâtiment : cette longueur aura deux ou trois fois la largeur, car ils fe racourciffent toujours afés à la vîë, \& les formes un peu longues font mieux fur le terrain, que celles qui paroiffent quarrées. Les rinceaux ne feront pas fi longs, afin que la vâe ne perde pas tout d'un coup l'intention generale de la Broderie, ainfi dans une grande piece l'on coupera le deffein par des Cartouches, des Maffifs \& Coquilles de gazon pour interrompre cette grande longueur: il faut toujours que la principale naiffance des rinceaux, des palmettes, \&c. forte, avec quelque efpece de raifonnement, \& fans confufion, des agraffes des enroulemens \& volutes des côtés, ou des feurons \& cartouches du milieu : lorfqu'il la faut chercher cela fait un mauvais effet.

Quand ces principaux traits font placés, le refte du terrain fe remplira de nilles, de graines, d'agraffes, culots adoffés contre les plates-bandes \& Cartouches; en forte que ne laiffant pas de grands vuides, le Parterre fe trouve efpacé également par tout. Si l'on vouloit bien faire on y mettroit peu de gazon, qui eft d'un entretien continuel. Dans de petites pieces, on peut faire au lieu de Maffifs gazonés, deux doubles traits de buis, dont le fentier foit de fable rouge, \& le milieu de terre noire ou de machefer pour détacher, mais c'eft la maniere de mettre beaucoup de gazon préfentement, \& il y a des gens qui ne trouveroient pas un Parterre beau fans gazon: c'eft une pure prévention, il y a de beaux Parterres où il n'y en a point; d'autres où l'ori eft obligé d'en mettre abfolument, pour rompre la trop grande portée des rainceaux.

Il faut remarquer qu'on ne laiffe plus monter le buis fi haut préfentement, \& qu'on ne met plus de grands ifs \& arbriffeaux dans les Parterres, parce qu'étant très differens des bois $\&$ des allées de haute-futaye, qui font le relief des Jardins, ils doivent être plats, unis \& dégagés commie des lieux découverts; quand on y mettoit de ces grands ifs, un Parterre reffembloit à un bois, offufquoit la vî̀ë, \& cachoit la beauté des Bâtimens, qui en font ordinairement voifins. Ainfi il ne fautaiffer monter ces ifs \& ces arbrifieaux qu' trois ou quatre pieds de hayteur. 
Les Parterres font encore très-differens des autres parj ties d'un Jardin, en ce qu'ils font plus beaux dès le premier jour qu'ils font plantés que dans la fuite: il n'y a que le grand entretien \& les foins continuels que l'on y apporte, qui puiffent faire éviter ce décroiffement de beauté: car les buis en groffiffant font perdre la délicateffe du deffein, les terres gâtées par les ravines ne font plus de niveau, les fables de couleur s'effacent en fe mêlant avec la terre dans le ratiffage, \& les gazons deviennent moüfleux. Il faut donc entretenir le buis très-bas, le tondre proprement deux fois l'année, fans que le contour en foit alteré par une main mal adroite, que les fables foient fouvent renouvellés, pour marquer \& détacher mieux la Broderie; \& fur tout, que les gazons foient fauchés \& bordés chaque mois, \& outre cela, changés tous les trois ou quatre ans. Voilà le mérite des Parterres, \& en quoi confifte leur principale beauté. Ce ne font pas ordinairement les morceaux les plus négligés dans un Jardin, ils font trop près des yeux du Maître pour cela.

Les plates-bandes des parterres fervent à les entourer \& enclaver, afin d'empêcher qu'on ne les gâte en marchant dedans. Elles leur fervent encore d'ornemens par les ifs, les arbriffeaux \& fleurs qu'on y éleve. On leur donne ordinairement quatre pieds de large pour les petites, \& cinq à fix pour les grandes: on les drefle toujours en dos d'âne, n'étant pas agréables à la vuë quand elles font plates : elles font bordées ordinairement d'un trait de buis, mais dans les pieces coupées, on les entuure fuavent de marguerites, Atatifées, penfées, mignardifes, \&c.

Il y a de quatre fortes de plates-bandes. Les plus ordinaires font celles qui font continuées tout au tour des Parterres, fans aucune interruption, qui font labourées en d'os-d'ane, $\&$ garnies de fleurs, d'arbriffeaux \& d'ifs.

La feconde efpece eft une plate-bande, coupée en compartimens d'efpace én efpace par de petitspaffages, on l'orne aufli de fleurs, d'arbriffeaux, \& elle eft en dos-d'âne.

La troifréme efpece, fnnt des plates-bandes tout-unies \& plates, fans aucune fleur, avec fimplement un mafif de ga 


\section{LA THEORIE-DU JARDINAGE.}

zon au milieu, bordé de deux petits fentiers ratiffés \& fablés. On les orne quelquefois d'ifs \& d'arbriffeaux, ou bien de vafes, de pots de fleurs pofés fur des dez de pierre, \& placés par fimetrie au milieu du maffif de gazon.

Les plates-bandes dela quatriéme efpece font toutes nuës. \& fimplement fablées, ainfi que dans les parterres d'Orangerie: ce font les caiffes rangées parfimetrie, qui rempliffent ces plates-bandes, qui du côté des allées font bordées d'un trait de buis, \& de l'autre par les tapis \& pieces de gazon du parterre. Quelquefois on plante des ifs entre chaque caiffe, pour rendre ces plates-bandes plus riches, \& les parterres plus beaux pendant le tems que les caiffes font Lerrées.

On voit aufli des plates-bandes adoffées contre des murs, bordées d'un trait de buis, \& remplies de grands arbres, comme des tillots, marroniers, entre lefquels on met des ifs, des arbriffeaux \& des fleurs de la grande efpece.

On fait des plates-bandes droites, circulaires, \& à pans, dont on forme des volutes, des enroulemens, des maffifs \& autres compartimens.

Les Fleuriftes font encore des plates-bandes ifolées, ou le long des murs, qu'ils entourent de bandes de menuiferie peintes en verd, ce qui eft d'une tres-grande propreté. Ils élevent là-dedans des fleurs très-rares \& très-belles; mais c'eft ce qu'il ne faut pas rechercher dans les grands Parterres, ot l'on doit fe contenter de les bien garnir de fleurs de differentes faifons, qui fe fuccedent les unes aux autres, fans aucun vuide, comnme on le verra dans la troifiéme Partie.

On ne fait plus regner préfentement les plates-bandes fur le devant $\&$ en face d'une Maifon, afin que les arbriffeaux \& les fleurs ne cachent point la broderie \& la naiffance d'un Parterre, \& qu'on puiffe mieux juger du deffein. On y fait quelquefois fortir des feuilles, des palmettes \& des coquilles, qui jouënt fur le fable; mais cela eft fujet à fe ruiner, n'étant point fermé d'une plate-bande, qui em. pêche de marcher deffus.

Les fentiers des Parterres ne font point faits pour marcher c'eft feulement pour détacher les pieces de cumpar. 
46 PREMIERE PARTIE, CHA P. IV. timens, il n'y a que dans les Parterres de pieces coupées où les fentiers étant plus larges, peuvent fervir à la promenade.

Les ux premieres Planches reprefentent en grand les mêmu .effeins de Parterres, que ceux qui font marqués en petit, dans la premiere Planche des Difpufitions generales, Chapitre précédent.

La premiere Planche qui fuit, eft un grand Parterre de broderie mêlée de maflifs de gazon, entourée d'une platebande de fleurs, garnie d'ifs \& d'arbriffeaux. Ce deffein quoiqu'il ne foit point coupé dans le milieu, étant tout entier, eft ici répété de l'autre côté, avec une contre-allée d'arbriffeaux \& d'ifs, \& un grand baffin au bout: ce que l'on pratique quand la place ef un peu large. La volute que l'on voit à l'un de fes angles, paroitra fans doute extraordinaire : mais quand on confultera le Plan general, Figure Ie

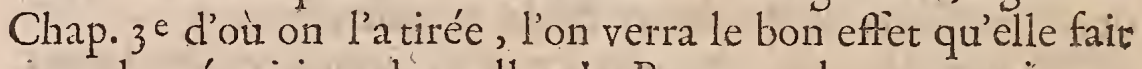
avec la répetition de celle du Parterre de compartiment à côté. L'on pourra retrancher cette volute angulaire, fi l'on fefert de ce deffein pour une feule piece, en y ajotitant quelque feuille, \& en cintrant la tête pour former une allée circulaire autour du baffin. Les maffifs \& les enroulemens de gazon rejettent fort à propos toutes les feüilles \& palmettes de cette broderie : qui fe découvre aifément par l'interruption de la plate-bande fur le devant.

La feconde Planche fait voir un long Parterre de compartiment, avec un baffin dans le milieu, entouré d'une plate-bande coupée, ainfi que celles des côtés, où viennent fe joindre les enroulemens des autres plate-bandes, qui forment le compartiment. Le refte eft rempli de coquilles, de pieces de gazon, \& aux deux extremités, de cartouches de broderie, qui font un mélange fort agréable. Il fort encore de perites palmettes $\&$ des culots, de tous les enroulemens des plates-bandes: le fond de ce Parterre eft fablé, \& les fentiers font en ciment. Il eft accompagné de deux allées d'arbriffeaux ifolés, \& de quatre vafesaux encoignures.

Le Parterre de la troifiéme Planche eft des plus magnifigues; il eft aufi de compartiment' mais il ne peut s'exe- 
cuter que dans une grande place quarrée. Il eft compofé de quatre cartouches de broderie dans fes faces, \& de coquilles de gazon dans fes quatre angles, le tout fablé de differentes couleurs, \& bordé d'un trait de buis. Au milieu eft un baffin entouré d'une plate-bande coupée, garnie d'ifs \& d'arbriffeaux, avec des pots de fleurs pofés fur des dez de pierre. Les plates - bandes du tour font interrompuës en face de chaque cartouche, \& forment des volutes dans les angles. On a fuppofé au bas de ce parterre, un talus de gazon bớdé haut \& bas d'un rang de caiffes \& d'ifs, avec un efcalier de pierre dans le milieu, orné de figures \& de vafes. L'échelle en fera connoître toutes les proportions:

L'on voit dans la quatriémePlanche un Parterre de broderie coupé en deux pieces répétées \& variées de deux façons. Il y a une allée dans le milieu, qui mene à un baflin aut deffus duquel eft une patte d'oïe percée dans un bois. On pourra choifir de ces deux pieces celle qui conviendra le mieux. L'explication des Parcerres précédens doit affés inftruire de ce qui les compofe.

La cinquiéme Planche repréfente un Parterre de broderie d'un goît très-nouveau. C'eft un grand tableau cintré par un des bouts avec un baffin au-deffus. Lue milieu eft rempli de broderie, \& de maffifs degazon avec une plate. bande autour, qui eft coupé dans toute la face d'en bas, Il n'eft extraordinaire que dans fes extrémités. L'on y voit à l'une deux têtes de Dauphin, qui forment des enroulemens, d'où les fenticrs \& les maflifs prennent naiffance. La face d'en-haut eft ornée d'un mafque de Griffon, avec des â̂les de Chauve fouris, formées par des côtes de gazon'; les feuilles de la broderie forment le nez, les yeux, les fourcils, la mouftache \& l'aigrette deffus la tête de ce mafque, Sa cravatte ou bavette eft exprimée parune coquille de gazon. Les fables de differentes couleurs contribuënt beaucoup à détacher toutes ces petites pieces, qui font des merveilles fur le terrain. Il y a déja deux ou trois Parterres executés dans ce genre.

La fixiéme planche eft la plus remplie, elle contient trois deffeins de Parterres de differentes efpeces; celui de la pre= 
48 PREMIERE PARTIE, ChAP. IV. miere figure eft un parterre à l'Angloife, c'eft-à-dire, tout de gazon, comparti en plufieurs deffeins, \& entouré d'une place-bande de fleurs, coupée en differens endroits, \& garnie d'ifs \& $\cdot d^{\prime} a r b r i f f e a u x$. Ce deffein pour n'être que de gazon ne laiffe pas d'être affés riche.

Le Parterre de la $2^{e}$ Figure elt de pieces coupées, ou de découpé. Il eft prefque qquarré, \& cintré par le haut avec. un baflin; fes angles font échancrés avec des ifs. Il eft compofé d'un Ovale ralongé dans le milieu, \& de cartouches aux quatres coins, a vec des volutes \& coquilles qui font toutes coupées en differentes pieces, formant des plates-bandes, ornées de fleurs \& d'arbriffeaux, placées parfi. metrie. Toutes ces pieces font entourées d'un trait de buis, $\&$ d'un large fentier ratiffé, qui vous conduit tout an tour fans rien gâter. Il y a encore de petits fentiers autour de l'ovale, \& des quatre cartouches qui doivent être fablés de rouge.

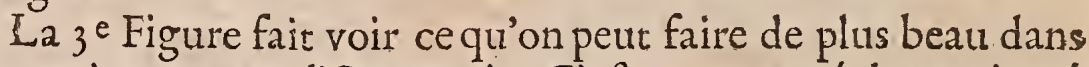
un petit parterre d'Orangerie. C'eft un quarré long cintré dans les deux bouts, où l'on voit deux ronds de gazon avec des Figures : le milieu eft rempli d'une petite piece d'eau. Ces trois pieces font entourées d'un fentier \& d'un trait de buis, qui forme avec celui du bord, des plates bandes, regnantes auffi autour des ronds de gazon. Ces plates-bandes font fablées \& tout unies: elles font garnies d'ifs, entre lefquels on place les caiffes d'Orangers, de Jafmins, de Mirthes, de Lauriers, \&c. qui doivent s'aligner fur les deux rangs des côtés.

La $7^{\mathrm{e}} \&$ derniere planche renferme trois petits Parterres convenables à des Jardins de Ville, dont on trouve des difpofitions entieres \& toutes differentes. Les murs \& les places en font biaifées extraordinairement, afin de faire voir comment on peut corriger ces défauts dans de petits Jardins ou ils deviennent plus fenfibles que dans de grands Jardins de Campagne, L'on fuppofe que ces biais font caufés par l'alignement des ruës, \& que les Parterres font placés à la defcente du Bâtiment. L'échelle leur eft commune.

La ${ }_{1} \mathrm{r}$ Figure offre un Parterre d'un Compartiment trèsdélicat , avec une Figure dans le milieu, \& quatre vafes 
LA THEORIE DU JARDINAGE. aux encoignures. Le biais des murs des côtés, eft racheté par des plates-bandes de fleurs", qui viennent mourir à rien de part \& d'autre. A l'égard de celui du fonds, on y a ajufré un Portique de treillage des plus riches, àvec des bancs \& des figures en face de chaque allée. Il s'eft trouvé un petit retour qui faille affés pour y avoir pratiqué une ferre pour des fleurs, ou fi l'on veut, une falle de bain ou une voliers.

On trouve dans la $2^{e}$ figure une place fort irréguliere, \& fur des fens tout differents : le coude que l'on voit au bout eft fauvé par une charmille broufaillée par derriere, qui fuivant l'inégalité du mur, eft néanmoins conpée régulierement de plufieurs pans \& retours qui formentunefalle; \&r dans la pointe un cabinet de yerdure; l'on y voit deux bancs avec une figtire ifolée, qui font affés bien: le refault de Ia façade du Bâtiment, \& la largeur fur le côté, ont donné occafion d'y planter une allée, pour gagner le biais de ce terrain: il n'y a de l'autre côté qu'un rang d'arbres, derriere lefquels la place eft drefiée par le trait de buis de la plate-bande. La broderie de ce Parterre eft fort mignone \& fort ligere, on l'a accompagnée de deux bandes de gazon, oir font pofés par fimetrie iur des dez de pierre, des $\checkmark a$ fes de faïance remplis d'arbriffeaux \& de fleurs de faifon: dont l'afpect eff fort agréable \& moins commun que des ifs.

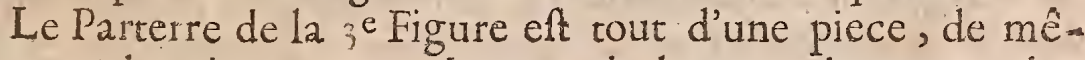
me que les deux autres, le peu de largeur de ces emplacemens ne permettant pas de faire deux pieces : le deffein en devient gracieux; le dedans des enroulemens \& des fentiers qu'on a fair anfif regner autour du Baffin, doivent être fablés en rouge, pour fe détacher du fonds. Ce baffin eft enclavé exprès dans le Parterre, afin de gagner du terrain. On a ménagé au-deffus deux perites pieces de gazon entourées de marroniers, qui donnent un couvert fort agréable dans toute cette demi-lune occafionnée par la difpofition des murs du fond. Les autres biais fur les âles font redreffés par une paliffade de la hauteur des murs, dans laquelle on a pratiqué des renfoncemens pour des bancs, ainfi qu'on le voit en face du baffin \& à la defcente du bâtiment: un de ces bancs fe trouve deflous un petic berceau de verdure.

On évitera de remplir de marguerites ou de ftatifées a le 
dedans des palmettes $\&$ des rinceaux de broderie, comme la mode s'en eft introduite prefentement : cela eft oppofé au bon goût, \& ne convient qu'à des maflifs, des fentiers, des coquilles \& cartouches, pour varier \& faire oppofition avec ceux qui font gazonnés.

Il ne faut pas manquer de fabler ces parterres de differenres couleurs, c'eft ce qui en fait la beauté. L'on fe fervira de ciment pour le rouge, de terre noire, de limaille ou machefer, ou de charbon battu \& pilé pour le noire, \& de fable ordinaire ou de fablon pour le blanc \& le jaune.

Pour connoître fur les Planches les endroits qui doivent être fablés en rouge, en noir, \& en jaune; l'on obfervera que tout ce qui eft pointillé marque le fable ordinaire; \& ce qui eft exprimé par de petits points plus ferrés, comme dans les fentiers autour des mafifs, eft de la terre rouge ou du ciment. Le dedans des feüilles de la broderie, eft rempli de limaille ou de machefer, ce qu'on connoîtra par des lignes croifées l'une fur l'autre. Le gazon des maffifs \& des coquilles, eft diftingué par des lignes droites entremêlées de petits points.

Chaque Parterre a fon échelle particuliere, qui fera juger de l'étendü̈ \& de la dimenfion de toutes les parties qui le compofent. On peat cependant en changer les proportions, en élargiffant, allongeant ou diminuant ces Parterres fuivant la place qu'on aura: mais cette augmentation ou diminution fe doir faire avec beaucoup de difcernement, \& 'ne doit pas être fort confidérable, comme de la moitié, parce que cela changeroit tout le deflein, $\&$ en altereroit la grace. Il faut là-deffus confulter l'uil cie quelyues gens connoiffeurs \& de bon guat ; car fouvent d'une bonne chofe l'on en fait une fort mauvaife.

On croit que ces fept Planches, qui renferment douze Parterres, pourront fuffire pour donner l'idée de toutes leurs

IIs fe trou. rent chèz le Sร Mariette, differences. On n'a pas voulu en mettre davantage à caufe du grand nombre de Parterres gravés qu’on a déja donné au Public. 


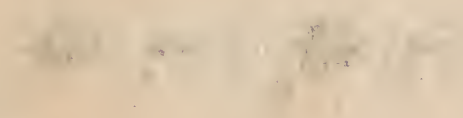

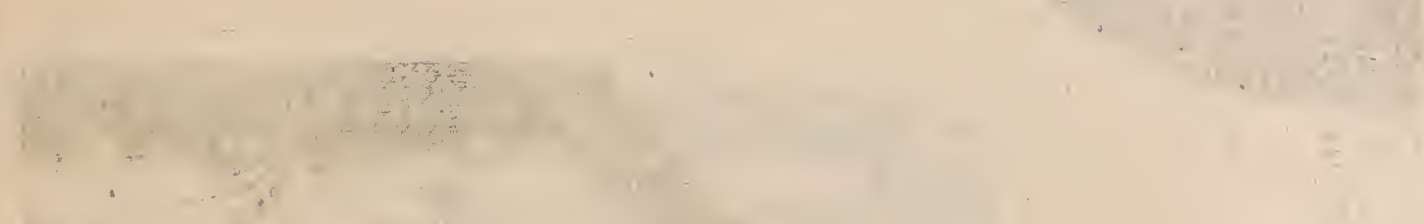

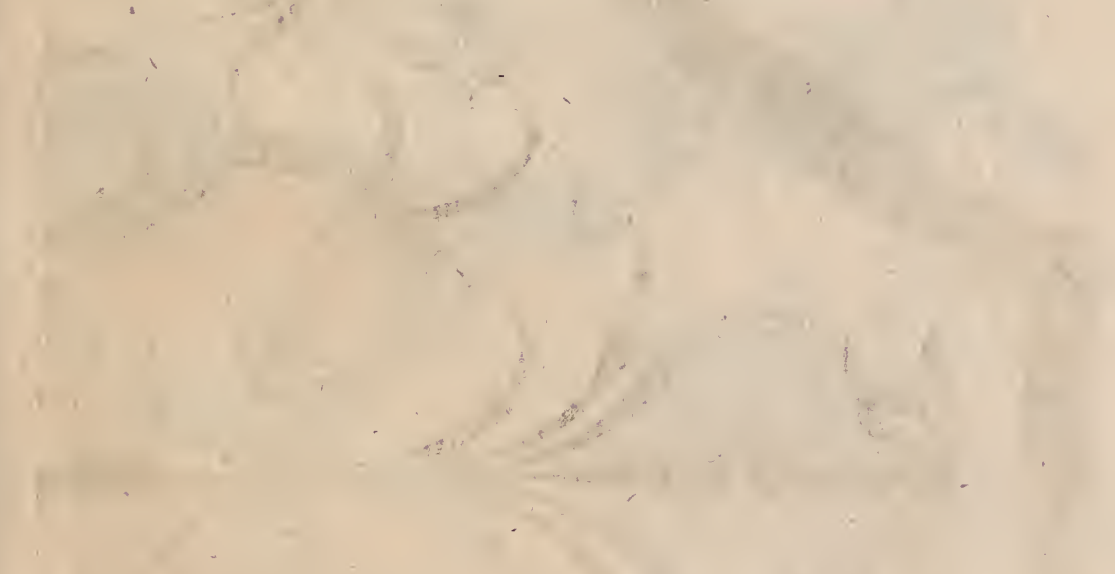$$
1^{1}+1
$$

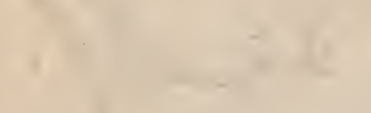

) 



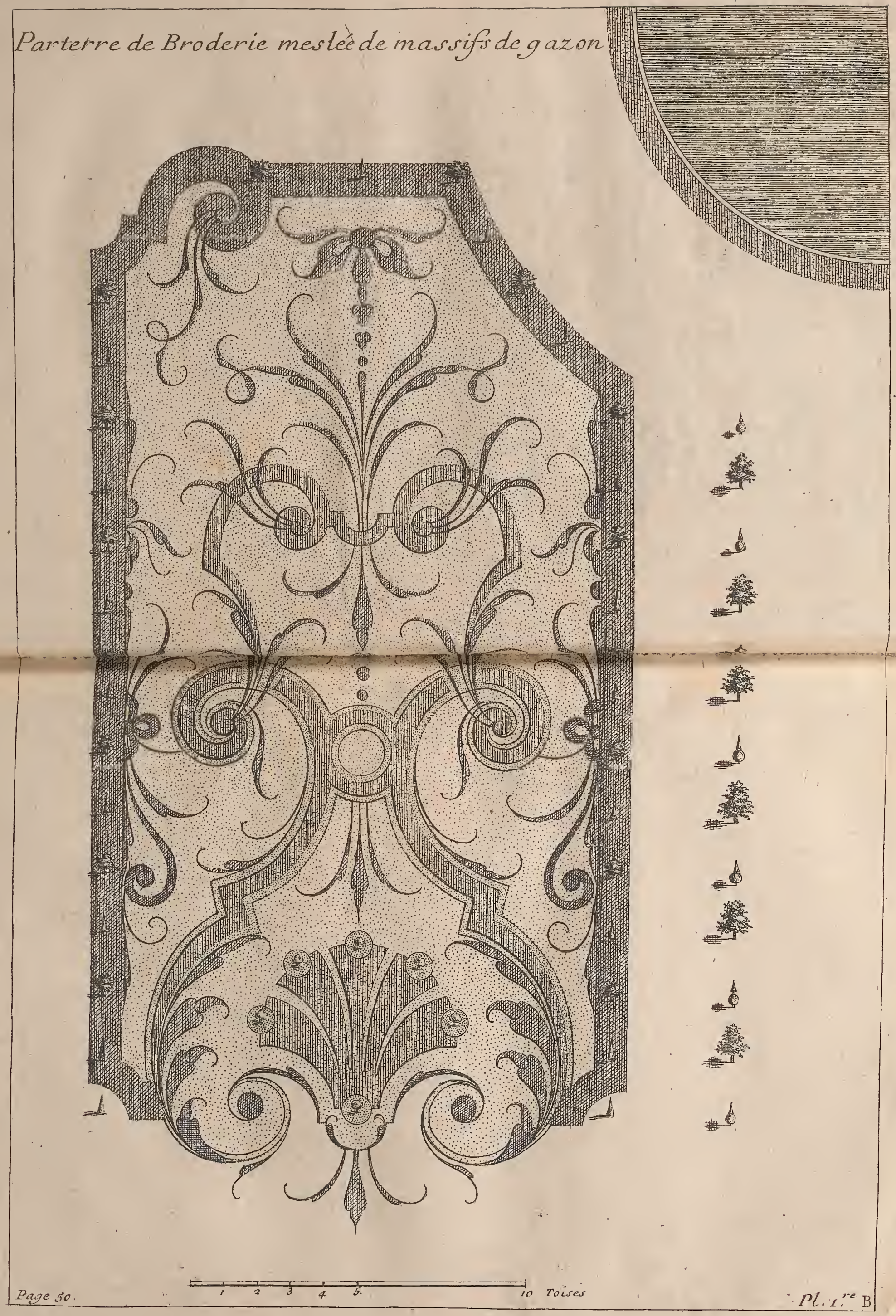





* औ

a der

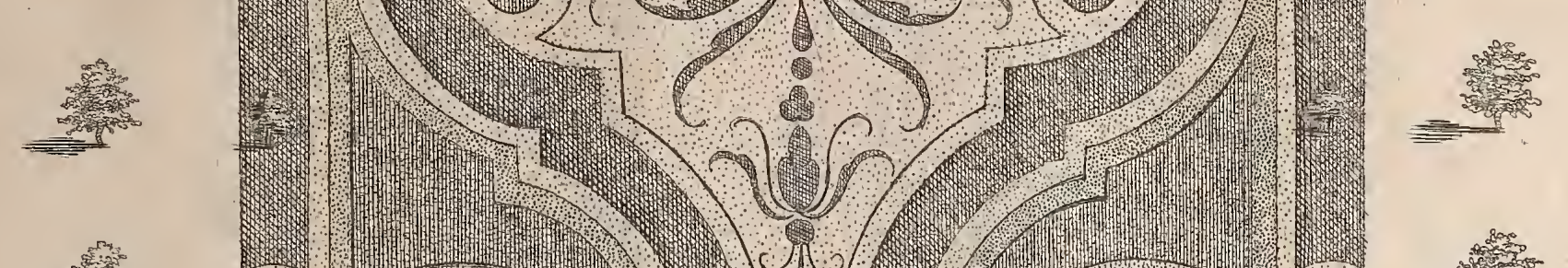

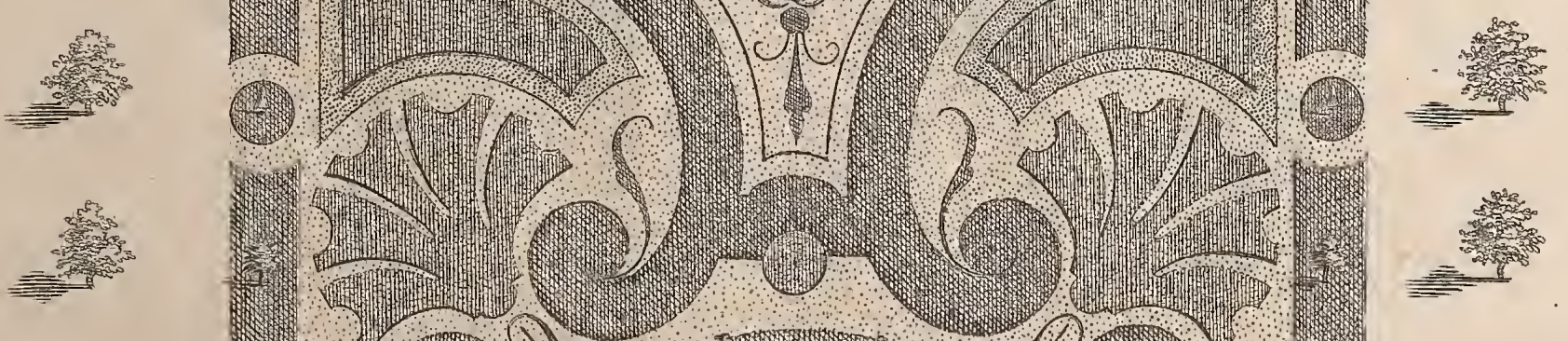

a. $90=0$

(1)

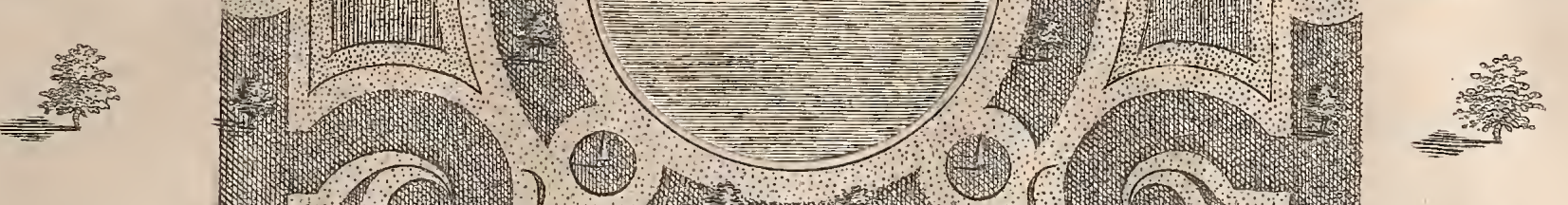

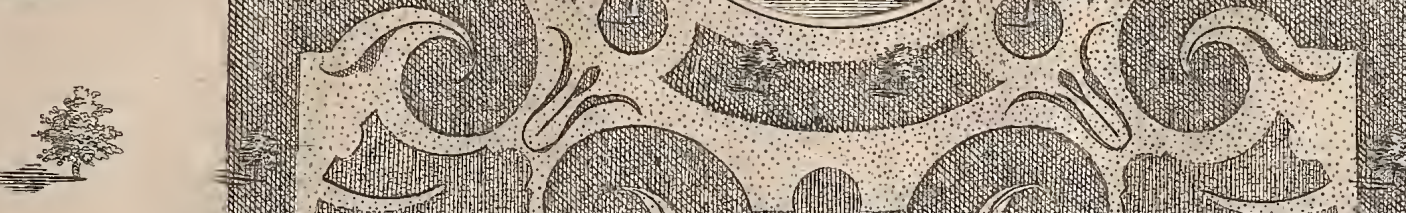

$n$
$\Rightarrow$

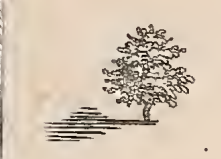

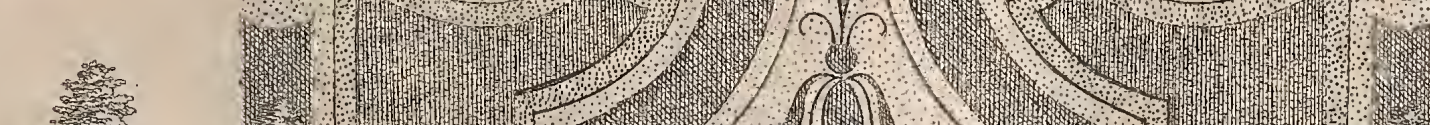

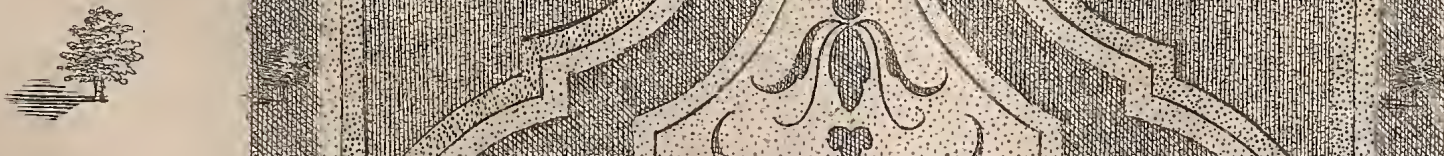

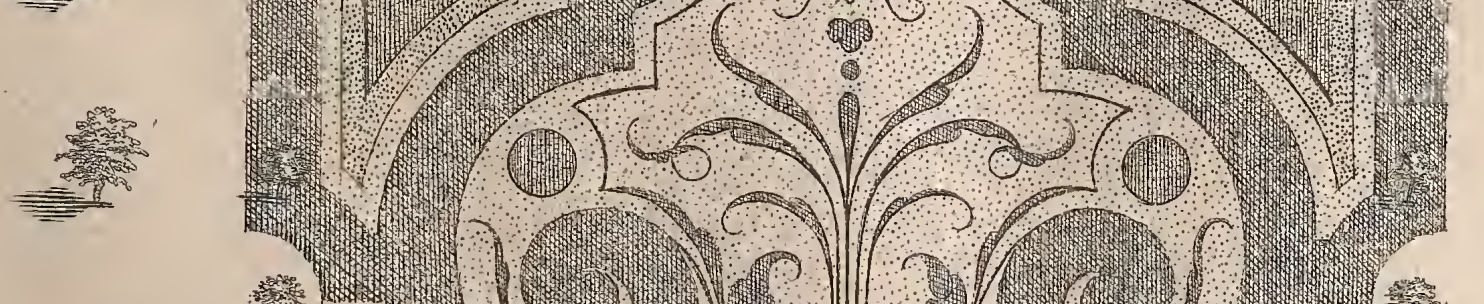

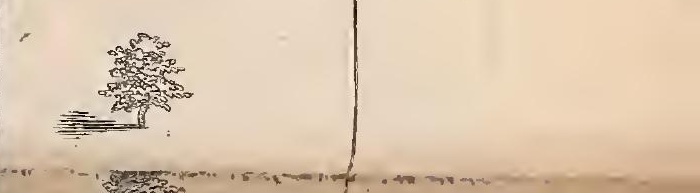

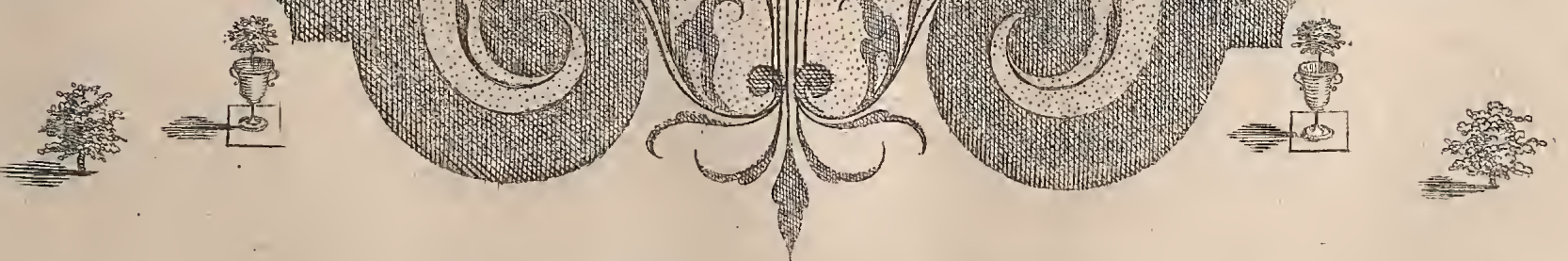




Grand Parterre de Compartiment.



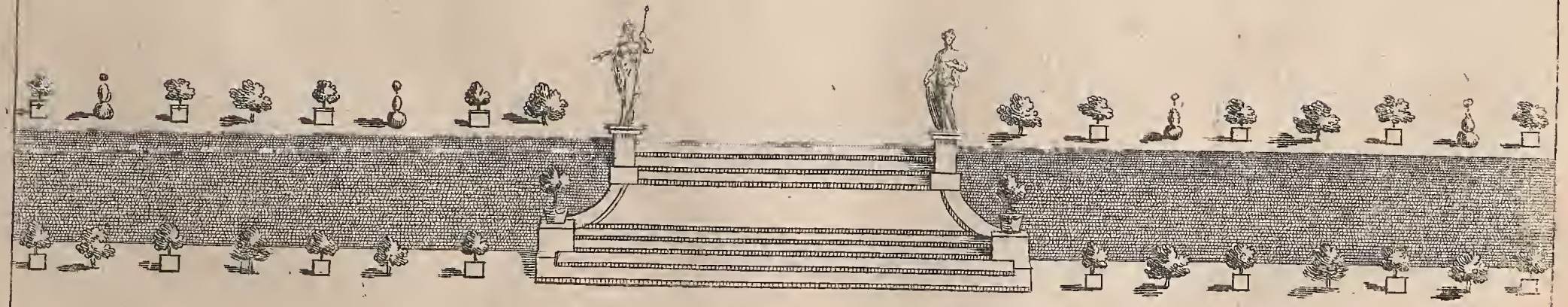






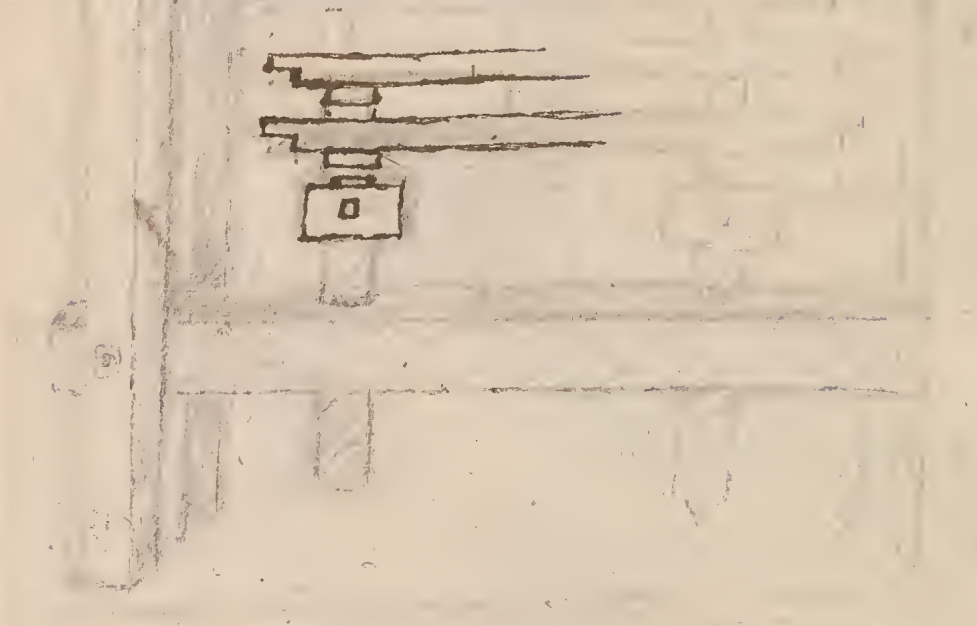


Parterre de Broderie variéde dewx façons

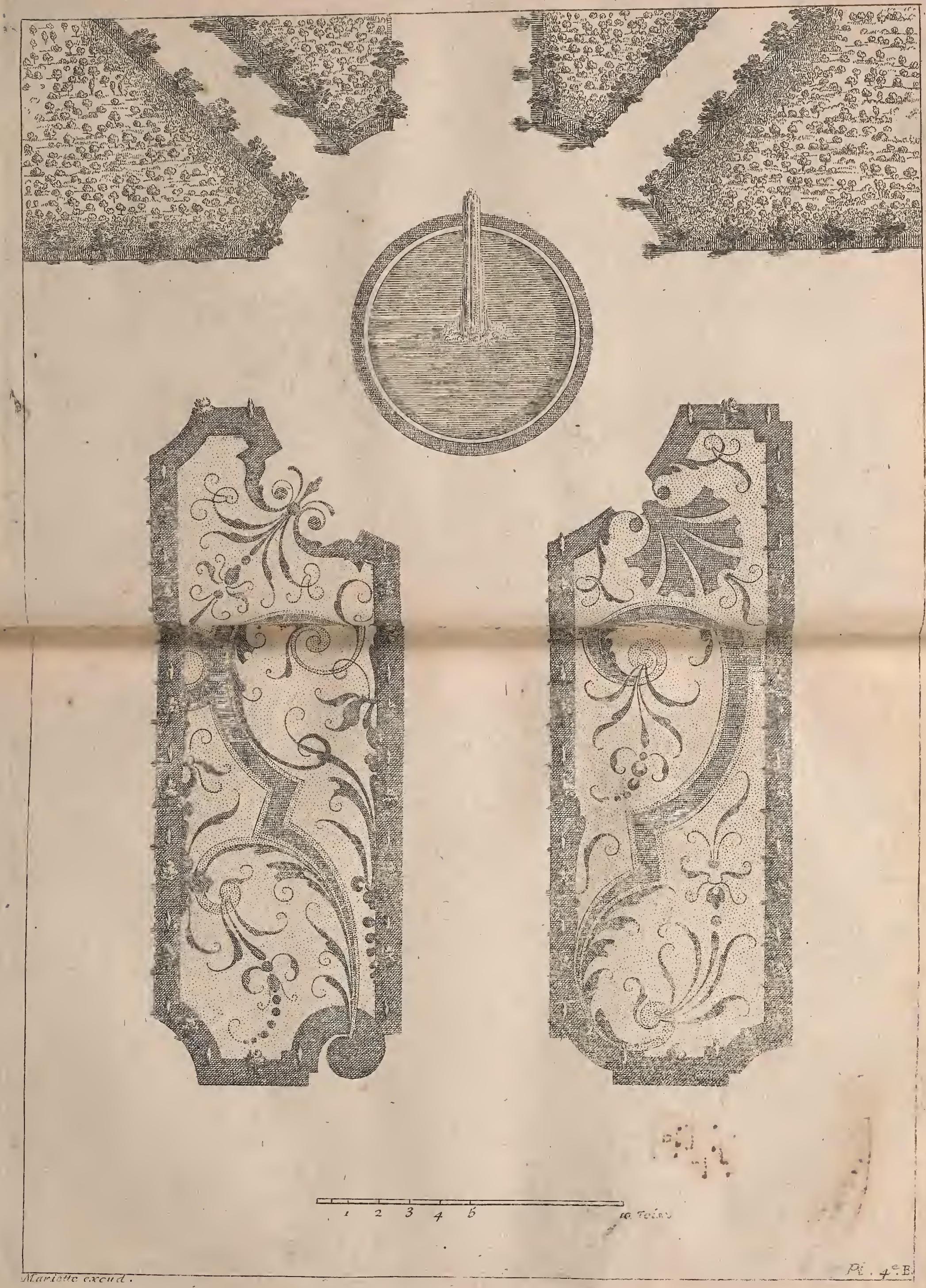




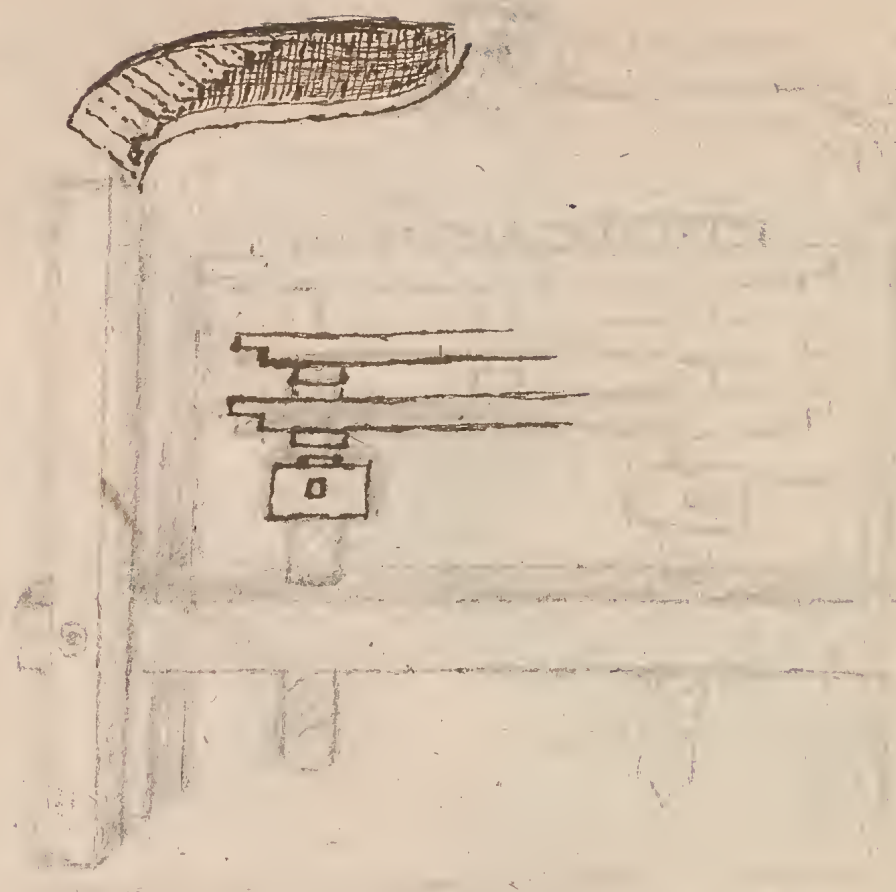





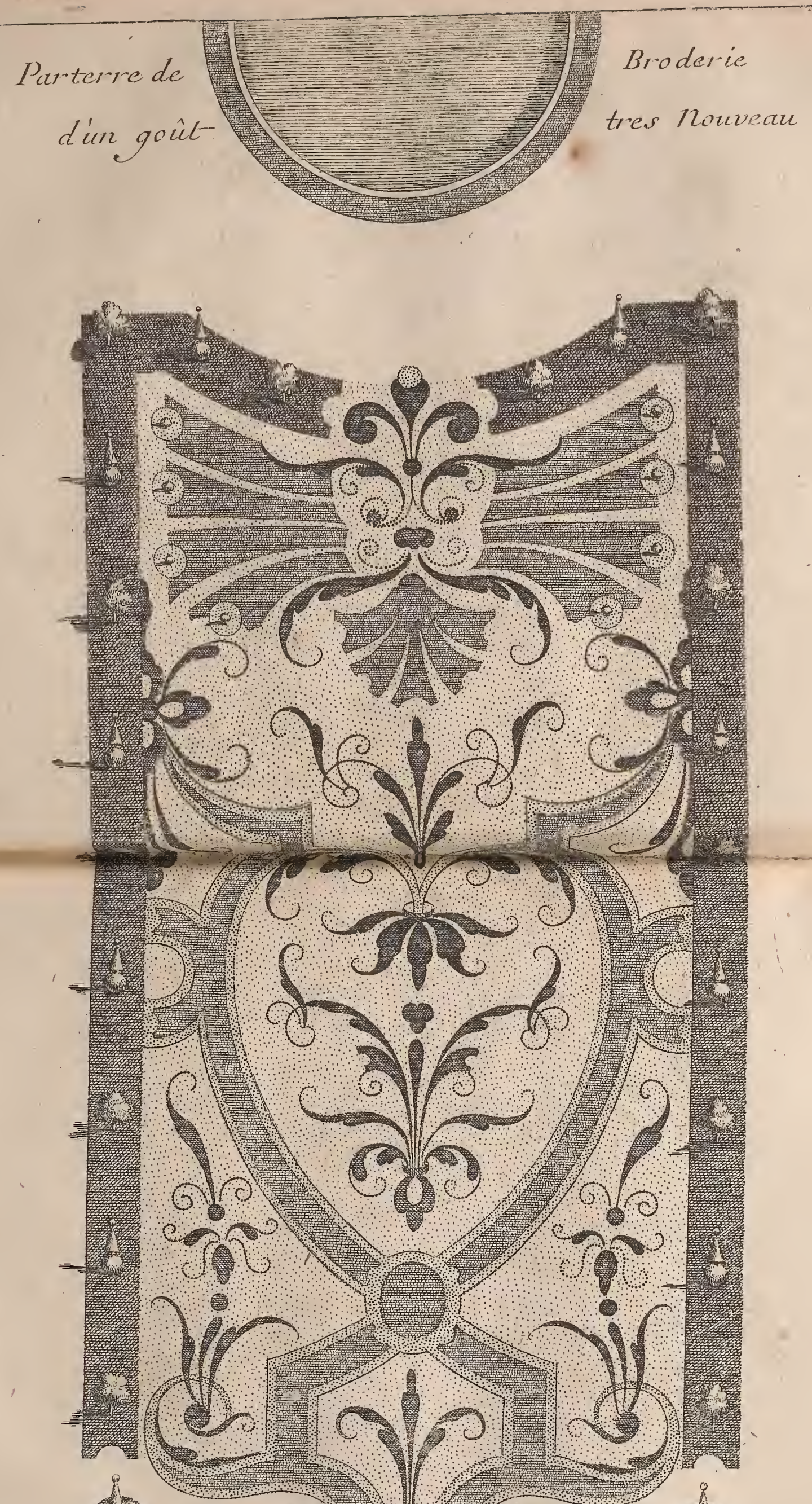

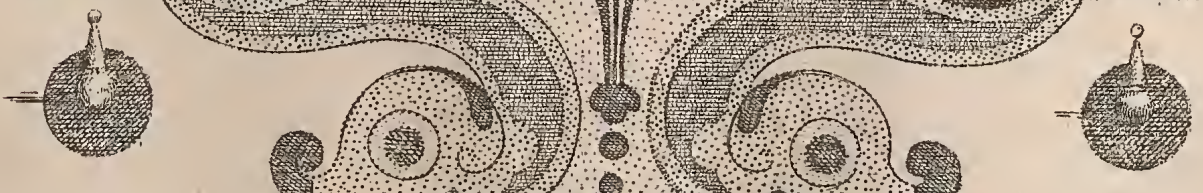

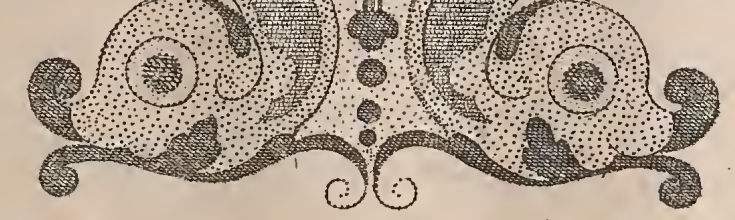







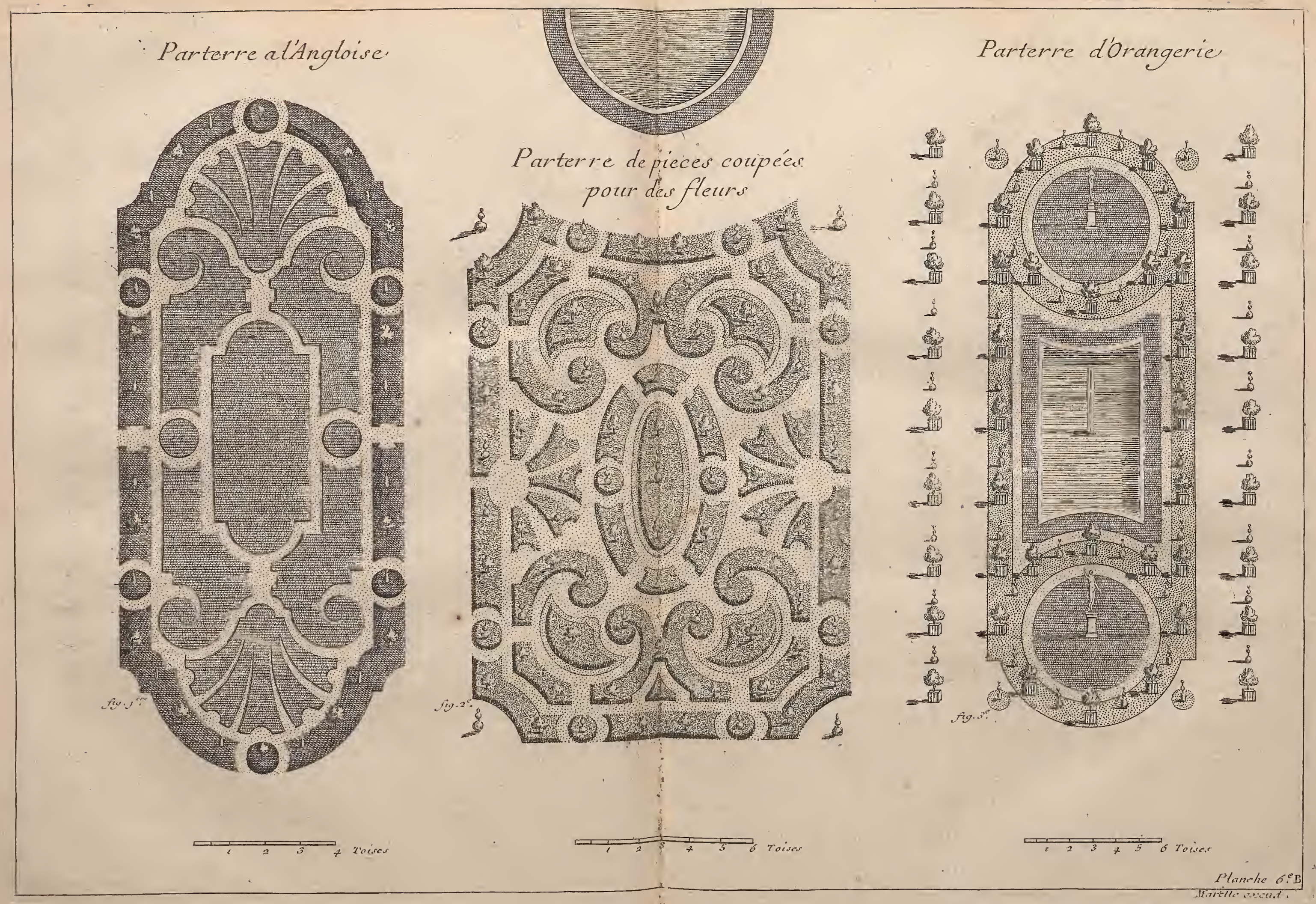







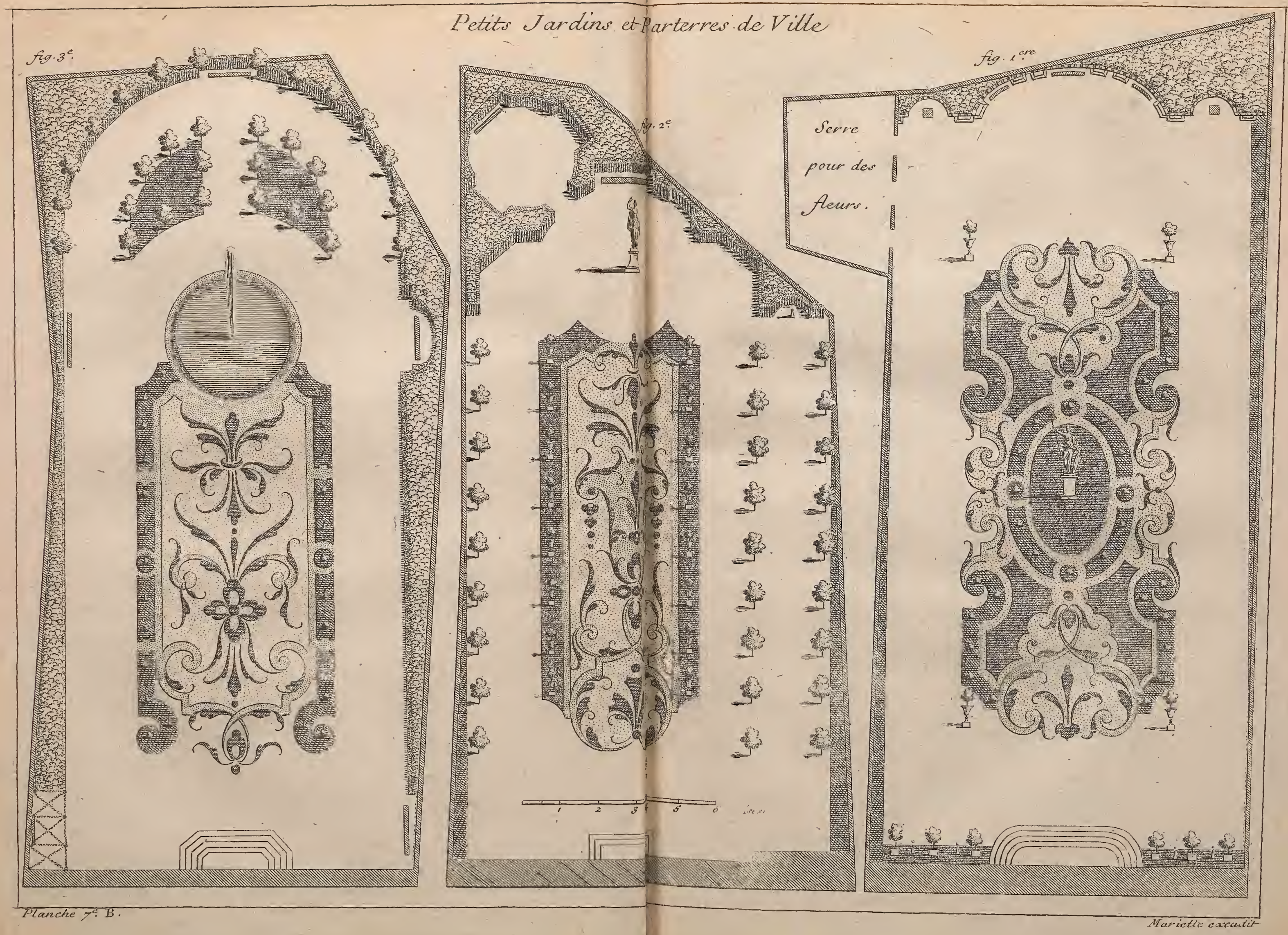





\section{IA THEORIE DU JARDINAGE. SI}

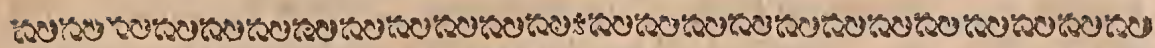

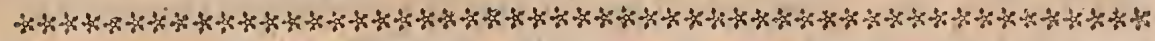
เง

\section{H A P I T RE V.}

\section{DES ALLE'ES; CONTRE-ALLEES ; of Paliffades.}

T Es Allées dans les Jardins font comme les ruës d'une 1 Ville, elles fervent de communication d'un lieur à uts autre., \& font comme autant de guides \& de routes pour conduire par tout un Jardin. Outre l'agrément \& la commodité que les Allées offrent fans ceffe pour la promenade, elles font une des principales beautés des Jardins, quand elles font bien pratiquées $8 x$ bien drefrées.

On diftingue de plufieurs fortes d'Allées, les couvertes\& les découvertes, les Allées fimples \& les doubles, les Allées blanches \& les vertes.

Les Allées couvertes font celles qui font formées par des arbres ou des Paliffades, qui fe joignant par en haut, empêchent la vûe de découvrir le Ciel, \& par leur obfcurité caufent une fraîcheur impénétrable aux ardeurs du Soleil.

On doit moins donner de largeur aux allées qu'on veut couvrir qu'aux autres; il faut alors moins de tems aux arbres pour s'aprocher \& fe joindre par en haut. Ces allées ont leur agrément dans les grandes chaleurs, puifqu'on s'y peut promener à l'ombre, même en plein midi.

Les allées découvertes fe peuvent divifer en deux efpeces; fçavoir les allées des Parterres, des Boulingrins, des Potagers, \&rc. qui ne font formées que par les ifs \& les buiffuns des plates-bandes; $\&$ les * Allées, qui quoique plantées de grandes paliffades \& d'arbres de haute futaie, ne laiffent pas d'être décotivertes par enhaut, foit en arrêtant les paliffades à une certaine hauteur, ou en élaguant les arbres des * On les appelle atifi Aliées ì Ciétr ouvsex. deux côtés, en forte qu'on y puiffe refpirer la douceur de lair.

C'ef une regle générale de découvrir les principales allées, $\mathrm{G}$ ij. 
I. grande Allée des Tuileries eft $f$ couverte,qu’à peine découvre-t'on du kour, la porte dia gros $\mathrm{Pa}$ villon, ce qui eft très-défeEqueux. Cela vient des marronniers qui ont été mal Eoscuirs. Cafcades, \&c. \& même il les faur tenir plus larges que les autres, affn que du bout d'une allée on puiffe voir une partie de la façade d'un Bâtiment ou autre bel afpect: il n'y a rien de fi défagréable dans une allée, quand vous êtes au bout, de ne voir qu'à peine la porte du veftibule d'un bâtiment. Il ne faur laiffer couvrir qué les contre-allées, pour former comme deux berceaux de verdure, \& les allées qui font dans des endroits de peu de conféquence, \& où il n'y a aucun point de vûë confidérable.

Les allées fimples font celles qui ne font compofées que de deux rangs d'arbres ou de palifiades, à la difference des Allées doubles qui en ont quatre, qui forment trois Allées jointes enfemble, une grande dans le milieu \& deux de chaque côté, quil l'accompagnent, 8s que l'on appelle contreAllées. Les deux rangs du milieu doivent être plantés d'arbresifolés, c'eft-à-dire, qui nc foient point engagés dans quelque palifiade, \& autour defquels on puiffe tourner, \& les deux autres rangs doivent être garnis $\&$ bordés de paliffades. Comme les allées doubles font efimées les plus confidérables, elles occupent auffi les plus beaux endroits des Jardins.

On ne met plus d'ifs \& de pieces entre les arbres ifolés des allées doubles, car ils empêchent en quelque façon le paffage; l'on fe contente d'en mettre entre les arbres planrés fur des terrafres, à caufe du bel effer que cela fait d'enbas.

Les allées blanches ne font autre choíe que des allées routes fablées que l'on ratiffe entierement, au lieu que les allées vertes font prefque toutes femées en gazon, à l'ex-

It fe voir ception des. deux fentiers ratinés le long des palifiades: elles keaucoup de fervent dans les endroits écartés pour épargner le grand entes dans les Jardins hauts de Marly\&de
Meudon. trecien.

A l'égard des noms \& des figures differentes des allées, on les peut tous renfermer dans ceux-ci: Allée paralelle, Allée droite, Allée de traverfe, Allée tournante ou circulaire, Allée retournée d'equerre, Allée diagonale ou de biais par raport au trait quarré.

- On peut encore difinguer de deux fortes d'Allées par la 
fituation oì elles fe trouvent; les Allées de niveau, \& les Allées en pente ou rampe douce. Rarement une Allée eft d'un parfait niveau, l'on y pratique toujours une petite pente imperceptible pour écouler les eaux: cependantil s'en trouve qui font parfaitement de niveau, comme les Allécs d'un Mail , \& celles qui font aut tour d'un Parterre ou d'une piece d'eaut.

Les Allées en pente ou rampe douce font les plus ordinaires : elles doivent être dreflées de maniere qu'on ne foit poine incommodé en fe promenant, par leur pente qui doit être imperceptible : quand elle eft trop roide, elle blefie le coup d'cil, \& devient fort fatiguante en marchant. Cette pente ordinairement ne doit jamais paffer trois pouces par toife, de peur d'être gâtée par les ravines. C'elt la meilleure regle qu'on puilfe fuivre pour les bien dreffer: néainmoins quand le terrain ne permet pas de la fuivre, \& qu'on eft obligé de s'en écarter de beaucoup, comme dans une Allée qui defcendroit le long d'une Cafcade, alors on remedie à cette grande roideur par des arrêts \& des marches de gazon pofés en zic-zac, appellées chevrons, que l'on fair traverier l'allée d'efpace en efpace, ou bien par de petits arrêts faits de planches de bateau, qui n'excedent pas l'Allée de plus de deux pouces, lefquels retiennent les eaux \& les rejettent des deux côtés. C'eft par ce moyen qu'on les peut entretenir propres.

On obfervera pour l'écoulement des eaux, de tenir le milieu des Allées un peu élevé, afin que l'eau s'écoulant des deux côtés, n'ait point le tems de gâter le niveau de l'Allée : cette eau par ce moyen ne deviendra pas inutile, elle fervira à arrofer les palilfades, les plates-bandes \& les arbres des côtés. A l'égard des Allées de niveau, comme celle d'un Mail, ou des Allées qui font très-larges, $8 x$ dont on ne peut rejetter les eaux des denx côtés, on elt obligé pour les égoutter, d'y conftruire dans le milieu des puifarts bâtis de cailloux \& de pierres feiches.

On doit proportionner la largeur des Ailées fuivant leur longueur, c'eft ce qui en fait la beauté. Nous a vons eu d'habiles gens dans le Jardinage, qui ont manqué à cette jufte proportion, en donnant trop de largeur aux Allées par rap.

Ainfi qu'on le voir à la grande Cafeade de Scezuz. Girj

L̨ Nótre:

Bouticous 
port à leur longueur. On peut tomber dans un défaute contraire, en faifant les Allées trop étroites: Une Allée par exemple de 100 toifes de long, qui n'auroit que deux ou trois toifes de large, feroit trés-defectueufe, \& ne paroîtroit qu'un boyau, au lieu que cette Allée ayant cinq ou fix toifes de large, deviendroit très-belle \& bien proportionée, fuppofé cependant qu'elle füt fimple; ainfi les Allées de 200 toiles de long, auront fept à huit toifes de largeur : celle de 300 toifes, neuf à dix, \& celles de 400 , dix à douze. Voilà à peu-près leur jufte proportion, à moins qu'elles ne foient doubles, car en ce cas elles doivent prelque doubleren largeur.

Voici des obfervations qu'il eft bon de faire au fujer de $1 n$ largeur des Allées, bordées de jeunes Taliffades, qui par leur hauteur, contraindront un jour, \& referreront trop la vûë : ce qui rendroit alors l'Allée trop étroire, ou bien ces paliffades \& arbres des côtés, en grofliffant \& épaiffiffant, occuperont dans la fuite deux pieds de chaque côté : chofe inévitable, \& qui retrecit encore confidérablement une Allée. Ce font ces petites remarques qui doivent engager les gens du métier, à confidérer ce que deviendront les Allées étant anciennes, \& ne les pas regarder telles qu'elles font d'abord, car un vieux plan eft bien different d'un nouveau. Un peu plus de largeur remediera à tous ces petits inconveniens.

On n’eft pas obligé à obferver toutes ces chofes pour la longueur des Allées, qu'il faut prolonger tant qu'il fera pofa sible, elles ne peuvent jamais être trop longues.

I a proportion la plus ordinaire des Allées doubles, eft de donner la moitié de la largeur genérale, à l'Allée du mi. lieu, \& de divifer l'autre moitié en deux pour les contreAllées, qui doivent fe rapporter à la grande: par exemple à une Allée de huit toifes de large, l'on donnera quatre toifes à l'Allée du milieu, \& deux toifes à chaque contreAllée, à une de douze toifes, fix pour l'Allée du milieu trois pour chaque contre-Allée, à une de feize toifes, huit pour le milieu, \& quatre pour chaque contre-Allée. Suivant ce calcul on peut tout au plus diminuer une demie toife de largeur aux contre-Allées, quand on n'a pas affés 

'de place, ou bien dans les Allées doubles en face d'un Bầtiment, ou d'une Cafcade, en tenant l'Allée du milieu plus large, de ce qu'on diminuë fur les contre-Allées, afin qu'on découvre plus aifément du bout de l'Allée la beauté de cette vûë.

On ne doit nullement approuver les Allées doubles, dont les contre-Allées fortant de cette regle font fi étroites qu'à peine deux perfonnes peuvent s'y promener de front. Surauoi l'on dira qu'il faut environ trois pieds de large pour un homme: ainfi dans la largeur d'une toife, deux perfonnes fe promenent de front fort à l'aife, \& par conféquent dans une Allée de deux toifes de large, quatre perfonnes marchent fans fe toucher.

A l'égard des Allées de bofquets éloignés, \& du pourtour 'd'un parc, qui n'ont aucune enfilade ni alignement principal, il n’eft pas néceffaire de les faire fi larges, comme étant des endroits peu fréquentés, \& qui ne paroiffent pas tant à Ia vû̀ë-

Quelques perfonnes prétendent, que dans une Allée trèslongue, comme de trois à quatre cent toifes, on peut l'élargir de quelques toifes dans une des extrêmités, pour évi. zer l'effet de la perfpective qui en retrécit la largeur confi. dérablement, cela ne devient pas fenfible fur le terrain.

Le plus grand entretien d'un Jardin font les Allées, Therbe y croiffant fans ceffe : ceft pourquoi le Jardinier doit avoir grand foin de les tenir toujours bien nettes \& bien propre. Il fe fervira de ratiffoire pour les petites Allées, \& d'une charruë pour les grandes: enfuite il les repaf. Sera avec le rateau, \& les baliera, quand il s'y trouvera des feuilles \& des ordures. Tout ce qu'il doit obferver dans cet ouvrage, c'eft de choifrr un tems qui y foit propre, c'eft-àdire, un tems qui ne foit point trop fec, parce qu'alors la terre étant trop terme, il ne feroit que couper les herbes dans la fuperficie, \& en laifferoit les racines en terre, qui repoufferoient encore plus vivement. Il ne faut pas auffi que le tems foit trop mou, parce qu'en coupant les racines, la terre ou le fable qui en eft proche s'enleveroit auffi, ce qui gâteroit l'Allée.

Pour éviter le grand entretien des Allées, qui ont bean-

Ainfi que la grande Allée de maroniers du Luxembourg.
Les herbes les plus difficiles à détruire, font le chien-dent \& le lizeron, à caufe des lon. gues racines qu'elles pouf- 

on y pracique des tapis de gazon dans le milieu, qu'il faut faucher fouvent pour la propreté.

Quant à ce qui regarde la maniere de bien dreffer les' Allées \& les metrre de niveau, l'on renvoye le Lecteur ciaprès au Chapitre 2 de la feconde Parrie, oì il en elt parlé fort amplement. On en fera autant pour la maniere de planter \& d'élever les Arbres \& les paliffades des Allées, dont il eft traité dans les Chapitres $2 \& z$ de la $3^{\text {E Partie. }}$

Venons à la maniere de fabler \& de battre les Allées? qui eft le plus für moyen de remedier aux herbes qui y croiffent, \& d'empêcher les trânalfes de Taupes, qui font les ennemies jurées des Jardins, aufquelles on trouvera le fecret de remedier, auffibien qu'aux autres infectes $\&$ vermines, dans la $3^{e}$ Partie.

La meilleure maniere de fabler les Allées, eft de faire une aire de recoupe de pierre de taille, qui fe pratique ainfi: On met dans le fond des terres qu'on a ôtées, cinq à fix pouces de hauteur de groffe recoupe, que l'on arrange \& que l'on bat groffierement; on érend par deffus environ deux pouces de menuë recoupe, paffée à la claye, on bar le tout à troịs volées, e'eft à-dire trois fois, \& l'on arrofe à chaque volée ; enfuite l'on répandra le lable que l'on battra en. core. Quand on met un lit de falpetre fur ces recoupes., comme dans un Mail, \& dans les Jeux de boule, on les bar huit à neuf volées : fi l'on ne pouvoit point trouver de recoupe dans le Pays, on prendra des gravois \& des pierailles que l'on arrangera dans le fond, avec un lit de terre par deffus pour faire corps, après cela l'on jettera le fable que l'on aura foin de bien battre auff,

Cette maniere de fabler \& de battre les Allées, va à de grandes dépenfes, \& fait que dans les Maifons particulieres on fe contente de bien battre la terre, \& de répandrele fa. ble par deflus ; enfuite les pluyes achevent \& contribuent beaucoup à affermir ces Allées, oì l'on ne doit pas mettre trop de hauteur de fable, pour qu'elles ne foient pas fil laffantes, ni fi longtems à fe battre, deux pouces de hauteur font fuffíans.

Comme il n'y a point de recoupe dans ces Allées, \& que 
LA THEORIE DU JARDINAGE.

h terre eft fort proche du fable, les herbes y croirenc 97 la terre eft fort proche du fable, les herbes y croiffent plutôt que dans les autres, joint qu'à force de ratiffer, lesterres fe mêlent avec le fable, \& redeviennent, pour ainfi dire par ce mélange, de la pure terre. de terre.

Le fable de riviere eft le plus beau \& le meilleur. Pour le bien choifir, il le faut prendre un peu graveleux, qui ne foit ni trop fin ni trop pierreux, \& fur tout un peu pefant, afin que le vent ne l'enleve pas fi aifément. On paffe ce fable à la claye ou au gros fas, pour en ôter tous les cailloux \& le rendre plus beau.

Les Bateliers tirent le. fable de riviere avec des dragues dans leurs baitelets, mais tous les endroits de la riviere ne font pas propres à donner de beau fable : l'on n'y trouve fouvent qu'un fablon fin \& limoneux, cela oblige a funder la riviere en bien desendruits, avant que d'en pouvoir trouver de bon.

Le fable de terre, appellé ainfi, parce qu'on le tire des terres fablonneufes, ne laiffe pas d'être bon, \& de bien fabler les Allées: on s'en fert dans les Païs éloignés des rivieres.

Ce que l'on veut dire ici au fujet des Paliffades, ne regarde point la maniere de les planter, dont on fe réferve à parler dans la fuite. Il s'agit feulement ici de dire un mot de leur beauté, \& des différentes formes qu'on leur peut donner.

Les Paliffades, par l'agrément de leur verdure, font d'un très-grand fecours dans les Jardins, pour couvrir les murs de clôtures, pour boucher \& arrêter la vî̀ë dans de certains endroirs, afin de ne point découvrir tout d'un coup l'étenduë d'un Jardin, \& pour corriger, racheter les biais, \& les coudes des murs. Elles fervent encore à renfermer, à border les quarrés de bois, \& à les féparer des autr es pieces du Jardin, ce qui empêche d'y entrer que par les Allées.

La forme la plus commune des Paliffades, eft une grande longueur \& hauteur toute unie, formant une muraille ou tapifferie verte, dont-toute la beauté confifte à être fort garnie, fur tout par le pied, peu épaiffe \& bien tonduë des 
* verfailles, Marly, S. Cloue, จุ. deux côtés à pié droit: on lestond ordinairement en évantails en rideaux \& en banquettes, felon la nature du lieu.

Les évantails \& les rideaux ne font autre chole que de grandes Paliffades très-élevées, qui, fervent à fermer $\&$ à boucher des vûës \& des endroits défagréables, ou des féparations de Jardin : c'eft pour cet effet qu'on les appelle ainfi : leur hauteur fera des deux tiers de la largeur de l'Allée, les Paliffades fi hautes \& qui fortent de cette proportion, rendent les Allées trop petites, \& par là défagréables à la vîë, qui y eft. trop refferrée.

Si cependant on avoit deffein d'élever des Paliffades trèshautes, comme de so à 60 pieds, on joindra les arbres de haute-futaïe enclavés dans la Paliffade, avec la Paliffade même, en les tondant à pied droit devant \& derriere, de forte que la Paliffade garnic jufqu'à 20 pieds, \& l'arbre forme le refte. Et comme il feroit difficile de récéper par deffus ces hautes murailles, on laiffera le bouquet des arbres qui ne fait pas un mauvais effet. Il arrive quelquefois. que ces Paliffades fe dégarniffent par le pied, alors on $\mathrm{y}$ remedie, en garniffant le bas avec, du buis ou des ifs, foutenus d'un perit treillage de 5 ou fix pieds de haut, ainf qu'il fe voit dans beaucoup deJardins *.

Pour les Banquettes, ce font des Paliffades baffes à hauteur d'apui, qui ne doivent pas paffer ordinairement 3 ou 4 pieds de haut, elles fervent dans les côtés des Allées doubles, où étant ainfi ravalées, elles n'empêchent point de joüir d'une belle vûë entre les arbres : elles deviennent dé-fagréables quand elles n'ont que 2 pieds $\&$ demi, \& à 4 elles. font trop hautes, leur vraye mefure eft de 3 pieds $\&$ demi. L'on voit des Banquettes ornées d'efpace en efpace de petites boules échapées de la Banquette même, c'eft pour tenir la place des arbres qui font plantés dans les autres : ces fortes de Banquetres avec des boules fe mettent dans des endroits où l'on ne peut pas planter de grands arbres, \& oir il ne faut prefque rien pour accompagnement, à caufe de la vûü.

On peut encore pratiquer d'efpace en efpace des niches \& 2 des renfoncemens dans les Paliffades, pour y placer des bancs, des figures, des vafes \& des Fontaines, comme dans. 


\section{IA THEORIE DU JARDINAGE.}

les bofquets \& dans les bouts des allées, ce qui fait le plus grand mérite des Paliflades, car alors leur verdure qui fert de fond à ces figures, fontaines, \&c, en releve infiniment la beauté, en les détachant, \& les fait beaucoup valoir par l'oppofition qu'elle y produit ; mais dans les bolquets \& les endroits particuliers, comme les cloîtres, les galeries, les falles qu'on pratique dans les quarrés de bois, on perce les palifiades en arcades \& en portiques de. differentes formes; ces fortes de palifiades font encore un plus bel effet que les autres. Voici toutes les formes les. plus belles $8 x$ les plas variées qu'on puiffe imaginer, fans fortir du bon. goût \& de la poffibilité de l'execution, on n'a pas voulu rifquer de donner cés morceaux d'invention, crainte qu'ils ne paruffent trop extraordinaires à bien des gens, \& même impolfibles; on a mieux aimé en chercher des exemples executés dans les Maifons Royales, \& dans les Jardins les plus en réputation, que l'on a nommés exprès, afin qu'on les puiffe aller vifiter fur le lieu pour fe guérir de fon incrédulité, \& juger de leur belle execurion.

Cette Plancherenferme fix exemples dont le Ir eft à l'Italienne: la Paliffade eft tonduë deffus \& deffous, \& lailfe paroître les tiges desarbres à une hauteur convenable; l'on s'en peut fervir à border une allée, ou quand on veut joüir de la vûë par deffus un Bois : le deffous peut être planté en quinconce, ainfi qu'il eft marqué ici : ces fortes de Paliffades font fort communes dans les Jardins d'Italie.

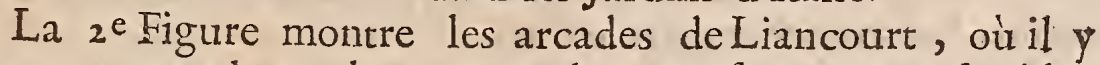
en a un grand nombre, cependant prefque toutes femblables; elles entourent dans cet exemple un Canal \& y font un effet admirable par le miroir des arcades \& des trumeaux dans l'eau : elles font plantées de tillots, dont la rige eft découverte à 8 pieds de haut, l'arcade a environ is pieds. fans la bande de deflus qui a encore 2 ou 3 pieds de haut: ces arcades doivent être peu épaiffes, au plus de deux pieds \& bien tonduës réguliérement devant \& derriere.

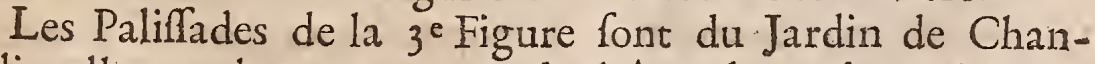
tilli : elles enclavent un grand cloître de verdure : les trumeaux en font garnis jufqu'au bas, \& les arcades ne portent pas de fond, mais fur une banquette à hauteur d'appui 
l'ou a fait des ouvertures aux enfilades d'Allées. Au deffurs de chaque trumeau, s'éleve un gros arbre, foit tillot ou orme, dont on laiffe voir un peu de la tige, le reftes'entretient en groffe boule irréguliere, c'eft-à-dire, qu'on ne coupe que les branches qui s'emportent trop.

La $4^{\mathrm{e}}$ Figure eft de Trianon, le deffein de ces arcades eft fort ingénieux, $\mathrm{y}$ ayant un cintre de verdure autour de chaque arcade qui excede les trumeaux : ce cintre eft ce qu'on apelle Archivolte en terme d'Architecture: entre deux cintres, s'échape une boule d'arbre affés grofle, comme de tillots ou de marroniers, dont les têtes font entretenuës grofo fiérement, les trumeaux en font plus larges que ceux des aus tres Paliffades, à caufe des têtes d'arbres qui le logent entre chaque arcade : il y a aufi une banquette, fur laquelle viennent tomber toutes les arcades, hors dansl es enfilades d'Allées, oì elles font ouvertes en forme de porte.

On voit dans la. ge. Figure un autre genre d'arcades qui portent toutes de fond, c'eft-à-dire, toutes ouvertes en portiques, les trumeaux n'ont que deux pieds de large, \& forment des montans en pilaftres, par un petit focle en bas, \& par une Impufte à la naiffance du cintre : l'on a auffi tailé des Claveaux au deffus de chaque arcade, \& de perites boules réguliérement tonduës fur chaque trumeau. Les focles, Impoites \& Claveaux faillent d'environ 2 pouces Cette Paliffade, quoique.ifolée, eft accompagnée d'un grand rideau de verdure qui lui fert de fond, à la différence des autres cídeffus qui tranchent fur le Ciel.

Enfin la $\sigma^{e}$ Figure repréfente la Paliffade d'un des Bofquets de Verfailles, nommé le Théatre d'Eau; elle a quelque rapport à celle de Liancourt, les trumeaux en étant découverts à une certaine hâteur, \& les arcades formées de même, à l'exception des vafes ménagés fur chaque trumeau, qui l'enrichiffent de beaucoup : elle eft élevée fur une eftrade de gazon., cintrée dans le milieu, \& elle a pour fond ainfi que la précédente, un grand rideau de verdure, le tout eft planté en charmille; la magnificence Royale y éclate parles bafins \& jets d'eau pratiqués entre chaque arcade, cela réveille infiniment cette belle verdure, mais on l'a mis plûtôt ici pour la reffemblance du. lieu que pour un exemple à fuivre chés un particulier. 
On donne à toutes ces arcades pour jufte proportion de leur hauteur, deux fois leur largeur, \& pour plus de grace encore, deux fois \& demi : plus elles font élevées \& mieux elles font: ces arcades font belles à $\mathrm{r} 5$ pieds de haut fur 6 ou 7 de large: l'on éleve par deffus une corniche ou bande plate de 2 à 3 pieds de haut, \&r les trumeauxauront 3 ou 4 pieds de large, plus ou moins, felon le deffein qui reglera aufí la forme $\&$ la proportion des boules tonduës en forme de vafes: s'il y a quelque corps faillant, comme un focle, un Claveau,.$\& \mathrm{c}$, ce ne doit être au plus que de deux ou. 3 pouces.

Ces décorations de verdure compofent une efpece d'ordre d'Architecture champêtre, de même que l'on nomme l'ordre ruftique d'une grotte, d'une cafcade: il n'y a aucune difficulté pour les executer, ce que l'on connoîtra encore mieux quand on parlera dans la fuite de la maniere de les planter: mais il y a de la fujertion \& de l'induftrie à les conduire \& à les bien élever pour leur faire prendre une forme convenable ; \& c'eft en cela qu'on peut dire certainement, que l'art furpaffe la nature, qui eft gênée \& affljettie au genie du Jardinier. On fuit toujours l'intention de celui qui en a donné le deffein, qui les deftine àde certaines figures, qu'elles n'acquierent qu'avec le terns. Il eft conftant que ces morceaux ont quelque chofe de furprenant, \& un air de magnificence qui diftingue fort un Jardin : ils conviennent principalement dans les grands terrains, où la conformité des Paliffades fatigue la vüë, fi elle n'eft réveillée par ces verdures extraordinaires, qui font en moindre nombre par l'entretien continuel qu'elles demandent, tant pour les bois \& fils de fer, que parce qu'il faut tou. jours paliffader, \& les tondre quatre fois l'année, à la différence des autrés Paliffades qui le font une ou deux fois tout aut plus.

Voilà ce qu'on peut faire de meilleur goût en fait de $\mathrm{Pa}$ liffades \& en même tems de plus riche \& deplus diftingué dans le Jardinage. A utrefois on leur donnoit: mille formes, extravagantes, qui font encore fort en ufage dans les Jardins a d'Italie \& b d'Épagne; l'on y' formoit des hommes à chea Fralcari. Tivoli. b Aranjuez, val, des fangliers, des cerfs, des chiens, en un mot une chaffe 
a Loo.

Honflardick,

Soefdick,

b Enguien, $B$ rurelles,

C S. James, Hampioncourt,

d Yacobdal Droinholm.

- Strafbourg. Saverne.

62 PREMIERE PARTIE, CHA P. V. entiere. D'autres y tailloient des pyramides, des obelifques \& des boules; avec des enroulemens qui continuoient jufqu'au bout des Paliffades. On en voit encore des exemples dans quelques anciens Jardins aux environs, de Paris. Cette mode perfifte toujours en ${ }^{a}$ Hollande \& en $b$ Flandre, oì ces deffeins bizarres font plus en regne qu'en tous autres Pays: ce goût fingulier ne regarde pas feulement les Paliffades, les Bofquets, les Parterres, les Fontaines \& les autres parties de leurs Jardins s'en reffentent beaucoup: les Anglois \& les Suédois fuivent plus nos manieres dans leurs Jardins ; on leur a envoyé de nos deffeins, qu'ils ont affés bien executés; \& de plus, ils ont fait venir des Architectes \& Jardiniers François qui y ont laiffé de leurs productions. Il fe trouve dans e l'Allemagne des arbres taillés \& contraints d'une maniere fort ingénieufe: l'on y pratique des falles élevées de terre de 7 à 8 pieds que l'arbre même couvre par deffus \& des côtés, avec des arcades percées autour. Le bas de la falle eft plancheyé \& foutenu par des piliers de charpente, ou par des colonnes de pierre, avec des efcaliers pour y monter. Le tronc de l'arbre traverfe la falle \& fe termine au-deffus en pyramides \& en boules de différentes formes. Le refte de leurs Jardins eft fort commun. On ne donne plus aujourd'hui en France dans tous ces colifichets, quelques bien entretenus qu'ils puiffent être, il y a toujours quelque chofe à redire. L'on aime mieux une régularité plus fimple \& moins embroüillée, cela tient plus du noble \& du grand.

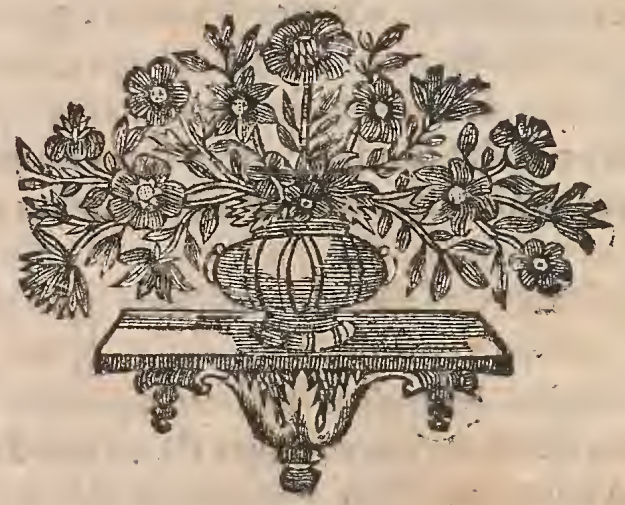






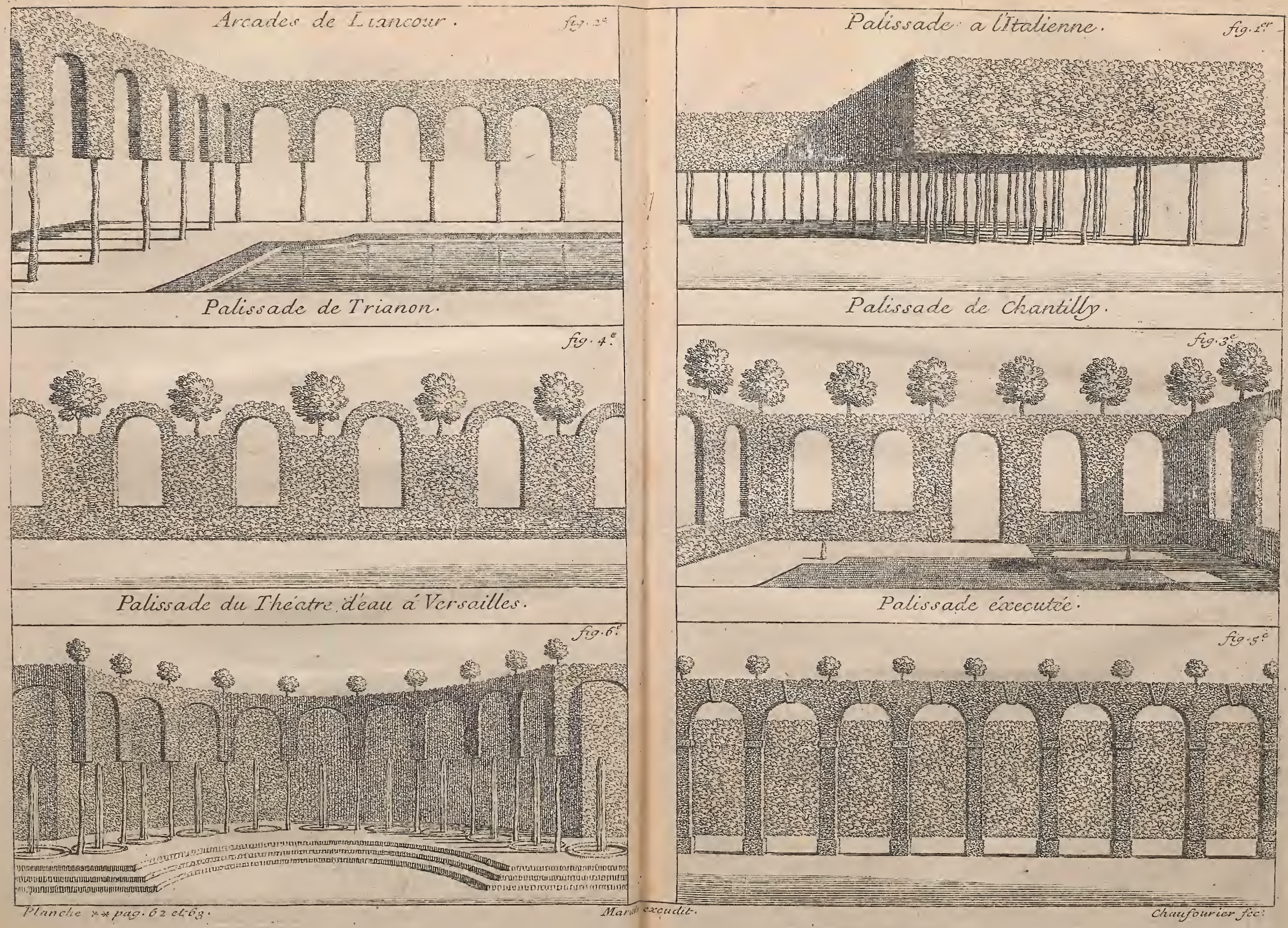





\section{H A I T R E VI. \\ DESBOISET BOSQUETS en général.}

CE Chapitre renferme tout ce qu'il y a de plus beau $\&$ de plus agréable dans un Jardin : fçavoir, les Bois \& lès Bofquets, fans lefquels on ne peut pas compter un Jardin pour beau, puifqu'ils en font le plus grand ornement. Les Buis font un fecours pendant l'Eté dans les grandes ardeur's du Soleil, \& c'eft dans ces lieux couverts qu'on peut fe promener à l'ombre, même en plein midi. A commencer depuis les grands. Jardins, où il s'y en rencontre toujours en quantiré, il n'y en a giteres de petit, qui n'ait un Bofquet ou quelque allée cotiverte.

On peut donc convenir que l'effentiel d'un Jardin ce fontles Bois, d'oùl'on conclura qu'une Maifon de campagne fansBois, eft défectueufe en une de fes principales parties.

On appelle Bofquet du mot Iralien Bofquetio, un petit Bois de petite étenduë, comme qui diroit un Bouquet de verdure.

LesBois \& les Bofquets font le relief des Jardins, \& fervent infiniment à faire valoir les pieces plattes, comme font les Parterres \& les Boulingrins. On leur doit deftiner des. places où ils ne cachent point la beauté de la vîeë, car il arrive fouvent qu'on eftobligé dans la fuite d'arracher ou d'é-têter un Bois, par le regret que caufe la perte de cette belle wûe : c'eft ce quon a déja remarqué en parlant des difpofi tions générales de Jardin.

Pour ce qui regarde leur forme \& leur deffein ; on les peut varier de differentes manieres, en tenant pour regle genérale de les percer d'allées le plus qu'on pourra, de n'y point faire trop d'ouvrages \& de retours, en confommant tout le garni du bois, \& auffi d'en faire trop peu, en laiffant de 
64 PREMIERE PARTIE, CHAP. VI.

grands quarrés de bois tout pleins, fans aucun ornement. Leur forme la plus ordinaire eft l'étoile, la croifée ou Craix de $S$. André, \& la patte d'Ö̈e : cependant on y pratique les figures fuivantes, comme Cloîtres, Labirinthes, Quinconces, Boulingrins, Sales, Cabinets, Chapelets, Guilochis, Sales de Comiedie, Sales couvertes, Berceaux naturels \& artificiels, Fontaines, Ifles, Cafcades, Galeries d'eau \& de verdure, \&c.

Il faut remarquer qu'on doit toujours faire une belle piece dans le milieu d'un Bois, comme une Sale de Marroniers, une piece d'Eau ou calcade: \& que dans ces fortes d'endroits on doit domner plus de largeur aux allées : fi les allés du Bois ont quatre toifes de large, celles dumilieu en doivent avoir cinq ou fix: Quand il y a une piece d'eau, l'on ne doit point faire d'allées doubles autour, afin de découvrir plis ag réablement l'eau, \& de rendre ces lieux plus aërés $\& x$ moins marécageux.

Il y a des Bois de plufieturs natures qui fe peuvent réduire aux fix efpeces fuivantes : les Forêts \& grands Bois de hautefutaie, les Bois taillis, les Bofquets de moyenne futaïe à hautes paliffades, les Bofquets découverts à compartiment, les Bofquets plantés en quinconces, \& les Boids verds.

Les deux premieres efpeces, qui font les Forêts ou grands Bois de haute-futaie, \& les Bois taillis, ne conviennent que dans la Campagne, ou bien dans un grand Parc de deux ou trois lieuës d'étendıë. Cependant pour ne rien oublier, nous en parlerons comme des autres Bofquets fuivans, qui tont ceux qui regardent le plus nos Jardins de propreté.

Les Forêts \& grands Bois de haute. futaie font ainfi appellés, à caufe de leur hauteur \& de leur étendue confidérable. On y compte au moins une lieuë ou plufieurs arpens de circuit : ils font compofés de grands arbres très-élevés \& très - proches l'un de l'autre, qui forment une hauteur touffuë \& fort épaiffe. Ces bois n'ont point de paliffades ni d'allées ratiffées, ce ne font que des routes pour la chaffe. Ils font ordinairement plantésen étoile, avec un grand cercle dans le milieu, oì viennent aboutir toutes les routes. Ces Bois font brutes \& champêtres, comme la Forêt de S. Germain en Laye, celle de Fontainebleau, deSenlis, le Bois de Boulogne, de Vincennes, \&xc. 
LA THEORIE DU JARDINAGE. Gs

Les Bois taillis ne different des Bois de haute-futaie, que parce qu'on ne les laiffe pas monter comme les Futaïes, \& qu'on les coupe rez terre tous les neuf ans, dont ils prennent le nom de Taillis. On fait la divifion de cent arpens de ces Bois en neuf parties, qui font de onze arpens, que l'on coupe chaque année : de cette maniere le Bois ne fe dégrade \& ne.fe ruine point, un côté recroiffant pendant qu'on coupe l'autre. L'on eft obligé d'y laiffer, felon les ordonnances, i 6 Baliveaux par arpent, outre les anciens des autres coupes: par fucceffion de tems, cela fait d'un Bois taillis, une haute-futaïe.

Les Bois de moyenne futaïe à hautes paliffades, appellés Bois Marmanteaux, ou de Tousche, \& les trois autres efpeces fuivantes, font ceux que l'on pratique dans les beaux Jardins; ce font veritablement les Bofquets de propreté : On les appelle moyenne futaïe, parce que les arbres quiles compofent ne parviennent jamais à cette grande élévation de la haute-futaie; ils ne paffent gueres 30 ou 40 pieds de haut. Ces Bois font ornés de Sales, de Cabinets, de Galeries, de Fontaines, \&c. Leurs quarrés font bordés de Paliffades \& de Treillages, \& les allées en font bien drefrées \& bien fablées, ce qui eft d'une grande propreté.

Les Bofquets découverts \& à compartiment, que quelques gens appellent, Bofquets parés, différent des autres Bois, en ce que l'on ne plante point d'arbres dans le milieu de leurs quarrés, pour former de la futaïe ou du garni. L'on plante leurs allées de tillots ou de marroniers, conformément au deffein, \& l'on y met une petite paliffade réfepée à hauteur d'apui, d'environ trois pieds de haut, qui dégage \& découvre par le deffous tout un Bofquet, \& fait qu'en fe promenant, on joüit de la vûë, à la différence des Bois ordinaires, où les paliffades \& le garni viennent très-haut. Dans les quarrés de. ces Bois, on pratique des comparimens \& des tapis de gazon, avec un fentier ratiffé de deux pieds de large, regnant par tout entre les paliffades \& les pieces de gazon. On les orne d'ifs \& d'arbriffeaux placés par fimetrie. Ces fortes de deffeins font les plus beaux \& les plus riches; ce font prefque comme de vrais parterres, tenant de ceux à l'Angloife \& à compartiment, \& retenant quelque chofe du Bois. On y fait des cabinets, des falles $\&$ des enfilades quife communiquent l'une dans l'autre. 


\section{PREMIERE PAR TIE, CHAP.VI.}

Les Bofquets plantés en quinconce ne font autre chofe que plufieurs allées ou rangs d'arbres de hante-futaïe, plantés en échiquier, ou à angles droits, ou bien en lignes paralelles: il n'y faut point de brouffailles ni de paliffades. On les apelle Quinconces, à caufe de la conformicé qu'ils ont avec la figure du cinq des cartes à joüer; on ratiffe le deffous de ces arbres, ou on le gazonne, en ménageant feulement quelques allées blanches dans le milieu, \& quelques petits cabinets \& enfilades, le tout fans paliffades; on doit voir de tous fens des allées droites $\&$ bien alignées.

Les Quinconces qu'on fait préfentement, font très-différens de ceux des Anciens, dont parle Vitruve, qui étoient très-femblables au cinq des cartes à joüer, en ce que les Anciens plantoient un arbre dans le milieu des quatre, ce que l'on ne fait plus, parce qu'il fe rencontroit des allées plus. étroites les unes que les autres. On fe contente de planter les. Quinconces en lignes retournées d'équerre, qui forment un échiquier ou trait quarré ; cela rend les allées plus régulieres. \& d'égale largeur par tout.

La fixiéme efpece, qui font les Bois verds, font les plus. beaux de tous, par leur verdure continuelle pendant l'Hiver, comme pendant l'Eté ; ils font plus rares dans les Jardins; le long-tems qu'ilis font à crô̂tre pour former de la hautefutaïe, dégoûte fouvent del'envie qu'on auroit d'en planter.

On trouvera dans les deffeins fuivans tout ce que l'on peut fouhaiter en fait de deffeins de Bois. On peut dire que cette matiere eft épuifée, \& qu'on ne peut aller au-delà de l'invention de ces dix Planches.

On a donné beaticoup plus de Planches de Bofquets que de Parterres, par la raifon, qu'il y a un grand nombre de Parterres gravés, \& fort peu de Bofquets.

La I e Planche contient deux deffeins de grands Bois de haute-futaïe, des mieux percés $\&$ des plus magnifiques.

La re Figure repréfente un Bois percé en étoile double, avec une grande Salle dans le milieu, ornée d'une piece d'ears avec trois Jets, \& quatre autres Baffins efpacés dans le Bois, dont les Jets s'enfilent avec ceux de la piece d'eau : cesfontaines font un fort bel effet, parce qu'en vous promenant, vous découvrés dans les Allées au moins trois jets, dans d'autres cinq, \& vous voyés tous les fept dans l'Allée du milieu. Outre 
IA THEORIE DU, JARDINAGE. 67 ces ornemens, ce Bois eft percé fi avantageufement, que de quelque côté que vouss tourniés, vous avés toujours en face au moins trois allées, qui forment une patte d'ö̈e dans les huit entrées; un peu plus avant, vous trouvés de petits ca rafours à quatre allées, \& dans les grands qui font ornés de baffins $8 x$ d'ifs, il y a fix allées aboutiffantes au centre, qui compofent des étoiles. On a fait les huit allées principales plus larges que les autres. Cette compofition ingénieufe rend ce Bois des plus agréables, quoi qu'on n'y ait point pratiqué de Cabinets ni de Galeries, ainfi que dans l'autre deffein à côté.

La $2^{\mathrm{e}}$ Figure repréfente un autre Bois percé en étoile fimple, où fe voit pareillement une grande Salle dans le milieu, avec une piece d'Eau ornée d'un gros jet vî des huit allées: à peu près dans leur milieu, l'on trouve un grand ovale qui vient le joindre aux allées de l'étoile. dont on a coupé les pointes, pour former huit carrefours. On trouve encore en fe promenant dans cet ovale, d'autres allées qui conduifent dans huit Cabinets ou Bofquets tous différens les uns des autres. Le I er Cabiner, à commencer par en bas à droite, eft un grand cercle de charmille coupé de niches pour des bancs \& dés arbriffeaux : au milieu eft un octogone renfoncé, qu'on apelle autrement un Boulingrin. Le $2^{\mathrm{e}}$ en remontant eft compolé de trois petites pieces qui s'enfilent l'une l'autre, dont celle du milieu eft un quarré long orné d'ifs, \& les deux des bouts font de forme circulaire avec des bancs. Le $3{ }^{\mathrm{e}} \mathrm{Cabinet}$ eft une galerie d'eau compofée de fept boüillons, qui retombent dans une rigole ou petit canal, pratique dans le milieu. La paliffade eft bordée defcabellons, de figures, avec des ifs entre-deux, \& il y a deux niches avec des bancs aux deux extrêmités de cette galerie. Le $4^{e}$ eft de figure quarrée, cintré dans les quatre faces, avec une piece de gazon dans le milieu, \& quatre ifs dans les angles. Le $g^{\mathrm{e} C a b i n e t}$ enfuivant, eft une figure à pans, qui forment un octogone irrégulier; il y a dans le milieu un Boulingrin circulaire. Le $\sigma^{\circ}$ eft tune galerie trèsdifférente de l'autre, en ce qu'elle elt formée par desarbres en boule, \& terminée par deux baffins ovales avec des bancs.

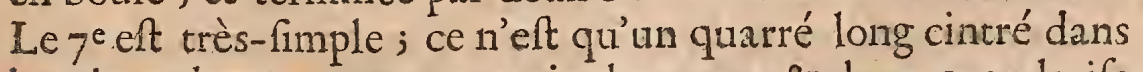
les deux bouts, avec un tapis de gazon \& deux grands ifs plantés au centre des portions circulaires. Enfin le 8• Cabinet 

dont le milieu eft rempli d'une piece de gazon échancrée aux quatre coins.

Ces deux Bois contiennent environ fept arpens : ils ne conviennent que dans de grands lieux. On peut cependant les executer en plus petit \& en plus grand, felon la place; mais plus ils feront grands, mieux ils feront, parce que les allées ne fe toucheront pas fi près l'une de l'autre. L'échelle qui eft commune à ces deux deffeins, en fera connoître toutes les proportions.

La $2^{\mathrm{e}}$ Planche contient quatre deffeins de Bois de hautefutaie, dont la forme eft barlongue, \& dont l'étenduë eft d'environ fix arpens. Dans les trois premieres Figures ce font des Bois propres pour une grande enfilade, où il faut conferver une allée large dans le milieu, qui partage le deffein en deux. On ne laiffe pas cependant d'y trouver un tout fort agréable \& fort régulier.

Dans la Ire Figure ce font de petites allées comparties en guillochis, qui aboutiffent à fix Cabinets différens, ornés de de berceaux, de pieces de gazon, de bancs \& d'ifs. Au milieu de la grande allée, l'on a pratiqué une Salle à pans, \& une

Cela con. vient dans de certains enaroits, tant pour la varieté, que pour fauver le grand eatre. piece d'eau avec un Jet. La plus grande partie de cette allée eft remplie par un tapis de gazon qui regne autour de la piece d'eau. Ces fortes d'allées vertes font fort à la mode prefentement.

Les allées de la 2 e Figure font difpofées de maniere, que les Cabinets des coins viennent fe rendre l'un dans l'autre; mais la falle eft très-différente des autres, étant cintré dans fon milieu, \& préfentant une patte d'ö̈e de chaque côté, avec quatre piedeftaux pour des figures ou vafes. Les allées de ces pattes d'ö̈e viennent aboutir chacune aux Jets de la piece d'eau, ou l'on en a mis exprès trois ; cela rend ces Allées circulaires fort agréables, tous ces Jets fe voyant l'un après l'autre. La piece d'eau eft d'un deffein fort particulier, elle eft fituée au milieu de la grande allée plantée d'arbres ifolés.

La compofition de la ze Figure eft un grand cercle, dans l'intervalle duquel, \& de la Salle du milieu, l'on a pratiqué deux Cabinets a pans, avec des pieces ovales de gazon; de cette grande allée circulaire l'on entre par des coudes d'al. 
lées, dans des Cabinets qui font aux quatre coins du Bois: où il fe trouve d'autres allées d'enfilade au Jet de la piece d'Eau, avec des bancs vis-à-vis, ce qui eft fort heureux. On fort de ces Cabinets \& de ces allées däns la grande du milieu plantée d'ormes taillés en boàles.

$\mathrm{La} 4^{e}$ Figure eft un deffein entier fans enfilade dans le miComme l'on lieu; il fe trouve percé par des allées cliagonales, qui forment quatre croix de S. André, au centre defquelles on a pratiqué des carrefours \& des pieces de gazon. Toutes les allées viennent fe rendre dans une grande Salle, qui mene dans quatre Cabinets différens, placés vis-à-vis l'un de l'autre. Deux de ces Cabinets fervent de Salles de. Bal; les autres font ornés de gradins de gazon, avec des figures $8 z$ des fleurs dans le haut. On voit dans cette Salle une piece de gazon terminée par deux Bafins, qui eft affés extraordinaire, cependant cela fait fort bien, parce que les allées diagonales viennent aboutir aux jets de ces Bafins.

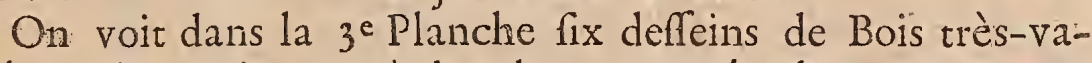
riés, quil conviennent à des places quarrées de quatre arpens d'étenduë.

Dans le Bois qui eft repréfenté dans la i $\mathrm{y}^{\mathrm{re}}$ Figure, l'onentre par les angles, ou l'on trouve deux allées aboutiffantes à des carrefours circulaires, qui vous menent dans une Figure à huit pans. Cette figure eft difpofée de maniere, que préfentant quatre angles dans les carrefours, \& les quatre autres venant à des renfoncemens pour des bancs, elle allonge les allées des entrées, en forte qu'une perfonne affife fur l'un de ces bancs, peut découvrir les deux allées des bouts, fans celle vis-à-vis, qui avec trois autres allées en face des bancs, vous conduit dans la piece du milieu enrichie d'une Ifle \& de quatre boüillons d'Eau, qui fourniffent le foffédu tour. Il'y a: une figure au milieu de cette Inle \& un pont pour y aller.

$\mathrm{La}_{2}$ e Figure eft un Bois qui a douze allées pour entrées, les droites enfilent la place du milieu 、 \& les Diagonales viennent rendre à une piecede gazon circulaire, entourée d'une double paliffade ifolée, \& percée vis-à-vis de chaque enfilade.. Ces carrefours préfentent des paties d'oïe, d'oì l'on. paffe à une grande figure quarrée qui forme un cloîre; les. angles en. font. occupés par des niches avec des bancs. Les. 
quatre allées du milieu vous conduifent à une piece d'Eaus quarrée, done les oreillons faillent en forme de baftions. Il s'éleve du milieu un grand jer perpendiculaire, \& des quatre coins ou oreillons, quatre autres jets obliques, formant des berceaux.

Le Bois de la $3^{\mathrm{C}}$ Figure eft le plus fimple de tous, auffi peute on l'exécuter dans l'efpace de deux arpens, \&x même d'un. C'eft une fimplc croix de S. André, entourée d'un grand. octogone, d'où par quatre allées on vient rendre dans une grande Salle circulaire, ornée d'un Baffin à pans, \& d'un rang d'arbres \& d'ifs ifolés, àvec quatre niches pour des bancs.

La $4^{e}$ Figure offre un deffein bien plus compofé , \& d'une invention affés particuliere. C'eft pareillement une Croix de S. André, qui vous mene dans un cloître ; l'on trouve au milieu de chaque allée des renfoncemens en demi-lune, avec des baffins; en face defquels il y a des allées qui viennent rendre à la piece du milieu, aufi-bien que celles de la croifée. La Salle du milieu êt de forme circulaire, coupée de huir niches pour des bancs, entre chaque allée. Elle eft remplie d'un grand Baffin octogone, ou il y a une Ifle au milieu, avec une figure entourée de caifes \& de pors de fleurs. L'eau de ce baffin vient de la décharge des quatre autres.

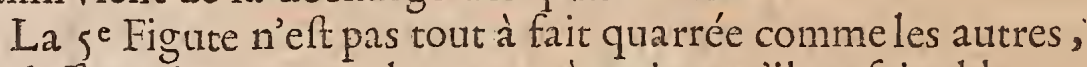
ce deffein n'ayant pas de grace, à moins qu'il ne foit oblong; cela a obligé d'y pratiquer aux deux côtés des allées \& des pie. ces de gazon découpées. Ce Bois fe trouve percé de plufieurs deffeins, comme d'un grand ovale, d'une lozange, \& d'une croix de S. André, qui compofent tous enfemble un affés beau compartiment. On y trouve deux pattes d'oïe, huit carrefours, \& deux renfoncemens, avec des bancs. Les qua tre entrées des encoignures, \& les deux du milieu, viennent aboutir à une Salle circulaire, ornée d'un baffin \& de niches pour des bancs \& des arbriffeaux.

Dans la 6e Figure l'on voit un Bois dont les entrées font dans le milieu pour la varieté ; elles font interrompuës par les quatre angles d'une grande lozange qui vous mene à des Cabinets pratiqués dans les quatre coins du Bois, tous differens les uns des autres. Il y a de petits carrefours triangulaires vis-à-vis ces Cabinets, lefquels ouvrent l'entrée d'un cloître, d'où par quatre iffuës, vous paffés à la Salle du mi- 
LA THEORIE DU JARDINAGE. 7 I lieu qui eft à pans, avec un baffin ovale. En face de ces quatre petites allées, on trouve des niches avec des bancs. Il eft inutile d'expliquer les quatre Cabinets des coins; on peut juger de ce qu'ils contiennent, par ce qu'on a déja dit, au fujet de ceux qui fe font rencontrés dans les autres deffeins, \& qui ontété détaillés affés amplement.

La 4 e Planche eft la plus remplie de toutes; elle contient dix Bofquets différens: les quatre premieres Figures font propres à des places oblongues, d'environ un arpent \& demi, ou deux arpens d'étenduë ; les fix autres fuivantes font voir ce qu'on peut exécuter dans des languettes de terre $\&$ des boyaux de Jardin. Ces bois font très-variés, \& quoique fimples, ils ne laiffent pas d'être bien percés \& bien ouvragés. L'afpect feul \& l'échelle qui eft au bas, fuffifent pour en donner toute l'intelligence nécefraire.

On fuppofe les places biaifes des Figures I re \& ge de cette 4e Planche, afin de faire voir comment on peut les régularifer \& y pratiquer des deffeins agréables. On prend d'abord dans ces biais, la moitié de chaque ligne qui bornent la place, pour placer les allées du milieu, foir en long ou en large : les diagonales enfuite fe tracent d'un angle à l'auttre, \& déterminent le centre de la Salle, qu'il faut ajufter au terrain, enforte qu'elle foit bien brouffaillée par tout : le refte du deffein s'accommodera au lieu, foit pour les carrefours, pattes-doile , entrées \& autres allées. On ne doir pas s'embaraffer , fi les quarrés de Bois viennent de différentes forme \& grandeur; on ne juge de cela que fur le papier, ces différences ne paroiffant jamais fur le terrain. Tous les deffeins ne conviennent pas au même biais ; c'eft au bon goût \& à l'expérience qu'eft refervé ce choix. Les Figures $2^{\mathrm{e}}, 3^{\mathrm{e}} \& 4^{\mathrm{e}}$ par exemple, y feroient moins bien que la $\mathrm{Ir}_{\mathrm{e}}$ à caute des allées retournées quarrément en forme de cloître, qui paroîtroient gauches dans un biais aufii fenfible que celui-ci. Le boyau de terre de la se Figure n'oblige à aucune fujettion par fon biais : on prendra feulement la moitié de la largeur des deux extremités pourl'allée du milieu; \& ce deffein que l'on nomme Chapelet, s'y accommodera de mềme que dans une place réguliere.

Les deux Planches fuivantes, qui font la ge \& la 6 crepréfentent des Cabinets \& des Salons propres à placer dans les: bois; en cas que les deffeins de ceux qui y font, ne convien- 
Ce Bofquet contient tout au plus un arpent.

nent pas aux places qu'on auroit, ou qu'ils ne pluffent pas tant: on pourra alors choifir dans les douze figures qui font dansces deux Planches. On a fait graver ces Salons un peu grands, pour les pouvoir planter d’après ces"deffeins, fans être obligé de les deffiner une feconde fois.

La $7^{\mathrm{e}}$ Planche préfente un Bofquet d'une autre nature que les précédens; c'eft ce qu’on apelle un Bofquet découvert à compartiment. On n'en a mis qu'un feul deffein fur la Planche, afin que devenant plus grand, on pût mieux juger de fa difpofition. Ce Bofquet eft croifé de deux allées, qui aboutiffent à un Baffin formant un octogone irrégulier, \& entouré d'une falle ovale, coupée dans ces quatre milieux, d'allées qui vous conduifent à de petits cabinets \& enfilades pratiquées dans les quarrés de ce Bois; d'oì par des bancs placés avantageufement, vous découvrés le Jet du milieu. Les entre-deux de ces cabinets font occupés par des pieces de gazon comparties en volutes \& en ronds, ornés d'ifs placés avec fimetrie. On tiendra les paliffades de ce Bofquet à hauteur d'apui, afin de découvrir toutes les pieces du compartiment.

Il y a un quart du deffein où l'on n'a marqué qu'un fimple trait pour la paliffade, \& des $O$ pour la place des arbres, afin qu'on puiffe mieux l'executer fans embarras, ce qui feroic arrivé, fi l'on avoir élevé en perf́pectiveles arbres \& les palifiades, comme le refte du deffein.

On voit dans la se Planche des pieces féparées, dont on

Comme l'on en roit dans les Jardins de Trianon. peut fe fervir dans le nilieu d'un bois, en cas que les deffeins cideffus ne plaifent pas tant. Ce font des falles plantées d'arbres ifolés, avec des ifs entre-deux.

La Salle de la r re Figure eft la plus magnifique. On la fuppofe au milieu d'un grand bois, \& n'ayant que deux entrées: cependant on en pourroit faire quatre felon le lieu, par le retranchement des Cabinets des deux bouts; elle n'en feroit pas moins belle. Son étenduë eft d'environ un arpent \& demi; mais on peut l'executer dans un terrain plus petit de moitié. On l'a orné de quatre baffins, qui s'alignent l'un l'autre, avec des bancs pratiqués de maniere, qu'ils font en face de chaque allée , \& enfilent les Jets des baffins. La piece du milieu eft un grand tapis de gazon, qui étant coupé à pans dans les quatre angles, forme aux quatre coins de cette falle des octogones que la Paliffade racheve. Le refte s'explique afís de lui-même. 
LA THEORIE DU JARDINAGE.

$\mathrm{La}_{2}{ }^{\mathrm{e}}$ Figure eft encore une grande Salle différente de l'autre, en ce qu'elle eft fituée dans une grande piece de gazon. On peut aufifi la placer dans le milieu d'un bois. Cette Salle eft un quarré long cintré dans les deux bouts, oì l'on a pratiqué deux baffins octogones, au centre defquels viennent aboutir les entrées diagonales de cette Salle. L'on a placé des figures dans les deux boits, \& deux bancs à chaque angle de la Salle, bordée fimplement par le gazon \& par des arbres, fans aucunes paliffades ni fentiers derriere.

La $3^{\mathrm{e} F i g u r e, ~ e f t ~ u n e ~ p e t i t e ~ S a l l e ~ f o r t ~ f i m p l e ~ e n t o u r e ́ e ~ d ' u n e: ~}$ paliffade à hauteur d'appui, avec des arbres efpacés dedans : Elle eft placée, ainfi que l'autre, dans des tapis de gazon, quî̀. font diftingués d'avec la paliffade par un fentier ratiffé. Il y ä dans le milieu une figure à l'enfilade des allées $\&$ des bancs.

Dans la $4^{\mathrm{e}}$ Figure l'on voit un bois planté en quinconce, avec une Salle \& des Cabinets, qui compofent un compartiment ; ce qui paroîtra d'un goût fort nouveaul : ces fortes de deffeins n'érant ordinairement compofés que de grandes allées paralleles, plantées en échiquier, fans aucun autre ornement. Quoiqu'on ait pratiqué une Salle dans le milieu, avec un baffin \& des cabiners qui forment un Cloître, \& s'enfilent l'un l'autre, cela ne dérange cependant rien du quinconce, \& n'interrompt point l'enfilade des arbres, dont on n'a ôté que queiques-uns dans le milieu \& dans les coins, pour former cette Salle \& ces Cabinets. Le deffous de ce quinconce eft gazonné dans quelques endroits, ce qui détache \& fait valoirle ratiffage des allées $\&$ de la Salle.

La 9 Planche donne l'idée de quatre morceaux de Jardin fort extraordinaires, \& cependant magnifiques dans leur efpece; on les appelle des Cloîtres.

$\mathrm{La}_{y^{e}}$ Figure eft la plus fimple de toutes; c'eft un grand quarré de gazon, avec une figure dans le milieu, entourée d'une double allée de charmille, percée dans les enfilades des autres allées \& des bancs. CeCloître eft dans le milieu d'un bois; l'on y arrive par quatre allées diagonales, qui rendene' à des carrefours ornés de pieces de gazon.

La $2^{e}$ repréfente un Cloître de forme circulaire, fitué dans un bois, avec un baffin octogone, entouré de berceatux natuzels, e'eft-à-dire, furmés par des arbres, que l'on plie l'un

Ainfi que les Quinconces des Tuileries
Le Cloitre de Meudon en eft un bel exẹmple. 


\section{PREMIERE PARTIE, CHAP. VI.}

fur l'autre. Les quatre allées qui y conduifent font aufi cour: vertes de berceaux, \& il y a un petit fentier ratiffé aux deux côtés qui forment des contre-allées; c'eft pour détacher ces berceaux d'avec la paliffade du bois.

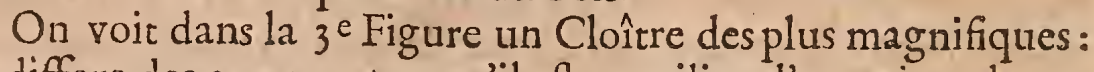
Il differe des autres, en ce qu'il eft au milieu d'une piece de gazon ; cependant on le peut placer auffi dans un bois. C'eft un grand octogone ralongé, couvert de berceaux de treillages, avec quatre Cabinets en face des allées qui y conduifent. Le milieu de ce Cloître ent renfoncé : l'on y defcend par trois rangs de marches de pierre de taille, ou de gazon, fi l'on veut. Le fond en eft orné par une piece de gazon, \& par quatre petites fontaines en buffets, pratiquées fur les gradins, en face de chaque allée.

i Ia moitié de ee Cloître eft gravée en arcades, \& l'autre moirić en boules, pour en laiffer le choir.

Ces ornemens de fleurs Cont fort nouvcaux dans un bois, \& y font des merveilles.

Le Labisinte de VerSailles, \& celui de Cbantilly, ront fort bien coupés. Ils Sont ornés de tout ce que P'Art peut: joindre ì la Narure.

La $4^{\text {e }}$ igure eft un Cloître en galerie, formé par une palif fade en arcades, ou par des Ormes en boules, avec de la charmille au pied, tonduë en caiffes; ce qui imite affés bien l'Oranger. On y a placé des bancs de telle maniere, qu'ils s'enfilent à travers les arcades \& les boules; c'eft pour continuer le coup d'œil. On a pratiqué au milieu de ce Cloître, une piece à l'Angloife bordée d'une plate-bande coupée, ornée d'arbriffeaux \& de fleurs, \& terminée par deux bafins, entourés pareillement de cette plate-bande.

Enfin la roe Planche de ces Bofquets, contient un deffein de Labirinte en volute ou Spirale, au centre de laquelle eft un baffin accompagné d'une Salle percée de huit allées, qui rendent à quatre carrefours, d'où infenfiblement vous paffés dans des culs de facs, ornés de cabinets, de berceaux de treillage, tapis de gazon, fontaines, figures, \& c. qui furprennent \& amufent agréablement ceux qui s'y font égarés. La quantité d'allées \& de détours différens quife rencontrent dans la compofition de ce Labirinte, le rendent des plus embaraffants; fans cependant lui ôter la régularité \& la grace du deffein. Il n'y a qu' une feule entrée, qui fert auffi de fortie, où l'on a placé exprès un cabinet de treillage pour la rendre plus difficile.

Ce Labirinte demande un peu de terrain pour devenir beau en execution, \& ne peut gueres fe planter dans une efpace moindre de 7 à 8 arpens, fans cela les alléés fe toucheroient de trop près, ce qui en ôteroit l'embarras, \& en même tems tout le mérite. 




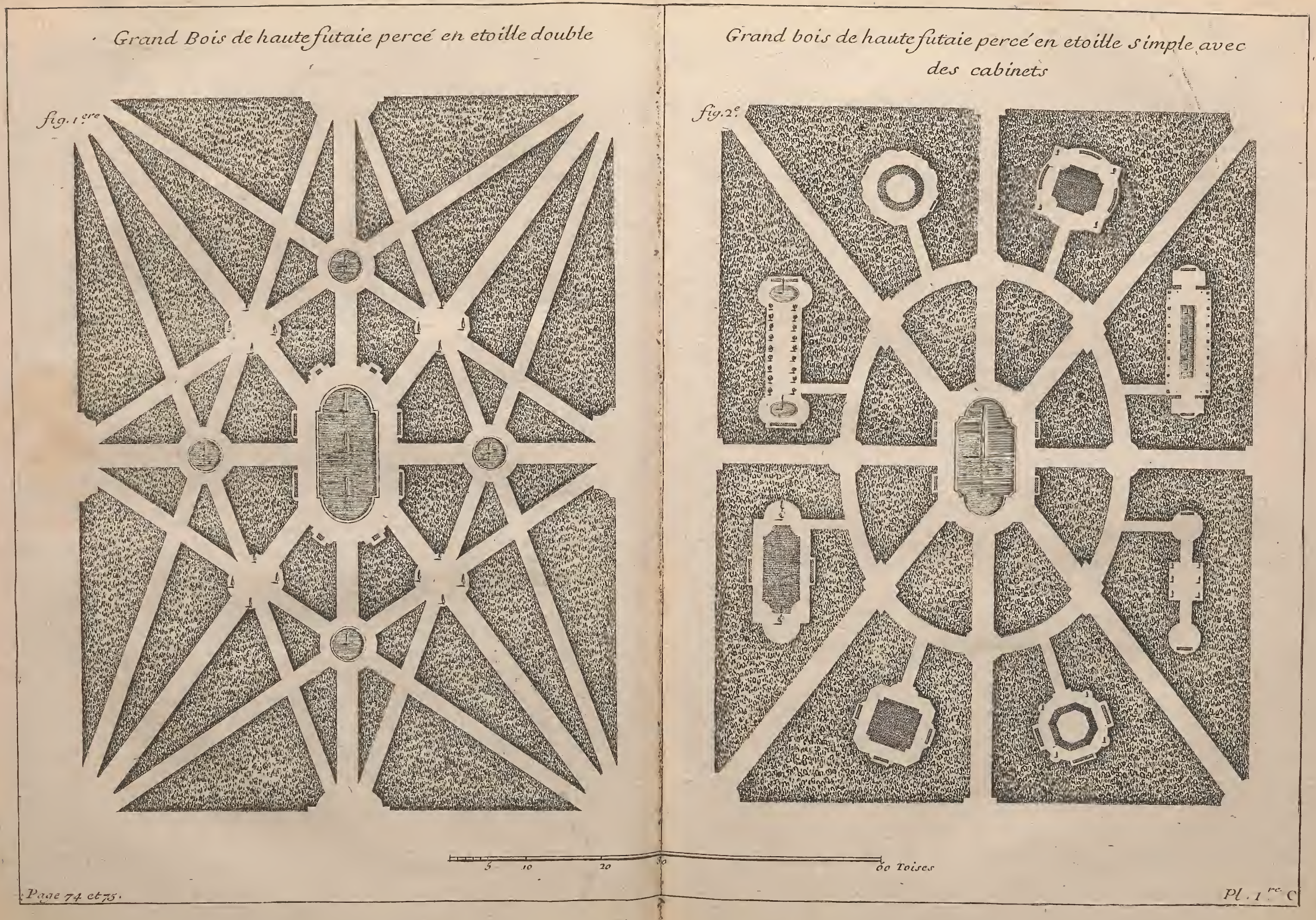







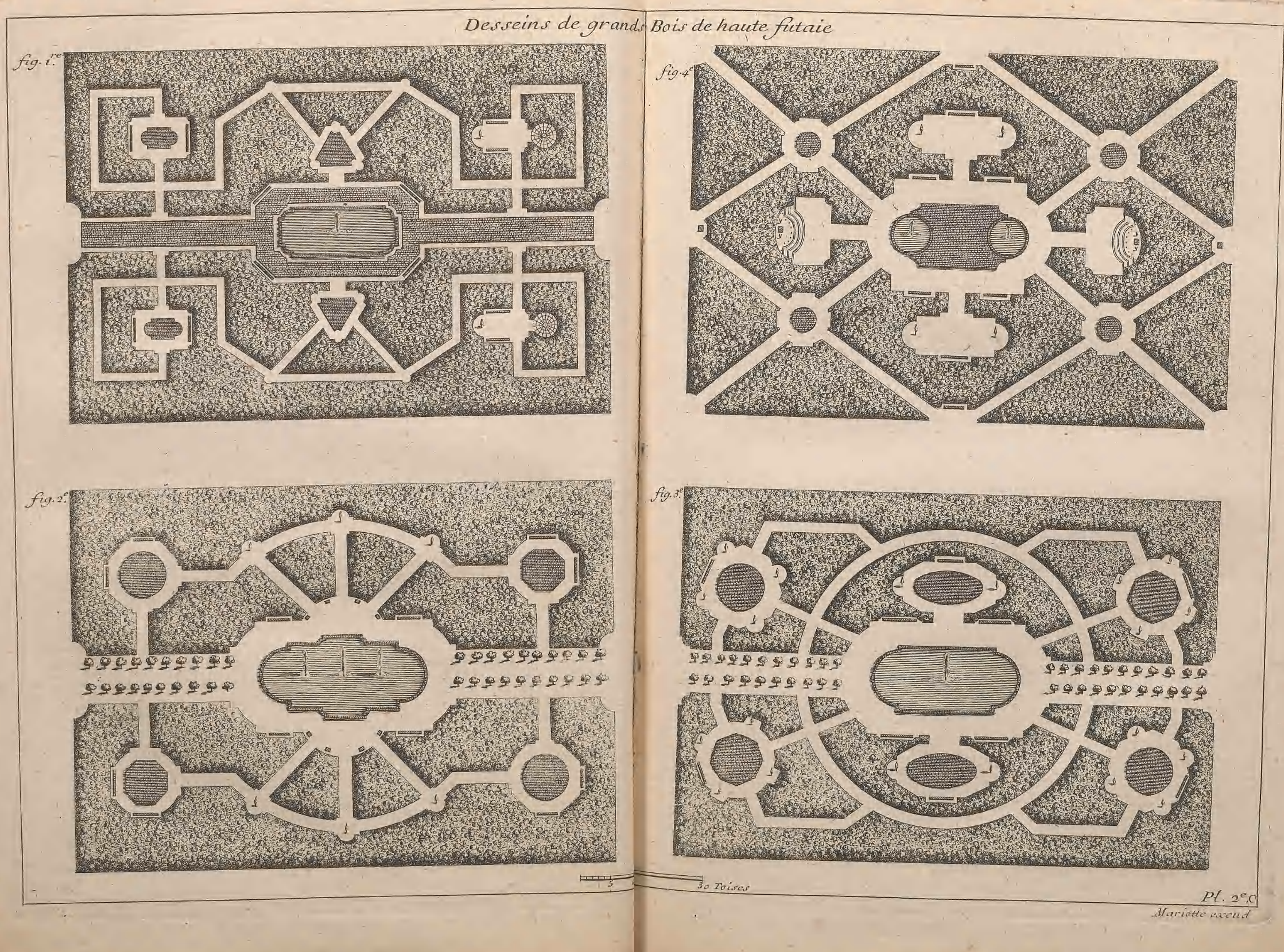







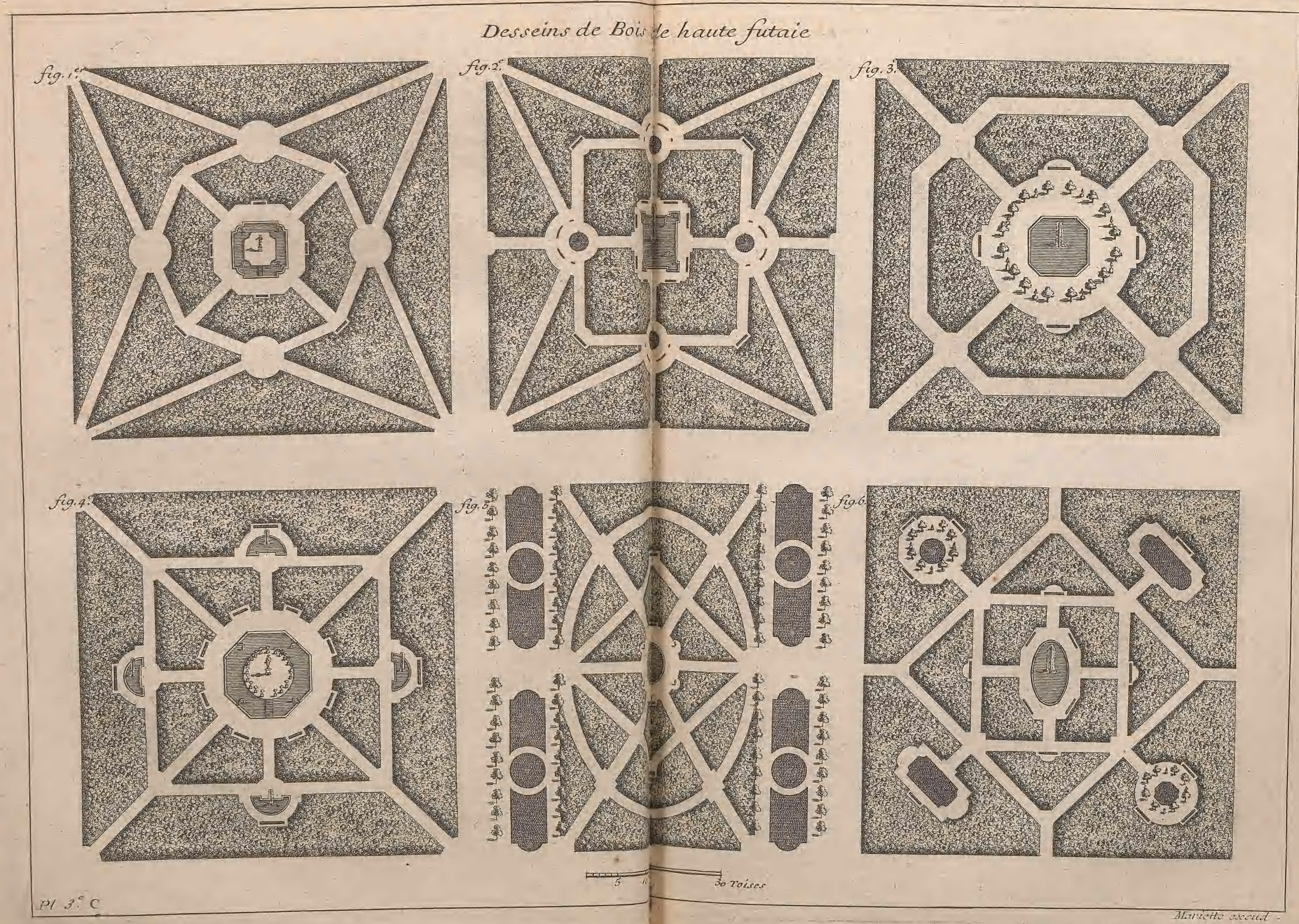







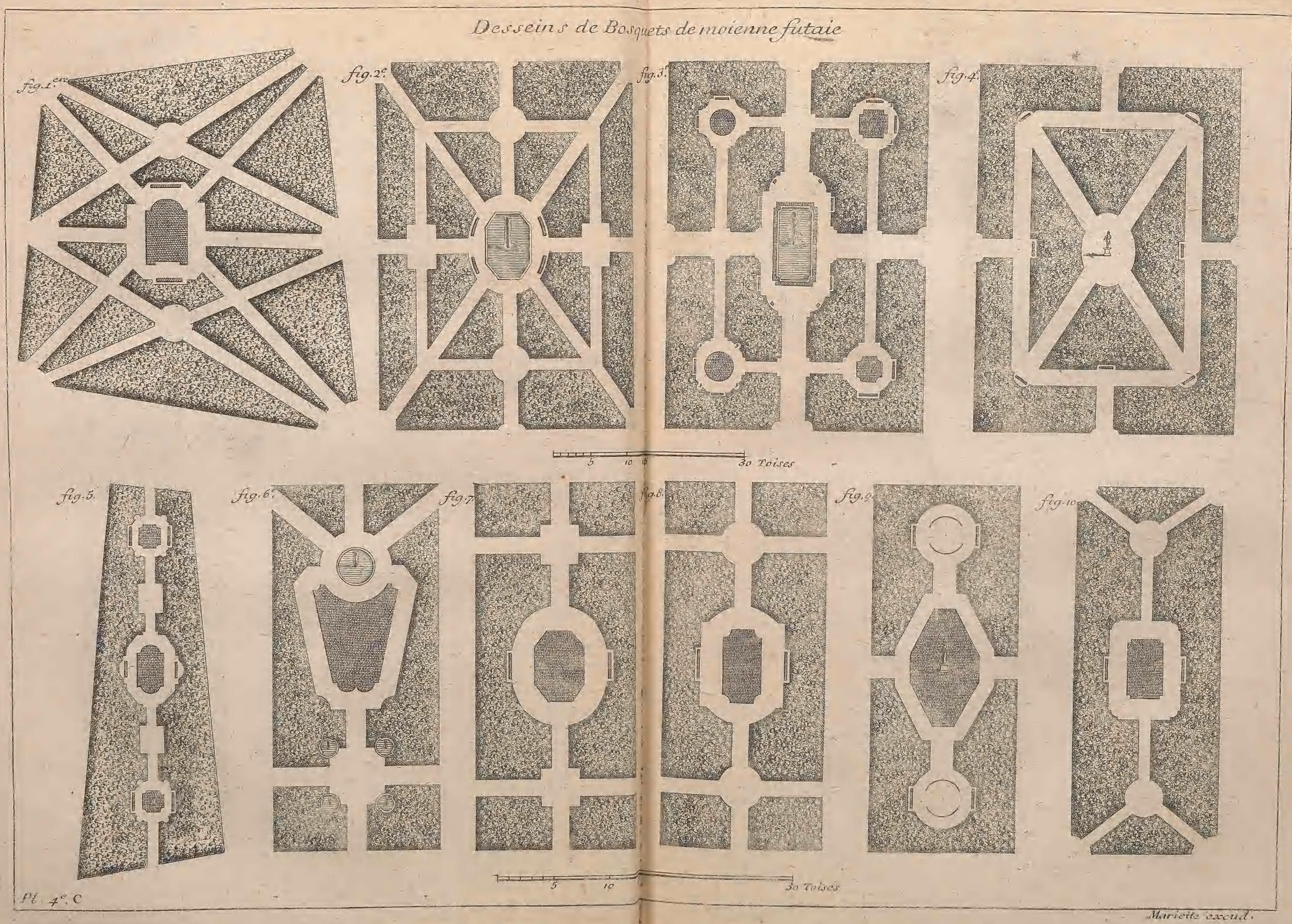





Desseins de cabinets etsatons pour des bosquets.
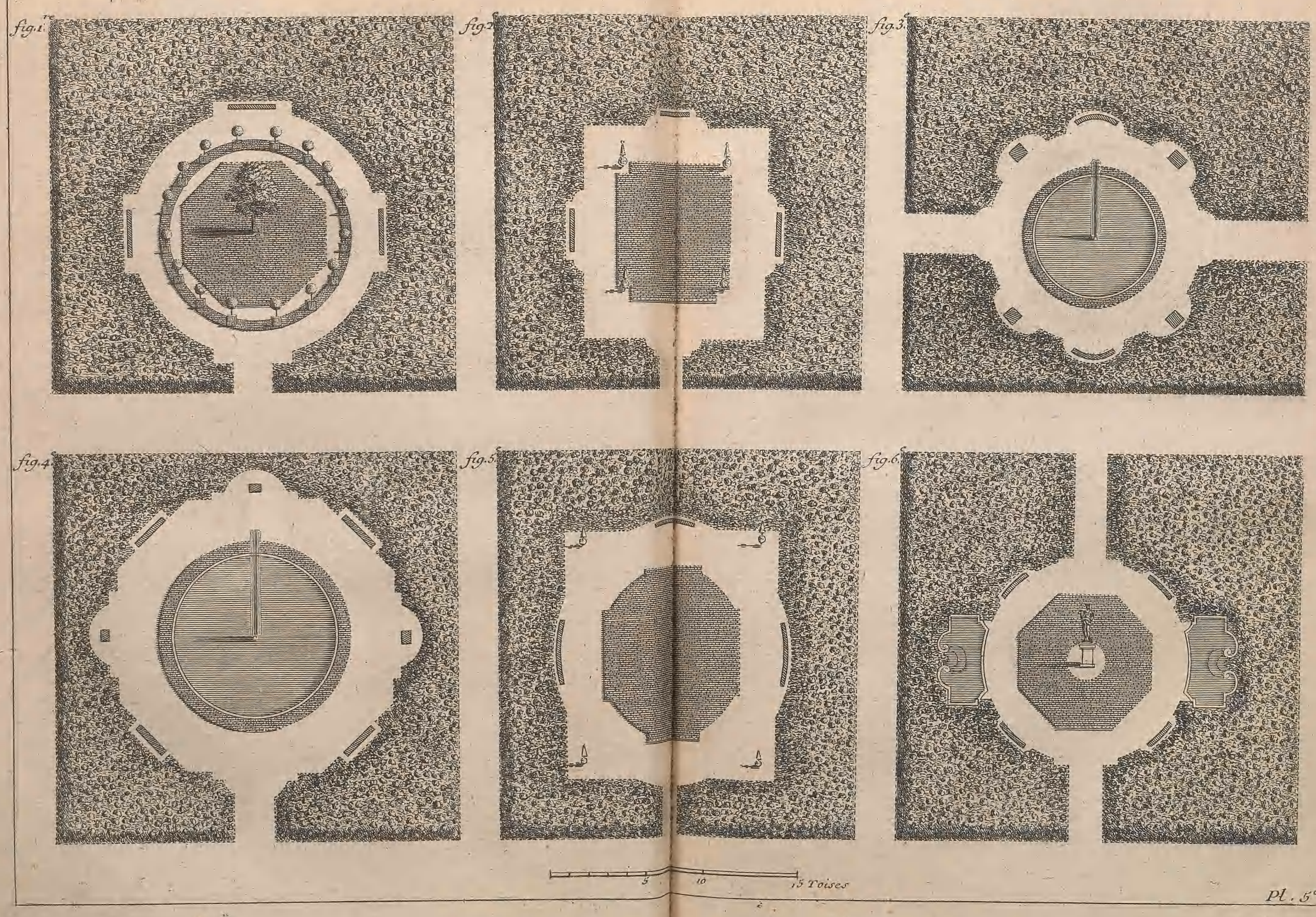





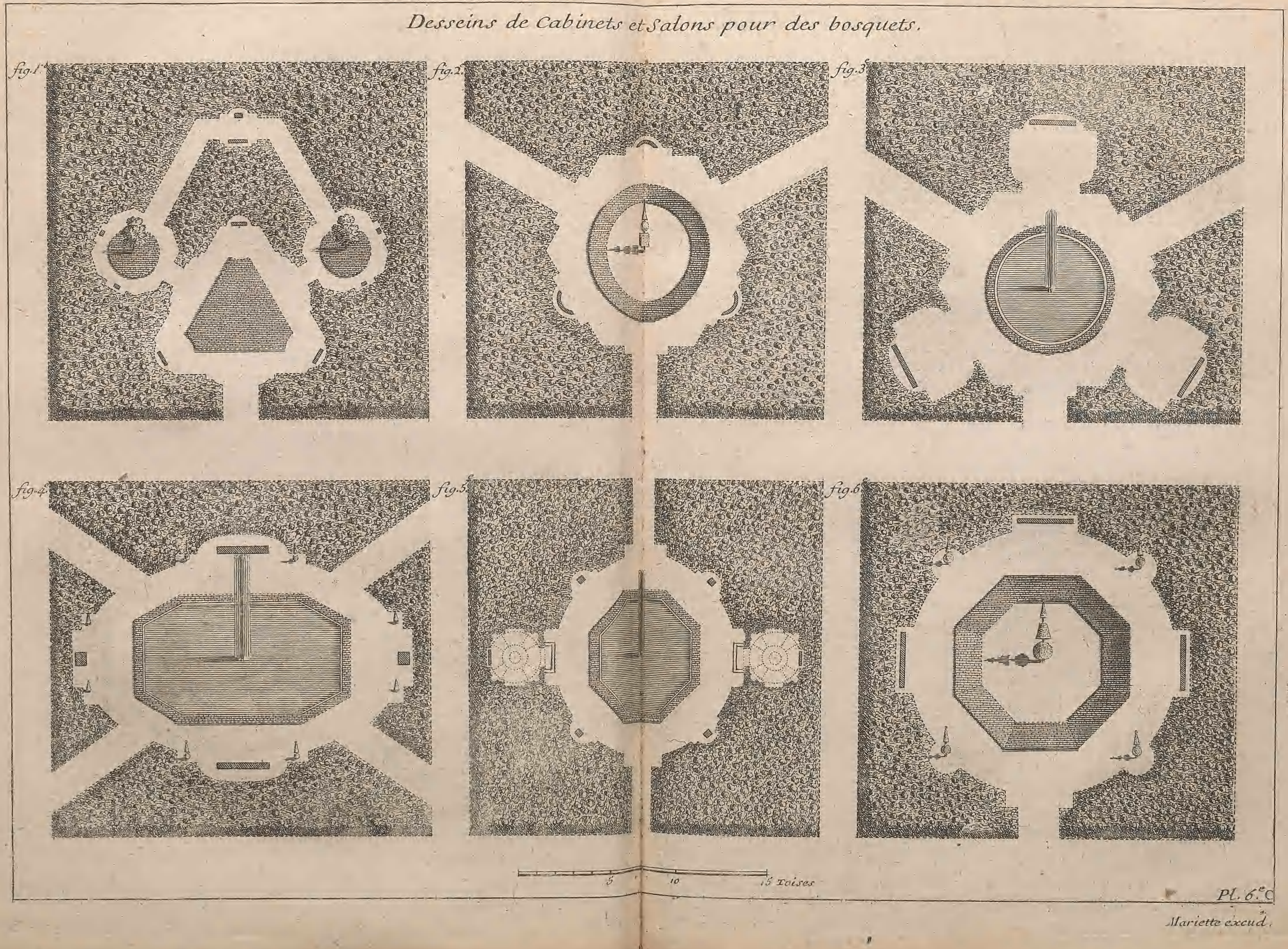







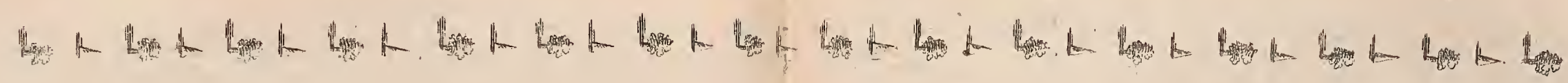

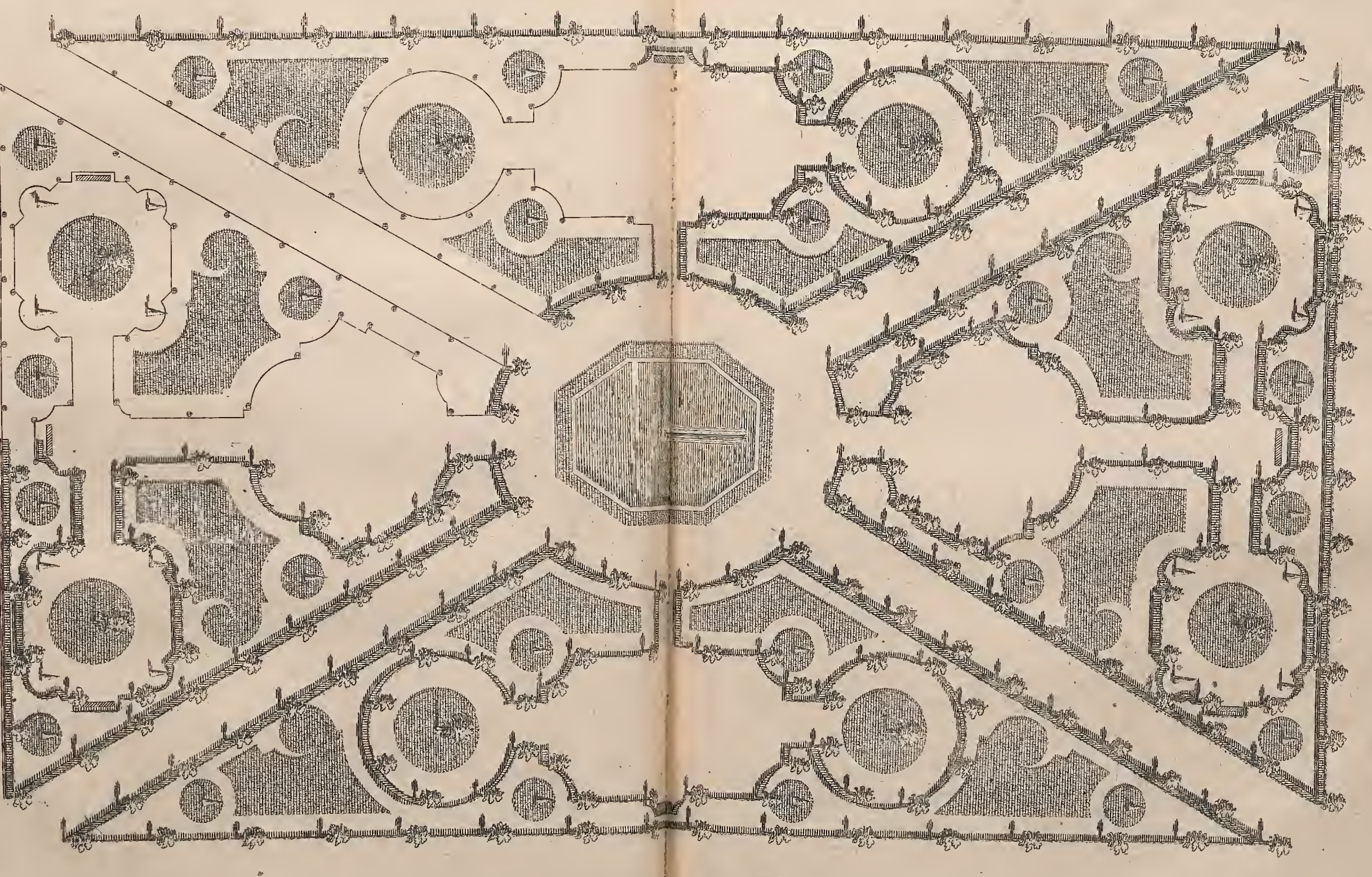

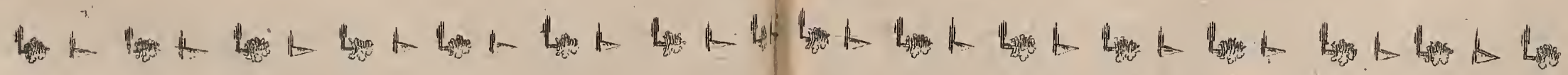







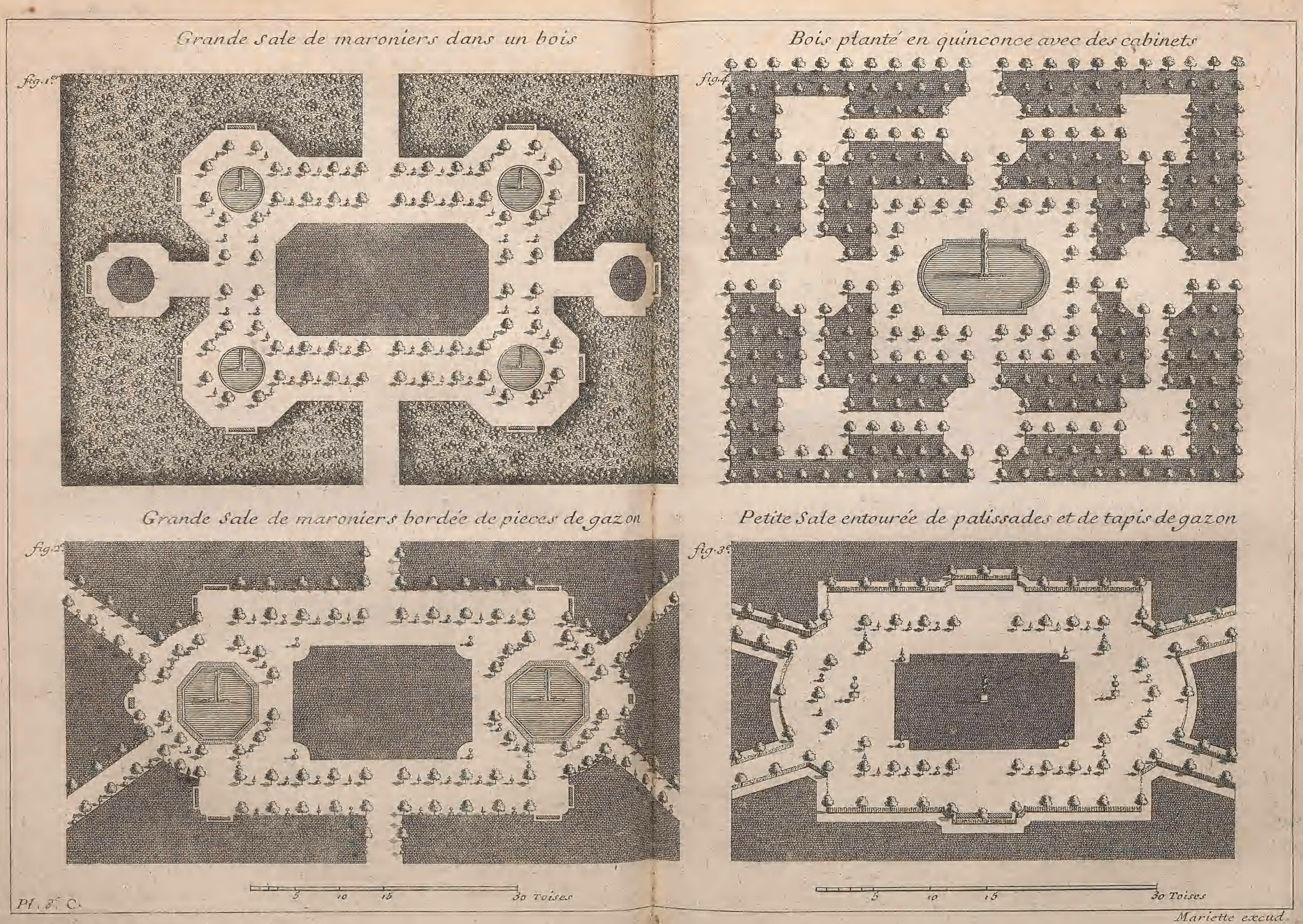







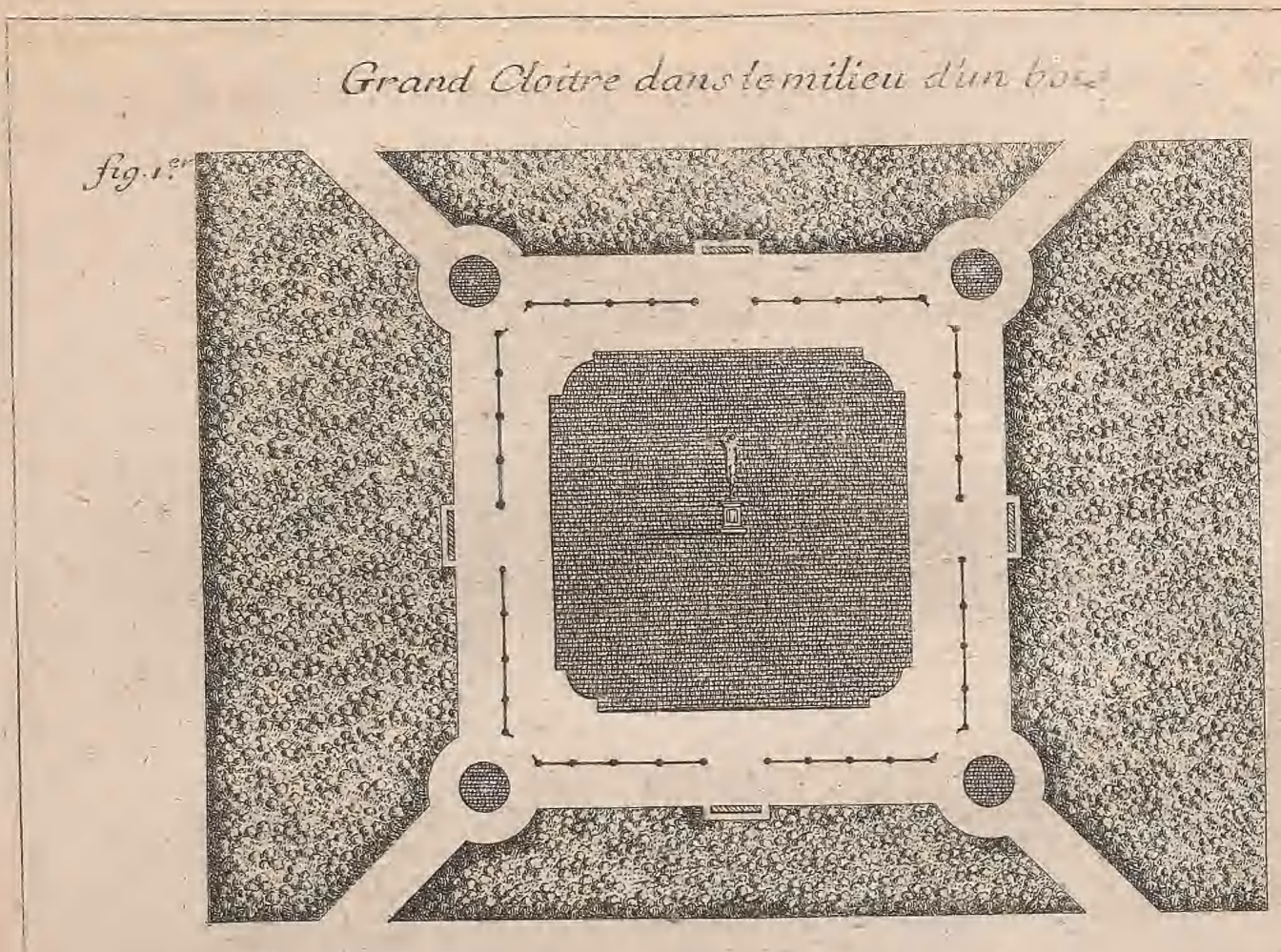

cloitre couvert de berceaux de treiltage entouréde tapis de gazon

Petit cloitre avec des berceaux formés par des arbres

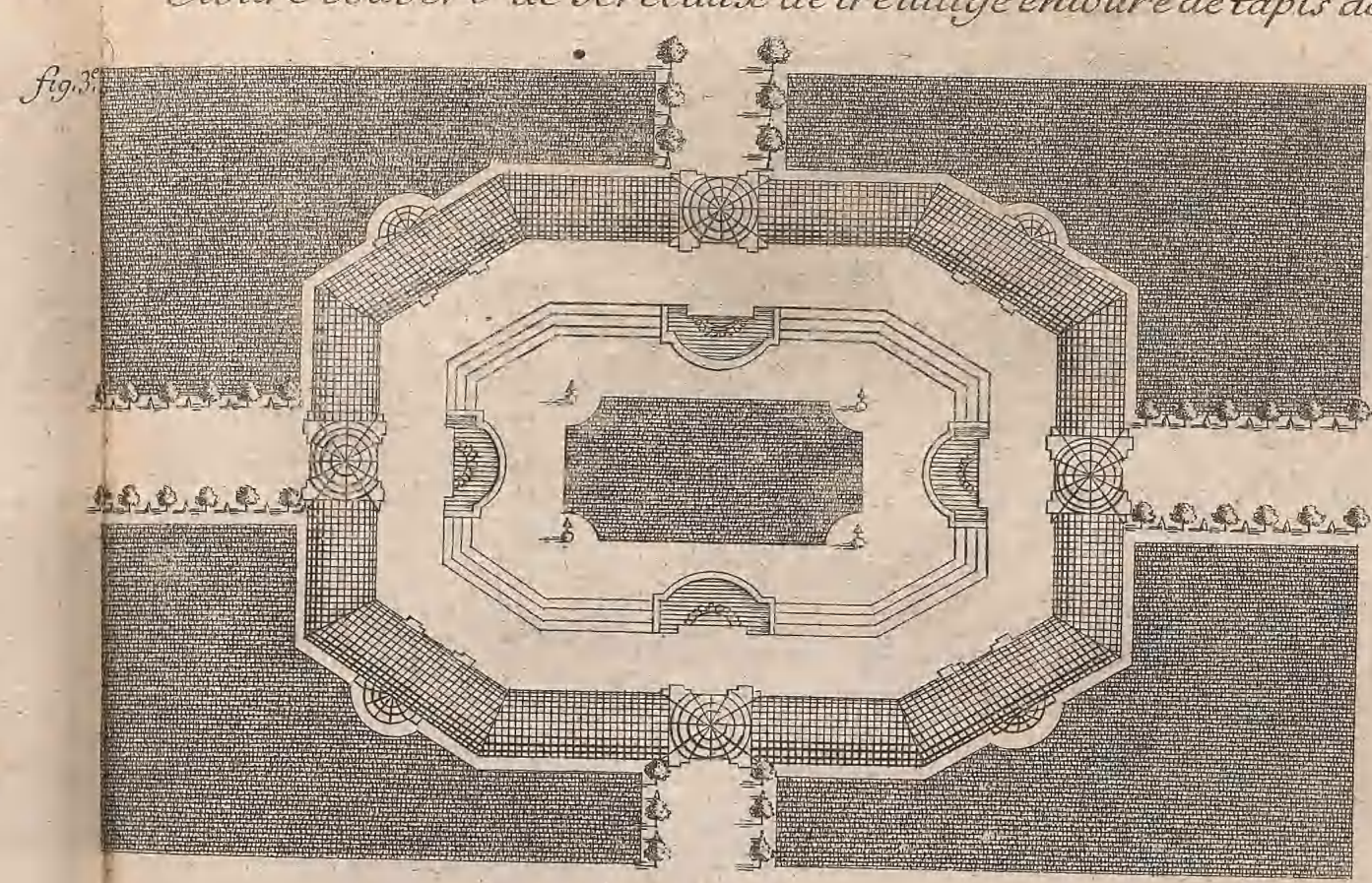

Petit doitrearec des berceaus formes piar des ar-bres

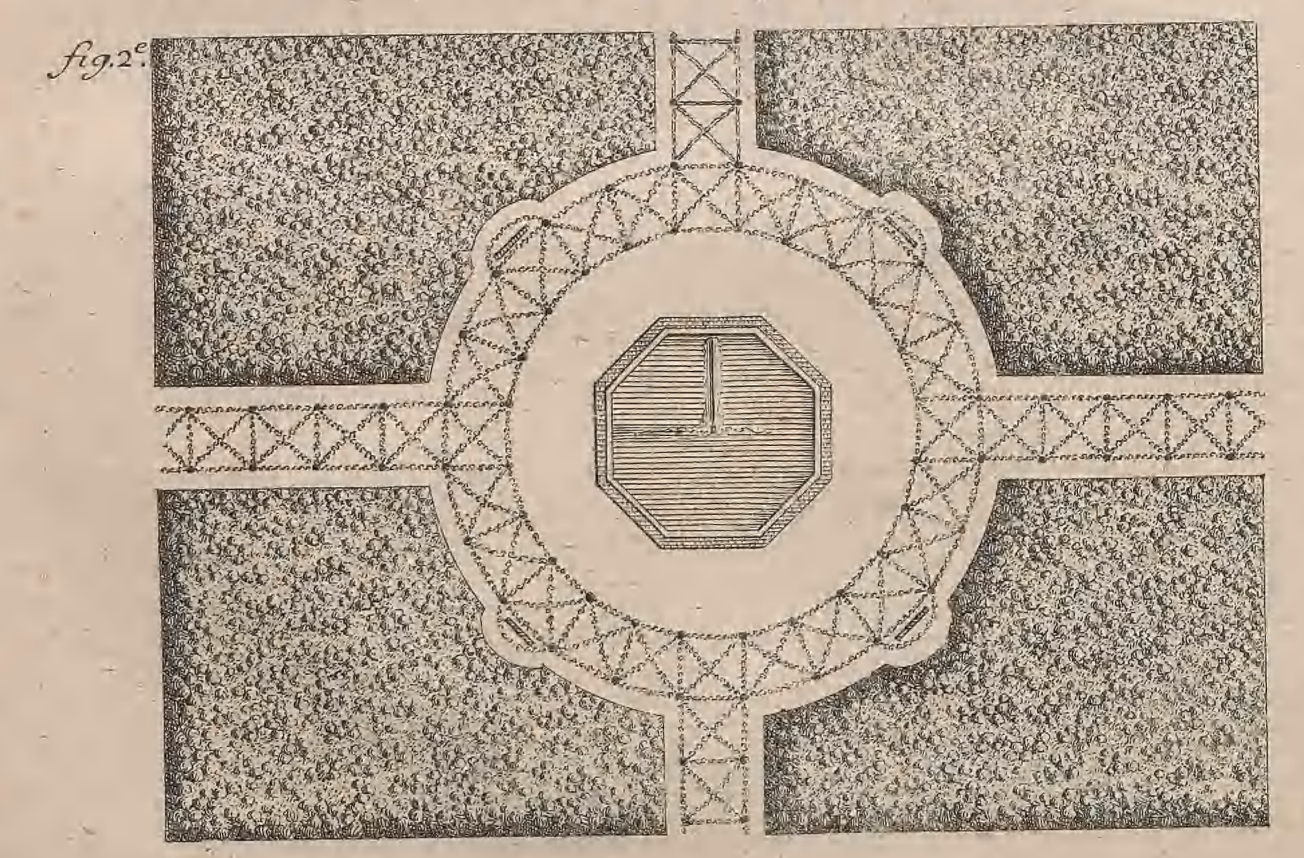

Ploitre engaterie avec des patissades pencées en arcades

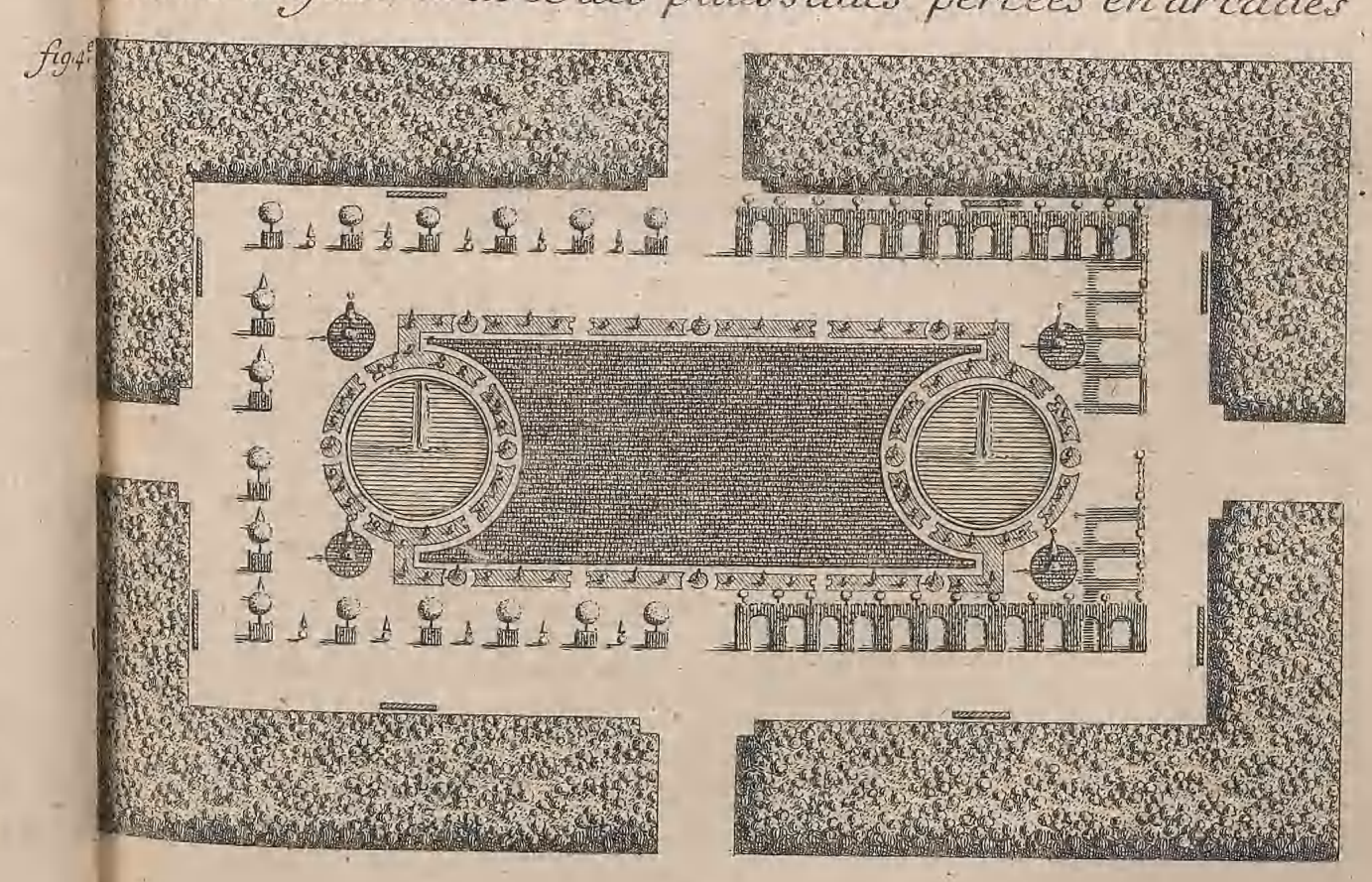

Def $=$. C.

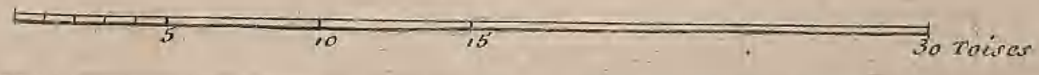





Dessein diun Labirinte avec des cabinets et Fontaines

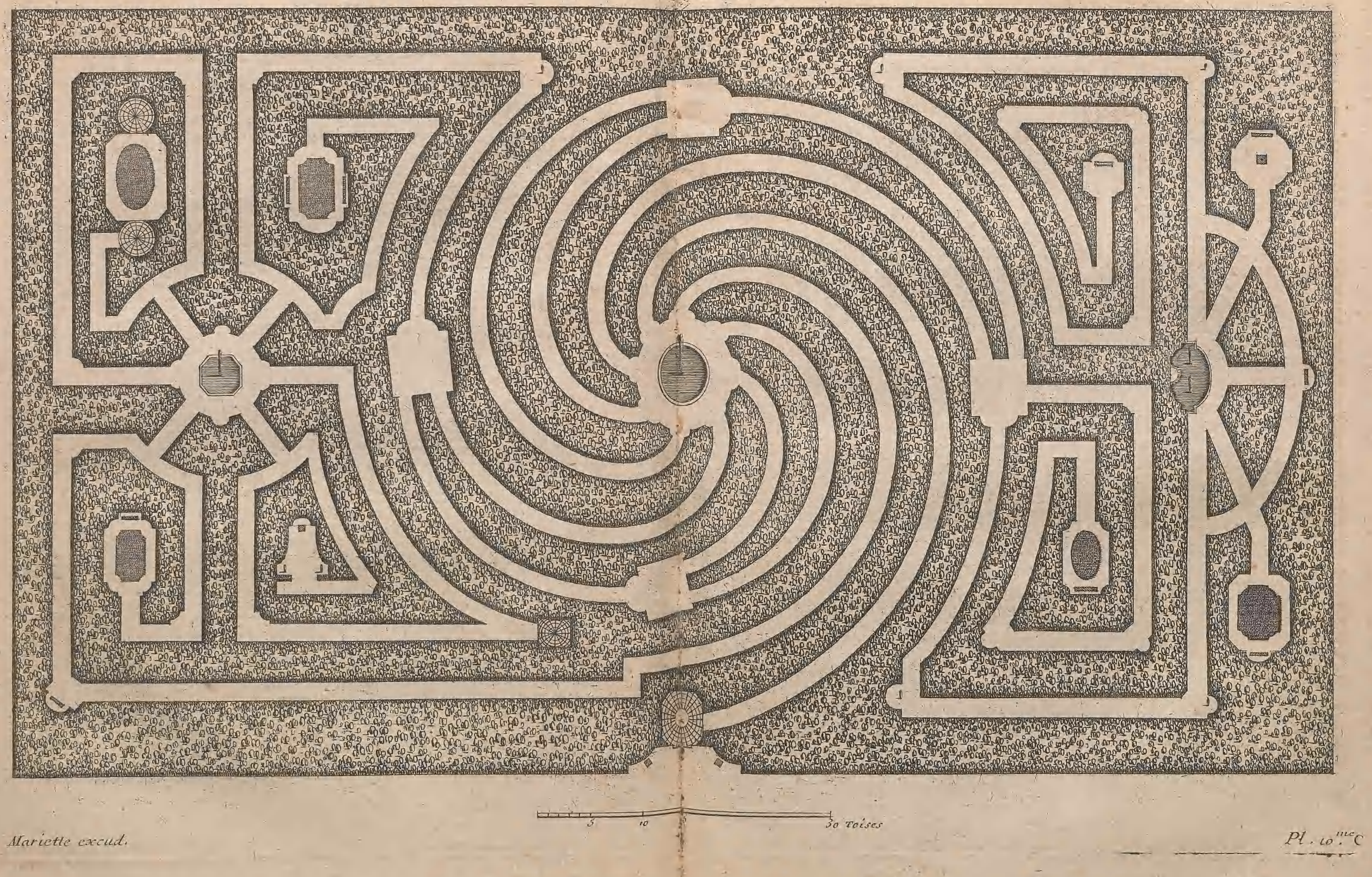





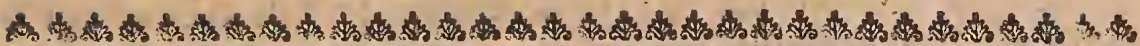

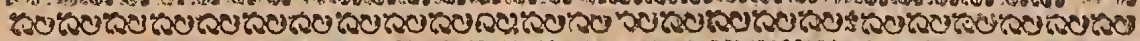

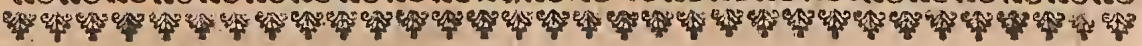

\section{CHAPITRE VII.}

DES BOVLINGRINSOV Renfoncemens de gazon, des grandesRampes, Glacis, Talus, er Tapis de gazon, avec la maniere de les plaquer, Semer. of entretenir.

T E terme de Boulingrin eft un des plus ufités dans les L Jardins de propreté , \& cependant celui qu'on entend le moins; la plûpart des gens n'en connoiffent pas la veritable fignification, ni l'étimologie.

L'invention \& l'origine du mot de Boulingrin vient d'Angleterre. Plufieurs Auteurs le dérivent de deux mots Anglois; fçavoir de Boule, qui fignifie Rond, \& de Grin, qui veut dire prez ou gazon, peut-être à caufe de la figure renfoncée, qui eft le plus fouvent ronde $\&$ couverre de gazon; d'autres ont dit que le mot de Boulingrin a été donné à de grandes pieces de gazon, ou l'on a accoutumé en Angleterre de joüer à la Boule; \& pour cet effet, les Anglois ont grand foin d'entretenir ces tapis de gazon bien courts \& bien unis.

Un Boulingrin en France eft forr différent de tout cela. L'on ne peut apeller de ce mot, que certains renfoncemens \& glacis de gazon qui fe pratiquent, au milieu de grandes pieces \& tapis de gazon, dans un Bofquet, \& quelquefóis au milieu d'un parterre àl'Angloife: ce qui fait que bien des gens confondent le parterre à l'Angloife \& le Boulingrin, croyant que c'eft la même chofe, à caufe que l'invention de ces deux pieces vient d'Angleterre, \& qu'elles font toutes deux couvertes de gazon. Cependant on en doit faire la différence dans les Jardins, \& ne pas donner indifferemment ce mot à tout ce qui eft gazon, ou improprement à d'autres parties d'un Jardin, comme à de grands tapis de gazon qui Cont dans des Bofquets, à moins quu'ils ne foient renfoncés

Dict. de l’A: caden. Iirancoife.

Dict. de Das viler.

Furetiere.

On en rois de toutes ees efpeces dans le Jardin des. Tuileries, $\mathrm{K} \mathrm{ij}$ 
On a exeen. ié de beaux Boulingrins à Choiff. parce que cèn'eft que le renfoncement qui fait le Boulingr.n joint au gazon qui le couvre.

Le Boulingrin eft une des plus agréables pieces d'un Jardin, quand il fe trouve bien placé, rien ne flate plus la vûe. Sa figure renfoncée, couverte d'un beau gazon bien uni \& bien verd, entouré le plus fouvent d'un rang de grands arbres, avec des arbriffeaux pleins de fleurs, le rendent d'une jolie compofition; outre le plaifir de pouvoir fe coucher fur les glacis de fon renfoncement, pendant la grande chaleur, \& d'y être à l'ombre.

Il y a de deux efpeces de Boulingrins, de fimples \& de compofés : les fimples font tout de gazon, fans aucun autre ornement; \& les compofés, font coupés en compartiment de gazon, mêlés quelquefois de broderie, avec des fentiers \& des plates-bandes, ornées d'ifs \& d'arbriffeaux de fleurs. On les fable de différente couleur, \& on les accompagne de figures \& de vafes de pierre, pour réveiller leur grande verdure. On peut encore y pratiquer dans le fonds du glacis, un bafin ou une piece d'eau, pour les enrichir davantage.

Leur vraye place, eft dans un endroit découvert, parce que les Büling rins ne cachent point la belle vîë; cependanton peut en placer dans le milieu des Bofquets, ainfi qu'on le verra dans les exemples fuivants.

Le Boulingrin que repréfente la premiere Figure, eft d'une étenduë bien plus confidérable que les autres: il peut feplacer au bout d'un grand parterre, ou remplir un grand efpace qu'on veut tenir entierement découvert. C'eft un quarrélong, dont les quatre iffuës en diagonales viennent aboutir à quatre pieces de gazon rondes, ou l'on a placé pour figures les quatre Saifons. On a bombé les angles du talus, atin de continuer l'allée circulaire autour des gazons, \& dans le fonds du Boulingrin, on y a pratiqué une grande piece de gazon, qui varie affés bien avec le refte. Toutes les allées ne font formées que par les tapis de gazon, n'y ayant ni arbresni paliffades, ni bois, comme dans les autres fuivans.

Le Boulingrin de la feconde Figure, eft un.quarré prefque parfait percé en étoile, au milieu duquel fe voir un octogone régulier qui a dans fon renfoncement une piece circulaire de gazon. Il n'elt orné que d'un trait ou bordur ede buis zatous 
'de chaque piece de gazon, \& d'un petit fentier ratiffé entre-deux. On a échancré différemment toutes les encoignures des pieces de gazon, \& l'on a placé dans celles du milieu, feize ifs ou boules de buis. Ce Boulingrin eft accompagné de deux grandes allées doubles, plantées de marroniers.

La troifiéme Figure repréfente un Boulingrin affés bien accompagné. C'eft un grand ovale renfoncé, dont le milieu eft rempli d'une piece de gazon coupée à pans pour la varieté: Ce Boulingrin eft entouré de grands arbres, comme de marroniers ou tillots, efpacés réguliérement, fans interrompre les enfilades des allées \& des bancs, à quoi il faut toujours bien prendre garde. L'allée du tour eft octogone, \& formée par une paliffade à hauteur d'apui, où il y a des cabinets $\&$ des niches pour mettre des bancs. Dëriere la paliffade font des tapis de gazon, avec un fentier ratiffé de trois pieds de large entre-deux, tant pour conferver la palifiade \& borner le gazon, que pour la grace \& le coup d'œil.

On voit dans la quatriéme Figure un Boulingrin pratiqué dans le milieu d'un bois, où il fait affés bien, à caufe de la découverte que l'on en a fait à travers les árcades de la paliffade. C'eft un octogone irrégulier, dont le renfoncement eft orné d'une piece de gazon ovale. Il elt entouré d'une allée double, féparée d'une paliffade percée en arcades, avec des boules ménagées fur chaque trumeau.

Les Boulingrins de la deuxiéme Planche font beaucoup plus riches, plus compofés, \& d'une plus grande étenduë que les autres.

La Ie Figure donne l'idée d'un grand Boulingrin, dont la tête échancrée de plufieurs formes qui varient affés bien, eft ornée d'un buffet d'eau, adolfé contre le talus, \& compofé d'une coquille de pierre ou de plomb doré, d'où il fort un boüillon d'eau, qui retombe en nape dans le baflin d'enbas, ou il y a deux jets pour accompagnement. Ce baflin eft entouré d'une tablette de pierre de taille, pour faire oppofition au gazon. Le fond du Boulingrin eft rempli de deux zrandes pieces à l'A ngloife, entourées d'une plate - bande, ornée d'ifs \& d'arbrilieaux, bordée en dedans par le gazon \& en dehors par un trait de buis : ces pieces font terminées par un bout en volutes, \& par l'autre en perits enroulemens 
8r échancrures, qui quoique fimples, ne laifent pas de bien faire fur le terrain : il faut beaucoup de place pour executer ce deffein \& le fuivant.

On voit dans la $2^{e}$ Figure un grand Boulingrin tout des plus riches; le fond en eft comparti en pieces de gazon, coupées \& liées enfemble par de petits cartouches d'une broderie très-legere. Le milieu eftoccupé par un tapis verd, cintré dans les bouts, \& entouré de même que le refte d'un fentier bordé de buis. On fera valoir toutes ces pieces par desfables de différente coulcur, pour les détacher: on remplira la broderie de machefer; le fentier autour de toutes les pieces fera fablé de rouge, \& tout le fond, de fable ordinaire. Ce mélange de couleurs fair des merveilles étant vî d'enhaur. Les deux bouts de ce Boulingrin font cintrés en dedans, avec des pans coupés aux encoignures : ces cintres fur le haut peivent convenir atu bout d'un baffin pour conferver l'Allée du tour. On auroit pû encore ; pour rendre ce morceau parfait $\&$ des plus magnifiques, faire un baffin à la place de la piece de gazon du milieu, ou y mettre une belle figure.

Le Boulingrin de la $3^{\mathrm{e}}$ Figure eft d'une forme plus quarrée que les autres, \& cintrée différemment dans les angles: le fond eft découpe en quatre pieces femblables, avec un ovale, \&deux ronds de gazon dans le milieu : il y a des paffages pour conduire dans les allées qui entourent toutes ces pieces; le compartiment en eft fimple \& fablé de la même couleur; mais il eft rehauffé infiniment par une belle figure dans le milieu, \& par quatre vafes de fculpture, pofés aux quatre coins du fond. On le peut fabler de rouge dans les Pays où l'on trouve facilement des terres rougeâtres: cela fait très-bien; mais couteroit beaucoup en ciment.

A l'égard de celui de la $4^{\circ}$ Figure, il eft d'une forme trèsparticuliere, \& qu'on ne peut execurer qu'en de certains endroits: fes bouts font cintrés en dehors \& coupés de plufieurs pans \& retours, fon milieu eft orné d'un Jet dans une petite piece d'eau, bordée d'une tablette de pierre de taille, $8 z$ d'un fentier fablé en rouge, pour détacher tout le gazon: Des fix pieces quil l'entourent, les deux des extremités font octogones, à caufe des allées circulaires du tour. On a mis gुuatre figures dans les angles d'en-haut, pour varier d'avec 




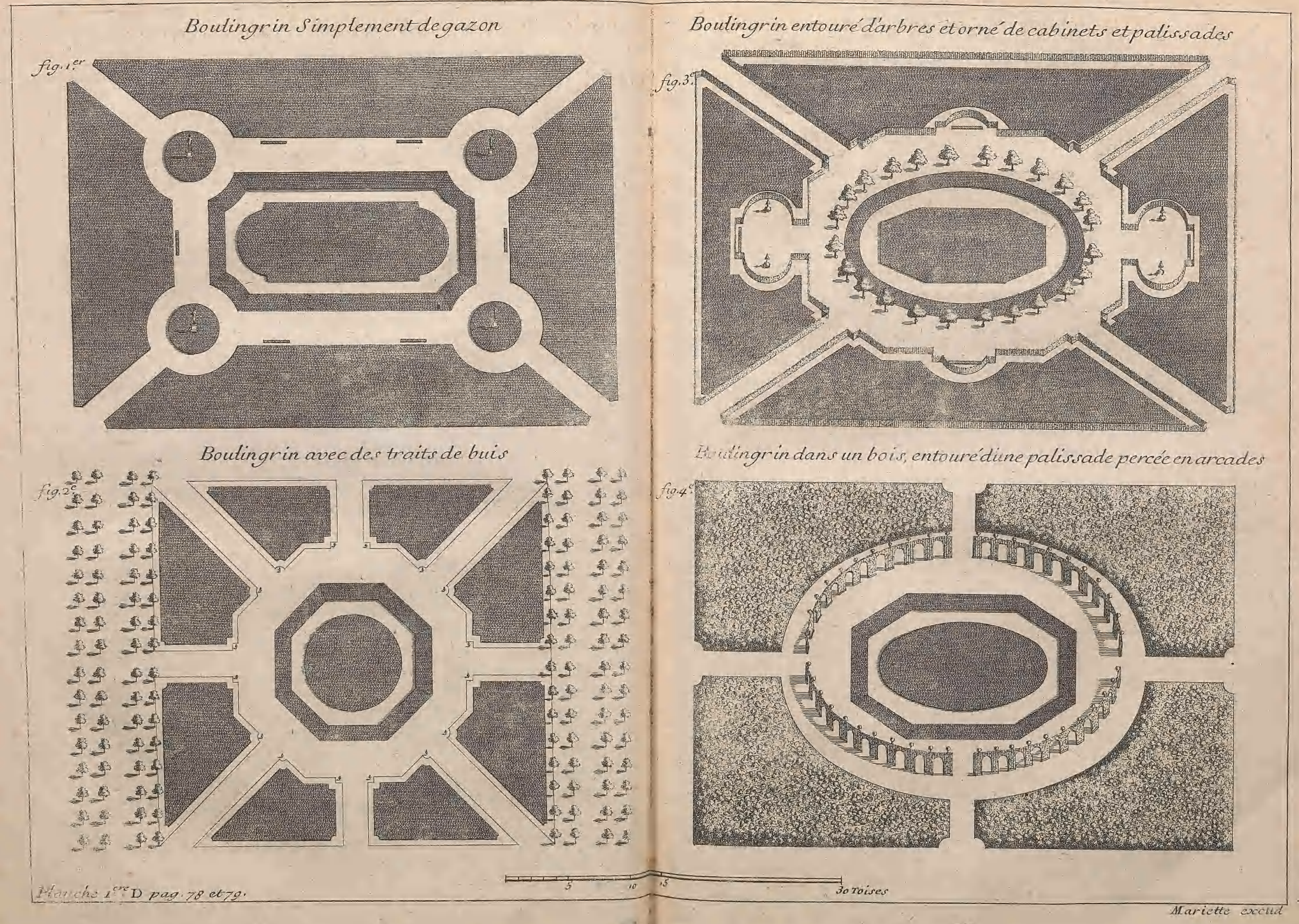





Boulingrin découpé avec une figure et des. Vases.
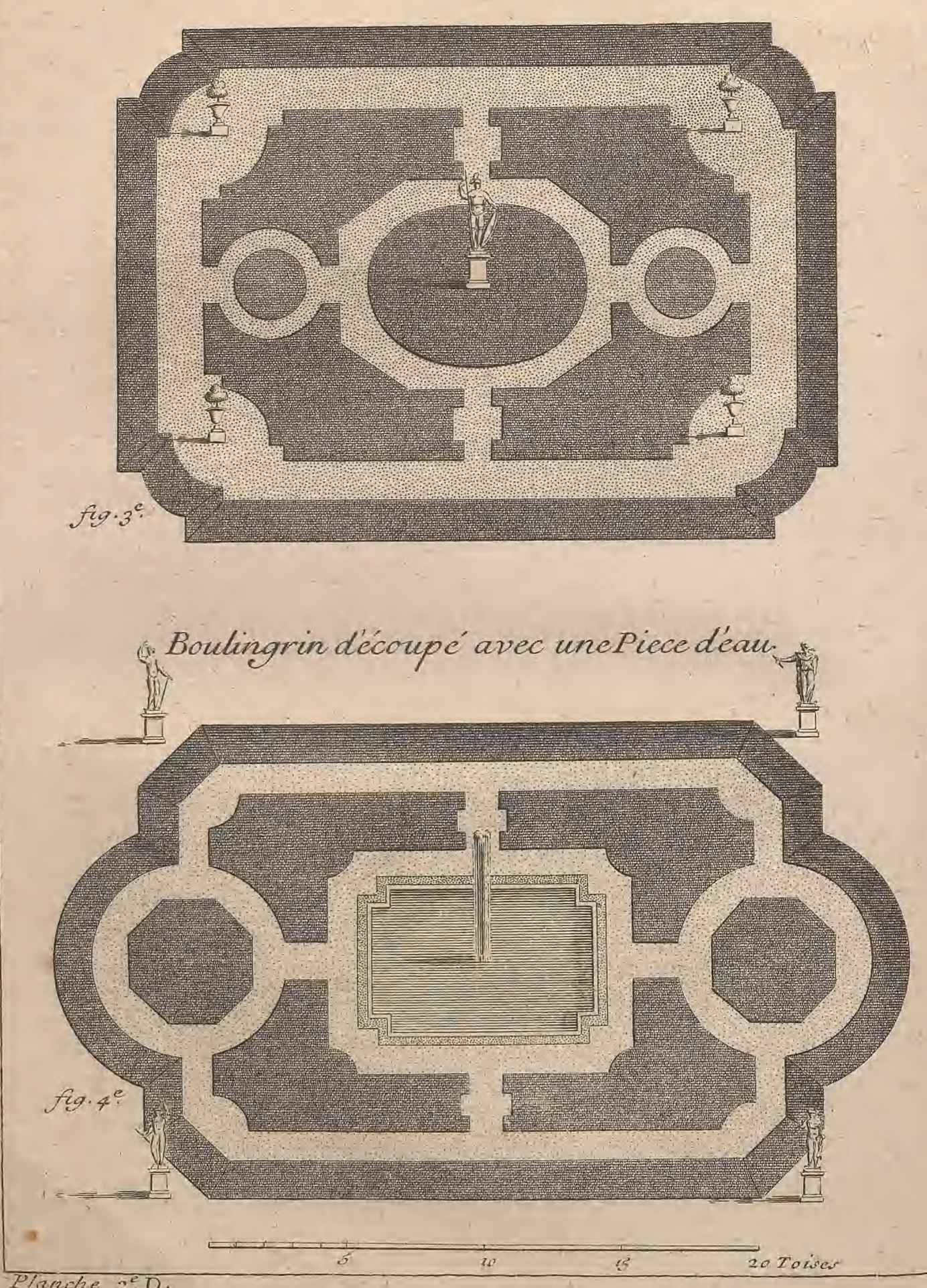

d'arbrisseaux et de Fleurs.

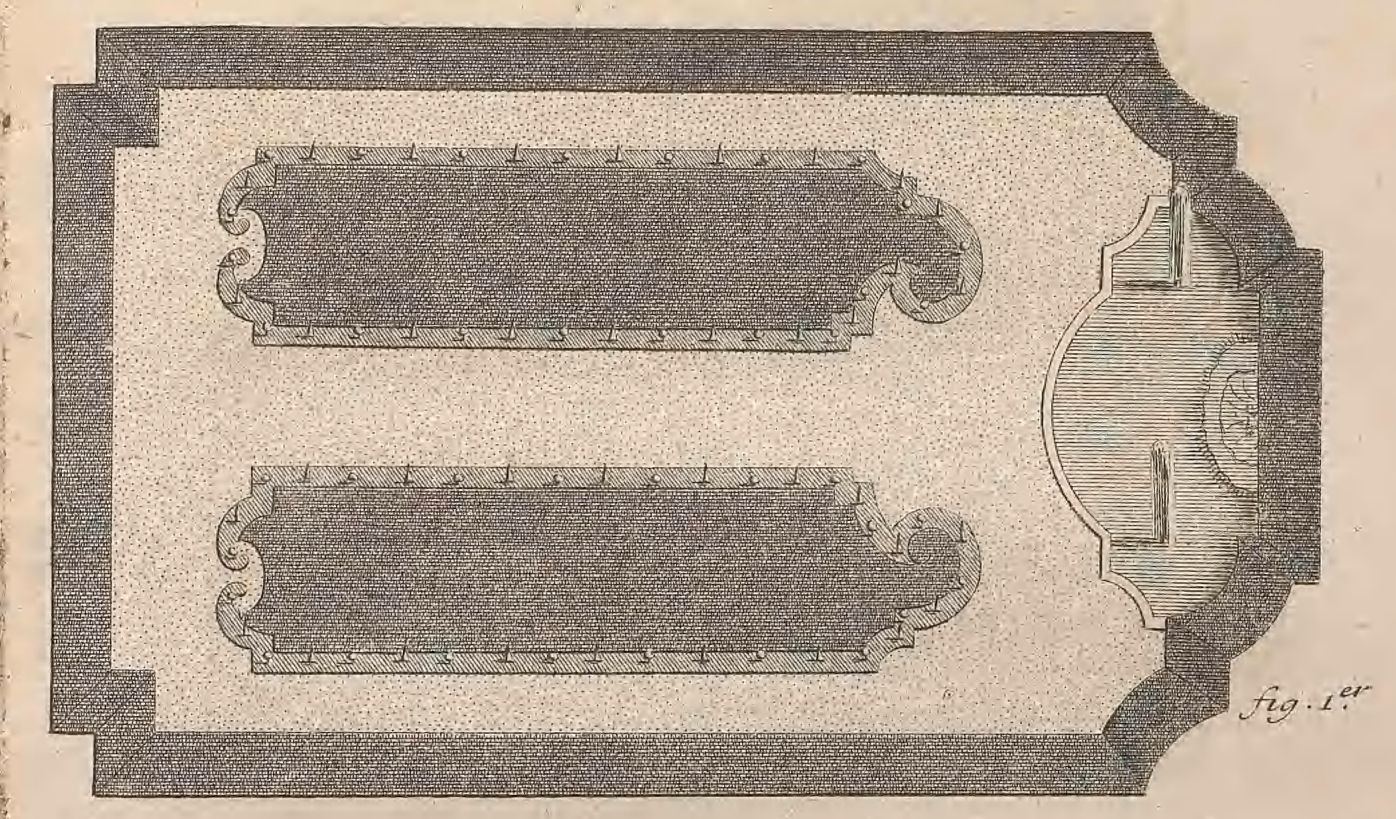

Grand Boulingrin compartiavec de la Broderie

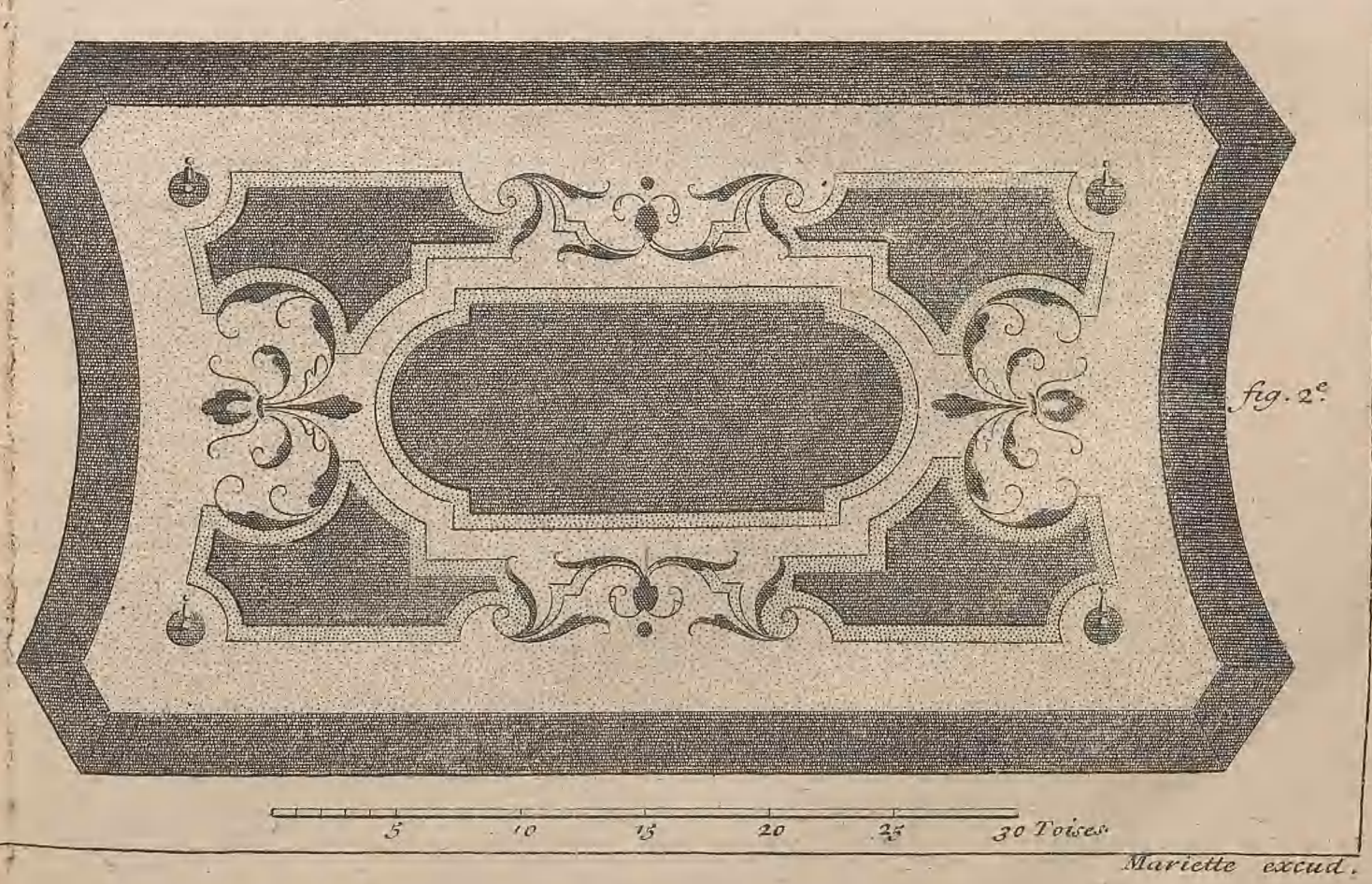



IA THEORIE DU JARDINAGE. 79 les quatre vafes placés dans le fond du précédent. Les échellès feront juger de l'étenduë \& de la proportion de ces différens morceaux.

On obfervera en faifant des Boulingrins; de ne les point trop renfoncer, car ce n'eft pas le mieux. Il fuffit de donner un pied \& demi de profondeur pour les petits Boulingrins, \& deux pieds tout au plus pour les grands.

A l'égard des Talus \& Glacis qui compofent le revêtiffement des Boulingrins, c'eft-à-dire, qui en forment les renfoncemens; on leur donne fix à fept pieds de long pour les petits, \& huir à neuf pieds pour les grands; on ratiffe les fond tout entier dans les petits Boulingrins, parce qu'il n'y a point affez de place pour y mettre des pieces de gazon; mais dans les grands, on y en pratique de belles, \& quelquefois de découpées. Alors on laiffe un ratiffage de trois ou quatre pieds entre le talus \& le gazon, ce qui fert à détacher ces pieces l'une d'avec l'autre.

Les rampes, les tapis \& les peloufes de gazon, ne different gueres entr'elles, à moins que ce ne foit les rampes, qui font fuppofées être de grands tapis de gazon en pente douce ; comme celles qui accompagnent les côtés d'une Cafcade, ou qui fervent à raccorder deux inégalités de terrain. Pour les tapis \& peloufes, c'eft la même chofe : on les place dans les cours \& avant-cours des Maifons de Campagne, dans les Bofquets, dans les Boulingrins, dans les Parterres à l'Angloife, \& dans le milieu des grandes allées \& avenuës, quii feroient trop longtems à ratifler fans cela.

Les Talus \& Glacis font fouvent confondus \& pris l'un pour l'autre: l'on y trouve cependant une différence, c'eft que le Talus eft plus roide que le Glacis, qui doit être très-doux $\&$ imperceptible à la vûë. Venons à la maniere de gazonner toutes ces pieces.

La maniere de gazonner eft différente, felon les lieux oì l'on s'en fert: car on gazonne un tapis \& une peloufe d'une autre maniere qu'un Talus \& Glacis, ce qui fe réduit où à femer le gazon, ou à le * plaquer.

Pour femer du gazon dans une piece, faites-la labourer d'un bon fer de bêche, enfuite dreffer \& paffer au rateau fin, en ôtant toutes les mottes \& les pierses qui s'y pourroient

Ces rame pes font en grand nombre à Meudop.
* Matrais terme ufité, de dire poler du gazon. Il faut dire pla?

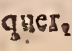



rencontrer, \& répandés un pouce ou deux de bonne terre par deffus, pour faciliter la graine de lever. Votre place étant bien unie, femés-y la graine très-druë, afin qu'elle devienne épaiffe \& courte : paifés enfuite le rateau pardeffus, pour enfoüir \& couvrir un peu la graine, qu'il ne faudri pas femer par un tems venteux, de crainte qu'elle ne s'envolât ; au contraire, l'on choifira un tems calme, qui promette bien-tôt de la pluïe, afin que cette eau plombant la terre, \& enfonçant la graine, lui donne plus de facilité à paroître.

La meilleure faifon pour femer eft à la fin de l'Automne, les graines de leur nature, ne demandant que de l'humidité pour croître, n'en manquent point dans cette faifon, nonplus que le long de l'Hiver. Quand on attend à femer ces graines à la fin de Février ou au commencenent de Mars, on court rifque de ne point voir fit-tôt verdir un tapis, fle l'Eré eft un peu fec, comme il arrive fouvent, à moins qu'on. n'ait le foin d'arrofer continuellement, ou plûtôt d'innonder un tapis, ce qui eft d'une grande fujettion \& d'une grande dépenfe.

Toute la difficulté de faire de beaux tapis en les femant; eft d'avoir de bonne graine, que l'on doit examiner foigneufement avant que de la femer. On fe fert de graine de petic trefle de Hollande, de Bas-prez, de Pinvain, d'Herbe à chat, de Terrenuë \& de petites herbes fines qui reffemblent à la Civette. Il y a encore quantité d'autres graines, dont on ne fçait point les noms, \& oil l'on eft fouvent trompé.

Il ne faut pas faire comme bien des gens, qui vont ramaffer des graines dans un grenier à foin, \&r quil les fement indifféremment, efperant par là faire venir de beaux tapis de gazon; c'eft en quoi ils s'abufent: car ces graines montant trop haut, \& faifant de gros tuyaux, ne fe garniffent poine du pied; \& l'on a beau les faucher fouvent, elles ne formene jamais de beau gazon: bien au contraire, ce ne font que des touffes de méchantes herbes qui different peu des prẹz de la campagne.

Venons à la maniere de plaquer le gazon: il faut en premier lieu l'aller choifir dans la campagne, tant dans les chemins, que fur le bord des pâturages \& prairies, où les motz- 
IA THEOR IE DU JARDINAGE. \&I trons \& les vaches vont paître : car ces endroits font les meilleurs, l'herbe y étant très-fine $\&$ broutée fort court. On prendra garde dans le choix qu'on en fera, qu'il ne s'y rencontre point de chien-dent \& de mauvaifes herbes, \& que la terre ait un peu de corps. On levera ce gazon à la bêche, en le coupant par quarrés d'un pied environ fur tous fens, \& de deux ou trois pouces d'épaiffeur, ç'en eft affés pour le tranfporter fans le rompre.

Pour plaquer ce gazon furle terrain, tendés le cordeau dans les lignes droites, \& fuivés la trace dans les circulaires, \& petits defleins mignons, comme font les coquilles, les enrou-lemens \& mafififs des parterres. On creufera \& enlevera de la terre le long de ce cordeau, de l'épaiffeur des quarrés de gazon, afin qu'il fe trouve à l'uni de la terre, ç'en eft la beauté. L'on évitera la maniere de certaines gens, qui le polent fur la terre fans en ôter deffous, ce qui releve trop le gazon \& le déchauffe. On taillera avec un couteau ces quarrés de gazon, fuivant le cordeau \& la trace, en les arrangeant \& ferrant I'un dans l'autre, \& avec une petite batte ou maillet de bois, on les battra jufqu'à ce qu'ils foient bien preffés \& réduits au niveau de la terre. L'on ne peut, pour ainfi dire, trop battre \& trop enterrer le gazon, l'herbe de fon naturel s'éleve toujours affés en pouffant. Quand les quarrés de gazon ne fe joignent pas bien, on les garnit de terre, \& l'on y met de perites pieces pour boucher les trous \& les fentes: on rend parlà un tapis auffi beau \& auffini, que s'il étoit crû dansle lieus même.

On obfervera qu'aufin-tôt que le gazon eft plaqué, il le faus arrofer, afin que s'uniffant plùtôt à la terre, fur laquelle il eft pofé, il prenne racine, \& n'air pas le tems de jaunir \& de fe fecher, ce qui feroit à craindre, fil l'on manquoit à le moüiller.

Le plus für moyen d'avoir de beaux tapis de gazon bien unis 8 bien veloutés, eft de les plaquer ; cela vaut toujours mieux que de les femer; mais quand on a de grandes pieces à gazonner, comme elles coûteroient infiniment à plaquer toutes entieres, on fe contente deles femer de graine choilie ; \& comme l'on auroir de la peine à borner jufte ces tapis avec de la graine, l'on en plaque les bords, de morceaux quarrés 
de gazon fuivant le cordeau tendu fur la trace, \& l'on en feme le dedans à l'ordinaire.

Sil'on ne vouloit pas faire la dépenfe de plaquer les bords d'une piece de gazon, il faudroit femer beaucoup de graine dans la trace, afin que cela marquât davantage \&x plus vîte. Pour les perites pieces de gazon, qui font dans les Parterres, comme maffifs, coquilles, volutes, pieces découpées, bordures de baffins, \&xc. il faut toujours les plaquer, elles en font plus belles, s'executent plus proprement, \& s'en confervont mieux.

Quand on veut regazonner quelque coquille ou quelque enroulement dont le gazon elt ruiné, il faut enfoncer des piquets aux extremités, pour remarquer le plus que l'on peut l'ancienne trace, \& enfuite enlever de terre le mauvais gazon $\&$ le chien-dent. Quand la place fera bien nettoy ée $\&$ rétablie, l'on retranchera fuivant les piquets la coquille que l'on gazonnera proprement.

Les Talus \& Glacis font bien plus difficiles à gazonner que les rampes, tapis \& peloufes, en ce qu'il faut plaquer le gazon, de maniere qu'il ne s'éboule point, \& conferver la ligne de pente, fans faire de coudes $\&$ de jarets.

Les Talus \& Glacis qui ne font pas confidérables par leur hauteur, comme de cinq à fix pieds, tels que font ceux qu'on pratique pour les petites terrafies \& dans les renfoncemens des Boulingrins, font les plus aifés à gazonner, on n'a qu'à plaquer les quarrés de gazon, fuivant ce que l'on vient de dire:

11 ne faut prefque jamais femerles Talus \& Glacis, parce que l'herbe n'y vient pas fi aifément que dans les tapis plats; cependant fi l'on vouloit les femer, on plaquera la bordure d'en-haut \& d'en-bas, avec des quarrés de gazon pour entretenir les terres \& les empêcher de s'ébouler; on en femera le milieu très-dru, afin que la graine ne fe metre point par pelotons.

Pour les grands Talus \& Glacis, comme de quinzeà vingt pieds de haut, ils demandent plus de circonfpection dans la maniere de les revêtir de gazon, de crainte qu'ils ne s'éboulent. Ils font confruits par lits de terre \& de cläionnage, ainfl qu’il fera expliqué dans la fuire. 
Le gazon dont on fe fert, doit être levé en forme d'un coin de bois, \& non pas d'égale épaiffeur, comme celui que l'on plaque dans les tapis ordinaires. On apelle ce gazon, à pointe ou à queuë. Cette pointe de terre que l'on laiffe par deffous, fert à l'affeoir \& à l'entretenir de crainte qu'il ne s'éboule. On plaque ce gazon le long du cordeau qui fuit le principal trait, enforte qu'il touche par l'un des bouts ce cordeau, \& de l'autre, les facines ou claïonnages, obfervant felon * quelques-uns que l'herbe foit tournée en deffous, ce qui n'eft bon que pour les ouvrages de Fortifications, \& non point pour les Talus des Jardins, fur lefquels on affit le gazon I'herbe deffus, en le plaquant fuivant la ligne de pente, avec la précaution, de peur que ces gazons ne s'éboulent, de les cheviller tous avec de bonnes chevilles de bois de chêne ou d'aulne, pour les entretenir jưfqu à ce qu'ils ayent pris racine.

Les tapis \& les talus de gazon font une des principales beatztés des Jardins, quand ils font bien entretenus : ç'en eft toute la difficulté; quand mêmela graine feroit bien levée, \& l'herbe très-druë, ou que les gazons plaqués feroient repris $\&$ d'un beau verd, cette perfection changeroit en peu de tems, fi l'entretien n'y éroit pas.

Cet entretien confifte à faucher fotivent le gazon, non pas quatre fois l'année, comme le difent quelques* Auteurs, mais au moins une fois le mois. Il y a même des endroirs oì l'on fauche le gazon tous les quinze jours. L'herbes'en épaiffit \& devient plus belle, plus elle eft coupée. Elle doit être d'un ras, qu'un brin, pour ainfi dire, ne paffe pas l'autre. Il faut encore rogner de tems en tems, \& borner le pourtour des pieces de gazon fuivant le cordeau, ç'en eft toute la propreté, parce que fans cela l'herbe courroir dans l'allée, \& interromproir la forme \& le deffein des compartimens.

La maniere dont on entretient le gazoñ en Angleterre, c'eft de le faucher très-fouvent, \& de le battre quand il eft trop haut, en y roulant deffus de gros cylindres ou rouleaux de bois ou de pierre, afin de l'affaiffer \& d'arrazer l'herbe de bien près. On ne peut mieux faire que de fuivre cette maxime d'Angleterre, oì les tapis de gazon font d'une beauté fl parfaite, qu'à peine peitt-on ici en approcher.

Marolois, Rohault, $\mathrm{O}$. zanam; Traítez des Forti: fications.

* Furetiers, Daviler, Dic。 rion.de l'A cadémie Erassçoile.

Sorbicre voyage d'Asto gleterre, gage 17. 
84 PREMIERE PARTIE, CHAP. VII.

On peut dire, que if les beaux gazons font d'un grand ornement dans un Jardin, c'eft auffi ce qui demande le plus grand foin d'un Jardinier qui doir être prefque toujours après; mais enfin, c'eft une chofe néceffaire $\&$ indifpenfable, au lieu que $f_{i}$ on les néglige, les herbes venant par touffes, ne formeront plusces tapis unis \& ras, \& fe changeront en chiendent \& mauvaifes herbes, qu'il faudra entiérement ruïner, pour en plaquer ou femer de meilleures. On peut donc éviter de changer tous les deux ou trois ans le gazon, par le grand foin qu'on apporterra à le bien entretenir.

Quelques perfonnes prétendent, que pour avoir toujours de beaux tapis de gazon bien entretenus, il faut tous les ans dans l'A utomne, y femer legerement quelques graines, pour les renouveller, \& remplir les places qui ne font pas affés garnies, ou qui font mortes. Cela peut être fort bon, pourvît que l'on choifife bien les graines qu'on y femera.

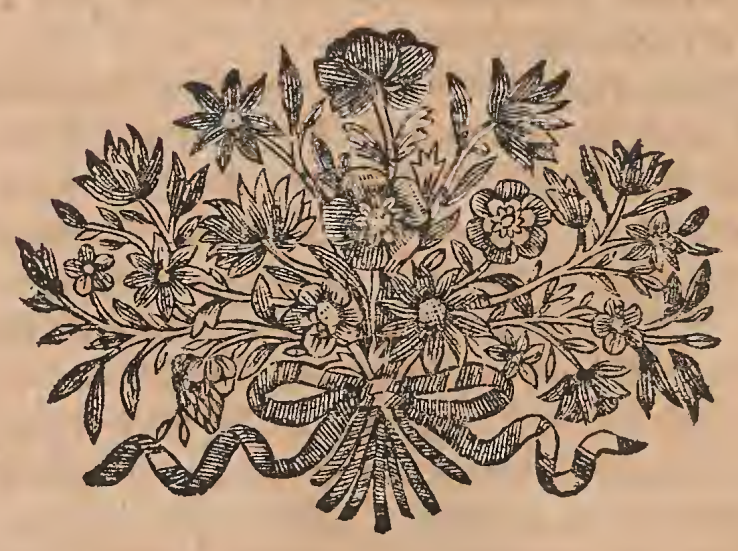




\section{A THEORIE DU JARDINAGE. If}

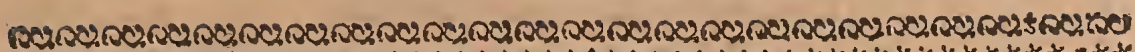

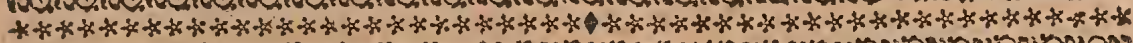
KUR०

\section{H A PIT R E VIII.}

DES PORTIQUES, BERCEAVX, Cabinets de Treillage es de Verdure, Figures, $V$ ajes, er autres ornemens Jervant à la décoration embélifement des fardins.

Uoique nouss venions de parler généralement de toutes les parties qui compofent un beau Jardin, nous ne devons pas cependant oublier les chofes qui contribuent à $\mathrm{fa}$ décoration \& à fon embéliffement. On fera dans cet endroit fort circonfpect; ne voulant point ici propofer des exemples hors de la portée des particuliers, qui pourroient trouver des difficultés capables d'en empêcher l'exécution. Ce font de ces dépenfes Royales dont on veut parler, qu'il n'eft permis qu'aux Princes, qu'aux Miniftres d'Etat, \& aux perfonnes de cette volée d'entreprendre.

Il n'eft plus à préfent fi fort à la mode de conftruire dans les Jardins, des Portiques, des Berceaux \& Cabinets de treillage; cependant on ne laiffe pas encore d'en faire dans quelques endroits; il eft conftant que ces morceaux d'Architecture, quand ils font bien placés, ont affurément quelque chofe de beau \& de magnifique ; ils relevent \& rehauffent infiniment la beauté naturelle des Jardins : mais comme ils coûtent bèa ucoup à executer \& à entretenir, joint à ce qu'ils fe rü̈nent facilement, on eft fort dégoûté de cette mode.

Il s'eft fait de ces ouvrages dans quelques Jardins, qui coûtoient jufqu'à vingt mille écus. \& qui font à préfent prefque tous ruïnés, il n'y a que la quantité de fer qui les puiffe foùtenir long-tems.

On diftingue de deux fortes de Berceaux ou Portiques; les artificiels \&r les naturels.

Les Berceaux \& Cabinets artificiels font faits tout de treil-

I'Hotel de Condé.

L'Hốtel de Lourois. 
\$6 PREMIERE PARTIE, CHAP. VIII. lage, foùtenus par des montans, traverfes, cercles, arboustans \& barres de fer. On fe fert pour ces treillages d'échalas de bois de chefne bien planés \& bien dreffés, dont on fait des mailles de fix à fept pouces en quarré, liées avec du fil de fer. On fe fert auffi de bois de boiffeau pour contourner les moulures \& les ornemens des corniches, \& de chevrons pour les larges plares-bandes \& les focles.

On compore avec tout ce fer \& ce bois, des Berceaux, des Portiques, des Galeries, des Cabinets, Salons, Niches \& Coquilles, ornés de colonnes, de pilaftres, de corniches, frontons, montans, paneaux, vafes, confoles, couronnemens, domes, lanternes \& autres ornemens d'Architecture. L'on doir fuivre dans ces deffeins une jufte proportion, en reglant un module, \& y raportant toutes les parties de POrdonnance, comme fi c'étoit un bâtiment.

Il fauc remarquer, que les ornemens les plits riches ne

Il y a à Clagni, des Com lonnes loniques affés belles, dans un Cabinet Ireillage. conviennent pas au treillage, ils font trop difficiles à exécuter avec du bois; il y en a de certains qui leur font affectés \& qui font parfairement bien en ouvrage. L'on évitera de faire des colonnes, \& l'on fe fervira toujours de pilaftres, ous de montans avec des paneaux. L'ordre Ionique eft celui qui convient le mieux aux treillages, \& qui s'execute plus facilement.

On diflingue un Berceau d'avec un Cabinet, en ce qu'un Berceau eft une grande longueur cintrée par le haut, en forme de galerie ; \& qu'un Cabinet eft compofé d'une figure quarrée, circulaire, ou coupée à pans, formant un falon qui peut fe mettre aux deux extremités, \& au milieu d'un long berceat.

Les Portiques font encore différens de tout cela : c'eft l'en' trée extérieure des Cabinets, Salons \& Berceaux de treillage, qui eft ordinairement décorée d'un fronton, d'une belle corniche, avec des pilaftres ou montans; c'elt auffi une lon. gue décoration d'Architecture, placée contre un mur, otz à l'entrée d'un bois, dont les faillies \& les retours font peu confidérables.

On fe fert ordinairement des Berceatx, Cabinets \& Portiques de treillage, pour terminer un Jardin de Ville, \& enboucher les murs \& les vî̀e défagréables, en formant un 
LA THEORIE DU JARDINAGE. $\$ 7$ bel afpect par cette décoration, qui peut fervir auffi de fond $\&$ de perfpective à une grande allée. L'on en pratique encore dans les Bofquets, dans les renfoncemens \& niches des paliffades, pour des bancs $\&$ des figures. On les couvre fouvent de rofiers, de jafmins, chevre-feüilles, vignes-vierge, pour y pouvoir jouiir d'un peu d'ombrage.

Il faut fur tout choifir un bel amortiffement ou couronnement pour un portique \& pour un "berceau de treillage, c'eft ce qui paroît le plus : on en verra des exemples dansla Planche fuivante, qui renferme toutes les différentes fortes de treillage, \& les plus belles décorations qu'on leur puiffe donner.

La Ie Figure eft la plus magnifique \& la plus compofée de routes : c'elt un grand portique de treillage d'ordre Ionique, compofé de plufieurs pilaftres accouplés, qui foutiennent une belle corniche, avec un perit focle au-deffus en forme d'Attique, orné de vafes, pofés à plomb fur chaque pilaftre. Dans le milieu, c'eft un grand renfoncement couronné d'un cintre formé de la même corniche, \& de quelques bandes d'ornement. Le bas de ce renfoncement eft eccupé par un baffin de toute la largeur, d'où il fort un boüillon de fix à fept pieds de haut, d'entre deux enfans qui font portés fur des enroulemens au deffus d'un gradin, dont l'eau en retombant, forme une nappe circulaire, accompagnée fur les côtés de deux autres boüillons. Aux deux extremités de ce portique, font deux niches circulaires, remplies chacune d'un chandelier d'eau fait en gaîne, orné de trois mafques qui rejettent l'eau dans le baffin d'en-bas. Tout ce treillage eft rempli de ronds, de lozanges, de moulures, de bandes \& autres ornemens des plus riches, dont on connôitra la proportion par l'échelle. L'on en auroit donné le plan, fi la grandeur de la Planche l'avoit pû permettre. Ce Portique peut fervir de fond à un Jardin de Ville, ou au bout d'une grande allée, oì il formeroit une belle perfpective; la nappe du milieu ferois vûë de la grande allée, \& les deux niches des bouts fe trouveroient en face de chaque contre-allée.

Le Portique qui eft repréfenté dans la ze Figure eft moins confidérable par fon étenduë \& fa richeffe; il n'y a point d'ordre d'A rchitecture, cependant il fera un fors bel effẹt en. 
8 PREMIERE PARTIE, ChAP. VIII. execution. Il conviendroit pareillement pour le fond d'un Jardin, ou au bout d'une grande allée, en mettant un banc dans fon renfoncement; il fervira auffi d'entrée dans un bois en perçant l'arcade du milieu, comme l'on en voit une moizié dans le deffein. Ce Portique eft compofé de montans \& paneaux de treillage, avec la même corniche que celle dus grand Portique. Son couronnement eft un grand cintre, furmonté d'un fronton triangulaire, qui eft porré dans les boưts par des paneaux \& des confoles: le bas eft orné de deux fcabelons ou gaînes, qui portent des buftes. L'échelle du grand Portique lui eft commune, \& donnera l'intelligence du refte.

On voit dans la ?e Figure un Cabinet de treillage, propre à placer dans un bofquet, ou au bout d'une allée découverte. Sa figure à pans eft d'un deffein affés fingulier. Il eft décoré de paneaux fimples, \& d'un fronton circulaire, furmonté d'une calote à pans, qui porte une lanterne percée à jour, auffi-bien que le tynupan du fronton.

La 4e Figure eft une grande niche circulaire toute des plus riches; fes montans font remplis d'ornemens, \& couronnés d'une belle corniche cintrée, dont le fond eft occupé par une coquille à côtes. On a placé dans cette niche un bufet d'eau, compofé d'un chandelier ou champignon, dont la coupe eft portée par des dauphins \&x des confoles; l'eau en retombe par deux napes dans le baffin d'en-bas. Cette niche conviendroit fort dans un bois, ou au bout de quelque allée qu'on ne pourroit percer plus avant.

Le Salon de la se Figure ferc de portique \& d'entrée à un berceaulong, dans lequel il eft pratique. Il eft fort fimple dans fes ornemens : ce ne font que deux montans, avec uine arcade ornée d'impoftes \& d'archivoltes; le tout couronné d'un fronton triangulaire, furmonté d'un dome cintré , \& ouvert par le haut.

On ne donne ici aucun deffein de Cabinets de fimple treillage fans ornemens, cela feroir fort inutile: fi l'on en vouloit executer quelques-uns, \& qu'on les voulût orner d'tine corniche ou d'un beau couronnement, on en pourra choifir dan les deffeins précédens, d'où on les peut détacher, pour le pulacer fort aifément par tout. 
I A THEORIE DU JARDINAGE. ig

Les Berceaux naturels ou de vérdure, appellés champêtres, font fimplement formés de branches d'arbres, entrelaffées avec art \& induftrie, tirées: l'une fur l'autre par des fils de fer, \& foutenuës par de gros treillages, cerceaux \& perches qui compofent des Galeries, Porriques, Berceatix, Cabinets, Salles, Colonnades, Niches \& Enfilades de pieces couvertes naturellement, fans y employer aucun treillage ap. parent ; leur place eft la même que celle des Berceaux artificiels ou de Treillage. L'on en va voir des exemples executés à Marly \& dans quelques autres Jardins : car on n'a pas voulu donner rien de genie dans cet endroit, ainfi que l'ons a fait ci-deffus dans les paliffades extraordinaires; cela en prouvera mieux la poffibilizé ; il eft fùr que ces Berceaux, Portiques \& Colonnades paroîtront encore plus impraticables que les paliffades percées en arcades; une Colonne de charmille eft un chef-d'ouvre \& un miracle en fair de Jardinage , ausfi eft-elle très-rare.

$\mathrm{La}_{1} \mathrm{e}$ Figure repréfente la Colonnade de verdiure des Jarding de Marly, au bas de la i te terrafe, en defcendant du Château vers la grande piece d'eau: elle borde une Salle verte entierement couverte \& tonduë par deffus, à caufe de 12 vûë ; c'eft où étoit autrefois le baffinides carpes : cette Colonmade eft d'abord fur une ligne droite', enfuite elle retourne' en portion circulaire des deux côtés de la terraffe : la fimétrie \&\& l'afpect en font furprenants \& dignes d'admiration. Les colonnes ont environ dix pieds de haut fur trois de tour, y compris un pied de chaque bout pour les bazes, chapiceaux \& filers qu'on y voit. Le focle ou piedeftal a un pied \& demi, \&. la corniche un pied de haut. On a fait exceder de trois pouces, le piedeftal $\&$ la bande d'en-haut à chaque colonne . \& directement au-deffus on a pratiqué des vales d'une figure bien particuliere. Pour lier chaque colonne au bofquer, ce font des traverfes ou poutrelles de verdure bien tonduës en. équariffement; cela eft fi merveilleux, qu'il faut le voir pour mieux le concevoir.

La $2^{\circ}$ Figure fait encore voir quelque morceau de cesTardins enchantés; ce font les Portiyues, Berceaux \& Galeries de verdure qui regnent tout le long des â̂les de la grande piece, fuivant les douze pavillons, entıe lefquels \& l'allée des bout 
les, ces Portiques font fitués, rien n’eft plus ingénieux ni plus artiftement executé. Il y en a deux rangs qui forment un Berceau ou une Galerie, \& ces arbres font dans des platesbandes, ornées cntre-deux d'ifs \& de fleurs de faifon, les tiges des arbres font découvertes d'environ fix pieds de haut, \& garnies de feüilles au deflus, pour former un montant ou pilaftre jufqu'à l'arcade qui vient fe cintrer delfus. On a échapé une tige \& un petit vale entre chaque arcade: ce qu'il y a de plus beau; c'eft que ces Berceaux fe croifent l'un fur l'aurre par des arcs de verdure, \& même fe retournent quarrément fans aucune confufion; le tout forme une woute fort longue \& toute verte : ces cintres, ces bandes \& ces montans fout peu épais, \& ont bealicoup de délicateffe, chofe encore très-remarquable, qu'on puife entretenir des ormes dans cet état un fi long-tems; les jours qui regnent, dans le plat-fond contribuent à donner de l'air deffous ces. Berceaux, \& à faire réfifter cesarbres dans la gêne \& la contrainte où on les tient toujours.

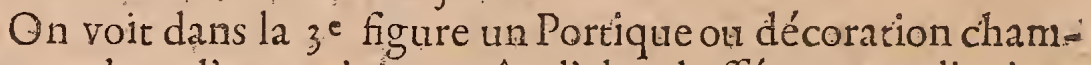
pêtre, dont l'execurion paroît d'abord affés extraordinaire. n'y ayant aucun treillage vifible : elle eft placée au bout d'une grande allée double pour en terminer la vûe ë plus agréablement; le milieu eft une grande niche cintrée avec un banc en face de la grande allée du milieu, \&x il y a deux renfoncemens quarrés, avec des figures fur des piedeftaux en face de chaque contre-allée. Entre cette niche \& les deux renfoncemens, on a pratiqué quatre avant-corps de huit colonnes de verdure, ifolées de la paliffade du fond; ces colonnes portent fur des focles, \& ont leurs bazes \& filets taillés en chamfrain les chapiteaux \& filets d'en - haut font de même, \& portent une corniche qui regne par tout; elle fait reffaut fur chaque avant corps, \& retourne en fronton triangulaire au-deflus de la grande niche du milieu : ce deffein eft couronné par un attique qui fuit la corniche fur les avant-corps de colonnes, au-deffus defquelles il fe trouve des boules toutes rondes. Les figures, les piedeftaux \& le banc font de pierre de taille, pour faire oppofition.

Le Portique de la $4^{e}$ Figure eft circulaire $\&$ occupé dans fon milieu par un grand baflin il reftemble affés aux Portic 



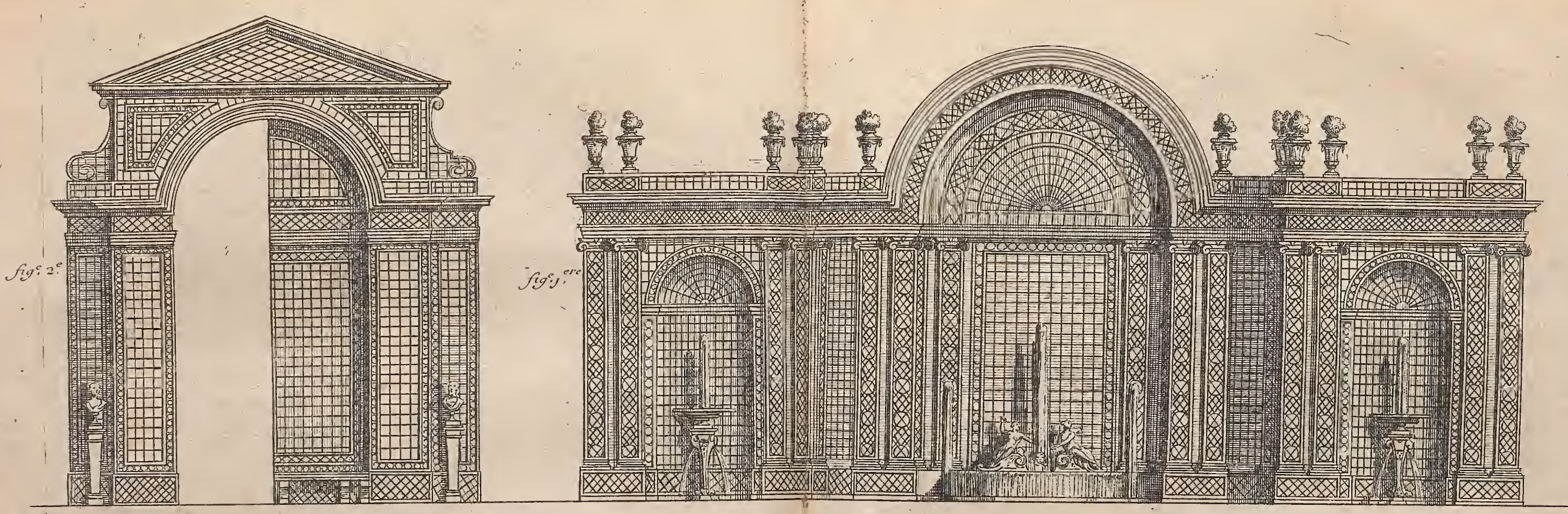

Cabinet de Treillage percéajour.
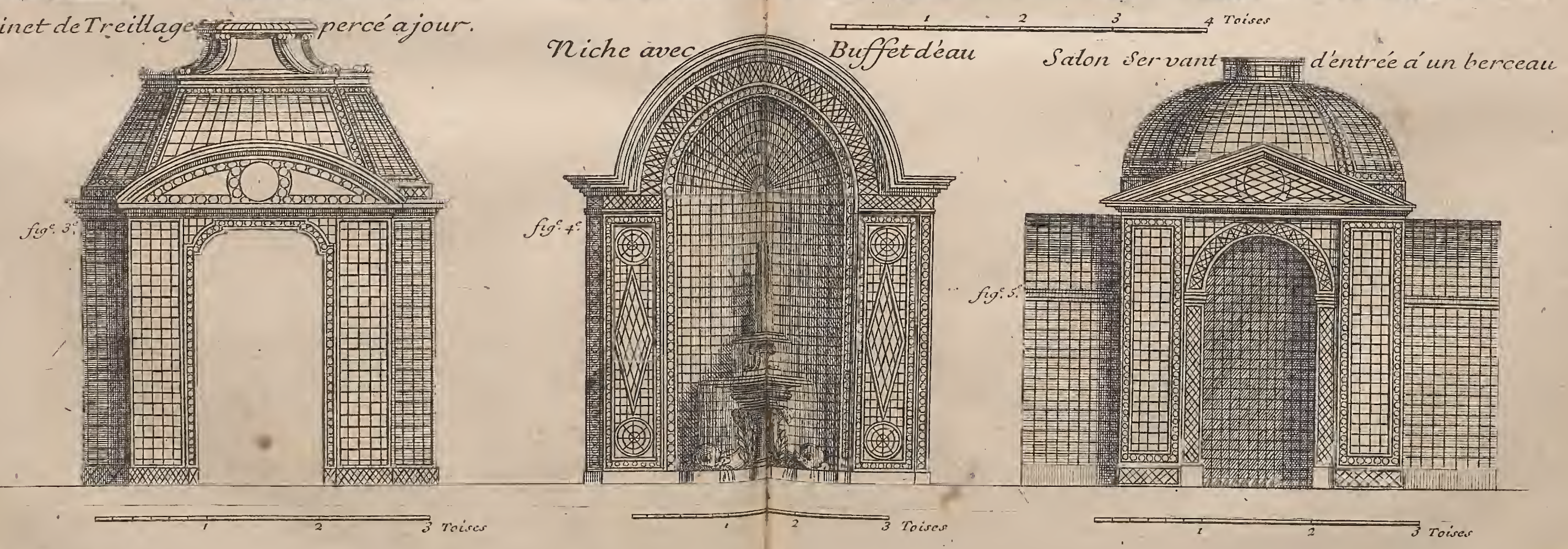

Plinche iter erag no etgr. 





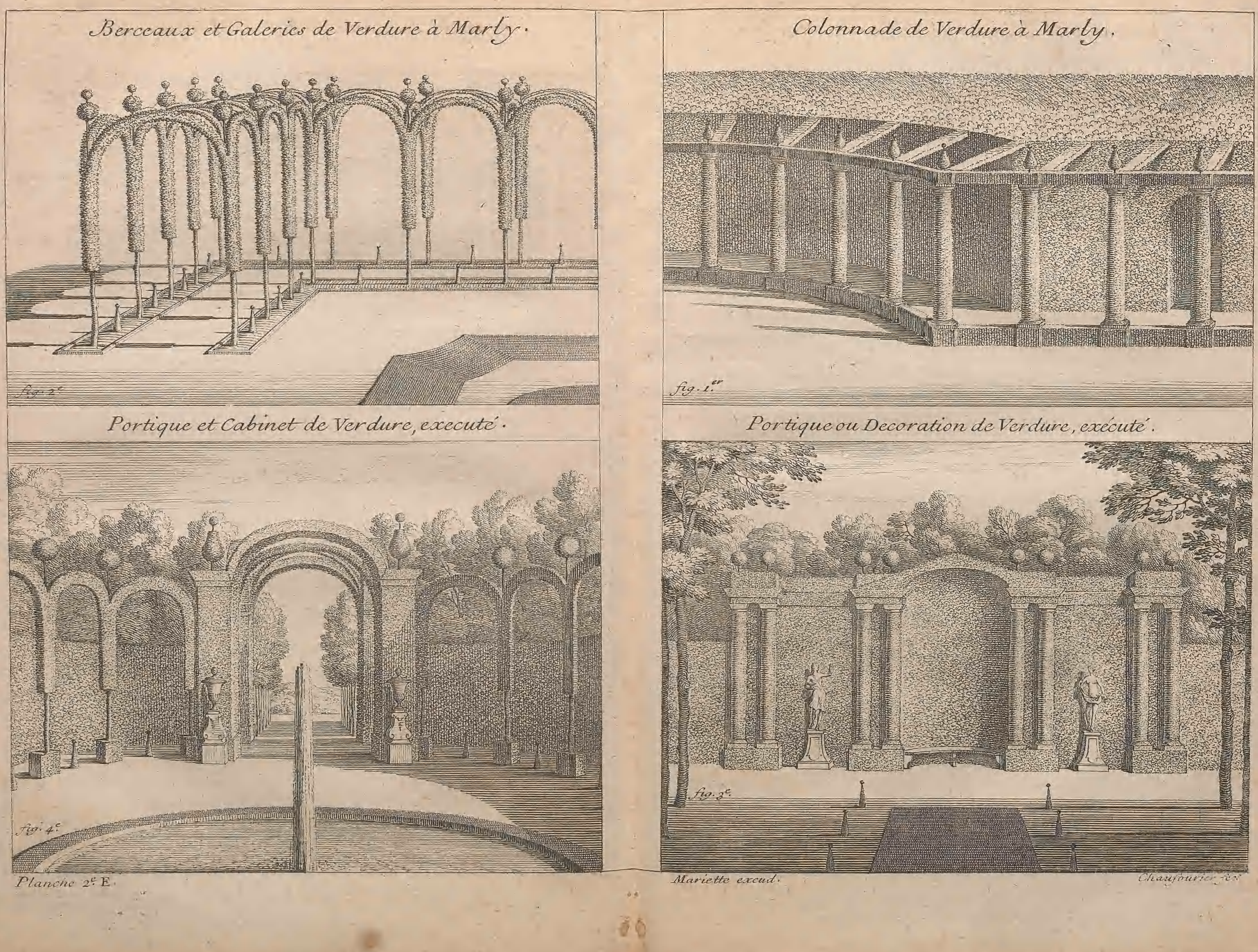



LA THEORIE DU JARDINAGE. 91 ques de Marly, hormis qu'il ne retourne \& ne croife point l'un fur l'autre, n'y ayant qu'un rang ifolé: ce qu'il a de fingulier, ce font de petites caifles avec une tige, ménagées à chaque pied des arcades cntre lefqucls il y a des ifs moutés. Ces Portiques ont un fond de verdure, ainfi que l'on a vû à la colonnade de Marly. Le cabinet de verdure eft fort nouveau dans fon efpece : il fe trouve à lenfilade de la grande allée aboutiffante au Jet, \& l'on pourroit en planter trois autres, qui avec celui-là fe croiferoient fur le baffin. Sa forme eft quarrée, joignant d'une face le tour des Fortiques, \& de l'autre la palifiade du fond, enforte que de l'allée du pourtour on paffe deffous : les quatre montans des encoignures fe croifent l'un fur l'autre par des bandes de verdure, qui laiffent quelque jour entre deux, comme aux Portiques de Marly. La décoration de fa façade en dedans, ent compofée de deux grands montans qui portent fur des focles, \& font couronnées d'une corniche en chamfrain, qui retourue en cintre dans le milieu. Au-deffus de chaque montant, ce font de grofles boules tonduës en vafes. On a orné ces montans de deux grands vafes de fculpture, pofés fur des fabellons de pierre, pour relever un peu l'A rchitecture champêtre.

Paffons maintenant aux autres ornemens, qui fervent à la décoration. \& à l'embeliffement des Jardins, \& fans parler de ceux de verdure, comme de paliffades percées en arcades, de Salles de comedie \& de bal, de galeries vertes, dont on a trouvé des deffeins ci-deffus $;:$ comme aufil des amplaithéatres., eftrades, gradins \& efcaliers de gazon, que l'on: verra dans la fuite; lefquels ornemens font les plus effentiels, puifqu'ils font valoir tous les autres: nous ne parlerons ici: que de ceux quileur font acceffoires, tels que les fuivans.

Les fontaines font après les plants, le principal ornement des Jardins; ce font elles qui les animent par leurs murmures. \& qui caufent de ces beautés merveilleufes, dont les yeux peuvent à peine fe raffafier. On les place dans les plus beaux endroits \& les plus en vì̀e de tous côtés. S'il y a quelque pente dans un Jardin, on y pratique des cafcades, des buffers deau, qui fe répétent par plufieurs napes, accompagnées de boüillons \& de jets. Quand l'eau: fe trouve facilement on fait des pieces d'eau \& des canaux, qui font des morceaux enchantés 
dans un Jardin; On met deftus ces canaux de petits bâtimens en gondoles dorées pour s'y promener, \& on les peuple de quantité de poiffons, pour avoir le plaifir de là pêche. L'on met encore fur ces eaux pour l'ornement, des cygnes, des canards \& des ö̈es de différente couleur'; ce qui eft fort agréable à la vûë. L'on décore les fontaines d'un ordre rultique enrichi d'ornemens maricimes, avec des figures convenables aux eaux.

Il n'y a point

Les terraffes étant bien fituées, font encore d’un grand de Jardin, où les terraffes foient fi belles fu'à Metidon.

ornement dans les Jardins, par leur régularité \& leur découverte, fur tout quand ces terraffes font bien bâties \& ornées de beaux efcaliers, an de belles rampes. On y pratique quclquefois des voutes, des grottes, des cafcades \& bufets d'eau, avec un ordre d'Architecture, \& quantité de figures dans les niches: fur la tablette d'en-haut l'on met des vafes \& des pots de fleurs rangés par fimétrie.

Les Serres ou les Orangeries font de grands morceaux de bâtiment, comme des galeries, qui par leurs façades augmentent la beauté des Jardins; la néceffiré que l'on a d'en bâtir, pour ferrer les orangers \& les autres caifles pendant l'Hyver, demande ordinairement l'expofition da Midy, ce qui n'empêche point que l'on n'obferve de les placer le plus avantageufement que l'on pourra, pour flatter le coup d'œil ; elles ferviront alors de galerie l'Eté, pour fe promener L'Orangerie pendant la pluie. L'on en pratique quelquefois fuus les voude Meudon. tes d'une terraffe, dont les arcades \& les trumeaux forment. une affés belle décoration de loin.

Les figures \& les vafes contribuënt beaucoup à l'embéliffement $\&$ à la magnificence des Jardins, \& en relevent infiniment les beautés naturelles. Il s'en fait de différentes formes \& de plufieurs matieres, dont les plus riches font de bronze, de fonte, de plomb doré \& de marbre; les moindres font de fer, de pierre \& de ftuc. On difingue parmi les figures, les groupes qui font compolés au moins de deux figures enfemble dans le même bloc, les figures ifolées, c'eft a-dire, autour defquelles on peut toumer, \& les figures qu'on place dans les niches, qui ne font finies que par devant: il y a encore les buftes, termes, figures à demi corps, demi-nature \& plus grande que nature, appellées Colofiales, pofées fur 

des piedeftaux, fcabelions, gaînes, piedouches, focles, fans compter les figures d'animaux qui ornent les calcades, aunibien que les bas-reliefs \& les mafques.

- Ces figures repréfentent toutes fortes de Divinités \& de perfonnages de l'antiquité, qu'il faut placer à propos dans les Jardins, enmettant les Divinités des eaux, comme Naïades, Flcuves, Tritons, au milieu des fontaines \& des baflins; \& les Divinités des bois, comme Sylvains, Faunes, Driades dans les bofquets. On repréfente encore en bas-reliefs, des Sacrifices, Baccanales, Jeux d'enfans fur les vafes \& piedeftaux, qu' on peut orner de feftons, de feüilles, de moulures \& autres ornemens.

Les places ordinaires pour les figures \& les vafes, font le long des paliffades, en face \& fur les côtés d'un parterre, dans des niches \& renfoncemens de charmille ou de treillage fairs exprès. Dans les bofquers on les place au centre d'une étoile ou d'une croix de S. André, dans l'entre-deux des allées d'une patte-d'oie, au nilieu des Salles \& des Cabinets, entre les arbres ou les arcades d'une galerie de verdure, \& à la tête d'un rang d'arbres ou de paliffades ifolées. On les place encore au fond des allées \& enfilades, pour les bien décorer ; dans les portiques \& les berceaux de treillage, dans les baffins, les caf́cades, \& c. généralement elles font bien par tout, \& l'on ne fçauroit en avoir trop dans un Jardin; mais comme en fait de Sculpture, il faut de l'excellent, aufi-bien qu'en peinture \&z en poëfre, il convient mieux à un particulier de fe paffer de figures, que d'en avoir de médiocrement belles, quifont toujours défirer cette perfecion; on doit laiffer cette dépenfe aux Princes \& aux Minintres.

On orne les bouts $\&$ les extrêmités d'un parc, de pavillons de maçonnerie, appellés Bellevedere, ou Pavillons de l'Anrore; c'eft un agrément pour fe repofer après une longue promenade, que de trouver ces fortes de Pavillons qui forment un bel afpect de loin; ils fervent aufi de retraite pendant la pluie. Le mot de Belvedere eft Italien, \& fignifie Bel le-vì ë, qui eft donné fort à propos à ces Favillons, qui pour l'ordinaire étant élevés fur quelque hauteur, decouvrent \& commaudent tout le $\mathrm{Pa}$ is d'alentour.

Les Perfpectives \& les Grotes ne font maintenant prefque $\mathrm{Mi} \mathrm{ij}$

Il y a aufi des Bellevedere tout de gazon dans les Jardins hauts de Marly, \& dans le bois d'Ecoitan 
La perfpectirive de Ruël étoit fi bien peinte, que les oileaux venoient fe caffer la tête consre le mur, croint paffer de, où l'on: avoit peint le ciel.

94 PREMIERE PARTIE, CH A P. VIIT. plus à la mode, fur tout les Grottes qui font fort fujettes à fe gâter. On les plaçoitordinairement au bout des allées, \& deffous des terraffes. A l'égard des perfpectives; elles fervent à cacher les murs de pignon, \& les murs du bout d'uneallée, qu'on ne peut pereer plus loin. Elles font une belle décoration, \& très-furprenante par leurs percés trompeurs. On les peint à huile, ou à frefque, \& on les couvre par en: haut, d'un petit toir quî rejette l'eau de la pluye qui couleroit fans cela le long du mur, ¿ gâteroit la peinture en. tierement.

Les grilles font des ornemens très-néceffaires dans les enfilades d'aillées, pour en prolonger la viüé, \& découvrir bien du Païs. On fait préfentement des claires - voyes appellées, des $a b a b$, qui font des Oatvertures de murs fans grilles, , \& à niveau des allées, avec un foffé large \& profond au pied, revêtul des deux côtés pour foûtenir les terres, \& empêecher qu'on n'y puiffe monter; ce qui furprend la vâee en aprochant \& fait crier $a b$ ab, dont ils ont pris le nom ; ces fortes d'ouvertures bouchent moins la vûe que les barreaux des. grilles

Les caiffes \& les pots de fleurs fervent encore d'ornement aux Jardins. On éleve dans ces Caiffes, des Orangers, des. Jafinins, des Grenadiers, Mirthes, Lauriers, \&cc. quii fe placent avec fimetrie dans les parterres d'Orangerie, le long des Terralfes, ou ì côté des. Parterres, \& qu qui forment des allées: on y met entre-deux , des pots \& vafes de faïance remplis de fleurs de toutes les faifons, que l'on place auffi fur des gradins, fur les tablectes des murs de terrafie , \&z à la defcente des efcaliers, ou fur des dez de pierre dans les plates-bandes. \& bordures de gazon.

Les Bancs outre la commodité qu'ils offrent fans ceffe dans les grands Jardins, où l'on n'en peut jamais trop mettre par le grand befoin que l'on en a en fe promenant, font encore un allés bel effet, quand ils font mis dans de certaines places qui leur font deftinées, comme dans des niches ou renfoncemens en face des grandes allées \& enfilades, dans. les Salles \& Galeries des Bofquets : on en fait de marbre, de pierre de taille $\&$ de bois, qui font les plus communs, \& dont il $y$ a deux efpeces, les bancs à doflier qui font les plus beaux 
LA THEORIE DU JARDINAGE.

\&x que I'on tranfporte l'Hyver, \& les fimples qui tont fcellés en plâtre dans la terre.

On remarquera qu'il faut paffer une couleur à huile, foit werte ou autre, fur tout ce qui eft expofé à la pluye dans un Jardin, \& qui fe peut aifément pourrir, comme font les Treillages, les Bancs, les Caiffes, les Gradins, \& c c. c'eft nonfeulement pour leur confervation, mais encore pour une plus grande propreté.

On ne donnera point de Planches de tous les ornemens dont on vient de parler, comme de chofes appartenantes plus à l'A rchitecture, qu'au Jardinage, \& dont on n'a parlé ici que pour dire les endroits des jardins où il convient le mieux de Les placer.

FIN DE LA PREMIERE PARTIE:

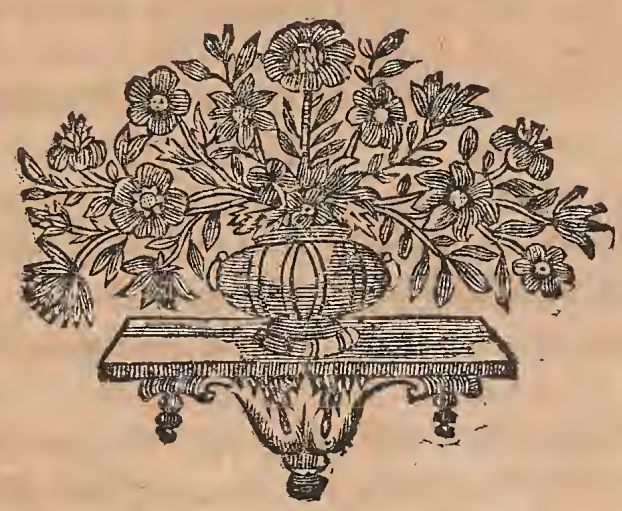




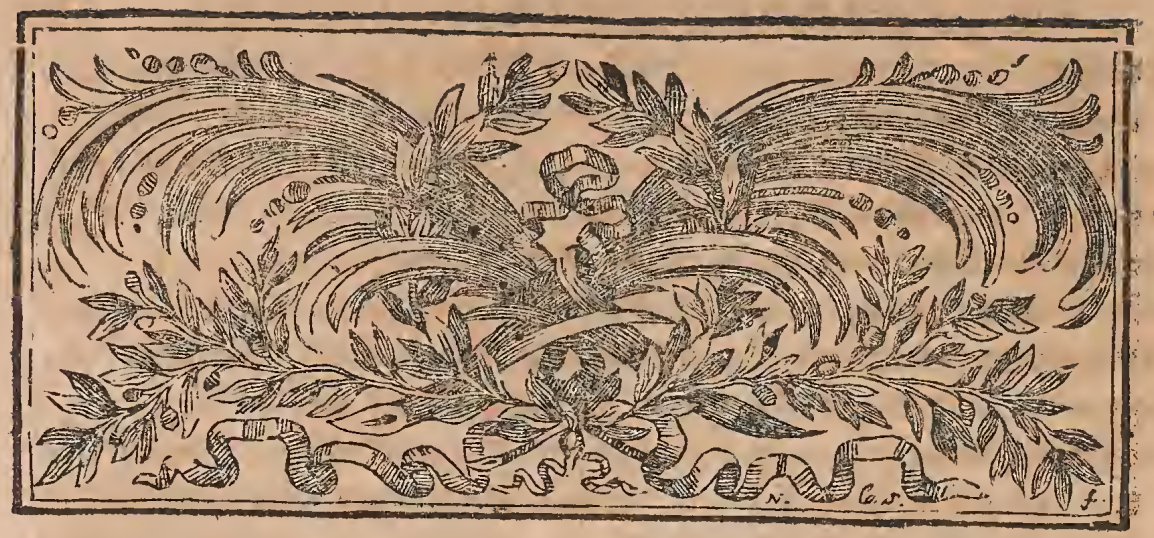

\section{SECONDE PARTIE QUI CONTIENT \\ LA PRATIQUE $\mathrm{DU}$ J A R D I N A GE}

En ce qui regarde la maniere de Tracer.

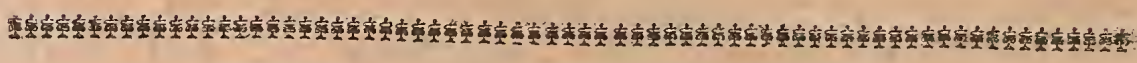
CHA P I RE PREMIER.

\section{PRELIMINAIRE DE QUELQUES}

Pratiques de Geometrie, décrites jur la papier, aves la maniere de les raporter fidélement. Jur le Terrain.

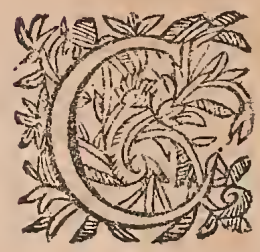

En'eft pas affés.d'avoir parlé dans la premiere Partie, de tout cequi compofe un beau.' ardin, \& fait voir le choix qu'on en doit faire, par les exemples que nos deffeins en donnent; il faut enfeigner préfentement la maniere de mettre en pratique \& en exécution, ces belles idées, qui feroient autant d'énigmes fans ce fecours. En: Effet j tout ce que l'on a dit dans. les Chapitres précédens , n'étant 
IA PRATIQUE DU JARDINAGE. 97 n'étantà proprement parler, que la Théorie de cet Ouvrage, tous ces Chapitres ne feroient d'aucune utilité, fans ceux des trois Parties fuivantes qui en renferment la Pratique : La Theoria saiente fenza la pratica, dit l'Italien. C'eft où manquent la plûpart des Auteurs, quis'étendent très-amplement fur la fpéculative d'une Science, \& ne parlent que très-peu, ou point du tout de fa pratique; ce qui rend leurs Ouvrages de peu d'utilité, \& fait regreter le tems que l'on a paffé à les lire, fans en pouvoir tirer aucun fruit.

La maniere de tracer fur le Terrain, confifte plutôt dans une grande pratique, que dans une profonde fcience: il ne. faut Çça voir que quelques regles de Geometrie pratique, poutr $s^{\prime} y$ rendre très-habile en peu de tems. L'expérience, la pratique du Terrain, \& une certaine routine, y font plus néceffaires, qu'une longue reflexion dans le cabinet: Cependant fi l'on négligeoit de s'inftruire de ces regles, \& qu' an travaillât d'abord fur le Terrain, avant que d'avoir deffiné fur le papier, ou du moins avant que de connoître la maniere de rapporter les figures du papier fur le Terrain, on courroic rifque de fe tromper fouvent. On ne dit point qu'il faille fe rendre habile Geometre, pour être capable de tracer fur le Terrain, cela eft hors de la porrée d'un Jardinier; fi cela éroit néceffaire, un Jardin feroit long tems en friche, en attendant que fon Maître fe füt rendu habile dans une fcience, oì la vie de l'homme fuffit à peine.

On re veut pas même impofer à un Jardinier la néceffiré de lire un Traité de Geometrie pratique, quoiqu'il y en ait de fort bons \& de trés courts*. On lui a épargné cette peine, en recherchant dans cette fcience, tout ce qui peut avoir * Le P. Par dies, le Cles. rapport aux deffeins de. Jardinage, dont on a compofé ces Préliminaires, ouElemens de la maniere de tracer, réduite aux vingt Pratiques fuivantes.

Pour tracer fur le Terrain, on fe fert de plufieurs inftrumens; les plus ordinaires font le Graphomettre ou demiCercle, \& l'Equerre ou Cercle parfait.

Le Graphometre ou demi-Cercle, eft ordinairement de cuivre, \& doit avoir depuis un demi-pied, jufqu'à 12. ̀̀ 15 . pouces de diametre. Plus il eft grand, plus on a de facilité à s’en fervir. Ce demi-Cercle eft divifé en 180. degrés, qui eff 
la moitié duCercle parfait en 360. On le met fur 90 degrés quart duCercle, pour former un angle droit \& fe retourner d'équerre. Il a deux regles, l'une immobile qui lui fert de baze, \& l'autre mobile appellée Alhidade, qui par le mö̈en d'un clou rivé daris'fon milieu, fe meut autour de centre, \& fert à prendre les ouvertures d'angles. Ces deux regles font terminées par des pinules ou vifieres élevées en angles droits, qui dirigent \& conduifent le raion vifuel. On remplit ordinairement le milieu de cet infrument, d'une Bouffole pour orienter les plans. Le demi-Cercle eft monté far un genou, par le moïen duquel on le trouve fur tout fens, y ayant une vis qui: ferre \& delferte ce genou tant que l'on vent. On le pofe fur le Terrain, en fourant dans les trois ouvertures au-deffous du genou, appellées doüilles, trois piquets ferrés par le bout d'enbas, que l'on enfonce en terre. En voici la figure.

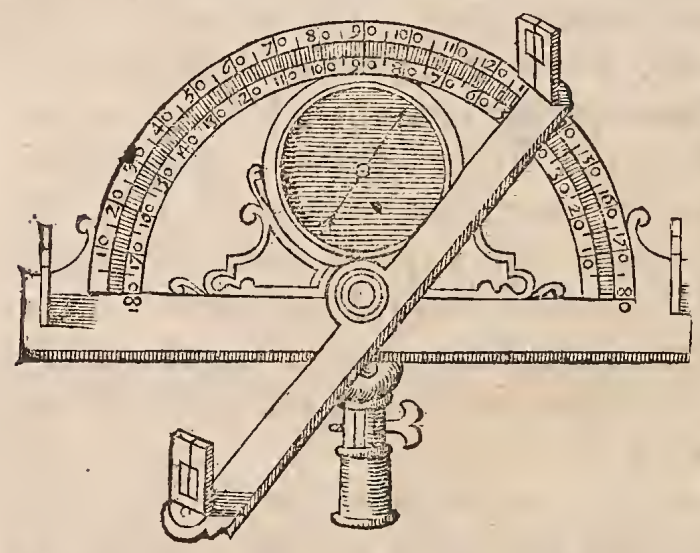

Les petirs demi-Cercles font montés fur un genou, qui n'a qu'une doüille, \& par conféquent où il ne faut qu'un feul piquet, quel'on pofe jufte fur un point pris fur le Terrain. Pour les. grands demi - Cercles, qui ont un pied triangulaire, comme il feroit difficile de les pofer jute fur un point déterminé, il y a un plomb qui pend par deffous, cela fait connoître quand il eft précifément fur le point en queftion.

L'Equerre ou Cercle parfait, qui eft un inftrument done on fe fert beaucoup dans le Jardinage \& dans l'Arpentage differe de beaucoup des Equerres de Maçons \& autres Ouvriers. C'eft un Cercle parfait coupé en quatre parties égales, par deux traverfes ou regles immobiles tenantes au Cercle qui forment la figure d'une croix, ainfi qu'on le voit dans la figure fuivante. Aux quatre extrêmités de ces traverfes \& au centre; il y a des pinules ou vifieres, qui fervent à fe retourner d'équerre $\&$ à angles droits. Cet intrument n'eft ordinaire- 

ment que de fer: on en fait néanmoins de cuivre. Il eft monté fur une fimple doiille fans genou, ou l'on fourre un piquet, quand on s'en veut fervir fur le Terrain. Cetce Equerre eft appellée fimple, parce qu'il n'y a point de dégrés divifés fur fon Cercle, \& qu’elde n'a point d'albidade ou regle mobile. C'eft pour cela qu'on ne peut prendre d'ouverture d'angle avec cette Equerre, \& qu'ellen'eft propre fur le terrain, qu’à . aligner de grandes lignes droites, \& $\grave{a}$ former des angles droits. Ce défaut lui fait préférer le demi-Cercle qui ef un

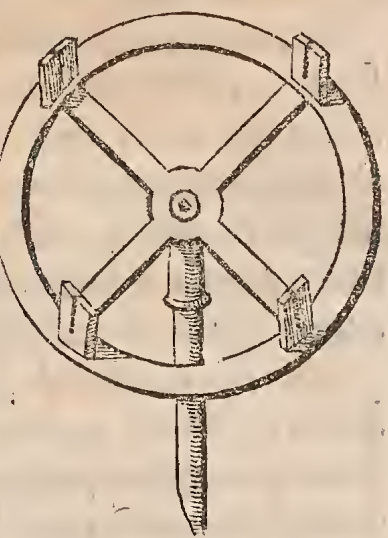
infrument bien plus parfait; il fert non-feulement à lever $\& a ̀$ tracer des plans, mais encore à plufieurs belles opérations de Geometrie.

On porte fort commodément ces inftrumens en Campagnedans des étuis, \&zon lie les piquets \& les jalons en(emble.

Onfe fert encore fur le Terrain, de la Toife, du Cordeau, de Jalons \& de Piquets; ce qui eft fi néceffaire dans le Jardinage, qu'on peut dire que leur ufage eft journalier, n'y ä̈ant prefque point de jour dans l'année, qu'un Jardinier ne foit obligé de fe fervir des uns ou des autres.

La Toife eft un bâton bien droit, \& long de fix pieds de Roi, dont la divifion eft marquée par de pecits clous : un pied de Roi eft divifé en I 2 pouces, le pouce en I 2 lignes, $8 x$ la ligne en Iz points. La Toife regle la longueur \& la largeur des allées, \& fert à prendre de grandes mefures, comme le pied fert à prendre les petites.

On fe fert auffi d'une chaînette de trois ouz quatre Toifes de long avec des piquets; elle eft beaucoup plus fùre dans les grandes mefures, que la Toife.

Le cordeau n'eft autre chofe qu'une petite corde ou ficelie, que l'on torille autour d'un bâton, \& que l'on défile felon la longueur néceffaire; l'on remarquera que pour empêcher' qutil ne s'alonge, il faut le mettre en double \&r y faire des noeuds de quatie pieds en quatre pieds; on : y fait auffi des On regle ordinairement la longueur du Cordean de 15 a boucles aux extrênités, pour les paffer dans les Jalons, 
IOo SECONDE PARTIE, CHAP. I. comme quand on veut tracer un cercle, un ovale, une de: mi-lune, \&c.

Comme le Cordeat eft fujet à quelques inconveniens, qui font de s'alonger ou de fe racourcir felon qu'il eft plus ou moins tiré; de diminuer de beaucoup quand il eft moüillé, \& de s'étendrequand il vient à fécher. On pourra fe fervir de fil de fer bien mince, de cordes faites d'écorces de Tillot, ou de branches de Viorne liées enfemble; ce qui n'eft point fujet à s'alonger ni à racourcir.

On dit, tendre ou bander le cordeau, quand l'aïant attaché à deux jalons, vous le tirés tant que vous le pouvés, en obfervant que le cordeau ne foit ni lâche ni forcé; c'eft-à-dire; qu'en pinçant la corde, elle touche égalenient-par tout fans trouver de terre où de bute, qui l'éleve, la force \& la contraigne tant foit peu.

Les jalons \& les piquets font de fimples bâtons, quon choifit toujours les plus droits qu'il fe peur, cela facilite à bien aligner. On les éguife par un bout pour les ficher en terre, \& l'on unit \& plane l'autre par deffus, ce qu'on appelle la tête du jalon.

Les jalons ne different des piquets, qu'en ce qu'ils font plus grands, \& qu'ils doivent avoir cinq à fix pieds de haut; au lieu que les piquets n'ont que deux pieds tout au plus, \& le plus fouvent moins.

Les termes de jaloner, aligner, mirer, bornoïer, fignifient tous la même chofe; c'eft quand celui qui aligne, met l'œrl fur la tête d'un jalon, pour dreffer deffus tous les autres de la même ligne; cela fe fait en fermant un cil, \& n'ouvrant que celui dont on fe fert pour aligner: cetre action s'appelle ligne de mire, ou raion vifuel.

Il arrive que quand on met l'œil $\subseteq$ près du jalon, on ne peut pas fi bien remarquer le défaut des autres, parce que le raion vifuel s'écarte toujours; il faut donc fe placer un peu aut-defus du jalon, environ à trois ou quatre pieds, \& en fe baiflant à fa hauteur \& fermant un œil, mirer avec celui qui eft ouvert, fuivant la tête du premier jalon \& de ceux qui feront pofés dans le milieu \& à l'autre extrêmité, tous les autres jalons, de forte qu'ils fe couvrent tous, \& ne paroifent qu'un feul, y en eut-il trente fur le même alignement. 
LA PRA TIQUE DU JARDINA GE. IOI

Il n'eft pas néceffaire que les jalons foient enfoncés d'égale hauteur dans l'alignement qu'on fera, cela n'eft effentiel que dans le nivellement : ainfi quand un jalon en excederoit un autre d'un demi-pied, cela ne feroit rien; il fuffit qu'ils fe couvrent bien l'un l'autre.

On a encore befoin fur le Terrain d'un inftrument appellé Traçoir, qui eft un grand bâton droit \& ferré par le bout d'en bas, dont la pointe eft triangulaire ou aplatie en langue de chat; c'eft avec le Traçoir qu'on forme \& qu'on deffine toutes les figures des Jardins; en un mot, c'elt le porte-cräion du Traceur furle Terrain.

II faut pour tracer, tendre un cordeau d'un jalon à un autre, \& fuivre avec le Traçoir ce cordeau, fans cependant le forcer \& le contraindre en aucune maniere. Dans les grands alignemensil eft à propos de ficher de petits piquets, d'efpace en efpace fur la trace, de crainte qu'elle ne s'efface, \& auf pour la diftinguer de loin.

Quand on trace, l'on doit enfoncer un peu avant leTraçoir, pour rendre la trace plus large \& plus creufe; l'on repaffe plufieurs fois le Traçoir dans la même trace, \&x quelquefois la main en travers, pour la marquer davantage, de peur que les vents \& les pluies ne l'effacent.

On ne doir jamais relever les jalons, que la Trace ne foit bien marquée fur la terre, \& l'on en doit toujours laiffer deux au moins fur chaque alignenient, tant pour fervir à planter les arbres, que pour reprendre de nouvelles mefures, s'ilétoit néceffaire dans la fuite.

On appelle fe retournerd'Equerre ( terme fort ufité dans la maniere de tracer) quand fur une ligne droite tracée avec le demi-cercle, ou avec le cordeau, l'on y fait tomber une au. tre ligne d'à-plomb, appellée perpendiculaire, qui forme un angle droit ou ligne d'Equerre, que les Ouvriers nomment le trait quarré.

Il faut avoir la précaution en traçant, d'avoir près de foi un petit cordeau de trois ou quatre toifes de long, pour prendre les petites mefures \& faire les petites opérations ; comme aufli d'avoir une grande * Equerre de bois pour former les petits retours qui fe rencontrent dans les deffeins, ou il eft int.

Cetre Equerre eft $1 / 3$ même dont $f_{e}$ tile de fe fervir du demi-cercle ou du cordeaú pour fe retour les Ouvriass. ner d'Equerre 
Quand dans les pratiques fuivantes vous lirés, tracés cezte ligne par la $3^{\mathrm{e}}$ par la $5^{\mathrm{e}}$ pratique, \&c. cela fignife, que c'eft la mêmeopération que l'on a déja faite dans la 3 e ou $5^{\mathrm{e}}$ pratique ci-deffus, où l'on aura recoars pour éviter les redites. On les a chiffrées exactement dans cette intention.

Il eft à propos de dire ici une chofe, avant que d'entrer dans les pratiques fuivantes, \& cela afin de ne point effraïex un Jardinier, qui defire d'apprendre à tracer, parles difficulrés qui lui furviendroient, loit au fujet du deflein qu'il croiroit indifpenfablement néceflaire pour fçavoir tracer, foit par la grande peine qu'il fe formeroit, pour concevoir $\& \dot{<}$ mettre en ufage toutes les Figures fuivantes.

On dira au fujet de la premiere difficulté, pour tous les Jardiniers \& gens de la campagne en general, qu'il n'eft pa néceffaire qu'ils fachent deffiner, mais feulement qu'ils dojvent avoir l'intelligence d'un plan, de maniere qu'en leur donnant tout defliné, ils fachent le rapporter fidelement fur le Terrain; ce qui fe fait par le mö̈en d'une petite ligne double, divifée par toife, qu'on appelle l'Echelle du plan', 26 qui eft toujours au bas du papier. Comme toutes les parties d'un deffein font faires fur cette Echelle, \& que c'eft une regle infaillible pour les rapporter juftes furle Terrain, de la fuivre exactement; le Jardinier n'a qu'à examiner cette Echelle, \& regarder en combien de toifes elle eft divifée. Pour cet effer, -il fatit qu'il ait un compas, avec lequel il mefurera toutes les parties de fon plan, une regle pour prolonger les lignes, \& les centres qu'il faut trouyer fur le papier, \& les mefurant fur la divifion de fon Echelle, il faura combien de toifes elles ont en longueur \& en largeur. Il aura befoin encore d'un petit Inftrument, qu'on appelle un Rapporteur, tel que le repréfente la Figure de la page fuivante : c'eft pour prendre les ouvertures d'angles. On applique le Rapporteurfur un des côtés de l'angle, \& comptant de fon centre, la quantité de degrés, depuis fa bafe jufqu'à l'endroit où l'autre côté de l'angle vient couper fa circonférence, on les chiffrera fur le papier, \& on les rapportera fidelement fur le Ter. rain de pareille proportion, en ouvrant le demi-cercle \& pofant l'alhidade fur un pareil nombre de degrés, parce que JeRapporteur eft divifé en aurant de degrés, que le grand 


\section{IA PRATIQUE DU JARDINAGE.}

demi-Cercle dont on fe fert pour tracer furle Terrain.

A l'égard de la feconde difficulté, qui eft la grande peine qu'un Jardinier fe formeroit par avance, pour concevoir les pratiques fuivantes; on peut l'affürer, que s'il veut les lire fans prévention, pour peu qu'il ait de jugement, \& qu'il s'y appli-

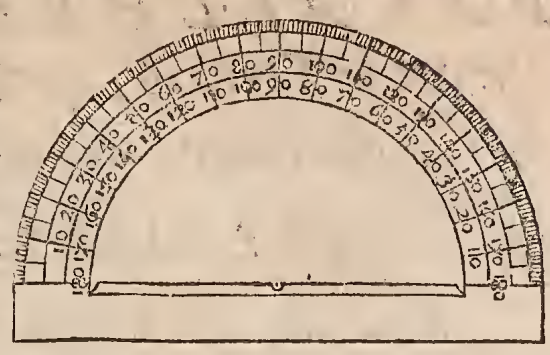
que, il ne trouvera rien de difficile \& hors de la portée d'un bon efprit. On a tâché de réduire toutes ces Pratiques à un petit nombre, \& à les mettre dans ùn ordre naturel $\&$ ailé $:$ outreque l'on a évité les longs détours \& les termes affectés à la Geometrie, qui auroient pû lui fembler barbares. En un mot, on n'a eu d'autre application que de fe faire entendre des Jardiniers, \& qu'à leur rendre facile \& palpable une chofe qui d'elle-même paroît difficile. Ce n'eft done point pour les Geometres que l'on écrit, ni pour les gens éclairés dans cette matiere, à qui les termes $\&$ les chofes les plus difficiles, font devenuës familieres par l'étude; c'eft fimplement pour les. gens de la Campagne, \& pour quelques curienx de Jardinage.

Après ce petit avertiffement, on peut paffer aux Pratiques fuivantes, qu'on fuppofe être deflinées fur des rouleaux de papier, appellés Plans, \& l'efpace à côté être le Terrain fur lequel elles font rapportées exactement \& de pareille proportion, c'eft-à-dire, réduites du petit au grand. Elles font contenuës dans les quatre Planches à la fin de ce Chapitre.

On jugera par ce Parallele du Papier avec le. Terrain; du rapport qu'il y a entr'eux. On peut dire certainement que ces Pratiques renferment tout ce qu'un Jardinier doit fçavoir de Géométrie, pour pouvoir tracer toutes fortes de figures fur he Terrain, quelques difficiles qu'elles puiffent être. 
Co SECONDE PARTIE, CHA I.

\section{$P A R A L L E L E$ DU PAPIER avec le Terrain, en ce quiregarde la maniere de tracer, réduit aे 20. Pratiques.}

\section{PREMIERE PRATIQUE.}

Tracer une ligae droite fur le Terrain, avec le Cordeau.

Frovs I. Soitla ligne droite $a b$, que l'on fuppofe ici être de douze PaÁrha I. toifes, on mefurera exactement cette longueur fur le Terrain de $A$ en $B$, où l'on plantera deux jalons, puis tendane un cordeau de l'un à l'autre, l'on marquera avec le Traçoir cette ligne fur le Terrain, en fuivant le cordea fans le forcer.

\section{$R E M A R Q U E$ :}

Cette Pratique ne pent fervir qu'à une diftance d'environ I 2 à I 5 toifes, à caufe de la difficulté qu'il y a de trạcer au long d'un cordeau, une plus grande ligne.

\section{SECONDE PRATIQUE.}

Fracer une ligne droite fur le Terrain, avec des piquets:

Suppofant que la ligne qu'il faut tracer foit trouvée fur le plan, de $I \otimes 0$ toifes de long, comme la ligne $c d$, il faut planter furle Terrain un jalon vers une des extrệmités de cette ligne,

1c. II. comme en $A, \&$ un autre à l'extrêmité $B$, diftans de IOO toifes l'un de l'autré, $\&$ en aligner un troifiéme vers le milicu comme en $C$, enfuite divifés la grande longueur de $A$ en $B$, en affés de parties, pour que chacune n'ait pas plus de I 2 à I 9 toifes de long; \& tendant un cordeau d'un jalon à l'aurre, vous tracerés cette ligne en plufieurs foiș, fativant la Pratique precederste. Enfuite vous pourrés ôter les jalons qui ont fervi à l'alignement, \& mettre des piquets de diftance en diftance, pour retrouver plus aifément la trace. 


\section{LA-PRATIQUE DUJARDINAGE。 IOS \\ TROISIE'ME PRA TIQUE. \\ Prolonger fur le Terrain une ligine droize.}

On fuppofe en cetre Pracigue que la ligne que l'on doit prolonger, eft l'a'ignement d'un mur, ou d'un bâtiment

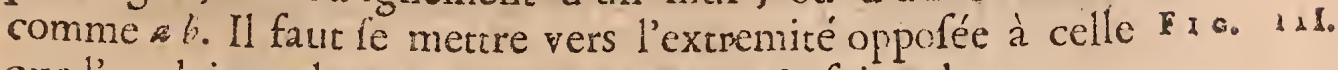
que l'on doit prolonger, comme vers $A, \&$ faire planter audelà de l'encoignure $B$ un jalon comme en $C$, en telle forte que ce jalon ne s'écarte point de la ligne $A B$, vers $D$ ni vers $E$, \& l'on tracera la ligne $B C$ par l'une des Pratiques précídemes, felon la longueur de certe ligne.

\section{QUATRIE'ME PRATIQUE.}

Tracer avec be Cordeau, une ligne droise qui foit d'ćquerre ou perpendiculaite à une autre ligne drotte tracée.

Soit la ligne droite C D tracée fur le terrain, \& le piquet E planté au point, d'où la perpendiculaire doit être élevée: portés de part \& d'autre du point $E$, environ fix ou huit toifes, plantés y deux piquets comme $F \& G$, puis paffant les boucles des extrémités du cordeau, dans les deux piquets, F 1 G. I V.

$F \& G$, on tirera la boucle du milieu du cordeau vers $H$, en forte que les deux côtés du cordeau $F H \& G H$ foient tendus également. On plantera un jalon en $H$, au devant de la boucle , c'elt-à-dire dans l'angle que formeront ces deux lignes \& tendant un autre cordeau de $E$ en $H$, on tracera la ligne $H E$ qui fera perpendiculaire à la ligne $C D, \&$ femblable à celle du plan $a b$.

$$
\text { PREMIERE REMAR QUE. }
$$

Pour l'execution de cette Pratique $\&$ des fuivantes, il faut prendre un cordeau de 15 . à 20 . toifes de long, faire une boucle à chacune de fes extremités, puis le plier en deux, \& tendant également les deux bouts, faire une troifiéme boucle al milieu.

$$
\text { SECONDE REMARQUE. }
$$

Cette pratique fe peut faire en traçant des portions de 
ro6 SECONDE PARTIE, CHA P. I:

F I c. IV. Cercle des deux piquets $F \& G$ diftans également du point $E$; par le moïen d'un petit piquet attaché au bout du Cordeau, ce qui formera des fections en $H$, \& dans l'endroit où elles fe cuuperont, appellé interfection, on y plantera le jalon $\mathrm{H}$, d'où l'on tracera jufqu'à celui $E$. la ligne perpendiculaire $H E$. Cette Pratique peut auffi fervir à toutes les fuivantes.

\section{CINQUIEME PRATIQUE.}

Tracer aves l'Inftrument, une ligne perpendiculaire à une ligne droite tracée.

Soit la ligne droite $A B$ tracée fur le terrain, \& le piquet $C$ planté au point, d'oì la perpendiculaire doit être élcvée, \$ \&. Y. ainfi qu'elle eft marquée fur le plan, par $a b$ : pofés le demicercle fur fon pied, bien à plomb au deffus du piquet $C$, alignés enfuite $f a$ bafe vers le piquet $A$, ou vers celui $B$, par le mö̈en des pinules qui font fur cette bafe, \& vous retournant d'équerre, mettés l'alhidade fur 90 dégrés, \& faites planter-un piquet comme vers $D^{\circ}$, que vous alignerés par les pinules de cette alhidade, à une diftance proportionnée à la longueur ique doit avoir cette perpendiculaire: Vous tracerés enfuite cette ligne du piquet $D$, à celuil $C$, par $l_{a} I^{c}$ ou $2_{2}$ Pratique, cette ligne fera perpendiculaire ou d'équerre à la ligne tracée $A B$.

\section{SIX I E'ME PR A T I UE.}

Tracer aves le cordeau, une ligne perperdiculaire à l'extremité d'une ligne droite tracée.

Aiant fur le papier la ligne $a b$ perpendiculaire à la ligne $b c$, qu'il faut tracer fur le terrain : pour y parvenir, de l'extremité $A$ de la ligne tracée $A B$, mefurés, fuppofé dix toifes, $8 *$ plantés-y un piquet comme $C$, prenés un cordeau double d'environ dix à douze toifes, paffés les deux boucles

I \&. VI. des extremités dans les piquets $A \& C$, tirés la boucle du milieu vers $E, \&$ plantés-y un piquet, retirés enfuite la bouche du piquet $A$; paffés dedans un autre piquet, \& tendant le bout de ce cordeau jufqu'à ce que vous foiés d'alignement avec les piquets $E \& C_{2}$ comme au point $G_{2}$ plancés-y ce piquet? 
IA PRATIQUE DU JARDINAGE. ro7 \& tendés un autre cordeau du piquet $A$ à celui $G$, la ligne $G A$ fera perpendiculaire à la ligne $A B$.

\section{R E M A R QUE.}

On peut élever cette perpendiculaire à l'extremité d'une ligne par le moïen du demi-cercle, en le pofant à plomb au-defius du piquet d'une des extrémités, \& alignant la bafe vers l'autre extremité, \& l'alhidade étant pofée fur le 90 dé grés, l'on opérera comme en la Pratique $\mathrm{g}^{\mathrm{e}}$.

\section{SEPTIE'ME PRATIQUUE.}

\section{Tracer aves le Cordeau, une ligne parallele is une ligne droite tracée.}

Soient les deux lignes paralleles fur le plan, $s, \& c d$ diftantes l'une de l'autre de $\mathrm{I} 2$. toifes, \& que la ligne droite $C D$ foit tracée fur le terrain. Elevés à chacune de fes extremités $C$ \& $D$ une perpendiculaire, fuivant la Pratique précedente, portés fur chacune la longueur de I 2 toifes, comme ici de $C$ en $E$, \& de $D$ en $F$, \& tracés du point $E$ à celui $F$ la ligne $E F$; elle fera parallele à la ligne $C D$.

\section{HU ITIE'ME PR A T IQUE.}

\section{Tracer avec le demi-cercle; une ligne parallele à une ligne droite tracée.}

Soient (comme en la précédente Pratique) les deux lignes paralleles fur le plan, $a b \& c d$, fuppofées diftantes l'une de I'autre de so toifes, \& que la ligne $A B$ foit tracée fur le terrain, à laquelle doit être tirée une paraliele à la même dif- Fra. VIII.

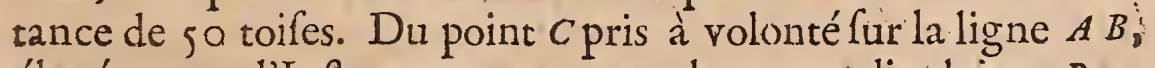
élevẹ́s avec l'Inftrument une grande perpendiculaire, Pratique $5^{\text {e }}$ tranfportés enfuite l'Inftrument au point $D$ éloigné du point $C$, de la diftance de so toifes, dirigés la bafe vers le piquet $C, \&$ l'alhidade étant fur 90 dégrés, alignés par fes pinules, un piquet rers $E \&$ un vers $F$, \& tracés la ligne $E F$; par la I e on 2 e Pratique, felon la longueur que cette ligne contiendra fur le plan.

FI6. VII.

PLANCUEII 
$R$ E M R QUE.

Quand on aura plufieurs lignes à tracer, paralleles à une niême, il ne faudra que porter les diftances des unes aux autres, foit felon ta Pratique $7^{\mathrm{e}}$, en élevant des perpendiculaires aux extremités, ou fuivant celle-ci, en fe retoumant d'équerre avec le demi-cercle, à chacun des points mefurés fug la grande perpendiculaire du milieu.

\section{NEUVIE'ME PRATIQUE.}

Tracer avec le cordeam, un angle égal à un angle maraué Jur le papier.

Mefurés fur le plan une löngueur à volonté, comme ici de huir toifes. Faites avec le compas, du point de l'angle $a$, un arc tel que $b c$ qui joigne les deux côtés de cet angle, $\& x$ FI d. IX. mefurés la difance des deux points $b \& c$, fuppofée de quatre roifes, qui eft ce qu'on appelle la corde de l'arc $b \& c$. Mefurés enfuite fur une ligne tracée fur le terrain, huit toifes, comme de $A$ en $B$, \& prenant un cordeau de quatre toifes, dont la boucle fera pafféc dans le piquet $A$, \& un de huit toifes, dont la boucle fera pareillement paffée dans le piquet $B$, on les joindra enfemble au point $C$, ou l'on plantera un piquet; après quoi l'on tracera la ligne $C B$ qui formera avec la ligne tracée $A B$, l'angle $A B C$ égal a celui du plan.

\section{DIXIEME PRATIQUE.}

Tracer avec l'Inftrument, un angle égal à un angle marqué furle plan.

Mefurés l'angle marqué fur le plan avec le Raporteur, en plaçant fon centre fur le point a \& fa bafe le long de la ligne

I \&. $x$. a $b$, comptés combien il fe trouve de dégrés depuis c jufqu'à $d$, comme 30 dégrés, rctenés ce nombre pour le rapporter fidélement fur le terrain, en fuppofant la ligne $A B$ tracée, \& le point $B$ celui d'oì doit être tracé langle égal à celui du Plan. Póés le centre du demi-cercle bien à plomb au-deffurs du poinz $B$, alignés fa bafe fur le piguet $A$, \& pofés l'alhi- 
IA PRATIQUE DU JARDINAGE. IO dade au point $C$, fur le même dégré que vous avez trouvé fur le papier avec le Raporteur ; par les pinules de l'alhidade vous ferés planter un piquet vers $D, \&$ tracerés la ligne $B D$, par celle des deux premieres-Pratiques, la plus convenable à la diftance qui fe trouvera de $B$ en $D$.

\section{ONZIE'ME PRATIQUE.}

Tracer avec le Cordeau, un triangle igal à un triangle marqué fur le plan.

Soir fuppofé le triangle $a b c$; mefurés chacun de fes côtés, \& les chiffres fur le plan, tracés enfuite la bafe $A B$ trouvée, $\mathrm{F}_{\text {s o. } \mathrm{x}}$ par exemple, de 10 toifes; prenés, fuivant la mefure des deux autres côtez, un cordeau de i 2 toifes de long, paffés: en la boucle dans le piquet $A, \&$ un de 9 toifes; dont vous pafferés la boucle dans le piquet $B$, \&xjoignant leurs extremités comme en $C$, plantés-y un piquet, tracés enfuite lẹs deux lignes $A C \& B C$, \& le triangle $A B C$ fera femblable à celıi du plan.

\section{PREMIERER.EMARQUE.}

Si le triangle a voit les trois côtés égaux, que l'on nomme Equilateral, il faudroit feulement prendre deux cordeaux, dont la longueur füt égale à celle de la bafe, aux extremités de laquelle il y auroit deux piquets où l'on en pafferoit les boucles, \& joignant par le haut les deux bouts de ces cordeaux enfemble, \& l'on planteroit un piquet oì ils fe croife. roient, \& l'on traceroit enfuite ces deux lignes.

$$
\text { SECONDEREMARQUE. }
$$

Si le triangle fe trouvoit tellement grand, qu'on ne pût le tracer avec le cordeau, il faudra mefurer un des angles, comme celui a avec le Raporteur, fuppofé de 50 dégrés, \& le côté $a^{\prime} b$ de 100 toíes, $\&$ a $c$ de 120 toífes. Après avoir tracé fur le terrain la ligne $A B$ de 100 toifes, par la 2 e Pra- F I S. XX T. tique, placés le demi-cercle au poinc $A$, en alignant $f a$ bafe fur le point $B, \&$ mettant l'alhidade fur go dégrés, vous alignerés par les pinules, des jalons \& vous mefurerés i 20 toilés du piquet $A$; Vous planterés à cette diftance-le jalon 
110. SECONDE PARTIE, CHAP. I: $C$, duquel vers celui $B$, vous tracerés la ligne $C B$, qui for mera avec les lignes $A C \& A B$ le triangle propofé.

\section{DO UZIEME. PRA T I QUE.}

Tracer un quarré long appellé Parallelogramme Rectangle.

Après avoir mefuré la longueur $a b$, \& la largeur $b c$ dur quarré long décrit fur le papier, \& les avoir cotté comme de is $\&$ de 8 toifes, il faut tracer la ligne $A B$ de is toifes, \&

Erc. XIr. élever à une de fes extremités comme $A$, une ligne perpenPraws. III. Pratique. Attachés enfuite un cordeau de I 5 toifes de long
aul piquet $C, \&$ un de $\&$ toifes au piquet $B$, croifés-les par. les extremités en $D$, où vous mettrés un piquet, \& tracés les lignes $A D \& C D$; elles formeront avec $A B \& B C$ le quarré long $\triangle B C D$.

\section{PREMIERE REMAR QUE.}

Si le quarré long fe trouvoit de beaucoup plus grand que celui-ci, l'on élevera avec l'Inftrument, deux perpendiculaires aux extremités de la ligne $A B$, fuivant la remarque de la $G_{e}$ Pratique, \& l'on fera chacune de ces deux perpendiculaires, égale à la largeur du quarré long.

$$
\text { SE C ON DE REM A RUE. }
$$

Pour tracer un quarré parfait, la Pratique eft la même que celle ci-deffus, à l'exception qu'il faut que les deux perpendiculaires foient tracées aufí longues que la bafe du quarré.

\section{TREIZIE'ME PR A T I QUE.}

Tracer avec le Cordean, une figure irréguliere de quatre côtés:

Suppofé la figure irréguliere $a b c d$, du point $a \&$ de l'inrervalle, $a c$, décrivés avec le compas un arc comme $c e, \&$. du point $b \&$ intervalle $b d$, faites un autre arc comme $d f$; mefurés les longueurs de $a b$, fuppofé de $2 g$ toifes, $a c$ de neuf; $b d$ de onze toifes, \& les cordes des arcs ou diftances de $c \in$ de ro toifes, $\& f$ de de I 4 toifes. Tracés fur le terrain la ligne 
IA PRATIQUEDU JARDINAGE. III ou bafe $A B$ de 25 toifes de long, portés de $A$ en $E$ neuf toi- Frs. XII X fes, \& de $B$ en $F$ I I toifes: Plantés deux piquets aux points $E \& F$, puis prenant un cordeau de neuf toifes attaché alz piquet $A, \&$ un de Io toifes attaché au piquet $E, \&$ on les. croifera par leurs extrémités au point $C$, où l'on plantera un piquet : On fera une femblable opération de l'autre côté, comme au piquet $B$, oì l'on attachera un cordeau de II toifes, \& un de I4 au piquet $F$, qu'on fera croifer pareillement par leurs extrémités au point $D, 8$ traçant les lignes $A C, C D \& D B$, elles formeront avec la bafe $\angle B$ le qua. drilatere propofé.

\section{QUA TORZIE'ME PRATIQUE.}

Tracer avee l'Inftrument, une figure irréguliere de quatre côtés.

Nous fuppofons que la figure quadrilatere $a . b c d$ eft conSdérablement plus grande que la précédente, comme fa bafe $a b$ longue de 100 toifes, le côté $c$ de 20 toifes, \& celui $b d$ de 30 . Méfurés avec le Raporteur, les deux ouvertures d'angle qui font fur la bafe a $b$; fuppofés ici l'angle $a$ de 60 dégrés, \& celui $b$ de 100 , chiffrés exactement toutes ces mefures fur le plan, \& tracés fur le terrain la ligne ou bafe $A B$. de 100 toifes de long, par la $2 e$ Pratique, placés enfuite le demi-cercle au piquet $A$, faites-y un angle de 60 dégrés, c'eft-à-dire, égal à l'angle ba $c$ du papier, par la I oc Pratique, donnés à fon côté $A C 20$ toifes felon le FIG.XI plan, plantés-y le piquet $C$ : faites de même au piquet $B$ un angle de 100 dégrés; donnés à fon côtél $B$ D 30 toifes, plan tés un piquet en $D$, d'où vous tracerés jufqu'au piquet $C$, la ligne $D C$, \& elle formera avec les lignes $C A, D B, \&$ la bafe $A B$, une figure quadrilatere irréguliére, \& fembla: ble à celle du plan.

\section{$R E$ M R QUE.}

Toute figure de plufients côtés, telle qu'elle foit régtz liére ou irréguliére, eft appellée Poligone. Elles prennent letus nom du nombre de leur côtés, depuis le quarré jufqu’à la Figure de 12 côtés, après laqurelle les Poligones non plus de nom particulier. 
Le Poligone de s côtés"s'appelle Pentagone. celui de 6 ..... Hexagone. de $7 . .$. . Heptagone. de 8 . . . . Octogone. de 9 ... Ennéagone. de ro ...: ... Décagone. de II . . . Ondécagone. \& de I 2 . . . Dodécagone. QUINZIE'ME PRATIQUE.

Tracer avee le Cordeas, us Poligone tel qu'il foit.

Soit le Poligone régulier de cinq côtés appellé Pentagone ; tirés de fon extrémité ou angle fupérieur a, deux lignes aux excrémités $b$ \& $c$ de $f_{a}$ bale, qui formeront le triangle $a b$ c. Mefurés une de fes deux lignes feulement, la chiffrés fur le plan, l'autre lui étant égale. Tracés enfuite fur le terrain le triangle $C D E$ femblable à celui $a b c$ du Fi G, Xv. papier, par la xIe Pratıque. Prenés deux cordeaux égaux à la bafe $D E$, paflés-en les boucles dans le piquet $C \& D, \&$ les faites croifer, ils vous donneront le point $G$. Tranfportés ces deux cordeaux aux piquets $C \& E$, \& les faites pareillement croifer, ils vous donneront le point $F$, où vous planterés un piquer aufi-bien qu'en $G$. Tracés les lignes $D G, G C$, C F \& FE, elles vous formeront avec la bafe $D E$, un Pen. tagone régulier femblable à celui a du plan.

\section{$R E M A R Q U E$.}

Pour tracer tel autre Poligone que ce foit, il faudra le réduire en triangle comme en la figure précédente, \& raporter cnluite chacun de ces triangles l'un après l'autre fur le terrain, dans le même ordre qu'ils font fur le papier ; ce qui fe doit entendre aufli-bien pour les Poligones irréguliers, que pour les réguliers, la différence étant que dans les Poligones réguliers les triangles font égaux, \& dans les irrégüWers ils font inégaux. 
LA PRATIQUE DU JARDINAGE. IIS

SEIZIE'ME PRATIQUE.

Traser avec l'Isaftrussert tel poligone que ce foit.

\author{
O B SER VATIO N.
}

Cette Pratique fe peut faire de deux différentes manieres : car il peut arriver que la bafe du Poligone foit tracée fur le zerrain, ou que l'on ait un point fixé où fon centre doit être placé.

\title{
PREMIERE OPERATION.
}

Soir la ligne $B C$ tracée, égale à un des côtés de l'Octogone $a$, fuppofé de I 5 toifes quatre pieds; mefurés fur le papier avec le Raporteur, un des angles formé par la rencontre de deux des côtés de l'Octogone, comme $c b \& b i$, c'eft ce FIG. XVI. qu'on apelle l'angle da Poligone ; placés fur le terrain le demi cercle au point $B$, oì vous ferés un angle égal à celui de l'Octogone, qui eft de 135 dégrés, fuivant la Table ci-deffous; donnés à fon côté $B I_{1}$ I 5 toiles quatre pieds, qui ent la longueur de la bafe $b c$ da plan; faites la même opération aux points I HGFED, oì vous mettrés des piquets, \& tracés les côtés de ce Poligone d'un piquet à l'autre, ce qui le rendra régulier \& femblable à celui a du papier.

\section{SECONDE OPERATION.}

Si l'on a feulement le centre de l'Octogone déterminé fut le terrain, comme le piquet $A$, il faudra tirer fut le plan des lignes du centre a à tous les angles du Poligone; prenés la loggueur d'une de ces lignes apellées raïons comme $a i$, les autres lui étant égales, \& toutes fuppofées de 20 toifes; enfuite mefurés fur le plan avec le Raporteur, l'angle formé Ers. XV.I par la rencontre de deux de ceslignes ou rä̈ons, au centre a, comme $a b z \approx a$, qui eft de 45 dégrés fuivant la Table, \& eft apellé l'angle du centre. Polés fur le terrain le demi - cercle au centre ou piquet $A, 8 x$ marqués de fuite huit angles de 45 degrés, par la 10e Pratique; fur chaque ligue de fes angles mefurés depuis le piquet $A$ zo toifes, \&z plantés-y des piquets. Tracés enfuite des lignes d'un poquet à l'autre, elles formesont un Octogone regulier femblable à celui du plan.

$$
\text { PREMIERE REMARQUE. }
$$

Comme il arrive quelquefois qu'on fe trouve embarraffé 
Ir SECONDE PARTIE, CHA P. I. en traçalat un Octugone, parce qu'une de fes pointes fe preä fente devant une allée, au lieu d'une de fes faces, voici ce qu'on doit faire pour le redreffer.

518. X Y I. On fuppofe d'abord la ligne milieu $K L$ tracée fur le terrain; \& le Centre $A$ déterminé, d'où au lieu d'ouvrir l'Inftrument de 45 dégrés, qui eft l'angle du Centre de lOctogone, on ne l'ouvrira que de la moitié 22 dégrés $\frac{*}{2}, \&$ l'on arrêtera par un piquet, le Raïon $A B$ d'une longueur convenable à la grandeur qu'on voudra donner au Poligone; l'on reportera enfuite de l'autre coté, la diftance du piquet $B$ à la ligne nilieu. $\pi L$, en fe retournant d'équerre, ce qui déterminera le piquet $C \&$ toute la face du Poligone que l'on achevera par l'une des deux operations précedentes.

On peut redreffer de cette maniere tous les Poligones regut: liers, dont le nombre de côtés eft pair, en prenanr le demiangle de leur centre.

$S E C O N D E R E M A R Q U E$.

Pour rendre certe feiziéme Pratique commune à tous les Poligones réguliers, mème pour le triangle \& le quarré, jufqu'à la Figure de douze côtés ou Dodécagone, l'on aura recours à la Table fuivante, oiz font compris les angles du Poligone \& ceux du centre, \& il fuffira de mefurer ou l'un des côrés du Poligone, ou la ligne tirée de fon centre à l'un de fes angles, c'ent a-dire le raion.

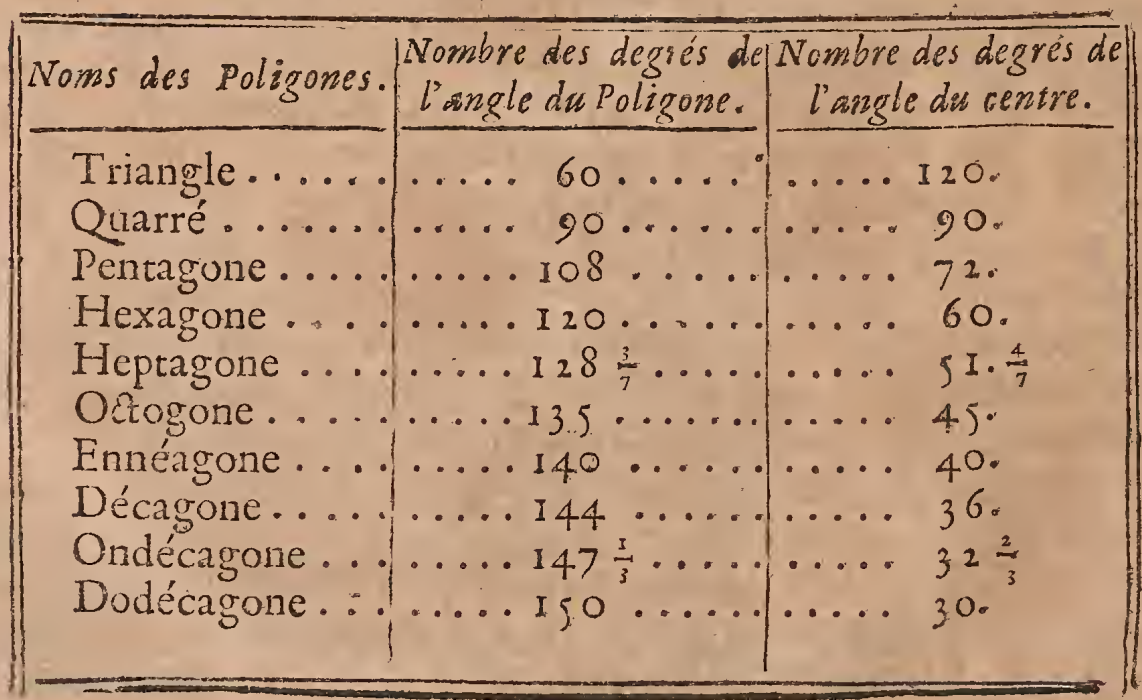




\section{LA PRATIQUE DU JARDINAGE. IIS}

\section{'TROIS I E'ME REMARQUE.}

'A l'égard des Poligones irréguliers, on pourra fe fervir des moyens enfeignés dans cette Pratique, foit en les divifant en triangles, d'un point ou centre pris à volonté au dedans d'iceux, dont on mefurera avec le Raporteur tous les angles, \& tous les rayons tirés aux angles du Poligone, aufquels on donnera fur le terrain les mêmes ouvertures.\& longueurs trouvées fur le plan, ou bien en mefurant chaque angle du Poligone avec le Raporteur, \& enfuite fes côtés comme on Le vient de dire ci deffus.

\section{DIX-SEPTIE'ME P.RA TIQUE:}

\section{Tracer us cercle fur le Terrain.}

Stxppofant que le piquet $A$ foit le centre du cercle que Pon veut tracer ; mefurés fur le plan la diftance du centre à la circonférence, comme depuis a jufqu’à $b$, fuppofée de fix toifes, qui eft le demi-diametre ou raîon; paffés la boucle d'un cordeau de fix toifes de long au piquer $A, \&$ mettés la F I G. XVits. pointe dut traçoir dans une boucle qui doit être faite à l'autre extremité $B$. Promenés le cordeau \& le traçoir tout autour du centre $A$, jufqu'à ce que vous rejoigniés l'endroit d'oir vous êtes parti comme $B$ : par ce moyen vous tracerés entiérement votre cercle, en obfervant que le cordeau foit toûjours également tendu fans que rien ne l'arrête, \& tenant toujours le traçoir dans une même difpofition fans écarter fa poince ; outre cela faites tenir le piquet $A$ du centre, par un homme qui l'entretienne dans fon à plomb, de craintequ'en bandant trop le cordeau, on ne le fir obéir, ce qui rendroir Le cercle plus grand que celui du plan.

\section{R E M A R QUE。}

Il eft aifé de comprendre que l'aplication de cette Pratique peut fe faire, pour tracer des demi ou quarrs de cercle ¿ généralement telle portion circulaire que ce foit.

\section{DIX-HUITIE'ME PRATIQUE.}

Iracer un ovale furle Terrain.

Do l'Ovale a fur le papicr, dont le grand diametre feulez $P \mathrm{ij}$ 
ment eft déterminé de 12 toifes 5 tracés fur le terrain la ligne $A B$ de 12 toifes de long, \& la partagés en trois parties égales, où vous planterés des piquets comme aux points $C \& D$ Prenés un Cordeau de la longueur de $D B$ ou de $C A$, avec lequel vous tracerés legerement deux cercles, dont les cen= \$10. XVIII. tres feront aux piquets $C \& D$, lefquels cercles fe croiferont aux points $E \& F$, oi vous planterés deux piquets, \& les points $C D E F$ feront les quatre centres de l'Ovale. Attachés un cordeau au piquet $F$, qui rafe $\&$ effleure celui $D$, alignés le fur les piquets $F \& D, \&$ l'étendés jufqu'à ce qu'il coupe la circonférence d'un des deux cercles, en un point oì vous planterés un piquet comme en $G$; faites la même opération: de l'autre côté, pour planter le piquet $H$ fur la círconférence, \& du centre $F$ fans changer le cordeat, tracés l'arc $G H$, jufqu'à ce que vous rencontriés les piquets $G \& H$. Changés le cordeau \& le raportés au piquet $E$, où vous pratiquerés la même chofe, pour planter les piquets $L \& I$, \& tracer l'arc $I L$ : \& joignant ces deux traces aux deux portions circulaires des extremicés $A \& B$, vous effacerés le refte de ces cercles marqués par des points, qui fe trouvent au dedan de l'Ovale, qui demeurera feul apparent.

\section{DIX - NEUVIE'ME PRATIQUE.}

Tracer un ovale; dont les deux diametres foient désermints Jur le papier.

Soit l'Ovale $a \bar{b} c d$, dont le grand diametre eft de so toifes \& le petit de $x_{2}$, chiffiés fur le papier. Tracés fur le terrain la ligne $A B$ de 20 toifes de long, qne vous terminerés par des piquets; divifés-la en deux parties égales comne au pon $E$, fur lequel vous éleverés la perpendiculaire $C D$ de 12 toifes de long, par la 4 e pratique, en portant fix toifes de chaque côté du point $E$; prenés enfuite une des moiciés $E C$ de cette perpendiculaire arec un cordezu que vous tendrés fur le grand diametre $A B$, en commençant à l'une de fes exere-

I G. XiX. mirés, comme depuis le point $B$ vers $F$ ivivifés l'elpace qui refte depuis $F$ jufqu'au point milieu $E$, en trois parties égales; reportés fur $\mathrm{l}_{\text {a }}$ méme ligne une de ces parties, au-delà du. point $F$, conme en $G$ : Prenés la diftance qu'il y a depuis le
point $G$, jufqu'au point milieu $E$, $\&$ portés-la de l'autre côté 
LA PRATIQUEDU JARDINAGE. 117 comme depuis le poinc $E$ jufqu'à celui $H$; plantés-y des piquets que vous alignerés fur ceux des extremités $A \& B, 8$ de ces deux piquets $G \& H$, tracés les deux triangles Equilatéraux $H$ IG \& $H L G$, fuivosnt la 1 Remargue de lax se Prati. que. Prolongés enfuite les côtés de ces triangles, par des lignes indéterminées, que vous tracerés legerement comme I $H N$ \& I G $M$, \&C. les quatre points $G H I L$ feront les centres, d'ou vous tracerés l'Ovale de cetre maniere. Paffés la boucle du cordeau dans le piquet $G$, étendés-le jufqu'au piquet de l'extremité $B$, \& tracés une portion circulaire jufqu'aux lignes indéterminées $M \& P$, qui arrêteront la trace. Reportez enfuite ce cordeau de la même longueur à l'autre côté oppofé, \& paffés-en la boucle dans le piquet $H$, d'où vous tracerés une autre portion circulaire, avec la même obfervation d'arrêter la trace à la rencontre des lignes indéterminés $N \& O$. Fichez de petits piquets dans la fection de ces lignes, comme aux quatre points $M P N O$. Prenez enfuite un cordeau plus long, paffés-en la boucle dans le piques $I$, ajuftés-le de longueur au point $D, \&$ tracés l'arc $N D M$ 。 jufqu’à ce que vous trouviés la trace, \& les piquets des portions circulaires, où le traçoir doit rentrer jufte. Achevés de tracer la circonférence de l'Ovale, en reportant la boucle du cordeau de l'autre côté, \& la paffant dans le piquet $L$, đ’oì vous décrirés pareillement l'arc $O C P$ : Ces deux arcs qui fe joindront aux deux portions circulaires, fermeront entierement l'Ovale, après quoi l'on effacera les lignes qui n'ont fervi qu'à la conftruction, afin qu'il ne refte quela feule trace de l'Ovale, qui fe trouvera proportionné $z$ femblable à celui du plan, qu'on fuppofe avoir été tracé par la même Pratique, dont on fe fert ordinairement furle papier.

\section{REMARQUUE。}

Quand on a deux Ovales à tracer l'un dans l'autre, comnes pourroit être l'allée ovale autour d'un baffin ovale, après avoir tracé le premier ovale du baffin, Juivant la pratique. précédrate , l'on n'aura qu'à alonger les lignes des fections , de la largeur qu'on veut donner à l'allée, \& des mêmes Centres tracer le fecond Ovale, qui doit être paralelle au pres mier. 
II SECONDE PAR TIE, CHAP. I,

VINGTIE'ME ET DERNIERE PRATIQUE:

Tracer fur le Terrain un Ovale apellé communément l'Ovale du Jardinier.

Si l'on veut tracer un Ovale à volonté, fans avoir aucun plan, ou que l'on en ait un fur le papier, tel que l'Ovale a dont les diametres ne foient point déterminés par des chiffres; tracés fur le terrain la ligne $A B$, que vous terminerés par des piquets, \& prenés-y une longueur à volonté environ du tiers, comme depuis $A$ jufqu'à $C$. Reportés cette même longueur depuis l'extremité $B$ jufqu'en $D, \&$ plantés deux piquets fixes \& ftables à ces deux points $C \& D$, qui feront les deux centres de l'Ovale. Prenés un cordeau fans boucles, tournés-le autour du piquet $D$, \& l'étendés en double jufqu'

F.t. Xx. l'extremité $A$, où vous joindrés les deux bouts par une boucle, dans laquelle vous pafferés le traçoir. Promenés \& faites aller ce traçoir d' $A$ en $E$, d' $E$ en $F$, d' $F$ en $G, \& c$, en prenant garde que le cordeau foit toujours bien tendu égalenient, \& qu'il gliffe \& tourne librement à l'entour des deux piquets $C$ $\& D$. Continués toujours à faire marcher le cordeau \& le traçoir, jufqu'à ce que vous rejoigniés le piquiet $A$ d'où vous ériés parti ; \& par les différens triangles que le cordeau formera fucceffivement, en s'alongeant ou en fe racourciffant, il tracera l'Ovale fans être changé, fuivant la plus ordinaire méthode des Jardiniers, ce qui lui a fait donner ce nom.

$R$ EMARQUE。

Si l'on vouloit faire paffer l'Ovale du Jardinier par 4 points donnés fur le terrain, il ne s'agir que de trouver les deux centres: on fuppofe que ces 4 points font les extremités des deux diametres $A B, F H$, il faut avec le cordeau prendre la longueur $B K$, ou $A K$ moitié di grand diametre, \& la porter

Ir. X x à l'extremité $F$ ou $H$ du petit diametre, $8 x$ de -là comme centres décrire avec le traçoir des arcs de cercle coupants la ligne $A B$ aux points $D \& C$, qui feront les deux centres ou foiers d'ou l'on tracera l'Ovale, fuivoant la pratique précédente.

Oa ne donne point icí de démonftration de toutes ces Pratiques; elles font affés connuës dés perfonnes un peu verfées dans la Geometrie: A l'égard des Curieux \& des Jardiniers qui s'en ferviront, ils doivent être perfuadés qu'elles font certaines \& fondées fur de bons principes, 


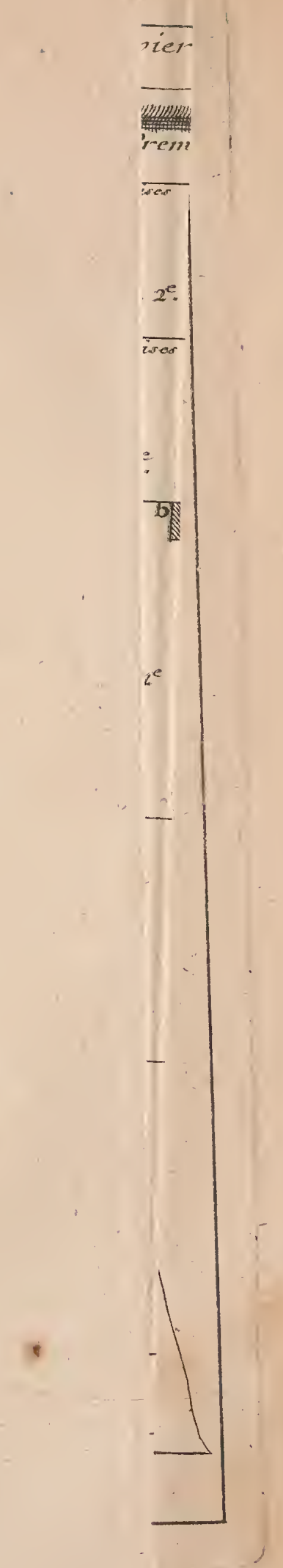





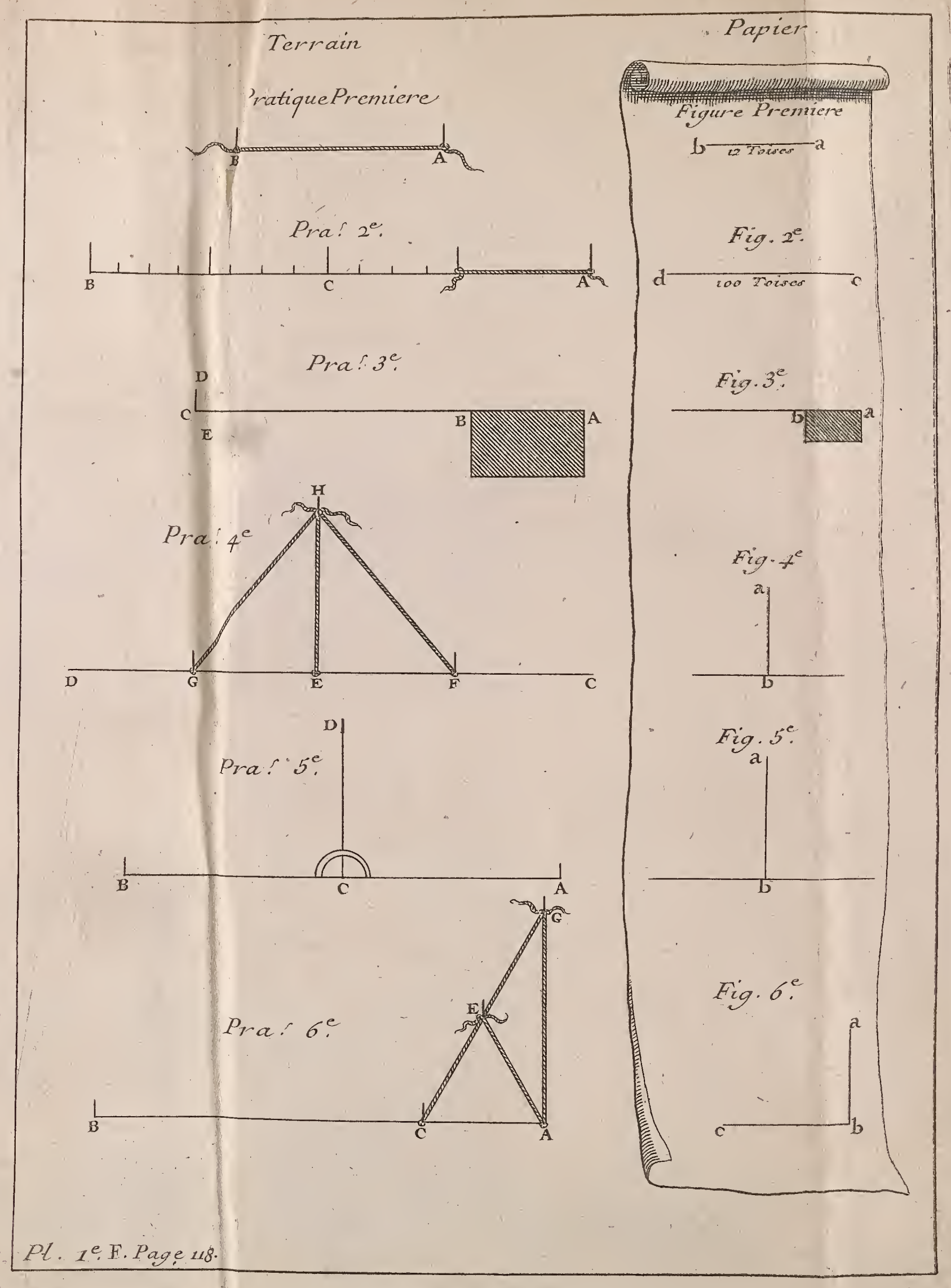




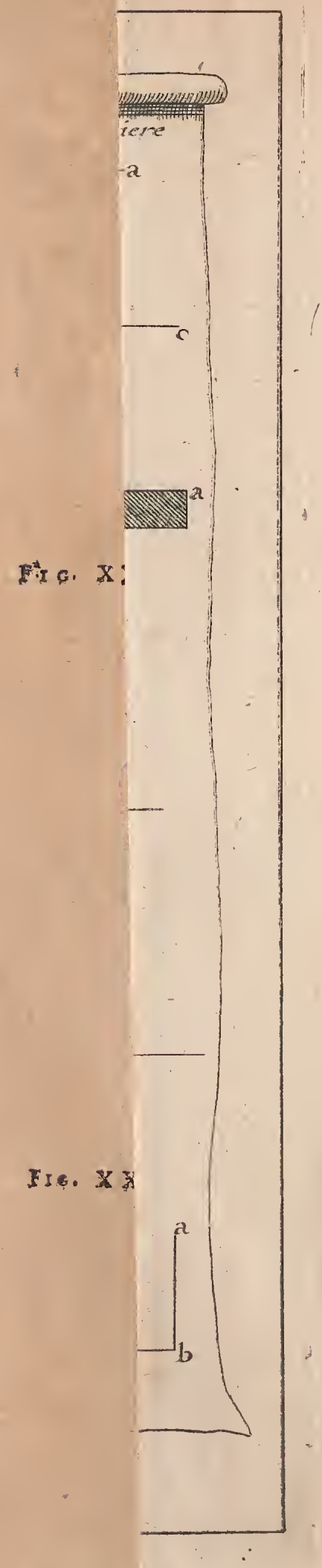




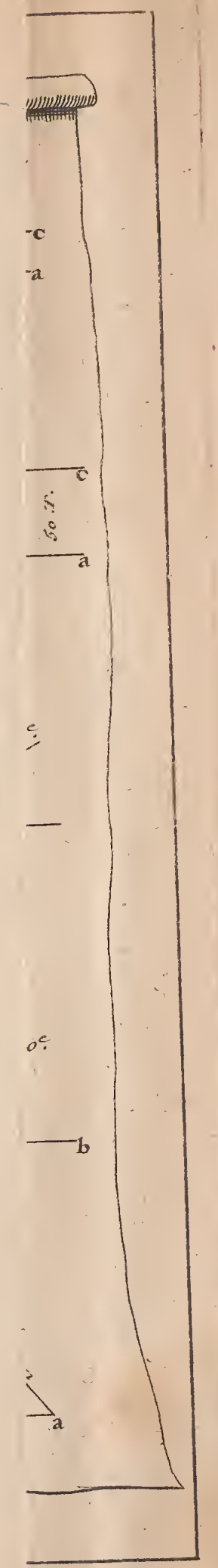

$\therefore \quad \therefore$ a 



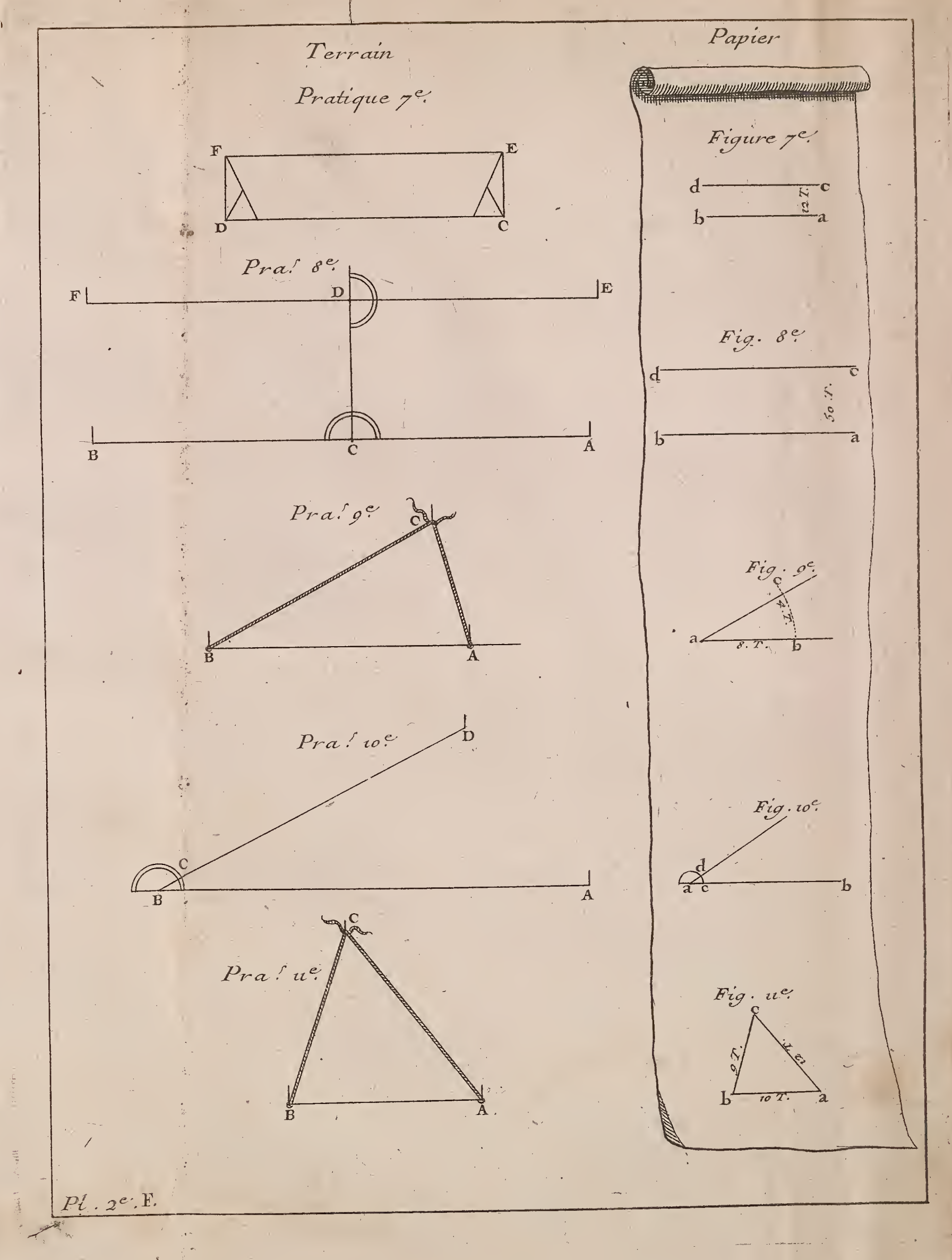





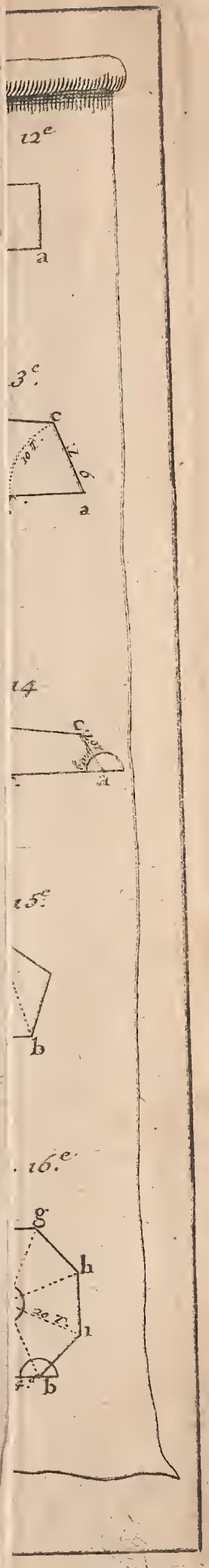





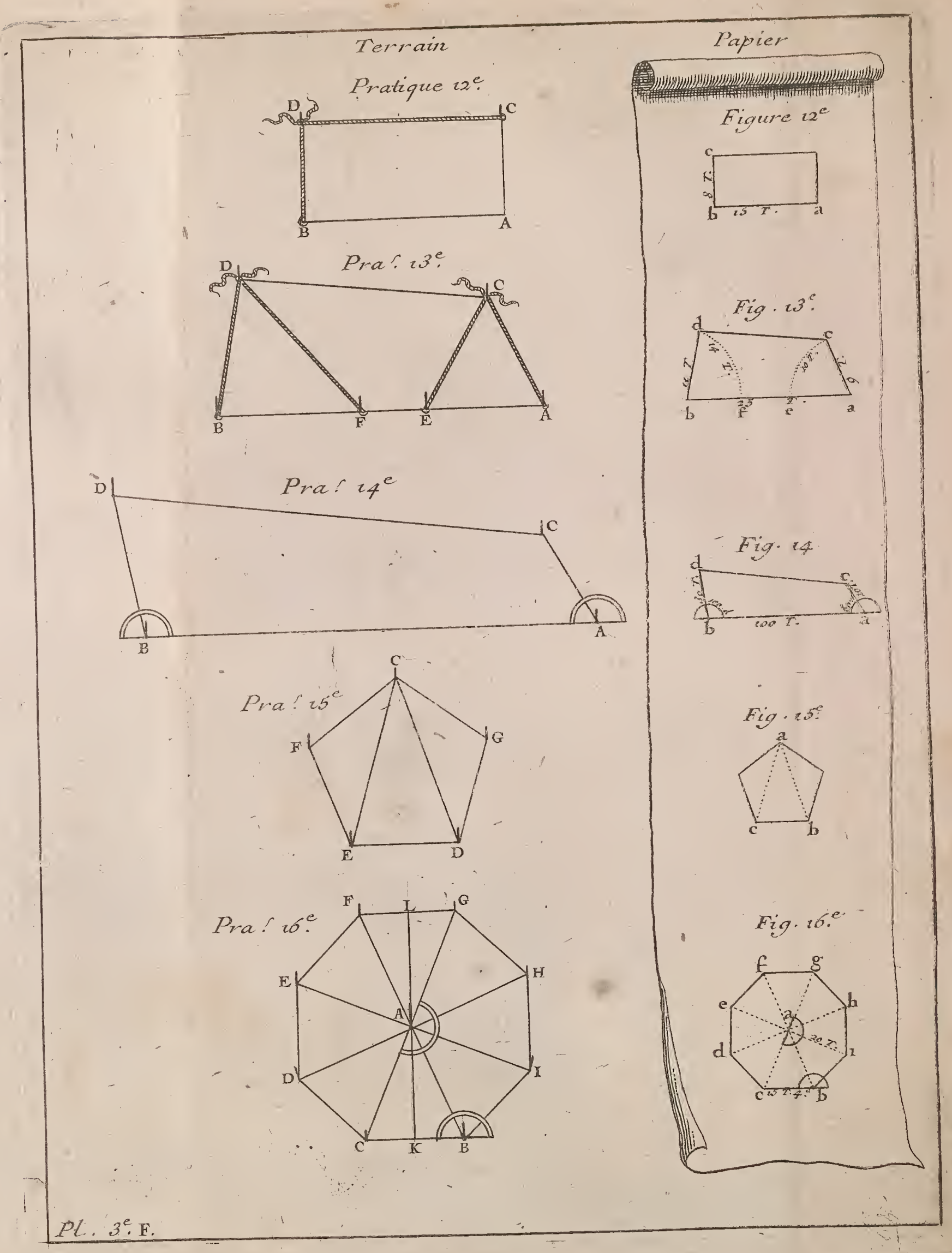





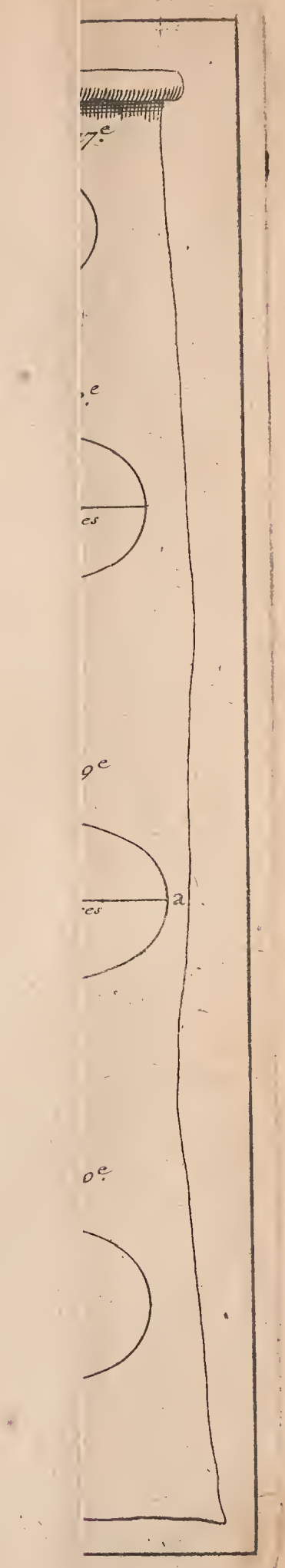





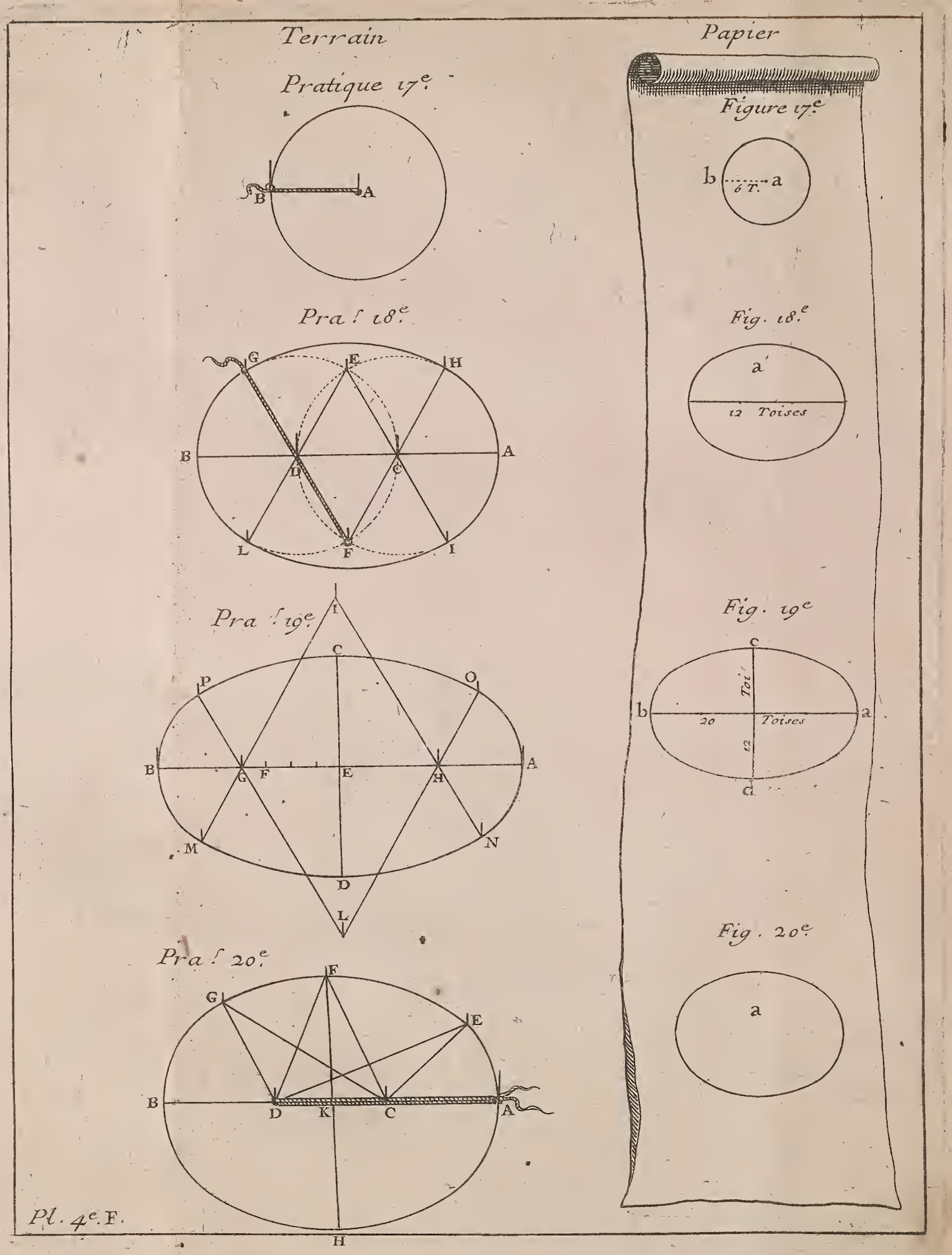





\section{H A P I T R E II.}

\section{$D E \quad L A \quad M A N I E R E \quad D E$ drefer un Terrain, é de foüiller er tranjporter les terres.}

U AND on atira fait choix d'un terrain, \& qu'ors en aura déterminé l'étenduë pour l'enclorre de murs, on travaillera à le dreffer, \& à le mettre le plus de niveau qu'il fe pourra. Comme les terrains fur lefquels on fe propofe de travailler, fe trouvent prefque toujours inégatux \& irréguliers, on eft indifpenfablement obligé, ou de les dreffer fuivant leur pente naturelle, ou de les mettre parfaitement de niveau.

On apelle dreffer un terrain fur fa pente tiaturelle, lorfo qu'en fuivant la fituation du lieu, fans enlever de terre, nii en raporter confidérablement, on ne fair qu'en remplir les cavités, \& en arraler les buttes, en forte que le terrain fe trouve égalé \& dreffé par tout fuivant fa pente.

Dans les Jardins fecs \& pierreux, il faut donner très-peu de pente, afin de profiter de toute l'eau du ciel \& des neiges fonduës; mais dans les terrains humides, un peu plus de pente fert à les égoûter, \& même dans les terres noyées, on fait des faignées \& des canaux tout au tour, pour les def fécher, \& par là les rendre fécondes.

On apelle mettre un terrain parfaitement de niveau, lorfs qu'on le dreffe par le moyen d'un inftrument apellé Niveau, avec tant de précifion, qu'il ne refte aucune pente dans toute fon érenduë.

Il fe trouve rarement des terrains qu on puiffe mettre parfaitement de niveau : outre leur fituation ordinaire qui eft toujours inégale \& un peu en pente, la dépenfe qu’on feroir obligé de faire ponr enlever les parties trop élevées d'un lieu pour les tranfporter dans les baffes, empêche qu'on ne recher: 
On a fait cette obfervation en dreffaut le Jardin des Tuileries.
I20 SECONDE PARTIE, CHA P. II: che cette perfection de niveau. L'on aime mieux les dreffer fuivant leur pente naturelle, qu'on rend douce \& imperceptible à la vî̀̈, \& peu laffante pour la promenade; ce quięt d'autant plus utile que cette pente fert d'écoulement aux ravines \& aux eaux de pluie ; \& que s'il y a des bafins, ils fe déchargent les-uns dans les autres, \& font coujours pleins; leur eau fuperfuë s'écoulera par là, fans être obligé de faire des puifarts pour les perdre. Cependant comme l'on eft obligé quelquefois de metre certaines parties d'un Jardin bien de niveau, comme les Allées autour d'une piece d'eau ou d'un mail, on en donnera ici la Pratique.

Onfe fert de plufieurs inftrumens pour niveler furleter main, leur nombre ef: infini, puifque chacun en invente à $f_{\infty}$ maniere. A entendre parler la plúpart des gens, il n'y a ancun niveau de jufte que celui quils ont inventé, \& dont il $\$$ confeillent l'ufage à l'exclufion de tous les autres: comme dans le Jardinage l'on ne s'amufe point à tous ces rafinemens \& que l'ufage \& la facilité d'un niveau eft ce qu'on doit le plus confiderer , on n'en propofera que deux, le Niveau d'eau $\&$ le Niveau ordinaire.

Le Niveau d'eau eft le meilleur \& le plus jufte, auflis'en fert-on pour prendre les hauteurs \& les penees confidérables; fur tout par raport aux eaux que l'on veut conduire dans un Jardin, C'eft pour cela que nous n'en parlerons point ici; l'on réferve à en démontrer l'ufage dans la 4 Partie de cet Ouvrage, qui traite des Fontaines \& de la conduite des Eacux.

Le Niveau ordinairc ou commun, quoiqu'inférieur $\&$ moins jufte que l'autre, ne laiffe pas ceperidant de l'être affés pour mettre de niveau tout un Jardin entier. C'clt de ce Niveau qu'on fe fert ordinairement dans le Jardinage, l'ufage en eft fort aifé , \& la facilité d'en trouver par tout fait qu'on s'en fert plus volontiers que d'un autre.

Pour connoître fi cette Equerre eft bonne, après l’avoir polée d'un côté, le plemb jufte dans l'entail. le, on la retourne de
Cet Inftrument n'eft autre chofe qu'tune Equerre ou Niveau femblable à celui dont fe fervent les Maçons \& autres Ouvriers, comme cette Figure le démontre íci. Plus cette Equerre eft grande \& mieux on opere: Cependant a trois pieds de longueur pour chaque branche, elle devient fuffifament grande. Quoique l'ufage en foit fort commun, on a jugé à propos de le mettre ici pour l'inftruction des Curieux \& des 
jeunes gens, qui veulent fe perfectionner dans le Jardinage, en y corrigeant de méchantes pratiques qui fe font introduites parmi les Jardiniers, \& en y ajoûtant des particularités trouve de mê peu connuës, \& qui tendent à une plus prompte \& plus parm faite execution.

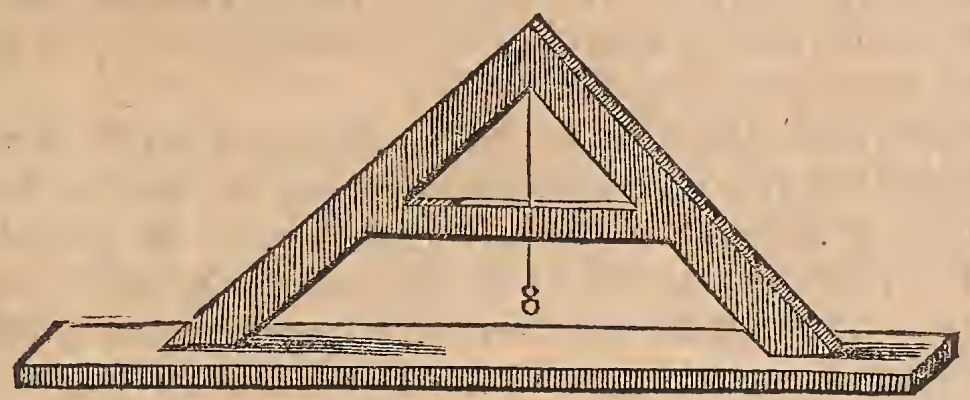

Mais avant que d'en venir àl'ufage de ce Niveau furle terrain, il eft à propos de faire les obfervations fuivantes.

Les mots de dreffer, unir, égaler \& planer, s'emplö̈ent également pour fignifier l'action de paffer la herfe ou le rateau. fur la terre, afin de l'égaler \& unir par tout.

On apelle plomber la terre, quand en la battant avec de gros rouleaus de bois, ou en marchant \& pietinant deffus. on l'affermit de maniere, qu'elle ne puiffe s'affaiffer \& baiffer davantage.

Pour aligner, niveler ou tracer, il faut être au moins trois ou quatre perfonnes enfemble, les uns pour porter les jalons, les changer \& remuer felon la volonté du Traceur ou Niveleur, les autres pour tendre \& changer le cordeau. L'on obfervera qu'il ne faut point parler en travaillant, fur tout dans les grandes diftances, ou la voix fe perd facilement, comme il eft difficile de s'entendre de fi loin, on aura des fignes dont on conviendra enfemble, \& l'on fera connôtre avec la main tout ce qu'on voudra dire. Par exemple, fi en alignant un jalon fur une ligne, \& qu'il verfe du côté gauche, il faut montrer avec la main en la menant du côté droit , que ce jalon doit être redreffé du côté droit ; comme aufi en hauffant ou baiffant la main, fignifier qu'il faut baifrer ou hauffer un jalon: Ceci eft un exemple qui peut fervir à tout ce qui fe peut faire entendre par fignes. 


\section{8}

SECONDE PARTIE, CHAP.II.

Il faut faire choix d'un jour propre a niveler, comme un tems calme, fans trop de chaud ni trop de froid, fans vents, fans pluie \& fans grand foleil : touces ces chofes nuifent fort à-la vûe. , par lęs réfractions qui caufent bien des différences, en abaiffant ou élevant le raion vifuel. Un tems un peu fombre \& couvert eft le plus favorable pour bien niveler, carles

Il y a des מiveaux के L।b. Deste.

$\because$ l.es Ouriers conmu. nément difent faire use hefsase. jalons en paroiffent mieux, \& les yeux diftinguent plus facie. lement les objets éloignés.

On met ordinairement du linge, du papier ou de la carte fur la tête des jalons, en les fendant un peu \& y faifant entrer ce papier on cette carte, cela facilite la vụ̂e \& \& la foulage très-fort, furtout dans tri long alignement. Quand le papier \& le linge ne paroiffent pas affés, on fait tenir par un homme, un chapean derriere le jalon; alors le blanc du papier par l'opofition du noir du chapeau paroîtra bien plus, \& par ce moïen le Bornoïeur pourra diftinguer facilement toures les têtes des jalons.

Il eft de très-grande conféquence dans le nivellement, que les têtes des jalons foient bien aplaties \& d'égale hauteur: car la ligne de mire doit paffer par deffus toures les têtes, \& les rafer uniment, ce qui regle le niveau de la fuperficie des terres.

On apelle butter un jalon, quand étant fiché en terre, il fe trouve être trop haut à la mefure requife, comme fi un jalon avoir fix pieds hors de terre, \& qu'il ne dût en avoir que qua. tre ou cinq felon le nivellement; alors on y fair aporter de la terre dont on fait une butte au pied, jufqu'à ce qu'il foit à la hauteur néceffaire; de mêtne, quand un jalon eft trop bas, un le fait décharger du pied, en ôtant.de la terre jufqua ce qu'il foit de hauteur.

Il eft à remarquerque quand on parlera de faire une rigole, un räion ou repaire *, ce n'eft pas d'ouvrir la terre, comme pour planter des paliffades, ce qui fe doit plûtêt apeller une tranchée, mais c'eft de faire aporter des terres le long d'un cordeau tendu d'un jalon à un autre, pour former une rigole qui fert à dreffer un terrain inégal. Ces rigoles doivent avoir un ou deux pieds de large; l'on marche fur la terre pour la plomber, enftiite on la paffe au rateau fin, juffqu’à ce que le cordeau touche \& effleure la fuperficie de la terre également par tour' 
IA PRATIQUE DU JARDINAGE, I 23 fans être forcé. Ces rigoles quelquefois fe coupent en terre ferme, quand le terrain eft trop haut, non-fewlement dans un païs plat, mais encore furles talus \& glacis; alors on tend un cordeau, \& l'on coupeles terres, jufqu'à ce qu'il touche égalemenr par tout.

Onfe fert de petits piquersque l'on enfonce rez-terre, \& à tête perduës aux pieds des jalons,en pofant deflus la mefure reglée, \& les mettant juftes à cette hauteur, quand on ne veut point butter ou décharger les jalons, cela eft arbitraire. Ces petits piquets fervent à retrouver les mefures, en cas que les grands jalons foient démarés, ou qu'on les ôte volontairement par rapport à l'embarras; on pofe le cordeau deffus, en le tendant d'un piquet à l'autre, pour faire des rigoles ou repaires.

Qand le terrain eft trop inégal \& trop raboteux, on commencera avant toutes chofes à le labourer à la charruë , pour couper les mauvaifes herbes; enfuite l'on y paffera la herfe partout, pour arrafer les buttes \& remplir les cavités. Cela fervira encore à rendre la terre plus maniable, tant pour la remuer \& tranfporter , que pour y enfoncer les jalons \& piquets neceffaires.

Il ne refte plus, avant que de paffer aux Pratiques du $\mathrm{Ni}$ vellement, qu'à parler de la maniere de foüiller \& de tranfporter les terres.

Quand on veut foüiller \& couper des terres pour faire une Terraffe, un Talus, creufer un Boulingrin, un Canal, \&c. on fe fert de befoches, de pioches, de houës \& de pelles, l'on a des hommes qui vont derriere cetx qui foüillent, \& qui ne font que charger les paniers, les hottes \& les broüet tes. Pour avancer dans ce travail, fuppofé que l'on ait de grandes hauteurs à couper, on fappe avecla pioche au pied de cette hauteur, \& l'on creufe un peu avant en deffous, avec cette précaution, de ne point marcher fur le haut de la terre, de crainte qu'elle ne s'éboule \& ne bleffe ceux qui travaillent au. pied. Quand on a un peu avancé de creufer tnut autour, on fait retirer les hommes de deffous, \& l'on monte fur le haut des terres, où l'on enfonce quelques morceaux de bois , \& fe mettant quatre ou cinq hommes à pefer deffus, vous faites tomber de grands quartiers de terre tout d'un coupa 
24. SECONDE PARTIE, CHA P. II. L'experience a fait conoître que cette maniere avance fort l'ouvrage. Quand on rencontre des roches \& des carrieres, on fe fert de poudre à canon pour les faire fautér en l'air, en gliffant cette poudre, dans des fentes pratiquées dans le rocher, ou bien mettant au pied quelques petits barils de pourdre, oit l'on met le feu par des amorces \& traînaffes; c'eft ce qu'on apelle miner.

On doit laiffer des buttes apellées témoins, en foüillant les terres, jufqu'à ce que l'ouvrage foit entiérement fini : cela: fert à toifer la vuidange des terres, \& à payer lesTerraffiers, qui ne laiffent pas fouvent que de tromper, en relevant ces témoins par les terres dont ils les chargent par deffus On paye ces Terraffiers à la toife cube, qui doit avoir fix pieds de tous lens, \& contenir en tout 2 I 6 pieds cubes, au lieu que la toife quarrée n'a que 36 pieds en fuperficie.

Venons à la maniere de tranfporter les terres, qui eft une chofe des plus nécellaire à fçavoir : on remarquera qu'il fau toujours les porter le plus près qu'il fe pourra, ces travaux étant très-longs d'eux mêmes, \& d'une dépenfe inconcevable, pour peu que le trajet foit long.

On peut trantporter les terres de quatre façons différentes, dans des tombereaux tirés par des chevaux, dans des paniers mis fur des ânes, \& dans des broüettes out des hottes fervies par des hommes. La meilleure des quarre eft fans doute celle qui va le plus vîte \& qui coûre le moins; c'eft la difficulté de la bien connoître.

Les deux premieres manieres font à préférer, quand le lieur où l'on tranfporte les terreseft fort éloigné ; quand il eft proche, les hottes \& les broüettes conviennent mieux : elles. embaraffent moins l'atelier que les tombereaux \& les ânes.

Les tombereanx à un cheval, contiennent environ 10 ou 12 pieds cubes de terre, \& valent chacun 5 à 6 voyages d'un âne qui porte 2 pieds cubes dans fes deux paniers, mais quelque frpputation qu'on faffe, les combereaux coûteront toûjours un peu plus.

Lorfque la diftance n'elt ni fort élorgnée ni fort proche, l'on peut fe fervir également des ânes, comme des broüetres \& deshottes, \& même la maniere d'employer des ânes paroît la meilleure, en voici la raifon. 
LA PRA TIQUE DU JARDINAGE TQ

Toutes les hottes \& broüettes contiennent environ un pjed cube de terre, les paniers que portent les chevaux \& les ânes contiennent environ la même quantité de terre; mais comme une âne a deux paniers, il porte le double de terre à la fois ; ainfi un voïage d'âne en vaut deux d'un hotteur oubrouietteur \& ne coûte pas plus, quoiqu'il faille une femme ou un petit garçon pour le conduire. Il y a encore une bonne raifon pour les préferer, c'elt que les ânes \&z les bourriques ne s'amufent gueres, ils font accoûtumés à un certain pas, qui quoique lent, ne laiffe pas d'avancer l'ouvrage, parce qu'il continuë du matin au foir, fans autre interruption que celle qu'on leur donne pour manger.

Si l'on veut fe fervir de Broüetteurs ou de Hotteurs, il faudra abfolument avoir des gens prépofés pour les faire hâter, c'eft ce qu'on apelle des Piqueurs, qui ont foin de les empêcher de fe parler \& de s'amufer enfemble, \& furtout, qu'ils ne s'embarraffent point l'un l'autre, en leur faifant faire differens chemins pour aller \& venir. Les Broüetteurs fe relaïent cing ou fix, \&z même plus, felon la longueur du chemin, "enfe donnant les broüettes pleines \& reprenant les vuides : c'eft un affés plaifant manege à voir.

La fituation des lieux affrujettic à l'une de ces quatre manieres; de forte qu'on ne peut plus choifir, comme feroit une defcente un peu roide fur un Côteau, où il faut abfolumene des Hotteurs, les tombereaux \& les autres y devenant pour lors fort inutiles.

\section{PREMIERE PRATIQUE。}

\section{Dreffer une ligne de niveau fur le Terrain.}

Suppofé que le terrain fe trouve dans ine fituation plate; comme feroit une

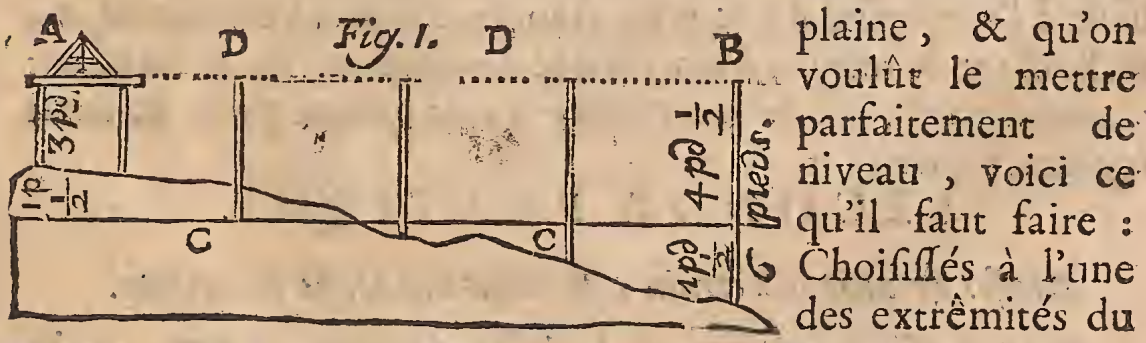
térrain, l'endroir qui lera le plus úni comme $A$, otz vous 
ficherés deux jalons de cinq à fix pieds de haut, dont les tê tes foicnt bien aplaties, pour metre deffus une regle de Maçon de huit à dix pieds de long, qui fera bien droite \& fans cambrure. Pofés fur le milieu de cette regle, votre miveau, comme on le voit à l'extremicé $A$, enforte que le plomb qui eft au bout de la petite corde, attachée au haut de ce niveau, fe trouve jufte, \& fe repole dans les deux entailles faites exprès dans l'angle, \& dans la traverfe de cet Inftrument. Si votre niveau hauffe plus d'un côté que de l'autre, du côté qu'il hauffera, enfoncés le jalon jufqu'à ce qu'il foit à la même hauteur que l'autre; reglés ainfí ces deux jalons, en les hauflant \& baiffant, jufqu'à ce que le niveau foit jưte. Enfuite ôtés le niveau de deffus la regle, metrésvous à l'extremité $A, \&$ mirant tout du long de la regle: faites pofer des jalons de diftance en diftance fur touite la longueur de l'enclos, comme depuis $A$ jufqu'à $B$, \&x les faites enfoncer ou relever de manicre, que leurs têtes paroiffent juftes à la hauteur de la regle, \& n'excedent point la ligne de mire $D D$. Mefurés enfuite le jalon de l'extremité $B$, dout la hauteur fera, par exemple de fix pieds : méfurés. pareillement l'un des deux jalons, qui foutiennent la regle a l'extremité $A$, dontla hatuteur ne fera que de la moitiéde l'autre, c'eft-à-dire de trois pieds. Remarqués la difference de ces deux hauteurs, qui eft de rrois pieds : divifés cette difference en deux, qui fera un pied \& demi : faites enlever un pied \& demi de terre à l'extremité $A, \&$ la faites porter l'extremiré $B$ : mais prenès garde que dans ces remuëmens de terre, l'on ne démare vos jalons \& votre regle, qui doivent encore vous fervir. Vous ferés fûr par cetteoperation, d'avoir la ligne $C C$ bien de niveau, étant parallele à la ligne de mire $D D$. La raifon en eft, que les jalons airant fix pieds de haut à l'extremité $B, \&$ n'en aïant que trois à l'extremité $A$, en baiffant le terrain d'un pied $\&$ demi en $A$, \& le hauffant d'autant en $B$, ils fe trouveront avoir quatre pieds \& dem égalemen:par tout.

$$
\text { SECONDE PRATIQUE. }
$$

Dreffer of unir le Terrain, fuivant sne ligese de nivean:

Pour dreffer entierement la ligne de niveau $C C$, après 

avoir fait poirter en gros; les terres de l'extrémité $A \dot{a}$ à celle $B$ prenés un bâton bien droit, mefurés à l'extremité $A$, l'un des deux jalons qui foutiennent la regle, dont la hauteur eft fuppofée de quarre pieds \& demi, y compris l'épaiffeur de la regle, Coupés ce bâton de cette longueur jufte, ce fera une mefure portative pour tous les antres jalons, en la préfentant par la tête

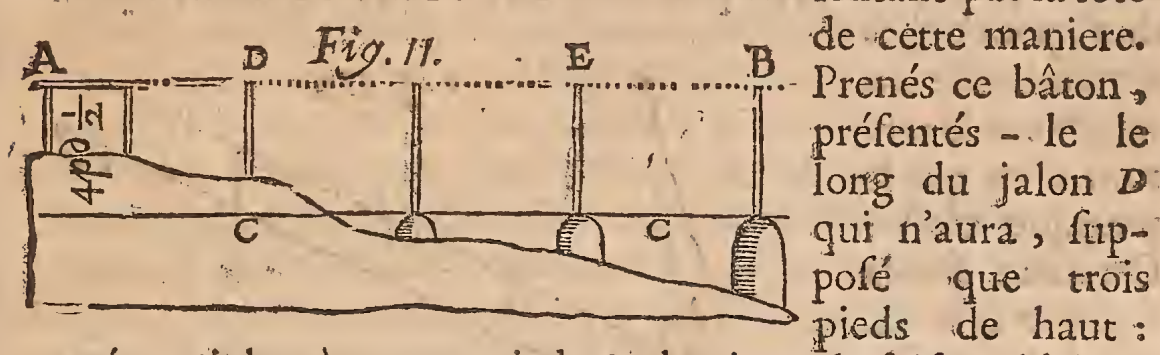

mettés ce jalon à quatre pieds \& demi, en le faifant décharger du pied, jufqu'à ce qu'il foit à cette havteur. Reportés votre mefure au jalon $E$, qui étant plus haur qu'il ne faut, c'eft-à-dire, ayant plus de quatre pieds \& demi, vous le ferés butter, en y faifant apporter de la terre au pied, que vous battrés \& plomberés, de peur qu'elle ne s'affaiffe. Ayant mis pareillement ce jalon $E$ de hauteur convenable, vous pafferés aux autres, \& par les exemples différens de ces deux jalons, vous les réglerés tous de même, en faifant butter ceux qui auront trop de hautetri, \& faifant décharger: diu pied ceux qui n'en auront pas aflés. Cela fait, vous prendrés un cordeau de I 2 à I 5 pieds de long; que vous attacherés:aux pieds dès jalons $B: \& E, \&$ que vous tendrés le plus que vous pourrés; \& en cas que les jalons $B \& E$, foient trop éloignés pour votre cordeau de is pieds, vous alignerés un autre jalon entre-deux, qui fera de la même hauteur: enfuite vous ferés apporter de la terre, ou en ferés couper le long de ce cordeau, potir y faire une rigole ou repaire. Faites-en autant de jalon en jalon, en reportant le cordeau, \& y pratiquant des rigoles de l'un à l'autre; c'eft par ce moyen que vous aurés la ligne CC bien dreffée \& parfaitement de wiveau. 


\section{TROISIE'ME PRA TIQUE.}

\section{Dreffer cout un Terrain entier quelque grand qu'il joit, \& le mettre de niveau.}

La rigole $A B$ étant bien dreffée, fuivant les desx PratiE \& III. ques precedentes, le jalon $A$ doit être confidéré comme immobile, \& doit fervir plufieurs fois à faire la même opération, pour achever de drefler entiérement le terrain ; ce quile pratique ainfi : On fiche fur la ligne $A E$ le jalon $C$, à peu près à la même diftance du jalon immobile $A$,qu'eft pofé celui $D$, dont il ne doit être éloigné que de trois ou quatre pieds tout au plus. On pofe en. firite la regle \& le niveau fur les

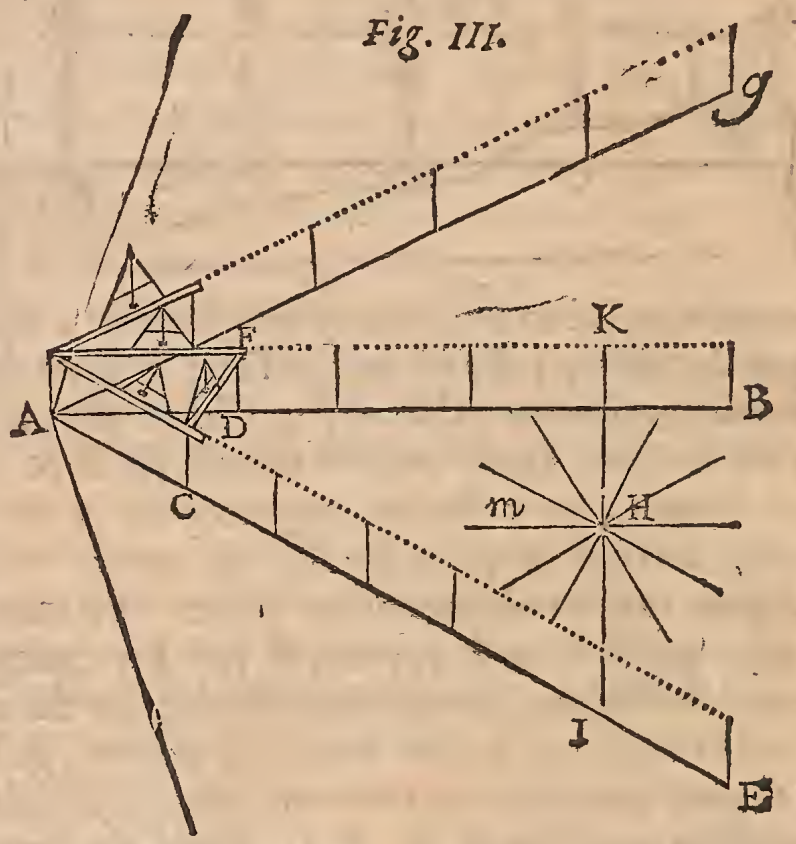
jalons $A \& C$, \& pour verifier fi cette opération eft jufte ; l'on reporte en travers la regle $\&$ le niveau fur les jalons $C$ $\& D$, ce qui forme un triangle; avec les derux lignes $A B$, \& $A E, \&$ vous doit perfuader de la jufteffe des deux nivel. lemens, s'ils fe raportent à ce troifiéme. Enfuice par la $4 \mathrm{e} \mathrm{Pra-}$ zique, vous jalonerés la ligne $A E, \&$ Par la 2 e vous la dref. ferés bien de niveau, en y faifant une rigole. Pofés un autre jalon comme en $F$, environ à la même diftance du jalon immobile $A$, que fone pofés les jalons $C \& D$, \& pareillement à trois pieds du jalon $D$. Pofés-y le niveau pour dreffer la ligne $A G$, en verifiant la jufteffe de l'opération, comme nous venons de dire, c'eft-à-dire, en reportant le niveau 
I I IRATIQ I I I T JARDINAGE. 129 fur les jalons, $D \& F$, Dreffés cette ligne $A G$, de là même maniere que vous avés fait la ligne $A E$. Continués de dreffer des lignes, \& de faire des rigoles de cette maniere dans toute l'étenduë du terrain, en obfervant que ces lignes foient à peu près à mème diftance les unes des autres, que celles qui lont déja faites : cela étant execuré avec toute la précifion neceffaire o vous achevés de dreffer entierement le terrain, en faifant tenir un cordeau par deux hommes, quile trainerone bien bandé, en travers d'une rigole à une autre, ou plùtôt d'un jalon à un autre, au mö̈en de quoi vous ferés arraferles buttes \& remplir les cavités entre ces rigoles, en paffant le rateau par tout. Mais comme vers les extremités des lignes. $B E G$, les rigoles fe touveront quelquefois trop écartées, pour que le cordeau puiffe fe tendre commodément d'un boutàl'autre, vous remedierês à cet inconvenient, en plan- Fy 8. III. tant le jalon $H$ entre les deux rigoles $A E$ \& $A B$, enforte qu'il s'aligne par la tête fur deux jalons pofés fur ces lignes. conme fur ceux $I \& K$. Mettés le jalon $H$ à la hauteur des autres, , \& y attachant un cordeat au pied, vous le traînerés de tous les côtés; in raportant on enievant des terres felon le befoin, \& vous ferés fuivre le rateau, ce qui dreffera l'efpace compris entre les jalons $I K E B$ H. Faites-en? de même pour dreffer les places d'entre les autres rigoles.? \& par-là vôtre terrain, quelque grand qu'il foit, fera uni \& dreffé également par tout.

$$
\text { REMARQUE. }
$$

Dans un grand Jardin, comme la dépenfe feroit fort grande de le dreffer par tout fuivant cette liatique, l'on fe contente de dreffer \& d'unir les places découtrertes, qui doivent fervir aux.Parterres, Salles, Galeries, Cabinets; \&c. A l'e-"' gardide-celles gui font deftunées four les kois, ön arefieflement les allées \& lesicutés on laiflantes guarrés \& lieux des bois, inégaux \& naturellemenrcomme ils fe trou-. vent.

$$
\begin{aligned}
& \text { QUATRIEME PRATIQUE. }
\end{aligned}
$$

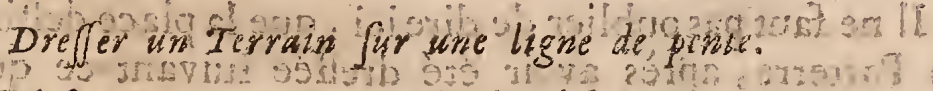

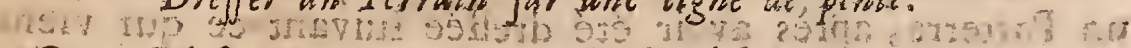
Quand il fe rencontre ung teraing ficué fur une pente douse 
raturellement; \& qu'on ne veut pas faire la dépenfe de remuer toutes les terres, pour les mettre parfaitement de niveau ; l'on peut dreffer ce terrain fur fa pente naturelle, enforte néanmoins que cette pente foit fi douce \& fi imperceptible, qu'on ne s'en apperçoive pas en fe promenant, comme pourroit être la pente d'un demi pouce out d'un pouce par toife, fuivant la longueur de la côte. Voici comme il faut $s^{2} y$ prendre. Fichés un jalon fortant de terre de quatre pieds. de haut, à l'endroit le plus élevé du terrain, comme en $A$, où vousunirés ex-

près une perite place. Fichés - en un autre de pasalle hauteur l'extremité $B$, qui elt fuppofé l'endroit le plus bas

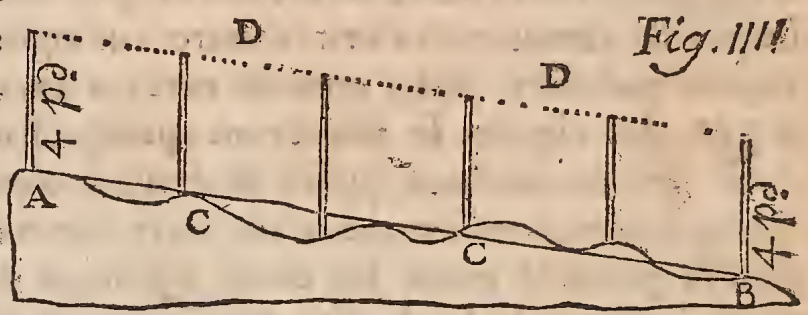
du terrain ; alignés plufieurs jalons fur les deux pofés en: $A$ $\&$ en $B, \&$ les. faites planter de maniere, qu'en les bornoïant d'A en $B$, leurs têtes n'excedent point la ligne de mire oì raïon vifuel $D D$. Prenés enfuite un bâton ou mefure portative de quatre pieds de long, préfentés-la fur tous les jalons; \& mettés-les tous à la hauteur requife de quatre pieds, en les faifant butter ou décharger felon le befoin. Faites enfuite une sigole en pente $\mathrm{d}^{2} A$ en $B$, comme il eft dit dans la 2 e Pratigue vous ôterés par là les ferpentemens \& corrigerés l'inégalité du terrain, quir fera bien dreflé fur la ligne de pente $C C$

\section{PREMIER REMARQE:}

Si lon veut dreffer tout le terrain entier fur une pente douce, l'on fera la même opéracion plufieurs fois dans touta fon étenduë, \&l'on pratiquera par des rigoles \& avec le cordeati, ce que nous venons de dire dans la Praitique précédente, arec cetre différence, qué les rigoles doivent être en pente.

\section{SECONDE RENARQU E.}

Il ne faut pas oublier de direici, que la place deftinée pour an. Parterre, après avoir été dreffée fuivant ce qui vient d'Âtre dit, demande encore une façon, c'elt d'épierrer \& 
LA PRATIQUEDU JARDINAGE. I3I de paffer à la claïe les terres de deffus, \& de les unir enfuite au rateau fin : fans cela elle ne feroit pas propre à être maillée \& à tracer les rinceaux de broderie.

Voilà la meilleure maniere de niveler \& de drefferles terres, c'eft la plus facile \& la moins embaraffante dans l'execution. On n'y voit point les mauvaifes pratiques obfervées par ceux qui nivelent ordinairement, entrautres* celle de le coucher le ventre par terre, $\&$ de faire ouvrir un trou pour $s^{\prime}$ affeoir ou s'agenoüiller à la hauteur de la regle.

Nous venons de donner la prarique de dreffer les Ter. rains fitués dans une plaine, \&x fur une pente douce : il ne nous refte plus qu'à parler de la maniere de dreffer un Terrain fitué fur une montagne ou demi-côre, ce qu'on ne peut faire que par le moyen des Terraffes, comme l'on va voir dans le Chapitre fuivant.

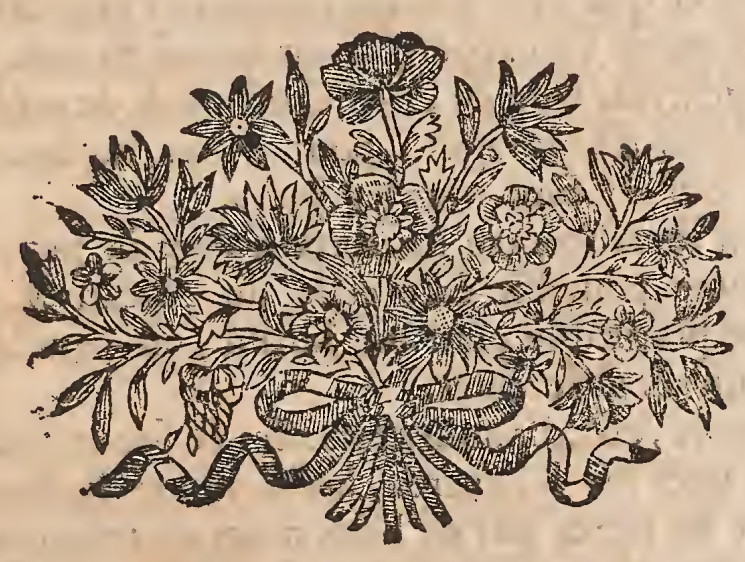

$\mathrm{R} \mathrm{ij}$ 


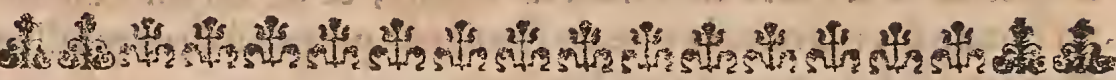

\section{H A P I T R E. III.}

DES DIFFERENTES TERRASSES O Efcaliers, avec leurs plus juft:s proportions.

- Y'E s r ici où confifte la plus grande dépenfe des Jardins: \& $\&$ c'eft à quoi l'on doir le plus prendre garde, quand on fe trouve indifpenfablement obligé, par la trop grande pente d'un terrain, d'en foutenir les terres par des terraffes. On ne peut difconvenir, que les tranfports \& les remuëmens. de terre, ne coûtent infinimert: Ces dépenfes exceflives \& fourdes qu'on ne connoît prefque pas, quoique tres-confiderables, font cependant celles qui font le moins d'honneur 2 leur maître. L'on s'imagine quand on voit un terrain bien dreffé, des terraffes bien de niveau \& bien foûtenuës, que cela devoit être ainfi difpofé naturellement; en forte que pour fçavoir ce que c'eft que ces travaux, il faut les a voir v $\hat{u}$. faire : car à peine s'en apperçoit-on quand ils font faits. On ne peut donc avoir trop de circonfpection \& de ménagement dans ces fortes d'Ouvrages, pour éviter les erreurs \& les tromperies qui s'y font tous les jours.

Frcuar 1. Quand il fe rencontre un terrain dunt la pente eft fore roide, comme pourroit être celle du côteau $A$, que l'on veut rendre praticable pour un Jardin, on peut le difpofer de trois manieres differentes.

Fro. II. La premiere, en faifant des terraffes \& fou-terraffes, c'eftà-dire, les unes fur les autres, à differentes hauteurs, dont on foûtient les terres par de bons murs de maçonnerie.

Fic. III. La feconde, en pratiquant de même des terraffes, qui fe foutiendront d'elles-mêmes fans aucun mur, par le moïen des talus \& glacis que l'on coupera à chaque extremité des terraffes.

La troifiéme maniere, c'eft de ne point faire des terraffes -en lignes droites, ni de longs plein-pieds entre-deux; mais feulement de trouver des palliers ou repos à differentes haus: 
teurs, \& des rampes douces \& efcaliers, pour la communication, avec des eftrades, des gradins, des volutes, vertugadins, talus \& glacis de gazon placés \&:'difpofés a vec fiméérie, ce qu'on appelle des amphitéấtres. On orne ces amphitéâtres, d'arbrifeaux, d'ifs \& charmilles à hauteur d'appui, avec des vafes, des caiffes $\&$ des pots de fleurs, pofés fur des dez de pierre. Les figures \& les fontaines n'y doivent point être oubliées, comme faifant la perfection de ces pieces, dont la diverfité, tant dansl'arragement, que dans ce quiles compofe, forme un effet tres-agréable aux yeux, ainfi qu'on le voit dans ce Deifein.

De ces trois manieres celle qui coute le moins, eft celle des talus; \& la pluș magnifique eft celle des amphitéâtres, en forte que les murs de terraffe peuvent tenir le milieu en tout : on choifira celle qui conviendra le mieux a la fituation du lieu, \& à la dépenfe qu'on voudra y faire.

L'Architecte, ou celtri qui donnera le deffein du Jardin, doit examiner avec exactitude la pente \& le ferpentement d'un côteau, \& en lever \& defininer cơrrectement le profil, afin que profitant des avantages de la fituation, \& diftribuant fes terrafies avec ceconomie \& difcernement, il ne faille pas beaucoup remuer de terre, il fera en forte que ce qui fortira des endroits trop élevés, puiffe fervir à raporter \& rehauffer les endroits trop bas; ce qui fe doit faire avec un tel ménagement, que les terraffes étant achevées, on ne foit point obligé de raporter ni d'enlever des terres.

On fuivra ici le même ordre que dans les Chapitres précédens, en expliquant quelques termes, \& faifant des obfervations neceffaires, avant que d'entrer dans les Pratiques de la conftruction des terraffes. Lés obfervations qui font dans ces trois Chapitres, quoique feparées, ont tant de raport entr'elles, qu'elles peuvent également fervir par tout; comme ellesauroient été trop longuies tout de fuite, ,'on a tâché de les mettre dans. leur vraie place', \& de choifir celles qui cenvenoient le mieux à la matiere de chaque Chapitre.

Les terraffes ne doivent point être trop frequentes, ni fi proches l'une de l'autre, c'eft-à-dire; qu'il en faut faire le moins qu'on pourra; \& par le moïen des plein-pieds qu'on pratiquera les plus longs que le terrain le peut perme tre. $\mathrm{R}$ iij 
134 SECONDE PARTIE, CHAP. III. on évite le défaut d'entaffer terraffe fur terraffe, il n'y 2

Meudon qui ent un beau lieu eft un des plus laflanes Jardins qu'il $y$ ait.

rien de plus défagréable dans un Jardin que de defcendre ou de monter continuellement fans trouver prefque aucun repos.

On appelle plein-pied, l'efpace de terre compris entre-deux terraffes, c'eft à-dire la plate-forme foutenuë par les murs, ou talus des terraffes, ce qu'on nomme Terre-plein en terme de Fortification.

Quand on dit prendre le profil d'une montagne, c'eft en niveler exactement la pente, $\&$ en chiffrer toutes les ftations fur le plan, pour en avoir le ferpentement \& les courbures, aufquelles on doit s'ajufter dans la difpofition generale d'un Jardin.

On apelle marquer en contre-bas, qui eft un terme fort ufité parmi les Ouvriers, quand on commence à compter du haut d'une perche en tirant vers le bas, pour'marquer quelque mefure : comme l'on dit au contraire marquer en contre-haut, quand on commence du bas vers le haut.

On fe fervira dans les opérations fuivantes du même niveau, \& on le pofera de la même maniere qu'il vient d'être. enfeigné dans le Chapitre précédent : il en eft de même du cordeau $\&$ du rateau, pour unir $\&$ égaler les terres, en faifant des rigoles ou repaires.

Il faut ajoûter à l'ufage des jalons \& des piquets, celui des grandes perches de quinze à vingt pieds de haut, parce que les jalons feroient trop courts, pour niveler par ftations la pente d'une montagne. L'an dreffera ces perches de bout avec un plomb, \& l'on attachera au haut un carton blane coupé à l'équerre.

L'endroit où l'on pofe le niveau pour faire l'opération du. niuellement, s'appelleftation, de forte qu'un coup de niveat: eft compris entre deux ftations.

Une ligne d'arrêt, en fait de terraffes, eft l'endroit où fo vient terminer la carne du mur, ou le talus d'une terraffe.

Les Terraffers appellent Fondis, un endroit très - cretix qui eft à remplir. Pâté eft une butte qu'il faut artazer : Your les termes de Déblai \& de Remblai, l'on fe fert da pre. mier, dans l'évaluation des terres , poun fignifier qu'il faut ent ôter de quelque endroit, \& du fecond, pour marquer quén 

doit remplir quelque cavité: l'on dit alors, ce Déblai fera pour ce Rembläi.

Il faut oblerver de laiffer toujours une petite pente imperceptible fur les terrafies pour l'écoulement des eaux, comme d'un pouce ô demi pouce par toife, felon la longueur de ta terraffe. Cette pente fe prend toujours fur la longueur, \& jamais fur la largeur.

Il vaut beaucoup mieux couper les talus en pleine terre, c'eft-à-dire, en terre ferme, que de les conftruire de terre raportée avec du clayonage, ils s'en confervent beaucoup mieux, étant ainfi naturels, \& coûtent moins à faire : cependant quand on ne peut faire autrement, on fe fert de clayonages \& de fafcines, ce que l'on trouvera dans ce Cbapitre.

\section{PREMIERE PRATIQUE.}

\section{Couper un Côtean fur fo longueur, en terraffes foúcenutes par des muss de maçonnerie.}

Soit le perron du bâtiment $A$, fitué fur le haut du côteau, d'ou l'on veut faire commencer la premiere terraffe: mefurésfur le profil , Fig. $2^{\mathrm{E}}$, la longueur de cette terraffe, chi- $F_{\text {s }}$. $\forall$. frée de 30 toifes : faites tenir par un homme au bout de 30 tojfes, comme en $B, F i g .5^{e}$, une perche un peu longue, oir vous mettrés du carton ou du linge à l'extremité d'en-haut. Uniffés une petite place au pied du bâtiment comme en $A$, \& pofés-y le niveau pour dreffer une rigole, comme il a été enfeigné ci-deflus dans la Ie Pratique du Chap. précedent: avec cette remarque, de faire defcendre ou haufer la perche qui eft en $B$, jufqu'à ce que la tête ou bout d'en-haut le trouve à l'alignement des autres têtes des jalons . c'eft-à-dire, n'excede point la ligne de mire $E$. Vous drefferés cette perche bien d'a plomb, \& la ferés feller en plâtre avec des moilons au pied, de crainte que fa pefanteur ou les vents nela faffent tomber, ne fuffifant pas de l'enfoncer en terre, comme l'on feroit des jalons. Prenés la hauteur d'un des jalons qui foutien. nent la regle fur laquelle on a pofé le niveau, en y comprenant auff l'épaiffeur de ladite regle, laquelle hauteur eft fuppofée dé quatre pieds:-mefurés'en contre-bas quatre pieds fur la perche B, \& y ajoutés ce qui.fera néceffaire poưr la pente qui eft fuffifante ici de is pouces 5 cela fait en tout cing 
pieds trois pouccs. Ce point marqué avec du charbon fur 12 perche déterminera la ligne de niveau \& de pente de la terraffe. Mefurés enfuite la hauteur que doit a voir la terraffe fuivant le profil, Fig ¿ $^{e}$, qui êt chifrée à I s pieds de haut. Marqués encore en contre-bas fur la perche $B$, depuis le point noir, Is pieds, \& faites décharger ou butter le pied de la perche, jufte à cette hauteur. Uniflés pareillement une petice place au pied de la perche $B$, comme vous avés fait en $A$; pour y pofer le niveau; faites dreffer une autre perche cn $C$ a la diftance qui fera marquée fur le profil, \& par cette pra. tique réiterée à chaque ftation, jufqu'au bas $D$, vous drefCerés toutes les lignes de vos differens niveaux.

\section{$R E M A R Q U E$.}

Cette operation étant faite, ne vous donnera qu'une feule ligne fur la longueur de la côte, \& à l'une de fes extremités; ainfi pour achever de la dreffer entierement, iI faut y joindre la Pratique fuivante.

\section{SECONDE PRATIQUE.}

\section{Dreffer entierement un Côteau fur fa largeur, en le coupant en

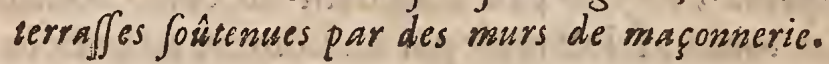

Suppofé l'operation précedente faite depuis le hauc de la coline $A$ où eft le bấtiment, jafqua au bas $D$, en autant de

Is $\begin{aligned} & \text { Atations qu'il y aura de terraffes, il faut en faire autant à l'au- } \\ & \text { tre extremité. } F \text {, en dreffant une ligne de niveau d' } A \text { en }\end{aligned}$ $F$, qui fera à peu près parallele au bâtiment. On pofera le niveau fur la ligne $A F$, en fichant in nouveau jalon pour fuporter la regle, \& fe fervant de celui de l'encoignure $A$, Jiviant la jc Pratique du Chap. précedent: on dreflera enfuite une rigole d $A$ en $F$, \& lon plantera en $F$ un jalon, qui fera bien bornoié fur la hauteur de celui qui ett à l'extremité $A$, pour pofer la regle $\&$ le niveau comme on le voít en $F$, \& cnfuite lon fera én defcendant la côte depuis $F$ jufqu'uà $I$, autant de ftations qu'on en a déja fait depuis l'autre extremiré $A$ jufqừà $D$, en obfervant tố jótirs de faire lés terraffes des mêmes longeurs \& largeurs, autant que faire fe pourra \& de dreffer à chaque ftation une ligne de niveau de travers en travers d'uiné perche à l'autre, comme de. $B$. 
LA PRA TIQUEDU. JARDINAGE. I3.T en $G$, de $C$ en $H$, de $D$ en 1 ; ce qui reglera le niveau de c haque plein-pied. Cela fait, on unira ces terraffes dans toute leur érenduë, par le mö̈en des rigoles \& repaires qu'on fera dans le milieu, \& de travers en travers, qui fe doivent tous jours raporter au niveax des deux lignes des extrémités A \& F. fusivane la ze Pratique áu Chap. précédent.

\section{R E M A R QU E.}

On ne pourra terminer la ligne d'arrêt des terraffes, qu'après que les murs feront bâtis: alors on comblera la tranchée jufqu'à l'uni de la terre. L'on gardera ces vuides pour le dernier ouvrage, afin d'y emploier les terres que l'on pourra 2 voir de reite.

TROISIE'ME PRATIQUE.

Couper un Côteau fur fas longucur, en terrafjes joûscnües par des $F_{I G}, V_{I I L}$ talus of glacis de gazon.

Si l'on ne veur pas foûtenir les terraffes par des murs, à caufe de la dépenfe, \& que l'on fe contente de couper les terres en talus qui eft la feconde maniere de rendre praticable le côteà $A$, Fig. $\mathrm{I}_{\mathrm{e}}$; pofés votre niveat au pied du bâtiment $A$, fuivant la $1^{\circ}$ Pratıq. de ce Chapitre, Fig. ge : méfurés fur le profil, Fig. ze, la longueur de la premiere terrafe, chifrée de 30 toifes; portés cette mefure, du pied du bâtiment $A, \&$ plantés un jalon à l'extremité comme en $B$, c'eft où fe terminera l'arrête du premier talus. Faites tenir une perche à fix pieds delà, qui eft la pente du talus fuivant le profil , comme en $C$; bornoïés-la jufte fur les autres jalons, mettés-la bien d'a-plomb \& la faires feller, ainfi que nous l'avons déja dit. Marqués en contre-bas fur cette perche, la hauteur des jalons, l'épaiffeur de la regle, \& la petite pente pour l'écoulement des eaux; \& diminuant le tout fur la hauteur de la perche, faites-y une marque noire: ce point déterminera la ligne de niveau de la terraffe; après quoi vous drefferés une rigoled' $A$ en $B$. Reporcés en contre-bas fur la perche depuis cette marque, la hauteur que doir avoir la terralle, que l'on fuppofe être de io pieds; buttés ou déchargésle pied de la perche, jufqu'à ce qu'elle fe trouve jufte à certe hauteur, $\&$, sendant un cordeau du pied de la perche $c$, qui dérermine 
T.3 SECONDE PAR TIE, CHAP. III.

le basdutalus, au pied du jalon d'en haut $B$, qui en déternine l'arrête, vous ferés couper à la bêche ce talus, en fajfant une rigole ou repaire fuivan le cordeau ; après quor vous reporterés le niveau en $C$, en $D, \&$ co où vous ferés toûjours a mẹme opération jufqu'au-bas de la montagne $E$.

\section{QUATRIE'ME PRA.TIQUE.}

Drefger enzitierement un Cốreau fur fa largeur, en le coupant en teven rafes foùtenus par des talus \& glacis de gazon.

Poưr couper tout le côteau $A$ eń talus, \& le dreffer entie-

Es. VIIn. rement, l'opération ci-deffüs étant faite par profil depuis le bâtiment $A$ jufqu'au bas du côtealt $E$, ill la faut recommencer pareillement à l'autre extremité $F$, cn dreffant une rigole de niveaut d' $A$ en $F$, comme l'on a fait dans la 20 Pratique de ce Cbapitre. L'on pofera le niveau en $F$, \& l'on fera les mêmes ftations $\mathrm{d}^{\prime} F$ en $G$, de $G$ en $H$, d' $H$ en $I$ jufqu'au bas, comme lon a déja fait de l'autre côté depurs $A$ jufqu'en $E$, en obferyant toû jourrs les mêmes longueurs \& largeurs. de plein-pieds \& de dreffer à chaque ftation une rigole bien de niveau, de travers en travers. Cela fait, avant que de couper les talus : dreffés entierement toute l'étenduë de vos plein-pieds, Juivantla je Pratique du Chap. précédent.

A l'égard des talus, pour les bien couper \& dreffer fur leur ligne de pente, il faut fur la ligne $K L$ qui détermine la ligne

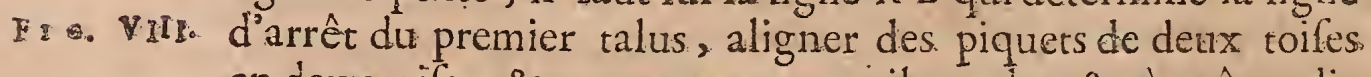
en deux toifes, \&r en mettre en pareil nombre $\&$ à même diftance for la ligne $M N$, qui termine le pied du talus : tendés un cordeau de hauten bas, d'un jalon à fon oppofé, \& faites une rigole ou repaire d'un pied de large fuivant le cordeau.. Coupés la terre ainfi par rigoles, en tendant le cordeau de piquet en piquet. Pour dreffer ce talus qui eft entre-coupé par des rigoles, faites ce qui eft marqué à la feconde terraffe comme en 0 : paffés la boucle du cordeau dans un. piquer, il n'importe lequel, traînés \& promenés ce cordeau de tous fens, \& d'une rigole à un autre, en faifant fuiv re un homme qui coupera \& arrafera à la bêche, les endroits où il y autra trop de terre, en fuivant exactement le cordeau fans le forcer : ainfi donnant communication d'une rigole à une autre, bon unira \& aplanira tout le talus avec le rateau. 




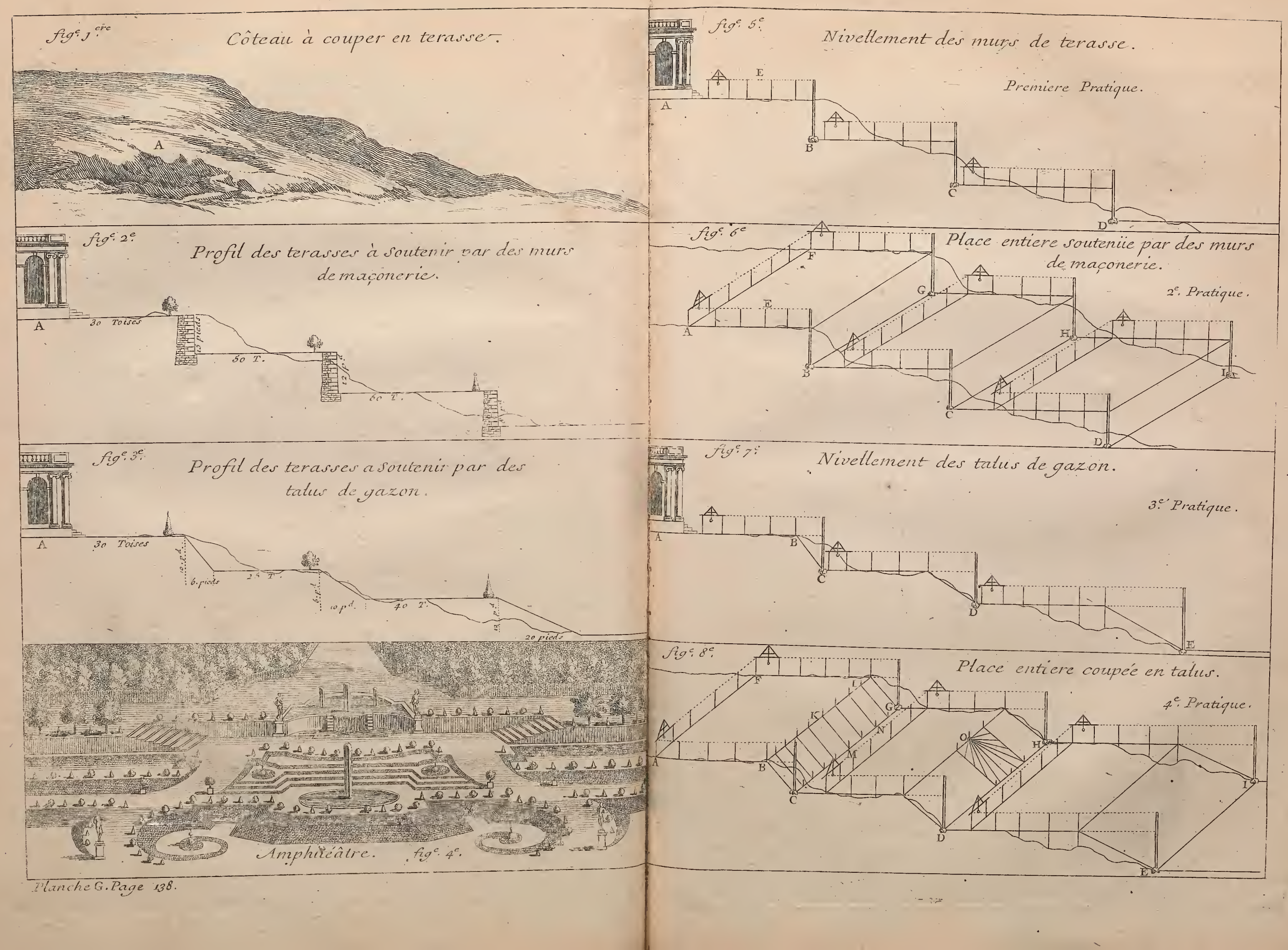



PREM I ER E RE MARQUE.

Si l'on ne pouvoit pas couper le talus en terre ferme, la lituation du terrain ne le permettant point, on fera apporter des rerres pour dreffer des rigoles environ de I 2 pieds en I 2 pieds. On plombera ces terres; \& on les dreffera fuivant le cordeau, jufqu'à ce qu'il foit bien garni de tous côtés fans être forcé ; enfuite l'on fera remplir de terre les vuides d'entre les rigoles, \& l'on dreffera ce talus fur toute fa longueur, de la même maniere que nous venons de dire.

\section{SECONDE REMARQUE.}

Quand le talus n'excede point fept à huit pieds de long, on pourra au lieu de cordeau, fe fervir d'une grande regle de maçon bien épaiffe, qui ne puiffe point fe cambrer. On couchera \& l'on promenera cette regle fur le talus qui fera dreflé dans toute fon étenduë fuivant cette regle, pourvû que les bords de la terre d'en-haut \& d'en-bas, foient bien dreffés de niveau. Cette Pratique eft fort bonne pour les petits talus des terrâles \& des boulingrins.

On ne donnera point icide Pratique particuliere pour dreffer un côteau en amphithéâtre, elle feroit affés inutile, parce que ces morceaux étant compofés de terraffes, de talus \& glacis de gazon, on n'aura qu'à fuivre ce qu'enfeignent les Pratiques précédentes.

Si les talus ne font point coupés en terre ferme, - \& que les terres rapportées dont on les veut former, ne puiffént fe foûtenir d'elles-mêmes, ils demanderont alors beaucoup plus de travail dans leur conttruction, car on fera obligé de fe fervir. de claionage \& de fafcines en la maniere fuivante.

A près avoir mis delaterre un pied de haut, en commen =çant parle bas, il faut mettre deffus un lit de fafcines, ou claionage de fix pieds de large, rangés t'un contre l'autre, 8. faire en forte que le grós boutou rácine regarde la face du talus, \& vienne aboutir à un pied près du revêtifiement; on nettra enfaite un lit de terre par deffus, \& 'un continuera de même jufqu'en-liaut.

Lesmeilleures fafcines \& claies font faices de bois verd, comme de branches \& perches de faule, a ciufe que prenant 


\section{SECONDE PARTIE, CHAP. III.}

racines facilement; elles fe lient mieux is la terre. il eft bon. de leur laiffer les racines, quand elles ne font point incommodes, parce qu'elles peuvent fervir à entretenir cette liaifon. On afti le gazon defus ce clä̈onage, en le couvranc auparavane d'un demi pied de terre.

Pour la proportion des talus, on leur donne ordinairement les deux tiers de leur hauteur', pour a'être point trop roides " quelquefois on ne leur donne que la moitié, on le riers de leur haureur, furtour aux petits talus. Il y a des gens qui les font d'une pente égale à leur hauteur, d'autres quileur donnent celle d'une ligne au-deffous de la diagonale de leur quarré, parce que l'humidicé tombe toujours en bas, \& que le haut devienc aride pendant l'Eré, ce qui fait fécher \& mourir le gazon.

Ondoit examiner la qualité de la terre, fur laquelle on éleve des talus de gazon; fi les terres font fortes, fi elles ont du corps $\&$ de la liaifon, elles fe foûtiendront prefque d'ellesmêmes, \& fix pouces par pied de haut, fuffront pour bien entretenir le talus; a lieu que fi ces terres font mouvantes. \& fabloneufes, on donnera au talus neuf pouces par pied.

A l'égard des murs de terraffe, l'on doit auffi avant que de les bâtir, confulter le fond naturel de la terre : car on doic affurer la maçonnerie fur la terre ferme \& fur le bon fond. Dans les terres fabloneuf́es, mouvantes \& marêcageufes, on fait des grils cle charpente, des plates-formes, racinaux, \& pilotis, fur lefquels on affure la fondacion des murs.

La proportion du fruit \& empatement des murs doit être Luivant leur hauteur, à caufe de la pouffée des terres. Pour les grands murs, on leur donne de talus, le cinquiéme ou fixiéme de leur hauceur, c'eft-à-dire, deux pouces par pied; pour les murs de I 2 à Is pieds de haut, un neuviéme ; \& depuis Is jufqua za, un huitiéme pour les petits murs de fix à fept pieds de haut , un douziéme, $\&$ ainfi des autres : leur épaiffeur fe donne aufi a proportion de leur hauteur \& de la qualité des terres.

Pouren venir aux efcaliers, on les doit placer avantageufement, comme au bas d'une allée de parterre, ou en face des principaux alignemens, \& jamais dans des endroits perdus. Il eft bon d'en trouver de diftance en diftance, pour 
LA PRATIQUE DU JARDIN A GE. P4I n'avoir pas la peine d'aller chercher fil loin à defcendre. On les conftruit ordinairement de marches de pierre de taille ; cependant on en fait de gazon, qui étant bien entretenus font fort ag réables à la vûë.

On doit obferver que les efcaliers \& perrons foient trèsdoux \&. peu nombreux en marches : leur nombre doit être impair, \& ne pas paffer dans tune rampe i $\mathrm{a}$ I 3 marches, fans un paillier ou repos de deux pas de largeur, \& auffi long que le perron. Chaque marche peut avoir I 5 à I 6 pouces de giron, fur cinq à fix de haut, compris trois lignes de pente, que doir avoir chaque marche, pour l'écoulement des eaux; qui fans cela pourriroient les joints de recouvrement.

Les rampes douces fans nuarches doivent être prifes de loin, afin d'éviter une trop grande roideur; elles feront foutenuës par des murs de terraffe ou glacis de gazon ; \& pour empêcher que les ravines ne les gâtent, on y met d'efpace en efpace des arrêts de gazon ou de bois, pour rejetter les eaux dés deux côtés.

Les deux premieres Planches donnent des exenples de totrtesfortes d'efcaliers de pierre, convenables aux beaux Jardins. La premiere de ces Planches, contient quatre efcaliers executés dans les Maifons Roüales, dont la décoration \& la beauté fe peuvent confulter fur le lieu; on en a donné l'élevation \& le plan avecl'Echelle, pour pouvoir juger de leur proportion.

La $I^{e}$ Figure eft un grand efcalier des Jardins de $\mathrm{M}^{\mathrm{r}}$ le Duc d'Orleans à Saint Cloud, qui defcend du Château aux Cafcades.

La ${ }_{2} \mathrm{e}$ Figure eft un petit efcalier du Jardin du Luxembourg ì Paris, dont le plan eft fort ingénieux ; ileft fitué dans le milieu des terraffes, vis-à-vis le baffin.

$\mathrm{La}_{2} 3^{\mathrm{e}} \& 4^{\mathrm{e}}$ Figure, reprefentent deux efcaliers du Jardin des Tuilleries à Paris. Le grand eft fitué au bout du Jardin, en defcendant de la terrafie du côté de la riviere, vers la piece d'eau octogone, \& le petiteft furla terraffe du côtéd u Manege.

$\mathrm{La}{ }_{2}$ Planche contient fept differens Efcaliers, qui ne font pas encore exécutés. Le grand differe des autres, en ce que l'on y monte par les deux bouts, comme on le voit par fon 
plan \& fon élévation, Fig. se. Au deffus des perrons, vous trouvés des pailliers \& une rampe qui vous conduit fur la terraffe d'en-haut. La compoficion en eft affés particuliere, \& quoiqu'ornés de fimples paneaux, clle ne laifle pas d'être enrichie dansle nilieu, d'un beau bas-relief $\&$ de corps de refend: Cet Efcalicr ne convient qu'à une place, dont le milieu fera occupé par un parterre ou autre piece, avec des allées aux deux côtés, qui viendront aboutir aux deux perrons.

Dans la $2 e$ \& la 3 e Figure, font deux Efcaliers à langle d'une terraffe; l'un eft de figure octogone, \& l'autre forme un quarré parfait : On les fuppofe à la pointe d'un bois, avec un banc dans l'échancrure, \& deux alléés en terraffe qui viennent former cet angle. Ces Efcaliers ont une defcente en face de chaque allée, \& vous y trouvés un grand paillier \& des perrons, qui vous menent dans le bas.

On voit dans la 4e Figure un Efcalier d'un goût fort nouveau qu'on peut placer au bout d'une patte-d'oie percée dans un bois, fa forme eft ovale, \& en face de chaque allée il y a des defcentes, avec de petit talus de gazon, bordés d'une tablette de pierre, qui en interrompent la rampe. L'on a placé par fimétrie des ifs dans le haut. Cès trois defcentes vous menent fur un grand paillier ovale, d'ou par d'aurres marches circulaires, vous defcendés dans les autres Jardins.

Dans les trois Figures fuivantes, ce font de petits Efcaliers fort limples, dont l'un eft pratiqué au milieu d'un talus de gazon, Fig. gel'autre eft un Efcalier en fer à cheval, Fig. 6e, avec une fontaine dans l'entre-deux des rampes, le tout accompagné, \& à la defcente d'un bois aufi-bien que le petit Efcalier qui eftreprefenté dans la Fig. $7^{\mathrm{e}}$.

Voilá pour ce qui regarde les Efcaliers de pierre : il s'agit prefentement de ceux de gazon, qui forment des Amphiréatres des Eftrades, des Gradins, \& c. comme on le va voir dans la $z^{\text {e Planche. }}$

Les Amphithéâtres conviennent à régularifer un côteau ou une montagne, qu'on ne veut pas couper par de hautes terraffes \& trop tréquenres pour la commodicé de la promenade; les Entrades \& les Gradins féront bien placés au bout d'une alléc \& dans les niches renfoncées d'une palifiade, comme il s'en pratiquc dans les bofquets décorés. Les Efcaliers \& Mar- 
L A PR A TIQUE DU JARDINAGE 143 ches de gazon fervent de defcente dans les talus \& glacis qui fouttiennent les terraffes; mais on ne peut jamais en conftruire dans des murs de maçonnerie, où il faut abfolument des efcaliers de pierre, au lieu que dans un talus de gazon, on peut y mettre des marches de pierre de taille, pour détacher un peu la grande verdure, cela fait un contrafte agréable.

La premiere Figure fait voir un Amphitéâtre de gazon à la defcente d'un bois, \& à la tête d'un grand Canal: la place d'en-haut eft bordée en partie d'une paliffade, avec des niches, où font des figures en Terme : elle eft remplie par un grand bafin avec un jet, qu'on découvre de l'aliée du milieu , $\&$ de celle de maronniers plantés le long de la terraffe. Cette efplanade eft foûtenuë d'abord par un petit mur de maçonnerie, couvert de treillage \& d'ifs; ce mur fait avant-corps dans la face de l'amphitéâtre; il eft interrompu par les deux rampes douces tournantes qui defcendent dans les allées d'enbas, où elles viennent fe terminer en volitites rachevées par le contour de la piece d'Eau, avec un if pour en marquer le centre. L'on a placé au haut de la terraffe, un banc dans le milieu, \& des ifs plantés par fimétrie : il y a un paillier au pied du mur jufqu'aux trois marches de gazon, après lefquel. les on trouve encore un autre plein-pied joignant le talus qui fauve toute la pente jufqu'au bord de l'eau. Les deux murs, les marches \& le talus de gazon, avecles trois pailliers, fe découpent\&fe varient affés bien;c'eft ce tout enfemble qui compofe un Amphitéâttre ; on l'auroit enrichi. de vafes \& de pots de fleurs fur chaque paillier, fans l'ornement d'en-bas quil l'embellit affés ; c'eft une petite Cafcade ou buffet d'eau, compofé dans l'avant-corps du milieu, de deux jeunes Tritons avec leurs conques d'où fortent trois boüillons, tombant dans un petic baffin quife décharge en nape dansla piece d'cau'; fur les côtés \& aux deux bouts, ce font quatre chandeliers ou chanrpignons d'eau qui retombent encore en nape dans cette piece. L'on a pratiqué entre deux chandeliers, des rochers fuants, c'eft-à-dire, où il y a un boüillon au haut qui fe brife fur des: rocailles à fleur d'eau. Ce buffet eft fourni par le grand baffin au deffus, dont la pente eft affés forte pour cela. Le terrain au delà des rampes eft coupé en terraffes \&r fou-terraffes, foutenuës par des talus de gazon, hormis le mur d'en-haut quu regne tout dulóng. 


\section{I44 - SESONDE PARTIE, CHA P. III.}

L'Amphitéâtre que prefente la $2^{\circ}$ Figure convient dans un endroit ou la chûte neft pas fi roide, comme feroitla rampe d'un petic côteau, afin que la pente d'en-bas foit rachetée par un grand boulingrin en rampe : on n'y pourroit pas éxécuter un Canal pareil à celuidu deffein precedent, car le niveau de l'eau obligeroit à faire la chúte d'en-haut bien plus roide; la tête de cet amphitéâtre forme une falle quarrée, entourrée de portiques \& de berceaux naturels, dont l'effet eft admirable d'en bas; elle eft remplie d'un baflin quarré échancré dans les angles avec un jet d'Eau. La décoration du fond eft réhauffée par des figures entre chaque arcade. On a foûtenules terres en face du baffin par un mur coupé de plufieurs paneaux \& de corps de réfend; dans celui du milieu il y a deux coupes fournies par un gros boüillon d'eau, lefquelles retombent en napes dans un baffin affés grand, qui occupe toute la place entre les murs de terraffes \& la naiflance des Rampes tournantes : ces coupes font enrichies de rocailles, \& font un bel effet de loin, elles font accompagnées de deux Jets fur lescôtés, dont l'eau vient du réfervoir au-deffus; les rampes retournent d'abord quarrément, \& enfuite forment une portion circulaire; elles font foûtenuës d'un côté par des murs de terraffe, à la difference de celles du premier amphitéâtre qui le font par des talus de gazon : de l'autre côté c'eft le ter rain en pente d'un bois de haute-futaïe, caché par une banquette de charmille avec des boules, qui fait un petit retour au bout pour entrer fous les berceaux entourés du même bois : on a mis des chevrons de gazon en zigzac, pour rompre le coutrant des ravines, \& les rejetter dans les bois des côtés. Ces deux rampes viennent rendre fur un grand plein-pied revêtu d'un talus de gazon, qui fait avant-corps audevant du baffin $\&$ des deux allées des rampes, ou l'on a pratiqué des marches \& efcaliers de gazon. On yoit des ifs fur le haur du glacis avec des vales de faience, pofés fur des dés de pierre, \& il y a quatre belles figures à l'extremité des rampes. Le bas eft rempli par deux grands tapis de gazon en rampes, bordés d'allées \& d'ifs. On les peur fuppofer dans une boulingrin en continuant les talus tout autour, ou bien en faifant venir à rien dans les bouts, les côtés de ces talus. On remarquera que les plein-pieds font plus grands \& plus larges que dans. 
I A PRATIQUE DU JARDINAGE. I45 Iaut re deffein, parce qu'il y en a moins, \& que les chtites font plus précipitées.

Les deux Figures fuivantes font des morceaux bien différens des premieres en grandeur \& en magnificence, ce ne font que de petits gradins \& eftrades de gazon fans aucun mur, dont l'un [Fig. $\left.3^{e}\right]$ convient à décorer le bout d'une allée, \& lui fervir de perfpective : il eft renfoncé dans un bois avec un treillage qui vient fe terminer fur le haut. On y monte par trois marches de gazon pratiquées dans le premier talus; de ce plein-pied on paffe fur un glacis qui mene fur un aurre, oiz l'on trouve un fiege ou banquette de gazon, au-deffus c'eft un grand plein-pied ovale bordé de la paliffade du bois. Le

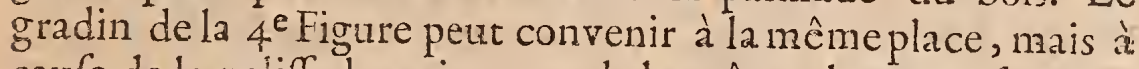
caufe de la paliffade qui monte de la mêne hauteur fur chaque gradin, il eft fait pour mettre dans le renfoncement d'tn Bofquet où l'on en pratiqueroit un aurre vis-à-vis, car ces fortes de gradins renfoncés fe mertent à la place des bancs. C'eft un glacis à pan, qui mene fur le premier paillier, au deffus duquel on voit un vertugadin ou eftrade detrois marches, qui ferwent aufifi defieges pour s'affeoir, le giron en eft fablé pour varier d'avec l'autre. L'on enrichit ces gradins, de caiffes, d'ifs, de pots \& de vafes de fayance, remplis d'arbriffeaux $\&$ de fieurs de faifon, dont le mélange des couleurs réveille infiniment la grande verdure de ces pieces.

Les deux dernieres Figures font de fimples efcaliers de gazon, convenables à des endroits où l'on vett flatter le coup d'oil , comme à la defcente d'une terraffe foutenuë par un

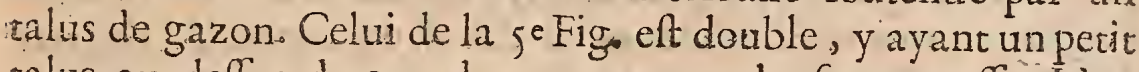
talus au-deffus du grand pour appuyer la fou-terraffe. L'on defcend du haut par deux rampes fablées qui menent fur un paillier ovale, d'o upar par trois marches circulaires vous allés fur la fou-terraffe, ou trois autres marches de gazon vous menent dans le bas. L'autre efcalier [Fig. Ge] eft fingulier. en ce que fes rampes font coupées de marches de groile charpente peintes en verd ou en blanc, \& ablées fur leur giron, cela fait affés bien \& ne laiffe pas de durer. Ces nuarches font aflemblées fur des limons de bois, tournans en forme de ban-: quetre, avec des dés de pierre dans le bas pour y mettre des. vafes. Le milieu avance en glacis de gazon, \& le bas eft orné d'un grand tapis verd bordé d'ifs \& d'arbriffeaux, ainfi que 
146 SECONDE PARTIE, ChAP.III.

le talus d'enhaut.-On voit au fond de cette terraffe une grande paliffade qui fe renfonce en face de l'efcalier, cela a donné lieu d'y mettre un banc, avec un rond de gazon \& un vale de fculpure dans le milieu.

Dans la conftruction des efcaliers \& des gradins de gazon on emploïe pour leur donner plus de durée, de fortes planches de bateau, avec des pieux ou pilots enfoncés aux encoignures ; \& des piquets des deux côtés des planches pour les entretenir de champ. On brûle à demi tout ce bois, c'eft-à-dire, on le noircit dans le fea, pour le rendre plus dure, \& qu'il refifte davantage en terre; il fe pourroic peindre ou goudronner, cela le conferve auffi. L'on ne met ces planches que pour foûtenir la fuperficie des pailliers, \& pour former les dés des encoignures, car les marches de gazon fe plaquent fur la terre même, fil'on n'aime mieux les former toutes avec des planches quel'on revêtit de buis de bois; ordirairement la premiere pouffée desterres fe foutient par des murs dans les amphithéatres, mais les petits gradins \& les marches n'ont pas befoin d'autre foutien que la terre même \& l'herbe qui y prend racine, à moins que ce ne foir des terres fabloneufes ou glaifeufes, qui n'ayant point de corps \& de foûtien, fe remuënt fouvent, alors on conftruit ces pieces avec du clayonnage, comme l'on a déja vî̀.

On donne une petite pente imperceptible fur toutes ces marches pour l'écoulement des eaux, toûjours vers le gazon pour l'arrofer. Dans les rampes qui font trop roides \& qui peuvent être gâtées par les ravines, on les croife de bandes de gazon, qui rejettent les eaux des deux côtés. A l'égard des efcaliers de charpente, ou faits de bandes de menuiferie, on les peint en verd, \& on remplit le giron, de gazon ou de recoupes bien baruës qu'on aura foin de garantir de la ravine qui dégrave le fable d'avec le bois. On fe fervira toujours de gazon plaqué dans ce qui eft un peu roide, \& pour la durée des marches dont le giron n'eft pas gazonné, il faut un petit setour deffus pour conferver l'arrête de la marche.

On doit battre ces pieces vertes toutes les années au Prinsems, cela les raffure \& les fait durer bien davantage: on les bornera \& on les taillera chaque mois aux cizeaux, car la faux n'y feroit rien; fans cet entretien l'herbe devient trop haute \& corrompt toure la grace du deffein. 



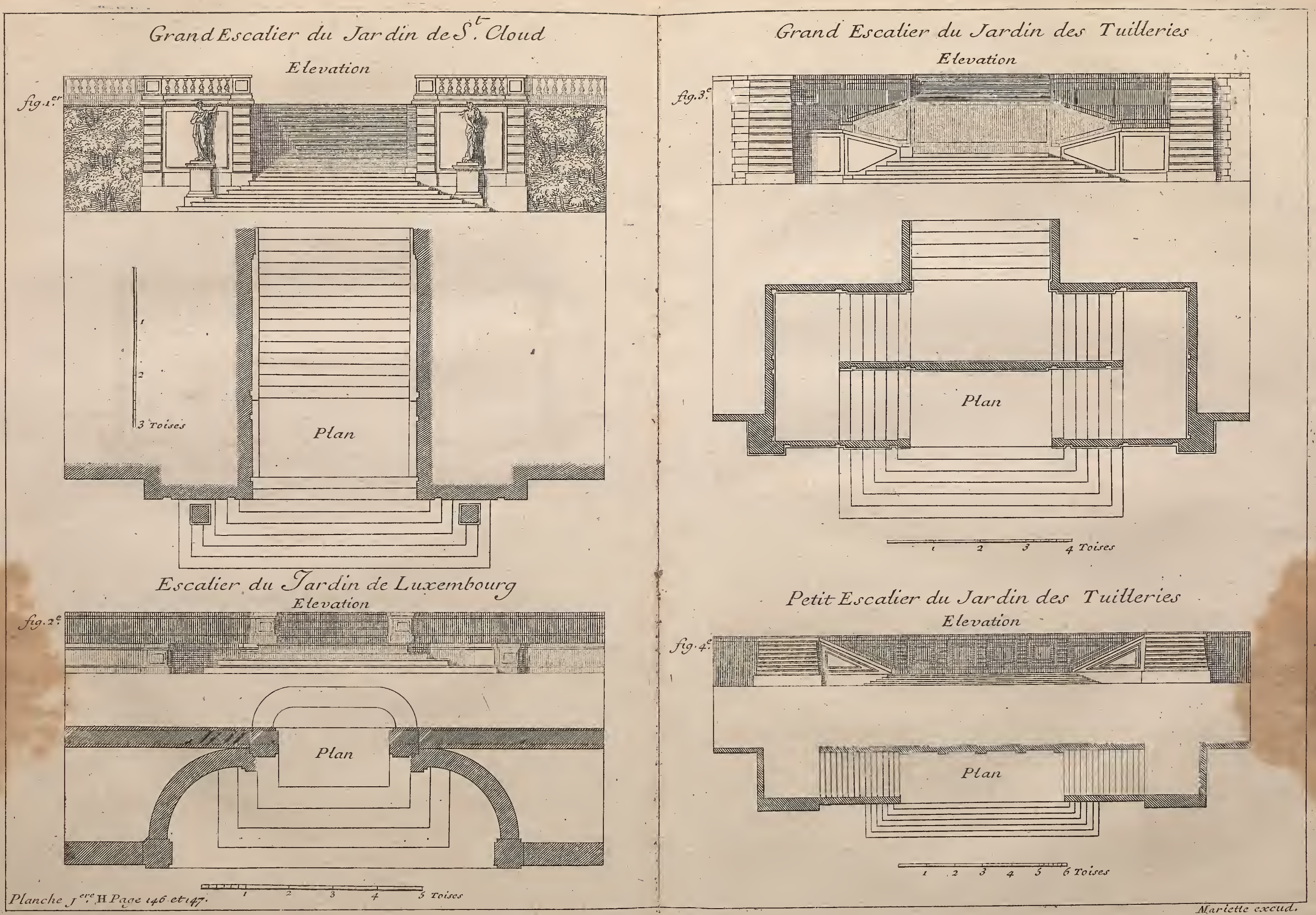

a $\cdots$ 



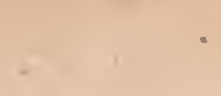

. 


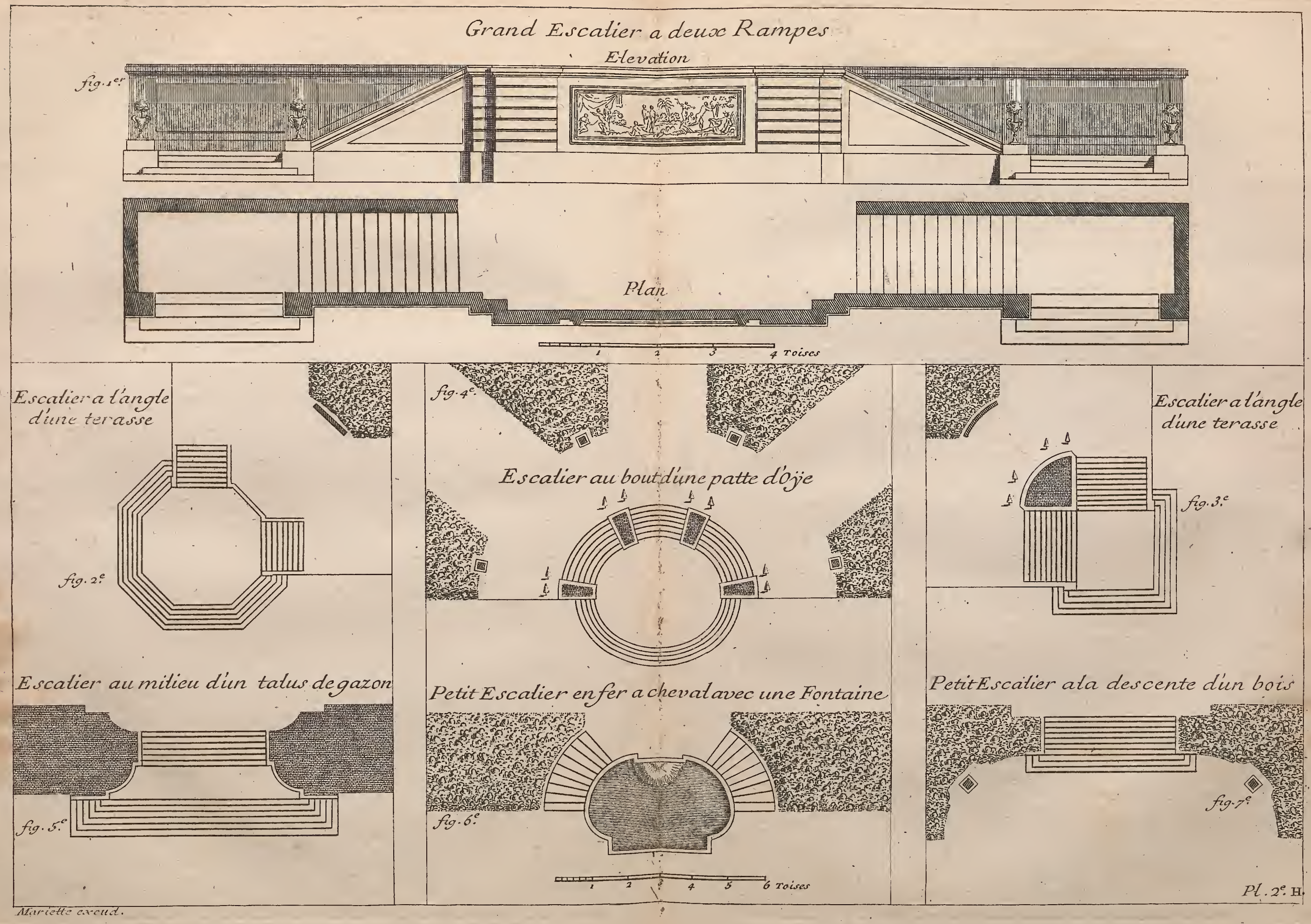






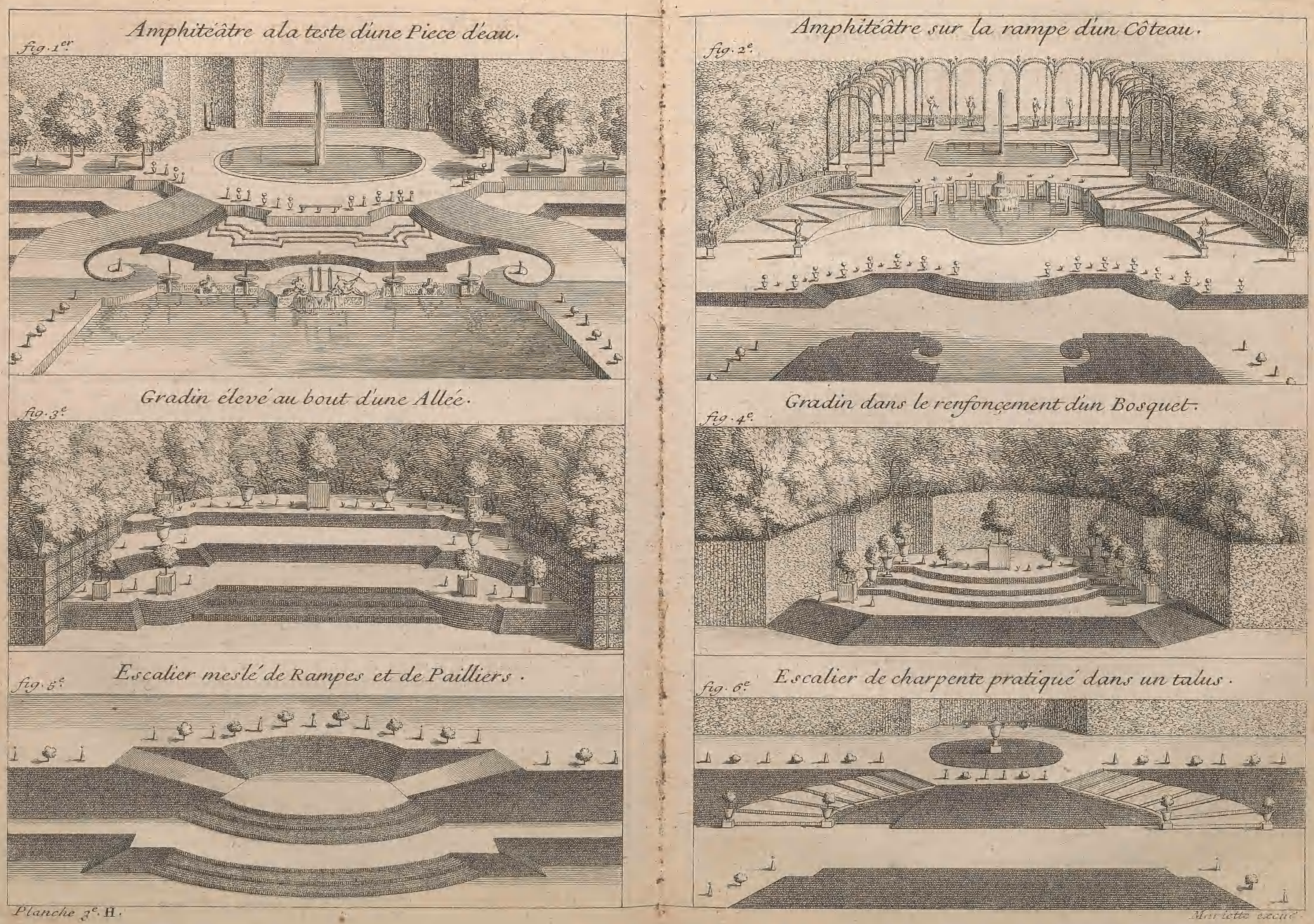



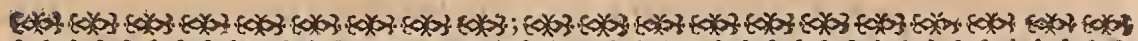

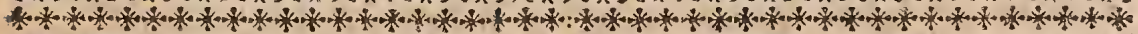

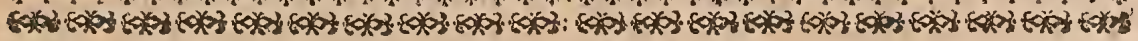

\section{H A P I T R E IV.}

\section{DE LA MANIERE DE TRACER Sur le Terrain toutes fortes de defjeins.}

T L ne fuffit pas d'avoir donné toutes les Pratiques précédentes pour l'inftruction des Jardiniers, quoiqu'elles foient bonnes en elles-mêmes \& très-faciles dans l'éxécution, néanmoins comme ce ne font que des chofes détachées, on pourroit objecter, que c'elt encore une nouvelle difficulté de les fçavoir coudre enfemble pour compofer un tout : c'eft - àdire, que ce feroit un nouvel embarras, quand on auroit à rracer une difpofition generale de Jardin. C'eft ce qui a déterminéà donner ici la maniere de tracer un plan général, où il fe rencontre toutes les différentes parties qui compofent un beau Jardin. On efpere par là donner la perfection à cet Ouvrage, en rendant un homme capable de tracer \& d'executer fur le terrain les deffeins les plus dificiles.

On fuppofe que cet homme aura bien examiné \& conçûu toutes les Pratiques qui font dans le Chapitre $\mathrm{I}^{\mathrm{r}}$ de cette $2^{\mathrm{e}}$ Partie, \&r les aura éprouvé \& tracé fur le terrain l'une après l'autre, ce qu'on a déja nomméles Elemens de la maniere de tracer. Donnons-lui maintenant les moyens d'appliquer en general toutes ces parties détachées, \& les mertre en ufage. dans une difpofition generale de Jardin, comme il fe voit dans la Planche fuivante.

Le terrain étant dreffé \& tout préparé à tracer fuivant ce qui vient d'être enfeigné dans les premiers Chapitres de cetre 2 e Parcie, \& le defiein de la dífpofition generale du. Jardin érant auffi arrêté, nous fuppoferons le bầiment fini \& achevé, aufí bien que les murs de l'enclos, n'étant point. de notre fujet de traiter de l'A rchitecture.

On propofe ici pour exemple une difpofition generale de Jardin, ou il fe rencontre des Parterres, des Bolquets, des. 
Boulingrins, des fontaines, \& $\mathrm{c}$. en un mot tout ce qui peus former un beau jardin, comme il fe voir dans cette Planche où ce plan eft fuppofé defliné fur un rouleau de papier. Fig. Ie.

$\mathrm{La}_{2}{ }^{\circ}$ Figure à côté, ou font marqués de fimples traits, eft pour reprefenter le terrain, \& ce qu'on doit faire pour y tracer \& raporter fidelement toutes les parties du petit plani, c'ef-à-dire les placer \& mettre en maffe.

On obfervera que pour raporter fidelement fur le terrain: toutes les parties \& mefures de ce plan, il faut fuivre exactement celles qu'on tronvera avec le compas, fur l'Echelle qui. eft au bas de ce rouleau de papier : ceque nous avons. dé.ja remarqué dans le Chapitre Ir de cette feconde Partie:

Quand on lira dans les Praciques ci-après, fuivantla 4 e, je; ou 6ePrasique; cela s'entend des Pratiques qui font dans le Chap. ${ }^{\text {er }}$ de cette Partie, \& non pas de celles qui font dans les. $2^{\mathrm{e}} \& 3$ echapitres précédens.

Pour en venir à la Pratique de tracer fur le terraín ce plan général, on commencera ̀̀ prolonger la façade du bâtimenı $A$, Fig. 2 e par des. jalons qu'on pofera de diftance en dif tance des deux côtés, d'alignement au bâtiment, comme eft la ligne $B \quad B$, fuivant la $\zeta_{e}$ Pratique : mefurés avec le compasfurl'Echelle du plan, combien il y a de toifes depuis le bâtiment $A$ jufqu'au parterre $C$, vous trouverés que cette allée de traverfe a cinq toifes de large $i$ portés certe mefure à la toife furle terrain, du pied du bâtiment, \& mettés un piquet au bout comme en $D$. Prenés le milieu de la façade du bâtiment $A$, plantés-y au devant la perche $E$, \& mefurant pareillement le milieu de l'autre façade dans la cour, plantés-y. une autre perche comme $E$, en les alignant l'une furr l'autre. à travers le Veftibule : pofés enfuite le demi-cercle, fuivant ce quel'on a dir ci-deffus, àla place du piquet $D$, de maniere que les pinules de fa bafe s'alignent fur les deux perches $E E$. Prolongés par des Jalons la ligne milieu $G G$, \& vous retournant d'équerre en mettant l'alhidade fur 90 dégrés, fuivas la $\mathrm{g}^{\mathrm{e}}$ pratique, alignés plufieurs jalons d'un bout à l'autre, qui vous donneront la ligne $F F$. Mefurés fur le plan la longueure que doit avoir le parterre $\epsilon$, qui eft de 18 toifes, prenés. encore la moitié de la largeur de la grande allée de traverfe. 
I A PRA TIQUE DU JARDINAGE. 149 $H H$, qui a cinq toifes de large, ce fera deux toifes \& demi, qui jointes à I 8 que le parterre $C$ a de long, font en tout 20 toifes \& demi. Portés cette longueur à la coifefur la ligne milietı $G G$, en commençant à l'endroit $D$, où vous avés pofé l'inftrument, \& aïant fixé un point à 20 toifes \& demi en delà comme en $I$, plantés-y un piquet; ce fera de ce point apellé centre, que vous tracerés tous vos principaux alignemens, vos maîtreffes allées \& les cercles du baffin \& de fon pourtour. Reportés l'inftrument qui eft en $D$ à ce centre $I$, fur lequel vous le poferés bien d'a-plomb ; mettés fa bafe d'alignement aux deux perches $E E$ près du bâtiment, \&i aux piquets de la ligne milieu $G G$; Alignés deffus plufieurs jalons d'un bout du Jardin à l'autre, environ jufqu'au point $K, \&$ mettant l'alhidade du demi-cercle fur so dégrés, retournésvous d'équerre pour l'allée de traverfe $H H$, où vous alignerés pareillement des jalons d'un bout à l'autre. Ces alignemens vous donneront les lignes milieu de vos grandes allées, \& portant par les deux bouts deux toifes \& demi de chaque côté de ces lignes milieu, fichés-y des jalons, \& fur ceux-là alignés-en d'autres, de cette maniere vos allées auront cinq toifes de large fuivant le plan.

Otés enfuite l'inftrument, \& au centre $I$ plantés un bout de perche, que vous enfoncerés un peu avant à la place du piquet : mefurés au compas fur le plan, le diametre duibafin , de fix toifes ; prenés un cordeau de trois toifes de long, qui eft le demi diametre, paffés-en la boucle dans cette perche $T_{\text {, }}$ \& tracés ce cercle, fuivani la I $7^{\circ}$ Pratique. Tracés enfuite du même centre $I$ l'allée d'en bas $L$ du tour du bafine qui eft la portion circulaire du parterre $C, \&$ ralongeant le cordeau à la mefure requife, tracés l'allée du pourtour d'en-haut pour former la demi-lune $M M$. Terminés cette demi-lune $M \cdot M$ aux rencontres des allées, par des jalons que vous. mettrés d'alignement aux autres $\&$ dans la trace de la demi-lune, ce qui marquera les quatre encoignures 0000 . Prenés enfuite fur le plan, la largeur du parterre $C$, de ro toifes; portés de chaque côté de la ligne milieu $G G$, cinq toifes, \& tracés ces deux lignes, par la Ie Pratique; qui avec celle d'en-bas FD F. \& la portion circulaire $L$, vous enclaveront \& borderont las place deftinée pour le parterre C.Il faúdra enfuite porter de= 
puis cette trace, la largeur des allées $P$, de trois toifes \& demie, \& aligner les jalons de ces allées, fur ceux des encoigaures 00 de la demi-lune, \& à la rencontre des deux allées de traverfe $H H \& F F$, plantés des jalons aux encoignures, qui borderont de ce côté les bofquets $2 \mathscr{2}$

Pour terminer vos grandes allées, melurés fur le plan combien de longueur l'allée en face du bâtiment doit avoir depuis la demi-lune $M M$ fupofé de 30 toifes de long: portés à la toife cette longueur, depuis les encoignures 00 de la demi-lune, $\&$ terminés-la parle piquet $K$ ou vous poferés le demi-cercle, en alignant fa bafe fur la ligne milieu, \& fur les jalons \& perches I GGE E, \& vous retournant d'équerre, vousalignerés des jalons des deux côtés fur toute la largeur, qui vous donneront la ligne d'équerre $R R$; mefurés enfuite proche du bâtiment $A$, la longueur de l'allée detraverfe $F F$, depuis la ligne milieu tirée fur le plan; cette longueur fera trouvée de 26 toifes pour chaque côté ; portés fur le terrain, depuis la ligne milieu ou perche $E 26$ toifes de chaque côté. Allés vous-en à l'autre bout, \& du piquet $K$ portés pareillement fur la ligne $R R 26$ toifes de chaque côté : terminés ces longueurs par des jalons, \& alignés-en plufieurs autres deffus; fur toute la longueur de ces deux côtes; ce qui vous donnera les lignes $S S \& T T$, \& vous terminera \& enclavera les places deftinées aux bofquets 22 , au bois $Y$ au boulingrin $X$, dont vous arêterés les encoignures par des jalons. Les allées du pourtour des murs fe traceront après cela fort aifement; en portant à la toife dans les deux bouts depuis les alignemens $R R, S S \& T T$, la largeur dont clles feront trouvér $S$ fur le plan, étant paralleles aux lignes tracées. A l'égard des: deux quarrés de potagers $Z Z$ qui font aux côtés de la cour, il eft inutile de dire que pour les tracer, on n'a qu'à prolonge $r$ les alignemens $S S \& T T$, \& $\&$. pour la longueur \& pour la largeur, porter depuis la trace de la ligne de traverfe $B B$, la quanticé de toifes dont ces potagers feront trouvés fur le plan : on cn aura par ce mö̈en les quarrés fans difficulté.

$$
\text { PREMIERE REMAR QUE. }
$$

Quoique l'on donne ici pour exemple un plan d'nne forme bien quarrée, néanmoins li l'on avoit un Jardin à tracer o thi 



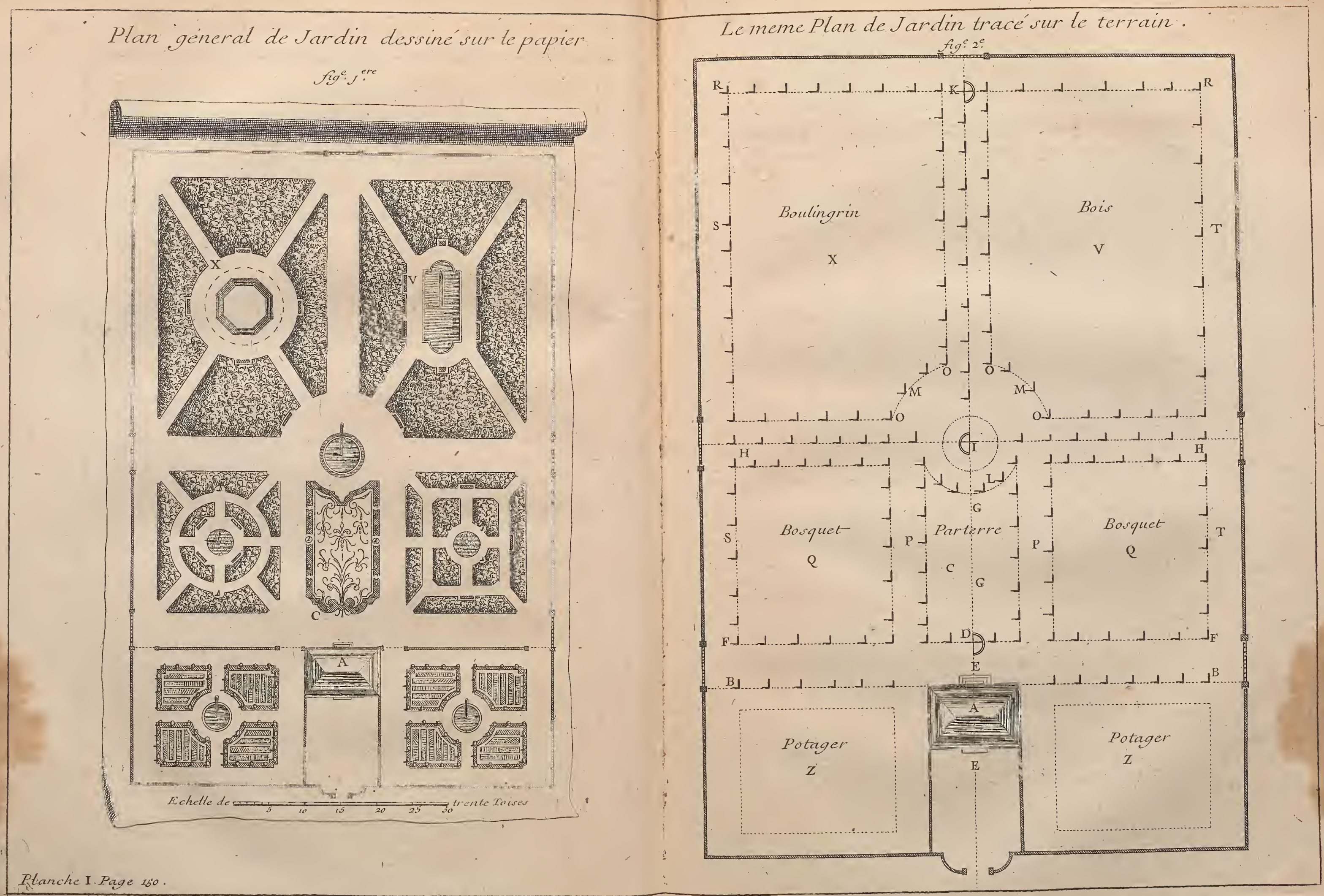



LA PRATIQUE DU JARDINAGE. ISI il fe trouvât des biais, comme ceux de la s, Planche des Difpofitions genérales Partie ie, l'on n'y auroit aucune nouvelle difficulté, finon d'ouvrirle demi-cercle, \& le mettre fur le même dégré, que le Rapporteur auroit fait connoître, en prenant fur le papier les ouvertures d'angles.

\section{$S E C O N D E R E M A R Q U E$.}

A près a voir tracé entierement un Jardin, il faut ôter tous les jalons \& piquets inutiles, comme ne faifant qu'embroüiller, \& ne laiffer que ceux qui font néceffaires; par exemple dans les bofquets $22^{2} z_{z} \cdot 2^{\circ}$ il $n^{\prime}$ en faut laiffer que quatre aux encoignures.

Voilà la meilleure maniere \& la plus expeditive de tracer un grand Jardin, en trouvant d'abord les principaux alignemens, toutes les lignes milieu, \& mettant en maffe toutes les parties differentes marquées fur le plan. Il ne refte plus qu'à donner la maniere de tracer le dedans de ces pieces, ce que l'on va voir dans les trois Pratiques fuivantes; la premiere pour tracer un Parterre, la feconde un Bofquet, \& la troifiéme un Boulingrin, qui font les trois principales parties d'un Jardin \& les plus difficiles à tracer. On a pris pour deffeins ceux qui font marqués dans le plan général deffiné fur le papier, Fig. Ie, comme le Parterre $C$, le grand Bofquer $V$ \& le Boulingrin $X, \&$ on les a raporté en grand dans cette planche, qui les reprefente toujours deflinés fur des rouleaux de papier, avec la pratique de les tracer fur le terrain qui $y$ eft jointe.

\section{PREMIERE PRATIQUE.}

\section{Tracerun Parterre fur le Terrain.}

La place étant bien unie \& bien préparée, comme nous avons dit ci-deffus dans le Chap. 2 e de cette Partie, il faut mailler fur le papier, le deffein du Parterre $C$, Fig. I e en le fé parant par des lignes tirées aucraïon, qui formeront en fe croifant de petits quarreaux d'environ trois pieds fur tous fens, felon lEchelle du plan. Ne vous embarraffés pas s'il refte au bour de la divifion une demi-maille ou quart de maille parce qu'il en reftera autant fur le terrain. Pour bien faire, il 
I54 SECONDE PARTIE, CHA P. IV. celle $A$. L'on en fera autant de $C$ en $D$, d' $E$ en $F$, de $G$ en $H$, d' $I$ en $K$, en y mettant des petits piquets : de cette maniere on prendra telle mefure, \& en aufli grande quantité qu'il fera nécelfaire, pour trouver exactement le contour de chaque feiille. Il y a moins d'embarras que de repaffer cent fois d'un côté à l'autre, pour prendre avec la toife ou le pied malgré les quarreaux, quanticé de mefures néceffaires, \&z même l'on ne rapporte jamais fi exactement cette moitié de deffein. Il eft fûr que ces cordeaux ne peuvent point vous tromper dans la pofition d'une figure, pourvâ que les piquets du milieu foient bien enfoncés, \& qu'on ne démare point les bouts croifés qu'on tient avec la main, cela eft tres-effentiel pour l'égalité des triangles.

\section{$S E C O N D E$ PRA TIQUE。}

\section{Tracer un Bofquet fur le Terrain.}

Les lignes du pourtour du Bofquet $V$, Fig. $3 e$, étant tracées furle terrain, \& les encoignures $A B C D$ terminées par des piquets. Pour tracer les deux allées apellées diagonales $A D$ $\& C B$, des jalons des angles $A B C D, F i g \cdot 4^{e}$, alignés-en d'autres fur toute la longueur, ce qui vous donnera les lignes milieu de vos allées; \& à l'endroir où elles fe croiferont comme en $G$, plantés-y une perche qui fera le point milieu; mefurés enfuite la largeur de ces allées fur le plan fupofé de deux toifes; portés aux deux bouts une toife de chaque côté de la ligne milieu, \& mettés-y des jalons fur lefquels vous alignerés le bord de vos allées. Après cela mefurés à la toife les decux largeurs du bois $A B \& C D, \&$ les deux longueurs $A C$ $\& B D$, en commençant des piquets des angles, \& marquésen jufte les milieux haut \& bas, par les jalons $E E \& F F$ * prolongés ces alignemens par d'autres jalons fur toute las longueur \& la largeur. A l'égard de la Salle du milieu, qui eft un quarré long ou parallelogramme, mefurés fur le plan, Fig. 3 e, combien il y a de toifes depuis le point milieu de la piece d'eau, jufqu'au centre des portions circulaires, cette longueur fera trouvée de cinq toifes fuivant l'Echelle; portés fur le terrain , Fig. $4^{e}$, furl'alignement $E E \&$ depuis le point milieu $G$. cing toifes de chaque côté , \& fichés-y des piquets 
LA PRATIQUEDU JARDINAGE. I 5 comme $H \& I$, ce feront les deux centres d'où vous tracerés toutes vos portions circulaires; pofés le demi-cercle fur un de ces piquers, comme en $H$, en mettant ŕa bafe fur l'alignement du milieu $E G E, \&$ fon alhidade fur 90 dégrés, pour vous retourner d'équerre, \& pour tracer la ligne $K K$; at deffus de dette ligne vous porterés de chaque côté, la largeur des allées du pourtour de la piece d'eau, trouvée de deux toifes \& demi fur le plan, pour tracer la ligne $N N$. Otésl'inftrument, prenés un cordeau, paffés-en la boucle dans le piquet $H$, \& tracés la portion circulaire $O$ fuivant le diamezre crouvé fur le plan, en arêtant votre trace à la rencontre de la ligne $K K$, par des piquets qui formeront les oreillons de la piece d'éau ; portés enfuite fur la ligne milieu $E G E$, depuis la trace de la portion circulaire $O$ la largeur des allées du pourtour de deux toifes \& demi, mettés-y un piquer, \& ralongeant le cordeau à cette longueur, tracés du même centre $H$ la portion circulaire $P$ de la Salle, jufqu'à ce que yous rencontriés la trace de la ligne $N N$, out vous metrrés des piquets qui détermineront les oreillons de la Salle. Vous poferés enfuite le demi-cercle à l'autre bout, comme au centre $I$, en faifant la même opération pour tracer les lignes d'équerre $L L ; \& M M, \&$ reportant le cordeau dans le piquet $I$, vous tracerés les portions circulaires $2 \& R$ des mêmes, longueurs qu'à l'autre extremité. Cela fait vous porterés fur les lignes $K K \& L L$ depuis les piquets $H \& I$ de chaque côté, la moitié de la largeur de la piece d'eau, qui ent de deux. roifes \& demi , où vous mettrés des piquets, d'où vous porterés encore la largeur des allées du pourtour. Jalonés toutes ces lignes d'un bout a l'autre, tracés-les en tendant le cordeau de piquet en piquer, \& les terminant par des jalons, d'alignement aux bords des deux allées diagonales $A D \& C B$, cela achevera de former la piece d'eau \& la Salle du tour. A l'é-gard dés renfoncemens \& des niches pour les bancs \& les figures, on fe fervira de l'équerre de bois pour en tracer les resours, \& l'on fuivra les mefures marquées fur le plan Fig. $z^{\mathrm{e}}$.

$$
\text { R E M A R QUE. }
$$

On doit en traçant une piece d'eau ou de gazon cintrée parles bours, remonter un peu le centre de quelque pouce, 
I56 SECONDE PAR TIE, ChAP. IV.

cela fait toujours mieux en ouvrage, auffi-bien que de faire les oreillons de ces pieces forts petits, étant très-défag réables. à la vîë, quand ils font trop grands.

\section{TR OIS IE'ME PRA.TIQUE.}

\section{Tracer un Boulingrin Jur le Terrain.}

On fuppofe le Boulingrin marqué $x$ fur le plan, fig. ge zracé en octogone fur la fuperficie de la terre, fuivant la I $6^{\circ}$ Pratique, ainfi l'on n'a plus befoin que de la maniere de lé renfoncer. Plantés des piquets aux huit angles de l'oetogone, fig. $\sigma^{\mathrm{e}}$, enforte qu'ils excedent tous également la fuperficie dela terre, comme d'un pied de hatit, en fupofant que cette fúperficie fera bien dreffée de niveau. Remarqués fur l'Echelle combien les talus doivent avoir de largeur d'angle en angle, par exemple de fix pieds, mettés plufieurs piquets à l'aventure à huit à neuf pieds en dedans de ceux des angles, ils ferviront à faire creuferla terre tout autour, fans en enlever versles bords, que l'on doit conferver pour couper les talus en terre ferme, c'eft ce qui eft exprimé par le ferpentement a a a a. La plus grande partie de votre terre étant en. levée, felon ce qu'on a dit dans le chap. $2^{\mathrm{e}}$, \& a äant dégrofil le talus tout au tour, c'eft-à-dire, l'aïant coupé à peu près-dépuis les piquets d'en-haut, jufqu'au ferpentement a a a a ; pour. unir \& égaler parfaitement le fond du Boulingrin, enfoncés des jalons vis-à-vis de chaque angle, \& à huir à dix pieds de diftance, qui s'alignent fur les piquets de ces angles, \& qui fe trouvent d'égale hauteur. Vous méfurerés fur ces jalons en contre bas, un pied qu'ont de hauteur les piquets des angles, \& vous y ferés une marque a vee du charbon. Joignés -y ce que vous voulés donner de renfoncement au Boulingrin, fupofé de deux pieds. Vous ferés butter ou décharger du pied ces jalons fuivant le befoin , de maniere qu'ils aient en tout trois pieds de haut. Enfuite vous attacherés un cordeart. au pied d'un des piquets des angles, comme en $H$, \& fur la marque noire faite furle jalon $\mathbf{X}$ vis-à-vis, vous y attacherés l'autre bout du cordeau : Vous mefurerés deffus ce cordeau bien tendu, fix pieds qu'a la largeur du talus d'angles en angles, au bout defquels fix pieds vous ferés tomber un à-plomb 








IA PRA TIQUE DU JARDINAGE 157 jufques dans le fond, en faifant arrazer \& dreffer les terres pour y planter un piquet à tête perduë. Faites la même operation aux feptautres angles du Boulingrin ; aïant ainfi trouvé \& arrêtépar des piquets, les huit angles d'en-bas, tendés le cordeau d'angles' i en angles, \& tracés le fecond octogone du fond. Cela fait, vous alignerés des jalons par tout, dont les têtes s'ajuftent à la hauteur des jalons \& des piquets des angles d'en-haut, comme on le voit par les jalons $B C D E F$ $G$, que vous mettrés tous à la hauteur de trois pieds. Vous tendrés un cordeau de l'un à l'autre jufqu'aux jalons d'enbas, \& par des rigoles vous unirés tour le fond de ce Boulingrins, fuivant la ze Pratique du Chap. ze. A l'égard de la nraniere de couper \& de dreffer le talus, on aura recours à ta $4^{\mathrm{C}}$ pratique, \& aux remarques du chap. précédent.

Quand on entendra bien ces trois Pratiques, \& qu'on atira tracé fur le terrain ce Parterre, ce Bofquet \& ce Boulingrin, on en tracera après fort aifément une grande quantité; car quoique les deffeins foient differens, cela fe raporte toujours à la même méthode. Ainfi un Jardinier qui aura un Parterre ou un Bofquet à tracer, n'a qu'à confulter la Pra. rique de tracer un Parterre, un Bofquer, \&c. en fuivant exactement ce qui y eft enfeigné , il en viendra facilement à bout.

On ne parle point ici de tracer un Potager, un Bofquet en Quinconce, un Parterre à l'Angloife, \&c: ces fortes de deffeins feront fort aifés à tracer, quand on aura bien pratiqué ce que l'on vient de dire au fujet de deffeins plus compofés, \& par conféquent beaucoup plus difficiles à raporter fur le terrain.

Il faur remarquer que dans les grandes mefures \& alignemens, on doit mefurer parles deux bouts, \& jamais dans le milieu, cela eft plus exact.

Quand: vous rencontrerés fur le Terrain', de l'erreur avec le plandur papier, ce quì arrive affés fouvent, il faut verifier \& examiner toutes les mefures l'une après l'autre, pour fçavoir où l'on aura manqué, \& fil l'on ne peuc le trouver \& que l'erreurfoit peu confiderable, on la partagera en deux; or ne s'apperçoit jamais de cela fur le Terrain ; quelque circonfpect qu'on puiffe être, il eft prefque impoffible d'éviterces petites fautes.

$\mathrm{V}$ iij 
Is SECONDE PARTIE, CHAP. IV.

S'il naît quelque difficulté dans la Pratique touchant le demi cercle, la toife, le cordeau, ou fur quelque terme qu'on n'entende point, on aura recours aux trois Chapitrés précédens.

Il ne fera pas hors de propos, avant que de finir cette Partie, de dire de quelle maniere on peut retrouver le centre d'un cercle, d'un octogone, ceux d'un ovale, \&x. dont les mefures ont été ốtées en plantant. On a fouvent befoin de ces Pra. tiques, quoique l'on ait un Jardin neuf, foic pour changer de tems en tems le gazon des pieces rondes, des bordures de Baflins, des Boulingrins \& des grands tapis cintrés par les bouts, foit pour faire d'autres changemens dans de vieux Jardins.

On fe fert d'une même prat:que pour un Boulingrin rond, $\&$ pour une piece circulaire \& plate : elle confifte à prendre le milieu des allées qui y aboutiffent, y mettre des jalons, \& dans l'endroit oì les deux alignemens fe croiferont, planter un piquet qui fera le centre cherché. S'il n'y avoit que deux allées fur le même alignement, on prendra exactement le milieu du diametre de la piece, c'en fera le centré.

Pour regazoner le pourtour d'un baffin rond, on paffe le cordeau fur l'ajoutoir du jet, \& on le plie en deux , cela fert à tracer cette circonference qui eft parallele à celle du baflin: il fe rencontre quelquefois des figures au milieu d'un baffin, ce qui caufe un peu d'embarras quand l'ajoutoir eft enclavé dans la figure, maison n'a qu'à ficher un bâton dans cet ajoutoir \& y paffer le cordeau.

L'octogone, l'ovale, fe retracent facilement par les methodes ci-deffus enfeignées, en obfervant de les taire paffer par les mêmes points oì ils paffoient auparavant, afin qu'ils fe raportent aux pieces voifines. A l'égard des grands tapis de gazon cintrés parles bouts, des pieces à l'Angloife coupées en compartiment, on les retracera en fuivant les piquets qu'on aura eu la précaution d'enfoncer tout au tour, avant que d'ôter le gazon, comme il a été dit ci-devantpage $S_{2} ; \&$ fi ces pieces font trop ouvragées, on peut le redeffiner furle papier, \& les maillerfurla terre, comme on fait les parterres.

Il n'y a de difficultés dans toutes ces pieces, que lorfqu'il fe rencontre un piedeftal qui en occupe le centre, cela ne 
IA PRATIQUE DU JARDINAGE. I59 fait rien dans l'octogone, car au lieu de le tracer de l'angle du centre, on le tracera de l'angle du Poligone. L'ovale ne donneroit aufli aucun embarras, les deux centres étant de hors un piedeftal placé au milieu, on le tracera prefque tout au tour, \&l'on-achevera le refte à l'ocil ; mais dans les pieces où il fe trouve des cercleś, au centre defquelles font des figures, on ne laifferoit pas d'être fort embarraffé, fans les deux mö̈ens fuivans. Le premier, en fe fervant d'un cerceau de bois affés fort pour pleïer difficilement, que l'on liera au tour du piedeftal, de maniere qu'il affleure fes quatre carnes: vous y attacherés un cordeau convenable à la grandeur du cercle, \& vous ferés foûtenir le cerceau par un homme, en telle forte qu'il tourne facilement au tour du piedeftal, \& qu'il foit à peu près parallele, de même quele cordeau, à la ligne de terre; vous pafferés le traçoir à l'extremité du cordeau, \& vous tra- lent ea terze. cerés ainfi votre cercle dans une jufteffe fuffifante dans la Pratiquie, car on ne prétend pas que cela foit dans toute la rigueur Géométrique. Dans un Boulingrin on tracera les deux cercles paralleles l'un après l'autre. On fupofe que le piedeftal foit circulaire ou un quarré parfait, qui font les figures les plus ordinaires; fr cétoit un Rectangle, cette pratique feroit inutile. Le fecond moïen ne peut fervir qu'en cas qu'il y ait des arbres ou une paliffade au tour d'un rond de gazon, alors on portera de chaque arbre ou du pourtour de la paliffade, la même diftance de pied en pied, en s'alignant toujours à peu près au milieu du piedeftal, comme le centre, \& l'on fichera de petits piquets par où doit paffer le cercle, que l'on tra. cera le plus précifément qu'il fe pourra à l'œil ; cette méthode n'eft jamais fi bonne que l'autre, étant fujette à des jarets, mais imperceptibles fur le Terrain.

On peut éviter en partie la peine de retrouver des centres, en y enfonçatat bien avant, de gros piqueis de bois de chelne, quand on les trace; mais à la longue ces pi- 


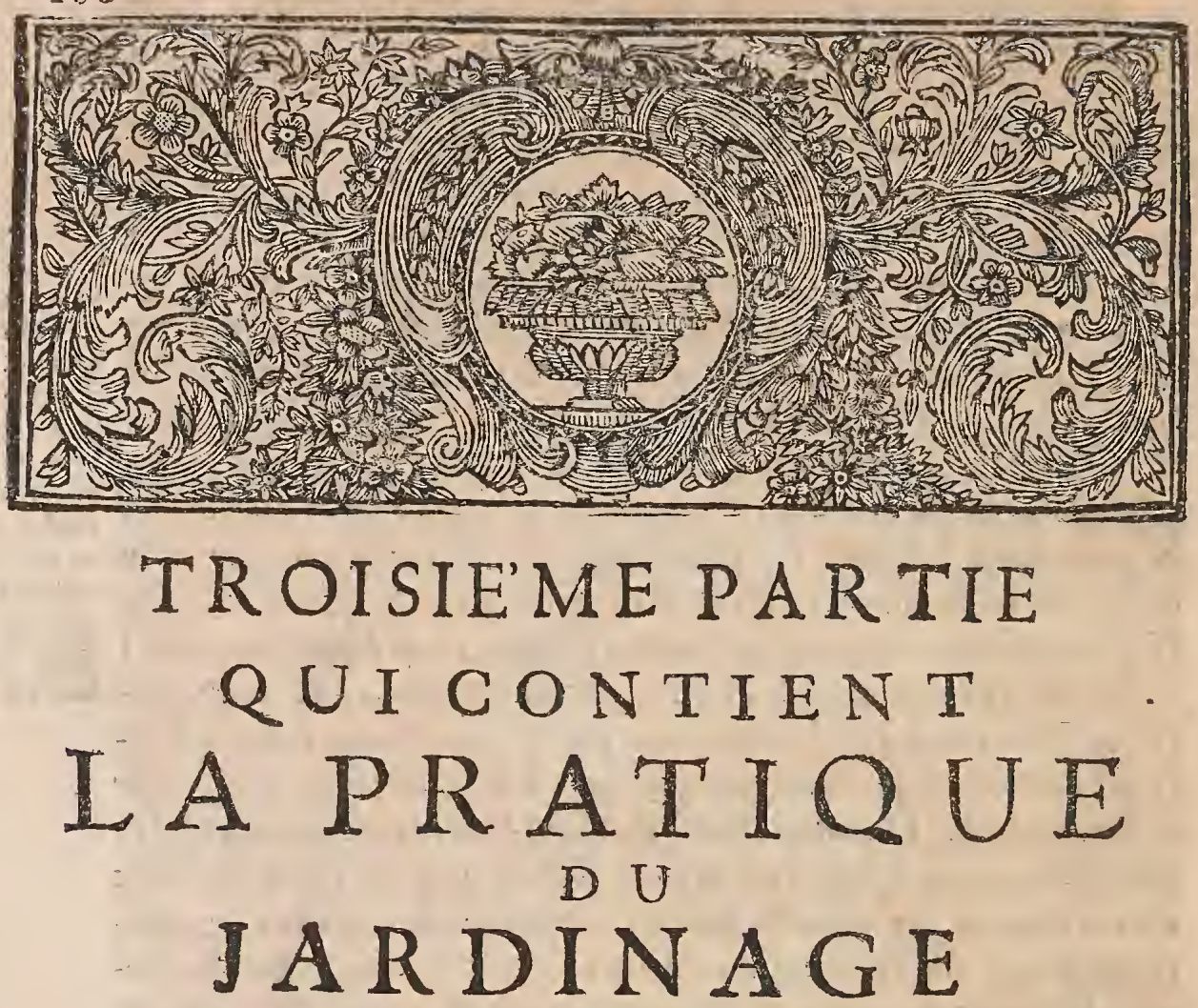

En ce qui regarde la maniere de planter.

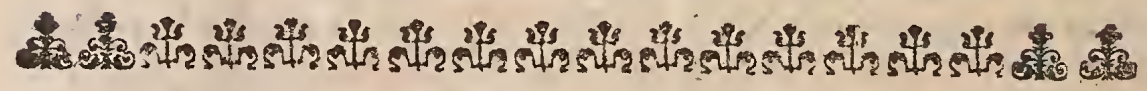

$$
\text { C H A P I TR E PR E M I ER. }
$$

DU CHOIX QUE L'ON DOIT FAIRE des Arbres convenables aux fardins de Propreté, or de leurs bonnes marvailes qualités.

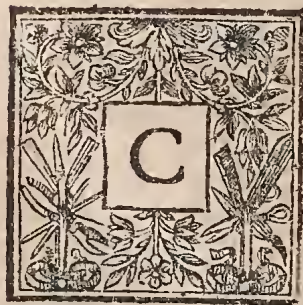

En'eft pas feu de chofe, que de fçavoir bien choifir les A rbres, \& lesPlants dont on doit fe fervir dans les Jardins. Les plus habiles connoiffeurs s'y trouvent fouvent trompés malgréleur expérience:cependant il y a des marques affés certaines, pour fçavoir diftinguer les bons Plants d'a vecles mauvais; c'elt ce qui fe verra à ia tin de ce Chapitre, oì l'on referve à en dire tout ce que l'on peut 

haiter, pour pouvoir faire un jufte difcernement de leur bonté.

On appelle tous les arbres qui fervent communément dans les Jardins de propreté, de deux fortes de noms, les Sauvages \& les Aquatiques.

Les A rbres Sauvages font ainfi apellés, à caufe que de leur nature ils croiffent dans les bois \& les forêts, comme le Chefne, l'Orme, le Chataignier, le Charme, \&cc.

Les Arbres Áquatiques, qui font en bien plus petir nombre, fe nomment ainfi, parce qu'ils fe plaifent dans l'eau, \& qu'ils y croiffentmieux qu'autre part; tels font le Tremble, le l'euplier, l'Aulne, \&c.

A vant que d'entrer dans le détail de tous les Arbres fuivans, il eft bon d'expliquer ce que c'eft que Bouture, Jettons ou Rejettons \& Marcotte. Quand on dit qu'un Arbre vient de Bouture, c'eft-à-dire, qu'on n'a qu'à en couper une branche, en aiguifer le bout \& la ficher en terre, elle prendra racines \& produira un arbre de la même efpece: Au lieu que jettons ou rejettons font des brindilles \& rameaux qu'un Arbre pouffe du pied, \& quel'on leve tout enracinés, quand ils ont un peu de force : C'eft à proprement parler des racines éclatées du mâ̂tre pied. Marcotter n'eft autre chofe que de choifir au pied d'un arbriffeau, des rejettons $\&$ des branches pendantes qu'il fautéplucher, de maniere, que ce qui doit être en terre foit entierement dépoüillé de feüilles, \& fans les couper, on les couche cinq ou fix pouces avant dans la terre, pour leur faire prendre racines: Celles qui font trop roides feront arrêtées avec des crochets de bois; \& la feconde année on * les fépare du corps de l'Arbre, pour les replanter ailleurs.

Venons maintenant à la defcription de tous ces différens Arbres, en les fpécifiant l'un après l'autre, $\&$ en parlant de leur bonne \& mauvaife qualité, ce qui eft effentiel de bien connoître; pour en faire un bon choix ; commençons par le Chefine.

LE $C_{H E} S N$ E eft, pour ainfí dire, le Roi des Arbres. C'elt un des plus beaux quela terre produife, il eft fort long. tems à croître ; mais aufifi c'eft celui qui dure le plus. Il jette

* Cela s"apelle fevrer une marcorte.

$\mathrm{Ces}_{\mathrm{s}} \mathrm{defcrip}$ tions ne font point faites fuivant la Botanique, qui a d'autres objets que ceux de l'Agriculture, elles foint faites feulement pour donner l'idée de chaque arbie, par raport à fa pro. priciédans les besux Jardins.

LE CHESNE. un pivot en terre prefqu'auffi long que le brin qu'il poufe dans l'air, qui le garantit contre les grands vents. Il vient 
162 TROISIEME PARTIE, CHA P.I. droit \& haut. Son bois eft fort dur \& très-recherché pour les bâtimens. Sa feuille eft belle \& donne beaucoup de couvert. LeChefne eft plus propre dans les forêts \& dans les bois, qu'à former dés allées bien droites; il eft un peu fujet aux hanetons \& autres vermines. Son fruit que l'on apelle du gland, fe feme ou fe pique en terre; c'eft par-là quille perpétuë. Ce fruit fert eñcore à nourrir \& engraiffer des Porcs.

IOR ME.

L'O R M E eff encore un des plus beaux Arbres qu'il y ait On dit delui \& du Chefne, qu'ils font cent ans à croître, cent ans en étar, \& centans à dépérir: On peut juger par-là qu'il dure très-longtems. Il monte droit \& très-haut, fon feüillage eft petit, mais fort touffu; fon bois eft fort dur \& trèspropre pour le Charonnage, fon écorce eft un peu raboteufe. L'Orme crồt bien plus vîte'que le Chefne, \& il eft plus eftimé pour planter des Allées \&x des Bofquets. C’êt un de ceux qui eft prefentement le plus à la mode, quoique bien des gens n'en veulent point planter, parce quilis difent que l'Ormie eft trop gourmand, étendant fes racines trés-loin, en 'quantité, \& prefque à fleur de terre, ce qui peut ufer le terrain d'alentour : Il eft fort fujet à la chenille \& aux vers: Il produit de la graine, \& vient de rejettons aux pieds des g̀rands Arbres.

L'YPREAU', OU L'I M PERI A 2 .

* Opinión

fort incertaine, de croire que les arbres ont leur mâle \& femelle; cependant les Auteurs font fort partagés là-deffus, ce gui a rendu eetre queftion indécife jufqu’à prefent.

LE CHATAI. CHIRR.
L'Y P R E A U, qui n'eft autre chofe que l'Orme à largès feüilles, appellé communément l'Orme * femelle, eft fort recherché pour les belles allées, on le nomme Y.preau, à caufe quil vient originairement des environs de la Ville d'Ypres enFlandre. Sa feüille eft très-large, \& bien plus belle que celle de l'Orme ordinaire; fon bois vient droit, fon écorce eft fort claire \& fort unie : il croît trés-vîte; auffi ne duret t-il pas tant que l'autre Orme. Il donne de la graine, $8 x$ pouffe des boutures ; les hannetons \& les chenilles s'y atsachènt beaucoup.

LE CH A T'A I G'N I E R eft un Arbredes plus confidérables par raport à fon revenu: Il s'éleve trés-haut, mais il ne fe plaît pas par tout. Son écorce eft belle \& claire; il forme un bel ombrage par fes larges feüilles : il eft plus propre à planter des bois que des allées, à moins que ce ne foit dans la Campagne ou dans quelque Parc, que l'on en plante aux endroits écartés: Son bois eft blanc \& fe plie facilement. On 

s'en fert à faire des cerceaux : Son fruit qui eft la Chataigne eft eftimé, \& d'un gros profit ; on en mange quantité , \& il y a des Païs oì l'on en fait du pain. Cet A rbre dure affés longtems, \& n'eft fujet à aucune vermine. L'on prétend même qüe la Charpente faite de bois de Chataignier, ne fe pourric jamais: On feme la Chataigne comme le Gland.

LE TIL L E U L Ou TI L L O T eft undes Arbres des plus recherchés pour planter des allées $\&$ des bofquets: fa feüille, fa tige, fa têté, fon écorce, tout en eft beau : il jette dans, l'Efté des fleurs dont l'odeur eft fort agréable; fon bois n'eft pasdes plus eftimés, étant du bois blanc, auffi s'en fert-on peu dans les ouvrages, cependant on fait des cordes à puits avec fon écorce. Cet A rbre ne fouffre aucune infecte; mais. il fe verfe \& fe creufe aifément, \& par-là il n'eft pas d'une lon gue durée. Il y en a une efpece apellée Tillot d'Hollande; qui eft la plus eftimée à caufe de fon large feüillage : Il pro-, duit de la graine, \& vientaifément de marcottes.

LE MAR R ON I E R B'I N D E, àpelléainfi, parcequ'on aporté des Indes des Marrons, qui en ont multiplié l'elpece: en France, eft un des plus agréables Arbres à la vûë. Sa tige droite, fon écorce unie, fa tête réguliere, fon beau feüillage; fes fleurs en piramides le font rechercher plus qu'aucun autre. Il n'eft bon qu'à former des allées, étant un trés-mauvais arbre pour planter des quarrés de bois. Il ne s'éleve pas bien haut, mais il eft fort droit, fon bois eft tendre, caffe aifément \& n'eft propre à aucun ufage, pas même à brûler, noirciffant dans le feu; ainfi cet Arbre n'eft d'aucun raport. Sun fruit n'eft bon qu'à planter: on dit cependant qu on a trouvé le fecret depuis peu d'en faire de la poudre pourles cheveux: L'on prétend encore qu'il guérit les chevaux pouiffifs, d'oùil a pris le nom de chataignes de cheval. Tout le mérite qu'a le Mtarronier d'Inde, c'eft de crô̂tre fort vite ; auff eft-il de peu de durée, \& fort expofé aux hanetons, qui le dépoüillent entierement de fes feüilles, jufqu’à laiffer fa têt te toute nuë.

LE HESTRE OU FOUTEAU, eft encore Un bel AY LE HESTE

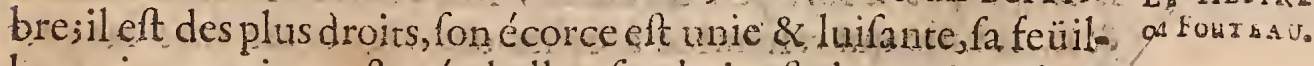
le quoique petite, eft trés-belle; fon bois eft dur \& s'emploï à quantité d'ouvrages. Cer A rbre eft trés-propre à former dos

LE MEARONIIR DitNDE, OU CHATAIGNIER DE CHEYA . $X i j$ 
I64. TROISIE'ME PARTIE, CHA P. I. allées, des paliffades $\&$ des bois ; mais il eft trés-fujet aux hanetons \& aux chenilles. Il produit un fruit apellé Faine, que l'on mange, \& qui a le gout de noifette; l'on en fait de l'huile, \& quelquefois du pain dans les tems de famine il l'on feme de ce fruit pour avoir de fon efpece.

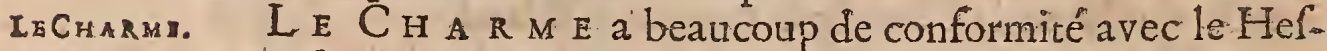
tre, fon bois, fon écorce, fa feüille étant fore femblables : il eft propre comme le Heftre, à former des allées, des paliffades \& des bois, mais furrour des paliffades où ì eft emploié plus qu'aucun autre plant. Alors il change de nom, \& on l'apelle Charmille, qui n'ettautre chofe que de petits Charmes d'environ deux pieds de haut; \& gros par en bas comme le petic doigt ; il ne raporte point de fruit, mais quantité de graine qui eft trés-longue à lever; fon bois eft des meilleurs à brûler. Cer A rbre eft difficile à la reprife, excepté dans les Pa is frais, \& fort-recherché par les chenilles \& les hanetons.

L'E R A B L E a un mérite particulier, c'eft qu'il vient

L'ERAFZ: ì l'ombre \& aux pieds des grandsArbres. Il croît allés haut, mais un peu tortu; fon bois eft fort dur \& vaineux, \& l'on s'en fert pour faire des meubles $\&$ des inftrumens de mufique; fon écorce eft fort raboteufe, fa feüille eft d'un verd pâle, \& r'eft pas fi belle que celle du Heftre \& de la Charmille: On l'emplö̈e à garnir des bois, \& à planter des paliffades, \& prefentement c'eft l'Arbre le plus à la mode ; fa graine leve promptement. Il eft un peu fujet aux hanetons.

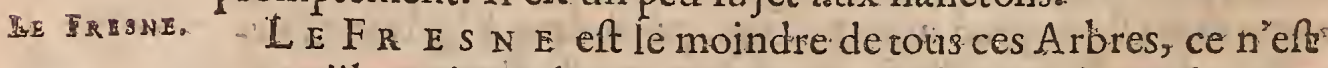
pasqu'il ne vienne beau $\&$ droit, mais fonpeu de verdure \& fon ombre mal faine le font emplöier rarement dans les Jardins., à moins que ce ne foit dans les bois ; fa feüille eft extrêmement petite $\&$ d'un verd pâle, fon bois eft fort uni \& fansnouds, ce qui le fait emplöier à quelques ouvrages : i donne de la graine qui leve fort vîte, les mouches cantarides s'y attachent particulierement. LI Ircoso . LE SYCOMORE s'éleve affés haut ; fon bois eft fort tendre, \& étant rompu il jette du lait comme le Figuier, il eft propre à forì peu de chofe; fon écorce eft alfés belle, \& fa feüille qui reflemble à celles des vignes eft fort large: il dure trés-peu \& meurt facilement; la meilleure qualité quil ait, c'eft de crốtre fort vîte \& par tout. Cet Arbre eft 
IA PRA TIQUE DU J ARDINAGE. 165 fi fort attaqué par toutes fortes de vermines, qu'il n'eft pas de grande recherche dans les Jardins; il produit beaucoup de graine, qui tombant d'elle-même, croî́ aufil facilement que les méchantes herbes.

LE BOU L E A U eft un des moindres Arbres, quoiqu'il monte affés haut. Son bois eft blanc, \& 'n'eft propre qu'à faire des balais \& autres bagatelles; fon écorce eft blanchâtre $\&$ raboteafe. Il donne peu d'ombrage, fes feüilles étant extrêmement petites \& femblables à celles du Peuplier. Cet.A $r$ bre fert de premiere verdure au Printems, \& ne fouffre aur cune vermine, c'eft ce qu'il a de meilleur, mais il fe verfe aifément. On eft en quelque conteftation pour fçavoir, fi c'eft un Arbre aquatique ou fauvage, parcequ'il vient également bien dans les Paîs fecs \& humides; il graine beaucoup.

L'A C A C I Á, apellé l'A cacia commun de l"Amerique, a été autrefois fort en vogue. Il ne s'éleve pas bien haut, fon bois eft dur \& raboteux, fon feüillage petit; donnant peu d'ombrage, \& fes branches pleines de piquants. Tout le mérite que peut avoir l'A cacia, dont on plantoit autrefois quantité d'allées \& de berceaux, c'eft qu'il crô̂t fort vîte, \& produit dans le Printems des fleurs d'une odeur fort agréable. Mais comme il eft forr fujet à fe verfer, que fon écorce eft raboteufe, \& fa feüille trés-petite, l'on n'en fait prefentement nul cas. On a côtutume de l'étêter de tems en tems, ce quï lui caufe encore un grande difformité. Cer Arbre graine, ainf que tous les autres.

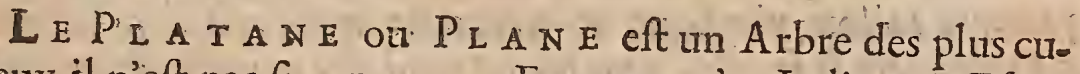
rieux, il n'eft pas fi commun enFrance, qu'en Italie \& enEfpagne, la raifon eft, que de fa nature il aime les $P$ ais chauds. Le Platane devient trés-beatz, fort droir \& donne beaucoup d'ombrage; fon bois eft dur \& blanchâtre; auffi-bien que fon écorce qui eft fort unie : fa feüille reffemble à celles. du Sycomore; il vient de graine en France, mais aflés difficilement.

LE T R E M B L $\Sigma$, auffi-bien que-les troisArbies fuivans, eft de la nature de ceux qui fe plaifent dans l'eau, c'eft-àdire, des Arbres aquatiques : H vient haut $\&$ droit; fon bois blanc \& leger fert à plufieurs ouvrages : fon écorce eft unie \&blanchâtre : fes feüilles font rondes, d'un verd pâle, 8

LEPIATANE OU $P_{1} A M E$.

LE TREMA Bप़. $\mathrm{X}$ iij 
L $R$ LURE OU MIVERN.

IS PEO2355R.

EE SAULE.

L'EPIN E BLANCHE, apelléc vulgairement.

NoBLE EPISE.
166 TROISIE'ME PAR TIE, CHA P. I. tremble toujours au moindre vent, d'ou il a pris le nom de Tremble. L'on en plante de belles allées autour des étangs \& canaux; il croît fort vîte, \& vient de jettons \& de marcottes.

L'A U L N E ou I E V E R N E s'élevetrés-haut \& trésdroit ; fon bois eft à peu près femblable à celui du Tremble, \& fa feüille à celle du Coudrier; fon écorce eft fort unie \&z de couleur noirâtre. L'on s'en fert dans plufieurs ouvrages, mais particulierement à conduire des eaux, en le creufant en forme de tuiaux; il vient pareillement de boutures $\&$ de marcottes.

L E P E U P L I E R differe peu de ces Arbres. Son bois eft blanc, facile à fendre, \& n'eft prefque d'aucun ufage; fonécorce eft unie \& blanchâtre, ainfi que fes feüilles, qui font larges, gluantes \& d'un verd poli ; il crôt aufif de bouture.

LE SA U L E ne monte pas bien-haut, \& c'eft le moindre de tous les Arbres; fon bois eft blanc \& propre à faire des paniers \& des perches; fon écorce eft fort vilaine, fes feüilles. trés-petites, longuettes, \& d'un verd alteré. Le Saule eft fort fujet à fe creufer \& a verfer; auffi ne dure-t-il guere ; on l'étête tous les trois ou quatre ans. Il croît de boutures, apellées Plançons, qu'ón plante au bord des ruifleaux, \& dans les lieux marêcageux.

Les Arbres aquatiques ont un mérite qui les diftingue fort des fauvages ; c'eft de n'être fujets à aucune vermine, par une raifon phyfique \& naturelle qui, eft, qu'ils font d'une nature fi froide, que les infectes n'y peuvent faire leurs œuts.

On nomme en général tous les Arbres dont on vient de par: ler, bois de haute-futaie ; les fuivans ne font que des arbriffeaux, dont on fe fert dans un bois, pour faire du garni \& de la brouffaille au pied des grands arbres.

L'EPINE BLA C C E, autrement dite, L'A U B EI' I N E OU L'A U B E P I N, eft un arbriffeau des plus confiderables, tant à caufe de fesfleurs qui rendent une odeurr trésfuave, que parce qu'il atrireleR oflignol, qui eft le muficien le plus agréable des bois. Cet arbriffeau croît facilement:Il eft ar. mé de piquans fort aigus \& par cet endroit trés-propre à plan-- 
LA PRA TIQUE DU JARDINAGE. 167 ter des haies vives, dont il défend l'aproche par fes pointes; fes feüilles font dentelées $\& \mathrm{~d}$ d'un fort beau verd.L'Epine blan. che eft trés-fujette aux chenilles, elle vient de graine ordinairement.

LE COUDR I ER OU NOIS ETIER eft encore un des plus beaux arbriffeaux pour garnir des Bofquets; fon bois eft fortclair, \& jette quantité de brańchages; fa feüille NoIs $\mathrm{DTX} E \mathrm{Q}$. eft belle \& trés-large, furtout celle du Noifetier franc, dont le fruit eft le plus eftimé: l'on ferne ce fruit apellé Noifette, qui en perpétuë l'efpece, ou bien on en fait des marcottes. On attribuë à cet arbriffeau des propriétés admirables pour plufieurs fécrets, comme pour découvrir les eaux, les vols, \& affafinats, les tréfors cachés, mais cela n'eft pas fort fûr.

L E MARSAULT eft aquatique \& fauvage, \& monte $L$ E MAXaffés haut. Il a le bois blanc, la feüille ronde-\& d'un verd s $A \cup \mathrm{L}$. clair, il fe multiplie de marcottes \& de jettons.

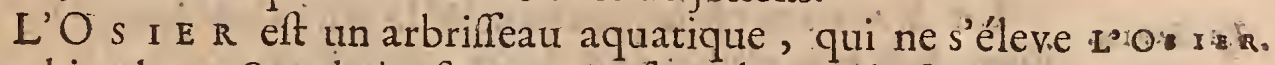
pas bien haut. Son bois eft menu $\&$ ' fort pliant. Il eft propre à faire des paniers, des hottes \& quantité d'autres ouvrages, qui le rendent d'un bon revenu, parce qu'on le coupe fouvent : fes feüilles reffemblent à celle du Saule ś. il vient de boutures \& de Marcottes.

It y a encore des arbres \& arbriffeciux de plufieur's efpeces, dont la defcription particuliere meneroit trop loin; c'eft pourquoil l'on fe contentera de les nommer en général ; tels font l'Alifier, le Mirabolanier, le Cormier, le Cornoüiller, le Figuier, le Murier blanc, Sureau, Sanguine, Fufin, Merifier, Azerolier, \&cc. dont la plûpart fe perpetuënt de leurs frúits.

On fe fert auffi pour garnir les bois, des plants de Charmille, d'Erable, d'Ormeaux, Chefneaux, Chataigniers, que l'on refepe par la tête, afin d'en faire de belles * touffes \& fe- " Les Jardipées de brouffailles.

Il ne refte plus qu'à parler des arbres \& arbriffeaux quii ine ces touffes. fe dépoüillent point de leurs feüilles enA utomne, confervant leur verdure dans les plusgrands froids de l'Hyver, ce qui leur donne le nom de bois ou arbres verds. Voici ceux que l'on emploïe ordinairement dans les Jardins.

L'I F eft un des plus beauxarbriffeaux verds; il devient 'fi L'I : 
grand \& $\mathbb{1}$ petit qu'on veut, en un mot de toute forte de for: mes, étant fujet à la tonture. Son bois eft fort dur, fon feüillage trés-garni \& d'un verd foncé des plus agréables à la vuë. Il eft propre aux paliffades, comme auffi à garnir les platesbandes des Parterres. On prétend que fon ombre eft fort dangereufe \& malfaine. Il donne de la graine qui eft trés. long-tems à lever, il vient auffi de marcotte.

* Fatale oft Lormire fub Ifum.

IE PreEA.

LE SABIK. LE P I C EA, appellé vulgairement E P I C I A, reffemble affés à l'If, pour le bois \& la feüille; mais il s'éleve bien plus haut, \& ne devient nifi beau ni figarnique l'If. Il ne convient que dans les bois \& dans les grandes allées doubles, où on le place entre les arbres ifolés. On ne met plus de Picea prefentement dans les Parterres, parce qu'ils s'élevent trop hauts, \& qu'ils font fujets à fe dégarnir du pied. Le Picea produit de la graine, qui n'eft pas fi longue à fortir de terre que celle de l'If.

LE S A P I N eft le plus haut \& le plus droit de tous les arbres. Son bois eft blanc $\&$ leger, maisil eft trés-roide; c'eft ce qui le fait emploïer pour les mâts de vaiffeau : l'on en fait auffi des planches qui fervent à quantité d'ouvrages; fes feüilles reffemblent à celles de l'If, il n'eft propre que dans les bois \& les forêts, furtout dans les lieux élevés. Il dunne un fruit écaillé de figure piramidale, apellé Pomme de Sapin, qui en renferme la graine.

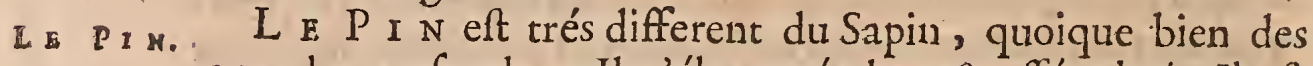
gens les confondent. Il s'éleve trés-haut \& affés droit. Il eft trés-rameux par en haut, \& tout nud par le bas. Son bois eft rougeâtre \& pefant, fes feüilles font érroites, longues \& piquantes, fon écorce eft noirâtre \& fort raboteule. L'on en tire une refine propre à faire du goudron pour les vaiffeaux. Cet arbre aime les lieux élevés, auffi-bien que le Sapin. Son fruit eft apellé Pomme de Pin, ou fe trouve la graine.

LE CYPRE'S.

LE CYPRE'S eft un trés-bel arbre, fort élevé naturellement. Il eft touffu depuis fon pied jufqu'a fa cime qui fe termine en pointe. Son bois eft fort dur \& de bonne odeur : fon feuilllage qui eft d'un verd blanchâtre, eft fort épais; il eft également propre à former des allées \& des paliffaces. Ses fruits'apellent Pommes de Cyprès, \& renferment fa graine. II eft un peu long à élever aux environs de Paris. 
Pommier.ou Poirier: fa hauteur eft moindre que celle du. Chêne ordinaire, \& fon bois eft different : mais fes feüilles \& fon gland font femblables, à l'exception qu'elles font plus petites, \& d'un verd blanchâtre. Cet arbre eft bon: à former des allées : le gland qu'il rapporte en perpetuë l'efpece.

Les fuivans ne font que des arbriffeaux \& arbuftes, dont: on fe fert pour former des palifiades \& du garni dans les bois verds.

L E H O U X paffe pour un des plus beaux arbriffeaux LE verds qu'on puiffe voir, il monte affés haut, \& fa verdure eft. luiirante \& très-agréable : fon bois eft verdâtre : on en fair des baguettes \& houlfines. Ses feüilles font dentelées \& garnies de piquants, quelquefois panachées; il vient de graine.

LE Genevrier ou GeNiEvRE s'éleve affés: il fent très-bon : fon bois eft fort dur, fes féüilles font petites \& piquantes, il produit de la graine.

Le Phileria ou Phillyrea, appellé communément Fr LAR IA, eft un arbriffeau fort garni \& des plus recherchés pour les paliffades : fon bois eft noirâtre, fes feüilles: reffemblent à celles de l'Olivier, mais font plus courtes \& d'un affés beau verd. Il crô̂t facilement, même à l'ombre, il graine \& fe marcotte aufli.

LA SABINE OU SAVINIER mionte beaucoup pour un arbrifieau: fon tronc eft gros, $\&$ fon bois fort dur; fes feüilles reffemblent à celles du Cyprès. Elle fe multiplic de femence \& de marcotte.

L'A L A T E R N reffemble par fes feüilles à l'Olivier, elles font d'un verd foncé \& affés épaiffes : le bois en elt grifâtre, L'Axatarail eft très-propre à faire des paliffades $\&$ vient de marcotce.

Le Bu I 5 ou Bou is eft l'arbriffeau verd le plus en ufage La Bus. \& le plus necelfaire dans les Jardins. Il y en a de deux fortes: le Buis nain appellé Buis d'Artois, dont les feuilles font femblables à celles du Myrthe, mais plus verces \& plus dures. Il fert à planter la broderie des parterres, \& les bordures des plates-bandes, \& on le womme Buis nain, parce que naturellement il ne crôit pas beaucoup. La feconde efpece eft le Buis de Bois qui s éleve bien plus haut \& a les feuilles flus 
170 TROISIEME PARTIE, CHA P. I. grandes que l'autre, ce qui le rend propre à former des pa: liffades \& des touffes vertes pour le garni des bois; on en voic de panachés : il vient à l'ombre, mais il lui faut beaucoup de tems pour acquerir un peu de hauteur: fon bois eft jattnâtre \& très - dur. On en fait quantité de petits ouvrages, comme des peignes, des boules, \&c. Ces deux efpeces de Buis donnent de la graine, mais ils viennent ordinairement de boutures.

Il faut dire une chofe à l'avantage des arbres \& arbriffeaux verds, qui eft que la dureté de leurs bois \& de leurs feirilles, les garentit de toutes fortes d'infectes \& de vermines.

L'utilité qu'on peut tirer des arbres verds, regarde plus la Medecine [ qui en compofe plufieurs remedes] que l'ufage qu'on en fait dans le commerce, foit pour les bâtimens, ouvrages ou chaufage; ainfi que font les premiers arbres dont on a parlé au commencement de ce Chapitre. C'eft pour

Faux-bourg cette raifon que tous ces arbres verds fe trouvent en grand 3. Victor. nombre au Jardin du Roi ${ }^{*}$ pour lesplantes medecinales.

Voilà tous les arbres \& arbriffeaux dont on fe fert ordi: nairement dans les beaux Jardins. On a tâché de renfermer dans leur courte defcription, une idée genérale de chaque arbre, en parlant de fon élevation, de fes feüilles, de fon bois, \& de l'ufage qu'on en fait, de fa proprieté dansles Jardins, les vermines aufquelles il eft fujet, \& la maniere dont il perpetuë fon efpece; cela peut déterminer fur le choix qu'on aura à en faire. L'on va cependant dire ici ceux qui paroiffent les meilleurs, \& dont on confeille l'ufage dans les Jardins.

Les arbres dont on fe fert ordinairement pour former de belles allées, font les Ormes, les Y preaux, les Tillots \& les Marroniers d'Inde : Les allées d'Ormes \& d'Y preaux étant bien dreffées viennent très-hautes, d'un beau feüillage \& durent fort long-tems : Les allées de Tillots font auffi très-belles, furtout quand ce font des Tillots d'Hollande. Ces arbres, comme l'on fçait, s'élevent beaucoup, ont l'écorce unie, une verdure agréable $\&$ produifent quantité de fleurs, dont l'odeur eft très-douce, outre qu'ils ne font fujets à aucune vermine. Cefont ces trois efpeces d'arbres que l'on con- 
LA PRATIQUEDU JARDINAGE. I I I feille d'employer préférablement au Marronier d'Inde, quiqu'il foit fort à la mode. L'on ne peut difconvenir que leMarronier ne foit beau; il eft conftant qu'il vient très - droit \& d'une belle tige, qu'il a l'écorce polie, \& la feüille grande \& belle : mais toutes les ordures qu'il fait continuellement dans les allées, par la chûte de fes fleurs au Printems, defes écalles \& de fes marrons en Efté, \& de fes feüilles au commencement de l'Automne, en diminuënt bien le merite: joint à cela, qu'il eft très-fujet atx bannetons \& aux chenilles, qui le dépoüillent tout nud pendant l'Efté ; que fon ombre, à ce que l'on prétend, eft très-mal faine, qu'il ne s'éleve que médiocrement haut, qu'il dure très-peu, \& qu'il eft d'un fort mauvais raport.

Dans les avenuës en pleine-Campagne, l'on employera des Ormes ou des Chataigniers; \& dans les terres humides, des Peupliers, des Trembles, \& c.

On obfervera de ne point placer d'Ormes, fi près des Potagers, des Fruitiers, des Fleuriftes, parce que leurs racines qui courrent fur terre, la fechent promptement, \& les fruits \& les fleurs auroient de la peine à s'y élever comme il faut. On plantera à la place, des Tillors \& des Marroniers, dont les racines occupent moins d'efpace.

La veritable maniere de bien choifr les Ormes, les Ypreaux, les Tillots, les Marroniers, \& generalement tous les arbres ci-deffus nommés, confifte dans les trois Obfervations fuivantes, qui renferment tout ce qu'on peut dire fur ce fujet.

La premiere, c'eft d'examiner fi un arbre eft droit, d'une belle tige, d'une écorce unie \& claire, fans aucune mouffe, $s^{\prime i l a}$ des racines bien garnies $\&$ bien cheveluës, s'il eft bien arraché fans être éclaté ni offenfé dans les groffes racines. On ne fe trompera point de croire qu'un arbre ainfi conditionné eft très - bon, ayant toutes les qualités requifes pour devenir un jour fort beau. Mais fi il étoir tortu, bas, rabougri, d'une écorce galeufe \& pleine de mouffe, \& qu'il eùt des. racines rompuës \& éclarées, ou bien trop dégarnies de chevelu, il n'y a aucun doute que cetarbre ne vaut rien, 22 on doit le rebuter entierement. On pcut fe fier hardiment à cetts. 
772 TROISIE'ME PARTIE, CHAP.T. Obfervation qui eft la plus effentielle de toutes, \& qui tiendra lieu de regle generale pour tous les plants imaginables.

La feconde chofe de confequence à obferver dans le choix des arbres, ceft de les prendre dans un terrain plus mauvais que celui oit on les veut planter: la raifon eft que les arbres goûtant cette meilleure terre, en reprennent plus facilement, en deviennent plus gros \& plus droits, \& croiffent infiniment plus vîte, outre qu'ils ne font point couverts de mouffe. Au lieuque fi ces arbies viennent d'une bonne terre \& meilleure que celle oì on les a plantés, ils languiffent, deviennent tortus \& rabougris, pleins de mouffe, enfin ils meurent \& femblent regretrer, pour ainfi dire, leur premiere nourrice,

La troifiéme Obfervation, c'eft de ne point trop s'arrêter à la groffeur des arbres; car j'eftime mieux un arbre d'une groffeur mediocre, que tous les gros qu'on recherche avec tant d'empreffement, \& l'on eft plus affuré de fa reprife, quand il a environ fix à fepe pouces de pourtour, que quand il eft $f i$ fort. On voit plus mourir de ces gros arbres, quelque précaution qu'on y prenne, que de ceux qui font de la groffeur dont je parle.

A l'égard des paliffades, les plants les plus eftimés font la Charmille, le Hêtre \&z l'Erable, qui pour être bons, dojvent a voir l'écorce claire \& unie, \& la racine bien cheveluë." On les doit prendre dans une pepiniere, où ils foient élevés de graine ; l'on connoît aifément que le plant vient de pepiniere, quand il eft droit \& clair, \& que fon pivot n'eft point crochu, carles planits de Charmille \& d'Erable que l'on arrache dans lesbois, ne valent rien à replanter, n'étant que des boutures \& traînaffes de racines, ce que les Jardiniers appellent de la Croffette, à caufe que les racines ont la figure: d'une croffe.

Le plus beau de ces trois plants au fentiment de tout le monde, c'eft la Charmille : mais à moins qu'elle ne foir plantée dans un terrain frais \& fortaêré, elle a de la peine à s'élever : l'Erable au contraire vient fort bien partout, à l'ombre, comme en plein air ; le défaut qu'il a, eft d'être un peu fujet ส̀ jaunir.

Les Plants qui conviennent le mieux aux Portiques, Coon- 
LA PRA TIQUE DU JARD IN A GE. I73 nades, Arcades, Trumeaux, Cabinets \& Galeries de ver. dure, font le Charme, le Tillot \& l'Orme. Le génie du Charme eft difpofé à faire des paliffades, érant rameux jufqu'au pied, \&z demandant à avoir la tête coupée, fujette fans cela à périr. Le Tillot naturellement fe plie \& prend quelque figure qu'on veut ; il forme par la quantité de fes petits ranieaux un branchage très-touffu. Mais* l'Orme mâle cft préférable à tous les deux, capable de toutes fortes de formes, venant fort vîte; moins fujet à fe dégarnir \& à mourir que la Charmille, \& moins caffant que le Tillot, plus aifé encore à reprendre dans toute forte de terrain. Tout le défaut quáa l'Orme, eft d'être de plus grand entretien que les autres pour la tonture : car il pouffe continuellement des brindilles qui s'échapent du contour des Arcades, \& de l'a - plomb des Pilaftres.

Pour les quarrés des Bois que l'on veut élever en hautefutaye, tous les arbres ci-deflus nommés y peuvent être employés; cependant ceux qui font les plus eftimés font le Chefne, l'Orme, le Chrataignier, le Hêtre \& le Charme, lefquels s'élevent très-haut, forment un beau cottvert \& font d'un bon rapport. Pour planter du garni \& de la brouffaille au pied des grands arbres, la Charmille, l'Erable, le Noifetier, le Tillot \& l'Epine blanche font les neilleurs plants, \& cenx qui forment les plus belles touffes; cependant tous les plants en general y font propres.

Dans les lieux bas \& marécageux, on plantera des Trembles, Peupliers, Bouleaux \& Aulnes, comme les meilleurs pour former une futaye \& de belles allées; \& pour garnir, on fe fervira d'Ofiers, Saules, Marfaults, Coudriers, \& $c_{0}$

Pour ce qui regarde les bois verds, le Cyprès, le Sapin, le Pin, le Picea \& le Chefne verd doivent être choifis pour former les allées \& la futaye du dedans, comme étant ceux qui s'élevent les plus hauts \& les plus droits. On plantera les paliffades avec des Ifs, Buis, Phileria, Cyprès; $\&$ la brouffaille avec du Genevrier, Sabine, Laurier, Alaterne, Houx $\&$ les autres arbres verds dont on a parlé ci deffus.

Tous les arbres \& arbriffeaux verds, pour être bons, doivent être d'un verd foncé \& très-vif, tirant fur le noìr, fans. être alterésni jaunâtres, car c'efr là leur Maladie. Ils fe le-

$$
\text { Y iij }
$$

* Tour ce qu'il y a de plus beau à Marly ; eft planté d'Ormes $\&$ de Til. lots. 
I74 TROISIEME PARTIE, CHAP. I. vent en motte dans des manequins, ou l'on prendra garde qu'ils foient au moins depuis un an ou deux, ce qu'on appelle vieux enmanequinés, c'eft une précaution qui ne lera point inutile, pour les faire mieux reprendre.

Le Buis qui fert à planter les Paliffades, eft le Buis de Bois ; on le prendra un peu haut $\&$ fort, avec de bonnes racines bien cheveluës: Pour le Buis nain dont on plante la broderie 'des Parterres, il faut qu'il foic fort jeune, bien chevelu, point trop fec, \& que la feüille en foit petite $\&$ très-délicate, c'ett la plus recherchée. Si l'on fait cette obfervation en le choififant, on ne fera point obligé d'arracher un Parterre tous les cinq à fix ans, par la hauteur où monte le Buis, quoiquion ait foin de le tondre fouvent.

Nous n'avons point déterminé la nature des terres converables à chaque efpece d'arbres, comme ont fait la plûpart de ceux qui ont écrit de l'Agriculture: car en general une terre médiocrement bonne leur con vient à tous, cela n'eft pas de fi grande confequence que pour les fruits, les legumes \& les Heurs; voici cependant les arbres qu'il eft à propos de planter dans chaque terrain. Le Charme \& le Hêtre fe mettront dans une terre fraîche ; l'Orme, l'Y preau, l'Erable, le Til lot, le Marronier, le Bouleau \& le Sicomore dans un Pâ̂s fec, leChefne \& le Chataignier dans des terres fortes, le Peuplier, le Frefne, l'Aulne, le Tremble \& le Saule dans une terre humide.

On apelle un lieu planté d'Ormes, un Ormoïe; planté de Chefne, une Chenaiie, de Chataigniers, une Chataigneräie, d'Ofiers, une Oferaïe, \& d'Aulne, une Aulnaie, de même qu'on apelle une Cerifaie ou une Saulfä̈e, un lieu planté de. Cerifiers \& de Saules. 
L A PRATIQUE DU JARDINAGE. 175

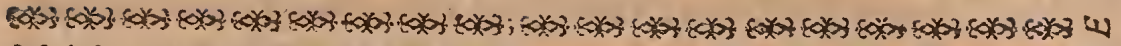

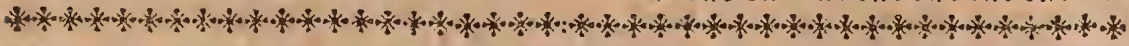

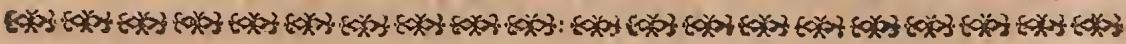

\section{H A P I T R E I I.}

DE LA MANIERE DE PLANTER

toutes les différentes parties d'un beau Jardin.

TOur ce que nous avons dit dans les Chapitres précé1 dens, ne fervira de rien, fi l'on n'y joint ce que renferme celui-ci \& le fuivant, dont l'utilité \& la néceffité font affés connuës de tout le monde. L'on aura beau avoir bien dreffé, bien tracé un Jardin, \& avoir fait choix de beaux arbres, toutes ces peines deviendront inutiles, fil'on ne fçait la vraye maniere de planter, \& les foins qu'on doit prendre des jeunes plants pour les élever comme il faut.

La maniere d'élever les arbres d'une belle hauteur \& en peu de tems, dépend de deux chofes, du bon plantage \& du foin qu'on en doit avoir felon les diverfes faifons de l'année. Voïons dans ce Chapitre ce qui regarde la maniere de bien planter, \& remettons à parler dans le Chapitre fuivant des foins que demandent les arbres.

Le plantage eft different, fuivant les parties differentes qui compofent un Jardin, que nous allons parcourir toutes, pour fçavoir comme il les faut planter. Commençons par les Parterres.

Un Parterre étant tracé fuivant ce qui a été dit ci-deflus dans la ${ }_{2} \mathrm{e}$ Partie, \& le Buis étant bien choifi, comme on l'a remarqué dans le Chapitre précédent ; la terre bien préparée \& bien dreffée ; prenés un plantoir \& une bêche (qui font les deux outils dont on fe fert le plus dans le Jardinage ,) \& après avoir rafraîchi les racines du buis, \& en avoir coupé un peu du chevelu, vous enfoncerés le plantoir environ d'ua denii-pied, en fuivant exactement la trace du deffein : retirés le plantoir, \& écartés un peu le côté en dedans de la trace, pour rendre l'ouverture plus large ; enfuite vous arsangerés 

dans cette ouverture, les racines du buis que vous enfoncerés jufqu'au collet, c'eft-à-dire, qu'on ne voye fortir de la terre que fes feüilles: après cela l'on donne deux ou trois coups de plantoir en terre, tout autour de ce que l'on vient de planter, ce qui fait rapprocher la terre, \& rebouche encierement la petite rigole. Le Buis étant ainfi enterré, on le borne avec le dos du plantoir, ou avec les mains, \& on lui donne la forme \& le contour qu'il doit avoir fuivant le deffein, en plombantbien la terre toutau tour, de peur qu'il ne s'évente.

Il faut fe fervir du plantoir par tout, excepté dans les grandes longueurs \& grands traits de buis, comme font les platesbandes, \& les grands rinceaux de broderie, ou l'on peut fe fervir de la bêche; alors on tend un cordeau fuivant la trace d'un bout à l'autre, l'on ouvre une rigole à la bêche, \& l'on y arrange le buis que l'on recouvre enfuite de terre; cela va bien plus vîte qu'au plantoir.

Le Parterre étant ainfi planté, on labourera à la bêche l'endroir deftiné pour les plates-bandes, ou l'on fera apporter du terreau mêlé a vec de la bonne terre, que l'on dreffera en dos-d'âne; enfuite l'on elpacera \& marquera avec des piquets, lesplaces ou il faut planter les Ifs \& les arbriffeaux fuivant le deffein, \& l'on y fera faire des trous felon la groffeur de ces Ifs Nous avous dit dans le Chapitre $4^{e}$ de la $y^{\text {re }}$ Partie, que les grands Ifs \& arbriffeaux n'étoient plus d'ufage prefentement, parce qu'ils offufquoient trop la vî̀̈ ; ainfi ces Ifs devant avoir tout au plus quatre à cinq pieds de haut, les trous feront fuffifamment $g$ rands à trois pieds d'ouverture en quarré , \& deux pieds de profondeur. Ces trous écant faits, vous ferés apporter un If a l'un des bouts de la plate-bande, vous couperés fon manequin, \& en découvrirés la motre, dont vous rafraîchirés les petites racines qui pafferont; jettés un peu de bonne terre au fond du trou, \& pofés votre arbre dans le milieu que vous mefurerés exactement; affurés - le un peu en jettant de la terre deffus, \& le comblantà moitié, plantés un autre If fur la même ligne à l'autre bout, \&r en ayant ainfi planté deux, vous efpacerés \& alignerés tous les autres deffus.

- Dans les plates-bandes on efpace pour l'ordinaire les If 
LA PRA TIQUE DU JARDINAGE. 177 de I 2 pieds en I 2 pieds, \& l'on met un arbriffeau entre-deux; mais on eft obligé de fortir de cette regle, quand les platesbandes font coupées ou font en compartiment; alors c'eft le deffein qui vous regle, \& vous affujettit à de certaines places.

On obfervera dans les plates-bandes tournantes \& circulaires, de planter les Ifs dans le milieu, à diftance égale les uns des autres, \& le plus droit qu'il fe pourra à la vûë ; c'eft le plus fû̀r moyen, n'y ayant aucun alignement à prendre, \& le cordeau n'y pouvant fervir de rien. On trouvera dans cẹtte Partie, les fleurs qui y conviennent avec leur Culture.

Voilà toute la difficulté des Parterres, qu’il ne faut tondre que la feconde année qu'ils font plantés, pour laiffer prendre terre au Buis \& fe fortifier. Alors on revifite un Parterre d'un bout à l'autre, \& l'on regarnit de Buis, les endroits où il en manque. L'on fe fert de grands cifeaux pour la tonture des Parterres, qui doivent être ferrés de près fans alterer le deffein: dans les plates-bandes \& traits de Buis en ligne droite, l'on tendra un cordeau pour les tondre.

Le tems le plus propre pour tondre un Parterre eft le mois de Mai. Les beaux Parterres font condus deux fois l'année, directement après les deux Seves. Si la terre étoit un peu feche, il faudroit arrofer le Buis la premiere année qu'il elt planté, afin de faciliter fa reprife.

Les allées \& contre-allées qu'on plantera d'Ormes, de, Tillots, de Marroniers, \&c. étant tracées, on y efpacera de I 2 pieds en 12 pieds des piquets, qui marqueront la place de chaque arbre. Cette diftance eft pour garder un milieu entre ceux qui ne donnent que neuf pieds d'arbre en arbre, ce qui n’eft pas affés, \& ceux qui en donnent I 5 \& I 8 , ce qui eft trop aufi ; à I 2 pieds la diltance elt raifonnable $\&$ plus ufitée que les deux autres. Dans les avenuës \& les allées plantées en pleine Campagne, l’on efpace les arbres à 18 pieds \& quelquefois à $2 x$, pourmenager le revenu desterres fur lefquelles on plante ces arbres. De cette maniere l'on joüir du delfus \& du delfous. Il faut entourrer d'épines mortes ces arbres pour les garentir des beftiaux \& des gens malins.

On fera faire à chaque piquet dés trous de quatre pieds en quarré, \& de trois pieds de profondeur. Si le fond de la terre

Les bons

Jardiniers 225 la tonture racommodent Couvent latrace d'unParter. re, en lâchan quelques endroits, \& en ferrant de prés d'autres, cela fait tour ner un Rinceau : les mal. adroits au contraire eftropient rout un Deffein.

Quand on fera creuler des trous, il faut faire mets tre Cépatément les terres de deflus, $\&$ celles du fond, afin qu'en plantant les arbres vous les couna vriez de la terre de deffus, qui eft la meilleure: laurre fors i 
les combler ; pat ce remuënicertesserres s'dboitilfent.

eít bon, vous vous en fervirés, mais fi la terre vous paroît ufée \& féche, vous en ferés aporter de meilleure, ou vous prendrés de celle de deffus, dont vous jetterés un bon demipied de hauteur dans le fond du trou. Vous pourrés y mettre encore un lit de feüilles ou de gazon retourné, fi vous en pouvés trouver aifément, avec un demi pied de terre pardeflus, cela fe confomme \& vaut dans la fuite du fumier. Cette preparation remplic un pied de hauteur, des trois qu'on a donné aux trous : Les deux pieds reftans funfifent pour planter l'arbre.

Avant que de planter vos arbres, il les faut refeper à huirt ou neuf pieds de haut, en leur coupant la tête, à moins qu'ils ne foient levés en motte, comme on le dira ci-après.

On tâchera pour la régularité de mettre tous ces Arbresà même hauteur, en les coupant fur une mefure commune. Il les faut encore rafraîchir par les racines, en ôtant l'extremité du chevelu, \& les racines éclatées \& brifées, ce qu'on apelle babiller un arbre. Cela fait, vous polerés la racine de l'arbredans le milieu du trou, vous étendrés bien toutes les petites racines \& les garnirés de terre avec la main, en prenant garde qu'il ne s'y trouve deffous des pierres, ou des vuides, apellés Caves, qui mettent les racines en l'air, \& les empêchent de fe lier à la terre. Votre Arbre étant bien garni, vous le ferés combler entierement de terre, en faifant abattrela Berge autour du trou; la terre en eft toujours meilleure \& plus fraîche que celle de deffous, outre que cela agrandit le labour; enfuite vous plomberés l'arbre en marchane deffus.

Outre les piquets qui marquent les trous, il faut encore aligner 3 ou 4 jalons fur la même ligne \& qui foient fichés entre les places deftinées aux Arbres, afin de pouvoir quand les trous font faits \& tous les piquets ôtés, planter deux ou trois arbres fuivant ces jalons, c'eft-à-dire, un arbre à chaque bout \& un dans le milieu de la ligne; vous pourrés enfuite faire ôter tous les jalons étant alors inutiles. Ces trois arbres vous ferviront pour aligner tous les autres de la même rangée. Ceci eft une regle generale pour planter toutes fortes d'arbres, en augmentant ou diminuant la grandeur des trous felon leur force.

Aux arbres nouvellement plantés, après avoir plombé les 
LA PRATIQUE DU JARDINAGE. I79 terres, faites jetter le lendemain 3 ou 4 arrofoirs d'eaux felon la force de larbre, cela fait des merveilles pour faire del. cendre les terres, \& leur donner de la liaifon : il feroit dangereux de moiiller les arbres fur le champ, crainte de faire du mortier, ou de trop faire pancher les têtes.

Les perfonnes quî veulent avoir un beau Jardin \& en peu de tems, fans fe foucier d'un peu plus de dépenfe, fe fervent d'arbres levés en motte; ils gagnent par-là cinq ou fix années d'avance, parce que ces arbres étant levés avec une motte de terre qui couvre leurs racines, fe plantent tout de leur hauteurfans rien couper; au lieu que les autres arbres dont ler racines font décuuvertes, n'aïant pas affés de force pour nourrir leur tête, l'on eft obligé de leurabattre, en les refe. pant à huit ou neuf pieds de haut, comme l'on vient de dire. On voit par-là, qu'un particulier en plantant des arbres en motte, gagne le tems qu'il faut à ces arbres pour pouffer une autre tête, outre qu'ils en font infiniment plus beaux, ne montrant point leur reprife, comme ceuxque l'on étête. J'ai fait planter des Ormes en motte de 3 o pieds de haut \& gros comme la cuiffe, quiont repris à merveille; par ce mö̈en on plante des arbres tout grands, ce qu'on ne faifoit pas autrefois, $\&$. l'on joüit d'un Jardin dix ans plûtôt par cette invention merveilleufe.

Il faut bien fe donner de garde de fuivre l'opinion de quelques * Jardiniers, qui prétendent qu'on peut planter hardiment un arbre toutdefa hauteur, fans y rien couper \& lans qu'il y ait une motte de terre püer leur opinion, difent que cette motte de terre refferrant trop les racines qu'on eft obligé de couper courtes, cela les empêche de faire leur fonction \& des'étendre fi vigoureufement; au lieu que les racines d'un arbre étant découvertes $\$$ toutes de leur longueur, on les arrange \& on les garnit de terre beaucoup mieax, outre qu'étant ainfi mouvées de tous côtés, elles ont plus de facilité à pouffer $\&$ à fe lier à la terre.

C'eit une opinion que l'experience a fait fouvent trouver fauffe, \& que lon ne confeille nullement de fuivre:car quand les arbres n'ont point de terre au pied, ou que la motre s'eft caffée en les apportant, ils font en trés-grand danger de mourir j la féve ne pouvant pas d'elle-même ayoir aflés de force

* Ces Jardiniers ont écrit des Arbres fruitiers, dont ils ont fait quelque experience en ce genre: $8 x$ fous ce prérezte, ils prétenden: qu'on peut aumiti les en crotre, fur la maniere de transplanter fans morte, Jes Ormes \& les autres atbres des Jatdins de propreté, don: la culture le 2 eft prefquei.iso connuë. 
I80 TROISIEME PARTIE, CHAP. II. pour monter jufqu'au haut de l'arbre, \& pour nourrir fa tếte; fi elle n'eft aidée par cette motte de terre, qui eft la même oì l'on a élevé l'arbre, \& qui nourrit \& entretient fes racines, jufqu’à ce qu'elles ayent la force de percer dans la nouvelle terre d'alentour. On donnera dans le $4^{\mathrm{C}}$ Chapitre fuivant, la maniere de lever les arbres en motte.

Pour planter les palifades, on tendra un cordeau fuivant la trace ou la rangée d'arbres, s'il y en a, \& l'on ouvrira à la bêche une tranchée ou rigole d'un pied de profondeur, en prenant garde de conferver un de fes côtés fans l'ébouler, \& d'ouvrir cette rigole en dedans de l'allée, ce qui vaut toujours mieux pour le plant. Cela fait, agenoüillés-vous du genou gauche au bord de la rigole, \& prenés le plant brin à brin, après en avoir un peu rafraîchi l'extrêmité des racines, efpacés-le de deux ou trois pouces felon fa groffeur, \& acôtés-le contre la terre, qui fera coupée à pied droit d'un des côtés de la rigole; foutenés le plant avec le revers de la main gauche, \& de la droite jettés de la terre fur les racines, jufqu'à ce qu'elles foient couvertes. Prenés garde que le plant foit bien dreffé \& bien accommodé l'un dans. l'autre : après cela comblés la rigole, \& plombés la terre avec les pieds.

Les paliffades plantées fi fortes \& f hautes, comme de fix à fept pieds, ne font pas fi fûres à la reprife, que la jeune Charmille qui eft infiniment meilleure : les. Jardiniers one la méchante coùtume de refeper une Charmille à fleur de terre, ce qui lui nuit beancoup, \& l'empêche de devenir droite, ne faifant alors que des chicots qui s'épanoüiffent de côtés \& d'autres. J'ai fait l'experience d'une Charmille ainfi rognée, \& d'une autre qu'on avoit laiffé toute de fa hauteur, \& j'ai trouvéque celle qui n'avoit pas été rognée, étoit mieux venuë \& bien plus droite que l'autre, quoique dans le même terrain.

On doit laiffer un pen de place derriere les paliffades, quard on les plante contre un mur, en partie pour la palifíade, afin qu'on la puiffe labourer $\&$ tondre par derriere, $\&$ en partie pour le mur qui s'en conferve beaucoup mieux \& plus longrems.

Comme il n'y a rien de plus difficile à faire venir dans un Jardin, que les paliafades, elles demandent beaucoup plus. 


\section{LA PRATIQUE DU JARDINA GE. 18r}

d'attention que le refte. Pour les élever belles \& les faire durer long-tems, il faut les expofer hors d'un bois au grand air, \& outre cela qu'il n'y ait point d'arbres plantés dedans, fur tout des Ormes; à moins que la paliffade ne foit refepéc à Io ou I 2 pieds de haut, \& que l'on n'élague beaucoup les arbres au deffus. Si au contraire elles font plantées dans un bois de haute-futaïe, ou fous des Marroniers, elles creveront bien vîte, \& ne s'y. feront élevées que pendant que les arbres étoient jeunes, ou à la faveur d'un bon terrain frais. On peut cependant élever de belles paliffades dans un bois, en obfervant ce qui fuit.

La maniere ordinaire en plantant des bois, eft de border les allées par des Ormes, des Tillots, des Marroniers, \&c. avec dela Charmille ou de l'Erable au pied pour former la paliffade : néanmoins fi l'on vouloit s'épargner le chagrin infaillible de la voir mourir dix ou douzc ans après, parce qu'clle s'étouffe fous les grand's arbres, on y remedieroit en plantant les bordures d'un bois, de Charmilles feules fans aucun arbre, \& laiffant par derriere une liziere de 7 à 8 pieds de large regnante tout aiu tour, c'eft-à-dire, une clairiere fans futaïe ni brouffailles entre les paliffades \& le bois. Alors elles joüiffent d'un grand air des deux côtés, \& fe maintiennent longrems en état, cela n'ôte point la futaïe, car les bois s'élevant. pardeffus, forment de loin des feüillages fort agréables. Cette place vuide fert encore à labourer commodément les paliffades \& à paffer l'échelle double pourles tondre par derriere. l'on obfervera qu'il faut couper à pied droit les branches quis'échapent du bois, afin qu'elles ne dérobent point cet efpace d'air fi néceffaire à la paliffade, en tombant deffus \& l'offufquant.

Il faut avoüer cependant que ces fortes d'allées font plus long-tems à fe former \& à donner du couvert que les autres, où les arbres marquent dés la feconde année : l'on peut dans wn grand Jardin, avoir des allées plantées de l'une $\&$ de Pautre maniere, afin de $s^{2} y$ pouvoir promener à l'ombre à toutes. les différentes heures du jour.

Voici une autre pratique fort fimple de planter les allées. d'un bois, qui êt d’ifoler les rangées d'arbres des deux côtés: 2. à 3 ou 4 pieds derricre, planter.les brouffaitles des quarrés. 
de bois en alignement, de maniere qu'étant tonduës à pieddroit, elles forment des efpeces de paliffades, qui à la verité ne font jamais fi belles ni fi garnies que les autres : mais qui dureront bien davantage, \& faus demauder grand entretien. Ces fortes de paliffades font toujours un foud uni \& verd qui ne laiffe pas d’être fort agréable à la vâë.

Venons à la maniere de planter les portiques \& les décorations champêtres qui font compofés de colonnes, de trumeaux, de montans ou pilaftres faillants, \&xc. Choiffrés dans une pepiniere des Ormes hauts \& menus, rameux le long de la rige, toùjours des mâles à caufe de leur petite feüille ferrée $\&$ toufrë, qui fe tond mieux que la femelle, plantés - les fansleur couper la tête \& avec toute leur ramille; fi c'eft pour quelque trumeau un peu large, vous en mertrés plufieurs, \& fi c'eft pour ane colonne, cherchés un arbre branchu tout au tour, que vous conduirés \& élaguerés dans l'intention d'une olonne, le faifant ramiller de tous côtés, \&. profitant avec adreffe de toutes les branches pour former cette rondeur. Il faudra le dépoüiller à 3 ou 4 pieds de haur, afin de le faire monter, \& l'on garnit lé bas de la colonne, de charmille \& d'ormeaux, pour faire la bafe \& le focle. Au: deffus de la colonne on formera du même arbre fon chapi-: teau, \& pourla corniche \& l'entablement on fe fervira de branches échapées de la paliffade du fond, que l'on tirera avec des fils de fer, pour les attacher fur des perches traverfantes d'un bout à l'autre, \& portées par d'autres perches ou montans de bois, fur lefquelles on attachera toutes les petites branches de l'Orme deftiné à former le trumeau ou la colonne, en les contraignant avec de l'ofier à prendre le fens que l'on veut. Ces branches tirées artiftement \& bien entre-lallées les unes dans les autres, cachent \& recouvrent ces perches, \& compofent des colonnades toutes vertes, avec des corniches $\&$ des entablements, faillants d'un pied \& plus, s'il eft néceffaire.

Ces colonnes fe plantent prefque toujours ifolées, afin de pouvoir paffer le cifeau tout au tour pour les tondre. Pour les piedeftaux, ils peuvent être ifolés ou non, cela ne fait rien a leur conftruction. Les chapiteaux, bafes, \& corniches fe tail lent en chanfrain à l'extremité des colonnes ou des pilaftres, 

au deffus defquels on pratique des boules \& des vafes de verdure, formés par le bouquet de l'arbre qui fait la colonne ou le trumeau, ou bien pardes brins de charmille tirés de la paliffade. L'on détache ces vafes de leurs boules \& de la corniche, par une petite tige d'un pied ou deux, felon la hauteur du Portique, à caufe de l'effet de la perfpective.

Pour les paliffades percées en arcades, fir elles font ouvertes Les' Archi. tektes obfervent la mêtne chole dans les jufqu'en bas dans le deffein, on tracera fur terre une ligne, ou l'onprendra la largeur des ouvertures, \& l'on marquera celle des trumeaux ou pilaftres quel'on fera ouv rir en rigoles pour y planter le plan deftiné. Si au contraire elles font enclavées d'une banquette oì elles viennent mourir, c'eft-à-dìre, qu'elles ne defcendent pas jufqu'à terre, à l'exception des portes, on fera faire une rigole toutdu long fans referve, \& l'on y plantera la charmille, en obfervant pour joüir plutôt, d'en mettre de la plus haute dansl'endroir des trumeaux, ou biend'y planter un Tillot ou un Orme, afin de former promptement la corniche \& le vafe d'en-haut, qui font toujours les pluslongs à venir. On foûtiendra ces jeunes plants avec des treillages groffiers, furlefquels on paliffe promptement les branches, jufqu'à ce qu'ils foient affés élevés pour être ceintrés \& former l'arcade, autour d'un cerceau attaché aux deux montans du treillage.

Les Berceaux, les Cabinets \& Galeries de verdure fe plantent de même que les Portiques \& les Arcades, à la differen-' ce feulement qu'il faut deux rangs de Portiques à 4 piliès pour compofer ces galeries; alors les Ormes plantés aux 4 piliers fe croifent fur des cerceaux dans le haut, \& par leur branches tirées avec des fils de fer $\&$ contraintes fur ces cerceaux, forment des voutes vertes fort agréables, étant percées à jour.

On tond ces Arcades, Colonnes, Portiques, \& Cabinets prefque tout aux cifeaux, hormis les corniches $\&$ les trumeaux, quel'on tond au Croifant , en ménageant quelques branches pour en garnir les vuides: on aura une mefure de bois pour contourner les colonnes, une pour les ceintres, \&une autre pour tailler les corniches, bafes \& chapiteaux en chanfrain : toutes ces mefures feront taillées fuivant le deffein qui a fervi à leur premiere conftruction. Ces morceaux étant une fois devenus 
forts, fe foûtiennent alors d'eux - mêmes fans aucun entretien des treillages, qui n'ont fervi qu’à les élever \& à les faire. monter.

On obfervera que fi l'on ne fe fert que de grande charmille pour former ces décorations fans aucun arbre, on la doit planter très-ferrée \& fort garnie pour l'empêcher de trop groffir. Si l'on y employe des arbres, il ne les faudra plier qu'après la feconde ou la troifiéme année qu'ils font plantés \& bien repris, fans cela l'on pourroit trop ébranler leurs racines, \& les enupêcher de fe lier à la terre.

Pourles Boules d'Ormes en maniene d'Orangers, on choifira des Ormes bien droits, dont la tige ait fix à fept pieds de haut, \& l'on taillera en boule de trois pieds environ de diamettre, la tête de ces arbres. Si ces boules d'Ormes font accompagnées de leur caiffe, l'on plantera au pied des arbres des brins de charmille que l'on tondra quarrément de tous côtés, ou en maniere de pors a vec des anfes, pour faire croire que la caiffe \& l'arbre ne font qu'un.

La chof'e la plus effentielle à remarquer dans le plantage, c'eft de ne point mettre du fumier dans les trous où vous vou. lés planter des arbres, fous prétexte de les fumer: car fi vous mettés le fumier trop bas, il devient inutile, à caufe que fon fel ne tombera pas fur les racines, \& fi vous le mettés un peu au deffus, il pourrira le tronc de l'arbre, y engendrera des vers \& fechera la terre, ce qui n'eft que trop capable de caufer la mortalité aux jeunes plants. On ne doit mettre dans ces trous que de la bonne terre neuve, ou bien un lit de feüilles ou de gazon, comme nous venons de dire; \& pour garantir des grandes chaleurs de l'Eré, les arbres nouvellement plan-. tés, on étendra tout au tour de leur pied fur la fuperficie de la terre, environ un demi pied d'épais de bon fumier peu confommé, parce qu'alors il eft plus rempli de fels \& d'efprits vegetaux, que les pluyes \& les arrofemens feront fondre fur les racines des arbres.

Si vous avés des trous \& des rigoles à faire dans des terres rapportées, fabloneufes, \& méchantes d'elles-mêmes, foit pour planter des paliffades ou des rangées d'arbres, il faut faire de bonnes tranchées d'un bout à l'autre fans interruption, de guatre pieds de large \& de trois de profondeur, \& y faire 
L A PRA TIQUEDU JARDIN A GE. I 85 aporter de la bonne terre pour en remplir la tranchée : l'on pourra planter hardiment les arbres dans cette terre, fans cela ils n'y feroient que languir.

A l'égard des Bois \& des Bofquets, on en diftingue de fix fortes, ainfi qu'il a été dit ci-deffus dans le Chapitre $6^{\mathrm{C}} \mathrm{de} / \mathrm{a}$ ${ }^{\text {re }}$ Partie; fçavoir lesForêts \& les grandsBois de haute-futaïe, les Bois taillis , les Bofquets de moïenne futaie à hautes palifrades, les Bofquets découverts \& à compartiment, les Bois planrés en quinconce \& les Bois verds. Il eft bon de les parcourir l'un après l'autre, en diftinguant les differentes manieres de les planter.

Les Forêts \& les grands Bois de haute-futaïe fe fement ordinairement de differentes graines \& fruits. Onfe contente dans les terres deftinées pour le Bois, d'y faire donner un labour, \& d'y femer du gland, de la chataigne, \&c. comme on fair le bled; ou bien l'on fait piquer du gland en terre de fix pieds en fix pie ds, fuivant des traces faires à la befoche, ce qui va trés-vîte, \& fait que les arbres fe trouvent un jour efpacés plus régulierement.

La meilleure méthode de planter les Bois, c'eft d'avoir du plant enraciné ; pour lors il faut planter ces jeunes plants a fix pieds de diftance l'un de l'autre, \& obferverfur tout de ne leur point couper la tête, car cela les empêcheroit de monter \& de former un jour une belle futaïe.

Les Bois taillis fe plantent ou fe fement de la même façon que les Bois de haute-futaïe; mais avec ces deux differences, que l'on efpace les plants, ou qu'on pique les fruits à trois piedsl' l'un de l'autre, \& que l'on coupe le haut du jeune plant, pourle faire pouffer en branches \& s'écarter en buifion. On doit couper ordinairement les Bois taillis tous les neuf ans, \& les prendre rez-terre fur les vieilles fouches qui repouffent incontinent après.

Les Bofquets de moïenne futaïe à hautes paliffades, demandent plus de foin dans la maniere de les planter. Après a voir fait labourer la terre, l'avoir ameliorée en cas de befoin, avoir tracé exactementle deffein du Bois, vous planterés les Allées, Salles, Cabinets, 8ic. comme nous venons d'enfeigner dans ce Chapitre en parlant des Allées. Vous planterés de même les Paliffades, en fuivant exactement les contours 
186 TROISIE'M E PAR TIE, ChAP. II. \& retours du deffein, \& en faifant ouvrir des rigoles, ainfi qu'il vient d'être dir ci-deffus. Pour remplir le milieu du Bois dont il s'agit ici, faites des traces au cordeau à la diftance de fix pieds l'une de l'autre, que vous ferés ouvrir en rigoles, de la largeur \& profondeur d'un fer de Bêche ; plantés-y du plant d Ormeaux, Chataigniers, \&c. à trois pieds de diftance. Après que le plant fera planté \& recouvert entierement, femés entre chaque rigole ou piqués du gland, de la chataigne \& de toutes fortes de graines; cela formera du garni \& de la brouffaille, \& les,rangées du plant enraciné formeront un jour de la futaie, par les foins qu'on prendra de l'élaguer, \& de le conduire trés-haut.

On obfervera encore pour garnir un Bois plus vîte \& en avoir plûtôt du plaifir, de planter du plant un peu fort dans les quarrés, \& de marcotter les longues branches traînantes à terre, au lieu de les couper; cela avance bien plus que de femer du gland, comme l'on fait pour planter lesgrands Bois \& les taillis.

Les Bofquets découverts \& à compartiment font trés đifferens des futaïes \& des taillis, en ce que le milieu de leurs quarrés eft vuide de Bois, \& rempli feulement de piece de gazon à compartimens, que l'on femera ou plaquerá dans la même intention qu'il eft marqué dans le deffein, \& fuivant ce qui en a été dit dans le Chapitre 7 e de la IrePartie. Al'égard desAllées $\&$ des Paliffades de ces Bois, elle $S_{s}$ fe planteront toujours ¿̀ hauteur d'apui \& en banquettes, à caufe de la vîü.

Les Quinconces fe plantent comme les Allées, n'étant effedivement autre chofe que des rangs d'arbres, \& plufieurs allées paralleles, qui s'alignent $\&$ s'enfilent l'une dans l'autre; l'on prendra garde feulement en plantant ces Bois, de fe bien retourner d'équerre, \& que les arbres foient droits, s'enfilent d'angle en angle, \& fe raportent jufte l'un à l'autre, c'en eft la beauté. Il ne faut ni paliffades ni brouffailles dans ces Bois, ainfi il eft fort aifé de les planter. On y feme quelquefois fous les arbres, des pieces de gazon, en y confervant des allées ratiffées.

Les Bois verds fe plantent de la même maniere que les attres, il n'y a pas plus de difficulté ; l'on aura recours au Chapitre précédent, pour faire choix des arbres qui convien- 
LA PRATIQUEDU JARDINA GE. I87 nent le mieux pour planter les Allées, les Paliffades \& les Quarrés de ces Bois.

Comme il n'y a rien de plus long à croître qu'un Bois, il faut confulter le terrain où on le veut planter, en examinant par des foüilles faites en plufieurs endroits, le fond naturel de la terre, \& regardant les herbes qui la couvrent. Sila terre fe trouve humide, \& qu'elle foit couverte de rofeaux \& de joncs, on y plantera des arbres aquatiques; fi elle eft feche, les arbres appellés fauvages y conviendront mieux ; car on doit toû jours regarder ce qui peut plaire au naturel de la terre, autrement les Bois feront long-tems à s'élever.

On voit par-là la différence qu'il y a des Bois avec les Parterres 8 les Boulingrins, qui font plus beaux dés le premier jour qu'on les a plantés que dans la fuite, au lieu qu'un Bois dans fa jeuneffe n'a rien que d'imparfait, étant privé de cet ombrage qui fait tant de plaifir dans les Jardins ; on lui fouhaite toûjours un peu d'ancienneté.

Quand on aura à regarnir d'anciens bois dégradés, foit dans leurs quarrés ou dans leurs lifieres $\&$ bordages plantés d'arbres $\&$ de Paliffades, on aura plus de peine à y faire venir quelque chofe, que dans un jeune plant ; car les arbres meurent facilement fur une futaie, quand même on choifiroir l'efpecela moins délicate, L'on n'y pourra élever que des brouffailles de Lilas, Sureau, Sycomore, du Buis \& de l'Ormille, \& ff. l'on veut abfolument y planter quelques arbres, il faut percer au deffus un jour perpendiculaire, pour leur donner de l'air: car fans cel 2 les arbres viendront rabougris, \& étant offufqués mourront. La terre confufe de racines \& ufée entierement eft peu propre encore à faire reprendre de jeunes plants; ainfi l'on aura foin de faire des trous un peu grands \& profonds, de les vuider de leur mauvaife terre, \& de les remplir de la meilleure que l'on aura, c'ent-à-dire, une terre neuve \& frấ. che. L'on marquera ces arbres avec de la paille ou de l'ofier, afin de les diftinguer des autres, \& d'en prendre foin dans 1'Efté. En faifant les trous, prenés garde d'endomager quelques groffes racines voifines, cela feroit mourir de grands ar bres, \& par-là vous dégraderiés encore plus le Bois.

Pour ce qui regarde le tems de planter les arbres, il vaut mieux en général's'y prendre avant l'Hyver, dans les mois de 
188 TROISIE'ME PARTIE, CHA P. II.

Novembre \& de Décembre, qu'au commencement du Printems, comme au Mois de Mars. Les arbres \& leurs racine ont le tems pendant l'Hyver, de s'accoûtumer à la terre \& de la goûter en attendant la féve, outre que les pluyes \& les neiges fonduës trempent $\&$ humectent les racines, ce qui les lie à la terre. Les arbres n'ont point tous ces avantages, lorfqu'on les plante après l'Hyver, étant mouvés \& tranfportés trop près du tems de la féve, ils ont plus de peine à s'accoûtumer à une nouvelle terre, \& à y produire auffi-tôt des racines.

On obfervera que dans les Pä̈s fecs, il convient mieux planter avant l'Hyver, afin que les arbres nouvellement plan. tés, profitent des pluyes \& neiges fonduës, dont ils ont grand: befoin, pour temperer cette féchereffe naturelle. Il ne faudra pas auffi planter fi avane, parce que les eaux, tant de pluye que des arrofemens, feroient imbibées en terre avant qu'elles puffent defcendre jufqu'aux racines; au lieu que dans les terres bumides, il faut attendre le mois de Mars, ou la terre s'étant déchargée de cette grande humidité de l'Hyver, fera plus propre à la reprife des jeunes plants. Dans les Pays machantilly, récageux onleve les vannes des Canaux \& des Eftangs, pour liancours. y pouvoir planter, fans cela l'eau feroit dans les trous des arbres, on plantera autant profondément que le niveau de l'eau. le pourra permettre.

On choifira toujours un tems fec pour planter, parce que la terre étant bien feche, fe gliffe mieux autour des racines, fans y laiffer aucun vuide, \& qu'il ne s'y fait point de mortier, qui elt fort nuifible à la reprife des arbres.

Quelques perfonnes prétendent, qu'on doit faire une obfervation en plantant unarbre, qui eft de le tourner à la même expofition du Soleil où il étoir avant que de le déplanter: cela n'eft bon tout au plus que pour les arbres fruiciers, \& parô̂t une de ces difficultés inutiles, où l'on ne doit jamais $s^{3} a r$. rêter.

Quelquefois quand il fe rencontre un arbre dont la tige a quelque coude, l'on obfervera en le plantant de tourner ce coude à l'oppofite du Soleil du Midi, qui l'atrire à lui, \& par ce moyen le redreffe. Sans cela on doit toujours tourner un arbre fur le fens qu'il parốt le plus droit fur fon alignement. 
LA PRATIQUE DU JARDINAGE. I89

Il peut furvenir une autre difficulté, qu'il eft bon d'éclaircir. Voici en quoi elle confifte: Quand un deffein eft tracé ; furtout celui d'un Bois, ò̀ il y a des allées tournantes, don les arbres ne peuvent s'aligner l'un fur l'autre, l'on fe trouve fort embarraffé, après que le trou eft fait \& le piquet ôté, de planter un arbre fans aucun alignement \& mefure qui puiffent vous régler.

Pour fe tirer de cet embarras avant que de faire le trou \& d'ôter le piquet, pofés-en quatre autres, qui s'alignent en croix fur ce piquet du milieu, qui eft celui que l'on doit déplacer, ainfi qu'il fe voit dans cette Figure. L'on prendra garde de planter ces piquets un peu loin de l'endroit où l'on doit faire le trou, afin qu'on puiffe jetter les terres qui en fortiront, fans couvrir ces piquets. C'eft par ce moyen que vous retrouverés la place de votre arbre, en le mettantdirectement dans le milieu du trou, en forte que les quatre piquets s'alignent \& fe croifent fur l'arbre, de même qu'ils faifoient fur le piquet que vous avés ôté.

A près avoir donnéla maniere de planter toutes les différentes parties d'un Jardin, paffons maintenant aux foins que l'on doit prendre des jeunes plants pour les bien élever.

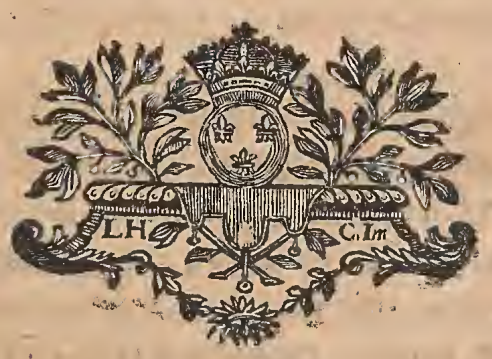


(c)

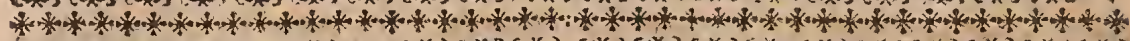

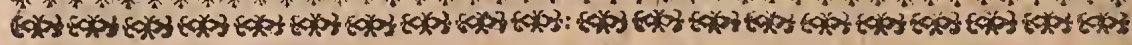

\section{CHA P I T R E III.}

DU SOIN QUE L'ON DOIT prendre des plants pour les bien élever, avec les moyens de les garentir des maladies or infectes qui les attaquent.

I l'on veut avoir en peu de tems de la fatisfaction desarSbres dont on aura planté un Jardin, c'eft fans doute en leur donnant les foins qui leur font néceffaires, felon les différentes faifons de l'année, cela demande à la verité beaucoup d'attention, mais auffi l'on eft agréablement récompenfé de fes peines, par le plaifir de voir avancer promptement fes. propres ouvrages. Sans cela on a le chagrin de voir mourir \& fecher fur le pied, la plûpart des arbres d'un Jardin, outre la dépenfe confidérable de replanter tous les ans, fans jamais pouvoir joüińr.

Les foins qu'on doit prendre des jeunes plants confiftent en trois chofes, dans les labours, dans les arrofemens, \& dans la maniere de les conduire pendant les premieres années.

Le plus néceffaire de ces trois foins eft le labour, dont il faut quatre par an, deux grands labours, \& deux petitsque l'on appelle binages. Le premier grand labour fe fait à l'entrée de l'Hyver, \& le fecond au commencement du Printems. Les deux petits fe font l'un à la $S$. Jean d'Efté, \& l'autre dans le mois d'Août.

La raifon de ces dịfférens labours \& des différens tems aufquels on les doit faire, c'eft qu'à l'entrée de l'Hyver les arbrès n'étant plus en féve, il n'y a point de danger de leur donner un grand labour, $c^{\prime}$ eft-à- dire, un profond labour; outre que cela coupe la trace des taupes, \& la racine des mauvaifes herbes, cela donne encore paffage aux pluyes \& aux neiges fréquentes en cette faifon, ce qui trempe la terre très-avant. Voilà pour le premier grand labour. A l'égard du fecond qui fe fait au commencement du Printems, comme dans le mois 
I A PRATIQUE DU JARDINAGE. I9I de Mars, on ne rifque rien de donner un labour un peu profond à la terre, qui ne travaille pas alors fi vigoureufement , \& qui ne craint point encore la grande chaleur.

Les deux petits labours apellés binages, c'eft - ̀̀-dire, $\mathrm{fe}$ conds labours, doivent être moins profonds que les autres, parce qu'ils font faits pendant les deux feves, où il y auroit du rifque a foüiller la terre trop avant, \& par-là d'évanter les racines, ou en couper le chevelu. Il ne faut dans les binages, que peler \& ratiffer la fuperficie de la terre, de crainte que la chaleur ne pénetre jufqu'aux racines, \& feulement pour couper les herbes, qui pouffent en abondance dans cette faifon, comme auffi pour donner entrée aux rofées du matin $\&$ aux pluies, qui facilitent beaucoup la feve.

Ondit ordinairement que pour a voir bien foin d'un bois, il le faut entretenir comme une vigne, où l'on ne fouffre jamais d'herbes.

Lesarbres ifolés, c'eft-à-dire, qui ne font point engagés dans une paliffade, dans un bois ou une plate-bande, \& autour defquels on peut fe promener, feront labourés de quatre pieds en quarré; \& les paliffades de deux pieds de large par derriere, l'allée ratifféeleur fervant de labour pardevant.

Onfe fert pour les grands labours de houës \& de bêches, \& pour les petits de binettes, de ratiffoires \& ferfoüettes, quand l'herbe eft trop grande, avant que de labourer, on la fair arracherà la main . ce qu'on apelle farcler.

Pour faire ces labours utilement \& les donner à propos, il faut confulter la qualité naturelle de la terie : car un tems propre pourlabourer les terreslegeres \& feches, ne le feroit point du tout pour les terres fortes \& humides; ainfi comme les terres legeres \& feches ont befoin d'humidité , pour corriger leur trop grande chaleur, on les labourera un peu avant la pluïeou incontinent après, afin de procurer un prompt écoulement aux eaux qui pourroient fe perdre ailleurs par trop de retardement. Au contraire, on labourera les terres fortes \& humides, dans les plus grandes chaleurs, dont elles. ont plus befoin que d'eau; ce qui empêchera encore ces terres de fe gercer \& de fe fendre. Ces labours étant faits de cette maniere \& avec ces obfervations, entretiennent la terre bien plus longtems fraîche, \& en valent infiniment mieux pour les Plants. 
192 TROISIE'ME PARTIE, CHA P. III.

Les arrofemens font le fecond foin qu'on doit prendre des jeunes Plants ; ils fervent ainfi que les labours à diffoudre, 8 à faire agir les fels de la terre, qui fans cela refteroient en maffe. Si nous avons dit dans le Chapitre fecond de la premiere Partie, que l'eau eft trés-néceffaire dans un Jardin, c'eft fans doute pour cette jeuneffe, qui fécheroit fur le pied fans ce fecours. Les arrofemens doivent être fréquens $8 \mathrm{r}$ abondans: Car étant petits, ils ne fervent qu'à alterer davantage la terre, femblables à une goute d'eau jettée dans un grand feu, qui en irrite encore la flâme.

L'heure la plus propre pour arrofer eft le matin ou le foir; pendant la grande chaleur du jour on ne doit arrofer que dans les bois \& les lieux à l'ombre.

Il faut obferver une chofe a vant que d'arrofer, qui eft de couvrir le pied des arbres \& des palififades, avec du grand fumier ou de la litiere, que l'on étendra fur la fuperficie de la terre, ainfi qu'on a déja dit. Les arrofemens en font bien meilleurs; l'eau paffe à travers ce fumier, comme par un cri. ble, ne fait point de mortier, \& la terre étant par le moïen de ce fumier à l'abri des raïons da Soleil, en conferve plus longtems fa fraîcheur.

Comme ce fumier feroir vilain à voir dans une belle allée, on l'enfoüit à fleur de terre, \& l'on fable l'allée par deffus, ce qui paroît aufi propre, \& eft de la même utilité pour l'arbre.

Onfe fert d'arrofoirs pour les lieuxx proches; mais quand il faut porter l'eau un peuloin, on remplit un petit tonneau comme un quarteau, que l'on mene fur une broüette aux endroits néceffaires; il faut enyiron deux arrofoirs ou deux feaux d'eau à chaque arbre, felon qu'il paroît alteré. L'on connoît cela, quand la terre fe fend, \& boit l'eau promptement. On creufera un cerne ou petit baffin au pied de l'arbre pour fervir d'entonnoir à l'eau qui couleroit fans cela autre part.

On peut encore fefervir de longues goutieres de bois ou de rigoles cimentées, pour conduire l'eau d'un baffin ou d'un puits, le long d'une allée, avec des tonneaux enfoncés en terre d'efpace en efpace pour recevoir ces eaux, \& y puifer dans le befoin ; mais cela n'eft gueres propre dans un Jardin, a moins quie ce ne foit dans un Potager. 
LA PRATIQUE DU JARDINA GE. 193

A l'égard des paliffades \& rangées de jeunes Plants dans. un bois, il faut leur donner de l'eau, tant qu'ils en auront befoin, en creufant auparavant une petite rigole tout du long. pour faciliter l'écoulement de l'eau.

Le troifiéme foin eft de conduire \& d'élaguer les jeunes Plants : cela ne demande qu'un peu d'intelligence, pour diftinguer dans un arbre qui a plufieurs branches qui lerendent difforme, celle qu'on doir laiffer pour l'élever un jour trésbeau \& trés- droit.

On doit tenir pour regle generale, qu'un arbre de hautefutaïe, pour être eftimé beau, ne doit avoir qu'un jet montant, qu'il doit être trés-haut de tige, comme de vingt à trente pieds, fans fourchẹs ni branches; après cela on lui laiffe former fa tête comme il veut. Au contraire, quand la tige d'un arbre eft trop baffe, les fourches en font défagréables à la vîië, aufi-bien que quand l'arbre a plus d'un montant : car il reffemble alors à un Pommier, ou à ces Chandeliers de Noël torrillés en fept branches.

Si ce font des arbres étêtés que l'on veut conduire, on les épluchera la premiere année, en ôtant avec la mạin tous les petits boutons qui font le long de la tige, afin que la fevemonte \& fe réüniffe toute en haut, pour former une nouvelle tête. La feconde année de leur pouffe, l'on choifira parmi toutes ces branches, celle qui fera la plus forte \& la plus droite fur le pied de l'arbre, c'eft à̀-dire, qui y tombera le plus à-plomb, \& l'on coupera fans réferve toutes les autres.

Lorfqu'on fe trouve embarraffé dans le choix d'une branche, n'y en ä̈ant pas de bien droite fur l'arbre, il en faudra laiffer deux jufqu'a l'année fuivante, que l'on coupera la moindre. Il arrive quelquefois qu'on ett obligé de lailfer trois branchesfur un arbre, quand celle du milieu qu'on doit élever commela plus à plomb fur le pied, fe trouve la plus foible de toutes, \& fouvent un peu verfée. Alors on paffe un. bâton à travers ces branches, pour contraindre \& dreffer celle du milieu. A près celạ on en pêle l'écorce tout autour, environ de deux pouces de large, à l'endroir d'ou elles fortent du maître bring , pour en arrêter la feve qui n’eft portée de cette maniere que dans la branche du milieu. Les deux

Tels font les Marroniers de la grande al. lée des Tuilleries, qui ont prefque tous ce défaut. 

autres branches meurent, \& qúand celle du milieu fe peut foûtenir d'elle-même, on les coupe tout-à-fait : ainfi des trois branches qu'on avoir laiffé d'abord, il n'en refte plus qu'une feule bien droice.

La raifon pour laquelle il ne faut laiffer qu'une feule branche à un arbre, c'eft qu'il s'en porte mieux, en devient plus gros, plus beau, \& crồt plus vîte : cette branche airant elle feule toute la nourriture \& la feve; au lieu que quand il fe trouve quatre ou cinq branches furle même arbre, cette feve étant partagée en quatre ou cinq portions, rend ces branches plus foibles \& moins élevées. J'ai conduir de cette maniere des Ormes étêtés, qui en cinq ou fix ans ont formé une tête belle. droite \& de quinze à vingt pieds de haut.

Quand on plante des arbres fans leur couper la tête, comme ceux qui font en motte, on ne leur laiffe qu'un petit bouquet en haut, afin que l'arbre ä̈ant peu de branches \& de charge, la racine puiffe plus facilement nourrir fa tête.

La meilleure maniere de bien élever \& direffer des allées,

On attache ces perches avec de l'ofier, ou encore mieux arec du fil de fer, en mettant entre $\mathrm{l}_{2}$ perche \& l'arbie, du foin, des copeaux de bois ou de cuir accommodés de telle façon, que le fil de fer ne puifle poine endommager L'arbre. eft de ne point épargner deux chofes : La premiere, de mettre des perches à chaque arbre pour les conduire, fans cela les arbres verfent, lear tête devient tortuë \& eft fort expofée à être éclatée par les vents. La feconde, c'eft de faire groffierement des treillages de petites perches liées avec de l'ufier, pour foûtenir \& élever les paliffades un peu fortes, qui fans ce fecours, ne fe dreffent jamais bien fur leur pied; cela va affurémentà quelque dépenfe, mais elle eft indifpenfable.

Pour redreffer de vieux arbres qui verfent ou qui font tortus, \& que bien des gens abattroient par la difformité qu'ils aportent dans un Jardin, on a trouvé un expedient, qui eft de les tirer fur leur fensavec un triteil \& des cordages, jufqu'à ce qu'ils foient droits, \& enfuite avec de gros fils de fer les contraindre \& les attacher fur d'autres arbres voifns les plus commodes à les entretenir dans cet état. On mer du cuir entreles boucles du fil de fer, crainte qu'il n'écorche l'arbre $\&$ ne le coupe. Si l'arbre avoit un coude confiderable, qu'avec le trïieil on n'eût pû redireffer, on y mettroit une piece de bois en étrefillon, qui arc-bouteroit contre le coude \& directement dans l'endroit, avec un morceau de cuir entre. 
L A PRATIQUE DU JARDINAGE.I9S l'arbre \& l'étrefillon, que l'on attachera avec de grands clous de peur qu'il ne gliffe. Cet arc-boutant doit refter pendant la feve, qui par lon fuc nourricier rend un arbre plus capable que dans tout autre tems, de prendre la nouvelle imprefion qu'on lui veut donner; cela n'empêche pas qu'il ne faille encore fe fervir du truëil pour faire revenir la tête de l'arbre à l'à-plomb du pied, \& l'entretenir avec un fil de fer comme dans la premiere maniere. Quand ce ne font que de jeunes arbres droits qui verfent feulement, on enfonce des piquets rez-de terre, pour en contraindre les racines, après les avoir tiré avec des cordages. Il y a de certains arbres, qui par leur grand âge, ou leur grande difformité, font prefque impoffibles à redreffer, ainfil l'on aura plûtôt fait en cette occafion de les abattre, \& d'en planter d'autres à la place.

Les jeunes paliffades la feconde année de la pouffe, après avoir été regarnies dans les bréches, fe prennent de près des deux côtés, c'eft-à-dire, par derriere, \& par devant, en les tondant aux cifeaux, c'elt le moyen de les faire monter \& élever droites. Il ne faut jamais toucher au montant, en les refepant par deffus pour les mettre d'égale hauteur : car cela les empêche de pouffer fi droit \& fi vîte, outre que ce n'eft point une difformité à du jeune Plane de le voir plus haut à un endroit qu'à l'autre. On s'attend bien que ce fentiment ne fera pas goùté de quantité de Jardiniers qui ne s'attachent qu'à leur vieille routine, de toujours couper \& maffacrer les arbres, mais on eft perfuadé que les gens raifonnables feront plûtôt de cet avis que du leur, qui n'eft fondé que fur une ancienne \& mauvaile pratique.

Il n'eft à propos de refeper une paliffade par deffis, que quand on n'en veut faire qu'une banquette à hautẹur d'appui, ou bien quand la paliffade eft parvenuë à vingt ou trente pieds de haut, ce qui empêche qu'elle ne fe dégarnilfe du pied, \& la rend regulierement glus belle, étant toute coupée à la même hauteur.

Pour bien entretenir les Paliffades, on ne les doit pas laiffer monter fi haut, crainte qu'elles ne fe dégarniffent. Il les. faut tondre \& les ferrer de près ayec le croilfant, par le moyen de grandes échelles doubles \& chariots roulans, tans par le deflus que par les dẹx côtés \& \&oujours le plus courc

Les Jardiniers font fi accoûtumés à couper, qu'ils difent entrecux par proverbe, qu'ils couperoiert la téte à leure pere, s'il éroi: arbre, 
I96 TROISIE'ME PARTIE, C H P. III. \&le plus ferréqu'il fe pourra, il n'y a rien de plus vilain que de voir une paliffade trop épaiffe, joint à ceque cela la ruine en peu de tems. Dans les Jardins bien foignés on tond les paliffades deux fois l'année, en Juin \& au commencement de Sep. tembre, après la pouffe de chaque féve, mais ordinairement on ne les tond qu'une fois, \& cela dans le mois de Juillet entre les deux féves.

Les arbriffeaux des Parterres, comme les Ifs, Houx, Rofiers, Chevrefeüilles, \&c. doivent être labourés \& arrofés de tems en tems. On les moule en boules \& autres figures : en les tondant avec les cifeaux; \& pour les bien entretenir, il les faut ferrer de près \& tondre deux ou rrois fois par an, afin qu'ils confervent mieux la belle forme qu'on leur a donné.

Dans les quarrés de bois oì vous voulés élever de la fuțaie, ayés l'oil fur les jeunes plants, \& après leur avoir laiffé prendre un peu de force, vous les émonderés avec la ferpette, en ne leur laiffant qu'un jet montant, vous en laifferés d'efpace en efpace quelques-uns des plus mal faits, fans les élaguer, \& dont vous pourrés marcotter les branches, pour brouffailler le bois

Enfin quand un bois eft parvenu à la hauteur de vingt à trente pieds, on fe fert d'une ferpe, \& l'on monte fur une échelle, pour élaguer les branches inutiles, avec la précaurion de les couper le plus près qu'il fe pourra du trone de l'arbre, \& un peu en glacis, ce qu'on appelle en pied de biche, afin que l'eau puiffe couler deffus fans pourrir larbre. It ne faut pas que cela faffe de la peine d'éclaircir d'abord un bois; $\&$ de lui ôter un peu de couvert dans les premieres années; cardans la fuite les arbres en deviendront plus hauts, plus droits \& infiniment plus beaux.

On aura la précaution en élaguant les arbres, de ne les point entamer de tous côtés, parce que ces playes donnant peu de palfage à la féve par l'écorce que l'on coupe, la peuvent arrêter \& fécher la tête, ou la faire geler dans l'Hyver. Ainfi l'on fera ces playes petit à petit \& d'année en année, en montant toujours ces arbres d'étage en étage, enforte que toutes les playes ne foient pas fraîches en même tens, \& qu'il n'y ait que les nouvelles à jour ; les dernieres fe feront recouvertes pendant l'année. 
LA PRA TIQUE DU JARDINA GE. I97

Le vrai tems pour élaguer les arbres eft un peu avant l'Hyver, ou bien au commencement du Printems, afin que les grandes playes qu'on leur fait, ne foient pas fi expofées à la gelée, \& puiffent fe recouvrir plus facilement. On plaque fur ces grandes playes de la bouze de vache ou des morceaux degazon pour les garentir de l'ardeur du Soleil, \& fi l'on voit que l'eau commence à y caver, ce qui pourriroit l'arbre dans la fuite, l'on y clouë des plaques de fer blanc ou de plomb, avec de la mouffe entre-deux.

Outre tous les foins dont on vient de parler, il faut avoir encore celui de vifiter les arbres de tems en tems, \& de les guerir des maladies, infectes \& vermines qui les attaquent. Voici les moyens d'y remedier.

Les maladies des arbres proviennent ou du fond naturel de la terre, ou de leur propre défaut \& mauvaife conftruction, ou bien de la guerre que leur font les animaux, infectes \& vermines, qu'on peut appeller veritablement les ennemis jurés d'un Jardin.

Les maladies qui viennent du fond naturel de la terie, font très-difficiles à guérir, comme feroit un terrain rempli de tuf́ \& d'argille dans fon fond. On a beau changer Ta terre de trois pieds de haut par tout, \& y en faire apporter tout de la meil: leure, quand la racine des arbres a une fois atteint ce mauvais fond, on les voit languir, jaunir, diminuer d'année en année, \& enfin mourir. Il n'y a aucun remede en ce cas, finon d'éviter dans le choix qu'on fera d'une fituation, les terrains qui feront ainfi compolés.

Si le terrain où l'on a planté des arbres eft trop fec, on y peut remedier, en déchauffant les racines d'un arbre, \& les regarnilfant de bonne terre neuve bien fraîche : fi le terrain fe trouve au contraire trop humide, il faudra pareillement déchauffer l'arbre, \& remplir le trou de fumier de cheval. peu confommé, pour donner de la chaleur à certe terre, avec la précaution de ne pas trop approcher ce fumier des. racines.

Les maladies qui font caufées par la mauvaife conftruction des arbres, \& par leurs défauts naturels, font prefque aufi fans remede : car fi l'arbre eft défectueux dans fes racines ou dans fa tige, l'on fera beaucoup mieux de le rejetter, $8 x$ d'en 

planter un autre mieux conditionné. Si cependant les maladies arrivoient à un arbre après être planté, \& qu'on ne le vît. point attaqué d'aucun mal exterieur, il faudra le faire déchauffer \& vifiter fes racines, afin de fçavoir s'il ne s'en trouve point quelques-unes de pourries ou de rongées : alors on les coupera jufqu'au bois vif, pour les rafraîchir \& les obliger de pouffer de nouveau chevelu. Quelquefois auffi cela provient de la négligence qu'on aura eu en plantant un arbre, de ne pas bien garnir de terre toutes fes racines, \& de laiffer des cavités ou des pierres fur quelques-unes, ce quiles empêche de fe lier à la terre, \& fait extrêmement pâtir un arbre. On peut faire cette operation en tout tems, hormis pendant les deux féves, \& auffi-tôt on remplira le trou de terre neuve, de crainte que les racines ne s'éventent.

Si le mal ne provient point des racines que l'on aura trouvées en bon état, \& que cependant l'arbre pâtiffe, il faut le décharger par la tête d'une partie de fes branches, ou arrofer fa tête pour le raviver, cela le foulage beaucoup.

On obfervera de plus, que dans les endroits oi il fera mort deux ou trois fois de fuite des arbres d'une même efpece, il faudra en changer: La terre étant ufée pour cette efpece, devient une terre neuve pour une autre. Comme fi plufieurs Ormes étoient morts de fuite à la même place, il faudroit y mettre des Tillots, des Marroniers ou autres efpeces.

Quand ce font des paliffades qu'on veut regarnir, on doic obferver la même chofe. Ainfi une paliffade de Charmille fera regarnie d'Erable, de Hêtre ou d'Ormeaux par la même raifon : car il eft plus difficile de faire venir des plants dans des bréches \& endroits morts, que dans une place neuve.

Si l'on a voit déchauffé une paliffade malade, \& qu'on n'y etut trouvé aucune maladie que la vieilleffe ou une terre ufée, l'on peut y remedier en ravalant une paliffade à quatre à cinq pieds de haut, ou en la ferrant avecla ferpe \& approchant de près des deux côtés jufqu'au maître brin, ce qu'on appelle ferpiller une paliffade; cela lui donnera de la vigueur pour poufler de nouvelles branches. On peut encore faire des tranchées des deux côtés, à deux pieds de diftance de la paliffade, de peur d'endommager les racines, vuider ces tranchées de leur mauvaife terre, \& les remplir de la meilleure \& de la plus fuấ. che qu'on pourra trouver. 
LA PRATIQUE DU JARDINA GE. 199

Les arbres ont encore des maladies particulieres \& exterieures, comme des chancres, de la mouffe $\&$ la jauniffe.

On ôte les chancres avec la pointe d'un couteau, en coupant toute la partie atteinte de ce mal, jufqu'au bois vif, \& P'on remplit cette pläie avec de la bouze de vache, qu'on fait tenir par le moïen d'un linge \& d'une corde liée à l'arbre. Comme le chancre gagne fort vîte, ille faut ôter fítôt qu'il paroît, car il fait mourirla moitié d'un arbre \& fouvent tout entier.

La mouffe nuit cxtrêmément aux arbres ; c'eft comme une gale qui les empêche de groffir $\&$ de devenir beaux: il faur pour la faire tomber, grater avec des couteaux de bois ou de groffes broffes, les endroits ou il y en a, ou bien prendre de la paille ou un torchon, dont on frotera la tige. L'on fera toujours cet ouvrage après la pluie, ou le natin après la rofée, car alors la mouffe fe dérache plus aifément que dans un tems fec, ou en frotant trop fort, on pourroit écorcher l'arbre. L'on prétend que la mouffe vient da tuf que les racines rencontrent.

La jauniffe \& la langueur d'un arbre proviennent ord inairement de quelque piquire de vers, à moins que l'arbre ne foir à demi-mort. On le déchauffera \& l'on coupera jufqu'au vif les racines endomagées, quel'on recouvrira promptement de la meilleure terre; par ce moïen la feve s'y portera de nouveau, nourrira \& fortifiera ces endroits. On pourroit encore avant que de déchauffer un arbre, y jetter du jus de fumier de porc, qui étant naturellement frais, fait réverdir tout un arbre. Ce remede eft moins dangereux que l'autre.

A l'égard des maladies qui arrivent aux arbres par la guerre que leur font les animaux, infectes \& vermines, elles ne font pas fans remede:

Les arbres ont pour ennemis principaux, lesLapins, les Mulots, les Taupes, les Chenilles', les Hanetons, les Fournis, Cantarides, Limaçons, Taons, Turcs, \& quantité de vers dont nous ne favons point les noms. Les infectes qui s'artachent aux Orangers \& aux fleurs, fe trouveront dans la fuite.

Les Lapins détruifent entierement un Jardin, quand ils y trouvent entrée ; ils broutent \& rongent les jeunes bois, les paliffades \& les potagers, \& coupent tour à fleur de terre, 
On peut faire aifément fut cetze defcripsion, de $\mathrm{pa}$ reilles boitics.

\section{'TROISIE'M E PAR TIEl, C H A P. III.}

le refte ineurrincontinent après, leur dent \& leur morfure étant trés-dangéreufes. On s'en peut garentir en bouchant avec des fils de fer, les ouvertures des murs \& les grilles par oì ils pourroient paffer ; \& s'il y a des terriers dans le Jardin, il faut les détruire par le mö̈en des Furets, ou en leur tendant des pieges.

Le Mulot eft une efpece de Souris qui foüit la terre comme la Taupe, \& coupe entre-deux terres tout ce qu'il rencontre. Il fe prend avec des fouricieres ou d'autres pieges, comme des terrines pleines d'eau, fur lefquelles on répand de la paille d'avoine, \& où il fe vient nö̈er; on l'amorce par des morceaux de lard ou de fromage que l'on met dans ces pieges.

Les Taupes font les animaux qui ravagent le plus un Jardin: elles nuifent non feulement aux jeunes plants, en foulevant la terre $\&$ mettant leurs racines à jour, mais encore par leurs traînaffes, elles gâtent les allées \& les tapis de gazon. On peut les attraper de plufieurs façons; premierement, en jettant dans leurs trous, du chanvre, de la poirée ou de la fiente de cochon dont l'odeur, à cequ'on prétend, les fait fortir. Secondement, en les guetant fuivant la couttume des Jardiniers, à differentes heures du jour, \& les tirant à la bêche, mais cela eft bien long \& fait perdre trop de tems, car le moindre bruit qu'entend la Taupe, qui eft naturellement fort fubrile, elle s'enfuit. Le plus fûr moïen de les attraper, c'eft d'avoir des inftrumens en forme de boïtes ou fourreaux apellés des Taupieres, faites de branches de fureau que l'on creufe \& que l'on fend en deux. On rejoint ces pieces enfemble parun perit cercle de fer. Ces boïces ont environ un pied de long fur deux pouces de diametre ; elles font fermées par un des bouts, " $\&$ l'autre eft celui par ou entre la Taupe, qui fait remuer un petit crochet retenant un reflort qui le lâche aufi-tôt \& l'empêche de forcir. De cette maniere on les prend toutes en vie. L'on doir enfoncer ces boïres d'un demi-pied avant dans les traînaffes des Taupes.

Les Chenilles fe détruifent en coupant pendant l'Hyver les feiilles oi elles s'attachent par paquets, avec des cifeaux fur les arbres bas, \& fur la furaile avec des crochets de fer \& cifeaux attachés. à une longue perche, que l'on apelle Echenilloirs: 
LA PRATIQUE DU JARD IN A GE. 2OI * Echenilloirs; \& quand ces paquers font à bas, il les faut aufi-tôt brûler. On doit faire cette recherche avec grande exactitude pendant l'Hyver, parce qu'en cette faifon on aper* On connoír affés ectre ma: çoit ces paquets plus aifément, les arbres étant dépoüillés de leurs feüilles; mais on a beau faire, on en laiffe toujours quelques-uns, qui fuffifent pour empoifonner tout un Jardin.

Les Hanetons font les plus aifés à exterminer : on étend pour cet effet un drap deffous les arbres où ils s'attachent, \& on les fecouëra fortement pour les faire tomber. On les portera aufi-tôt dans le feu ou dans l'eau, de crainte qu'ils ne reviennent. Il ne faut pas fe contenter de les écrafer dans les allées, car la terre obéiffant au pied, on n'en écrafe que trés-peu; \& ils volent fur les arbres incontinent après. $L_{2}$ pluie leur eft fort contraire, auffi-bien quaux Chenilles.

Les Fourmis nuifent fort aux arbres, quand elles s'y adonnent unefois. On leschaffe en repandant au pied de l'arbre. de la fcieure de bois bien menuë, parce que fentant cette poudre remuer fous elles, elles fuïent \& craignent de s'aprocher. On fefert auffi de vafes pleins d'eau avec du miel, que l'on porte au pied de l'arbre, ce qui les attire \& les noïe; ou bien l'on met dela glu à la tige, pour les empêcher de monter. Il y a encore un autre fécret, c'eft de jetter dans l'endroit de la Fourmilliere un os à demie décharné, qui dans un inftant fera couvert d'un million de ces infectes; on le retire auffi-tôt, on le trempe dans l'eau pour les noïer, enfuite l'on rejette cet os qui fe retrouve couvert dans le moment, \& par ce manége on les ruine entierement. Elles fe peuvent encore brûler avec de la paille ou de la cendre chaude répanduë deffus la Fourmilliere.

Les Cantarides font des mouches qui s'attachent au haut des arbres, principalement aux Frefnes. Elles fe détruifent en verfant ou jettant fur le haur des arbres, par le moïen d'une petite pompe, de l'eau où l'on aura fait boüillir de la ruë.

Les Limaçons aiment 'les jeunes boutóns d'un arbre , \& par leur glaire lui nuifent beaucoup. On les prend aifément à la main, \& on les va chercher le matin \& le foir, furtout après un tems de plüie, c'eft alors qu'ils paroiffent en plus grande abondance, ih les faut écrafer promptement. 


\section{TROISIE'ME P A R T I E, CHAP. III.}

Les Taons font de gros vers qui vivent en terre, \& qui rongent les racines des arbres, aux pieds defquels on foüillera, pour les chèrcher \& les tuer en même-tems. On remplira enfuite le trou de terre'neuve, après avoir taillé plus court les racines endomagées parces infectes, qui s'attachent fur tout à la jeune Charmille.

LesTurcs font de certains vers blancs quipercent les arbres, les picotent \& courrent entre l'écorce \& le tronc de l'arbre, $c$ 'eft un infecte des plus dangereux, il n'en veut pas feulemenc aux jeunes plants, mais les plus grands arbres de haute-futa ie ne s'en peuvent garantir. Ces vers fucent la feve \& l'arrêtent entierement. Il faut pour les exterminer, fans perdre de tems, faire déchauffer l'arbre, \& peler toute la fuperficie de fon écorce, jufqu'àl'endroit endomagé par ces infectes: alors on les aperçoit dans leurs trous, d'ou il les faut tirer, ou les écrafer dedans avec quelque ferpointu, fans cela montant toujours de leur naturel, ils attaqueront l'arbre affés fortement pour le faire mourir la feconde année.

On voit encore d'autres efpeces de vers, dont les noms fon inconnus, qui ne's'attachent qu'aux feüilles des arbres, \& quiles picotent comme de la dentelle ; on les détruira de même que les Cantarides.

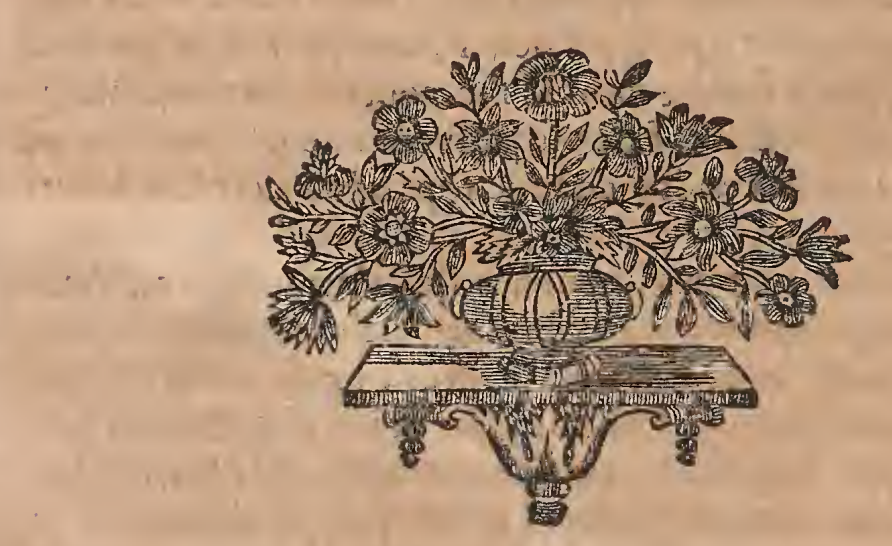




\section{CHAP I T R E I V.}

\section{DES PEPINIERES ET DU SOIN} qu'on en doit prendre, avec la maniere d'élever de graine, tous les Plants qu'en employe dans les fardins de'Prapreté.

CE Chapitre ne fera pas un des moins utiles de ce Traité, fi l'on confídére l'épargne \& la commodité qu'une Pepi niere offre fans ceffe à fon Mâtre. Une marque de fon utilité, c'eft que toutes les grandes Maifons en font ordinairement bien pourvîèes, comme d'une chofe très-néceffaire \& indifpenfable dans les Jardins d'une grande étenduë.

Le plus grand fecours qu'on tire d'une Pepiniere, c'eft que torfque quelque arbre meurt dans un Jardin, on le peut choifir chés foi, \& le trouver dans fa Pepiniere, fans être obligé de forcir pour l'aller chercher ailleurs, quelquefois bien loin, $\&$ avec tout cela l'acheter cher: les arbres qui font élevés. dans le même terrain en reprennent bien mieux , \& yiennent toujours plus beaux, leurs racines n'ayant pas le tems de s'éventer \& defécher, dans l'intervalle de tems qu'on eft à arra : cher un arbre pour le replanter auffi-tôt.

C'eft un accident qui n'arrive que trop fouvent aux arbres qui viennent de loin, dont les racines s'éventent ou font gelées \& fouffrent beaucoup dans les tranfports : de là fuit pour. l'ordinaire la mortalité de la plupart des jeunes Plants.

On place ordinairement les Pepinieres dans des endroits écartés comme au bour d'un Parc. Ce n'eft pas qu'elles ne foient agréables à la vûë par le foin que l'on en prend, \& qu'on n'ait du moins autant de plaifir à regarder une Pepiniere, que l'on en à voir un Potager ou un V erger: mais comme les lepinieres ne permetrent pas d'y pratiquer des allées dans les dedans pour s'y promener, \& qu'on ne peut y mar- 
204 TROISIE'ME PARTIE, CHAP." IV. cher fans gâter le labour, cela fait qu'elles ne font que con: tenter la vûë, \& que ne pouvant fervir à la promenade, on lés place ainfi à l'écart.

En fait de Pepiniere on $n^{5}$ en a jamais trop, ceft-à-dire, qu'il en faut toujours avoir plus que moins : un quarré, deux ou trois ; felon la grandeur du Jardin : fuppofé que l'on en ait trop dans la fuite, l'on trouve aifément à s'en: défaire, \& l'on en retire beaucoup de profit.

La place deftinée pour une Pepiniere étant arrêtée \& tracée fur le terrain, il la faut préparer ainfi : examinés fi la terre eft bonne, \& fi elle a la profondeur requife, fuivant ce qui a été dit amplement ci defius, dans le Chapirre fecond de la. premicre Partie, ou l'on aura recours pour éviter les redites. Comme il fe pourroit faire que cette terre ne feroit pas bonne; \& qu'il feroit difficile de changer la fituation de la Pepiniere; il faudra tâcher de l'ameliorer. Si la terre fe trouve ufée, l'on en fera apporter de meilleure ; fi elle eft trop maigre, on la fera fumer, \& fi elle eft pierreufe, on la fera effondrer $8 z$ épierrer, en paffant les terres à la claye. L'on ne doit pas manquer à ces obfervations \& à ces amandemens, car fans cela toutes les graines \& tout le petit plant que vous y mettriés languiroit \& ne profiteroit jamais affés pour former debeaux \& grands arbres, capables de remplacer un jour les endroits morts d'un Jardin.

Suppofons donc que cette terre foit ainfi ameliorée, fuivant le befoin qu'elle en aura, il lui faut donner un labour pour unir les terres \& les préparer à recevoir le plant. Vous tracerés enfuite de deux pieds en deux pieds des rigoles, en tendant le cordeau d'un bout à l'autre, \& ferés ouvrir ces rigoles d'un fer de bêche, c'eft-à-dire, d'un demi-pied de profondeur.

Semez enfuite vos graines dans ces rigoles, \& recouvrésles de terre, en prenant garde qu'on ne marche pas deffus. Si vouts avés des fruits, comme glands, marrons d'Inde, châraignes, \&c. vous pouvés fans ouvrir des rigoles, enfuivant le cordeau faire un trou avec le plantoir de pied en pied, \& y jetter dedans un maron ou un gland, \& enfuite vous reboucherés le trou, en y coulant de la terre avec le même plantoir ; c'eft ce qu'on appelle piquer des fruits en terre. Cette 
IA PRATIQUEDU JARDINAGE. $20 \xi$ maniere de planter va fort vîte, \& ne laiffe pas d'être bonne. Sil'on ne s'en veut pas fervir pour les fruits, on pourra ouvrir des rigoles, \& les femer dedans comme les graines.

Il faut teujours avoir une petite précaution qui ne laiffe pas d'avoir fon utilité ; c'eft de ficher des petits bâtons aux deux bouts de chaque rigole, afin de reconnoître les rangées du plant, \& les diftinguer d'avec les herbes, quand on viendra à farcler ou à labourerla Pepiniere.

Le vrai moïen d'a voir tune belle Pepiniere, $\epsilon^{5} e f t$ de la bien entretenir; cela demande un peu de foin \& un peu de fujettion, mais par le profit qu'elle fera un jour, on doir paffer par deffus toutes ces peines: Il n'y faut jamais fouffrir d'herbe, ainfi on la doit lábourer quatre fois l'année, \& farcler auffi. tôt que l'herbe paroît.

Pour connoître les tems les plus propres pour le labour, on aura recours au Chapitre précédent, où l'on donne la maniere d'entretenir les bois. Dans les grandes féchereffes, on y donnera un peu d'eau, pour foulager ces jeunes plants, qui font encore trop tendres \& trop foibles pour pouvoir réfifter d'eux-mêmes aux grandes ardeurs du Soleil.

Il faut remarquer que les plants qui viennent de graines, étant femés confufément dans les rigoles, doivent être relevés la feconde année, pour être replantés à un pied l'un de l'autre, dans d'autres rigoles, fans cela ils deviendroient trop drus, fe nuiroient les uns aux autres, \& on ne les pourroit lever commodément dans le befoin.

On peut comparer le tranfport de ces arbres, à ce qu'on apelle Bâtardiere en fait d'arbres fuitiers, que l'on leve au bout de deux ans de la Pepiniere, pour les replanter \& élever dans la Bâtardiere; l'on confeilleroit cependant une chofe, en cas que l'on en voulût prendre la peine, ce feroit quand le plant eft devenu un peu fort, conme la feconde année, de l'éclaircir \& de le dégarnir, en arrachant plufieurs petits plants d'entre ceux qui font les plus forts; enforte qu'ils fe trouvent efpacés au moins de pied en pied. Il faudroit avant que de fe mettre à cet ouvrage, faire farcler la Pepiniere, afin de mieux diftinguer le plant. C eft une grande peine affurément, mais aufli vorre plant ne fera point relevé la feC c i iij. 
206 TROISIE'ME PAR TIE, CHAP. IV. conde année pour être replanté ailleurs, \& en profitera mieux; aiant déja pris terre.

Si l'on vouloit élever des Pepinieres en peu de tems, au lieu de les fémer, on les plantera tour d'un coup de plant enraciné, \& un peu fort. Ce ne feroit pas une grofte dépenfe, le millier de ces jeunes plants coutant trés - peu de chofe. L'on gagneroir de cette maniere les deux années que les graines font à lever, \& à former de pareil plant; \& l'on ne feroit point obligé de le relever deux ans. après, pour le replanter ailleurs, ou bien d'avoir la peine de l'éclaircir comme l'on vient de dire. Cette manięre de planter une Pepiniere, eft la meilleure qu'on puiffe fuivre.

Supofé que vous aiés la commodité d'avoir du jeune plant, comme Ormeaux, Châtaigniers, Tillots, Marroniers, \&x. ouvrés des rigoles de deux pieds en deux pieds, a rrangés -y votre plant fuivant le cordeau, à un pied de diftance l'un de l'autre, \& jamais plus éloignés : car plus les plants font près, mieux ils fe conduifent l'un l'autre. Recouvrés enfuite les rigoles, \& plombés les terres, de crainte que les racines ne s'éventent. Il faut bien fe donner de garde de réléper ce plan à fleur de terre, comme fontbiendes gens; c'eft une fort mauvaife couttume; il ne faut que rafrâ̂chir les racines du plant, en coupant le petit bout.

Quand vos plants font devenus un peu forts dans la Pepiniere, comme à l'âge de trois ou quatre ans, il faut commencer à les conduire \& élever de cette maniere. Epluchés tous les petits boutons \& branchettes le long de la tige jufqu'en haut, \& choififfés parmi toutes les branches, celle quifera la plus droite fur le pied de l'arbre; enfuite fans rien couper, caffés le bout des branches inutiles, \& les tortillés de maniere au tour de la bonne, qu'elles fervent à l'entretenir \& à la bien dreffer. Quand ces branches tortillées font plus groffes que celle qu'on veut élever, de peur qu'elles n'emportent toute la feve, il les faut péler tout au tour environ de trois doigts de haut, ce qui en arrêtera la nourriture.

On conduira ainfi tous les ans, le montant de ces jeunes 

arbres de plus haut en plus haut, en cherchant de nouvelles branches pour les tortiller au tour \& l'entretenir droit, \& en coupant avec la terpette toutes celles qui font au deffous jufqu'au pied. C'eft par ce moïen qu'on fera monter ces jeunes plants hauts \& droits, \& qu'on aura le plaifir d'avoir un jour de trés-beaux arbres: pourvî, comme nous a vons dit dans le Chapitre précédent, qu’on ne leur laiffe qu'un feul montant.

Quand il y a dans une Pepiniere quelques arbres qui panchent, il les faut redreffer en les paffant \& tortillant avec ceux qui font proches, afin que l'un pour l'autre ils fe foûttiennent \& fe dreffent en groffiffant. Le tems de la feve eft le plus propre pour cet ouvrage, les arbres pliants aifément en ce tems-là, fans être fujets à fe caffer. Les coudes $\&$ les zigzac qui fe rencentrent le long d'une tige, $\mathrm{fe}_{\mathrm{e}}$ raccommodent en grofliffant: On peut les aidér, en fendant par filets, ces cavités que la feve en fe gonflant grofit \& remplic peu à peu.

Ces arbres aïant atteint l'âge de fept à huit ans, deviennent gros environ de fix à fept pouces, \& de quinze à vingt pieds de haut; pour lors ils font en état d'être mis en place dans le Jardin, fi l'on en a befoin pour regarnir quelques places vuides. Il ne les faut pas tirer fi-tôt de la Pepiniere, pour leur laiffer le tems de profiter, \& de devenir beaux: Quand on en voudra prendre quelques-uns, on les levera en motre de cette maniere.

Après avoir fait choix des arbres que vous voulés prendre dàns la Pepiniere, \& les avoir marqué avec de l'ofier, ou de la pailie, faites-les déchauffer tout au tour, en laiffant un cerne ou motte de terre au pied de l'arbre. L'on prendra' garde d'endomager les racines, \& de donner de trop groffes fecouffes à la motre, de peur de l'ébouler; ce qui doit faire emplö̈er des Jardiniers adroits, de crainte qu'en voulant enlever un arbre, ils en perdent deux ou trois à l'entour ? vrai mö̈en de ruiner bien-vîte la Pepiniere. Ces arbres ne font pas difficiles à lever, leurs racines étant prefque à fleur de terre.

Pour bien lever avec fuccès des arbres en motté , il faut obferver fi la terre a naturellement un peu de corps \& de

On peut lever hardiment les arbres vers 13 Touffaints, c'eft-à-dire, quand la feuiille commence à fe detacher \& à tomber. Il n'y a alors aucun danger, la feve ne travaillant prefo que plus. 
208 TROISIE'ME PARTIE, CHA P. IV. Quand on foútien, comme font les terres fortes; on les pourra lever achetera des au commencement du Printems, de même qu'avant l'Hyver, te,lon exami- il n'importe, la terre fe foutiendra également dans ces deux nera fila terre faifons. Mais fi la terre eft trop legere \& trop mouvante, de cette motre ce qu'on apelle Veule, c'eft-a-dire, qu'elle n'ait aucun foû\&la même qui tien, comme font les terres fabloneufes, il faudra aporter vecté levée a- un peu de circonfpection dans cet ouvrage. Comme la terre vec l'abre. le eft apliquée tion, on déchauffera l'arbre avant les gelées, en faifant une pour tromper- motte de terre au pied, $\&$ on le laiffera là fans l'enlever, jufquà ceque la gelée venant à donner fortement fur cette motte, elle l'affermiffe de maniere, qu'on puiffe tranfporter cet arbre fans craindre d'en rompre la motte. Cet ouvrage doit être fait avant l'Hyver, à caufe de la gelée, ces fortes de terres ne permettant pas de le faire au commencement du. Printems.

Si la motte d'un arbre étoit groffe de trois ou quatre pieds de tour, comme il arrive quand les arbres font forts, on renfermera cette motte dans des manequins faits exprès : Sans cela il feroit affés difficile de pouvoir mener ces arbresau lieu deftiné , fans courir rifque d'ébouler la terre de la motte.

On doit toujours faire des mottes les plus groffes que l'on peut pour renfermer plus de racines, \& s'il y a moïen en levant l'arbre, de referver de longues racines pendantes hors de la motte, il faut en profiter; elles fervent beaucoup à fa reprife, quoiqu'elles ne foient pas couvertes de terre. L'on rafraîchit feulement ces longues racines par le petit bouts, 2 on les étend dans le trou, en les garniflant de terre à l'ordinaire. De cette façon on profite de tout.

Avant que d'enlever un arbre de la Pepiniere, l'on doit avoir preparé l'endroit oì on le veut planter, en y faifant un trou de grandeur \& de profondeur proportionnée à fa furce. Si l'arbre n'eft point d'une groffeur extraordinaire', ni trop garni de la tête, deux hommes le porteront facilement fur un bar ou civiere, pendant qu'un troifiéme le. foutriendra, \& l'entretiendra tour droit ayec les mains, mais fi cet arbre étoit trop gros, que la motte eut un 
LA PRATIQUE DU JARDINAGE. 20y : grand circuit, \& que la tête fut bien garnie, comme font les gros arbres que l'on plante chés le Roi; alors pour le tranfporter, il faudra une machine faite exprès, qui eft comme une efpece de cheture out traîneau, où l'arbre eft un peu incliné \& furporté parla tête, de crainte que les branches ne fe caffent. Il y a encore une machine plus commode, qui eft comme une efpece de charette, avec deux grandes vis \& des chaines pour élever \& fufpendre la motte de l'arbre, l'entretenir fans le fatiguer dans le tranfport, \& le defcendre enfuite dans le trou. On fait tirer ces niachines par deux chevaux, \& plus s'ilen eft befoin.

Nots ne parlerons point de la maniere de planter ces. arbres, nous étant affés érendus fur ce fujet dans cette Partie. Il faut feulementremarquer que pour bien garnir de terre le pourtour de la motte, on y gliffera plufieurs fois le bout d'un bâton. V:enons maintenant aux graines \& aux fruits des arbres convenables aux Jardins de propreté; difons en quel tenis on les ramaffe, comment on connoît leur bonté, de quelle maniere on les conferve pendant l'Hyxer, \& quelle eft la faifon la plus propre pour les femer dans la Pepiniere.

Nous avons de plufieurs efpeces de graines, comme celle d'Orme, de Tillor, de Sicomore, de Frefne, de Charme, d'Erable, \& de Bouleau, qui produifent des arbres du même nom ; ce font les plus en ufage dans nos Jardins.

Outre cela, il y a de cinq fortes de fruits; le Gland, le Marron d'Inde, la Chầtaigne, la Faine \& la Noifette, qui forment le Chêne, le Marronier d'Inde, le Châtaignier, le Hêtre, \& le Noifetier ou Coudrier. Toutes ces graines \& ces fruits fe ramaffent pendant les mois d'Oetobre, Novembre \& Decembre, hormis la graine d'Orme qui fe recuëille au mois de.May, \& qui fe doit femer en même-tems, à la difference des autres graines.

Pour connoître fi les graines ont les qualités requifes pour être bonnes, examinés fi elles font grolfes, rondes, pleines en dedans, \& d'un verd vif \& non alteré. Elles doivent être fraîches \& de la niême année qu'on les veut femer. Ce font là les marques les plus afsûrées de leur bonté: Au contraire, fi ces graines étoient plates, vuides en dedans, un peu vieilles \& d'un verd fec, elles ne vaudroient

$D d$ 
210 TROISIE'ME PARTIE, CHA P. IV. rien du tout pour femer, \& ne léveroient jamais, étant incapables de vegetation, \& d'agir felon les ordres de la nature.

A l'égard des cinq efpeces de fruits, qui font le Gland, le Marron d'Inde, la Châtaigne, la Faine \& la Noifette, on les choifra gros, unis, clairs \& pleins, fans être ridés ni piqués par les vers, ou rongés par.les mulots; tous ces fruits doivent toûjours être de la même année qu'on a deffein de les femer.

On dira ici en paffant une chofe à l'égard da Gland: c'eft de le femer tout d'un coup dans les Bois, fans le mettre auparavant en Pepiniere, le Chêne étant de fon naturel très-difficile à la reprife, à caufe de fon pivot ; cependant fi l'on en a en Pepiniere, \& qu'on le veiille replanter, il faudra bien fe donner de garde d'en couper le pivor, parce que le Chêne ne profite plus tant, \& ne pouffe que de foibles branches toutes rabougries.

La faifon la plus propre pour femer les graines \& les fruits en queftion, eft à la fin du mois de Février, ou au commencement de Mars. Cette faifon eft plus favorable aux graines, que l'entrée de l'Hyver, où elles font expofées à plufieurs accidens, comme à pourrir \& moifir par la trop grande humidité de l'Hyver, à geler dans les fortes gelées qui penétrent très-avant en terre, ou enfin à êrre mangées par les mulots, ou par les oifeaux quil les tirent de terre. Voila des raifons affés fortes pour préferer de les femer plûtôt au commencement du Printemps, qu'à la fin de l'Automne. Rien ne peut empêcher de fuivre cette methode, que l'embarras oil l'on feroit de les conferver pendant l'Hyver, ce que l'on va expliquer.

Quand on voudra femer.il faut choifir un temps doux, point venteux, \& qui promette dans peu de la plüe, afin

LaQniainie à la fin de fon Livie parle amplement $8 x$ fort bien fur eette maticse. de plomber les terres qui auront reçû les graines, \& que cette eau leur facilite une plus prompre fortie. L'on ne doit nullement s'arrêter aux Pleines-lunes, ni aux Decours pour femer, érant une vifion toute des plus grandes \&, un vrai conte de bonnes gens du tems paffé ; l'experience nous a fait voir que c'étoit une pure rêverie, qu'il faut entierement rejetter. 
LAPRATIQUEDU JARDINAGE. 2 II

Pour conferver les graines pendant l'Hyver, on choifira un endroit fec, cel qu'un Grenier, ou l'on étendra les graines, quel'on aura foin de vifiter de tems en tems, \& de remuer comme l'on fait le bled, ou bien on les renfermera dans des fachers pendus au plancher d'un lieu pareillement fec \& aëré.

Les fruits, comme le gland; la châtaigne, \&c. fe confervent tout d'une autre maniere. L'on prend plufieurs manequins, au fond defquels on met un peu de fable ; enfuite l'on y met les fruits par rang ou par lit, c'eft-àdire, un lit de châtaignes, un lit de fable; \& l'on remplit ainfi les manequins, en les couvrant de fable par deffus. Ces fruits fe confervent fans fe gâter, \& germent dans le fable pendant l'Hyver, pourvî, comme l'on a dit, qu'ils foient dans un lieu fec $\&$ un peu chaud, s'il fe peut.

On portera ces manequins fans les défaire, dans l'endroit deftiné pour le plant, \& l'on prendra garde, quand on retirera ces fruits pour les planter, de rompre le germe qu'ils ont pouffé dans le fable, car cela les retarderoit beaucoup.

On ne doit pas oublier ici de parler des arbres verds, comme étant trés-recherchés \& très-nécelfaires dans les beaux Jardins.

L'If, le Picea \& le Houx font les plus confidérables de rous, \& ceux dont on fe fert le plus. Ils produifent une petite graine rouge que l'on ramaffe étant mûre, \&x que l'on feme de la: même maniere, que les graines des autresarbres dont nous venons de parler. Toute la différence qu'il y a, c'eft que ces graines font bien plus long-tems à lever, furtout celle de l'If qui eft la plus tardive ; aufifi demandentelles une meilleure terre, \& femblable à celle qu’on prépare pour les fleurs \& les Orangers.

$\mathrm{Si}$ l'on femoir ces graines dans la terre ordinaire, oì l'on fait les Pepinieres des autres arbres, elles auroient beaucoup de peine $\frac{a}{a}$ lever, \& les arbres verds qui pourroient y venir, feroient très-longs avant que d'être en érat d'être placés dans les Jardins, \& de donner aucun plaifir à leur Maître. L'on peut en faire des planches féparées femblables à celles d'un Porager.

$$
D d i j
$$


212 TROISIEMEPARTIE, CHA F. IV.

Ces graines étant levées, on aura grand foin de les tenir. propres fans aucune herbe, de les labourer \& arrofer fouvent: L'If \& le Houx font les plus longs à crô̂tre; le Picea vient bien plus vîte.

Le Buis eft encore un des arbriffeaux des plus en ufage \& dont on ne fe peut paffer abfolument dans les Jardins, étant propie également aux Parterres \& aux Paliflades. On en éleve de graine que l'on peut fémer dans de bonnes terres; mais le moïen d'en avoir promptement; c'eft d'arracher de vieux Buis $\&$ de le replanter en l'enterrant prefque tour à-fait, pour le faire repouffer du colet, \& par-là vous avés de beau \& jeune Buis, en coupantle chevclu \& les racines du vieux:

A l'égard des Ciprès, Pins, Sapins \& Chênes verd's, on ramaffera leurs fruits dans le tems, \& on les femera à l'or dinaìre, cn obfervant toujours que ce foit dans la meilleure terre, \& d'en avoir grand foin ; ces arbres étant toujours beaucoup plus longtems \& beaucoup plus difficiles à croîtro que les aurres: il n'y a que l'excellente terre qui puiffe les hâter de venir.

Quand les arbres \& arbriffeaux verds font parvenus à une certaine hauteur, .on commence à les former fuivant fon in tention, en les tondant avec des cifeaux, en boules, en piramides, \&c..

Comme tous les arbres verds aiment naturellement les Paìs chauds, d'où nous les avons aportés, \& que le climas de la Erance eft bien different de celui des Indes, pour le dégré de chaleur:; il vaut micux les élexer deboutures $\&$ de marcotres, que d'en fémer la grainequil fouvent manque. L'on peur faire ces marcottes au pied des grands. Ifs \& des Picea, ee qui réüfit fort bien : Car au bout de deuxans, on levera ces marcottes bien enracinées, \& on les plantera en Pepiniere. Pour les avancer d'avantage l'on. fendra les branches comme on fait à l'œillet, le bois en étant trés-dur à percer. L'on peut même acheter du petit.plant qu'on élevera chés foy. Tous ces mö̈ens gagnent beaucoup de tems.

Les autres arbres verds, comme le Phileria, le Genevrier, l'A larene , la Sabine, \& c. s'élevent de la mêmemaniere que les précédens, mais ils croiffent bien plus promptement. 


\section{H A P I T R E V.}

DES ORANGERS, JASMINS, Grenadiers, Myrthes a autres Arbriffeaux de fleurs, avec la méthade d'en élever de graine, de Marcottes, ou de choifir ces Arbres tous grands, cor la maniere de les planter, greffer, of le tems où ils. fleuriffent.

U. O I Q E E ce Chapitre \& les trois fuivans n'aïent: pas l'air de nouveauté, qu'a le refte de l'Ouvrage (cette matiere ä̈ant déja éré traitée plufieurs fois \& amplement) on a crû néanmoins devoir en parler ici, par une raifon crésnaturelle : Perfonne n'ignore que les Orangers, les Jafmins . les Grenadiers, joints aux fleurs de faifon, contribuënt beaucoup à l'ornement des Jardins, \&x par. conféquent feront ici. comme dans leur centre: L'on efpere même rendre en cela quelque fervice au public, en lui évitant de lire de longs. * Trairés remplis de grandes liftes, -fans les éclairciffemens. neceffaires, \&.en le détrompant de tout ce qui s'eft glifé de myfterieux \& de mauvais fur ce fujet. On fera furpris qu'une matiere fi embroüillée jufqu'à prefent, \& dont tant de gens fe font encore un phantôme, paroiffe ici fi fimple \&.fi.aisée : Quoique le fujet ne foitpas neuf, peut-être la maniere dont il êt traité paroîtra affés nouvelle; il'on y a joint la précifion ̀̀ la generalité.

Pour fe conformer à la méthode que Pon a fuivie au fujet des arbres fauvages., on commencera, avantque de parler de la culture des Orangers \& des autres arbres de fleurs; par faire une perite defeription de chacun en particulier, en fpecifiant leurs differentes efpeces, leur nom, leur qualité \& proprieté dans les Jardins; la maniere dont ils fe perpetuënt, ceux qui confervent leur verdure dans l'Hyver, ou qui fe dépoüillent; \& ceux qui reftent en pleine terre, ot qu'on eft: obligé de ferrer.

Dd $\mathrm{iij}^{3}$

\section{* Nourears Traité des $\mathrm{O}$ : rangers, $\mathrm{Ci}$. troniers; \& $c$. Inftruction facile pous connoître rou- te forte d'O rangers, Ci- troniers, \&c. Traité de la culture des Orangers pas: la Quintisie: Tome 20}


L'One

GE.

On met à

Trianon des

Orangers dans des feaux garnis de fer, que l'on enfonce en terre, ce qui les fait croire plantés en pleine terre. Il y en a non-feulement en buiflons, dans le parterre du petit Jardin duRoi, mais encore en paliffades, qui couvrent les murs. On les retire l'H $\mathrm{i}$ ver pour les ferrer avec les autres caiffes.

* La Provence \& le Languedoc.

LE G R ENA DIER. ** Il y a àverfailles des 0 . rangers of qui ont pres de 200 ans, comme le grand Louiis, les. Bourbons \&rc. qui font enco. re irès-vigoureur.

L g M хтин. $24^{\circ}$ TROISIEME I ARTIE, CHAP.V.

Ils fe diftinguent en Arbres, en Arbriffeaux \& en Arbuftes, à la hauteur de huit à dix pieds ce font des arbres, audeffous ce font des Arbriffeaux, autrement dit Frutex, \& les Arbuftes ou fous-Arbriffeaux n'ont qu'un pied ou deux de tige.

L'ORANGER eft fans contredit le plus beau de tous les arbres de fleur : fa tige droite, fon bois uni, fes grandes feüilles luifantes, fes belles fleurs, fes fruirs exquis, fa tête réguliere $\&$ d'un trés-beau verd, tout en eft adnirable; l'on en diftingue de plufieurs fortes, comme le Citronier ou Balotin, le Limier ou Limonier, le Bigaradier, le Cedrat, le Richedépoüille, le Poncyre, le Pomier d'Adam, la Bergamotte, l'Oranger de la Chine, \&x leurs différences font peu confiderables : elles ne confiftent qu'en ce que les uns font des arbres de tige, \& les autres des nains ou buiffons; ou parce que le fruit des uns eft doux, \& celui des autres plus aigre; ils confervent tous leur beau feüillage, \& l'on feroit trop heureux aux environs de Paris, où le Jardinage eft fort en regne, fi. l'on en pouvoit mettre en pleine rerre, pour former des allées \& des bofquets; il s'en voit ainfi en Efpagne, en Portugal, en Italie \& dans quelques-unes de nos * Provinces ou le dégré de chaleur eft affés confidérable, pour lés exempter d'être renfermés l'Hyver, comme l'on elt obligé de faire ici. Les Orangers viennent de Pepins renfermés dans le cour du fruit : ils font d'une très-grande ** durée.

LE GRENADIER n'eft pas à comparer à l'Oranger en toutes manieres, fón feiillage eft petit, longuet, \& ne fe conferve pas l'Hyver; la tête \&x la tige en font affés belles, d'une écorce blanchâtre \& peu unie; les fleurs font d'un rouge trèsvif. On en compte principalement de deux efpeces, celui à fruit, \& celui à Heur, qui eft le plus eftimé quand il eft panaché : il eft plus délicat que l'autre, \& fe ferre dans l'Hyver; mais le Grenadier à fruit eft affés vigoureux pour refifter en pleine terre : l'on fait beaucoup de cas des Grenades : ces arbres fe multiplient de jettons \& de marcottes.

LE MYRTHE n'elt regardé en France que comme un arbriffeau : il s'en éleve peu d'affés forts pour former un arbre : cependant il y en a d'une belle tige: fa feüille eft d'un verd tres-luifant, fes fletrs font blanches à peu près comme l'A ubepine, fon bois eft grifâtre \& fort uni, il a un mérite au- 
LA PRA TIQUE DU JARDINAGE. 215 deffus de tous les autres, qui eft que fes feuilles fentent une odeur fort agréable, mais il eft le plus délicat de tous les arbres, fans excepter l'Oranger. On en diftingue de cinq our fix fortes, le Myrthe commun, le double, le panaché, le Myrthe à cent feüilles, le Myrthe de la grande \& de la petite efpece. Ils s'élevent tous en caiffes \& gardent toûjours leur feüillage. Le Myrthe fe perpetuë de graine, de jettons, de marcottes \& aufi de boutures.

LE LAURIER eft un fort bel Arbre \& le plus varié de tous dans les fix efpeces que l'ón en connoît. 11 y en a qui confervent leur verdure comme le Laurier frane, le Laurier-thim, le Laurier-cerife \& celui d'Alexandrie, qui peuvent toûjours refter en terre, principalement les deux derniers: d'autres qui fe dépoüillent à demi, comme les Lauriers-rofes rouges \& blancs, \& celui à fleur double, qui font affés tendres à la gelée pour demander à être ferrés. On éleve dans des caiffes les Lauriers francs \& les Lauriers-thim prefque toutjours en arbres de tige : le Laurier-cerife s'emploie aux paliffades, \& celui d'Alexandrie fe tond en boule pour remplir une platebande: leurs feüilles font d'un beau verd-luifant, \& fentent un goût aromatique, particulierement celles du Laurier franc: leur fleur eft d'un blanc jaunâtre, \& d'une odeur trés-forte ; celle du Laurier d'Alexandrie vient en grapes, \& le Laurierthim feurit deux fois l'année. A l'égard des Lauriers-rofes \& de ceux à fleur double, on les éleve en groffes touffes fortantes de la caiffe, leur feüille ne fent rien \& n'eft pas d'un fi beau verd que les aurres : leur fleur reffemble à la rofe commune. Le bois des Lauriers eft un peu grifâtre \& fort uni. En general les Lauriers fe multiplient de boutures, de jertons \& de marcottes. Ils durent fort long-tems.

LE JASMIN eft un Arbriffeau des plus agréables \& des plus variés dins les fleurs : le bois en eft verd \& fort ra. meux; la feüille trés mignone, d'un verd clair, les fleurs blanches, d'autres jaunes, \& quelques-unes mêlées de rouge : il y en a de plufieurs fortes. Le Jafnin commun, celui d'Efpagne, de Virginie, des Indes, \& le Jafmin-jonquille: les plus beaux pour les fleurs\&la tige font ceux $d^{2} E f$ pagne\&de Virginie, qui craignant le froid, fe ferrent l'Hyver \& gardent lür feüille. Pour le Jafmin-jonquille, il refte en pleine

L. L I A Us R I $\mathrm{I}$.

LE IASBSBS, 
2iI 6 TROISIE'ME PARTIE, CHA P. V.

terre, ainfi que le commun qu'on emploïe aux paliffades $\&$ pour couvrir des berceaux de treillage; les feüilles en tombent l'Hyver. On a de l'efpece du Jafmin commun \& jonquille par les boutures \& les marcottes : pour les autres ils fe greffent fur du commun.

LE Rosin. Nous avons de plufieurs efpeces de Rofier, le commun., le panaché, celui d'Hollande ou à roo feüilles, le Rofier de Virginie, de Gueldres, Mufcats ou de Damas, \& le.Rofier de tous les mois. Les plus beaux de ces Rofiers font ceux à cent feüilles, les panachés \& ceux de tous les mois, apellés ainfi, parce qu'ils fleuriffent 7 à 8 mois de l'année; le bois en eft verd \& fort garni de piquants, la feüille oblongue, raiée \& dentelée, les fleurs agréables par leur fenteur, ordinairement rouges, hors celles de Gueldres \& Mufcates, qui font blanches, les aurres ne different que parce qu'elles font doubles ou panachées; tous les Rofiers fe dépoüillent, mais ils font affés vigoureux pour demeurer en pleine terre : on les éleve en arbriffeaux, en banquettes \& l'on s'en fert pour couvrir des treillages. Les boutures \& les marcottes en don. nent tantque l'on veut.

LE.LIAS. LELIIAS rend une odeur fort agrëable \& trẻs-douce, il a le bois blanc, la feüille longue \& pointuë, \& les fleurs difpofées en longues grapes, de couleur bleüâtre ou blanchâtre : nous en avons deux differents, le Lilas commun \& celui de Perfe, qui perdent leurs verdures dans le froid, mais reftent toujours en place. Le Lilas de Perfe ne vienr pas fi haur que le commun : il eft plus mignon dans fa feüille \& dans fes fleurs : il fert d'arbriffeau dans les parterres. Les jettons que les Lilas pouffent à leur pied en perpetuënt l'efpece.

Lu Gugr. LES GENESTS font encore des arbriffeaux trés.agréables dans un parterre, fur tour celui d'Efpagne, bien different du Geneft-jonquille, leur bois forme des verges longues \& routes vertes, femblables au Jonc: Elles s'élevent haur \& fans beaucoup de feüilles, leurs fleurs font grandes, de couleur jaune-doré, \& odoriferantes; ils fe perpetuënt feulement de graine.

L'ArTha L'ALTHE'A FRUTEX, qui fignifie un Arbrilleau, s'a-

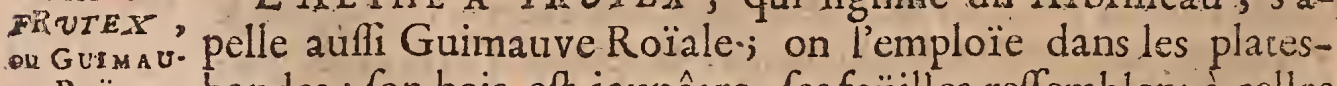
Is Roinas. bandes; fon bois eft jaunâtre, fes feüilles reffemblent a celles de 
L A PRATIQUE DU JARDINAGE. 217 de la vigne, les fleurs font en forme de clochettes, tantôt blanches, tantôt couleur de chair ; il fe dépoüille \& ne fort point de terre, on l'éleve ordinairement de graine.

LECHEVRE-FEUILLE eft fort commun, c'eft cependant l'A rbriffeau qui fent l'odeur la plus fuave, il fe tient fi haut \& fi bas que l'on veut, puifqu'on s'en fert à couvrir des berceaux, des murs, \& à former des boules dans les parterres; il y en a úne efpece qu'on apelle Romain, qui eft plus vif en couleur, \& d'une feuiille plus déliée. Son bois eft rougeâtre, de nature à être paliffé, fes feüilles font rondes \& blanchâtres, fes fleurs difpofées en tuïaux de couleur blanche tirant fur le jaune \& le rouge. Sa feüille tombel'Hyver, pendant lequel il demeure en terre ; il produit beaucoup de jettons.

LE SERINGAI eft un arbufte d'une odeur affés bonne mais trés-forte; fon bois eft rouge, fes fleurs blanches, fa feüille petite \& pointuë, d'un verd brun; il refte en place \& perd tous les ans fa feüille, on s'en fert à cacher des murs \& a former des buiffons; il fe marcotte aifément.

LE TR OE $S$ N E eft le moindre de tous ces arbriffeaux: on en fait pourtant des boules $\&$ des paliffades affés belles. Il a le bois blanc \& uni, les feüilles oblongues, étroites \& d'un verd pâle, les fleurs blanches qui ont peu d'odeur. Cet Arbriffeau s'éleve de graine ainfi que de marcottes.

LE CYT I SUS eft auffi apellé Trifolium, à caufe de fes feïilles rangées trois à trois, \& reffemblantes au Treffle; elles font petites, rondes \& d'un verd agreable : Le bois en eft rougeâtre, la fleur jaune, il ne fort point de terre, mais il quitre fa feüille ainfíque le Troëfne, ilfert uniquement dans les parterres, \& vient de marcottes $\&$ de jettons.

LE ROMARIN eft robufte, \& fe met tant en caiffes qu'cn pleine terre, il ne fe dégarnit point l'Hyver: Son bois eft grifâtre \& garni de petites feüilles longues \& étroites, d'un verd brun pardeffus \& blanc par deffous, elles fentent un goût aromatique, fes fleurs tirent fur le bletı pâle :l'on en marcotte \& l'on en feme.

LE COLUT a A eft un petit Arbufte trés-agréable pour fes LE Cosybelles fleurs de couleur de pourpre; il ne s'éleve pas bien haut : Son verd eft pâle, fa feüille petite \& en ombelle comme

LIS SRINT+ cAt.

LA TROESA NH OU LIGUT STRUM.

Le Crtisure OU TRIF OI I U $M$.

IE RONAT SIN. $T=A$. E e 
Loticare DE JUDE'B OUDEUUAS.

LI BAGUENAUDIER.

LE LENTISQus.

L'A OMUM SL SOLAxU B.

LE LEONU. Rus.

$L^{S} E_{M}$ BRUS eU SYTURI:DACA.

I. BUISSOM $A R D E N T$ OU PIRACANA Is.
218 TROISIEME PARTIE, CHAP. V. celle de l'Acacia'; elle ne tombe point l'Hy ver dans la ferre: fon bois eft d'un verd mêlé de ronge, fa forme elt pyramidale, il produit de groffes coffes qui en renferment la graine.

L'ARERE DE JUDE'E eft fort recherché par raport $\frac{1}{z}$ fes belles fleurs rouges, il vient affés haut $\&$ tres.gros : Son bois eft rougeâtre, \& fa feüille reffemble à celle de l'A Abricotier : Il refifte fort bien en pleine terre, mais fes feüilles tombent; il fe multiplie de graine \& de marcottes.

LE BAGUENAUDIER monte affés, neanmoins il fe peut tondre en boule: Son bois eft clair, fes feüilles font petices, rondes \& d'un verd blanchâtre, fes fleurs jaunes: fes frutits nommés Baguenaudes, font d'une couleur verdâtre $\&$ font creux, de maniere qu'en les crevant ils font quelque bruit, il fe dépoüille \& refte en pleine terre : on le marcotte ordinairement.

- LE LENTISQUE eft tantôt grand, tantôt petit, cependant prefque toûjours A rbriffeau : Sons bois eft grifâtre, fes. feüilles reffemblent à celles du Myrthe, toûjours vertes \& d'une odeur affés. forte, les fleurs \& les fruits en font rouges. \& difpofées en grapes : il eft trop tendre pour fuporter en pleine terre les rigueurs de l'Hyver. Il fe multiplie de marcottes \& de jettons.

L'A момum eft un Arbufte agréable : le bois en eft brun; la feüille longue d'un verd noir, la fleur blanche, les fruits rouges \& ronds comme des Cerifes, il garde fes feüilles $\&$ fes. fruits dans la ferre, \& ne fe dépoüille qu' au Printemps. On en a de l'efpece par le moïen de la graine.

LE LEONURUS ne s'éleve pas bien'haut : ila le bois grifâtre, la feüille longue, étroite, la fleur rotige, il fe dépoüille \&r eft affés délicat pour vouloir être ferré l'Hyver : il croît de boutures \& de mareottes.

L'EMERU $s$ a lesfleurs jaunes, le bois verdâtre, la feüille à peu près comme le Jafmin commun $\&$ du même verd ; il forme des boules qui reftent en terre \& fe dégarniffent l' $\mathrm{Hy}$ ver. Les jettons \& marcottes en donnent de l'efpece.

LE BUISSON-ARDENT eft un Arbriffeaul qui ne vient pas bien haut: Son bois eft net \& garni de piquants, fa feüille. eft à peu prés comme celle du poirier. Ses fruirs rouges qui. fubfiltent en Hyver, \& qui le font paroître de loin comme 

plein de feu, l'ont fait nommer Buifon ardent : c'eft dans fes fruits que l'on trouve fa graine.

La plûpart de ces Arbriffeaux ont encore d'autres efpeces du même nom, étant d'une grande famille ; tels font le Solanum, le Colutea, le Cytifus, \&xc. On a feulement marqué ici les efpeces que l'on trouve le plus facilement, \& qui embéliffent davantage les Jardins.

Il y a encore certains A rbriffeaux étrangers qui fleuriffent, \& dont la culture eft fort difficile; conme ils fervent peu à l'ornement de nos Jardins, \& que les Curieux les recherchent plûtêt par raport à leur rareté \& à la Botanique, qu'à une vraye beauté, nous les pafferons fous filence.

Il eft queftion maintenant de donner la méthode d'élever rous ces Arbres, foit de graine, de marcottes; de boutures \& de jettons, ou bien de les choifir tout grands, a vee $12 \mathrm{ma}$ niere de les planter \& de les greffer.

On éleve en France l'Oranger de graine ou de pepin, comme auffi d'Arbres envoyés des Pays chauds.

Pour les élever de pepin, on prend la graine des Oranges les plus mures \& les plus belles; on la feme au mois de Mars dans de longues caiffes ou dans des pots remplis de terre préparée, dont on trouvera la compofition dans le Chapitre fuivant. On met ces pepins de trois doigts avant dans cette terre, \& à trois pouces de diftance l'un de l'autre: Quand il en leve trop, on les épluche, en arrachant les plus preffés, afin que les autres profitent davantage : Ces pepins au bout de deux ans, forment des Sauvageons, qui font bons à replanter féparément dans des pots de terre., \& au bout de 5 ou 6 ans $f e$ peuvent greffer: On fupofe qu'on aura le foin de les labourer fouvent, de les nétoyer des mauvaifes herbes, \& de les arrofer de tems en tems; comme auffi d'enfoncer les pots ou ils font, dans des couches chatdes pour les avancer. L'Hyver on retire de terre ces pots \& on les porte dans la ferre.

L'autre maniere d'élever les Orangers va bien plus vîte en France; les Arbres qu'on envoye de Genes, de Lifbonne \& de Provence ayant déja plufieurs années, il ne s'agit plus que de les fçavoir bien choifir. Ces Arbres arriventordinairement dans les mois de Mars, Avril \& May, les uns fans motte \& fans tête, les autres enmotés \& garnis de branches \& de 
feüilles, les:racines en font envelopées, crainte des gelées blanches fréquentes dans cette. faifon.

Aux Orangers étetés \& fans motte l'on choifit la tige 12 plus droite \& la plus élevée qu'il fe peut, fans s'arrêter à la groffeur qui vient dans la fuite. Les racines en doivent être bien confervées fans écorchure dans le tranfport, un peu fermes \& d'un verd jaunâtre, qui ne tire point fur le noir ou le jafpé , qui eft une très-méchante marque de leur étar préfent, \& très-affurée de leur prochaine mort. On en coupera l'extremité pour connoître fi elles ne font point trop feches ni trop humides. A près cela l'on racourcit toutes leurs racines \& on les met tremper quelques heures avant que de les planter dans de grands pots, que l'on enterrera enrierement dans une couche, pour faciliter leur reprife. Ils refteront là pendant l'année, jufqu'à ce qu'on les ferre l'Hyver, \& le Printems fuivant on les replantera dans'des caiffes proportionnées à leur groffeur, fans rien couper de leur motte; on les cultive enfuite comme les autres Orangers.

Il eft certain que les Arbres enmottés, garnis de branches \& de feüilles fout à préférer, pourvû́ que cette motte de rerre qui couvre leurs racines foit naturelle; en remuant un peu la tige, on s'aperçoit fi elle eft fuposée, car la terre apliquée tombe promptement; on les prendra toûjours d'une rige droite \& élevée, \& d'un choix de branches à former un jour une tête bien ronde : les racines qui excedent la motte \& les branches feront d'un verd jaunâtre, l'écorce d'un humide temperé \& plein de feve; les feüilles doivent être fermes, caflantes \& relevées, c'eft une marque de vigueur; quand on les voudra planter, on rafraîchira les racines qui excedent la motte, l'on ôtera les petites branches confufes, \& l'on racourcira les groffes qui font mal placées, jufqu'à trois ou quatre pouces du corps de l'Arbre, pour les. obliger à pouffer de nouveaux jets vigoureux \& mieux placés enfuite l'on trempe la motte un moment dans l'eau, \& après l'avoir laiflé égouter, on plantera l'Arbre dans une caife convenabłe à fa groffeur, de la même maniere que l'on rencaiffe les vieux Orangers. On le placera dans un lieu aëré, mais peu exposé au Soleil.

Il y a de certains. Orangers à quil l'on ne demande point de: 
LA PRATIQUE DU JARDINAGE. $22 I$ tige commeles nains, ceux en buiffons, \& les petits Orangers de la Chine ; cependant l'Oranger de tige eft toûjours le plus noble \& le plus beau. Il ne faut pas prendre tous Arbres greffés; les Sauvageons connus parleurs piquants deviennent fouvent plus beaux, font toûjours plus vigoureux \& plus élevés que les Orangers greffés ; leur défaut eft d'être d'une verdure plus jaunâtre que les autres, \& de raporter peu de fleurs, \& par confequent peu de fruit. On choifira auffi pour la varieté quelques Citroniers \& Linıoniers, qui fe connoiffent à la feüille, où il manque un petit cour au bout, comme l'on en voit aux autres Orangers.

Venons à la maniere de greffer ces Arbres, à laquelle on eft indifpenfablement obligé ; les Sauvageons fans cette opération, ne raporteroient jamais beaucoup de fruit, ni quantité de belles fleurs, femblables en cela aux autres Arbres fruitiers, qui ne produifent jamais de gros fruits $\&$ exquis , s'ils ne font greffés des meilleures efpeces.

On greffe ordinairement un Oranger fur un Orangcr, un Citronier, fur un Citronier : On peut greffer encore un $\mathrm{Ci}$ tronier, un Limonier fur un Oranger, mais cela ne réüifit jamais $f$ i bien, \& fait fouvent avorter un arbre. Cette greffe fe fait en écuffon ou en aproche, qui font fi generalement connuës, qu'on n'en devroit point parler ici; mais comme il faut écrire pour tout le monde, \& qu'il y a quelques petites differences dans la difpofition de l'écuffon, nous la donnerons le plus fuccintement qu'il fera poffible.

On apelle fujet ou franc, le Sauvageon fur lequel on aplique la greffe, \& l'on apelle greffe ou rameau, la branche de l'A rbre dont on veitt avoir de l'efpece ; l'écuffon eft une piece enlevée fur l'écorce de la branche en forme de triangle, dont le nom vient d'un écufton d'armoirie, avec lequel il a quelque reffemblance. L'aproche ne s'apelle ainfi, que parce que l'on aproche un arbre d'un autre pour l'y pouvoir greffer.

$L$ 'inftrument avec lequel on greffe, nommé greffoir, eft un couteau pointu à manche d'yvoire, dont le bout qui excede la lame eft aplati en forme d'une fpatule de Chirurgien.

Pour greffer en écuffor, on coupe fur un Oranger, des rameaux de l'année derniere, ou il fe trouve de bons yeux formés

Parle moyen du Rameau \& de l'Eculfon, on fe communique les arbres \& les fruiss les plus rates, d'un Royaume à l'autre, ce: qu'on ne peus: faire pa: ' $122-$ proche: C'efe une des plus. belles inventions de l'A gricaltures.

$$
\text { E e iij. }
$$


On met deux Eculfons fur une même tige des deux côtés, qu'une mêtme ligatisre peut colsvrir, afin que fi l'un masque, l'autte y cuplée.

C'eft une chole admirable que la fere foit con. trainte de paffer dans un corps érranger, \& de produire de fon efpece, en abandonnant In premiere quiselle noursiffoit depuis quelg̨ues ananés.
12: TROISIE'ME PARTIE, CHAP. V. au Printems, \& l'on en ôte toutes les feüilles. Il ne faut qu'un oeil à chaque greffe, ainfi l'on en peut prendre plufieurs fur une même branche. L'on commence à tailler fur le rameau, l'écuffon en forme de triangle, \&r l'on ménage dans le milieu l'œil \& fa petite branche. L'on enleve proprement cet écuffon, avec le couteau du greffoir, \& on laiffe à l'endroit de l'ceil un peu plus d'épaifleur de bois que dans le refte; enfuite l'on choifit fur le Sauvageon apellé le fujet à greffer, un endroit uni entre deux yeux; on fait une incifion en travers, \& l'autre en long qui fe rejoignent, de la longueur environ d'un pouce \& dẹmi, \& de l'épailfeur feulement de la peau ou l'écorce de l'arbre; l'écuffon étant tout prêt, \& le tenant dans la bouche par le bout de la petite branche, l'on détache avee le manche du greffoir la peau de l'incifion faite fur le Sauvageon, \& l'on y fait entrer l'écuffon par la pointe, en forte qu'il s'y cole bien, \& que les côtés de l'écorce le recouvrent entierement hors l'œil ; cela fait, prenés de la groffe filaffe pour lier le tour enfemble, bien fcrré \& le plus proprement qu'il fe peut, en laiffant toûjours paffer l'œil. On coupe un mois après cette filaffe, fans cependant l'ôter, afin de donner un paffage libre à la feve, qui fans cela poufferoit des jets fauvageons au-deffous de l'écuffon trop refferré.

Cette pratique eft ordinaire dans tous les arbres que l'on greffe; mais dans les Orangers, il y a une circonftance confiderable, c'eft le renverfement de l'écuffon; c'eft-à-dire, que cet écuffon doit avoir la pointe en enhaut, en obfervant quand on le taille que l'œil fe trouve toûjours dans la même fituation, le bouton \& le jet dreffé vers le ciel ; l'incifion fur le fujer doit auffi êrre coupée différemment, fçavoir la fente de travers, en bas, comme un I renversé, à caufe de l'eau qui entreroit plus aifément par la grande ouverture large qui d'ordinaire aux arbres fe fait en haut, \& qu'on fera fur les Orangers pour cette raifon par le bas. Cette eau pour peu qu'elle pénétre devient mortelle à la greffe.

On greffe en écufion dans le mois de May à oil pouffant, c'eft-à-dire, dans la feve, alors on racourcit fur le champ la branche du fujet à trois pouces prés de l'éculfon, afin que la feves'y porte toute entiere, \& le faffe pouffer plus promptement: On greffe encore en éculfon dans les mois de Juiller, 
LA PRATIQUE DU JARDINAGE. 223 Août \& Seprembre à œil dormant, \& l'on ne coupe point fur le champ la branche du fauvageon, on attend au mois de May fuivant qui eft le tems de la feve.

$\mathrm{La}$ greffe d'un Oranger en aproche, fe fair à l'ordinaire fans aucune difference; elle fe pratique également dans les deux feves, c'eft-à-dire, dans, les mois de Mai \& d'Août. On aproche du Sauvageon la caiffe d'un autre Oranger, dont la branche eft affés longue pour fe lier enfemble, \& qui eft difpofée à être greffée de cette maniere : L'on coupe ce Sauvageon par la tête, fur laquelle l'on fait une fente poury apliquer la branche de l'Oranger, dont on fouhaite de l'efpece : cette branche s'entaille \& fe fend en long par la moitié, ce qui forme un bout long d'un pied environ, que l'on éguife pour le faire entrer dans le milieu de l'entaille, de même que l'on fait $\grave{c}$ la greffe en fente ; l'on peur encore faire entrer cette greffe dans l'entre-deux du bois \& de l'écorce, quand le fujer eft bien vieux, comme à la greffe en couronne, dont elle ne differe qu'en ce qu'elle fe fair d'une branche aprochée. On lie cette greffe avec de la groffe filaffe le plus ferme qu'il fe peut pour l'entretenir contre les vents, \& l'on couvre le tout avec de la cire \& un peu de linge, ce qu'on apelle poupée or emmailloter la greffe, cela dure jufqu'à ce qu'elle paroiffe prife en pouffant vigoureufement ; enfuite l'on coupe la branche aprochée à l'endroic de la greffe que l'on recouvre de cire verte.

La difference de ces deux manieres de greffer confifte en ce que la branche de l'arbre doit être jeune de deux ou trois ans pour y pouvoir greffer en écuffon, au lieu que l'arbre doit être fort \& un peu âgé pour greffer en aproche.

Les Grenadiers, les Myrthes, les Laurieres-thims \& francs, le Romarin, l'Arbre de Judée, le Baguerraudier, le Lentifque, fe choifffent d'un belle tige formant une tête agréable \& bien garnie dans fa rondeur. Les branches \& les racines feront d'un verd vif. Ces Arbres font ordinairement enmotés, à moins que l'on n'en prenne des boutures ou des marcottes.

Les Lauriers-rofes \& cerifes, celui d'Alexandrie, le Buiffon ardent, ne veulent point de tige, leur beauté confirte être trés-garnis depuis le pied jufqu'à la tête, foit qu'ils foient en paliffades ou en caiffes. Il en eft de même des Rofiers, L

Cet:e maniere de greffer n'eft pas agréable, fai. rant uto méchant effer dans la déeo. ration des Jardins, par la proximité de deur caiffes: on les doit toujours mettre à l'écart.

II ne faut point d'œil dans l'endrois de l'aproche; il y en a affés tout du long de la branche. 
224 TROISIE'ME PARTIE, CHA P. V. $\mathrm{l}_{\text {as }}$, Genefts, Colutea, Chevre-feüille, Romarin, Seringals \& Jafmins communs, qui ne font que des Buiffons tondus en boule ou en pyramide.

On choifira l'Altea, le Leonurus, le Syturidaca, le Cytifus, le Troëfne, l'A momum \& le Jafmin d'Efpagne avec une perite tige d'environ deux pieds de haut pour foutenir leur tête. L'on fera une recherche exacte dans leurs branches \& leurs racines, pour en connoître l'état prefent, \& l'on obfervera les mêmes chofes qu'aux Orangers, pour les planter dans des caiffes, dans des pots ou en pleine terre.

La meilleure maniere \& la plus prompte d'élever tous ces arbres, eft d'en choifir des pieds d'une nature baffe \& fort rameufe, de les enfoncer en terre jufqu'au milieu des branches, \& d'en coucher tout autour les ramilles pour en faire des marcottes : ces meres en donnent une plus grande quantité \& en moins de tems qu'aucun autre moïen : on peut fans cela tirer des jettonsou racines éclatées que les arbriffeaux pouffent naturellement àleur pied, \& que l'on a foin de lever un peu forts \& bien enracinés. On fair encore des marcottes de branches que l'on couche dans la caiffe même au mois d'A vril, ou que l'on peut faire paffer dans le trou d'un pot élevé à la hauteur de la branche. Il faut environ fix mois à ces marcottes pour être bien reprifes. On excepte de cette méthode le Jafmin d'Efpagne qui fe greffe toûjours, le Geneft d'Efpagne, le Colutea, l'Amomum, le Piracanta \& l'Altea Frurex qui ne s'élevent ordinairement que de graine.

Il eft aisé de voir parce que l'on vient de dire, qu'il y a peu de ces arbres qu'on foit obligé de greffer ; les marcottes \& les jettons redonnent fùrement des mêmes efpeces, qui comme de bons enfans ne perdent aucune qualité de leur mere : voici néanmoins ceux qui-fe peuvent greffer.

Les Grenadiers \& les Myrthes panachés fe greffent fur des communs en écuffon ou en aproche, pour en avoir de race panachée. Les Jafmins d'Efpagne \& de Virginie ne pouffant point de jettons qui en perpetuent l'efpece, demandent à être greffés fur du Jafmin commun, foit en aproche ou en écuffon, il n'importe; l'on ne peut pas même en faire des marcottes, hors, du Jafmin commun dont on en fait beaucoup. Pour avancer les greffes du Jafmin d'Efpagne, il faut planter les 

marcottes de Jafmin commun un an devant dans des pors, cela fait mieux reprendre la grefre, que l'on couvrira de cire.

L'on choifit le fujet clair, uni, fans aucun noud, bien enraciné \& gros comme le petit doigt, on le coupe julqu'au dernier oil d'en-bas afin que la feve étant moins diflipée alleurs, y palfe entierement. Les Rofiers fe peuvent encore greffer: Quand on veut par exemple avoir de l'efpece de celui d'Hollande, des panachés, ou des Rofiers de tours les mois, on greffe de ces efpeces en écullon fur des Rofiers communs.

Il faut encore fçavoir le tems auquel ces Arbres \& Arbriffeaux font en fleurs, afin d'en pouvoir profiter pour la décoration des Jardins; en les y plantant à propos. Tout dépend de la variété, ainfi l'on obfervera que les Arbriffeaux que l'on plantera dans les parterres, ne foient pas feulement de differente efpece, mais qu'ils fleuriffent aufl dans des tems differens : il en faut pour diverfifier qui portent des fleurs dans le Printems, dansl'Efté, dans l'Automne, \& même dans l'Hyver, pendant qu'ils font ferrés.

On voic en fleur au Printems, le Laurier-Thim, celui d'Alexandrie, le Lilas commun, le Chevre-feiiille, le Seringal, le Rofier des mois, de Gueldres, celui d'Hollande à roo feüilles, le Romarin, le Trifolium, le Jafmin-jonquille, le Geneft d'Efpagne, le Cytifus \& le Syturidaca.

Dans l'Efé fleuriflent, l'Oranger, le Citronier, le Limier \& autrescfpeces, le Grenadier, le Myrthe, le Laurier-franc, le Laurier rofe, le Troëfne, le Jafmin commun, le Coluzea, le Lilas de Perle, l'Arbre de Judée, le Rofier des mois \& le Baguenaudier.

L'Auromne nous prefente les Jafmins d'Efpagne \& de Virginie, le Laurier-thim, l'Altea Frutex, les Rofiers des mois, les Rofes-muf́cates, le Buiflon-ardent, l'Amomum \& le Colutea.

Ceux qui fleuriffent l'Hyver \& qui fervent à embellir la ferre en formant des eftrades \& desamphithéatres, pour couvirir les murs, font l'Oranger, le Jafmin d'Efpagne, le Laurier-thim, le Lentifque, le Colutea, l'Amomum, le Leonurus \& le Myrthe panaché accompagnés de plufieurs plantes vivaces \& autres, comme le Piment ou Poivre-long, la Giroflée, l'Aloës, le Geranium-rifte, le Talafpic vivace, \&c.

La daifon of tous ces Arbres fe trouvent en Acursi- 


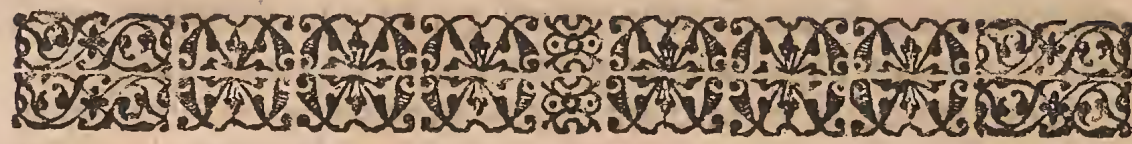

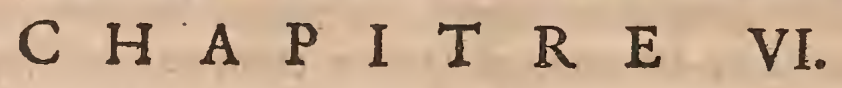

\section{DELA CULTURE DES ORANGERS Cr des autres Arbrifeaux de fleurs: Avecle moien de rétablir les infirmes.}

$N$ eft affés revenu prefentement de l'erreur oi l'on étoịc fur la difficulté de gouverner les Orangers \& les autres Arbres \& Arbrifeaux de fleurs, dont cerraines gens avoient fait une chimere, pour fefaire croire plus fçavants.

* Il faut dans ces pais des Serres d'Eté, comme des Sertes d'Hyret.

DE LA SER. RE DE SES Quaitiz.
On éleve bien de ces Arbres* en Angleterre, en Hollande, en Suede $\&$ dans les autres Païs du Nord, où le froid eft bien plus grand \& plus long qu'en France; ainfi il nous eft encore plus aifé que dans ces clinats, de les entretenir fans beaucoup de peine, convaincus que nous fommes qu'une culture generale convient à toutes leurs efpeces.

Plufieurs chofes contribuent à la confervation \& à l'entretien des Orangers : une bonne ferre, la compofition des terres, le rencaiffement, l'expofition dans les Jardins, la maniere de les tailler, l'arrofement, la faifon de les ferrer \& fortir, la maniere de les gouverner dans la ferre, \& enfin le moïen de les garantir des infectes qui leur font la guerre : Examinons chacune de ces conditions en particulier.

On peur dire certainement, qu'une bonne ferre eft la chofe la plus effentielle pour la durée des Orangers \& des autres Arbres que le froid oblige de ferrer. On doit en premier lieu l'expofer au Midy ou au Levant, \&z éviter de la bâtir au Couchantou au Nord, par le peu de chaleur \& les mauvais vents qui viemnent de ces côtés-là La grandeur de la ferre fera proportionée à la quantité d'Arbres que l'on a à ferrer, enforte qu'ilsn'y foient point trop entaffés : quand elle eft un peu élevée, l'on arange les perits Arbres entre les grands fur des échafauds \& des gradins de bois, cela épargne une grande longueur de bâtiment ; elle doit toujours être affés élevée pour ne pas gêner les Arbres, foit en place, foir en les enz- 

trant ou fortant: on percera la ferre dans la face la mieux expofée, d'une grande porte \& de plufieurs hautes fenêtres qui donnent encrée au Soleil dans les tems doux. Il y aura trois chaffis l'un devantl'autre, pour empêcher le froid de penetrer par ces ouvertures; le premier en dedans, fera de papier colé des deux côtés; on mettera en dehors un contrevent de bois, \& entre-deux un bon chaflis de virrage, le tout fermant jufte, \& outre cela bien calfeutré avec du foin dans les grands froids. Lies murs feront conftruits folidement d'environ deux pieds \& demi d'épaiffeur, a moins de deux pieds, \& le côté du Nord plus épais que les autres, comme le plus à craindre pour la gelée; ils feront tous couverts d'une natte de paille. Comme l'humidité \& le froid peuvent provenir égalemene de la couverture d'en-haut, \& du bas ou fol de la terre, que des côtés, on aura grand foin de bien couvrir la ferre ; fi c'eft un plat-fond cintré fans greniers au deffus, on garnira l'entre-deux du lambris \& de la tuille, de * paille delaiée avec de la terre; s'il y a des chambres ou des greniers, on les remplira de foin, \& l'on en fermera bien les fenêtres. A l'égard du fol ou plancher, il doit être fort fec \& batu en recoupes ou en falpêtre, d'un pied de haut, on le tiendra un peu élevé, ou du moinsau rés-de-chauffée du dehors; car quand il faut y defcendre, outre l'incommodité qui s'y trouve pour le tranfport des Orangers, cela caufe encore de l'humidité au pied des murs. Cette raifon doit faire rejetter les ferres Couterraines, comme les caveaux, d'autant qu'elles ne peuvent joüir des räions du Soleil. * Les ferres adoffées contre une montagne ou fous les ** voutes d'une terraffe; \& qui font expofées. au Soleil de l'autre côté , font excellentes.

Pour remedier au manque de chaleur de ces climats-ci, on Meudon. fait un mélange de terres convenables à la nature de l'Oranger, lefquelles étant enfermées dans une caiffe penetrée de. tous côtés de l'ardeur du Soleil, acquierent un-dégré de chaleur aprochant de celui que ces A rbres ont natu rellement dans les $\mathrm{Pa}$ ïs chauds, où ils reftent toú jours en terre.

La meilleure compofition eft un tiers de terre neuve graffe "Si cefü \& forte, fans être glaifeufe, laquelle étant remplie de fels fera moins conpouffer de beaux jets, un ciers de * crotin de mouton bien fommé, il confommé pendant 3 ou 4 ans, pour donner dela chaleur à brillanto 
LI RINCAISSEMEN

Les Gaiffes doivent être toujours plus perites que grandes, afin gue reflerrant un peu les racines de l'A rbre, fa tête fe fortifie \& en devienue plus belle.
28 TROISIE'ME PARTIE, CHÁP.VI.

la terre, \& on y mêle un tiers de terreau de vieille couche pour domner de la legereté. L'on paffera toute cette terre à la claïe pour l'épierer. Ce mélange eft meilleur que celui où il entre beaucoup plus de drogues, comme des curures de mares, de la fiente de pigeon; de la poudrette, du marc di vin, \&c. Il eft non feulement bon pour les Orangers, mais encore pour rous les autres Arbrés qu'on encaiffe \& pour les fleurs qu'on met dans des vafes de faïance.

On eft indifpenfablement obligé de rencaiffer un Oranger; quand la caiffe qui le renferme ne vaut plus rien, ou qu'elle. eft trop perite pour contenir fes racines, ou bien que l'Arbre ne travaille pas affés vigoureufement, la terre étant ufée à demi, ou entierement, \& par là denuée des fels neceffaires à la végetation.

Sil les tcrres ne font qu'à demi ufées, \& que la caiffe fois encore alfés bonne pour durer l'année $\&$ plus, on fe contentera pour foulager l'Oranger, de lui donner un demi rencaiffement, c'eft-à-dire, de tirer avec la houlette tout autour de la motte fans endomager les racines, les terres ufées, \& en remettre fur le champ de nouvelles, qu'on aura foin de bien plomber. Mais fi les terres font entierement ufées \& que la caifle foit pourrie ou trop petite par raport à l'A rbre, il le faut rencaiffer de nouveau en cette maniere.

On choifira une caiffe proportionnée à la grandeur de l'Arbre, faite du mieilleur bois de chêne, on la goudronera en dedans, \& on la peindra en dehors de deux couches à l'huile, foit en verd ou en jaune, pour la faire durer plus longtems. On prepare cette nouvelle cailfe par un lit de platras mis au fond, tant pour empêcher les racines de defcendre \& de percer le fonds de la caiffe, que pour la garantir de pourriture, en domnant par.là , paffage à l'eau fuperfluë des arrofemens, enfuite on remplit la caille à demi de terre preparée, qu'on fait plomber par un homme qui marche un moment dedans;on jecte un peu de terre-meuble par deffus, pour y pouvoir placer la motte de l'Oranger qu'on tire de la vieille caifle en la rompant de tous côtés; on retranche cette motte tout autour \& en deffous, environ de la moirié, \& l'on coupe les racines \& les chicots qui s'y rencontrent, crainte de la pourriture ; yous planterés cette motte bien dans le milieu, de 12 
LA PRATIQUE D U JARDINAGE. 229 caiffe \& d'a-plomb, pour le coupd'œil, \& vous éleverés l'A r. bre trois pouces au deffus des bords de la caiffe, car les arrofements \& les terres qui fe plomberont dans la fuite, ne le font que trop defcendre. Cette terre fera retenuë avec des planches \& dofes de bois, jufqu'à ce qu'elle foit affaiflée à niveau de la caiffe. Il faut bien plomber les terres autour de la motte pour affurer l'A rbre contre les vents, \& faire enfuite un petit cerne au pied de la tige, pour recevoir l'eau qu'on jettera auffitôt qu'on aura planté, afin de plomber les terres \& les faire defcendre plus vite.

Le rencaiffement fe fait ordinairement au fortir de la ferre, avant la grande pouffe, \& jamais à la fin de l'Automne, ì caufe de la proximité de l'Hyver, à moins qu'il n'y ait une neceflité indifpenfable.

On apelle improprement la ferre, une Orangerie, l'on ne devroit apeller de ce nom que l'endroit du Jardin où l'on range les caiffes pendant l'Efté, de même qu'on apelle une Cerifaie une place remplis de Cerifiers. L'expofition des Orangers dans les Jardins demande quelque intelligence, il eft certain que s'il étoient mal placés \& trop expofés aux vents s'ils feroient bien tôt gátés; on leur doit deftiner un lieu à l'abri des vents du Nord, par le moïen de quelque bâtiment, d'un bois ou d'une paliffade épaiffe ou bien de quelque mur, fans cependant leur ôter le Soleil qui leur eft fi neceffaire.

On range les caiffes en les alignant au cordeau, tant celles qui font ifolées, que celles qui ie placent dans les plates-bandes des parterres d'Orangerie entre les Ifs. Dans les tournans on les range à l'œille mieux que l'on peut, à moins qu'on ne les puiffe mettre fur quelque centre au co rdeau, on les dreffe en metrant des tuilles ou carreaux deffous les pieds de la caiffe, pour les empêcher d'efoncer trop avant en terre, \& d'y pourrir : l'ordinaire eft de placer une petite caiffe entre deux grandes, pour en garnir le deffus : on peut auffi pour la beauté, entre-mêler des pots \& des vafes remplis d'Arbriffeaux \& de belles fleurs de faifon : on connoît le bon goût d'un jardinier dans cette décoration, où la regularité ne doit point empêcher une agréable confulion qui les falfe paroître en beaucoup plus grand nombre qu'ils ne font effectivement.

IA MANIEO En taillant un Oranger, on ne doit envifager qu'une belle

L'EXPOST. TION DANS XES JARDINS

L'ARRAN* GEMENT.

RE DE IAS TAIIIAR。 Ff iij 
forme, tine tête fort ronde, des branches bien placées \& quile garniffent également de tous côtés fans trop fe foucier de fleurs ni de fruits, cela rend la taille des Orangers beaucoup plus facile que celle des autres arbres fruiciers, ou l'on demande plus de fruit que de bois, \& l'un \& l'autre enfemble. L'on taille ces arbres au fortir de la ferre, un peu avant la grande poufe, afin que les branches qui reftent profitent de toute la feve : leur tête doit être proportionnée à la tige, à la groffeur du pied, \& à la grandeur de la caiffe, on l'entretiendra en boule en coupant toutes les branches pendantes \& qui s'échapent de ce contour agréable : elle ne doit point être confufe \& trop chargée de bois, enforte que toutes les branches en dedans fe diftinguent aifément; quand un arbre a du vuide dans fa rondeur, on ravalle quelque vieille branche voifine, qui dans peu pouffera des jets qui regarniront la place, ou bien on en confervera quelques-unes dans léur longueur, fans rien couper pour les faire venir au bord; on s'attachera furtout à monter la tige le plus haut qu'on poura, en coupant les étages de branches de deffous, fort prés de la tige \& en pied de biche, pour écouler les eaux; on couvrira de cire verte toutes ces plaies, cela empêche que l'ardeur du Soleil ne les altere.

Il faut encore pincer \& ébourgeonner les Orangers dans les deux pouffes, en ôtant avec les doiges les jets foibles, con* On apelle. fus* \& mal placés; comme auffi les branches qui s'emportent ces jers, des trop, enforte qu'il ne refte qu'un feul jet \& vigoureux à

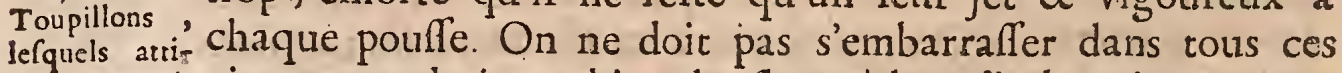
rent la punai- pincemens de jetter bien des fleurs à bas, l'arbre s'en portera fe. mieux \& pouffera plus vivement; la trop grande quantité de fleurs $\&$ de fruits fait fouvent avorter un arbre, ainfi même fans pincer, on eft obligé d'ôter le trop de fleurs, \& de ne laiffer noüer de fruit qu'à proportion de fa groffeur, 5 ou 6 Oranges fur les moindres, \& une douzaine environ fur les gros; on obfervera que les arbres étêtés ne doivent point être pincés la premiere année, parcequ'on a befoin de toute la longeur des branches, pour former promptement une nouvelle tête.

E’arrose- Les Orangers veulent peu d'eau, mais donnée à propos, ховнт. il vaut mieux leur laiffer avoir un peu foif que de les noïer trop fouvent. On connoît le befoin qu'un arbre a d'êcre arrofé 
L A PRATIQUE DU JARD I NAGE 23 I quand fes feüilles font molaffes, qu'elles baiffent ou fe fannent, cela fe connoît encore quand les terres fe fendent ; mais il ne faut jamais attendre cette extremité, ainfil'on arrofera les Orangers une fois la femaine avec médiocrité hors dansles tems de la pouffe \& de la fleur (qui arrivent en Mai \& Juin ) qu’on les moüillera deux fois la femaine ; les Sauvageons feront arrofés encore plus rarement fi on les veut faire fleurir : quand on entrera les Orangers dans la ferre \& qu'ils y feront placés, on leur donnera une bonne moüillure \& abondante, tant pour raffurer la tige ébranlée dans le, tranfport, que parce que cette eau fert pour tout l'Hyver : on pourra au mois d'A vril moüiller les A rbres qui fe fannent, \& cela quand on ouvrira les portes \& les fenêtres de la ferre. Dès que les Orangers font fortis \& mis en place dans les Jardins, ill leur faut donner un ample moüillure pareille à celle de l'entrée dans la ferre; l'on prend même des chevilles de fer pour percer la motte en plufieurs endroits, afin que l'eau puiffe penetrer plus avant pour raviver toutes les racines; dans les grandes féchereffes, on ne fera pas mal de moüiller la tête d'un Arbre pour la reverdir : on donnera aufi un petit labour tous les mois aux Orangers, hormis quand ils font dans la, ferre.

La faifon la plus propre pour entrer les Orangers dans la ferre eft à la my-Octobre, quand les nuits \& les matinées con1mencent à devenir plus froides, \& à faire craindre des gelées capables de gâter ces beaux Arbres. Le tems pour les fortir eft ordinairementà la my-Mai, où il n'y a plus de fortes ge. lées, enforte que les Orangers font 7 mois enfermés \& 5 dehors; c'eft la douceur du tems qui doit regler cette entrée \& cettefortie; quelquefois quand les matinées font frầches \& fujettes à des gelées blanches, à la my-Mai, l'on attend encore une huitaine \& plus à les fortir, pour les garantir des inconveniens, de même que fi le tems eft beau en Óctobre, l'on retarde leur prifon de quelques jours. Alors on aproche les Orangers de la ferre, pour être plus en état de les entrer promptement au premier froid. Dans les années pluvieufes, on fortira les Orangers de meilleure heure que dans les années feches \& venteufes, ainfir que dans les Jardins bas \& marécageux, on les fortira plus tard que dans ceux qui fons.

On peuter. core faire fleurir un 0. ranger à la feve d'Août, en foripous. drant la Cailfe, d'un pou. ce de terreau, Is la motiil. lant fort fouvent; mais par ce moien on court rifque de faire a vorter unAtbre.

Dans les grandes 0 rangeries, comme à Ver. failles, il $\mathrm{y} \mathrm{a}$. des, machines faites exprès pour atroler. les grandes Caiffes, par le mö̈en d'un tonneau élevé à leur haureur, \& de deuz tuyaus de cuir boiiil. Ii qui moivillent les Caiffes des deux cốtés : cela eft plus commode, que de le fervir d'arros foirs.

La sarson DE ZES SBRREREI SOORTIR, 
LEURTRANa SPORT.

LA MANIERE DE GOUAERNER IES ORANGERS DAN $S$ I A SHRRB.
232 TROISIE'ME PARTIE, ChA P. VI. élevés: où le vent diffipe les gelées, c’eft à la prudence du Jar: dinier que toutes ces chofes font remifes.

On obfervera qu'on doit toûjours ferrer \& fortir les Orangers par un beau tems, \& qu'auffi-tôt qu'ils font entrés dans Ia ferre, l'on ne doit pas fermer les portes \& les fenêtres; mais les laifler ouvertes jufqu'aux premieres gelées, afin que les Orangers fortant du grand air ne foient pas renfermés. fi vîte; il en eft de même pour les fortir . en les accoutûmant perit à petit à l'air, par l'ouverture des fenêtres \& des portes au commencement d'Avril, fans cela un contrafte fi fubir leur feroit grand tort.

On tranfporte les Orangers d'une mö̈enne force fur des civieres, ou fur des traîneaux ; deux hommes les portent encore facilement, avec de grofles cordes attachées à des crochets qui embraffent les 4 piliers de la caiffe : les grands Arbres fe mettent fur des chariots bas tirés par des chevaux.

La manicre de gouverner les arbres dans la ferre, regarde principalement la chaleur étrangere où il faut avoir recours pour empêcher les froids excefififs d'y penetrer, ce qui peut arriver, quelque bonne que foic une ferre, \& quelque bien calfeutrées que foient les portes \& les fenêtres : cependant il ne faut y faire du feu que le moins \& le plus tard qu'on peut; une chaleur naturelle eft toüjours meilleure aux arbres. On connoît quand il eft neceffaire d'y faire du feu, par de perits goders pleins d'eau que l'on met en plufieurs endroits de la ferre, furtout contre les portes $\&$ les fenêtres : On en placera aufli quelques-uns fur le bord des caiffes; c'eft par ce moïn quion connoît le dégré de froid, fi l'eau ne fait que prendre lans gêler il n'y faut point de feu, mais fi elle gêle \& prend entierement, alors on fera du feu continuellement tant que cela durera.

Cetre chaleur doit être moderée, car le trop de feu nuit fort aux Orangers; la difficulté conlifte à trouver une chaleur égale \& temperée, fans caufer beaucoup de fumée qui fait tomber les feüilles. Ordinairement on fe fert de poëles \& de terrines de fer où l'on met du charbon bien allumé, avant que de l'entrer dans la ferre, l'on place ces braziers à l'entrée de la porte, aux bouts \& au milieu des ruëlles ou des allées que forment les caifles, en prenant garde de ne les pas 
LA PRATIQUE DU JARDINAGE. 233 mettre deffous les branches de quelque Oranger qui en feroie dépoüillé fûr rement : d'autres condamnant l'inégalité du feur de charbon, qui eft d'abord ardent, enfuite très - foible, \& peut par fa fumée déffecher l'humidité de la féve, fi nécefLaire à la confervation des feüilles, employent des poëles couverts appellés Poëles d'Allemagne, qui jettent la fumée en dehors par le moyen d'un tuyau de fonte : on les entretient de bois moderément, \& par l'expérience de la durée d'une certaine quantité de bois, on les renouvelle fans interruption. On peut encore fe fervir de lampes fufpenduës au plancher, au milieu \& dans les coins dela ferre, principalement près des portes \& des fenêtres par ou le froid vient ordinairement. La chaleur qui en réftilte eft douce, continuellement égale \& uniforme; vous la renouvellés à l'heure jufte, fans crainte de ceffation de chaleur, par l'épreuve de la durée d'une lampe qui vous regle de maniere que vous fçavés quand elles doivent toutes finir : on mettra plus ou moins de ces lampes à proportion de la capacité de la ferre; \& on les élevera un peu haut, crainie que leur fumée n'endommage aucun arbre.

Il eft certain quele feu des lampes eftplus égal que celui du charbon allumé, mais comme on n'eft point encore exempt de la funée, les poëles d'Allemagne entretenus de bois moderément, femblent devoir être à préférer ; on s'en fert principalement en Angleterre, en Hollande, en Suéde, en Alle. magne, \&c.

On prendra garde d'aprocher fi prés des murs les Orangers, tant à caufe de la gelée, que pour les pouvoir vifiter de tems en tems; on les rangera en allées tirées au cordeau, $\&$ on les élevera fur quelque gradin ou billots de bois, depeur de l'humidité ; l'on pouria metrre contre les murs les Grenadiers \& les Laturiers.

Dans les grandes pluyes \& dégels, comme le rems eft fort doux, on aura foin d'ouvrir quelques fenêtres, cela donne de l'air aux arbres; on pourra moüiller un peu ceux qui en. ont befoin, ainfi que les fleurs empotées qui fe peuvent forcir pendant quelques heures.

Comme l'Oranger demande naturellement beaucoup de propreté, tant dans fes feüilles que dans fon bois, il faut

On fair rarement du feut dans les Serres voûtées fous des terrafles, comme à Verfailles \&a.Meudon; elles font affez chaudes d'elles-mêmes quand tout eft fermé. I1 n'y a que dans les grands froids qu'on y allume des lampes. Onfefese de feu de charbon à S. Cloud \&. à Sceaux, parce que les Serres fonides. galeriesau rea. de chaufíe. 
MOYEN de LESGARENTIR DES IN SECTES.

$23+$ TROISIE'ME PARTIE, CHAP. VI: avantque de les fortir, nétoyer avec de petites broffes toutes les branches \& les feüilles, \& en ôterle couvain des punaifes, les toiles d'araignées \& les.autres ordures; cela eft effentiel pour fa confervation.

Ce n'eft pas affez d'avoir romedié au froid \& aux vents qui nuifent aux Orangers, il faut encore donner le moyen de les garentir des infectes qui leur font la guerre \& qui les endonimagent confidérablement, tèls font la punaife, les fourmis les perce-oreilles.

Les punaifes ne font pas beaucoup de tort d'elles - mêmes à un Oranger, finon de le rendre mal-propre parle couvain qu'elles font en Automne fur les branches confufes qu'elles rencontrent en volant; ce couvain reffemble à des taches de rouffeur, \& étant parvenu le Printems fuivant à la groffeur d'une lentille, il éclot, \& par là multiplie le nombre des punaifes, qui produifent enfuite d'autres couvains. Si l'on a bien foin de tailler.le bois inutile dans la tête d'un Oranger, \& fi l'on nétoye foigneufement fes branches par tout, les punaifes n'y feront guere d'ordures.

Les fourmis ne font attirées fur les Orangers que par le couvain des punaifes; ainfí lorfqu'on a bien foin de l'ôter, on eft garentide la perfécution de fes infectes, c'eft le meilleur remede: l'on peut encore lier du coton autour de la tige, ou la froter de crä̈e blanche, qui, à ce qu'on prétend, les empêche de monter. La fourmis mange la fleur d'Orange, \& fait un amas de faleté fur les feüilles.

Lés perce-oreilles font plus difficiles à détruire, ils picottent toures les feüilles. On les prend dans des cornets de papier placés à differents endroits de l'arbre; l'on met auffi de petits vafes de terre, de plomb ou de fer - blanc pleins d'eau. fous chaque pied de la caiffe pour les faire tremper dedans cela empêche ces infectes ainfi que les fourmis de monter le long de la caiffe. L'on voit quelquefois des vafes ronds de deux pieces que l'on rejoint enfemble aurour de la tige, de maniere que ces vafes embraffent cette tige, \& ne laiffent aucun jour entre, après l'avoir garni entre-deux de filafie, de coton ou de mouffe d'arbre, on remplit d'eau ces vafes, \& quand le perce-oreille, qui naturellement craint l'eat, en aproche, il s'en recourne fur fes pas fans rien endommager 
I. PR A TIQUE DU JARD INA GE. 23,5

Les Grenadiers, les Lauriers, les.Myrthes, les Jafmins, \&c. fe cultiv ent de même que les Orangers, dont l'éducation peut fervir de modelle à tous les Arbres encaiffés ou empotés à quelque petite difference près, comme on va le remarquer.

Le Grenadier demande plus de nourriture, \& une terre plus fubitancielle que l'Oranger; on met moitié de bonne terre neuve \& moitié de terreau, \& par-là on empêche fes fleurs de tomber fi vîte ; il veur beaucoup d'eal, comme de deux jours l'un, \&z veut être fouvent labouré; on lui donnera outre cela un demi-rencaiffement tous les deux ans, \& l'on faupoudrera la fuperficie de la caiffe, de deux óu trois pouces de terreau; fa tête doit être ronde \& trés-touffu ë ', fans autre précaution pourla taille, que de pincer les branches qui s'emportent trop.

Le Myrthe n'a rien de particulier, finon qu'il demande pluss d'eau, \& un peu plus d'attention que l'Oranger, étant beatlcoup plus délicat.

Les Lauriers-francs; les Lauriers-cerifes \& les Lauriersrofes ont toujours foif, on ne leur peut jamais donner trop d'eau ; on les changera auficle tems en tems de terre; la taille en eft ordinaire.

Les Jafmins en general demandent deux tiers de bonne terre \& un tiers de terreau; on taille ceux d'Efpagne tous les ans à la fin de Mars, en coupant toutes les branches à un oil près de l'endroit où ils fortent de la tige, de même qu'on fait aux Ofiers; c'eft pour les faire fortifier du pied \& pouffer plus vigoureufement. Il veulent de l'eau amplemént \& fouvent.

Les Rofiers fe plaifent fort dans -une terre legere \& $f_{a}$ bloneufe, la culture en eft generale, exceptéle Rofier de tous les mois, qui fleurit fept à hiit fois par an, \& qui éxige de cerrains foins, fans lelquels il ne porte qu'une fois comme les autres; cesi foins, confiftent par exemple à-le tailler rés-de terre en Septembre, pour avoir de nouveaux jetsau Printems; on les taille encore à la fin de Mars, en aprochane ces nouveaux jets jufqu'aux yeux près-la tige lera après chaque pouffe, en coupant les branches au deflots: des nouds où étoìent les fleurs après qu'elles feront paffées c'eft paricette quantisé de taille que l'on oblige ce Rofier à Ena

$$
\mathrm{Gg} \text { ij }
$$

Custuxe DES AUTREE ARBRESa 
236. TROISIEME PARTIE, CHAP.VI. fleurir toujours ; pour a vancer cette frequente fleurifion, on répand un doigr de terreau fur le pied del'A rbre; \& l'on arrofe par defius pour en faire tomber les fels fur les racines.

Le Genert, l'Altea, de Chevre-feuiille, le Trifolium, le Seringal, \&c. demandent une terre naturelle, arrofée fouvent \& entretenuë de labours; on les tond en paliffades. en arbriffeaux, d'autres en boules: pour le Leonurus, l'Amomum, le Colutea, le Lentifque, ils font plus délicats; ils demandent la terre des Orangers \& leur propre culture.

On obfervera en taillant tous ces Arbres, \& pour entretenir leur rondeur, de couper le bois qui paroît ufé \& mal placé, ainfi que celui qui séleve au deflus de la tête \& qui s'empor re de tous côtés.

Ces Arbres petivent être empotés aifément, c'eft-à-dire, les perits, car les grands fouffrent trop dans la contrainte de leurs racines, qui fe récorvillent dans les pots \& les vafes: $\mathrm{Ce}_{t}$ empotement fe fait comme le rencaiffement. On garentit ces vafes des fecouffes du grand vent, en les arrêtant dans Les endroits fort expofés, par des fils de fer attachés à des piquets enfoncés rés-de terre. L'on doit arrofer les Arbres empotés beaucoup plus fouvent que ceux qui font en caiffe; il elt aífé d'en connoître la raifon ; les pots étant de moindre confiftence, font plûtôt pévétrés des raions du Soleil, \& par conféquent let terres plûtôt fechées \& mifes en maffe: On les doirferrer aux premieres gelées avec les caiffes, fans cela la gelée lesferoit fendre:

L'expofition de tous ces Arbres fera la même que celle des Oratigers, cependant on en peut placer par tour; comme ils craignent moins les méchants vents, on les ferre un peu plus tàrd', \& on les fort aufifi plâtôr que lesOrangers. Ces Arbres fe reffentent dans la ferre, du feu quel'on fait pour lesOrangers, \& l'on aura foin de les arrofer quand ils fe fanneront. On ne s’aperçoir pás qu'ils, foient fujets à- la punaife ni à aucune vermine, on les nétö̈era 'neanmoins' de leur pouffiere 8 malproprecé

Les A rbres qui reftent toujours en terre, \& qui font un peu délicats, fe couvriront l'Hyver avec de la liciere, ou avec MOYBN DE PITABIR IESINEIRdes paillaffons.

Il ne refte plus maintenant après avoir parlé des Arbres 
I A PR A TIQUE DU JARDINA GE. 237 qui font en fanté, \& qu'on fupofe tels par la bonne culture qu'on leur a donnée, qu'a dire comment on peut remedier aux infirmes pour les retablir \& ramener dans leur premier état de beauté ; c'eft ce qu'il y a de plus difficile \& deplus de confequence eis fait d'Orangers, cela demande beaucoup de jugement pour en bien diftinguer la caufe.

Les maladies des Orangers proviennent d'une mauvaife ferre, d'un rencaiffement défectueux; d'une terre ufée, de quelques racines pourries, de trop de feu, de trop de froid ou de trop d'eau quilis ont enduré, d'une mauvaife taille; des infectes \& vermines qui les font dépoüiller, ou enfin des vents $\&$ de la grêle qui caffent leurs branches, \& broüiffent leurs feüilles.

Si rôtqu'on voit un Oranger languiffant, on doit le feparer des autres \&r le mettre à part dans un * lieu qui foit à l'abri du cet endroit o Soleil, qui pouroit brûler \& jaunir bien-tôt fa nouvelle poufe. On le laiffe-là jufqu’à ce qu'il foit rétabli entierement, ce qui quelquefois ne laiffe pas d'être long : ces infirmes demandent beaucoup plus d'attention que ceux qui font en fanté.

Il n'y a point de remede contre une mauvaife ferre, finon d'en bâtir une autre pour y ferrer l'année fuivante les Orangers malades : à l'égard d'un rencaiffement défectueux, on ne perdra point de tems pour rencaiffer l'arbre de nouveau, c'eft le vrai moïen de le rétablir.

La terre eft la chofe la plus confiderable à examiner, comme le fondement de toutes chofes; fi elle paroît ufée entierement, on décaiffera l'A rbre tout à fait; mais fí on la croît encore affés bonne, l'on fe contentera de lui donner un demirencaiffement; on regardera fes racines en le décaiffant, \& s'il s'en trouve de pourries ou de mortes, on les taillera jufqu'au vif, enfuite l'on retranchera moitié de la motte, en la ferrant des côrés \& du deffous, pour l'obliger à faire de nouvelles racines capables de retablir fa tête.

Le trop de feu qu'on leur a fait, le froid qu'ils auront enduré en les fortant trop vîte, ou en ne les ferrant pas affés-tôt, la trop grande charge de bois qu'on leur a laifé, la faleté des branches, \&la perfecution des infectes $\&$ des vermines, font des marques évidentes de l'ignorance de celui qui les gouverne. Tous ces accidens; s'ils ne dépoüillent pas l'Oranger. 
238 TROISIEME PARTIE, C A P. VI.

font au moins mourir une partie de fes branches: alors on eft obligé de l'étêter. Quand on en elt quitte pour quelques branches mortes ou défechées, on les rogne courtes jufqu'au vif, \& on n'en laiffe qua proportion du pied, car la charge doit être à peuprès égale à la nourriture.

On ne doit point faire de difficulté d'abattre tout d'un coup ce qu'il faut, pour n'y pas revenir les années fuivantes, l'Arbre s'en portera mieux \& fe retablira plus vite. Quand on raprochera les branches près de la tige, l'on doit tâcher de referver les plus groffes \& tailler les menuës, quoiqu'elles donnent quelques feüilles ou des fleurs, jufquà même dépoüiller toutun Arbre pour le foulager. Lorfqu'un Oranger languiffant pouffe des jets vigoureux jufqu'au milieu de fes vieilles branches $\&$ proche du corps, il faut ravaler ces fortes de branches remplies de jets foibles jufque-là, pour profiter de la vigueur de l'Arbre déclarée à cetendroit. Ces.jets font d'abord jaunâtres \& langoureux, mais ils deviendront verds, dès que les racines fe feront fortifiées affés pour nourri: ces nouvelles pouffes.

On aura fön furtout de tenirles nouvelles branches trésnettes de tous infectes \& ordures, d'en ôter la fleur, \& de n'y laiffer noüer aucun fruit. Qu'eft-ce qu'on peut demander à des A rbres malades, que du bois \& des feüilles ? c'elt encore beaucoup quand ils répondent à notre attente.

- Pour les branches rompuës par les vents, \& les feüilles broüies par la grêlie, l'on fe contentera d'ôter ces feüilles, \& de tailler les branches rompuës, c'eft le feul remede : il eft inutile de rencaiffer pour cela un Oranger qui n'a nullement fouffert dans fes racines; s'il étoit ébranlé, on le tafermiroit en jetcant de la terre fraîche dans les fentes. Une bonne expofition dans les Jardins mes à l'abri d'une partie de ces accìdens.

On avertit qu'il faut fe donner patience dans le rétabliffement de ces arbres infirmes; un Oranger eft quelquefois deux ou trois ansfans pouffer nibranches nir racines, quoique bien foigné, \& nouvellement rencaiffé dans de bonne terre, \& dans unne caiffe qui n'eft ni rrop grande ni trop petite: Pourvû que cet Arbre paroiffe yerd dans fa tige $\&$ dans fes branches, il nefaut point le changer: avec le tems il fortira de cente létar- 
IA PRATIQUE DU JARDINAGE. 239 gie, \& pouffera après plus vigoureufement qu'un autre Quand un Oranger eft encaiffé depuis quatre ou cinq ans fans pouffer que quelques feüilles jaunâtres, il demande abfolument à changer de terre l'année enfuite, fans attendre à le faire qu'il foit tout -̀े-fait malade, il faut prévenir cet accident de crainte que l'Oranger ne fe dépoüille dans l'année du rencaiffement felon l'ordinaire: cet ouvrage fait à propos devancera la maladie future.

Les Grenadiers, Jafmins, Lauriẻrs \& les autres Arbres cideffus nonmmés, n'ont point de maladie particuliere qui ne fe. raporte à celles de l'Oranger, ainfi on peut y apliquer tout ce. qui vient d'être dit.

On ne peut rien ajoûter d'effentiel à la culture de ces Arbres; \& ce Traité, quoique petit, renferme tout ce qui les regarde; tâchons dans celui des fleurs qui va fuivre, de con: Lerver la mệme étendü̈ avec la même précifion.

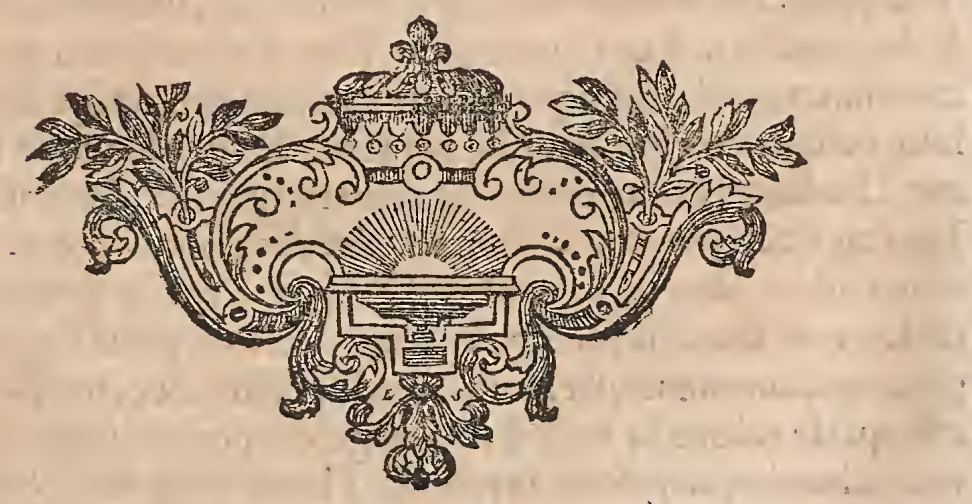


DES FLEVRS EMPLOYEES ordinairement dans les Plates-bandes des Parterres, avec la maniere de les femer, de les cultiver multiplier.

$r * 0$ fandas Gentes, quibus bac nafcustur in bortis, Numina? Juvera!. Sat. 15. verf. 10.

* Les Anciens Egyptiens 3dotoient les Lentilles, les Féves, \& les. Oignons-

Diodore de Sirile, liv. I.
VEN ONS aux fleurs qui garniffent les Plates - bandes. des Parterres dans chaque faifon', \& tâchons de nous tirer des erreurs' \& des caprices de la plûpart des Fleuriftes. à qui il ne manque que l'idolâtrie des* Orientaux. On fçair affés que l'amour qu'ils portent à leurs oignons, eft au-delâ de tout ce qu'on en peut dire : cette ardeur eft un peu rallentie préfentement en France, mais elle eft encore très-violente dans les Pays-bas.

La curiofité en fait de feurs, roule principalement fur les. Tulippes, les Anemones, les Renoncules, les Oreilles d'Ours, \& les Oeillets. Les Curieux ne font guere de cas de nos autres fleurs, qui, quoique moins variées dans leurs efpeces, ne leur cedent en rien pour la vivacité des couleurs, la belle forme, l'odeur, la durée \& l'agrement qu'elles. fourniffent aux. Jardins : ce font ces. Tulippes, ces Anemones, \&rc qui leur demandent tane de foin \& tant de peine, pour avoir le plaifre de les voir durer douze ou quinze jours au plus. Quion s'imagine un homme myfterieux, toujours inquiet, toujours craintif, qui fe releve la nuit dans les gelées pour couvrir fes fleurs, qui laboure, arrofe \& farcle fes Plates - bandes continuellement, qui en paffe les terres au crible fin, $8 z$ les prépare differemment pour chaque efpece, qui fait un mémoire écrit par ordre de fes plates-bandes, avec les noms $8 x$ portrairs de chaque fleur, qui auffi-iôt que les fleurs font paffées., leve leurs oignons \& les ferre dans des boütes \& tiroirs chacun dans fa câfe, \& en enveloppe d'autres dans du papier, \& qui pardeffus tout cela garde fics fleurs comme un tréfor, \& n'en laifie aprocher 
L A PR A TIQUE DU JARDINAGE. 24I aprocher qu'avec des yeux jaloux, on aura une idée veritable d'un grand Fleurifte; c'eft parlà que ces Curieux parviennent à un fi grand entêtement de leurs fleurs, qu'ilsont eftimé un oignon deTulippes'jufqu’à cent piftoles \& plus, \& même pour rendre leurs beaux oignons uniques, ils ont fouvent la malice d'en écrafer les caïeux.

Evitons cet égarement, s'il fe peut, \& donnons des regles certaines, \& une culture fimple oppofée à tous leurs grands mifteres, pour awoir fans tant de foin de belles fleurs de chaque faifon, \& des plates-bandes garnies fans aucun vuide pendant huit mois de l'année ; c'eft ce qu'on doit rechercher uniquement dansles grands Parterres, qui deviendroient fort à charge \& d'un entretien continuel, s'ils demandoient autant de foin que les Fleuriftes en donnent à leurs planches. Une terre un peu amandée, une expofition abriquée, un foin general, font tout ce qu'on demande ici, cela fuffit pour faire tout réüifir.

On tâchera de débroüiller autant que l'on pourra cette quantité de noms bizarres donnés à la même fleur, \& qui font énoncés féparément dans les * Catalogues des Fleuriftes. Ces grands noms ne fervent de rien, \& ne font qu'étonner la plüpart des gens; la nature eft fi variée dans fes productions, qu’à chaque efpece nouvelle qui fe forme, chacun fe croit obligé d'y donner un nom, fouvent le fien, une petite vanité y contribuë plus qu'une néceffité indifpenfable. Ainfi cette quantité de noms s'accumule tous les jours parmi les Curieux, jufque-là qu'ils connoiffent fouvent une fleur fous un nom, fans la connoître fous un autre.

Les fleurs proviennent de deux chofes, de plantes ou racines, \& d'oignons; cependant leur origine vient de femence ou de graine: car tous les oignons \& la plutpart des plantes aportent de la graine, quoique la nature leur ait donné une autre maniere de fe multiplier par leurs caïeux, ou par les marcottes, boutures \& talles qu'on tire de leur pied, ainfi c'eft au difcernement du Fleurilte que font refervées toutes ces diffetes productions.

On diftingue les plantes, en fibreufes ou ligamenteufes, en bulbeufes, \& en ligneufes ou boifeufes.

Les grands Curieux \& les Fleuriftes de profefion ne trouverone pas ici lear compte dans les raifons que l'on a de combattre leur doctrine; 8 dans la fim. plicisé de cette culture fit oppofée à la leur.

* Traité anonyme des Fleurs, à la fin in Tome 2 de la Quintinie.

Gulture des Fleurs par

Morin.

Le Jardinier Fleurifte 8r Hiftoriographe.

Traité de 12 maniere de femer les Fleurs, \&c. 
242 TROISIE'ME PAR TIE, CHA P. VIT.

Les fibreufes n'ont que des racines menuës ou de petits liga• mens, comme l'Amarante, la Balfamine, \&x.

Les bulbeufes font des oignons compofés de plufieurs envelopes, \& peaux, comme la Tulippe, la Jonquille, \& $c$.

Les ligneufes ou boifeufes ont leurs racines, leurs branches. \& leur tige, d'une confiftence allés dure pour former du bois, comme les arbres \& les arbriffeaux dont on vient de parler.

On divife les Plantes fibreufes en vivaces ou perennelles, \& en annuelles; les plantes vivaces font celles qui craignent peu la gelée, \& fe confervent pendant quelques années, les. annuelles ne durent que l'année, leur délicareffe ne pouvant. refifter à la rigueur de l'Hyver.

Les Flantes bulbeufes ou les oignons ne fe diftinguent pas en tant d'efpeces; ce nom eft emplöé en general pour toutes hormis à quelques-unes, don l'oignon eit fi fingulier qu'it reffemble à des pattes \& à des griftés d'animaux : c'eft delà que lespattes d'Anemones \& les griffes de Renoncules on pris leur nom:

A vant que d'entrer dans un plus grand détail touchant les: plantes \& les oignons, il eft a propos de dire les differents. endroits où l'on éleve les flcurs, \& la compofition des terres ๑ui leur font convenables, fans obferver tout le rafinement des Fleuriftes.

On éleve des fleurs fur des couches, fur des planches, dans des pors, \& dans les plates-bandes mêmes des Parterres.

La plate-bande en general, eft une grande longueur de rerre, écroite $8 z$ bordée ordinairement de buis, dont les terres font tenuës en labour \& relevées en dos-d'âne ou de carpe, On confond fouvent 12 planche \& 1 la plate bande.

Ies FleuriQtes entourens leurs planches, de brique, de pierre plate, on de bois, ne youlant pas y bais qui léche prement \& tripé enfemble; on y répand par deflus un demi. c'eft ou l'on tranfporte en motte les fleurs élevées fur les couches. On en a vû toutes les differences dans le Chap. des Parterres, Parc. Ic.

La planche eft auffi une grande longueur plate \& étroire fans aucun bord que celui du fentier, les terres enfont labourées fans être relevées que de deux ou trois pouces également. partout au-deffus des fentiers \& des allées, comme font les. planches d'un Potager.

La couche eft fort differente de tout cela, elle neeft conftruite que de 'grande litiere ou fumier de cheval entaffé pro- 
I A PRATIQUED U JARDINAGE. 243 pied d'épaiffeur de terreau, le tour montea da hauteur de 3 la terre \& 3. à 4 pieds au deffus de la fuperficie des terres; levr targeur eft mene du de 4 à 5 pieds \& d'une longueur proportionnée, ainfi que ils mettent doit être celle desplanches.

aufin un lit de platras au

Les pots dont on veut parler ici font ordinairement de terre fond de la terrouge, \& trés-differents de ceux de faïance qui contribuenc re, pour enà la décoration des Jardins, comme il a écé remarqué dass pecher looila premiere partié, ceux-ci fervent, étant remplis de bonne foncer \& de fe rerre, à élever des oignons de Tulippes, d'A nemones, de perdre; cela Tubereufes \& des fleurs de faifon, qu'on tient en referve pour corc les en pouvoir regarnir les endroits vuides des Piares-bandes : on y nafles des peut femer des graines, mais ordinairement on aime mieux fujection! lever les fleurs en motte de deffus la couche, \& les empoter un peu grandes. Ces pots fervent encore à ferrer l'Hyver les fleurs an y a en\& les plantes qui craignent le froid.

A vant que de planter ou de femer dans les pots, on met que foun apelun peu de gravier ou de plâtras au fond, pour l'écoulement mais elles ne des eaux : on les remplit de terre preparée, femblable à celle font jamais fi des Orangers, \& on plombe a fun les bords ne s' faif- chaudes que fent pas tant, on éleve la terre de deux doigts audeffus des bords, \& l'on met l'oignon avant.de trois doigts : fi.c'eft de la uns les pors graine, l'on en feme une pincée, qu'on recouvire d'un pouce on mer 4 ou de terreau.

Pour avancer les fleurs empotées, on les enterre jufqu'au bord dans des couches chaudes, \& l'on ne leve point les pots, que la fleur ne foit prêteà paroître; quand elles fonten place on a foin de les moüiller plus fouvent que les autres fleurs, qui font en pleine terre.

La terre des Plates-bandes \& des planches, doit être un peur amandée, \& foncée de deux pieds de bas ; fi elle eft urée l'on prendra la terre neuve des allées \& fentiers voifins, quel'on Tulippes, $A_{-}$ recomblera avec cette mauvaife terre. On paffe ces terres à la nemones, Reclaïe pour les épierrer, on les fume auffi tous les trois ans, quii noncules \&c eft le tems quel'on tire les oignons \& les plantes, pour en ôter mandent un le peuple : en voilà toute la preparation. On obfervera de ne pau plus de rien mettre dans les Plates-bandes, que le fumier ne foit bien compofition confommé \& bien mêlé avec la terre, par deux out trois la- re, comme on bours, fans cela les oignons \& les plantes feroient biẹn-tôt te verra bieno 
Il faute tolsjours avoir un endroit refer. té pour ćlever des Fleurs fur eouche, 8 en planches, cela fert de Pepio siere.
244 TROISIE'ME PAR TIE, CHAP.VII. brûlées. Ce fumier a le tems de fe façonner depuis le mois de Juin que l'on tire les oignons, jufqu'à ce qu'on les replante en Septembre. L'on tiendra les Plates-bandes \& les Planches bien nettes de pierres $\&$ de méchantes herbes, qui emporten toute la fubftance de la terre. On les labourera fouvent, \& l'on faupoudrera le deffus de terreau, cela rend les terres plus légeres.

Dans les terrains humides vous mettrés un tiers de fumier de cheval, un tiers de fable, \& l'autre tiers, de la terre naturelle de la plate bande, afin de deffécher un peu ces terres \& les rendre plus amandées. Dans les Pa ̈is fecs, vous y mêlerés deux tiers de terre fraîche, ou à la place, du fumier de vache qui eft naturellement frais, l'autre tiers fera de la terre du Pairs, le tout faupoudré d'un pouce de terreau; un demipied de hauteur de ce mêlange, fuffit pour élever les fleurs.

Les couches font necelfaires pour élever les graines des plantes délicates \& qui craignent la gelée ; elles font d'une grande utilité dans un Jardin, par le terreau qu'elles produifent, qui fert à poudrer les Planches \& les Plates-bandes, \& à garnir les caiffes \& les pots; en un mot on ne s'en peut gueres paffer dans tout ce que l'on plante.

On commence à faire les couches au mois de Mars: elles doivent toûjours être expofées au plus grand chaud, \& s'il fe peur contre un mur ou dans une meloniere renfoncée; on laiffe paffer leur grande chaleur pendant une quinzaine, avant que d'y rien femer, enfuite l'on faupoudrera d'un pouce de terreati les graines que l'on y feme', \& cela dans l'efpace que peuvent couvrir des cloches de verre : ces cloches garantiffent les graines des froidures du Printemps, \& étant échauffées du Soleil, les avancent de beaucoup : fi le froid étoit un peu fort, on couvrira ces cloches avec de la litiere.

Les couches ne durent gueres bonnes qu'une année ; la feconde, on les réchauffe, en rempliffant les fentiers entre les. couches, de bonne litiere chaude; c'eft ainfi que l'on remedie aux vieilles couches ou à celles qui font trop froides.

Qu'on ne s'arrête nullement à la Lune pour femer ni:pour planter, on en a déja averti: laiffons ces vifrons aux bonnes gens, nồtre fiecle eft trop éclairé pour donner dans ces conzes. On doit choifir feulement un tems commode, \& difpofé 

à la pluie, qui fervira à enterrer les graines \& à les faire germer plùtôt.

Commençons par les plantes annuelles; c'eft-àdire qui fe communiquent tous les ans par leur graine ou femence, \& diftinguons celles qui fe fement fur couche, d'avec celles qui fe fement en pleine terre.

Les graines fe recuëillent toûjourrs aux plantes les plus fortes, \& aux pieds les plus vigoureux, \& par deffus tout cela aux fleurs de la plus belle couleur; elles dégenerent tonjours affés, ainfi on ne peut les choifir trop bien : on remarquera que les fleurs doubles en general ne grainent jamais, excepté l'Amarante, la Rofe-d'Inde, le Pied-d'Aloüetre, le Pavot, le Cryfantemon \& l'Oeiller double. Ne laiffés que le maîtrebrin aux fleurs choifies, \& coupés toutes les autres tiges, afin que la graine refervée ait toute la nourriture, \& meurifle plus. furrement.

Les graines. font dans Ieur maturité $\&$ en état d'être củeillies. quand la coffe qui les renferme eft feche \& prêtre à s'ouvrir, de maniere que la graine va s'envoler. On eft fûr de leur bonté quand en les mettant dans un vafe plein d'eatr, elles vont au fond. Il y en a qui fe fement au Printemps, d'autres en Aucomne, les unes fur couche, \& les autres en pleine terre; celles que l'on attend à fenier au Printemps, fe confervent l'Hyver dans des fachets pendus au plancher de quelque lieu fec.

Les Plantes annuelles qui fe fement fur couche au PrinLes graines trop dures \&: un peu grola fes, feront rrempées un jour avant que d'être femées, cela les attendrit $\&$ les faic gonfler, fans cela elles fe. roient longa tems à lever.

Lagraine de Girofiée fe féme aufitôt reciieillie, afin que célles qui feront doubles, fe déclarent avant l'hyver, \& le priffent ferier pour lo Printems. fuivanio. temps, font:

La Girofflée double.

La Rofe-d'Inde.

L'Oeillet-d'Inde.

La Belle-de-Nuit ; ou Merveille du Perou.

L'A marante.

Le Cryfantemon, ou grande Paquerette.

Le Volubilis; ou grand Liferon.:

Le Paffe-velours, ou Queuë de Renard.
Le Tricolor blane \& noir.
Le Sain-Foin d'Efpagne.
La Balfamine panachée.
Le Stramonium, ou Pomme-
Epineufe.
Le Palma Chrifti, ou Ricinus.
Le Bafilic.
L'A mbrette, ou Chardon-be-
nit.
Lapucine, ou Creffon
d'Inde 
On Ceme au

Printemps

tane fur cou.

che que dans

les plates bain.

des, les fleurs

d'Eté \&ed'Au. romne.
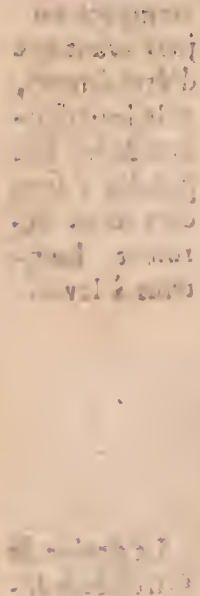

L'Amaranre, la Role d'Inde, le" Tricolor, la Ballanine, \& les autres fleurs d'A itomne veulent être piquées $50 u 6$ fois fur les couches, pour s'élargir davantage du pied, \& ne : pas inonter: fi haut.

Cette motte de terre que les fleurs ont au pied, les fait moins fouffrir dans le tranlport \& les fait " mieur reprendis:

\section{TROISIEME PARTIE, CHA P. VII.}

- Les graines que l'on feme au Printemps en pleine terré c'elt-à-dire, fur Planches, \& dans les Plates-bandes des Parterres, font lés mêmes que l'on femé en Automne: il n'y aura que la forte gelée, ou une inondation de Riviere qui puiffent retarder à les femer au commencement de Mars, car il vaut toujours mieux le faire en Automne. L'on aura foin d'éclaircir \& de farcler les fleurs fémées, quand elles font trop drüës, c'eft-à-dire, en arracher quelques-unes d'entre celles qui font en place; ces fleurs font :

Le Pied-d'Aloüette.

Le Pavot double.

Le Tálafícic annuel.

Le Soucy double.

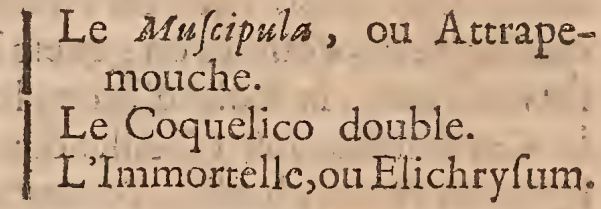

Il n'y a pas tant de difficulté à élever les fleurs femées en pleine terre \& en pots, que celles qui fe fement fur couche , lefquelles aïant environ 3 pouces de hauteur, s'accoutrument peu à peuà l'air, en élevantles cloches fur des fourchéttes de bois : dans les nuits chaudes on leve tour-à-fait les cloches, $\&$ on les remet le matin fur les fourchettes, \& cela pendant l'erpace d'un mois; lorfqueles fleurs font trop ferrées fur les couches , elles ne s'élevent pas:fi bien ; ainfi quand elles ont acquis un pert de force, on les replante en rang pendant un. tems pluvieux, fur d'autres couches nouvelles, your les hâter $\& z$ les empêcher de monter fi haut. Quand le plan eft un.peu fort, on doit bien moüiller les couches. On peut en élever quelques-unes fur des planches faute de fecondes couches. On couvre ces endroits de paillaffons la nuit pendant la gelée, \&z on les déconivire le jour dans le Soleil ; ces couvertures font foutenuës fur des fourchettes de bois, de crainté qu'elles rie touchentà rien:

- Les fleurts ontaffés d'étevation \&z débeauté un mois ou deux après, pour être tranfplantées dans les parterres o dans les vafes, alors on les leve en motte avec la houletre, \&ron lês porte doucement dans les. Plates-bandes, où on leur prèpare des trous proportionnés à leur motte. On prendra garde en falfant ces trous à la bêche, de-ne point couper d’oignon ni de plántés voiffnes ; de placer ces fleurs dans les interwales vuides qui y font jlefticés dans les Plates-bandes. 
Les Plantes \& racines vivaces, font:

Le Muffle-de Lion, ou Anthi- Oeillets fimpies \& doubles. rinum.

La Giroflée jaune.

Talafpic vivace.

oculus Chrifi, ou After - Atiticus.

Oeillet d'Efpagne.

Mignardife.

Statifée.

Sain-foin d'Efpagne.

Hepatique.

Prinevers.

Ancolie.

Matricaire:

Veronique.

Valerienne.

Rofes-tremieres.

Muguet.

Camomille.

Oeillets, ou Jacintes des Poë- Oeil - de - Bœuf, ou Buftaltes, autrement dits, Compagnons.

Campanelle, ou Clochette.

Violette de Mars.

Penfée.

Coquelourde.

Oreille-d'Ours.

Phafeole, ou poids des Indes.

I a Fleur de la Paftion, ou Grenadille.

Marguerites, ou Plaquettes.

Tournefol, Soleil, ou Heliotrope.

Jafée des Indes.

Julienne fimple.

Julienne double, ou Giroflée d'Angleterre.

Croix de Jerufalem, ou de Malthe.

Geraniunt Couronné.

mon。

Ces Plantes ordinairement ne viennent point de graine, quoiqu'on en pourroit élever quelques-unes : on fe contente d'en élever de Marcottes, de talles, \& auffi de boutures, comme la Julienne, la Giroflée jaune, l'Oeillez de Poëte \& les Marguerites ; ellesfe levent tous les ans en Automne pourles marcotter, \& $*^{*}$ couper les talles ou le peuple qui font à leur pied: comme elles font trés-vigoureufes, elles fe remettent en pleine terre außfi-tôt qu'on les a détallées.

Les Marcottes, Talles, Boutures, fleuriffent fouvent dès la même année, mais ordinairement il leur faur deux ans. pourfe fortifier \& produire de belles fleurs; on les éleve fur des planches en Pepiniere, \& même on les peut mettre tout d'un coup en place. L'on obfervera que les boutures mifes en pleine terre, feront ombragées pendant 5 ou 6 jours a vec des. 
248 TROISIE'ME PAR TIE, CHAP. VIT. paillaffons, crainte de trop de Soleil qui les faneroit; celles qui font en pots, fe mettent à l'abri. On plante ces boutures a trois doigts de terre, en laiffant toujours deux ou trois yeux dehors; on les éguife en flute par le bout qui entre en terre.

A l'égard des talles \& racines qu'on fépare du maître-pied, on le fait avec un couteau ou coin de bois quand elles font trop fortes, \& que la main ne fuffit pas. Il faut à chaque talle; pour être bonne à replanter, qu'il y ait un cil au moins, \& des racines. On recouvre enfuite avec de la cire d'Efpagne les grandes plaïes qu'on a faites en les féparant.

Les Plantes bulbeules, c'elt-à-dire, les Oignons, font :

Les Tulippes Printanieres \& Les Anemones fimples \& à tardives. péluche.

Les Narciffes communs \& dou- Les Renoncules de Tripoly. bles.

Les Narciffes de Cóntantinople.

Les Jonquilles fimples \& doubles.

Lys-flame, ou Oranger.

Lys blanc.

L'Hemerocale.

L'Iris bulbeux.

Jacintes.

Couronne-Imperiale.

Martagon.

Tubereufes.

Crocus, ou Saffran.

Ciclamen.

Baflinets, ou Boutons-d'or. I Pivoine, ou Pione.

Les meilleurs Oignons font les plus gros \& les plus fains, c'eft-à-dire, ceux qui n'ont aucune rongure ni tache; il n'y a que l'efpece inconnuë qui en fait route la difference \& le mérite. On diftingue parmi les Oignons, les Tulippes, comme lesplus confiderables, \& ce que nous en dirons, fuffira pour tous les autres Oignons en general, comme ceux de Jonquilles, de Narciffes, Jacintes, Lys, \&c. qui n'ont rien de particulierdans leur culture, \& qui ne fe puiffe raporter atx Tulippes.

Les Tulippes fe partagent en plufieurs claffes, en Printanieres, en medionelles \& en tardives, qui fe diftinguent par les faifons oì elles fleuriffent, en Tulippes de couleur qui font celles dont on recüieille de la graine; \& en panachées \& bordées, qui font les glus belles.

On 
L A PR A TIQUE D U JARDIN A GE. 249

On apelle Tulippe de coulear, celle qui marque de plufieurs couleurs pleines \& nettes fans interruption ni mélange, la Tulippe panachée eft une Tulippe de couleur qui eft raiée \& bordée de plufieurs autres couleurs qui la panachent. Celle qui revient tous les ans nettement panachée, fe nomme Tulippe parangonnée.

Les Panachées fe dittinguent encore en paltots, en morillons, en agates, en marquetrines; il y a outre cela les Tulippes, af́ées, les doubles, les raiées, celles qu'on appelle MonAtres, Dragons , Veuves, Bofuel, \& de quantité d'autres noms que chacun leur donne à fa fantaifie, commel'Impera. trice, la Triomphante, la Junon, \&c.

On eftime en general les Tulippes, quand elles font d'une couleur nette $\&$ fatinée, fans être aucunement broüillées: On leur demande le fond bleu \& les étamines noires ou violettes, les bizarres \& celles qui s'éloignent le plus du jaune \& du rouge font les plus recherchées: quelquefois elles dégenerent, furtout celles que l'on feme, d'autres travaillent à fe changer en mieux, \& c'eft ce qu'on apelle Tulippe de hazard. On met ces hazards à part pour fe rectifier, \& quelquefois ils donnent de trés-belles Tulippes au bout de deux ans. Les panachées un peu broüillées fe nétoïent fouvent l'année fuivante.

Les Tulippes ordinairement durene en fleur douze ou quinze jours, à moins quiou n'en ait planté en differends tems, pour en avoir plus longtems: elles aiment la terre fabloneufe \& legere; elles font fir robuftes, qu'elles ne craignent point la gelée' neanmoins pour conferyer lés belles, on ne laiffe pas de leur donner quelque legere couverure dans les grands froids. On les plante à la mi-Sepembre julqu'à la fin d'Oetobre, à 5 pouces à peu près l'un de l'aucre, fuivant le cordeaú, ' $\&$ tou jours au bord des-Plates bandes $:$ on les enfonce en terre environ 3 ou 4 doigts dans des trous faits avec un plantoir arondi par le bout \& non pointu, parce que les Oignons étant pofés au fond du trou, fe trouvent uniment fur la terre où ils fe peuvent lier fans aucun vuide entre-deux, au lieu que ces trous étant lier fans aucun vuide entre-deux, au lieu que ces trous étant faut Les bons
creufés en pointe, laiffent en deffous des cavités capables de oignons de. pourrir l'oignon, ou de retarder l'effet des fieurs; il. y a des Jonquilles gens qui enfoncent l'oignon à la main, qui eft une trés-mé- font tous.

Les Jonquil. les ont cela de particulier, qu'elles veulent être un peu couchées en les plan. tant : cela empêclie l'oigrion de trop $s^{2}$ alonger, qui eft leur déronds. 
Les belles

Tulippes r2ses qui fe mettent toujours à part, fe levent ordinairement tous les ans. $25^{\circ}$ TROISIE'M E P A TIE, CHA P. VII. chante pratique, car on peut écorcher \& bleffer un oignon par la rencontre de quelque pierre, ou bien en écraier le germe. L'on moüille les oignons en tems fec quand le bouton fort de la fanne, cela facilite la forcie des belles fleurs.

Les Tulippes fe multiplient de graines \& de caïeux, les graines fe prennent aux Tulippes de bonne couleur; il ne faut pas lailfer grainer les panachées ni les autres belles Tulippes, dont on doit couper les tiges après que la fleur eft paffée; l'oignon s'en porte mieux, \& la nourriture qu'il auroit fallu pour la tige \& la graine, fert à fa confervation \& à le faire grollir. On levera lesoignons tous les trois ans au plus tard, il y a des Fleuriftes qui les levent tous les ans, du moins tous les deux ans; mais le rerme de trois ans eft l'ordinaire pour toutes les fleurs. La raifon de cette levée eft, que les oignons naturellement s'enfoncent d'eux-mêmes en terre, \& fe perdent quelquefois. Si on laiffoir les oignons plufieurs années fans les lever, on en perdroit beaucoup \& la beauté des fleurs diminueroit au lieu que quand les oignons font replantés de tems én tems, les fleurs fé reffentent de ces remuémens, \& d'une nouvelle terre fouvent labourée \& fumée.

La faifon la plus propre à cer ouvrage eft depuis le commencement de Juin juf́qu'a la fin de Juillet, pendant un tems doux \& fec, quand on voit la tige \& la fanne des oignons fe fécher; on fe fervira de houlettes ou de déplantoirs, pour les tirer adroitement de terre, en prenant garde de rien couper.

Les oignonsétant tirés, on les érale fur quelque plancher pendant huit à dix jours, pour fe refluier de l'humidité. des terres; enfuite on les met dans des fachets, dans des boïtes, \& encore mieux dans des paniers pour avoir plus d'air.

On attendra jufqu'au tems convenable à replanter ces oignons, pour les examiner, les éplucher, les nétö̈er, \& couper jufqu'au vif les endroits pourris \& rongés par les infectes; c'eft afin d'empêcher que les oignons ne fouffrent dans leur dépoüille, en fe gâtant l'un contre l'autre, pour peu qu'ils saprochent dans les paniers. On détache alors avec la main les cä̈ex, cequ'on apelle, fevrer un oignon de fá mere. 
LA PRATIQUE DU JARDINAGE. 2SI

Pendant les trois ans que les oignons reftent en terre, les caïeux ont le tems de fe former \& de fe fortifier, de maniere qu'une partie fait des oignons portant dés la même année; ceux qui ne font pas affez forts, fe plantent dans une planche en pepiniere, qu'on cultive bien \& dont on leve de tems entems quantité de fleurs portantes.

On remarquera que les oignons qui n'ont point de robe, comme ceux de Lys, de Martagon, Hemerocale, Iris, Couronne Imperiale, Crocus, \&c. refteront toûjours en terre; on les levera feulement pour en ôter les cäieux, \& on les replacera auffi-tôt.

Les pattes d'Anemone \& les griffes de Renoncule font des efpeces d'oignons, qui fe tirent tous les ans, à la difference des autres qui ne fe levent comme l'on a vî, que tous les trois ans. Ces pattes \& ces griffes, fans cette précaution. feroient fort expofées à pourrir \& à dégénerer, elles fe choififfent comme les oignons, \& fe confervent de même dans des paniers, aprés les avoir étenduës quelques jours fur un plancher pour les laiffer efforer. Avant que de les replanter, on les nétoöera de leur pourriture, \& l'on en détachera les cä̈eux.

Les A nemones \& les Renoncules demandent une terre parriculiere femblable à celles des Tulippes, moitié terre-neuve, l'autre motié de fable \& de terreau, pour compofer úne serre féche \& legere; cela eft fort bon aufli pour les belles Jonquilles; telles ont encore une fingularité qui leur eft affectée, c'eft de vouloir être toutes feules dans une place, fans aucune mélange d'oignons ni de plantes. On les plante dans les mois de Septembre \& d'Oatobre, de même queles autres oignons; enfuite on les faupoudre de terreau; elles ne veulent gueres d'eau, \& elles ne craignent que les fortes gelées. pendant lefquelles on les couvrira de paillaffons ou de grande liciere; on tirera les belles aufí-tôt que la fleur fera paffée. \& que leur fanne jaunit.

Nous avons des Anemones fimples, de nuancées, de veloutées ou à peluche, de doubles, de bizarres luftrées, \& de panachées qui font les plus belles; on voit pareillement des Renoncules fimples d'une couleur \& $\&$ de deux couleurs . de doubles d'une conleur $\&$ de deux conleurs \& de pana- 
II $\mathrm{y}$ a des gens qui fe. ment dans de longues caiffes, pour être plus fûrs de la confervation de la graine.

2\{2 TROISIEME PARTIE, CHÄ. VII. chées qu'on eftime toûjours plus que les autres. Elles fe multiplient en féparant les petites pattes \& griffes qui viennent autour de la grande; \& aprés les avoir detachées, on les plante en pepiniere fur une planche de même que les cä̈ux, hormis celles qui font fortes, \& peuvent porter l'année fuivante; l'on en peut élever aufi de graine.

La graine d'Anemone s'apelle Bourre, à caufe qu'elle tient fi fort qu'il la faut mêler avec de la terre pour la detacher, avant que de la pouvoirfemer. Celle de Renoncule reflemble affez à la graine de Giroflée, mais elle eft un pea plus épaiffe. On la recueille toûjours aux Anemones \& aux Renoncules fimples de bonne couleur.

Il eft inutile de dire, que les pattes \& les griffes comme les cä̈ux, confervent la qualité de l'oignon dont on les. détache; \& que pour en avoir de differente efpece \& en quantité, l'on en éleve de graine que l'on garde jufqu'au mois d'Aouft, pour la femer fur une planche bien préparée en la maniere fuivante. Uniffez d'abord la terre avec une baguette, femez à claire-voïe vos graines \& faupoudrez-les de terreau; ne les couvrez d'abord qu'à demi pour les retenir, \& recommencés à femer là-deffus; faupoudrés encore cetre feconde femence, jufqu'à ce qu' elle foit couverte entierement environ d'un pouce d'épaiffeur, uniffés enfuite la terre avec la baguette, couvrés la planche de grande paille legerement, crainte du Soleil, \& arrofés par deflus. Au bout de Is jours ôtés cette paille fous laquelle la graine doir être levée, foignés de bien farcler cette planche pour tenir vos graines netres, \& couvrés-les dans les fortes gelées de l'Hyver. La feconde année quand les graines qui forment des pois, unt pouffé léur feconde fanne, \& qu'elle eft féchée, on les tire hors de terre, onles conferve dans du fable, \& on les replante l'A uromne fuivance fur une autre planche neuve, ce qui les avancera beaucoup à Heurir, car il faut quatre ou cinq ans au moins à ces graines, pour être en caïeu, patte \& griffe, formant un oignon portant fleurs.

Cette pratique fervira pour femer les graines de Tulippes, Narcifles, Jonquilles, Jacintes, \&c. ainfr pour éviter les redites, on reviendra à cet endroit.

Il y a de certaines fleurs qu'il elt plus à propos d'élever de 
LA PRATIQUE DU JARDINAGE. 253 ca ieux que de graines comme la Tulippe, l'A nemone, la $R$ e. noncule, les Narciffes, \&rc. des plantes qu'il vaut mieux aufi marcotter ou détaller, comme * l'Oeillet, la Julienne, ** l'Oreille-dOurs, \&c. elles en deviennent infiniment plus belles \& font plus fures. Le Caieu ou la Marcote ne donnent qu'iune feule fleur qui tiendra toûjours, fans beaucoup dégénerer, de la beauté de la plante ou de l'oignon quil'a engendré jainf c'eft un fur moïen de conferver l'épece des belles Tulippes panachées, des Anemones doubles à peluche, des Renoncules doubles de deux couleurs, des Juliennes doubles, des Oreilles-d'Ours panachées, \& c, au lieu qu'une plante, qu'un oignon qu'on a laiffé grainer en peuvent donner une grande quantité, dont la beauté eft fort incertaine, le plus fouvent de mauvailes efpeces fort à rebuter, quelquefois auffi de tresbelles \& de tres-variées dans les couleurs. Ces graines donnent feulement des Tulippes, des Anemones \& Renoncules fimples de couleur fantalque, \& de hazards, en un mot qui peuvent travailler en bien ou en mal.

On ne doir prefque referver que les fleurs panachées \& les doubles, \& quelques fimples, tant pour en avoir de la graine, que parce que leur mélange fert à faire valoir la beauré des doubles, qui font toûjours plus délicares \& plus tendres que les autres, \& par confequent demandent un peu plus d'attention.

Les fleurs en general exigent de certains foins, tant pour les élever, que pour les multiplier. Celui de les vifiter tous les matins à la rofée, n'eft pas un des moindres; on les netoie par-là des infećtes qui les attaquent, fur tout des limaces, punaifes, perce-oreilles \& toiles d'araignées, qui gâtent toutes leurs belles couleurs: Elles font d'une nature trop foible pour y pouvoir refifter d'elles-mémes.

On remarquera qu'il faut arrofer les fleurs aufítôt qu'elles font plantées \& les encretenir d'eau dans la fuice; l'on prend pour cet ouvrage le marin ou le foir, le foir vaut encore mieux que le matin, parceque la fraîcheur s'entretient plus long-iems la nuic \& dute jufqu'au lever du Soleil, les naiffantes demandent peu d'eau, leulement pour plomber les terres en les plantant; mais quand les fleurs font devenuës fortes, il leur faur beaucoup d'eau; il y a prefque toûjours pour cet

* Lsoeillet fe marco:te toujours: On le fend \& l'on couche les branches toue autour. On peut encore l'oëilleron. ner.

$* *$ L'Oreille d'Ours eft la fleur la plus changeante en couleur \& la plus vartée que nous ä̈ons.

On fe Cervira d’arrofoirs aे goulor, au lieu de ceux à pormme per. cés de plufieurs trous: ils lavene moins la tige \& les feiilles d'une fleur qui par fa dé. licateffe pourroit être fanés aufír tôt par le soleil. 11 ne lui faut de l'eau qu'all pied.

$$
\text { Ii iij }
$$


effer un bafin dans les Parterres fleuriftes $\&$ dans les melonieres où l'on éleve les fleurs.

On doit garentir les fleurs nouvellement plantées, de trop de Soleil pendant 5 ou 6 jours en couvrant avec des paillalfons celles qui font en pleine terre, $\&$ mettant à l'ombre les fleurs emportées.

- Les Plates-bandes de fleurs veulent être farclées de tems en tems \& trés-nettes de toutẹs ordures, la terre en fera tenuë en labour propre \& fouvent rafraîchi; dans les orages qui ravagent les fleurs, on aura foin de relever avec de petires baguettes celles qui feront batuës \& renverfées, comme auffi celles qui font montées trop haut $\&$ font trop foibles pour fe foutenir.

Il eft abfolument neceffaire pour la beauté \& la confervation des fleurs, d'obferver ce qui fuit. Quand on s'aperçoit qu'une fleur a trop de cä̈eux ou trop de peuples, enforte que fes fleurs font tres-petites \& en trop grand nombre, il les faut déplanter dans l'anuée pour les fevrer, en détachant les cä̈eux, \& feparant le peuple qui eft au pied, fans cela les Plantes avorteroient \& periroient à la fin.

Il faut encore tâche $r$ de n'aprocher jamais les Plates-bandes de fleurs, fi près d'un bois, d'une grande paliffade \& de hautes allées d'Ormes ou de Tillots, dont les racines délféchent toutes les terres d'alentour \& les ufent entierement. Sil'on ne peut - leur donner une autre place par raport à la fituation du terrain, \& à la difpofition du deffein, on fera faire tous les cinq à fix ans une tranchée dans le milieu de l'allée attenant la Plate-bande, \& l'on coupera à trois pieds de bas toutes les racines \& les traînaffes de ces arbres: car fans cela les fleurs ne réüfliroient point \& ne feroient pas long-tems à mourir.

Parlons maintenant de la piace convenable à toutes les fleurs, \& des differentes décorations qu'elles forment dans chaque faifon de l'année. 


\section{LA PRATIQUEDU JARDINAGE. 255}

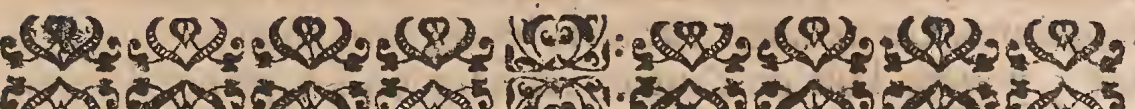

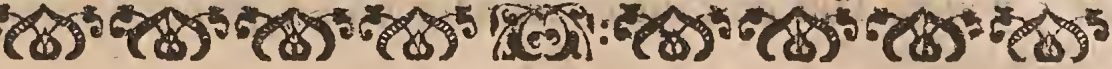

\section{H A P I T RE VIII.}

\section{$D E \quad L A$ PLACE CONVENABLE} à chaque Fleur dans les $\mathcal{F}$ ardins, $\sigma$ des differentes décorations des Parterres Juivant les Saifons.

COMM il y'a des Fleurs plus hautes les unes que les autres, on en a fait trois claffes differentes; les Fleurs de la grande efpece, celle de la mö̈enne, \& les baffes ou naines: Cetre diftinction eft fort néceffaire pour ne les pas mêler confufément les unes avec les autres; car les hautes. étoufferoient indubitablement les baffes; \& les moïennes en feroient alterées; ainfi l'on doit aporter quelque ordre en les plaçant dans les plates-bandes.

On prétend que la vraie place des Fleurs eft fixée par l'expofition qui leur convient le mieux, qui eft le Levant; cependant on ne peut pas toujours teur donner cette expofition dans les parterres, dont les places font deftinées de maniere à ne pouvoir être changées par raport aux bấtimens. Cette obfervation n'eft. bonne que pour les perites planches des Fleuriftes qui élevent des fleurs rares, car. dans un grand Parterre cela devient inutiles; il faut que les. fleurs'l'enveloppent de tous cốtés \& viennent en differentes fituations à caufe de la fimétrie, furtout dans les découpés \& dans les Parterres de compartiment.

Pour arranger les fleurs dans les Plates-bandes qu'on fu-' pofe être bien preparées \& bien dreffées, on tracera en grille des traits en longueur de 4 à 5 pouces de diftance, recroifés par d'autres, le tout tiré au cordeau. Les Plates. bandes de 6 pieds de large, pourront contenir 4 rangs d'oignons de chaque côté, c'elt-à-dire, 8 en tout ; maís dans les Plates-bandes de 3 à 4 pieds, 2 rangs de chaque côté fuffifent, parce qu'on y doit conferver des places dans 
2.56 TROISIE'ME PARTIE, CHAP. VIII. le inilieu pour les fleurs \& les plantes cu'on tranfporte dans les faifons. On arrange fur terre les oignons en échiquier à 4 ou 5 pouces l'un de l'autre, enfuite on les plante dans le même ordre.

Quand on a 4 rangs de chaque côté, on peut faire les deux proche du trait de buis tout de Tulippes, qui s'enfonçant de leur naturel, en font empêchées par une terre plus"ferme près du buis; que dans tout le refte de la platebande; les deux autres feront mêlés de Narciffes, \& de Jacinces. Voila les trois efpeces d'oignons de fleurs mö̈ennes qu'on plante dans les Parterres. Lorfqu'on ne peut avoir que deux rangs d'oignons, par raport au peu de largeur de Ia plate-bande, il y en aura un de Tulippes \& l'autre de Narciffes \& de Jacinthe, ou bien l'on peut mêler les oignons enfemble, c'eft-à-dire, une Tulippe, une Narciffe, une Ja. cinte l'une après l'autre, ce qui ne faic pas mal. On peut aufi mêler les fleurs de l'rintems \& d'Efté pour profiter de la place ; toujours les oignons avec les oignons, \& les planies avec les plantes.

On remplic les grands vuides du milieu des Plates-bandes, par le mö̈en des If́s moulés \& des Arbriffeaux de fleur taillés en boule, fans cependant rien gâter, car ces Arbuftes font entretenus perits par le moïen d'une tonture frequente. On met éncore dans ce milieu, les plantes des fleurs de moïenne taille, comme le Muffle de Lion, le Crifantemon, la Rofe-d'Inde, l'Oeillet de Poëte, l'Amarante, \&c. \&x les gros oignons de Lys, de Couronne Imperiale, de Marcagon, \&c. Il ne faur jamais mettre de plantes fur les bordures qui font refervées pour les oignons en les plantant \& en les labourant, on rifqueroit d'en couper beaucoup.

Ce milieu feroit auffi la vraïe place des Fleurs de la grande efpece, comme l'on faifoit autrefois; mais elles. font fi défagréables a la vî̀ par leur hauteur qui offufque tout un Parterre, quon les en doit bannir entierement, ainfi quon a fait les grands Ifs a les Arbriffeaux. Cesfleurs font laR ofetremiere, la Gigantine, la Pyramidale, Volubibilis, Fleur de la Paflion, Tournefol, Capucine, Phafeole, \&c. qui demandent à êtrefoutenuës par des bâtons aufquels on les attache. Ces grandes Fleurs conviennent mieux à couvrir des 
murs, fe paliffant bien contre le treillage, foit dans une Cour, ou dans un petit Jardin de ville, ou à mettre en touffes entre les rangs des arbres ifolez.

A l'égard de la troifiéme efpece de Fleurs qui font les baffes ou naines, elles ne font aucun effet dans les grands parterres, étant couvertes \& étouffées par les autres ; elles ne font propres que dans de petites plates-bandes \& pieces coupées où elles ne foient point mêlées avec les moyennes ni les hautes Fleurs : telles font l'Oreille-d'Ours, la Violette de Mars, les Marguerites, Pensées, Baffinets, Hepatiques, Primevers, Ciclamen, Crocus, Mignardife, Statifée, Camomille, dont on peut faire encore des bordures, des fentiers, \& des tapis entiers émaillez de Fleurs.

Les Anemones, les Renoncules, \& les Jonquilles font du nombre des Fleurs baffes; elles veulent auff être feules dans quelque piece coupée \& tapis émaillé, ou dans les volutes de la nailfance d'un grand parterre. On leur fera une place vuide de tous autres oignons \& plantes, \& elles occuperont entierement la plate-bande tant dans le milieu que fur les bords.

La Giroflée double, l'Oeillet, la Tubereufe, fe mettent rarement en pleine terre; elles s'élevent bien mieux dans des pots \& des vafes de fayance, où l'on peut aufifi.mettre des fleurs de faifon, comme des Amarantes, des Tricolor, Balfamines, \&c. pour fournir dans toute l'année.

Il eft aisé de voir, que les fleurs moyennes font les plus recherchées, c'elt-à-dire, celles qui s'élevent à un pied \& demi ou deux au plus, elles marquent fort bien de loin, \& ne gâtent nullement la vî̈ë : ce font aufli celles dont nous avons un plus grand nombre.

Sans s'arrêter à nommer les fleurs qui fleuriffent dans chaque mois, ou à en faire de grands* Catalogues, ou elles font repetées la plûpart durant plus d'un mois, nous les diftinguerons par les faifons où elles fleuriffent, defquelles nous exclurons l'hyver, comme l'ennemi le plus cruel aux. fleurs. Nous aurons donc le printems, l'efté \& l'automne, \& ces trois faifons donneront lieu aux trois décorations de fleurs dont on embellit les parterres pendant l'année, c'eft-à-dire que les parterres changent trois fois dans une année, formant.

* Morin. * Le Jardo arier Fleugifere. 


\section{TROISIE'ME PARTIE, CHA P. VIII.}

zrois différens afpectsou fcénes de fleurs. Ainfi il y a la décoration du Printems, la décoration de l'Efté, \& celle de. l'Automne.

La décoration du Printems eft la pluts gaye, \& l'une des plus agreables aux yeux; mais elle eft de peu de durée parla délicateffe de fes fleurs. La décoration d'Efté eft la plus: riche \& la plus confiderable par la quantité \& la diverfité de fes fleurs. Celle de l'Automne eft la plus belle \& la plus: durable, quoiqu'elle foir prefque dénuée d'oignons \& de: fleurs qui croiffent naturellement dans les plates-bandes.

Par cet artifice les Parrerres de Tria.won changeoient autre. fois de fleurs rous les quinze jours.

* On en 2 marqué les places dans les figures de 1. Ie \& dela ate Partie.
- Tes Plates bandes des. Tuilleries font fort bien garnies en iour rems, quoique de Aeurs communes, \& peu. vent fervir d'exemple de ce qu'on dit isi.

On pourroit avoir des décorations plus fréquentes par le: moyen des pots, en changeant tous les mois les parterres, \& les garniffant de fleurs empotées, que l'on enterre dans. les plates-bandes jufqu'au bord des pots; ce qui furprend \& trompe de maniere, que l'on croiroit ces fleurs élevées: en pleine terre : mais cela eft fort extraordinaire \& d'une grande dépenfe.

Il y a encore une autre décoration de fleurs qui ne regarde point les parterres, c'eft celle des * theâtres de fleurs . qui: ne confifte que dans le mêlange des pots avec les caiffes. ou dans l'arrangement que l'on en fait par fimetrie, fur des gradins \& eftrades de bois ou de gazon. Toutes les fleurs y conviennent affez, principalement l'Oeillet, la Tubereufe, l'Amarante, la Ballamine, le Tricolor, \& la Girofée. Ces: gradins \& ces amphithéâtres de fleurs changent felon les faifons, de même que les Parterres.

Il ne faut point s'arrêter dans le choix des. fleurs, à leur rareté, à leur cherté, \&z à la bonne odeur qu'elles exhalent. La rareté \& la cherté ne font pas toujours ce qui rend une fleur belle, \& l'odeur n'eft pas ce qu'on doit rechercher dans les grands parterres, dont les plates-bandes pourêtre eftimées belles, doivent être bien garnies toute l'anmée fans interruption:, ni aucun vuide : l'abondance des fleurs, leur durée, la varieté, la fimétrie, le mêlange émaillé de toutes fortes de couleurs, ce font les vrayes beautez de nos * plates.bandes, \& tout ce qu'on doit fouhaiter dans un grand Parterre. L'on conviendra que les fleurs communes marquent fonvent plus de loin que les doubles. Ainfi 11 faut avoir des unes \& des autres, \& des rouges \& blanches de 
I A PRATIQUE DU JARDINA GE 259 chaque efpece pourfaire opofition. Si l'on a cependant quelques belles fleurs rares, on les peur élever féparément dans de perits endroits, conme pieces coupées \& plates-bandes de quelque petit parterre defleurs. Venons à nos décorations \& à nommer les fleurs de chaque faifon.

Dans le Printems les oignons plantés \& les graines femées en pleine-terre dans l'Automne precedente, fourniffent les plates-bandes ; l'Efté d'autres oignons \& les graines femées au Printems en pleine terre, \& d'autres fur couche que l'on tranfporte en May, fourniffent de même les Parterres; l'Automne il y a peu d'oignons, mais beaucoup de fleurs femées fur couche \& fur planches dès le Printems, \& que l'on porte tout enmotées; dans les plates-bandes en Juillet.

Vous aurés pour premiere décoration au Printems, c'eftà-dire, pendant les mois de Mars, d'A vril , \& de May, peu de plantes, mais beaucoup d'oignons, comme Tulippes hatives de toutes | Jacintes de toutes fortes:
fortes.

OrgnONe,

Pattes, 8c

GRIEFES.

Anemones fimples \&z doubles Narciffes fimples \& doubles.

à peluche.

Renoncules de Tripoly.

Jonquilles fimples \& doubles. Couronne Imperiale.

Baffinets, ou Boutons d'or. ISafran, ou Crocus printanier.

\begin{tabular}{l|l}
\hline Oreilles-d'Ours. & doubles. \\
Hepatiques. & $\begin{array}{l}\text { Primevers ou Paralyfe. } \\
\text { Penfées. } \\
\text { Girofletes de Mars. } \\
\text { Girofées jaunes, }\end{array}$ \\
Vimples \& & $\begin{array}{l}\text { Marguerites, ou Plaquettes. } \\
\text { Muguet. }\end{array}$
\end{tabular}

La Décoration de l'Efté qui contient les mois de Juin, de Juillet, \& d'Août, eft moins abondante en oignons, mais aufi elle eft trés-riche en plantes \& en racines.

Tulippes tardives.

Lys blancs.

Lys orangers, ou Lys-flame. Martagons.
Pivoine, ou Pione.

Hemerocales; ou fleurs d'un orenons \&s

PALTES.
Plantes a

RACIABS. jour.

Tubereufes.

\section{$\mathrm{K} \mathrm{k} \mathrm{ij}$}


260 TROISIE'ME PAR TIE, CHAP. VIII.

Prasres \& Veronique.
Racines.
Campanelle, ou Clochette.

Croix de Jerufalem ou de Malthe.

Oeillets de diverfes efpeces.

Mignardife.

Sain-Foin d'Efpagne.

Coquelourde:

Jacée des Indes.

Girolée jaune.

Talafpic annuel.

Pavot double.

Pied d'Aloüette,

Balfamines.

Oeillet d'Efpagne.

Oeillet, ou Jacinte des Poëtes;

autrement Compagnons.

Ancolie.

Matricaire.

Vallerienne Grecque.

Coquelico double.

Camomille.

Mulcipula, ou Attrape-mouche.

Cryfantemun, ou grande $\mathrm{P}_{2}$ : querette.

Muffle de Lion, ou Anthirinum.

Soleil, Tournefol, ou Helio- Immortelle, ou Elichryfum. trope.

Julienne fimple.

Julienne double, ou Girofflée Statifée.

d'Angleterre.

Bafilics fimples \& Panachés.

Oeil de Boeuf, ou Buftalmon.

L'Automne comprend les mois de Septembre, d'Octobre \& de Novembre, il y a peu d'oignons dans fa décoration . mais quantité de plantes.

Oronons. Tubereufe.

Crocus, ou Saffran automnal.

Prinisas \&e After Atticus ou Oculus Chrifti.

RsCiNas. Palma Chrifiz; ou Ricinus.

Soucy double.

Belle-de-nuit, ou Merveille du Perou.

Amarantes de toutes fortes.

Paffe-velours, ou queuë deRenard.

Tricolor blanc \& noir.

Rofes d'Inde.

Oeillets d'Inde.

Vallerienne.

Ciclamen automnal.

Balfamine panachée.

Stramonium, ou pomme épineufe.

Cryfantemum, ou grande Paquerette.

Anthirrinum, ou Muffle de Lion.

Geranium couronné.

Talafpic vivace.

Tournefol, ou Soleil vivace:

Ambrette, ou Charbon benît.

Quoique l'on ait exclus la faifon del'Hyver pour les fleurs, 
L A PRATIQUE DU JARDINAGE. 26 I neanmoins, comme dans les petirs Jardins de ville que l'on habire en ce tems, on fouhaite quelque fleurs, malgré la rigueur des mois de Decembre , de Janvier \& de Fevrier, voici celles qu'on peut avoir.

Anemones fimples.

Ciclamen hyvernal.

Jacinte d'Hyver.

Crocus Printanier.

Narciffes fimples.

Perceneige, ou Leucoyon.

Primevers.

\section{Hepatiques.}

Il y a encore bien d'autres fortes de fleurs qui font de peu de conféquence, \& qui ne fervent qu'à embaraffer l'efprit d'un particulier, ou bien à groflir les Livres des Fleuriftes; on n'a mis ici que les fleurs les plurs belles \& les plus connuës d'un chacun, afin que la culcure \& la recherche en foient plus aifées. L'on a encore marqué les differens noms qu'on leur a donnés, pour en laiffer une idée plus diftincte.

On peut avoir dans l'Automne, des Anemorres \& des Renoncules, fi on les a plantées un peu tard, \& même l'on peutdire en general, qu'on eft fùr d'avoir prefque de toutes les fleurs en les femant à differentes fois \& à un moisl'une de l'autre, ce qu'on peut encore obferver pour bien garnir \& fournir chaque faifon. Mais quoiqu'on puife femer \& planter les mêmes fleurs dans differens tems pour en avoir pendant toute l'année, il eft certain qu'elles ne viennent jamais fi belles, que dans la faifon qui leur eft affectée. Il y a cependant quelques fleurs, quoique de la même efpece, qui ont un genie different; car l'une eft hâtive ou printaniere, l'autre tardive ou autommale, comme le Crocus \& le Ciclamen, dont il y en 2 un printanier, \& l'autre automnal.

Comme il eft impoflible d'éviter quelque dégarni dans les. décorations de fleurs, foit d'un oignon mort ou d'une plante qui n'a pas repris, on doir a voir des referves de toutes les fleurs, tant en pots que fur des planches, pour regarnir \& remplacer les vuides de chaque fairon. Il n'en faut pas quantité, mais c'eft une chofe effentielle d'en avoir, On verroit des plates-bandes vuides en certains endroits, fans y pouvoir remedier de l'année, faute de cette precaution.

FIN DE LA TROISIE'ME PARTIE.
OIGNONS.

Plantas. 8 RACINES,

Il y a des fieurs qu'on peut faire fleurir plufieurs mois de fuite, en coupantlears tiges quand la fieur eft pafrée, tels font le Muffle de Lion, le Crifantemum, la Matricaire, la Girofiée, \& $c_{a}$ 


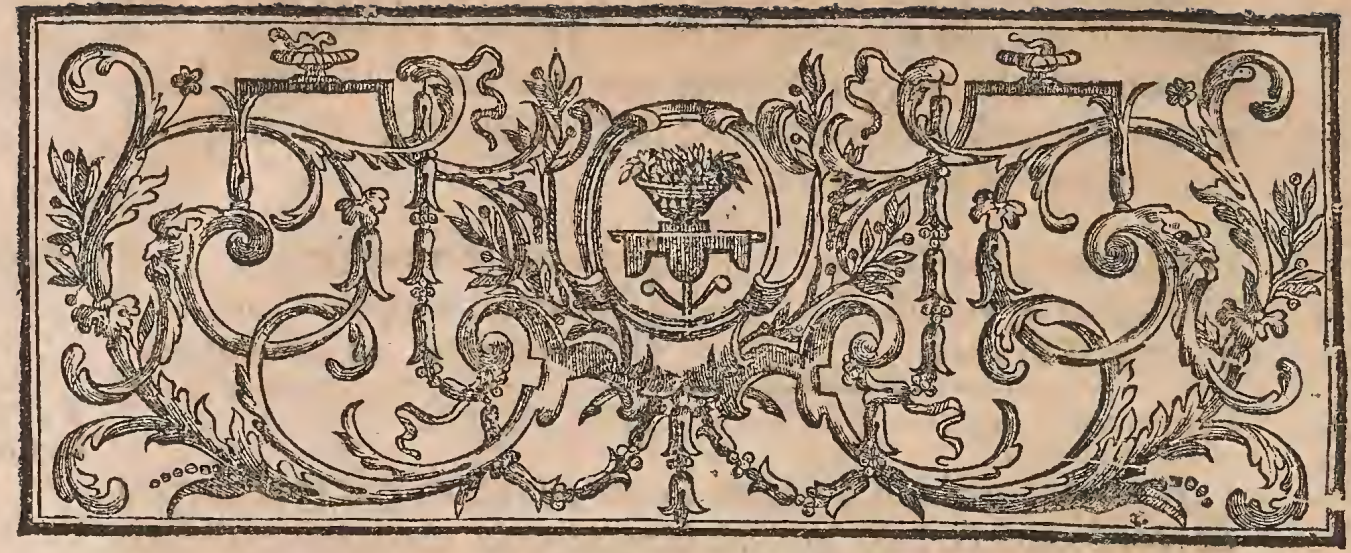

\section{QUATRIEME PAR TIE QUI CONTIENT \\ UN TRAITE' SUCCINT \\ DE S E A UX ET DES FONTA INES}

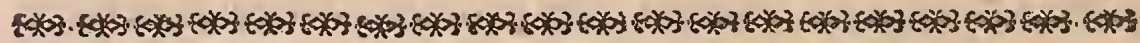
C H A P I T R E P E M I ER.

DELA RECHERCHE DES EAVX, o des differentes manieres de les conduire dans les Jardins.

Aqu nutrix omnivan Virgultormm, eb diverges fingulis un wiziftrat.

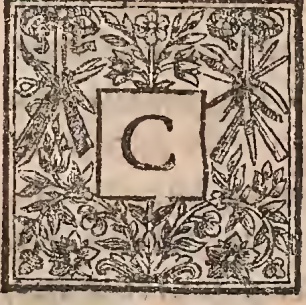

OMM E la néceffité d'avoir de l'Eaudans les Jardins eft indifpenfable, fuivant ce que nous avons dit dans le Chapitre ze de la ie Partie, il ne fera pas hors de propos d'en parler dans ce Traité, le plus fuccinctement que le peut permettre une matiere auffi ample, \& qui demanderoit feule un Traité particulier.

Les Eaux des Fontaines \& des Baffins viennent ou de fources naturelles, ou de machines qui élevent les Eaux; parlons premierement des fources \& de la maniere de les trouver. 
Sil'on eft voifin de quelque montagne ou côtear, l'on eft prefque für d'y trouver des fources, à moins que ce ne foit un Pays fec \& fabloneux; on examinera premierement les herbes qui couvrent la terre, fi ce font des.Rofeaux, Creffons, Baumes fauvages, Vitez, Argentine, Joncs \& autres. herbes aquatiques; ce fera. une marque affurée qu'il y a de l'Eau dans ces endroits, pourvî que ces herbes y croiffent bien d'elles-mêmes.

On peut connoîre les fources cachées, en fe couchant avant le lever du Soleil, le ventre contre terre, ayant le menton appuyé, \& regardant le long de la Campagne, fi l'on voit en quelque endroit une vapeur humide s'élever en ondoyant, on pourra y faire foüiller.

D'autres difent que des. nuées de petites mouches, qui volent contre terre à un même endroit, font des fignes certains qu'il y a de l'Eau, ou bien qu'on n'a qu'a enfoncer de longues terrieres de fer, qui étant retirées, font juger de ce qui elt compris fous la terre.

On obfervera que les endroits où feront ces herbes, \& oiz l'on verra s'élever des vapeurs, ne foient point humides dans leur fuperficie, comme feroit un marais : car il feroit inutile d'y faire foüiller, ces. Eaux ne provenant point de fources, \& n'étant que des amas de pluyes \& de neiges fonduës. On.a été fort longtems trompé par certaines gens, qui prétendoient trouver des Eaux, par le moyen d'une baguette de Coudrier, apellé Divinatozre, qui étoit une grande abfurdité : cependant elle a eu, \& a encore des * Sectateurs, mais en petit nombre.

Sans s'arrêter aux fentimens des Anciens, l'expérience nous aprend, que le feul alpect du terrain fuffit pour faire connoître s'il y a de l'eau dans un endroit, en examinant la fituation \& 1 a nature des terres.

La fituation la plus heureufe pour les fources, eft la my-côte commandée par beaucoup de hauteurs voifines, qui deviendra en ce cas l'égoût de toutes. les fources, eaux de pluye \& neiges fonduës dilpersées dans ces terrains élcvés. Pour ce qui eft de la nature des terres, on les doit trouver de couleur blanchâtre ou verdâtre, comme font les terres glaifeufes, lefquelles par le fommet d'une montagne, \& par le moyendes.

Vitruve Liv. 8. Chap. I.

Le P. Kircwer, $M$ undus: Substranewsor

Cafriodore:

L'Art des Fontaines du P. Jean François, Jefuire:

Palladius

* Vallemon" Phyfique osculte. 
264 QUATRIEME PARTIE, CHAP. I. caux qui s'y gliffent, fe remuent \& font poufsées à my-côte, ce qu'on diftingue aifément par les lits aparens de crayon \& de glaife.

Il y a encore plufieurs manieres de chercher les fources cachées, mais on les pafiera fous filence, auffi-bien que plafieurs Obfervations fur l'Origine des Sources, fur les Machines Hydrauliques, fur le Nivellement, la Jauge des Eaux, \&c. ou l'on travaille préferitement, \& dont on pourra faire part au Public dans la fuite.

On fait ordinairement la recherche des Eaux dans les mois d'Août, Septembre \& Octobre, à caufe qu'en ce tems, la terre étant déchargée de toutes fes humidités, eft plus $f^{\prime} c^{\prime} e_{2} \&$ que toute l'Eau qui s'y trouve, fe peut apeller Source.

Supofons donc que vous ayez trouvé de l'Eau en plufieurs endroits d'une montagne, faites faire des puits ou puifarts de diftance en diftance, tant pour connoître la quantité d'Eau, que pour en fçavoir la profondeur jufqu'au lit de glaife ou de tuf qui la retient, lequel lit il ne faut jamais percer, de crainte de perdre la Source. Cherchés toujours les endroits les plus élevés, afin de prendre la Source dans fon origine, \& que les Eaux venant de plus haut, s'élevent davantage dans les Jardins. Faites faire une communication d'un puits à l'autre par des pierrées bâties à pierres féches pour laiffer tranfpirer les Eaux , \& ramaffer les pleurs des hauteurs voifines. Choififfés un endroit de terre un peu plat, pour y raffembler toures ces Eaux dans un Réfervoir, d'où vous les conduirés par des tuyaux, aux places deftinées pour les Fontaines \& Jets d'Eau ; $\&$ pour connoître quelle hauteur auront ces Jets, provenans de l'endroit oì vous devés faire le Réfervoir, yous nivellerés cette côte felon la pratique fuivante.

On ne donnera ici que l'ufage d'un Niveau apellé communément, le Nivèau à Fioles, le plus jufte \& le plus fimple de tous.

C'eft un grand Tuyau de fer blanc d'un pouce de grofieur, \&x de trois oll quatre pieds de longs, comme $A A$, fig. I. fouttenu dans fon milieu par les liens de fer $B B, \&$ par la doüille $C$, qui fert à ficher un piquet quand on veut s'en fervir. Sur 
Le deffus de ce tuyau, aux deux extremités $\&$ dans le milieu, on foude trois

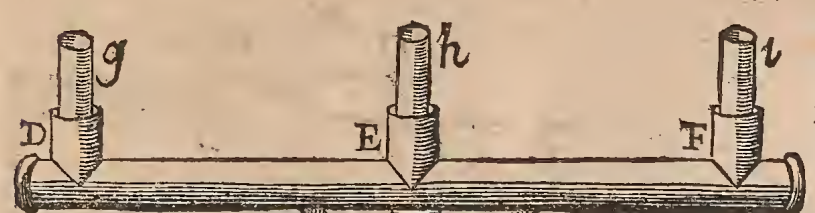

autres bouts de tuïau qui fe com. muniquent l'un l'autre comme $D$ A

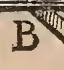

Fig.T.
Y

$\mathrm{B}$

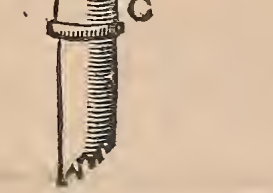

A dans chacun de ces tuyaux, les Fioles de verre $g h i$, ̀̀ peu près du même diametre : ces Fioles

font ouvertes par les deux bouts. On les joint a vec de la cire ou du maftic à fes trois tuyaux, en forte que l'Eau remonte dans ces Fioles, fans fe perdre par aucun endroit.

La perfection qu'on a donnée depuis peu à cet Inftrument, eft que le tuyau du milieu $E$ qu'on a ajouté, étant hors de l’alignement de ceux des deux bouts $D \& F$, \& en étant écarté environ de deux lignes, fert de pinules \& dirige beaucoup mieux le rayon vifuel.

Pour en venir à l'ufage de ce niveau, il faut fupofer la montagne $A$, Fig. 2. page fuiv. au fommet de laquelle on a ramarsé des Eaux dans le Réfervoir $B$, que l'on veut conduire au bas de la montagne comme en $C$, pour y faire joüer une Fontaine. Voici la pratique de niveler cette montagne.

Pofés le niveau at haut de la montagne $A$, comme au bord du Refervoir $B$; mettés-le le plus droit qu'il fera poffible, \& pointés-le vers le bas $C$ où vous devés faire le nivellement. Prenés de l'eau où vous mêlerés du vinaigre, afin qu'elle devienne colorée, \& fe puiffe diftinguer de loin : empliffés-en le tuyau de maniere que l'Eau remontant dans les trois Fioles, il y refte un peu de vuide par deflus. Laiffés repofer l'Inftrument jufqu'à ce que l'Eau ne balance plus; ayés même la précaution de couvrir avec du papier l'ouverture des Fioles, de peur que le vent ne caufe quelque agitation à l'Eau. Prenés enfuite une longue perche, au bout de laquelle il y ait un carton blanc bien équari; faites-la tenir par un homme à

On peut le fervir aufi d'une double toife, felon la maniere des Ingenieuss. L 1. 
266 QUATRIE'ME PAR'TIE, CHAP. I. quelque diftance du Niveau, comme en $D$, en la faifane

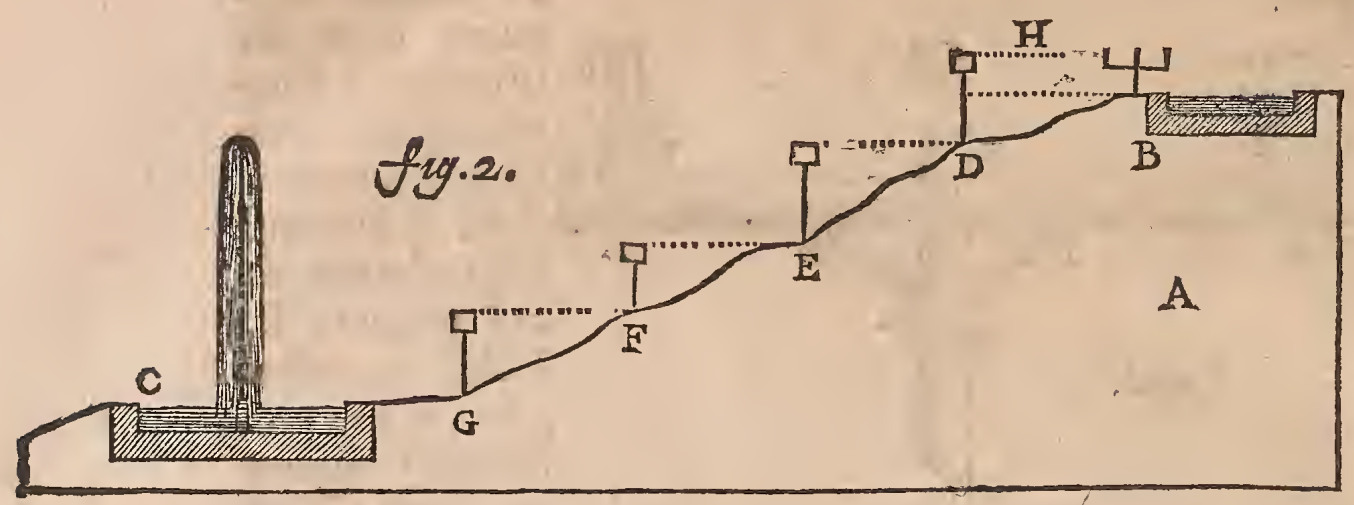

hauffer ou baiffer, jufqu'à ce que le haut diu carton fe trouve jufte à la ligne de mire $H$, qui fe dirige ainfi. Metrés vous à quelque diftance du Niveau, pofés l'œil, \& alignés-vous fus 1a furface de la liqueur comprife dans les trois Fioles, qui conduira votre rayon vifuel, fuivant lequel vous ferés arrêter la perche à la hauteur jufte. Cela fair, vous prendrés la hauteur qu'il y a depuis la fuperficie de l'Eau du Réfervoir $B$, jufqu'à la liqueur comprife dans les Fioles, que vous diminuërés \& marquerés en contre-bas fur la perche, dont la longueur fera feulement comptée depuis cette marque, jufqu'à I'uni de l'endroit où elle eft fichée. A yés un papier où vous chiffrerés cette premiere ftation du nivellement, \& les autres fuivantes. Faites ôter cette perche, \& à l'endroit $D$ où étoit fon pied, reportés le Niveau que vous établirés comme vous venés de faire, pour une feconde operation, \& enfuite par plufieurs ftations de $D$ en $E$, d' $E$ en $F$, d' $F$ en $G$, vous viendrés aboutir à l'endroit $C$ où doit être la Fontaine jailliffante. Vous fuputerés toutes les mefures chiffrées, que vous avés marquées fur votre papier à chaque ftation, \& les joignant enfemble, vous en aurés la fomme, \& fçaurés au jufte ce qu'il $y$ a de pente depuis le fommet $B$ jufqu'au bas $C, \&$ de combien de pieds le Jet s'élevera, l'Eau remontant toujours prefque aufli haut que fa Source.

La force \& la hauteur d'un Jet d'Eau, peut diminuer environ d'un pied par too toifes, c'eft-à-dire, que plus les Jets feront proches des Réfervoirs, \& plus ils iront haut. 
LA PRATIQUEDU JARDINAGE. 267

Les Eaux naturelles ne fe pouvant trouver dans un Pais plat \& fec, on a recours aux Machines Hydrálliques, qui élevent les Eaux des Rivieres, des Etangs, des Ruiffeaux ; comme auffi celles des Puits \& Citernes, dans' des Refervoirs \& lieux élevés, pour les defcendre enfuite dans les Jardins.

Ces Machines font prefentement fort en ufage, \& beaucoup de Gens les preferent aux Eaux naturelles, par raport Fontaines du ì la quantité d'Eau qu'elles fourniffent, à la proximité des pere J. FräRefervoirs \& au peu de longueur des conduites; ce qui coûte infiniment moins que d'amener des Eaux pendant une lieuë ; joint à ce qu'elles mettent la Source dans la Maifon, \& par là épargnent le chagrin continuel de voir crever les Tuïaux d'une conduite, parla malice des Païfans, qui prennent ce plaifir pour mortifier un Seigneur. On ne doit point auffi aprehender qu'on vous coupe $\&$ détourne l'Eau, d'où naiffent fouvent de grands procès, ou qu'enfin la veine de terre \& lit de glaife changent de fituation, \& faffent perdre la Source entierement.

On peut élever l'Eau par differentes Machines ; premierement, par la force des Pompes à bras \& à cheval. Secondement en fe fervant des deux Elemens; de l'Air \& de l'Eau, pour faire tuurner des Moulins.

Lès Pompes à bras, c'eft à-dire, qui font mouvées à force de bras d'homme, font les moindres Machines, par raport au peu d'Eau qu'elles fourniffent, \& ̀े la fatigue qu'il faut qu'un homme ait fans ceffe de lever les bras, pour faire marcher le balancier. Auffines'en fert-on que pour avoir un peus d'Eau pour arrofer, ou pour donner de l'Eau dans des auges de cuifine \& d'écurie : au lieu que les Pompesà cheval, c'eftà-dire, qui font ménées par un cheval, font d'une grandé utilité, \& fourniffent beaucoup d'Eau en peu de tems. Il y a de ces Pompes qui donnent plus d'Eau en une heure de tems, qu'une Source n'en ameneroit en quatre jours; c'elt une chofe de fait, joint àl'agrément qu'elles ont ; qu'on les peut placer dans tous les puics.

On diftingue encore de deux fortes de Pompes, la Foulante \& l'Afpirante; dont la difference elt affés connuë de tout le monde.

La ze maniere d'élever les Eaux par les Moulins qui vonk L $\perp$ ij 
* Verfailles Marly, Meudon, Argenville, Chatillon, \&c.

Liv. $\mathrm{X} . \mathrm{Ch}$. XII.
268 QUATR IEME PAR TIE, CH A.I. parle moïen du Vent ou de l'Eau, eft infiniment meilleure. Ces Machines fourniffent prefque toujours de l'Eau, \& pour ainfí dire jour \& nuit ; mais aufli c’eft une dépenfe bien plús confiderable, \&u qui-ne convient pas à toutes les fituations.

Il - faut être proche de la Riviere ou de quelque Ruiffeau, pour fé fervir de Moulins à l'Eau, qui reffemblent par l'exterieur aux Moulins à Bled, \& n'ont de difference que dans la compofition du dedans. Il y a de ces Moulins qui moulent du Bled, \& montent de l'Eat quand on veut, en décrochant la manivelle; mais dans les endroits éloignés des. Rivieres \& Ruifleaux, comme pourroit être un lieu élevé fur quelque côteaut, les Moulins à Vent y font des merveilles, lés Vents étant fort fréquens dans ces fortes de fituations. Ces.Moulins reffemblent aufi beaucoup aux Moulins à Vent ordinaires; mais ils ont une plus grande commodité, c'ett de fe mettre d'eux-mêmes au Vent, par le mö̈en d'une queuë en forme de gouvernail, qui fe tourne de tous fens. Ils font un peu plus rares que les Moulins à l'Eaut, n'aïant encore été exécutés qu'en quare ou cinq ${ }^{*}$ endroits, cependant leur réuffice \& leur bonté font de fûrs garands, dans l'execution qu'en voudroit faire un particulier.

On peut dire en general que les Maclines Hydrauliques fe réduifent prefque toutes au Pifton, \& qu'elles ont beaucoup de raport à celles des. Anciens; furtout à celle de Ctefibius dont parle Virruve.

1- Après avoir parlé des moïens de rechercher les Sources, \& d'élever les Eaux, il faut dire quelque chofe touchana les Refervoirs, avant que de paffer à la maniere de les conduire.

3. On ne pent diftinguer que de deux fortes de Refervoirs, ceux qui font fur Terre, \& ceux qui font élevés en l'Air.

Les Refervoirs quif font fur terre, font ordinairement des Pieces d'Eau ou Canaux glaifés, où l'on ramaffe des Sources $\&$ qui contiennent plufieurs milliers de muids d'Eau. On leur donne beaucoup de profondeur pour leur faire contenir davantage d'Eau, \& qu'ils ne fe vuident pas fi vîte, outre que cela donne plus de charge aux conduires, \& fait aller les 
LA: PRATIQUE DU TARDINAGE. 26.9 Jets plus haut. Quand on les peut placer dans fon Parc \& chés foi, cela n'eft que mieux, lans cela on les fait dehors en pleine Campagne, en les entourant de murs. Dans les Jardins en pente, les Baffins d'en-haut fervent de Réfervoirs aux Pieces d'Eau' d'en-bas is ce qui eft un grand avantage.

Les Réfervoirs élevés en llair, ne font pas à beaucoup près d'une fi grande capacité, les plus grands tiennent au plus cinq à fix cens muids d'Eau, \& font trés-rares de cette grandeur. Ils ne contiennent pour l'ordinaire que roo ou 200 muids. La difficulté de les foûtenir, \& la dépenfe dit plomb dont on les contruit; ne permettent pás de les faire auffi grands; que ceux qui font fur terre. On les éleve fur des Arcades ou Pilliers de pierre de taille, fur lefquels on pofe de groffe charpente pour fout tenir le fond \& les côtés, que l'on a foin de revêtir de fortes tables de plomb foudées enfemble.: Les fondemens \& la charpente de ces Réfervoirs doivent être trés-folides, pour pouvoir porter la grande charge de l'Eau.

On voit plus de ces Réfervoirs élevés, que des autres, ì caufe que ceux quis ont desiMachines: Hydrauliques, n'en peuvent guéres conftruire fur terre, par la fituation plate de leur Terrain:

Il s'agit préfentement de conduire les Eaux de ces Réfervoirs, jufques dans les.Baflins, pour y faire joüer des Jets, des Bouillons d'Eau \& des Cafcades.

Les A nciens a voient trois manieres de conduire les Eaux, par des. Aquedacs fôturerrains, par des tuyaux de plomb \& par des tuyaux de grés.ou de poterie, ces trois manieres font Vitrure Lip. encore préfentement en ufage, \& l'on n'y en a ajoutté quie deux, qui font les tuyaux de bois \& ceux de fer.

Les Aqueducs foûterrains doivent être bien bâtis de pierre de taille, \& couverts en deffus par des voutes ou pierres. plates apellées Delles, afin que le Soleil ne donne poirt. fur l'Eau : s'ilife rencontre du roc, on taillera la voute dedans, \& fi quelque montagne empêche le paffage, on la percera, ou l'on fera paffer ll A queduc tout autour, en praz tiquant des foupiraux de go toifes en go toifés, sour don wer un peu d'air àl'Eau. Les fonds \& vallées apellées. Vito. $\mathrm{L} 1 \mathrm{iij}$ 
tres qui interrompent le Niveau d'une conduite, feront remplis par des Blocailles: \& maffifs de Maçonnerie, ou par des Arcades \&Trumeaux, comme on voit l'Aqueduc d'Arcücil.

On fait couler l'Eau dans ces Aqueducs, de differentes façons, dans des Tuïaux de grés ou de plomb, dans des Auges de pierre de taille, c'eftla maniere la plus ordinaire, ou dans des rigoles faites de chaux $\&$ de ciment, ou de glaife dans les $P a i s$ où elle eft commune. Il fe rencontre quelquefois naturellement des veines de gravier, de tuf ou de glaife, où l'Eau coule fans fe perdre, L'on doit toujours pratiquer deux petits fentiers des deux côtés de ces.Auges, a fin qu'on y puiffe marcher quand il eft néceffaire; \& outre cela on donne un petite pente imperceptible à ces Auges, pour faciliter un plus prompe écoulement à l'Eau.

Ces fortes d'Aqueducs ne conviennent qu'à ramaffer des Sources, \& les amener dans un Refervoir, car les Eaux n'y étant pas refferrées, comme dans des Tuïaux, elles perdent la pente \& la force qu'elles doivent avoir, pour s'élever en l'air.

Les Tuiaux de plomb font les plus commodes pour conduire les Eaux. Onles peut faire defcendre, monter \& tourner, fans que cela nuife à l'Eau qui y coule. Il y en a de deux fortes, de moulés \& de foudés. Lés tuïanx moulés font jettés dans un moule, de la longueur qu'on veut, ordinairement de 12 pieds de long; on les fait plus épais que les foudés , crainte des foufflures; aufi font ils meilleurs \& plus eftimés, mais 1 ls cottent davantage à caufe du poids. Les tuïaux foudés ne font autre chofe que des tables de plomb que l'on courbe, \& que l'on foude fur la jointure. Les plus gros tuïaux de plomb ne paffent point fix pouces de diamerre, \& les plus petits vont à 9 ligues; on les emboite $\&$ on les joint l'un dans l'autre par des nouds de foudure. Hs font fujers ì fe crever. \& à fe miner dans les terres pleines de chaux.

Les tuiaux de grés ou de poterie, qui étoit la troifiéme ma. niêre de conduire les Eaux chés les Anciens, ef celle qui coûte le moins; mais auffi celle qui eft le plus d'entretien. Ces tuïaux font d'une compofition de terre cuite, pareille à celle dont on fair les póts \& les terrines. On encaltre les tronçons 
LA PRATIQUEDU JARDINAGE. 27 I qui font de deux ou trois pieds de long l'an dans l'autre, \& l'on met du maftic à feu avec de la filaffe à leur jointure fur l'ourlet. Quand ces Tuïaux fervent à conduire des Eaux forcées, on les entoure d'un maffif ou chemife de ciment de cinq à fix pouces d'épaiffeur ; ce qui les conferve quelque tems, pourvù qu'on air la précaution premierement, de laiffer fécher une conduite plufieurs mois avant que d'y mettre l'Eau, afin de donner le tems au ciment de durcir, \& fecondement d'affurer ces Tuïaux qui font tres fragiles, fur des maffifs \& fondemens de Maçonnerie, de peur qu'ils ne s'affaiffent. Ces Tuïaux font plus propres à conduire des décharges de Baffins, que des Eaux jailliffantes, aufquelles ils ont bien de la peine à refifter longtems: Ils font fujets aux queuës de Renard, qui font des racines d'arbres fort menuës, qui paffant par les pores du grés, ou par le noeud du maftic qui fe pourrit en terre, fe nourriffent dans l'Eau \& viennent fi grofles \& fi longues, qu'elles bouchent entierement le Tuiau. J'en ai trouvé de cinq à fix toifes de long. Il y a des gens qui prétendent que les queuës de Renard viennent de la filaffe qu'on met dans les nouds de maftic, ou bien de quelques graines qui entrent avec l'Eau dans la conduite.

Les Tuïaux de grés ont un merite particulier pour les Fontaines d'Eaux pour boire : Parce qu'étant verniffés par dedans, le limon ne s'y attache point, \& l'eau s'y conferve mieux \& plus fraîche que dans les autres tuïaux ; outre qu'elle n'acquiert point de mauvaife qualité en yípaffant, conme dans le plomb, le fer \& le bois.

Les deux manieres de conduire les Eaux, que nous avons ajoûtées à celles des Anciens, fone par tuïaux de boiş \& de fer.

Pour faire des conduites de tuiaux de bois, on prend de gros arbres, comme des Chênes, Ormes, Aulnes, les plus droits que l'on peut, \& que l'on perce de trois ou quatre pouces de diamettre. On les afute par un des bouts, \& on les fait freter \& cercler de fer par l'autre, pour les pouvoir emboîter l'un dans l'autre, \& ces jointures font recouvertes de poix. Ces fortes de tuïaux ne font bons que dans les Paîs marécageux \& humides naturellement ; car dansles Paîs fecsils fe pourriffent bien vîte.

Archirecture Françoife de Savot, Chap. xxx.pag.19I.

Les Eaux de Liancourt, de Dampierre, deCourances, \& en partie cellesdeChano tilly, : e font conduites que dass du bois. 
Les Fontainiers apellent ces perits Jets des piffotie-, res.

Traité du mouvement des Eaux par Mariotte, se. Partic p.340.
272 QUATRIEME PARTIE, CHAP. I.

Les tuiaux de fer font jettés en moule \& en fonte, \& font d'un grand ufage prefentement, il y en a de deux fortes, à Manchons \& à Brides; on n'emplö̈e plus que de ceux de Brides comme les meilleurs. Les tuiaux de fer ont les bonnes qualités de ceux de plomb, durent plus, \& coûtent quatre ou cinq fois moins. Il s'en fait jufqu'à 18 . pouces de diametrre : chaque tuïau ordinairement a trois pieds \& demi de long, \& à chaque boutil y a des Brides que l'on joint \& ferre enfemble, par des viz \& écrouës, entre lefquelles on met des rondelles de cuir \& du maftic à froid. Lans les endroits mal-aifés, on y met des rondelles \& croifants de plomb; comme auffi dans les coudes, robinets, foupapes, on eft obligé d'y racorderdes bouts de tuyaux de plomb. :

Ce n'elt pas affés d'avoir parlé des Refervoirs, \& des differentes manieres de conduire les Eaux, il y a encore une chofe de confequence qu'il ne faut pas oublier, c'eft la proportion \& la groffeur que doivent avoir les conduites \& les tuyaux, par raport aux Jets que l'on veut faire joüer. C'elt de là que clépend la beauté des Eaux jailliflantes : car fi les conduites font trop menuës, ou qu'elles fourniffent à trop de Baffins, fans avoir leur jufte proportion, elles ne formeront que des petits Jets foibles \& peu nourris : outre que ces conduites font fujettes à s'engorger aifément \& à crever, pai ce que les vents y étant trop refferrés n'en peuvent prefque fortir.

Voici la plus jufte proportion que l'on doit donner aux conduites, par rapport aux Jets d'Eau. Elles doivent être en raifon quadruple des ajutages; c'eft-à-dire, que le diametre des conduites doit être quatre fois auffi grand que celui des ajutages, afin que la colonne d'Eau foit proportionnée, \& que la vîtefle dans les tuyaux foit égale, joint à ce qu'il fe fait trop de frotement dans les petites conduites, par raport aux gros ajutages, \& au bord des petits ajutages, par raport aux groffes conduites; des exemples éclairciront ce qu'on vient de dire.

Pour faire joüer un Jet de quatreà cinq lignes de groffeur, c'eft-à-dire, dont l'ajutage foit percé de quatre à cinq lignes de diametre, qui font en fuperficie I 2 lignes $\& \frac{1}{2}$, il faut une conduite d'un pouce $\&$ demi de diametre ; pour un Jet de fix 
àrept lignes, il faut une conduite de deux pouces; pour un Jet de huit à neuf lignes, une conduite de trois pouces; \& pour un gros Jet d'un ponce defortie, une conduite de quatre pouces de diametre. Pour faire joüer encore un Jet plus gros, conıme de I 6 à I 8 lignes, ou une Gerbe, il fatidra une groffe conduite de fix pouces de diametre. L'on ne parlera point des conduites qui vont à un pied \& à I 8 pouces de diametre, elles coûtent de fi groffes fommes, qu'elles paroiffent hors de la portée des plus riches Particuliers.

Il y a de plufieurs fortes d'A jutages ou A joutoirs, comme des Gerbes, des Pluies, Soleils, Eventails, \&z de quancité d'autres formes que l'on donne à l'Eau; mais les plus ordinaires A joutoirs pour former un Jet, font élevés en Cone \&c n'ont qu'une feule forcie : ce font auff les meilleurs, ne fe bouchant pas fi fouvent que les plats qui font percés de plufieurs trous ou fentes placés à l'oppofite l'une de l'autre, ou que ceux où l'on a foudé plufieurs autres petits A jutages pour former une gerbe.

On prétend que les Jets d'Eau vont mieux, quand les A jou: toirs font percés d'un feul trou un pea gros fur une platine, que quand ils font élevés en Cone, parcequil fe fait moins de Mariotec, se
Partie, page frotement \& de refiftance au bord.

A l'égard des Conduites, plus elles font groffes, mieux les Eaux vont, c'eft l'ame des beaux Jets d'Eau, qui pour être bien nourris, doivent avoir une conduite continuée de la même groffeur depuis le Refervoir, jufques fous l'A jutage fans aucune diminution; cela fournic davantage d'Eąl \& donne plus de charge au Jet, qui fans cela fe trouve étranglé \& referré de trop loin.

Il y a des gens qui ont une opinion toute contraire, ils s'imaginent qu'on doit tenir une Conduite de roo toifes de long , plus groffe dans les 5 o premieres toifes depuis le Refervoir, que dans les 5 o dernieres jufqu'à l'A jutage, où ils prétendent qu'elle doit diminuer environ d'un pouce de diametre; afin, difent-ils, que l'Eau commence à être forcée \& refferrée un peu de loin dans cette cond uite, qui doit toujours venir en diminuant jufqu'à la fortie de l'eau:c'eft une opinion des plus mauvaifes en fait de Fontaines; il fuffit de contraindre \& de forcer l'Eau dans la fouche ou colonne du Jet, \& dansl'ajoutoir $\mathrm{M}$ in 
Cet exemple fera juger des autres, \& $\sqrt{1}$ les jets font de differente groffeur \& par confequent les fourches, on n'aura qu'à fupputer leur capacité torale \& faire toujours la grolfe de masierequelleles force de quelque chore.
274 QUATRIEMEPARTIE, CAAP. I. fanspour cela que la conduite diminuë de groffeur : cela eft fi vrai, que dévifant l'ajutage, l'eau n'a plus la même hauteur, ni la même force, \& ne fait pour ainfi dire que baver.

Nous n'avons qu'un feul cas, où les conduites doivent diminuer de diamerre, c'eft quand elles font trés-longues, comme de trois à quatre cent toifes; alors on met de trois fortes de groffeurs de tuiaux ; fans cela par le grand chemin que l'eau a à faire, elle dormiroit, pour ainfi dire, \& perdroit beaucoup de fa force : ces differentes groffeurs la réveillent \& Ini redonnent fa même hauteur. Par exemple, dans une groffe conduite de 300 toifes de long, on metra les too premieres toifes de huit pouces de diametre, les roo autres de fix pouces, \& les roo derniẹres de quatre pouces mais dans les conduites de 100 ou I 50 toifes, il faut continuer le même diametre, dans toute la longueur jufques fous l'ajutage.

Quand on aura plufieurs Jets à faire joüer dans un Jardin ; par exemple cinq ou fix, il n'eft pas neceffaire de tirer du Refervoir cinq ou fix conduites, c'elt-à-dire, autant de conduites que de Jets, ce feroit une dépenfe fuperfluë. On fait feulement deux ou trois conduites, fur lefquelles on foude des tuiiaux plus petits (apellés. Fourches ou Branches) pour fournir tous ces Jets : cela dépend de la proportion quion leur donne. Il doit paffer moins d'eau dans tous les petits tüiaux. enfemble que dans le gros, enforte que ne prenant pas toute l'eau, le gros force les petits, c'eft pour équivaler les frotemens \& donner de la vivacité à l'eau : par exemple, pour faire joüer trois jets d'eau, chacun de fix à. fept lignes de diametre, chaque branche felon la raifon quadruple, dont on a parlé cy-deffus auroir deux pouces de diametre, \&z il y palferoir quatre pouces d'eau, ainfi dans les trois enfemble ce feroit I 2 pouces, il faut dont que la maîtreffe-conduite ait 4 pouces de diametre, ou il paffera I 6 pouces d'eau, c'elt-àdire, qu'elle forcera d'un quart les trois autres. De cette maniere la force fubfitera jufques dans la derniere faignée, \& ces jets joüeront tous enfemble fans s'alterer l'un l'autre \& aller plus bas. On continuë la même groffeur de la mấrreffe-conduite jufques vis-à-vis les baflins, où la diftribution fe fair dans les branches. 
I A PRATIQUE DU JARDINAGE

On obfervera qu'à l'entrée d'une conduite, c'eft-à-dire, à la fortie du Refervoir, elle ait deux pouces de plus de diametre, comme fur une conduite de quatre pouces, on mettra une foupape \& ouverure de fix pouces au fond du Refervoir, afin que cette entrée étant plus grande, ferve d'entonnoir à l'eau, pour fortir plus promptement \& donner plus de charge au Jet.

Les conduites étant parvenuës jufqu'aux baffins, on fera un regárd, pour y mettre un robinet de cuivre, ou de groffeur convenable au diametre de la conduite, en prenant garde que par le trou ovale de la canelle \& du boiffeau, il paffe autant d'eau que par l'ouverture circulaire dut tuïau; nous avons de plufieurs fortes de robinets, comme à tête quarrée, à branches ou à potence, à deux \& trois eaux.

Il faut fouder une rondelle, ou colet de plomb un peu large autour du tuiiau, à l'endroit où il paffe dans le corroy dı Baffin, afin que l'eau étant ainfi arrêtée par cette - plaque, ne fuive point le long du tuïau, pour tâcher à fe perdre.

On doit toujours faire paffer les túiaux à découvert, fur le plafond d'un Baffin, \& jamais ne les enfoncer dedans, pour pouvoir mieux remedier aux fautes qui furviennent. On foudera fur la conduite un tuïau montant, apellé Sorthe, au cềntre du Baffin, qui eft l'endroit où doit être le Jet, \& aut bout de cette Souche, l'on foudera encore l'écroue de cuivre, fur lequel fe viffe l'ajutage. A deux pieds environ de la Souche, l'on coupera le tuiau \& on le bouchera par un tampon de bois avec une rondelle de fer chaffée à force au bout du tüau, ou par un tampon de cuivre à vis, que l'on y foudera. 'L'on peut dégorger une conduite, quand il y a des ordures, en ôtant ces tampons.

Evités toujours dans les conduites les coudes, les jarrets $\&$ les angles droits ou équerres, qui diminuent la force de l'eau. Quand vous ne pouvés faire aller une conduite bien droite, \& qu'il y a un tournant indifpenfable, prenés ces cout: des d'un pea loin, pour en diminuer la roideur.

Dans les conduites un peu longues \& fort chargées, on met d'efpace en efpace des ventoufes, ou foupapes renverfées ? $M \mathrm{~m}$ ij 
276 QUATRIE'ME PARTIE, CHA P. I. pour le foulagement destuïaux, \& pour la fortie des vents: \& quand après une pente roide, les conduites fe remettent de niveau, il faut dans cet endroit fouder un robinet pour arrêter cette charge; fans cela le tuïau ne refifteroit pas longtems.

On enfoncera toujours les conduites un peu avant en terre comme de deux ou trois pieds, à caufe de la gelée, \& crainte des voleurs. Il les faut faire paffer dans les Allées, \& jamais dans les Bois, dans les Parterres, \&c. afin qu'on en puiffe mieux connoître les fautes, \& les racommoder plus aifément fans rien déplanter. Quand les conduites paffent fous des terraffes, on doit faire une petite voute le long du tuiau, pour le pouvoir vifiter de tems en tems. $L_{2}$ pouffée des murs \& les terres qui travaillent fans ceffe dans ces endroits, ruineroient infailliblement lés tü̈aux, s'ils n'étoient garantis par la. route.

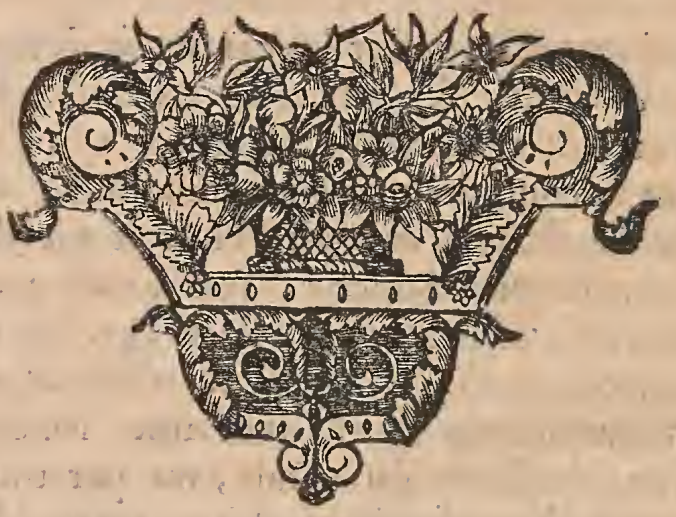




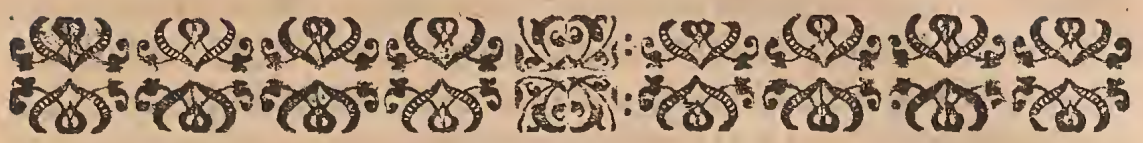

\section{H A P I T R E I I.}

DES FO NTAINES, BASSINS, Cafcades d'Eau, $\mathcal{F}^{2}$ de leur Conftruction.

T Es Fontaines \& les Eaux font l'ame des Jardins, \& en font le principal ornement; ce font elles qui les animent, \& pour ainfi dire les font revivre. Il eft conftant qu'un Jardin, quelque beau qu'il foit, s'il n'y a point d'eau, paroît trifte \& morne, \& manque dans une de fes plus belles parties.

La diftribution des Eaux dans un Jardin, eft ce qu'il y a de plus difficile : elle demande du genie \& de l'indurtrie, pour faire enforte qu'ume petite quantité paroiffe beaucoup, \& que ne prodiguant pas les eaux dans des Roquailles \& peritsBaffins ( qui font de vrais Colifichets) on la menage pour des lieux néceffaires, où elle faffe un bel effet, en formant de gros Jets bien nourris. Il feroir à fouhaiter, que les parties d'un Jardin fuffent bien pratiquées, \& les Allées percées avantageufement pour les eaux.

On doit prendre garde dans cette diftribution, que les. Fontaines forent difpofées de telle maniere, qu'elles fe puiffent voir prefque toutes enfemble, \& que les Jets d'eau s'enfilent, c'en eft la beauté : cette répétition caufe un embarras agréable à la vîë, qui les croit en plus grand nombre qu'ils. ne font effectivement.

On diftingue les eaux en plufieurs manieres, il y en a de: naturelles \& d'arcificielles, de jaillifiantes \& de plates, de vives \& de dormantes.

Les eaux naturelles font celles qui fortant de terre d'elles: mêmes, fe rendent dans un Refervoir, \& font joüer les Fontaines continuellement : au lieu que les artificielles font élevés dans un Refervoir, par le moïen des Machines $\mathrm{Hy}$ drauliques, ainfr qu'il a été expliqué dans le Chapitre précédent.

On apelle eaux jailliffantes, celles qui s'elevant en l'aix: M. $\mathrm{m}$ iij. 
Ainfí que

le Canal de Chantilly, de Berny, de Liancour, celui de Courances, de Tanlay, de Villacerf, \&e.

$-278$

QUATRIE'ME PARTIE, CHAP. II. au milieu des Baffins, forment des Jets, des Gerbes, des Boüillons, \& c. ̀̀ la difference desEaux plates, qui font fimplement des Canaux, Etangs, Viviers \& Miroirs d'eau, fans aucuns Jets ; ce qui n'eft pas d'une grande beauté dans un Jardin, parce que ces eaux étant toujours tranquilles \& dans le même état, n'animent point les Jardins comme les Fontaines jailliffantes quileur donnent la vie, \&x c'eft principalement de ces dernieres, qu'on dit qu'il y a de belles eaux dans un tel endroit.

Les eaux vives font celles qui courent fans ceffe, \& les plus belles de toutes par leur clarté ; ce mouvement continuel les rend faines \& trés-nettes; telles font les eaux des petites Rivieres ou ruiffeaux, dont on fait des Canaux \& Pieces d'eau dans les Jardins : On met de ce nombre les Fontaines qui vont jour \& nuit.

Les eaux dormantes font les plus défagreables de toutes, elles deviennent fales, verdâtres \& toutes couvertes de mouffe \& d'ordure, n'ayant point de mouvement, ainfi que dans les Baflins qui jouënt rarement ou dans les marais \& étangs, elles font fujettes à fe corrompre \& à fentir mauvais pendant l'Efté.

On ne peutfixer de vräies places pour les Fontaines \& les Baffins, ils font un bel effet par tout ; fi l'on en pouvoit placer à chaque endroit, cela n'en feroir que mieux; mais comme la dépenfe en eft confiderable, \& que quelquie quanticé d'eau quel'on ait en referve, elle n'y pourroit fuffire, on a beaucoup de ménagement pour leur nombre.

On place ordinairement un Baffin au bout ou dans le milieu d'un Parterre, en face d'un Bâtiment; c'eft un kieu oì l'on ne manque jamais, d'y en conftruire, aufi bien que dans un Potager, mais quand on peut en pratiquer dans les Bofquets, c'eft un double agrément, les eaux y étant comme dans leur centre, outre que la verdure des arbres leur fert de fond, \& fait valoir la blancheur de l'eau, leur gazoüillement $\&$ leur. murmure frapent davantage l'oreille par le repos \& l'écho qui regnent dans les Bois.

Il ne faut point mettre les Fontaines fir près des Bâtimens. parce que dans l'Efté il s'éleve de l'eau des vapeurs fi corrompuës, qu'elles peuvent communiquer à l'Air une malignité 
LA PRATIQUE D U JARDINAGE. 279 capable de nuire à la fanté, joint à ce que ces vapeurs caufent une humidité trés-grande aux murs d'un bâtiment, qui peut gâter les Peintures \& les meubles du dedans. On a encore l'incommodité d'entendre la nuit croaffer les grenoüilles, les crapaux, \&c. Ce font toutes ces raifons qui empêchent préfentement d'entourer les Maifons de Campagne de foffés d'eau, comme l'on faifoir autrefois, \& que l'on a mis à fec ou comblé entierement ceux de plufieurs * Châteaux.

La forme \& la figure des Baffins font ordinairement circulaires; cependant il y en a d'octogones, de longs, d'ovales, de quarrés, \&c. Quand ces Baffins paffent une certaine grandeur, on les apelle Pieces d'eaux, Canaux, Miroirs, Viviers, Etangs \& Refervoirs.

Pour la grandeur des Baffins, on dira en general qu'on ne peut jamais pécher en grandeur ; plus ils font grands mieux. ils font ; au lieu que l'on peut pécher en petitelfe, ce qui eft trés-difforme; il y a deux extremités qu'il faut éviter également, comme de faire un petit Baffin dans un grand lieu, ou de confommer la meilleure partie d'un endroit dans une grande Piece d'eati. On laiffe cette jufte proportion au difcernement de l'Architecte, ou de celui qui donnera des Deffeins de Jardinage.

Beaucoup de gens prétendent que la grandeur d'un Baffin doit être proportionnée à la hauteur du jet, afin, difent-ils, que l'eau poufiée en l'air, quoiqu'agitée par le vent, ne pafle pas les bords du Baftin, \& y retombe toute fans moüiller l'allée du tour. C'elt en quoi il fe trompent : Car pour peu qu'un Jet foit élevé, quoique dans un grand Baffin, le vent enlevera toujours l'eau, \& la portera trés-loin; c'eft une experience inconteftable : L'on convient a vec eux qu'il eft auffi défag reable de voir un petit * Jet menu dans un grandBaflin, que d'en voir ** un trés-gros \& trés-élevé dans un perit Bafinn. Il faut qu'il y ait autant que l'on pourra quelque forte de convenance entre le Jet \& le Baflin; mais on ne peut déterminer de jufte proportion de la grandeur des Baflins, par raportaux. Jets, cela dépend de la chute $\&$ de la force des eaux, ou de l'efpace que le terrain peut permettre de prendre pour les. Fonaaines.

A l'égard de la profondeur qu'on doit donner aux Baflins,

* S. Maur. Ramboiiller.
* Comme le petit Jer du grand Bafta du Palais Roïal.

$* *$ Comme celui du fecond Parterre vis-à-vis de la principale façade de Irianon: 
* Les FonCainicrs diSent, qu'un Baflí doit tenir l'eau comme un pot,

Ainfí qu'ats Bafin octogone qui eft dans le Parterre du $\mathrm{Pa}$ 'lais Roïal.

Pordinaire eft de I s à I 8 pouces, ou deux pieds tout au plus: cette hauteur eft fuffifante pour y puifer avec les arrofoirs, \& pour garantir le fond d'un baflin dans les grandes gelées. On leur donne plus de profondeur, quaud ils doivent fervir de Refervoirs, ou qu'on y veut nourrir du poiffon, comme il fe pratique dans les grands Baffins, Canaux \& Pieces d'eau, \& pour lors ils doiventavoir quatre à cinq pieds de creux; c'elt affés pour y contenir beaucoup d'eau de referve, pour que le poiffon $s^{\prime} y$ éleve comme il faut, \& pour y porter un Bâteau en cas qu'on ait deffein d'y en mettre un: car l'on eft obligé d'y en avoir un quand il y a desJets dans le milieu d'un Canal, pour aller déviffer l'ajoutoir, \& ôter les ordures qui empêchent l'eau de faire fon effet.

On obfervera furtout en fait de profondeur, de ne pas paffer quatre ou cinq pieds, foit que ce foit un Canal ou Refervoir; il y a du danger qu'il le foit davantage, comme de huit à dix pieds; on a vû arriver tant d'accidens de perfonnes qui font tombés en fe promenant, dans des Baffins trés-creux \& qui s'y font noïées, qu'en verité l'on doity faire un ferieufe réflexion, \& tâcher qu'une chofe faite pour le plaifir \& l'ornement d'un Jardin, ne puiffe pas dans la fuite caufer aucune peine.

Pour conftuire un Baffin, il faut bien prendre fes mefures, fi l'on veut le faire bon, $\&$ qu'il tienne bien l'eau. * On ne fauroitavoir trop de circonfpection dans cet ouvrage; l'eau de fa nature cherche toujours à couler, \& par fa pefanteur \& fa charge dans un Baflin, eft fujette à paffer par la moindre petite fente, qui crôit toujours de plus en plus. Si l'on manque à bien faire cette ouvrage du premier coup, il eft trés-difficile d'y revenir:car il y a des Baffins ou l'on a travaillé à plufieurs reprifes, faus pouvoir prefque y faire tenir l'eau, faute d'a. voir été bien fait d'abord. Ce travail, outre qu'il demande beaucoup de foin \& d'habiles Ouvriers, exige encore l'em. ploi de bons materiaux; ce qu'on expliquera dans la fuite.

Mais avant que de dire comment on conftruit les Baffins, il faut diftinguer les differentes manieres dont on peut fe fervir. Nous en avons de trois fortes, les Baflins faits avec de la glaife, avec du ciment, \& avec du plomb.

Commençons par les Baffins de glaize, comme les plus en ufage. 
La place étant tracée fur le terrain, il faut avant que de Ia faire foüiller, reculer \& agrandir cette trace de quatre pieds au delà, c'elt-à-dire, agrandir le diametre de quatre pieds de chaque côté, qui font huit pieds en tout. Le Bafin z'en déviendra pas plus grand pour cela, parce que cette augmentation de quatre pieds fera remplie \& occupée par les murs \& les corrois du pourtour. On creufera auffi pour lefond ou plat-fond d'un baffin, deux pieds plus bas que la profondeur qu'on lui voudra donner : Ces deux pieds de foüille feront pareillement occupés par le corroi de glaize, qui doit avoir 18 pouces d'épaiffeur, \& les autres fix pouces feront pour le fable \& pavé qu'on met deffus la glaize. En voici un exemple. L'on veut faire un baffin de fix toifes de diamerre, il faut faire l'ouverture des terres de fept toifes deux pieds de diametre, \& fi l'on veut lui donner deux pieds de profondeur d'eau ; l'on creufera quatre pieds de bas. Ainfi le baffin étant achevé, reviendra toujours à la grandeur \& hauteur requife de fix toifes de diametre, \& de deux pieds de creux.

On foüillera ces terres à pied droit, \& on les tranfportera, fuivant ce qui eft enfeigné ci-deffus dans le Chapitre fecond de la ${ }_{2}$ e Partie. Cette foüille étant faire \& la place bien nette, il faut y bâtir deux murs, \& renfermer la glaize entre-deux, afin que parce moïen les eaux ne la déläient point, qu'elle fe conferve fraîche, \& que les racines des arbres voifins n'y penetrent pas fi ailément.

Elevés contre la terre, c'eft-à-dire, adoffés le mur $A$. Fig. I. prg. Suiv. d'un pied d'épaiffeur, depuis le bas de la foüille jufqu'à fleur de terre ; vous le bâtirés de moilons, libages, cailloux, il n'importe, avec du mortier de terre, qui n'eft autre chofe que de la terre que vous déläierés en mortier; ce mur eft apellé Mur de Terre, à caufe qu'il n'eft bâti que pour foûtenir la pouffée des terres d'alentour, \& afin que la terre ne défeche pas fitôt les glaizes.

Ce mur étant élevé tout autour de la piece, l'on y fera aporter de la glaize que l'on jettera dans le fond \& on la préparera au travail $\&$ au manîment, en y jettant de l'eau de rems en rems, \& la labourant 2 ou 3 fois fans y fouffrir aucune ordnre. Votre glaize preparée, faites-1a étendre \& jet

Il y a des

Fontainiers qui ne donnent que quinas ze pouces d'épaiffeur de glaize au corroi du platfond, quoiqu'ils donnent I 9 pouces au corroi du tour. C'eft pour trouver guelque épargne dans la quantité de $s$ glaizes qui en. trent dans le plat - fond d'une gra nde Piece-d'E au. 

ter par pellerée, \& enfuite pétrir \& marcher petit à petit 2 pieds nuds de I 8 pouces de hauteur, \& de fept à huit pieds environ de large tout au pourtour de ce mur; l'on n'étend la glaize de 7 à 8 pieds de large, que pour mettre deffus la plare-forme $\&$ racinaux fur lefquels on bâcit le fecond mur $B$ apelléle Mur de Douve, n'étant pas néceffaire d'étendre d'abord la glaife dans tout le plat-fond d'un Baffin. Mefurés i 8 pouces depuis le mur de terre, \& laiffant cette intervale pour le corroi de glaiElevation des Murs ze $C$, il faudra bâtir en Fig.I \&Corrois d'unBar
fin de glaize. tion d'unBafin de glaize. delà, le mur de Douve $B$, qui doit avoir au moins I 8 pouces d'épaiffeur : \& comme l'on ne pourroit pas bâtir folidement ce mur, fi on le fordoir fur la glaize, il ent be-

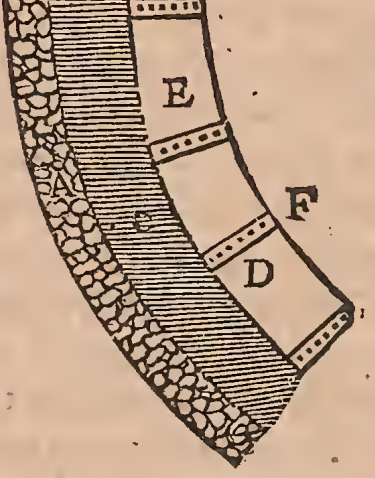
foin d'y pratiquer une plate-forme avec des racinaux, ce quife fair ainfi. Prenés du che. vron de trois pouces d'épaiffeur, ou bien des planches de batteau épaiffes de deux bons pouces, \& de fix de large; enfoncés - les à fleur de glaize de trois pieds en trois pieds, en forte qu'elles débordent un peu le parement du mur en dedans le baffin, c'eft cequ'on nommeles Racinaux D Fig.: . Metrés enfuite deffus de longues planches de batteau, don deux jointes enfemble, feront de la largeur du mur, que vous cloüerés ou chevillerésfur les Racinaux; c'ett ce qu'on apelle la Plate forme $E$ Fig. 2. Cet ouvrage fait , on pofe deffus la premiere affife du mur de Douve $B$, que l'o néleve de la hauteur de l'autre, \& de I 8 pouces d'épaiffeur pour le moins, ear dans les Pieces d'eau un peu grandes \& profondes, com. 
LA PRATIQUE DU JARDINAGE. $\quad 28$; me il y a baucoup de charge d'eau \& de longs pans de mur, on donne deux pieds d'épaiffeur au mur de Douve, qui s'en conferve plus long-tems ainfi que la piece.

On n'élevera d'abord le Mur de Douve qu'à moitié de fa hauteut, fupofé qu'il dût avoir fix pieds, ce feroic de trois pieds qu'on l'éleveroit parce qu'il feroit trop difficile de jerter \& perrir les glaizes dans le fond da corroi, fi ce mur étoir élevé de toute fa hauteur. On remplira de glaize l'efpace $C$, Fig.r. compris entre les deux murs, apellé le Corroi, jufqu’à la hauteur du mur qu'on achevera de bâtir au niveau de l'autre , \& l’on continuëra de petrir les glaizes pour élever le Corroi $C$ à fleur de terre.

Pour travailler au Plat-fond F, Fig 2. on remplira de glaize toute l'étenduë de la piece, pour y faire un corroi de 18 pouces de haut, en recommençant à petrir les glaizes que vous avez d'abord étenduës au delà desR acinaux, \& les liant avec celles du Plar-fond qu'on couvrira de fable de cinq à fix pouces de hauteur, comme l'on voit en $G$, Fig.r. ce qui confervera la Corroi , \& empêchera le poiffon de foüiller. Au lieu de ce fable, l'on peut y mettre du pavé; mais cela coute infiniment.

Si le Baffin eft dans un Bois, ou proche de grands arbres, il faudra bâtir le mur de Terre avec du mortier de chaux \& fable, afin d'arrêter pour quelque-tems les racines des arbres, qui cherchant la fraîcheur de la glaize pour s'y nourrir , fe fortifient de plus en plus \& abattent à la fin les murs dans l'eau. Il faut encore pour la confervation des Baffins, faire tous les fix à fept ans, des tranchées auffi profondes que le corroi da Plat - fond, autour des murs \& dans le milieu des allées, fans trop aprocher du Baffin \& de la Paliffade, crainte de les endommager; c'eft pour couper toutes les racines qui pourroient gagner le corroi de glaize.

Pour bâtir le mur de Douve, l'on choifira de bons moilons , qui ne s'écroutent \& ne fe délitent point dans l'eau, ou bien des cailloux, des pierres de montagnes \& de meuliere, qui rendent un ouvrage de longue durée, mais qui n'eft pas de la propreté des moilons piqués. On pofe de tems en tems des pierres qui tiennent toute la largeur du mur, c'eft à-dire, $\mathrm{Nn} \mathrm{ij}$ 
284 QUA T R IE'ME PAR TIE, CHAP.II. qui font le parement des deux côtés, ce qu'on apelle faire Parpin ; cela foûtient le mur \& le rend plus folide. Le mortier qu'on doit emploïer dans la conftruction de ce mur, pour être bon, doit être compoféde fable delaïé avec de la chaux, dont la dofe eft un tiers de chaux, \& deux ciers de fable.

Ondemandera peut-être pour quoi le mur de Douve $B$, ne prend pas de fond,

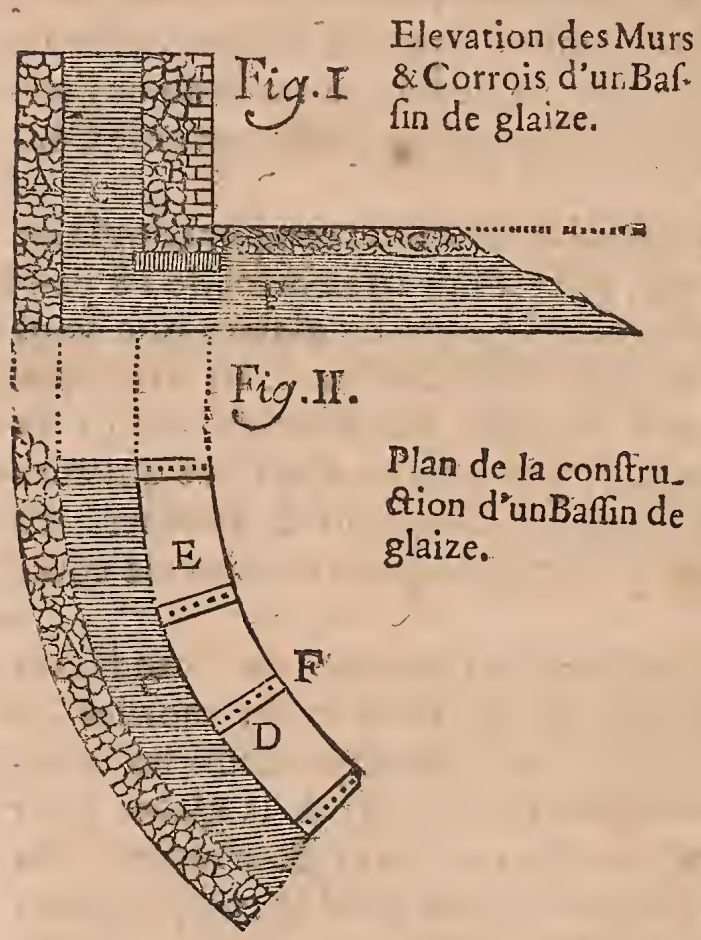
comme le mur de Terre $A$.En voici la raifon: Si ce mur étoit affuré fur la terre, comme l'autre mur, l'eau fe perdroit, \& louvrage de derriere deviendroit inutile, parce que le Corroi $F$ du Plat - fond, ne fe lieroit point avec celui $C$ des côtés, \& que les glaizes ne feroient point corps enfemble, ce qui en fait toute la conféquence, \& retient l'eau dans l'angle du mur. C'eft pour cela qu'on eft obligé de bâtir \& d'af. furer ce mur fur des

Racinaux \& Plate-formes au deffus de la glaize, afin de laiffer deffous une communication du Plat-fond avec les. côtes.

La veritable marque de la bonne glaize eft qu'elle foit ferme \& point fabloneufe, qu'elle s'alonge \& file en la rom. pant, \& qu'elle paroiffe graffe en la maniant. Il n'importe: gu'elle foit rouge ou verdâtre, la couleur n'y faifant rien : elle s'achete à la toife cube, qui compofe en tout 2 I 6 pieds cubes. La toife cube doit avoir de tous fens une toife quarrée, qui fait 3.6 pieds en fuperficie. La glaize n'eft chere que pas 
les voitures \& tranfports; il y a des Pä̈soù elle ne coûte qu' tirer, \& ou il y en a trop; d'autres, ou il la faut faire venir de loin \& avec de grands frais.

Les Baffins de ciment font conftruits d'une maniere bien differente; l'on recule la trace du Baffin, \& l'on agrandit le diametre, mais un peu moins qu'aux Baflins de glaize; il ne faut qu'un pied neuf pouces d'ouvrage dans le pourtour, \& autanc dans le plat-fond, ce qui eft fuffifant pour retenir l'eau. Ainfi pour un Baffin de fix toifes de diametre, il faut faire une foüille de fix toifes trois pieds \& demi, \& creufer un pied neuf pouces plus bas que la profondeur qu'on veut donner au Bafin.

Commencés par élever \& adoffer contre la terre coupée à pied droit, le mur de Conftruction d'un Baffin de Ciment. maçonnerie $A$, Fig. $3 \mathrm{e}$,

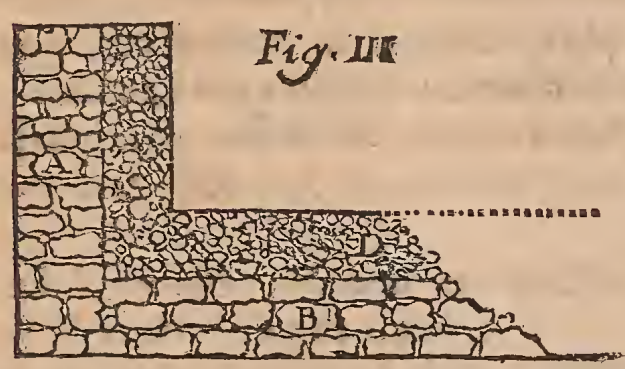
d'un pied d'épaiffeur, qui. prendra de fond \& fera bâti de moilons \& libages. avec du mortier de chaux \& fable. Ce mur étant fait tout au pourtour, on commencera le maflif du fond $B$, d'un pied d'épaiffeur, \& conftruit des. mêmes materiaux \& mortier que le mur $A$ : enfuite l'on adoffera contre ce mur le maffif ou chemife de ciment $C$ de neuf pouces d'épaiffeur, y comprenant l'enduit \& parement. Ce maffif fera fait de petits cailloux de vigne mis par lit, \& de mortier de chaux \& ciment, qu'il ne faudra point épargner, fi l'on veut faire un bon ouvrage. Tous ces cailloux ne doivent point fe toucher l'un l'autre, au contraire ils doivent un peu s'éloigner, \& regorger * de mortier de tous côtés.

Quand ce maflif aura environ huit pouces de large, \& qu'il fera continué dans toute l'étenduë du plat-fond $D$, il faudra. enduire le tout avec du mortier plus fin, c'eft-à-dire, avec du ciment paffé au fas, avant que de le délayer avec la chaux. \& unir cet enduit avec la truelle. Cet ouvrage demande une grande fujétion pour ôter les pailles \& les ordures qui peuvens.

*. Les Fonta. niers difent, metre des cailloux ì bouisis de cirmests 
fe rencontrer dans le mortier qu'on fera, dont la dofe eft deux tiers de ciment, \& un bon tiers de chaux. Il ne faudra pas faire ce mortier en jettant quantité d'eau, de peur de dé. graiffer la chaux; il fe doit faire à force de bras.

On choifira un tems chaud pour travailler aux Baffins de ciment, la pluye y étant trés-contraire. Quand le Baffin fera fini, il faudra pendant quatre ou cinq jours de fuite, froter l'enduit avec de l'huile ou du fang de bœuf, de peur qu'il ne fe fende \& ne fe gerce ; enfuite dequoi on y metra l'eau promptement crainte du hâle.

Le ciment a la vertu de durcir de telle maniere dans l'eau, que la pierre \& le marbre ne font pas plus durs ; car il fait un corps folide qui ne le ruine jamais.

Les Baflins de plomb font un peu plus rares dans les Jardins, par raport à la grande dépenfe, \& au rifque ou ils font d'être volés. Il faut agrandir la trace d'un pied feulement de chaque côté, \& faire l'ouverture plus creufe d'un demi-pied, que la profondeur qu'on veut donner au Baflin; par exemple, un Bafin de fix toifes de diamerre aura fix toifes deux pieds de fouille, \& un pied \& demi de creux fi l'on ne le fair que d'un pied de profondeur.

On donne un pied d'épaiffeur au mur $A, F i g \cdot 4^{c}$, des Confruction d'un Baffin de plomb. côtés, afin de mieux foûtenir les terres, quoiquion ne donne qu'un demi-pied

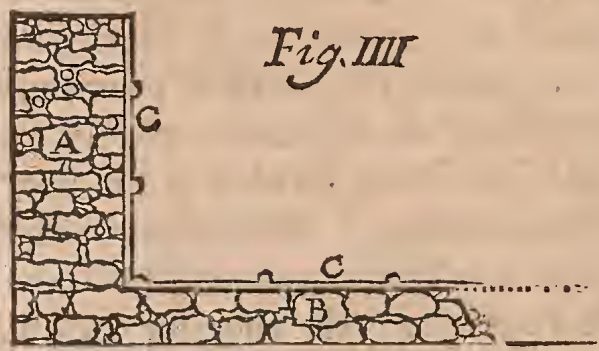
de haut, à l'aire ou platfond $B$. On bâtit ces murs de moilons, avec du mortier tour de plâtre, parce que la chaux mine le plomb, \& fur ces murs \& maffifs, on affurera les tables de plomb $C$ C, qui feront jointes l'une à l'autre avec de la foudure.

Quand on fait un Baflin dans des terres raportées ou mouvantes, il faut foutrenir le mur de terre de fix pieds en fix pieds, par des arcs boutans ou éperons de maçonnerie, dont l'empatement ait autant de largeur par le pied, que l'éperon a de hauteur, ainfi qu'on le voit dans la Figure ge. page Jwivante. 
L'on pourroit craindre fans cette précaution, que le Baffin ne s'affaifât entierement. Si le

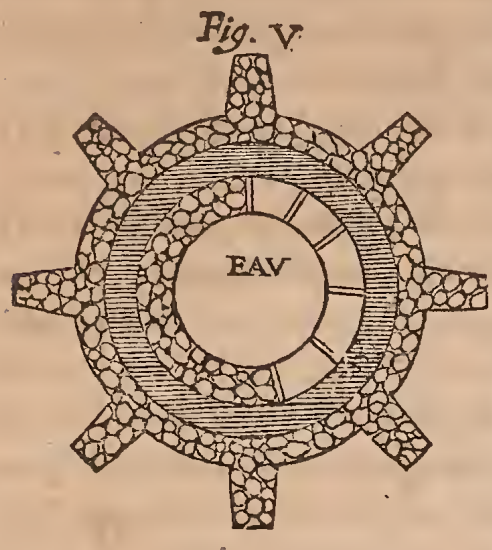
fond n'étoit pas bon, on fera des grils de charpente, des platesformes \& pilotis, fur lefquels on affurera le plat-fond.

Il eft bon de remarquer qu'en faifant le plat-fond d'un Baffin, on doit laiffer une petice pente d'un côté, afin de donner un écoulement depuis un boutjufqu'à l'autte, pour vuider entierement le Baffin \& le néttö̈er quand on veut, parle mo:̈en d'une foupape, \& décharge de fond.

A l'égard du bord \& de la fuperficie d'un Baffin, il le faut tenir bien de niveau, enforte que l'eau couvre également tous les murs, \& qu'il s'entretienne toû jours bien plein; ce qui eft d'une grande beauté à une piece d'eau, \& de grande conféquence, pour conferver les differens Baffins dont on vient de parler. Dans un Bafin de glaize, l'eau n'étant pas affés haute, la glaize du corroi du pourtour fe féche \& fait. perdre l'eau, e'eft pour cela qu'on met tout autour fur les corrois \& murs, une bordure de gazon de la même largeur, afin que le Soleil ne puiffe pas fi facileuent en attirer l'humidité. Si c'eft un Baffin de ciment, l'enduit des côtésfera fujet à être gâté par la gelée, \& à s'écrouter; fir c'eft un baflin de plomb, le Suleil le fera bouffer \& écarter les foudures ; car le plomb craint plus la chaleur que la gelée, \& l'eau enfuite fe perdra, à quoil l'on a beaucoup de peine à remedier.

On doit pour les décharges des Baffins, foir de fond our de fuperficie, obferver de les faire plus groffes que petires, étant trés-fujettes à s'engorger, nonobitant les crapaudines. que l'on met au devant. On conduit ces eaux de décharge: dans des pierrées., ou dans des tuïaux de grés, quand. ce n'eft que pour les perdre dans les puifarts \& cloaques. :mais quand elles fervent à faire joüer des Baffins plus bas. ilfauty employer des tuïaux ordinaires. 
Ces groffes décharges, outre qu'elles fervent à tenir les allées du tour d'un Baffin propres \& féches, elles font encore très-néceflaires à fa confervation : car lorfque l'eau paffe par deflus les bords, elle détrempe les terres fermes fur lefquelles on avoit affuré l'aire \& les fondemens d'un Baffin, $\&$ en affaiffent fouvent le niveau.

De ces trois manieres de faire des Baflins dont nous venons de parler, celle qui cotute la moins eft fans doute la glaize, où il faut avoir recours dans les grandes pieces d'eau, pour l'épargne. Mais c'eft auffi la plus fujette de toutes, étant très-facile à fe fécher \& à fe fendre, ce qui oblige de la remanier de tems en tems : celle qui coûte le plus c'eft le plomb, à caufe de fa pefanteur \& de la foudure qu'on y employe. La troifiéme qui eft le ciment, eft préférable à toutes par fa durée ; elle peat tenir le milieu pour la dépenfe entre la glaize \& le plomb; il n'y a jamais que l'enduit qui puiffe fe gâter ; cela eft fi vrai, que j'ay fait racommoder des Baffins de ciment, qui avoient été 10 our I 2 ans fans eau, \& qui fe font trouvés fort bons, après les avoir fait repiquer juiqu'au vif, \& enduire de nouveau.

On obfervera que la glaize dans les Pays humides, fe conferve mieux que dans les Pays fecs. Le ciment convient mieux dans les terrains arides \& fecs, \& où les glaizes font rares, parce que de fon naturel il aime la féchereffe \& la chaleur. Pour le plomb on l'employe par tout, mais avec beaucoup de ménagement: il fert plus à faire des tuyaux, que des Baffins, à moins que ce ne foit de petits Baffins fur des terraffes, dans des cafcades \& autres lieux oir l'on ne veut pas foüiller profondement, crainte de faire mourir de beaux arbres.

Il y a des Pays où il ne faut ni glaize ni ciment pour faire des Baffins, les terres tenant l'eau naturellement. Ce font des efpeces de terres franches, qu'il ne faut que délayer \& couler dans une tranchée de trois pieds de large, après a voir fait un revêtiffement du côté de l'eau pour retenir ees terres, par un mur de maçonnerie de deux pieds de large, qui fert de murde Douve.

On fe fert encore enLanguedoc \& enProvence d'une efpece 
de terre apellée Pozzolane, laquelle a la vertu de fe durcir dans l'eau, \& de durer fort longtems; c'eft de cette terre Virruve parle de cetre terte. dont on conftruit les Baffins: On la mêle avec de la chaux, vr. \& on l'emploïe comme le ciment, à quói on la peut comparer faifant prefque le même mortier.

Dans les endroits oi il y a beaucoup d'eau \& depente, l'on peut outre des Baflins \& pieces d'eau, y pratiquer encore des cafcades, des goulettes, des buffets d'eau, \&c. tantdans les allées, que dans les efcaliers \& rampes; rien n'eft plus agréable ni plus commode; les Baffins d'en-haut fourniffent ceux d'en-bas, \& de l'un à l'autre ils fe font joüer par des décharges de fond ou de fuperficie.

Les Cafcades font compofées de Napes, de Buffers, de Mafques ou Dégueuleux, de Boüillons, de Champignons, de Gerbes, de Jets, Moutons, Chandeliers, Grilles, Cierges, Lames, Croifées \& Berceaux d'eau.

On les accompagne d'ornemens maritimes convenables aux eaux, comme de glaçons, de rocailles, de congélations, pétrifications, coquillages, feüilles d'eau, joncs \& rofeaux imitant le naturel, qui fervent à revêtirle parement des murs \& bordures des Baffins. On les orne de figures, dont le naturel eft d'être dans l'eau, comme de Fleuves, de Naïades ou. Nymphes des eaux, de Tritons, de Serpens, Chevaux marins, Dragons, Dauphins, Grifons, Grenoüilles, aufquels on fait lancer \& vomir des traits \& torrens d'eau. Voilà à peu près ce qui entre dans leur compofition.

A l'égard de leur fituation \& de leur difference , les Cafcades n'en peuvent gueres avoir d'autres, que celle d'une pente douce en rampe, ou par chûte de perrons \& efcaliers de pierre, ou de talus \& glacis de gazon : on diftingue ces grandes Cafcades d'avec les petites, qui fe pratiquent, foit dans une niche de charmille ou de treillage, foit dans le milieu d'un fer à cheval d'efcalier, foit entin à la tête d'une piece d'eau, ainfi qu'on en voit des exemples dans la Planche fuivante, que nous allons expliquer.

La premiere Figure reprefente une Cafcade toute des plus fimples, \& des plus aifées à executer dans la maifon d'un paruiculier. Elle eft fuppofée fur une pente ou rampe douce, au. 
bout d'un bois percé en patte-d'oïe, dont les allées viennent: aboutir à un Baflin rond. où il y a un gros jet ; \& pour fournir davantage d'eau à la tête de cette Cafcade, l'on aura quelques décharges de Baffin au-deffus, qui viendront fe rendre à gueule-baye dans ce même Baffin. Cette tête eft entre deux efcaliers de pierre, ornés de quatre figures, \& elle eft formée partrois Mafques ou Dégueuleux, jettant de l'eau dans. des coquilles qui fon napes dans le Baffin, avec deux gros: jets qui l'accompagnent. De la largeur de ce Baffin, \& de celui d'en-bas, on a pratiqué une pelouze de gazon bordée. de deux allées, ou l'on a mis des chevrons ou arrêts de gazon: en zigzac, pour rejetter les ravines des deux côtés. Ces. allées font plantées de Marroniers \& d'Ifs entre deux, \&z derriere la petite contre-allée, on a fait regner des bois, afin de renfermer cette Cafcade, \&z lui faire un fond de verdure. L'eau fort de cette tête \& du premier Baffin par une rigole, \& vient fe rendre dans un fecond Baffin, où elle fait nape; il y a deux petits Baffins au-deffus, avec des boüil. lons, qui font aufli nape dans ce Baffin. L'eau enfuire coule dans une autre rigole, au bout de laquelle il y a un petit Baffin avec un boüillon, qui fait avant-corps \& forme une nape dans un autre baffin plus bas. Le refte de cette Cafcade eft une repetition jufqu'au grand baffin d'en-bas, qui reçoit toutes ces eaux, \& qui eft orné de deux gros jets, outre les trois perits au deffus qui font napes fur napes dans ce baflin. Il y a dans la paliffade deux figures pour l'accompagnement de toutes ces eaux.

La feconde Figure eft beaucoup plus magnifique \& plus. compofée ; ellè eft menagée fur une pente douce, coupée d'ef. caliers, perrons, palliers \& petits talus de gazon. Sa tête eft un grand baffin octogone, d'ou fort un gros champignon. d'eau faifant nape dans ce baffin : la coupe en eft foûtenü par des Dauphins qui jettent de l'eau. Il y a encore quatre boüillons placés avec fimetrie dans ce baffin, dont les eaux fe déchargent par une nape foutenuë par des. Tritons \& Dauphins qui ornent la tête de cette Cafcade. Ces eaux enfuite trouvent un repos dans des baffins, \& fe repetent par plufreurs autres napes, jufqu'à la grande d'en-bas qui eft de la 


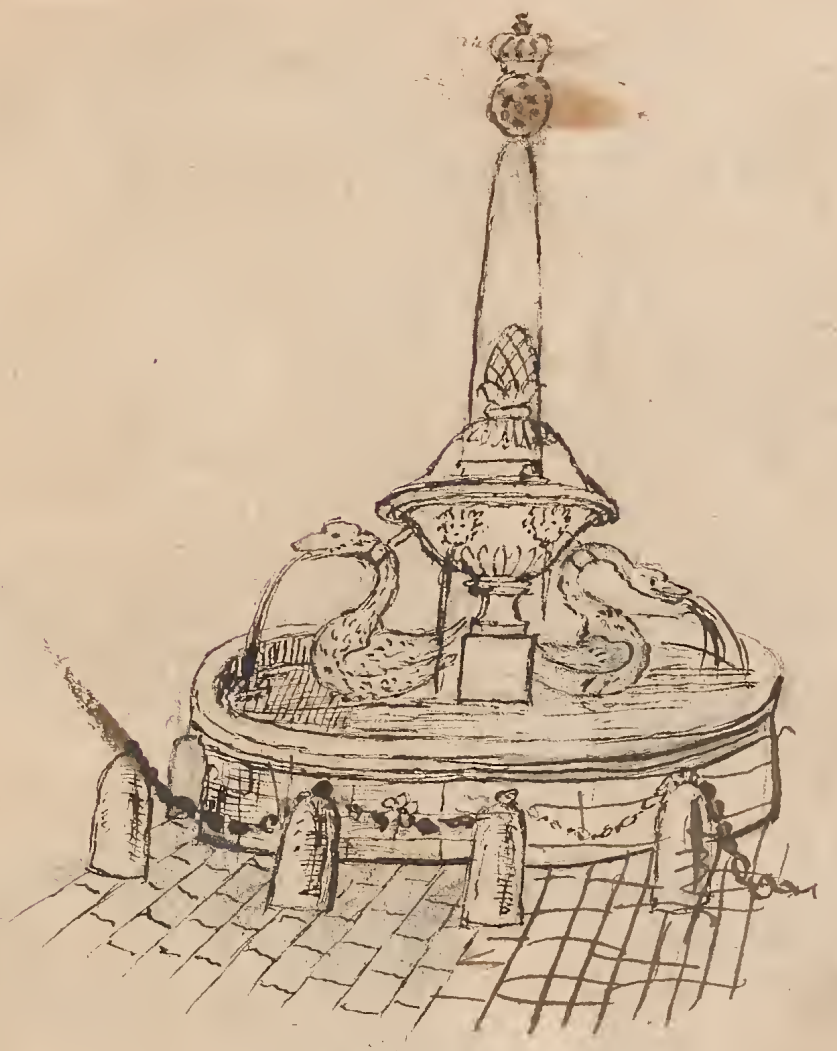





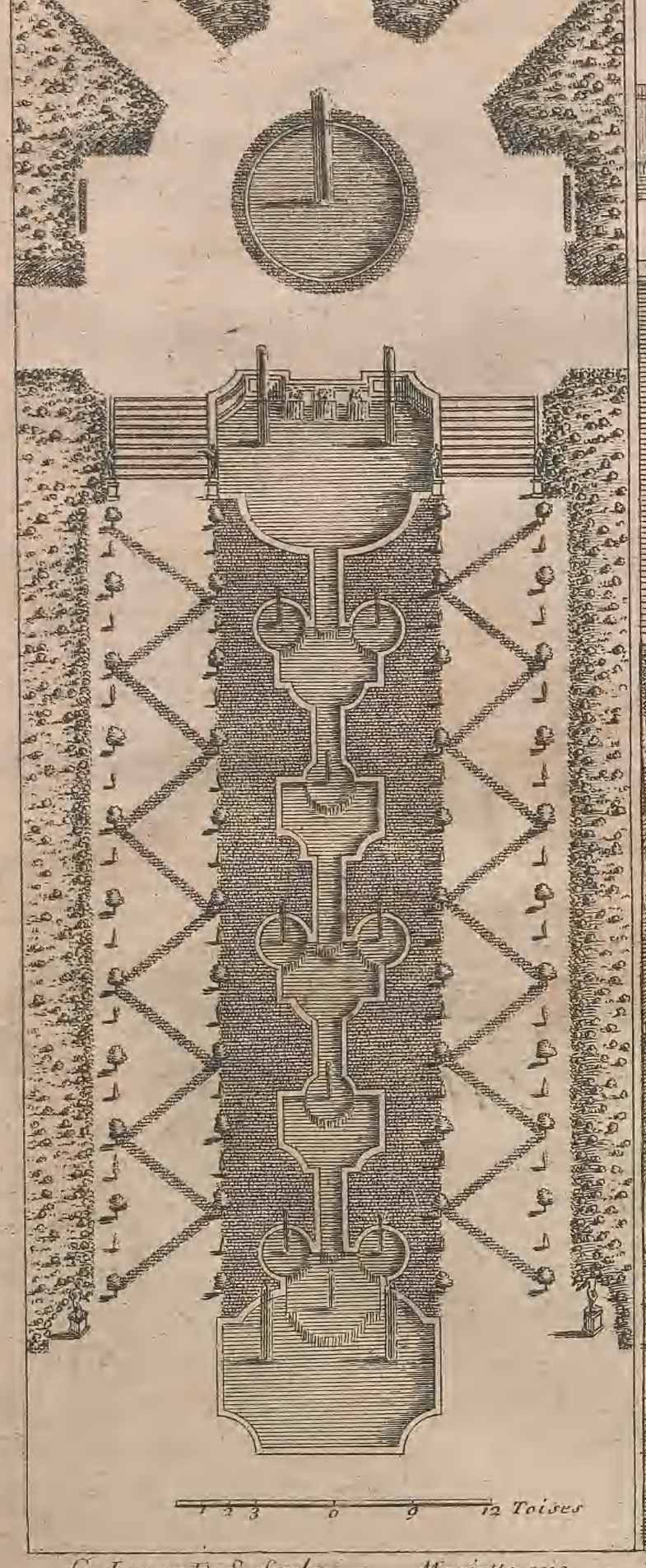

fig.3e

Elevation.

mind Fond

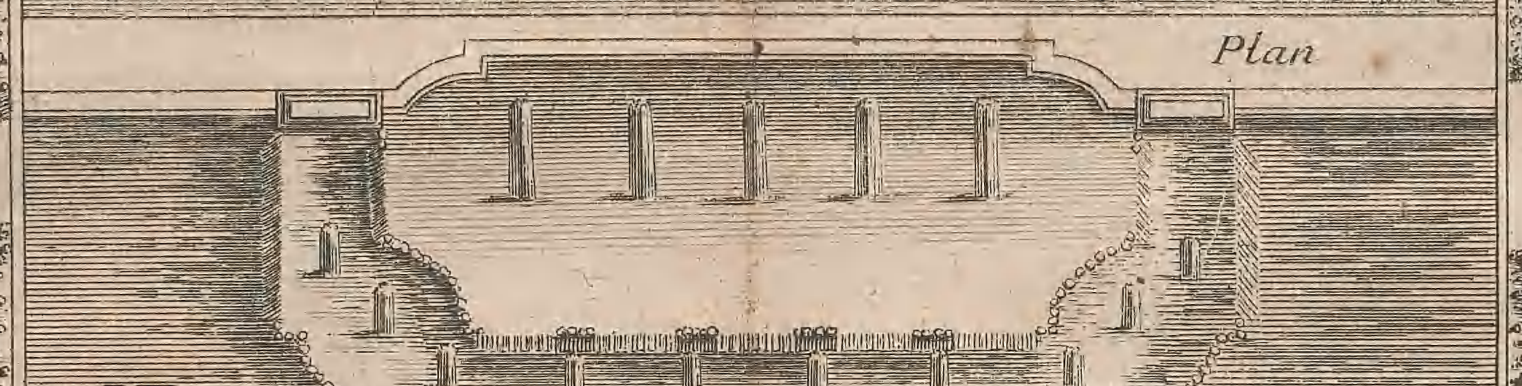

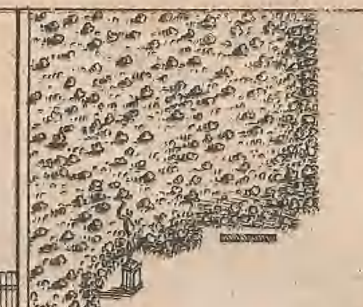

ind

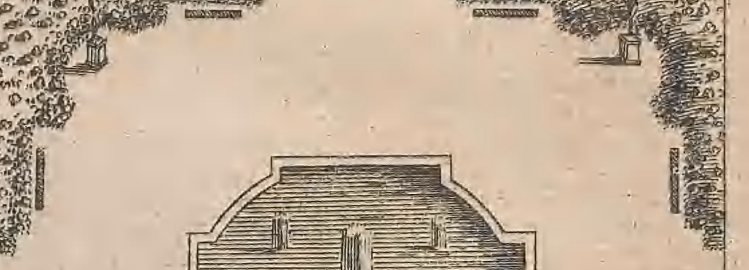
1
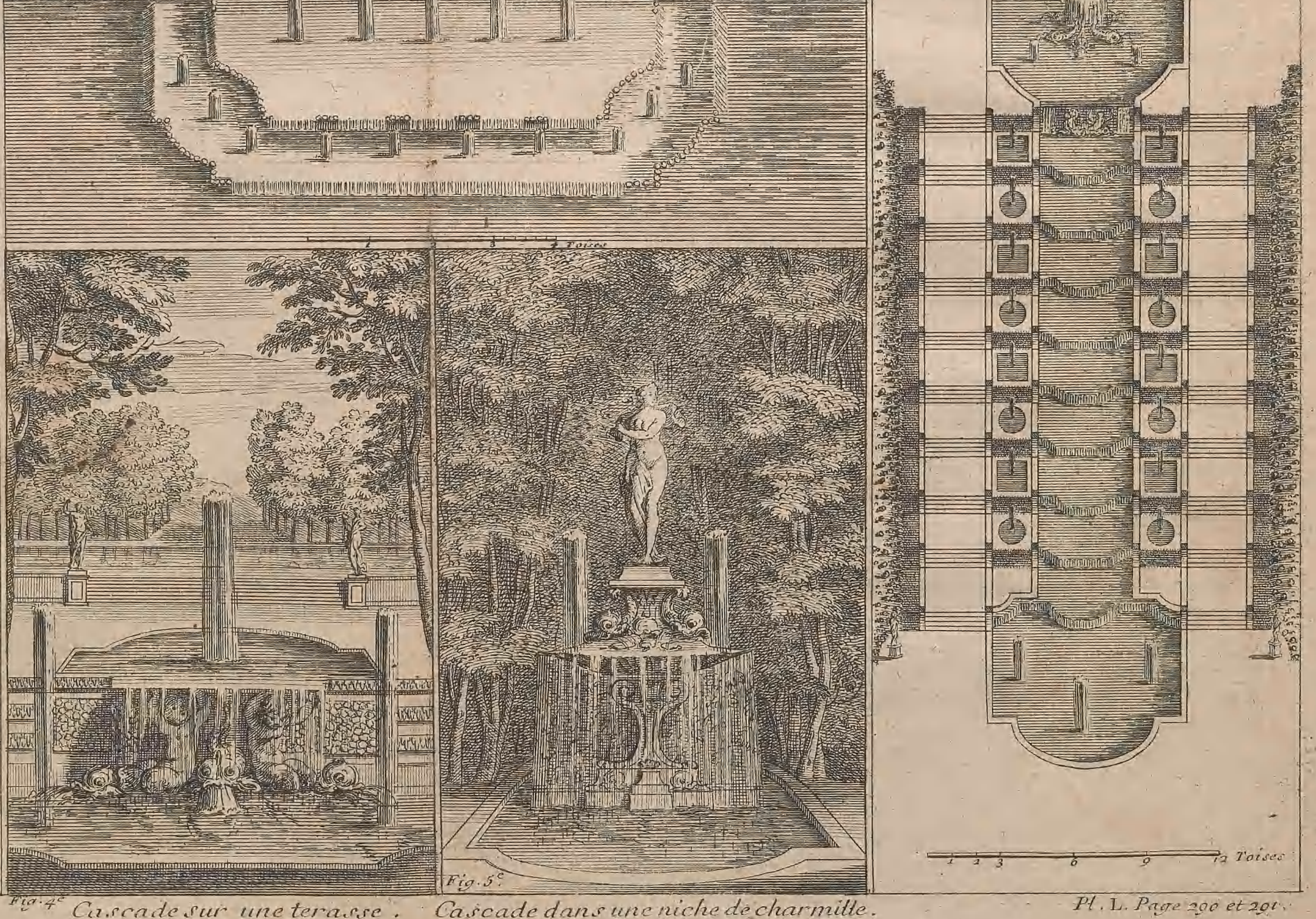

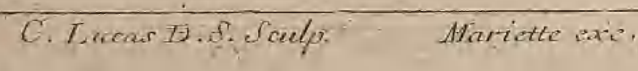



IA PRATIQUE DU JARDINAGE. 293 Largeur du grand baffin, qui reçoit toutel'eau, \& ou il y a troisgros jets, dont deux répondent à l'enfilade des jets où chandeliers des côtés, \& le troifiéme eft dans le milieu. Comme ces napes \& ces bafins feroient trop unis \& trop nuds fans jets, on a accompagné les côtés de cette Calcade de deux rangs de petits baflins apellés Chandeliers, qui font pratiqués fur chaque pallier. Ces jets n'empliffent point les baffins, qui one dans leur milieu une crapaudine \& un tuïau de décharge pour fournir aux autres, c'eft-à-dire, le premier jet fournit au troifiéme, le fecond au quatriéme, \& ainfi des autres: car en fournifiant les deux premiers jets de chaque rangée, l'on en fera joüer un cent tout de fuite. Il y a de petits talus de gazon entre cesbaffins, qui fe trouvent vis-à-vis des efcaliers, \& ce qui eft marqué en petit quarré noir fur la tablette de pierre, font des dez pourmetrre des vafes $\&$ des pots de fleurs, dont il y a trois rangs de chaque côté ; proche la paliffade eft un talus continué depuis le haut jufqu'en-bas, qui eft coupé à la rencontre des efcaliers. Cette Cafcade eft fituée comme l'autre au milieu d'un bois, car c'eft-là prefque toujours qu'on en pratique; la verdure des arbres \& des gazons, la blancheur des eaux, l'ornement des figures \& vafes y faifant un mélange \& une opofition des plus agréables à la vûë.

La troifiéme Figure eft un grand Buffet propre à mettre à la tête d'une piece d'eau, dont lecôté d'en-hautferoit foûtenu d'un petit mur de terraffe. L'on juge par l'élevation, du. bel effer que cette Cafcade feroit ; \& par le plan, dela place qu'elle occupe. Dans le bafiñ à niveau d'en-haur, qui eft le premier gradin, il y a cinq gros jets d'environ I 2 pieds de haut. Ce baffin fait un avance en forme de quarré long, échancré dans les encoignures, \& l'eau de ces jets forme des napes furle devant, qui font interrompuës par des rocailles placées dans l'entre-deux de ces jets. Dans les échancrures on voit encore des rocailles, \& fur les côtés il y a deux napes. Ces rocailles ne font ici placées que pour faire opofition, \& fervir de fond à Io boüillons d'eau, qui font dans le fecond baffin ou gradin, lequel varie affés bien avec le premier. La nape en face eft continuée diun bout à l'autre,

$0 \circ \mathrm{ij}$ 
On strouré un fixiéme deflein different de Galcades dans $\mathrm{Ja}_{2} \mathrm{e}$ difpofition generale Ch. 3. Par. I, une Cafcade en Buffet dans la Planche des Portiriques de Treillage, Ch. 8. Par. I. \& deux autres Buffets dans celle des Amphitéâtres \& Efcaliers de gazon, Chap. $3, \mathrm{Par}, 2$.
292 QUATRIE'ME PARTIE, CHAP. IY.

$\&$ fe répand dans la piece d'eau. Il y a encore deux napes affés larges fur les cốres, \& il ne fe trouve des rocailles que dansles encoignures: Ce Buffet eft orné dans le haut de deux groupes d'enfans, qui fuportent des paniers de fleurs, \& qui font pofés.fur des focles au. deffus de la tablette de la terraffe ; dans le bas il eft accompagné de deux figures de Nymphes des eaux; portées fur des Dauphins qui vomiffent de l'eau par les narines.

On voit dans la quatriéme Figure l'élevation d'un petit Buffet d'eau ou Cafcade, ménagée dans le milieu d'un efcailier en fer à cheval. Sur le plein-pied de la terraffe eft un baffin cintré par le bout, avec un gros boüillon ou gerbe d'eau., qui fe trouve en face d'un autre efcalier plus haur, \& d'une grande allée de bois, le long de laquelle eft un canal qui fournit l'eaut de cetre Cafcade. Ce gros jet retombe dans le baffin d'en-bas, par une nape foûtenuë de deux jênes Tritons \& de trois Dauphins qui bavent dans ce même baflin. Cette cafcade eft accompagnée de deux jetsfưr les côtés: les murs de la terraffe \& du fer à cheval font ornés de paneaux, de bandes de rocailles, de glaçons \& petrifications zaillées dans la pierre de taille.

La cinquiéme Figure eft propre pour le fond d'une allée', ou au bout de quelque enfilade ; elle eft pratiquée dans une niche, ou renfoncement d'une paliffade : c'eft une grande coquille élevée dans le bout d'un baffin, \& foûte: nuë de confoles \& feüilles d'eau; au milieu eft une figure de Venus fur un pied douche porté par deux Dauphins qui jettent de l'eau. Il y a deux boüillons fur les côtés de cette coquille, dont l'eau retombe par napes dans le baffin d'en-bas.

On peut faire les baffins de ces cafcades en glaize ou en ciment, avec un tablette de pierre de taille regnante par tout. Pour les petits bafiins des Chandeliers, on les taillera $\&$ creufera dans une feule pierre : les rigoles \& goulettes $\mathrm{fe}$ rontaufili creufées dans la pierre: ou bâties de cailloutages \& mortier de ciment. On pourroit encore faire tous ces baffins \& rigoles en plomb, mais cela coûteroit beaucoup . \& eft fort fujet à être volé. 
LA PRATIQUE DU JARDINAGE.

A l'égard des napes, elles feront foûtenuës par des murs bien bâtis, \& afin qu'elles faffent un bel effet, \& qu'elles ne fe déchirent point, on les fera couler fur des tables de plomb, ou fur des tablettes de pierre bien unie, \& pofées bien de niveau. Les figures dont on orne les Cafcades peavent être de marbre, de bronze, de plomb doré ou bronzé, ou au moins d'une pierre bien dure : car pourles ouvrages dans l'eau, l'on ne fçauroit emploïer de trop bons materiaux.

\section{FIN DE LA $2 U A T R I E^{\prime} M E$ ET DERNIEREPARTIE。}

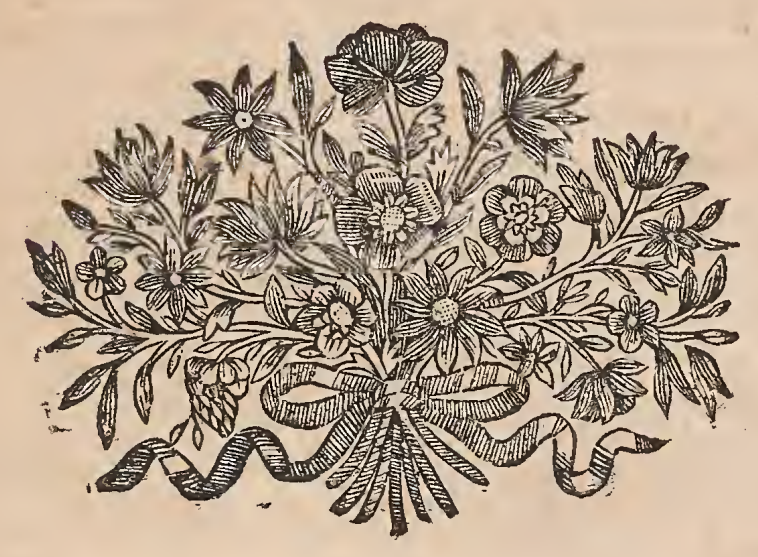




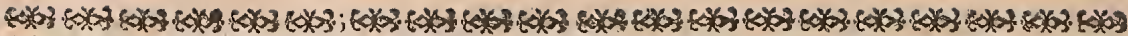

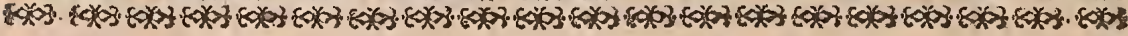

$$
\begin{array}{llllllllllllllll}
A & P & P & R & O & B & A & T & I & O & N
\end{array}
$$

T'Ai lû par ordre de Monfeigneur le Chancelier un Manufcrit intitulé : La Theorie for la Pratique du Fardinage; \& je crois que l’impreffion de cet Ouvrage fer 2 fort utile au Public. Fait à Paris ce I 5 e Décembre 1708.

\section{Signé HAYART.}

\section{$\begin{array}{lllllllllllllllllll}P & R & I & V & I & L & E & G & E & D & V & R & O & I\end{array}$}

I

OUIS PAR IA GRACE DE DiEU ROI DE FRANCE ET DE NAVARRE : nOS amez \& feaux COH feillers, lesGens tenant nos Cours de $P$ artement, Maître desRequêtes ordinaires de notreHôtel, Grand Confeil, Prevôt de Paris, Baillifs, Senechanx, leurs Lieutenans Civils, \& autres nos Jufti ciers qu'il appartiendra: SALUT. Notre bien-amé JEAN MAR1ETre Marchand Libraire à Paris, Nous ayant fait expofer qu'il défireroit donner au Public l'Impreffion d'un Livre intitulé : La Thicorie \& Pratique du Fardinare; enrichi de Tailles douces, s'il Nous plailoir lui accorder nos Letew tres de Privilege fur ce neceffaires : A CES CAUSES, Nous iui avons permis \& permettons par ces prefentes d'im Primer ou faire imprimerledit Livre, en telle forme, marge, \& caractere, \& ats tant de fois que bon lui femblera, de le vendre ou faire vendre par tout notre Royaume, pen * dant le tems de quinze années confecutives, à compier du jour \& date des prefentes : Faifons défenfes à tous imprimeurs, Libraires \& autres perfonnes de quelque qualité \& condition qu*elles foient, d'imprimer, faire imprimer, contrefaire, vendre, ni débiter, ledit Livre fous quelque pretexte que ce puifée ètre, même d'Impreffion étrangere, lans le confentement paz écrit dudit expofant, ou de fes ayans caufe à peine de confifcation des Exemplaires contrefaits, de quinze cent livres d'amande contre chacun des contrevenants, dont un tiers à Nous, un tiers के l'Hôtel Dieu de Paris, l'autre tiers audit Expofant, \& de tout dépens, dommages, \& intérêts : A la charge que ces Prefentes feront enregiftrées tout au long fur le Regiftre de la Conmunauté des Imprimeurs, \& Libraires de paris, \& cedans trois mois de la dare d'icelles sue l'impreffion dudit Livre fera faite dans notre Royaume, \& non ailletars, \& ce en bon papier, \& beaux caracteres, "conformément aux Reglemens de la Librairie, \&x qu'avant de l'expofer en vente, il en fera mis deux Exemplaires dans notre Biblioteque publique, un dans celle de notre Château du Louvre, \& undans celle de notre trés-cher \& feal Chevalier Chancelier de France le fieur $\mathrm{P}$ helipeaux Comte de Ponchartrain, Commandeur de nos Ordres, le tout à peine de nullité des $\mathrm{P}$ refentes : Du contenu defquelles vous mandons \& enjoignons de faire joüir P'Expofant, ou fes ayant caufe pleinement \& pailiblement, fans fouffrir qu'il leur foit fait aucun trouble ou empéchement. Voulons que la copie defdites Prefentes qui fera imprimée au commencement ou à la fin defdits Livres, foit tenuë pour duëment fignifiée, \& qu'aux Copies collationnées par l'un de nos amés \& feaux Confeillers \& secretaires, foi y loit ajoûtée comme à l'original. Commandons au preinier notre Huiffer ou Sergent, de faire pour $l$ execution d'icelles tous actes zequis \& neceffaires, fans autre permiffion, nonobftant Clameur de Haro, Chartre Normande \&\& rettres à ce contraires : CAR TEL EST NOTRE PLAIS1R. Donné à Palis le dix-huitiéme jour de $\mathrm{Mai}$, l'an de grace mil fept cent neuf, \& de notre Regne le foixante \& feptiéme. Par le Roi en fou Confeil.

Signé B E L L A VO INE.

Regifré fur le Regiftre No 2 de la Communauté des Imprimours ó Libraires, de Paris, page 462.

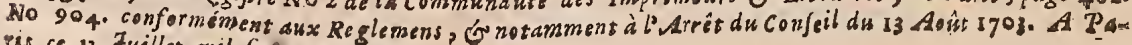
iis a 32 fuillet mil fept cont neufo

Signé, I, SE YESTRE, SYydic. 

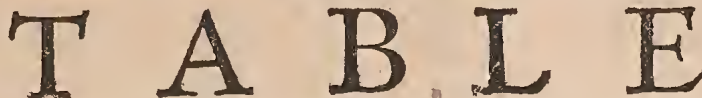

\section{ES M A T I ER E S}

\section{CONTENUES DANS CE VOLUME。}

A

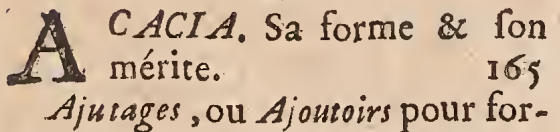

mer un jet d'eau, de combien de fortes, 273. Quels font les meilleurs, ibid.

A'atorne. Ses feiuilles, fon bois, 169. Comment il faut l'élever, 2 I: Allées dans un Jardin. Leur utilité, 5 r. Comment on doit les faire, 22.23. of fuiv. Adreffe pour profiter de la longueur du terrain pour une Allée, 3 6.Diverfes fortes d'Allées, ibid. Regles qu'on doit obferver pour la pente des Allées. 53. De la largeur des Allées, 53.\& fuiv. De leur longueur, 54. L'entretien des Allées, 55.Možen de l'éviter, 5.5. 56. Maniere de bien dreffer les $A l-$ lees, ibid. \& II 9 . \& fuiv. Maniere de les fabler\& de les battre, 56 . Les Arbres dont on fe fert ordinairement pour former de belles Allées, I 70. \& fuiv. La meilleure maniere de bien élever \& drefler desAllées, I94.

Altea Frutex, ou Guimauve Roïale. Son bois, fes feuiilles, fes fleurs \& fon ufage,

216 Amarante.Sa graine, 245.Com- ment il faut l'élever, 246 . Sa faifon propre, 260 Ambrette. Fleur, $\quad 245260$ Amomsm.Ses fruits, fes feuiilles, fon bois \& fa graine 2.28 Ancolie, Fleur, $247 \& 260$ Ancmones fimple \& à peluche. 25 I.Comment elles fe confervent hors de terre, ibid. De leur graine, 25.2. Leur place dans un Jardin. 257 . Leur faifon, $25926 \mathrm{I}$

Aqueducs, 269. Differentes fa. çons de faire couler l'eau dans les. Aqueducs . $2702.7 \mathrm{I}$ \& fuiv.

Arbres \& Avbriffeaux, qui confervent leur verdure enHyver, 167 io Juiv.

Arbres. Du choix que l'on doit faire des Arbres convenables aux Jardins de propreté, 160 . \& fuiv. Des Arbres fauvages, 161. Des aquatiques, ibid. Avantage des $A r$ bres \& Arbriffaux verds, 170.Obfervations à faire furle choix de ces Arbres, I7I. I 72. Du tems de les planter, 187 \& fuiv. Du foin pour les élever, 190 of fuiv. Expedient pour redreffer les vieux $A$ rbres, 194 199. De leurs maladies, \& les moïens d'y remedier, 197. I98. Du choix des Arbres qu'on doise 


\section{T A $A$ B $L$}

piendre dans une pepiniere, \& les moïens de lesbien lever en motte, 207 \& fuiv.209\& fwiv. Des graines $\&$ des fruitsdes Arbresconvenables aux Jardins de propreté , $2: 09$ \& fuiv. Des Arbres \& Arbriffeaux de fleurs, 2 I 3 of ruiv. Des Arbres emmotés, 220.Maniere de greffer les Arbres \& Arbriffeaux de fleurs.22I के fuiv. Saifon où ils font en fleur, 225

Arbres de Judée.Son bois, \& fa feiiille, 218 Arcades. Paliffades percées en Arcades. 183 Arrofement. Des bons Arrofemens, \& du tems de les faire. 192 Antbirrinum, ou muffle de Lyon, Alewr. 260 166

Aulne. Son bois \& fes ufages.

\section{B}

B Aguenaudier, ce que c'eft.Son bois, fa feüille, fa fleur $\&$ fon fruit.

218225

Balfaimine panachée. 245260 Bancs. Leur place dans un Jardin.

Baflic.

9495 Baffin. Sa place dans un Jardin. 278. Sa forme \& fa figure, 279. Sa grandeur \& profondeur, 279. Des $B$ a fins de glaize, 280281 \& fuiv. Elevation des murs \& corrois d'un $B a \int f i n$ de glaize, 282.284 Plan de conftruction d'un Bafjin de glaize, ibid Conftruction d'un $B$ affin de ciment , 285. Conftruction d'un $B a f j i n$ de plomb,

Baflinet,

248259

Belle-de-nuit, 245260

Bellevedere, Ce que c'eft, 93
Berceaux, ou Portiques, 85.Des naturels \& artificiels, 85.86. Leur compofition, 86. En quoi ils different d'un Cabinet, ibit. L'ufage des Berceaux, 86. 87. Exemple de divers Berceanx de treillage, 87 o Suiv.

Bois. Leur utilité dans un Jardin, 67. Voiés Bofquets. Six efpeces de Bois, 64. 65. Differens deffeins de Bois reprefentés en dix Planches, 6667 o fuiv. La meilleure méthode de planter desBois, I 85

Boulean. Arbre. Son bois, fon écorce \& fa feüille, $\quad \mathbf{6 5}$

Boulingrins. L'origine de ce mot 75. Differentes efpeces de Boulingrins, \& leur figure, 75.76 \& fuiv. Leur place, 76 . Leur agrément, ibid. Maniere de tracer un Boulingrin fur ie terrain, is6 Is7 6s fuiv.

Bofquets. Sont l'ornement d'un Jardin, $21.23 \cdot 63$. Leur place, ibid. Leur differente forme \& deffein, 63. 64. Bofquets parés. 65. Tracer un Bofquet fur le terrain, 152 \& fuiv. Maniere de planter un Bofquet. is 85 I 86 Branches. Du choix de la Branche d'unarbre, 193 . Pourquoi il n'en faur laifer qu'une, I94. Cas auquel on "en doit laiffer plufieurs. 193

Buis, Arbriffeau. De deux fortes, I69. Proprietés de l'une 82 de l'autre efpece. ibid. \& fuiv. Maniere de planter le Busis, 175 I76

Buiffon-Ardent, Arbriffeau.Son bois, fa feiville \& fes fruits, 218 225 
C

\section{DES MATIERES.}

Conflans, Ses Jardins.

21

Coquelico double, fleur, 246260

Abinet de verdure, $\quad \quad \quad 83$ Caijos de fleurs,

Camomille, fleurs 247260

94

Camparelle, fleur, 247.260

Cambarides, petits animaux, \&

le moïen de les détruire, ibid.

Cesprcine, fleur,

Cafcades Leur fituation, \&c.

289. Figures de plufieurs Ca/cades, ibid. of Juiv.

Ceratre. Nombre des dégrez de l'angle du Centre.

I I 4

Cercle parfait, 98. 99. Tracer un Cercle fur le terrain,

II 5

Chantilly. Ses Jardins naturels, as

Chardon-benit, fleur, $245 \cdot 260$

Charme. Son bois \& fes proprierez,

Charmille.Son mérite, 172 . Comment elle doit être pour être bonne. ibid.

Chataignier, Son écorçe, fes feüilles., fon bois \& fon fruit, $\quad 1 \sigma_{2}$ Chataignier de cheval, 163 Chenilles Le moïen de les détruire.

200

Chefne, Arbre. Sa beauté, 161:

Son bois \& fon fruit

162

Chefne. verd, Arbre, 169. En quoi il differe du Chefne. ordinaire, ibid.

Chevre-fëille, Arbriffeau. Son bois, fa feüille \& fa fleur, 217.225. Sa culture,

236

Ciclamen, fleur 248.259.260

Clochette, 247.260 i. 8

S. Cloud Ses Jardins naturels,

Colonades vertes, 182

Colutea, Arbriffeau. Son bois, fa feuille \& fa fleur, 217. Fleurit en Efté, 225 . Sa culture. 236
Coqueloside, fleur. 247260

Cordeau, 99. I00. Tirer avec le

Cordeau une ligne droite fur le terrain, I04 \& fuiv. Voilés Ligne.

Tirer avec le Cordeas un poligone, II.2. Vo:iés Poligone.

Côteau. Couper un côteau fur fa longueuren terrafles, I 3.5 of Juiv. Voiés Terraffes.

Couche.Plantes qui fe fement fur couches.

Coudrier, ouNoifetier, Son bois,

fa feiille \& fon fruit, $\quad 167$

Couronne Imperiale, fleur, 248

\& 259

Creffon-d'Inde, fleur.

Crocus, fleur. 248299261

Croix de Jerufalem, fleur. 247

260

Cryfantemon, fleur. $\quad 245260$

Cyprès, Arbre. Son bois, fon feiuillage \& fon fruit.

168

Cytifus. Son bois, fa fleur \& fa feuillle.

217225

D

TEblay. Ce que c'eft. I34 Derni-cercle. Ce que c'eft, \&? fon ufage. 9899

Deffein. Maniere de tracer toutes fortes de Deffeins pour un Jardin, 147 of fuiv.

Difpoftion d'un Jardin, Is fuiv. VoiésJardin. Les regles qu'on doit fuivre, 20 \& fuiv. De qu'elle confequence eft la Dipojition d'un Jardin

E

40. 4 I

TAux. Leurs fources, \& la mauniere de les trouver, $262.26_{3}$ Tems auquel on fait la recherche des Eaux, 264 fuiv. Machines $\mathrm{PP}$ 
differentes pour élever l' $E_{Q U}, 267$ difuiv. Des refervoirs, 268. Trois manieres de conduire les Eaux. 269. Eanx jailliffantes, ou Jetsd'Eanx , 272. La jufte proportion que l'on doit donner aux conduites par raport aux Jets d'Eaux , 272 . 273. Diftribution des Eaux dans un Jardin, 277. Eamx naturelles \& artificielles, ibid. Eanx jailliffantes \& plates, 277. 278. Eanx vives $\&$ dormantes. 268

Emerus. Son bois, fa feliille \& fa fleur. 2. 8225

Ef ine-blanche, ou Aubepine, A rbriffeau. Son bois, fes feitilles, $8 x$ fes fleurs.

2.66 167

Erable, Arbre. Sa feüille, fon écorce, fon bois, fon mérite, I.64

Efcalier d'un Jardin, Sa place, $\checkmark 40$ Des marches d'un Efcalier. \$4I. Figures reprefentans plufieurs Efcaliers de pierre, $14 t$ of fuiv. Efcaliers de gazons, 14,2143 \& friv.

\section{F}

1 Leurs. D'où elles proviénnent; 24 . Maniered'éleverdes Fleurs, 242243253 Lieu refervé pour les élever: 244 . Tems propre, 244 . 245 . Celles qui fe fement fur couche au Printems, 245. Celles qui fe fement en pleine terre, 246. Fli urs qui viennent de graine, 245 furv. Celles qui n'en viennent pas, 2 47. De la place convenable à chaque Elear dans les Jardins. 255. Fleurs duPrintems, 2.58 .25 .90 Fleurs de l'Efté, 259. Fieurs d'Hyver, 26 . Fleurs qu'on peut faire Heurir pluffeurs mois de fuite, 261 . tarfaifon de chaque Fleur. 2.25
Fleur de la Paflion. 247

Figure \& ftatuës de bronze, font les plus belles, 92. Figures d'efpeces differentes, 92. 93. Leur place dans un Jardin.

93.

Figure, Difpofition. Tracer avec lecordeau une $F$ igure irreguliere de quatre côtés, 110. Tracer avec linftrument une figure irreguliere de quatre côtés, III. Voïés Poligone.

Fondis. Ce que c'ett. 134

Fontaines. L'ornement des Jardins, 91 . Leur place dans un Jardin, ibid. \&

Forêts. Bois. 278

64

Eournis. Divers mor̈ens de les détruire. 201

Frefne, Arbre. Son bois \& fes feüilles. 154

Frnits pour femer, 209 \& fuiv.

Futaiie. Bois de haute \& moïenne Eutaïe.

6465

$$
\text { G. }
$$

Aleries de verdure. 183

IGazon. de fa graine, 80. Le tems \& l'art de le femer, 79.80 . Maniere de plaquer le Gazon, 80. $8 t$. Mö̈en fûr d'avoir de beaux Gazons, 8r.Du Gazon à pointe, ce que c'eft, 83. Comment on entretient un Gazon. 83

Geneft. Son bois \& fes fleurs, 216. 225. Sa culture. 236 Genevrier, ou Genievre, Arbriffeau. Son bois, fes feuilles, for odeur. 169.

Geraniam couronné, fleur, 247 260

Giroflée d'Angleterre. 247260 Giroflées doubles 3.245.0.259. Giroflée jaune.

247259. Glacis de Jardin. 7982 


\section{E S M A T I E R E S.}

Graines. Qualités requifes pour Être bonnes, 209. La faifon \& le tems propre pour les femer, 210. Moïen de les conferver, 2 I. Graines qui fe fement auPrintems,245. Celles qui fe fement en Automne, 246

Greffe. La maniere de greffer les Arbres, 22 r. L'inftrument avec lequel on greffe, ibid. Le tems de greffer, 222 \& fuiv.

Grenadiers. Son feüillage, fa tête \& fa tige, 2I 4. Deux efpeces de Grenadiers, ibid. Son fruit, 214. $\$$ a culture, 235 . Maniere de le greffer, 223 . Saifon où il eft en fleur, 225

Grenadile, fleur.

Grilles, de Jardin.

Grotes.

\section{$\mathrm{H}$}

247

94

9394

$\mathrm{H}$ Anetons. Comment on les extermine. 2 OI Heliotrope, fleur. Hemerocale, fleur. Hepatique, fleur. Heftre, Arbre. Son écorce, fa feüille, fon bois, fes proprietés, 163164

Houx, Arbriffeau, Son bo:s \& fes feiiilles.

\section{I}

169

Acintes. 248259261 Jalons. Ce que c'eft. 100 IOI Jardins. Jardinage. Combien la fçience du Jardinage eft noble \& agréable, 5 . L'utilité de ce traité du Jardinage. ibid.Sa divifion, 6. Quatre expofitions differentes duSoleit en fait de Jardinage, ro. Des difpofitions \&e diftributions des $J$ ardins, I5. Vraïe grandeur d'un beaus
Jardin, 18. 1 9.20. La proportion d'unJ ardin pour la longueur \&largeur, 20. Regles generales qu'on doit fuivre dans les difpofitions $8 c$ diftributions des Jardins, 20. 6 fuiv. Trois differentes fortes de Jardins qui fe peuvent pratiquer. 24. Jardins de niveau, 25 . Jardins en pente douce, ibid. Jardins ent terraffes , 25. Quels font les plus beaux, 25 of fuiv. Exemples de differents Jardins gravés en cinq diverfes Planches, 2526 of fuiv. De la maniere de planter les diffe. rentes parties d'un Jardin, I 75176 of fuiv.

Jafee des Indes, fleur. 247260 Jafmin, Arbriffeaus. Son bois, $\sqrt{2}$ feüille, fa fleur, fes differentes efpeces, 2 I 5 . T ems où il eft en fleur. 225 . Sa culture.

235

Jauniffe d'un Arbre. Sa caufe \&e fon.remede:

Jets-d'eau, 272. La proportion des tuïaux par raport au Jets,272. 273. Maniere de faire fervir une Conduite à plufieurs Jets, 274 . Voiés Eau.

If, Arbriffeau. Son bois \& fa feüille, 167.168 . Son ufage, 176 . Le lieu \& le tems de le planter. ibid.

Inmortelle, Fleur. 246260 Imperial, Arbre. Ses feüilles. fon bois, fon écorce, fa graine . 162

Jonquilles fimples 2 doubles, 248

Iris bulbeux, fleur. 248259 Arbre de Judée. Son bois, $\sqrt{ }$ a feüille, \& fes fleurs. $\quad 218225$ Julienne fimple, fleur. 247260 Julierne double, ibid. 


\section{T A B L E}

I.

L Aurier. Son bois \& fa feüille, 215. Six efpeces de Laurier. ibid. Sa culture, 235. La faifon où il eft en fleur. 225

Lentifque. Son bois, fa feuille $\&$ fa fleur, \& fon fruit, $z 218.225$. Sa culture. 256

Leonurus. Son bois, fa feiiille fa fleur $.2: 8.225$. Sa culture. 2.36

Ligne. Maniere de tirer une ligne droite furle terrainavecle cordeau, I04. ou avec des piquets, ibid. Maniere de la prolonger, Ios. Tracer avec le cordeau une ligne droite qui foit d'équerre ou perpendiculaire à une autre ligne droite tracée, 105, furv. Tracer avec l'inftrument une ligse perpendiculaire 2े une ligne droite tracée, so6. Tracer avec le cordeau une ligne perpendiculaire à l'extremité d'une ligne droite tracée, ibid.Tracer avec le cordeau une ligne parallele z̀ une ligne droite tracée. 107 Lilas. Son bois, fa feüille, fes Heurs. 216225

Limaçon, animal, 20r. Maniere de les détruire, ibid.

Lys-flame, fleur, 248.259. Lysblanc, ibid.

\section{$M$}

M Arguerites, fleur. 247259 Martagon, fleur. 248259 Matricaire, fleur. 247260 Marfault . Arbriffeau. Son bois \& fa feüille.

Meudon. Ses Jardins.

Mignardife, fleur. $\quad 247260$

Moulin à eau \& aे vent, 268 La maniere d'élever les eaux par les Moulins. Brouffe des arbres:

267268

299
Mufle de Lion, fleur. $247 \approx 60$ Muguet, fleur.

247259

Mulot, Animal, 200. Maniere de les prendre, ibid.

Adufcipula, heur. 246260

Myrtbe, Arbrifleau. Sa tige, $\sqrt{2}$ feiiille, fes fleurs, 214. Diverfes fortes de Myrtbe, 215. Sa culture, 235. Maniere de le greffer, 223. Saifon où il eft en tleur.

225.

\section{$\mathrm{N}$}

T Arciffes communes \& dous 1 bles, 247. 250. Narciffes de Conftantinople. $248 \& 259$. Niveau. Ce que c'eft, 120 . Deux fortes deNiveau, ibid. Son ufage, I2I \& fuiv. Le tems propre pour niveller, 122. Lamaniere dele faire, T22 \& fuiv. Dreffer une ligne de Niveau fur le terrain, 125. Dreffer \& unir le terrain fuivant une ligne de Niveau. $126 \quad 127$ Nivean à fioles. 264

Noifetibr, Arbriffeau, Son Bois, fes feiilles, fon fruito

167

o.

Culus-Chrifti, fleur. 247260 Oeilade-breuf. 247260 : Oeillet d'ESpagne, 247. Ociller, ou Jacinthe des Poëtes, ibid. Oeilo lets fimples $8 x$ doubles, $247: 260$. Oeillet-d'Inde. 245266

Oignons de fleurs. Maniere de les planter , 243. Differentes efpeces 248. Les meilleurs Oignons. 243 Oranger. Satige, fon bois, fes feuilles, fes fleurs \& fesi fruits, 214 . Diverfes fortes d'Orangers. ibid. Leur graine \& leur durée, 214. Le moien de les élever, 219. 220. Maniere de les greffer, 22 I, 222. Le tems qu'ils font en fieur, 2.25. De la culture des Orangers. 226 . De la ferre des Orangers, \& 


\section{DES M A T I ER E S.}

de leurs qualités, ibid. Compofition des terres, 227 . Maniere de rencaiffer des Orangers, 228 . Leur expofition dans les Jardins, 229. Leur arrangement, ibid. 你 juiv. L'arrofement, 230. La faifon de lesferrer \& fortir, 23 I. Leur tranfport, $2.32 \mathrm{La}$ maniere de gouverner lesOrangers dans la ferre, $\mathbf{2}^{2} \mathbf{2}$ 233. Moien de les garantir des infectes, 234. Des maladies des Orangzse, 237. Moïen de rétablir lesinfirmes, 236.237 . \% juiv. La longueur de leurs maladies,2,3 8

Oreille-d'ours, fleur.Changeante en couleur, \& trés-variée, $\$ 47$ 253 259

Orme, Arbre. Son bois, fon feuillage, fa durée.

162

Ovale. Maniere de tracer un

Ovale fur le terrain, i I 5 . de tracer un Ovale, dont les deux diamerres foient déterminés fur le Papier, I 16. I 17 . de tracer fur le terrain un Ovale, apellé communément, EOvale du Jardinier.

218

\section{$\mathrm{P}$}

D. Aliffades. De leur beauté \&s des differentes formes qu'on peut leur donner , 57. . Six exemples de differentes Paliffades, reprefentés dans une Planche, 5.9 \& fuiv. Les plants les plus eftimés à l'égard des Palißades, $17 z^{2}$ Lamanieredeplanter des Paliffades, 180. La difficulté de faire venir les Paliffades dans un Jardin, 180. I 8r. La maniere de les tondre, 195. Le moïen de bien entretenir des $P$ aliffades, 195 I.9.6. \& de les regarnir.

198

Palma-Chrifi, Aleur. 245260

Parallele du papier avec le termain $_{2}$ en ce qui regarde la maniere de errecer, 104 \& fuiv.

Parterre. L'origine du nom de Parierre. Terrain qu'il doit occuper, 20. Comment on décore la tête d'un Parterre, 22.39. D'où font tirées les broderies \& les compartimens des Parterres, ibid. Deffeins differens qui entrentdans leur compofition 3.9, Comment doit être la broderie des Parterres pour être belle, ibid. Quatre fortes de Parterres, 4.1. Parterres de broderies, pourquoi ainfi apellés, ibid. Parterres de compartiment. Parterres à l'Angloife, ibid. Parterres de pieces coupées, ou de découpés 42. De la difpofition desParteres, ibid. Leur vräre place, $4^{2-}$ Leur largeur \& leur longueur, ibid. of fuiz. On ne met plus de grandsArbriffeaux \& Ifs dans les Parter. res, pourquoi , 43. Les Parterres font plus beaux le: premier: jour qu'ils font plantés, que dans: la fuite, \& pourquoi, 44. Tracer un Parterre fur le terrain, is 1 \& Juiv. Maniere de planter un Poriterre, 175. 176. Comment il faut le tondre, \& en quel tems 177 . Fleurs emploriées dans un Partero: re, 240, \% juiv. Des differentes décorations des.Parterres fuivant les.faifons:

$255:$

Purfe-velours: fleur- 245260

Pate, en terme de Jardinage. ce que c'eft.

Pavot double.

Penfées, fleurs.

134

24759

Pente. Dreffer un terrain fur une ligne de Pente:

I.29

Pepinieres, Le fecours qu'on en retire , 203. Leur place; ibid. Du choix du terrain d'une Pepisiere. \& de la maniere de la preparer 
204. Le moïen d'avoir une belle Pepiniere, 205 . Pour élever des $P e-$ pinieres en peu de tems, 206. Pour redreffer les arbres d'une $P e$. piniere, 207. Ce qu'on doit faire avant que d'enlever un arbre de la Pepiniere. 208209

Perspectives \& leur utilité. 9394

Peuplier, Arbre. Son bois, fon écorce, fes feüilles. Phafeole, fleur. 166 Pbileria, ou Filaria, Arbriffeau. Son bois, \& fes feüilles. $\quad 169$ picea. Son bois', fa feuille, fon ufage. 168

Pied-d'aloüette, fleur. 246260 $P_{\text {in }}$, Arbre. Son bois, fon écor$c e$, fes feüilles, fon fruit, \& $\sqrt{2}$ graine. 168

Pivoine, fleur. $\quad 248259$ Plantage De la maniere de planier toutes les differentes parties d'un beau Jardin, 175 of fuiv.Le tems \& faifon de planter des arbres. 187188

Patane, ou plase, Arbre. Son bois, fon écorce $\&$ fa feüiile. I 65 Plantes vivaces. 247 Plants. Du foin que l'on doit prendre des jeunes plants, I 90 I 9 I of fuiv.

Plates-bandes. Leur ufage $8 x$ utilité; 44. Quatre fortes de Platesbandes. ibid. of fuiv. Fleurs emplöées ordinairement dans les $P$ lates-bandes des parterres, 240 to fuiv.

Poligone. Maniere de tracer avec le cordeau unpoligone tel qu'il foit, I Is Tracer avec l'inftrument tel poligone que ce foit, II3. II 4 . Noms des poligones, ir4. Nombre des dégrés de l'angle du Poligonse.

114
Pomme-épineuse, fleur. 245269

Pompes a bras \& à cheval, ${ }_{2} 67$. Pompes foulantes \& afpirantes, 267 268 .

Portiques de Jardins, ce que c'eft, 85 \& fuiv. Portigues de toute forte, 85 \& fuiv. jufqu'ă 9t. Vö̈és Berceau, Des plans qui conviennent le mieux aux ortiques, 172 . 173. La maniere de planter des Purtiques.

18

Primevere, fleur. 347259

$Q$
Uenë-de-Renard, fleur, 245
Quinconces, 66.73. Maniere de ies planter.

$\mathbf{R}$ 186

Acines vivaces.
Rampes. Remblay. Ce que c'eft 79 Renoncules de Tripoli. 248259 Refervoirsd'eaux. Deux fortes de Refervoirs. $\quad 268 \div 59$ Romsrin. Son bois, fa feüille \& fa fleur. $\quad 27225$ Rose-d'Inde. $\quad 245260$ Rofes.trernieres. $\quad 247$ Rofier. Ses differéntes efpeces $8 x$ fleurs, 216,225 . Sa culture. 235 Ruël.La fituation de fes eaux. I 3

\section{$S$}

Abine, Arbriffeau. Son bois \& $\checkmark$ fes feüilles. 169

Sable de riviere \& de terre. 57 Sain-foin d'Efpagne. $\quad 245247$ 260

Sapin, Arbre. Son bois, fa feüille, fon fruit, fa graine 8 fes ufages, 168. Different du Pin ibid.

Sceavix. Sa fituation \& fes Jardins. 18 


\section{E S M A}

Seringal.Son bois, fa feüille, \& fa fleur, 217.225. Sa culture, 236 Serre desOrangers, \& leurs qualités, 226 . O fuiv. Voïés Oranger. Situation d'un Jardin. Quelle elle doit être, 7. G\% Juiv. Les cinq conditions qui font n'éceffaires à une bonne frtuation, 8 fuiv. jufqu' à 14. Sitration d'une allée.' 5253

Souci double, fleur. 246260 Statifée, Aleur. 247260

Stramonium, fleur. . 245260 Sycomore, Arbre. Son bois, fon écorce \& fa feuille. 164165

\section{T}

TAillis. Talajpic annuel. Talappic vivace. Talus.

Taons. Gros vers.

Taupes. 200. Maniere de les prendre. ibid.

Tilleul, ou Tillot. Sa feüille, fa tige, fa tête, fon écorce, fes fleurs \& fon bois.

I 3

Terraind'un Jarđin de propreté, quel il doit être,7. Sa fituation, 7. Juiv. Le moïen de connoître fi. unTerrain eft bon. I 0. \& fuiv.Comment l'ameliorer, \& qualités requifes à une bonne terre, I I f fuiv. Dans le choix d'un Terrain, il faut qu'il s'y trouve aifément de l'eau, 1.3.Comment corriger un Terrain, I5. Maniere de dreffer un Terrain. 119. एँ Juiv.

Terraffes differentes, I 32 . Elles ne doivent point être trop frequen. tes, 133 - 134. Couper un côteau fur fa longueur, en Terraffes foutenuës par des murs de maçonnerie, I 3 5. Dreffer entierement un côteau fur fa.largour, en le coupant

\section{T I E R E S}

enT erraffes foutenuës par des murs de maçonnerie, 136. Couper un côteau fur fa longueur, en Terraf fes foûtenuës pardestalus \& glacis de gazon, 137. Dreffer entiere. ment un côteau fur fa largeur, en le coupant en Terraffes, foutenues pardes talus \& glacis de gazon, I3 8139

Terre. La maniere de foüiller \& tranfporter les Terres. Toife. Ce que c'eft. I 23 Tournefol, fleur.

Tracer. Cequ'il faut faire 247260 bien Tracer.

Traçoir.

$10 \mathrm{r}$

Treillage, Voïés Bersear.

Tremble, Arbre. Ses feiilles, fon écorce, fon bois \& fes proprietés. 165

Triangle. Tracer avec le cordeau un Triangle égal à un Triangle marqué fur le plan.

109

Tricolor blane \& noir. 245260

Trifolium. Son bois, fa fleur \& fa feiiille. 217225

Troëfne, Arbriffeau. Son bois, fa feüille \& fa fleur. $\quad 217225$

Tubereuse, fleur. $\quad 248259$

Tuilleries. Jardin des Tuilleries, \& $\sqrt{2}$ fituation. $23^{\circ}$

Tulippes de differentes claffes., 248. 259: Les plus belles, 249: Leur durée, 249 . Leur culture \& multiplication. 250

Turcs. Sorte de vers, $\quad 202$

Tuïax xour conduire des eaux 273 \& friv. Leur grofleus \& proportion . ibid.

\section{$\mathrm{V}$}

Alerienne, fieure. 2472.60
$V$ erds, Arbres verds, 67. L'a- $^{2}$ vantage qu'ils ont, \& l'ufage qu'on 


\section{TABLE DES A TIERES}

el peut tirer, I 70. Les proprietés de chaque efpece d'Arbre \& d'ArViolette de Mars. brifleaux Verds, I73. Qualités Volubilis, fleur. qu'ils doivent avoir pour être bons.

$173 \quad 174$

Verne, Arbre. Son écorce, fon bois \& fes feiilles.

Veronigue, fleur. 166

247269

\section{Y}

Y Prean, Arbre. Pourquoi ainfi apellé, I 62. Son bois, ia feiille, \&c. ibid.

\section{FIN DE LA TABLE DES MATIERES.}

De l'Imprimerie de JEAN-BARTISTE LAMESEE。 


